\title{
DEFORMABILIDADE DE \\ LIGAÇÕES VIGA-PILAR DE \\ CONCRETO PRÉ-MOLDADO
}

\section{Marcelo de Araújo Ferreira}

Tese apresentada à Escola de Engenharia de São Carlos, da Universidade de São Paulo, como parte dos requisitos para a obtenção do título de Doutor em Engenharia de Estruturas

ORIENTADOR: Prof. Dr. Mounir Khalil El Debs

São Carlos

1999 


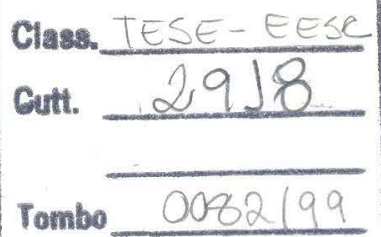

Ficha catalográfica preparada pela Seção de Tratamento

da Informação do Serviço de Biblioteca - EESC/USP

Ferreira, Marcelo de Araújo

F383d Deformabilidade de ligações viga-pilar de concreto pré-moldado / Marcelo de Araújo Ferreira. -- São Carlos, 1999.

Tese (Doutorado) -- Escola de Engenharia de São Carlos-Universidade de São Paulo, 1999.

Área: Engenharia de Estruturas.

Orientador: Prof. Dr. Mounir Khalil El Debs.

1. Concreto pré-moldado. 2. Ligações viga-pilar. 3. Ligações semi-rígidas. 4. Deformabilidade de ligações. 5. Mecanismos de deformação. I. Título. 
Candidato: Engenheiro MARCELO DE ARAÚJO FERREIRA

Tese defendida e aprovada em 22.02.1999

pela Comissão Julgadora:

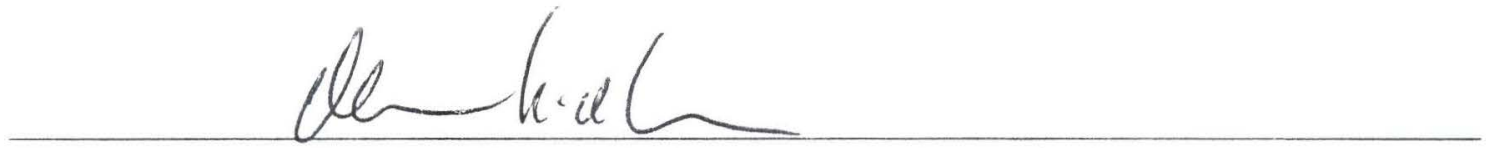

Prof. Assoc. MOUNIR KHALIL EL DEBS (Orientador)

(Escola de Engenharia de São Carlos - Universidade de São Paulo)

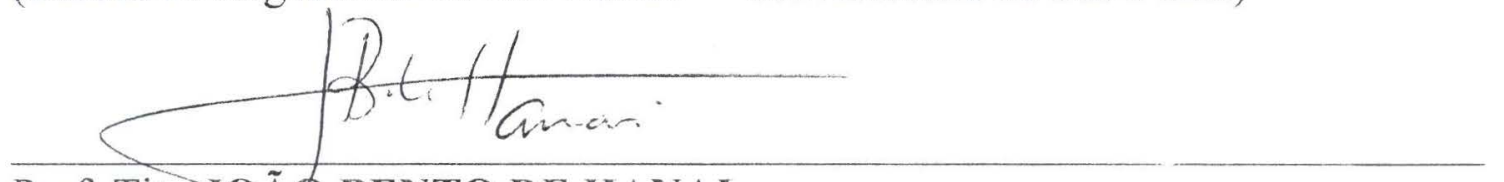

Prof. Tit. JOÃO BENTO DE HANAI

(Escola de Engenharia de São Carlos - Universidade de São Paulo)

\section{Prof. Dr. ROBERTO MARTINS GONCALVES}

(Escola de Engenharia de São Carlos - Universidade de São Paulo)

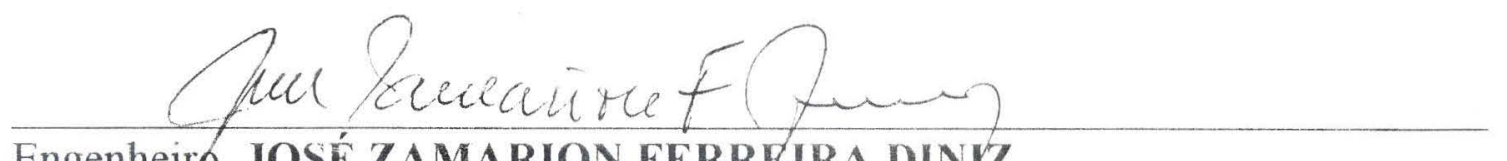

Engenheiro JOSÉ ZAMARION FERREIRA DINIZ

(Zamarion Consultores)

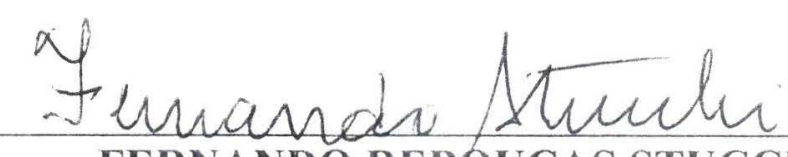

Prof. Assoc. FERNANDO REBOUCAS STUCCHI

(Escola Politécnica da Universidade de São Paulo)

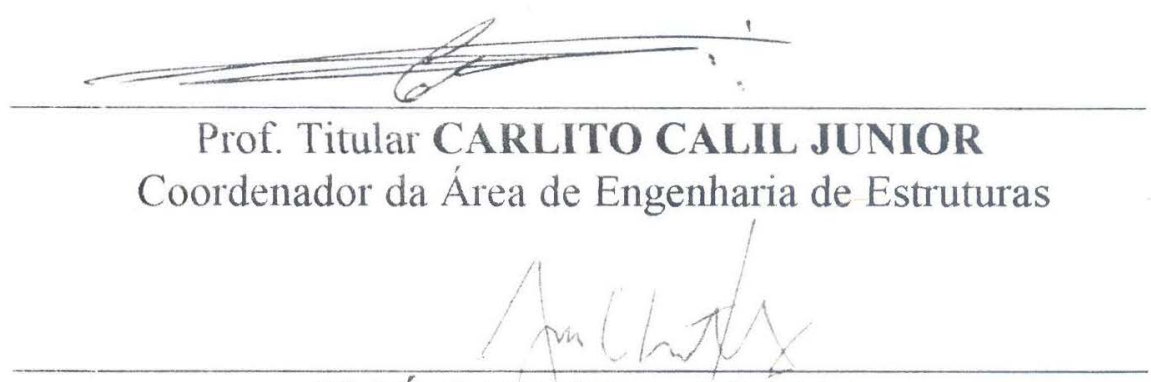

JOSÉ CARLOS A. CINTRA

Presidente da Comissão de Pós-Graduação da EESC 
À minha esposa Iza, amor e apoio que me deram condições de concluir mais este projeto.

À minha filha Vitória, motivação extra para eu não olhar para trás. 


\section{Agradecimentos}

Ao Deus Eterno, Àquele que deu aos homens a capacidade de descobrir coisas, de desenvolver e de fazer engenharia, seja a Glória. Ao meu Deus que me conduziu e me fortaleceu, seja toda Gratidão.

Ao Professor Mounir Khalil El Debs, pela sua firme orientação e apoio fornecidos durante a elaboração deste trabalho.

Ao Professor Kim Elliott, da Universidade de Nottingham, pela sua colaboração e pelas suas preciosas sugestões à este trabalho.

Ao Professor João Bento de Hanai, pela sua colaboração ao longo do trabalho.

Ao Professor José Samuel Giongo, pela consideração e amizade.

Ao Professor Humberto Coda, pela sua amizade e pela sua colaboração.

Aos técnicos do Laboratório de Estruturas, em especial ao Valdir, pela sua disposição durante as montagens dos ensaios.

À Rosi, da secretaria da pós-graduação, pela sua atenção. À Nadir, da biblioteca do SET, pela sua constante disposição. À Sílvia, pelos desenhos. Ao Massaki, pela disposição e logística na área de informática

A todos os colegas, em especial ao Elias e ao Daniel, da pós-graduação do Departamento de Estruturas da EESC/USP, pela colaboração.

À minha esposa, por ter enfrentado comigo os momentos difíceis ao longo deste trabalho.

À CAPES e ao CNPq, pelas bolsas de estudo concedidas. 


\section{Sumário}

LISTA DE FIGURAS $\quad$ i

LISTA DE GRÁFICOS — V v

LISTA DE TABELAS viii

LISTA DE SÍMBOLOS X $\mathrm{x}$

LISTA DE ABREVIATURAS E SIGLAS xii

RESUMO Xiii

ABSTRACT Xiv

1. INTRODUÇÃO 1

1.2 Preliminares 1

1.3 Objetivos 11

1.4 Apresentação do Trabalho 11

2 ESTRUTURAS COM LIGAÇÕES SEMI-RÍGIDAS 13

2.1Preliminares 13

2.2 Parâmetros Relacionados à Rigidez da Ligação 13

2.3 Método para Análise Linear de Pórticos com Nós Semi-Rígidos 19

2.4 Validade da Aproximação Linear para a Análise Estrutural 24

2.5 Influência da Deformabilidade da Ligação na Rigidez de uma Viga 26

2.5.1 Influência do Fator de Restrição da Ligação 26

2.5.2 Influência da Rigidez Equivalente da Ligação 27

2.6 Procedimentos Simplificados para a Análise de Vigas com Ligações Semi- 29

Rígidas

2.6.1 Método "Beam-Line" para Avaliação da Rigidez de Ligações 29

2.6.2 Procedimento Proposto pelo PCI 33

3. MECANISMOS BÁSICOS DE DEFORMAÇÃO PRESENTES NAS 36 LIGAÇÕES

3.1. Preliminares 36 
3.2. Mecanismo de Deformação de uma Barra Inserida em um Elemento de 38 Concreto

3.2.1. Mecanismo de Deformação por Tração de uma Barra Inserida em um 42 Elemento de Concreto (Comportamento Linear)

3.2.2. Mecanismo de Deformação por Cisalhamento de uma Barra Inserida em 46 um Elemento de Concreto

3.2.3. Mecanismo de Deformação por Cisalhamento de uma Barra Bi-Engastada em Dois Elementos de Concreto com Altura Livre

3.3. Estudo Teórico e Experimental da Deformabilidade à Compressão em Almofadas de Elastômero Simples

3.3.1. Preliminares

3.3.2. Propriedades dos Aparelhos de Apoio em Elastômero Simples 48

3.3.2.1. Características Físicas $\quad 48$

3.3.2.1.1. Dureza 48

3.3.2.1.2. Módulo de Deformação Transversal 48

3.3.2.1.3. Coeficiente de Poisson 49

3.3.2.1.4. Deformação Lenta 50

3.3.2.1.5. Efeito da Temperatura 50

3.3.2.2. Características Geométricas $\quad 51$

3.3.2.3. Expansão Lateral 52

3.3.3. Deformação por Compressão na Almofada de Elastômero Simples 54

3.3.4. Elasticidade da Almofada de Elastômero 56

3.3.5. Ensaios de Compressão Simples em Almofadas de Elastômeros 59

3.3.5.1. Ensaio Piloto 59

3.3.5.2. Ensaios de Compressão Simples (Série A) 63

3.3.5.3. Ensaios de Compressão Simples (Série B) 67

3.4.6. Ajuste do Equacionamento Teórico para o Cálculo do Modulo de 75 Elasticidade a partir dos resultados experimentais

4 LIGAÇÃO VIGA-PILAR COM ALMOFADA DE ELASTÔMERO E 79 CHUMBADOR

4.1. Preliminares 79

4.2. Modelo Clássico de Uma Barra Inserida em um Elemento De Concreto 82 Submetida à Força de Cisalhamento

4.3. Modelo Modificado para um Chumbador Inserido em Elementos de 86 Concreto considerando o Efeito do Atrito no seu Comportamento 
4.3.1. Cálculo Modificado para a Capacidade Total de Cisalhamento da Ligação 86

4.3.2. Estudo da Configuração Deformada do Chumbador 87

4.3.3. Cálculo da Tensão Normal no Chumbador 89

4.4. Deformabilidade ao Cisalhamento da Ligação 90

4.5. Proposta de Procedimento Gráfico para Representar o Comportamento da 93 Ligação Submetida ao Cisalhamento

4.6. Ensaios de Ligações Viga-pilar com Almofada de Elastômero e 96 Chumbador

4.6.1. Protótipos e Propriedades dos Materiais 96

4.6.2. Sistema de Travamento dos Protótipos 102

4.6.3. Instrumentação 106

4.6.4. Aplicação das ações 111

4.6.5. Resultados experimentais 117

$\begin{array}{lll}\text { 4.6.5.1. } & \text { Ensaios de Cisalhamento } & 117\end{array}$

4.6.5.1.1 Protótipo Piloto 117

4.6.5.1.2. Protótipo A 122

4.6.5.1.3. Protótipo B 129

4.6.5.1.4. Protótipo C 135

4.6.5.2. Ensaios de Flexão 138

4.6.5.3. Ensaios de Torção 143

4.7. Comparação dos Resultados Experimentais com os Valores Teóricos 148

5. LIGAÇÃO VIGA-PILAR COM RESISTÊNCIA À FLEXÃO COM 155 CHAPAS SOLDADAS

5.1. Preliminares

5.2. Deformabilidade à flexão da ligação 157

5.3. Ensaios de Flexão com Carregamento Alternado e Cíclico 163

5.3.1. Metodologia experimental 163

5.3.2. Protótipos e propriedades dos materiais 165

5.3.2.1. Protótipo Monolítico 166

5.3.2.2. Protótipo com Ligações Soldadas 170

$\begin{array}{ll}\text { 5.3.3. Instrumentação } & 177\end{array}$

5.3.4. Resultados experimentais 184

5.3.4.1. Deslocamentos verticais no centro dos protótipos 184

5.3.4.2. Rotações nas Extremidades dos Elementos de Viga para os Protótipos 190

5.3.4.3. Rotações Relativas entre o Elemento de Viga e a Face do Pilar no 195 
Protótipo com Ligações Soldadas (Rotações da Ligação)

5.3.4.4. Tensões nas Armaduras dos Elementos de Viga nos Protótipos 198

5.3.4.5. Configurações das Fissuras nas Extremidades dos Elementos de Viga 201

5.4. Comparação dos Resultados Experimentais com os Procedimentos Teóricos 205

5.4.1. Cálculo da Deformabilidade à Flexão da Ligação 205

5.4.2. Caracterização e Classificação da Rigidez da Ligação 210

5.4.3. Momento Máximo de Bloqueio e a sua Rotação Associada na Ligação 212

5.4.4. Aplicação do Método "Beam-Line” para a Avaliação da Ligação 213

6. CONSIDERAÇÕES FINAIS E CONCLUSÃO 217

ANEXO A: Detalhamento das Ligações Soldadas 224

$\begin{array}{ll}\text { 7. BIBLIOGRAFIA } & 228\end{array}$ 


\section{Lista de Figuras}

\section{Capítulo 1:}

Figura 1.1 Ligação viga-pilar com almofada de elastômero não fretado e chumbador

Figura 1.2 Ligação viga-pilar resistente à flexão por meio de chapas soldadas.

\section{Capítulo 2:}

Figura 2.1 Curva momento-rotação para uma ligação

Figura 2.2 Sistema de classificação para ligações semi-rígidas.

[BJORHOVDE et al. (1990)]

Figura 2.3 Sistema de classificação para ligações semi-rígidas. [EUROCODE 3 (1992)]

Figura 2.4 Influência da deformabilidade da ligação no comportamento da viga.

Figura 2.5 Influência da deformabilidade da ligação na estabilidade da estrutura.

Figura 2.6 Esquema com "molas" para representação das deformabilidades nas extremidades de uma barra [FERREIRA (1993)]

Figura 2.7 Representação das rotações nas extremidades dos elementos com rigidez modificada $(\theta)$, nas ligações $\left(\phi_{l}\right)$ e nas extremidades das barras com rigidez modificada $\left(\theta+\phi_{l}\right)$

Figura 2.8 Comparação entre os pontos de interseção da rigidez inicial da ligação, $K \phi$, e da curva $M-\phi$ da ligação com a reta "Beam-Line".

Figura 2.9 Variação dos momentos normalizados nas extremidades e no meio do vão de uma viga em função do fator de rigidez, $\gamma$.

Figura 2.10 Variação dos momentos normalizados nas extremidades e no meio do vão de uma viga em função da rigidez equivalente, $K_{S}$.

Figura 2.11 Reta Beam-Line com a curva $M$ - $\phi$ da ligação.

Figura 2.12 Diagrama Bi-linear para uma ligação, construído a partir do método Beam-Line.

Figura 2.13 Procedimento de Projeto proposto pelo PCI (1988)

\section{Capítulo 3:}

Figura 3.1 Comprimento efetivo de uma barra inserida em um elemento de concreto. em um elemento de concreto [DEI POLI et al. (1992)]

Figura 3.6 Formação da rótula plástica na barra do chumbador e zona de ruptura na 44 borda do concreto [DEI POLI et al. (1992)]

Figura 3.7 Mecanismo de ruptura, indicando $e_{z r} e \ell_{y}$.

Figura 3.8 Deformação da barra do chumbador devido à força horizontal 46

Figura 3.9 Variação do módulo $G$ em função do tipo e da duração do carregamento 
Figura 3.10 Geometria da almofada de elastômero.

Figura 3.11 Expansão lateral na almofada de elastômero [VINJE (1985)]

Figura 3.12 Limites para a largura da almofada entre elementos de concreto

[VINJE (1985)]

Figura 3.13 Configurações de deformação para uma almofada comprimida

\section{Capítulo 4:}

Figura 4.1 Exemplo de uma ligação viga-pilar com almofada de elastômero e chumbador

Figura 4.2 Modelo para o cálculo da capacidade ao cisalhamento em uma barra Inserida em um elemento de concreto. [ENGSTRÖM(1992a)

Figura 4.3 Modificação do modelo para a capacidade de cisalhamento: a) restrição ao giro do chumbador na interface da ligação; $b$ ) excentricidade da aplicação da força de cisalhamento [ENGSTRÖM (1992)]

Figura 4.4 Estado simplificado de deformação para o chumbador inserido em dois elementos de concreto. [ENGSTRÖM (1992)]

Figura 4.5 Esquematização por meio de molas para o mecanismo de deformação ao cisalhamento em ligação viga-pilar articulada em apoio sobre consolo com almofada de elastômero não fretado e chumbador.

Figura 4.6 Diagrama Simplificado da Força de Cisalhamento vs Deslocamento Horizontal na Ligação

Figura 4.7 Dimensões básicas utilizadas nos protótipos das ligações 96

Figura 4.8 Esquema da barra do chumbador 98

Figura 4.9 Detalhamento da armadura do elemento de viga 100

Figura 4.10 Foto da armadura utilizada no elemento de viga 100

Figura 4.11 Detalhamento da armadura do elemento do bloco suporte 101

Figura 4.12 Foto da armadura do elemento de bloco 101

Figura 4.13 Montagem do sistema de reação para o ensaio piloto 102

Figura 4.14 Sistema de travamento do bloco suporte por meio de barras atirantadas $\quad 103$

Figura 4.15 Sistema de travamento do bloco suporte utilizado no Protótipo C 104

Figura 4.16 Colocação de almofadas de elastômero na base do Bloco Suporte. 104

Figura 4.17 Esquema dos transdutores no Ensaio Piloto 106

Figura 4.18 Vista dos transdutores no ensaio piloto 106

Figura 4.19 Esquema dos transdutores e relógios no Ensaio do Protótipo A 107

Figura 4.20 Medição dos deslocamentos relativos no Protótipo A 107

Figura 4.21 Esquema dos transdutores e relógios nos Protótipos B e C

Figura 4.22 Medidas dos deslocamentos relativos nos protótipos B e C. 108

Figura 4.23 Extensômetros elétricos nos chumbadores do Protótipo A 109

Figura 4.24 Vista da instrumentação nos chumbadores no Protótipo A 109

Figura 4.25 Extensômetros elétricos nos chumbadores dos Protótipos B e C 110

Figura 4.26 Vista da instrumentação nos chumbadores para os Protótipos B e $C \quad 110$

Figura 4.27 Aplicação da força de cisalhamento nos ensaios piloto e protótipo A 112

Figura 4.28 Aplicação da força de cisalhamento nos ensaios dos protótipo B e C 112

Figura 4.29 Disposição dos atuadores para aplicação da ação de torção na ligação $\quad 113$

Figura 4.30 Atuadores para aplicação de flexão na ligação 114

Figura 4.31 Travamento dos chumbadores com porcas e arruelas $\quad 115$

Figura 4.32 Atuador para aplicação da força normal na ligação. 116

Figura 4.33 Atuador sobre apoio móvel para aplicação da força normal durante o $\quad 116$ ensaio de cisalhamento 


\section{Capítulo 5:}

Figura 5.1 Modelo da ligação viga-pilar resistente à flexão por meio de chapas soldadas.

Figura 5.2 Hipótese da configuração deformada da ligação [FERREIRA (1993)].

Figura 5.3 Esquematização por meio de molas para representação da associação dos mecanismos de deformação presentes na ligação viga-pilar rígida.

Figura 5.4 a) Esquema de forças aplicadas b) Idealização de deslocamentos na extremidade da viga

Figura 5.5 Situação simulada de uma estrutura de pórtico.

Figura 5.6 a) Atuador INSTRON 8506 (ações alternadas e cíclicas, com controle de

Figura 5.7 Obtenção dos deslocamentos externos da ligação

Figura 5.8 Geometria do protótipo monolítico

Figura 5.9 Protótipo monolítico após a desforma

Figura 5.10 Modelo concretado com a sua lateral na posição horizontal 167

Figura 5.11 Detalhamento da armadura do protótipo monolítico 169

Figura 5.12 Geometria do protótipo com ligações soldadas 170

Figura 5.13 Vista geral do protótipo com ligações soldadas após a soldagem 170

Figura 5.14 Preparação para a concretagem dos elementos que compõem o protótipo 171 com ligações soldadas

Figura 5.15 Detalhamento da armadura do elemento de viga do protótipo com ligações soldadas

Figura 5.16 Detalhamento da armadura do elemento de pilar do protótipo com ligações soldadas

Figura 5.17 Ligação com solda na extremidade do elemento de viga (Detalhes)

Figura 5.18 Ligações com solda na armadura interna ao elemento de pilar (Detalhes) 176

Figura 5.19 Posicionamento dos transdutores no protótipo monolítico

Figura 5.20 Posicionamento dos transdutores no protótipo com ligações soldadas 178

Figura 5.21 Transdutores no protótipo monolítico (fotos)

Figura 5.22 Transdutores no protótipo com ligações soldadas (fotos) 181

Figura 5.23 Extensômetros nas armaduras do protótipo monolítico (fotos) 182

Figura 5.24 Extensômetros nas armaduras do protótipo com ligações soldadas (fotos) 182

Figura 5.25 Posicionamento dos extensômetros nas armaduras do protótipo monolítico 183

Figura 5.26 Posicionamento dos extensômetros nas armaduras do protótipo com 183 ligações soldadas

Figura 5.27 Esquematização das "Vigas-Equivalentes" para os protótipos ensaiados 185

Figura 5.28 Fissuras no lado direito do protótipo monolítico 201

Figura 5.29 Fissuras no lado esquerdo do protótipo monolítico 201

Figura 5.30 Fissuras iniciais no protótipo com ligações soldadas, decorrentes do efeito 202 da temperatura durante o processo de solda entre os elementos

Figura 5.31 Fissuras no lado direito do protótipo com ligações soldadas 203

Figura 5.32 Fissuras no lado esquerdo do protótipo com ligações soldadas 203

Figura 5.33 Configuração da ligação após a ruptura 204

Figura 5.34 Configuração da ligação onde não ocorreu ruptura 204

Figura 5.35 Configuração da ligação deformada da ligação, conforme observada no 205 ensaio

Figura 5.36 Definição da excentricidade" $e_{1}$ " 206

Figura 5.37 Definição do parâmetro " $h 2$ " 207 
Figura 5.38 Esquema com caminho das forças no elemento de viga 207

Figura 5.39 Elemento de viga virtual para a avaliação da rigidez da ligação 210

Figura 5.40 Diagrama teórico com as retas "Beam-Line” e da rigidez da ligação 214

\section{ANEXO A}

Figura A-1 Detalhes das ligações inseridas no elemento de viga

Figura A-2 Detalhes das ligações inseridas no consolo

Figura A-3 Detalhes das ligações inseridas no elemento de pilar 


\section{Lista de Gráficos}

\section{Capítulo 3:}

Gráfico 3.1 Ensaio piloto de compressão simples da almofada 1 (Etapa 1) 60

Gráfico 3.2 Ensaio piloto de compressão simples da almofada 1 (Etapa 2) 60

Gráfico 3.3 Ensaio piloto de compressão simples da almofada 2

Gráfico 3.4 Série A: ensaio de compressão simples em almofada de elastômero (CP-1) 64

Gráfico 3.5 Série A: ensaio de compressão simples em almofada de elastômero (CP-2) 64

Gráfico 3.6 Série A: ensaio de compressão simples em almofada de elastômero (CP-3) 64

Gráfico 3.7 Série A: ensaio de compressão simples em almofada de elastômero (CP-4) 65

Gráfico 3.8 Série A: ensaio de compressão simples em almofada de elastômero (CP-5) 65

Gráfico 3.9 Série A: ensaio de compressão simples em almofada de elastômero (CP-6) 65

Gráfico 3.10 Série B: ensaio de compressão simples em almofada de elastômero (CP-1) 68

Gráfico 3.11 Série B: ensaio de compressão simples em almofada de elastômero (CP-2) 69

Gráfico 3.12 Série B: ensaio de compressão simples em almofada de elastômero (CP-3) 70

Gráfico 3.13 Série B: ensaio de compressão simples em almofada de elastômero (CP-4) 71

Gráfico 3.14 Série B: ensaio de compressão simples em almofada de elastômero (CP-5) 72

Gráfico 3.15 Série B: ensaio de compressão simples em almofada de elastômero (CP-6) 73

\section{Capítulo 4:}

Gráfico 4.1 Ensaio de cisalhamento - protótipo piloto (ciclos 1 e 2) 118

Gráfico 4.2 Ensaio de cisalhamento - protótipo piloto (ciclo 3) 118

Gráfico 4.3 Ciclos da força de cisalhamento no protótipo piloto 119

Gráfico 4.4 Ciclos da força de cisalhamento no protótipo piloto (deslocamentos 119 residuais)

Gráfico 4.5 Obtenção gráfica de $F_{v y, \text { min e }} F_{v y}$ no protótipo piloto 121

Gráfico 4.6 Ensaio de cisalhamento - protótipo A (ciclo 1) 124

Gráfico 4.7 Ensaio de cisalhamento - protótipo A (ciclo 2, $\operatorname{com} N=10 \mathrm{kN}) \quad 124$

Gráfico 4.8 Ensaio de cisalhamento - protótipo A (ciclo 3, $\operatorname{com} N=30 \mathrm{kN}) \quad 125$

Gráfico 4.9 Ensaio de cisalhamento - protótipo A (ciclo 4) 125

Gráfico 4.10 Ensaio de cisalhamento - protótipo A (ciclo 5) 126

Gráfico 4.11 Ensaio de cisalhamento - protótipo A (Avaliação da interferência da força 126 normal)

Gráfico 4.12 Ciclos da força de cisalhamento no protótipo A 127

Gráfico 4.13 Ensaio de cisalhamento - protótipo B (Ciclo 1) 131

Gráfico 4.14 Ensaio de cisalhamento - protótipo B (Ciclo 2) 132

Gráfico 4.15 Ensaio de cisalhamento - protótipo B (Ciclo 3) 132

Gráfico 4.16 Ensaio de cisalhamento - protótipo B (Ciclos 1,2 e 3) 133

Gráfico 4.17 Tensões normais na seção de máximo momento no chumbador - prot. B 133 (ciclo 2)

Gráfico 4.18 Tensões normais na seção de máximo momento no chumbador - prot. B 134 
(ciclo 1)

Gráfico 4.19 Tensões normais na seção de máximo momento no chumbador - prot. $B$

(ciclo 3)

Gráfico 4.20 Ensaio de cisalhamento - protótipo C (ciclo 1)

136

Gráfico 4.21 Ensaio de cisalhamento - protótipo C (ciclo 2)

136

Gráfico 4.22 Ensaio de cisalhamento - protótipo C (ciclos 1 e 2)

137

Gráfico 4.23 Tensões normais na seção de máximo momento no chumbador - prot. $C$

Gráfico 4.24 Curva momento-rotação para a ligação no protótipo A

Gráfico 4.25 Tensões normais na seção de máximo momento na barra do chumbador -

Gráfico 4.26 Curva momento-rotação para a ligação no protótipo $B$

141

Gráfico 4.27 Tensões normais na seção de máximo momento na barra do chumbador -

Gráfico 4.28 Curva momento-rotação para a ligação no protótipo $C$

142

Gráfico 4.29 Tensões normais na seção de máximo momento na barra do chumbador protótipo $C$

Gráfico 4.30 Curva momento torçor-rotação para a ligação no protótipo A

Gráfico 4.31 Componentes normais na seção resistente à torção - protótipo A

Gráfico 4.32 Curva momento torçor-rotação para a ligação no protótipo $B$

Gráfico 4.33 Componentes normais na seção resistente à torção - protótipo $B$

Gráfico 4.34 Curva momento torçor-rotação para a ligação no protótipo $C$

Gráfico 4.35 Componentes normais na seção resistente à torção - protótipo $C$

Gráfico 4.36 Diagrama teórico para o protótipo piloto

151

Gráfico 4.37 Diagrama teórico para o protótipo A

151

Gráfico 4.38 Diagrama teórico para o protótipo $B$

152

Gráfico 4.39 Diagrama teórico para o protótipo $C$

\section{Capítulo 5:}

Gráfico 5.1 Deslocamento vertical no centro do protótipo monolítico (ciclos 1 ao 6)

Gráfico 5.2 Deslocamento vertical no centro do protótipo monolítico (ciclos 1 ao 7)

Gráfico 5.3 Deslocamento vertical no centro do protótipo monolítico (ciclos 7 e 8)

Gráfico 5.4 Deslocamento vertical no centro do protótipo com ligações soldadas

Gráfico 5.5 Deslocamento vertical no centro do protótipo com ligações soldadas

Gráfico 5.6 Comparação das curvas dos deslocamentos verticais apresentados pelos protótipos monolíticos e com ligações soldadas

Gráfico 5.7 Deslocamentos verticais no protótipo com ligações soldadas em função dos deslocamentos verticais no protótipo monolítico

Gráfico 5.8 Curva M- $\theta$ para o protótipo monolítico (a partir da leitura interna dos extensômetros elétricos)

Gráfico 5.9 Curva M- $\theta$ para o protótipo monolítico (a partir da leitura externa dos

Gráfico 5.10 Comparação das curvas $M-\theta$, para o protótipo monolítico, (a partir das

Gráfico 5.11 Curva M- $\theta$ para as rotações nas extremidades dos elementos de viga do protótipo com ligações soldadas

Gráfico 5.12 Curva M- $\theta$ para as rotações nas extremidades dos elementos de viga do protótipo com ligações soldadas (valores médios) 
Comparação entre as rotações nas extremidades dos elementos de viga

Gráfico 5.14 para os dois protótipos

Rotações nas extremidades dos elementos de viga no protótipo com

Gráfico 5.15 ligações soldadas em função das rotações no protótipo monolítico

Curva M- $\theta$ para as rotações relativas entre o elemento de viga e a face do

Gráfico 5.16 pilar, para o protótipo com ligação soldada (ciclos 1 ao 9)

Curva $M-\theta$ para as rotações relativas entre o elemento de viga e a face do

Gráfico 5.17 pilar, para o protótipo com ligação soldada (ações de serviço)

Tensão de tração na seção da armadura negativa para momentos

Gráfico 5.18 negativos no protótipo monolítico (ciclos 7 e 8)

Tensão de tração na seção da armadura negativa para momentos

Gráfico 5.19 negativos no protótipo com ligações soldadas (ciclos 7 e 8)

Comparação dos níveis das tensões de tração nas seções das armaduras

Gráfico 5.20 negativas do protótipo monolítico e protótipo com ligações soldadas

Tensão de tração na seção da armadura positiva para momentos positivos

Gráfico 5.21 no protótipo monolítico (ciclos 2,4 e 6)

Tensão de tração na seção da armadura positiva para momentos positivos

Gráfico 5.22 no protótipo com ligações soldadas (ciclos 6 e 8)

Comparação dos níveis das tensões de tração nas seções das armaduras

Gráfico 5.23 positivas do protótipo monolítico e protótipo com ligações soldadas

Gráfico 5.24 Comparação da curva experimental $M-\theta$ com a reta teórica para a ligação

Curvas $M-\theta$ da ligação em confronto com os procedimentos teóricos (lado

Gráfico 5.25 em que ocorreu a ruptura)

Curvas $M-\theta$ da ligação em confronto com os procedimentos teóricos (lado em que ocorreu a ruptura) 


\section{Lista de Tabelas}

\section{Capítulo 2:}

Tabela 2.1 Limites entre as classes de rigidez

Tabela 2.2 Variação da flecha em função da rigidez equivalente, $K_{S}$.

Capítulo 3:

Tabela 3.1 Classes de Dureza Shore A

Tabela 3.2 Módulo G em função da dureza Shore A, segundo a NBR-9062/85 48

Tabela 3.3 Influência da idade da almofada na dureza Shore A $\quad 50$

Tabela 3.4 Limites para a tensão média na almofada, segundo a NBIF 55

Tabela 3.5 Almofadas ensaiadas no ensaio piloto 60

Tabela 3.6 Obtenção do módulo En a partir dos resultados experimentais no ensaio $\quad 62$

Tabela 3.7 Ensaios de compressão simples em elastômeros (Série A) 63

Tabela 3.8 Obtenção do módulo En a partir dos resultados experimentais (Série A) 66

Tabela 3.9 Ensaios de compressão simples em elastômeros (Série B) 67

Tabela 3.10 Obtenção do módulo En a partir dos resultados experimentais (Série B) 74

Tabela 3.11 Comparação entre as almofadas com o mesmo fator de forma $B$

Tabela 3.12 Comparação entre os valores de cálculo e resultados experimentais para o 76 módulo En

Tabela 3.13 Comparação entre os valores de cálculo e os resultados experimentais 77 apresentados em [KERONEN (1996)], ( para $K_{1}=10$ e K2 $\left.=2\right)$

Tabela 3.14 Comparação entre os valores de cálculo e os resultados experimentais 78 apresentados em [KERONEN (1996)], ( para K1 = 7 e K2 =6)

Capítulo 4:

Tabela 4.1 Valores para ofator $C_{1}$ em função de $f_{c c}$ e $f_{c}$

Tabela 4.2 Valores do coeficiente de atrito " $\mu$ ” no elastômero [ENGSTRÖM(1985)] 87

Tabela 4.3 Parâmetros variados nos protótipos ensaiados 97

Tabela 4.4 Traço básico utilizado para o concreto 99

Tabela 4.5 Valores médios das resistências dos concretos nas datas dos ensaios 99

Tabela 4.6 Resumo das aplicações das ações nos ensaios 111

Tabela 4.7 Resumo dos ciclos de cisalhamento no protótipo piloto 117

Tabela 4.8 Inclinações nos trechos retos dos ciclos de cisalhamento no protótipo 119

Tabela 4.9 Resumo dos ciclos de cisalhamento no protótipo A 122

Tabela 4.10 Inclinações nos trechos retos dos ciclos de cisalhamento no protótipo A 122

Tabela 4.11 Força de compressão nos chumbadores, próximo à interface da ligação 127

Tabela 4.12 Tensões normais nos chumbadores, próximo à interface da ligação 127

Tabela 4.13 Resumo dos ciclos de cisalhamento no protótipo B 129

Tabela 4.14 Inclinações nos trechos retos dos ciclos de cisalhamento no protótipo B 129

Tabela 4.15 Resumo dos ciclos de cisalhamento no protótipo $C \quad 135$

Tabela 4.16 Inclinações nos trechos retos dos ciclos de cisalhamento no protótipo C 135 
Tabela 4.17 Valores experimentais para $F_{v y, \min } F_{v y}$ e $F_{v u} \quad 147$

Tabela 4.18 Valores experimentais para $\lambda_{\text {rlig }} \quad 147$

Tabela 4.19 Cálculo dos parâmetros de resistências para os protótipos 148

Tabela 4.20 Comparação das resistências teóricas e experimentais 148

Tabela 4.21 Cálculo da Deformabilidade ao Cisalhamento nos Protótipos 149

Tabela 4.22 Comparação das Deformabilidades ao Cisalhamento Teóricos e 149 Experimentais

Tabela 4.23 Cálculo dos Deslocamentos Horizontais na Ligação 150

\section{Capítulo 5:}

Tabela 5.1 Propriedades do concreto para o protótipo monolítico 167

Tabela 5.2 Propriedades do concreto para o protótipo com ligações soldadas 171

Tabela 5.3 Transdutores de deslocamento para o protótipo monolítico 178

Tabela 5.4 Transdutores de deslocamento para o protótipo com ligações soldadas $\quad 179$

Tabela 5.5 Inclinações das curvas obtidas no gráfico $5.7 \quad 184$

Tabela 5.6 Inclinações das curvas Rot(2) x Rot (1) no gráfico 5.14 191

Tabela 5.7 Parâmetros do protótipo com ligações soldadas 208 


\section{Lista de Símbolos}

A Área

$\mathbf{A}_{\mathbf{n}}$ Área da superfície de apoio em uma almofada de elastômero

A Área da seção transversal de uma barra de aço

B Fator de forma de uma almofada de elastômero

$\mathbf{C}_{1}$ Constante que relaciona o diâmetro do chumbador, a resistência do concreto e a reação transversal ao longo de uma barra de chumbador submetida à força cortante

$\mathbf{C}_{\mathbf{r}}$ Fator de restrição de um chumbador inserido em um elemento de concreto

$\mathbf{C}_{\mathbf{e}}$ Fator de excentricidade de um chumbador inserido em um elemento de concreto

E Módulo de elasticidade longitudinal

$\mathbf{E}_{\mathbf{c}}$ Módulo de elasticidade longitudinal do concreto

$\mathbf{E}_{\mathbf{n}}$ Módulo de elasticidade longitudinal de uma almofada de elastômero

$\mathbf{E}_{\mathbf{f}}$ Módulo de elasticidade fictício

$\mathbf{E}_{\mathbf{s}}$ Módulo de elasticidade longitudinal do aço

EA Rigidez à deformação axial

EI Rigidez à deformação por flexão

F Resultante de força

$\mathbf{F}_{\mathbf{c}}$ Resultante de compressão

$\mathbf{F}_{\mathbf{t}}$ Resultante de tração

$\mathbf{F}_{\mathbf{v}}$ Força cortante

$\mathbf{F}_{\mathbf{v u}}$ Resistência última ao cisalhamento em uma barra de chumbador

$\mathbf{F}_{\mathbf{v y}}$ Força de cisalhamento correspondente ao escoamento da ligação

G Módulo de elasticidade transversal

$\mathbf{I}_{\mathbf{c h}}$ Momento de inércia de uma chapa

I Momento de inércia de uma barra

K Constante

$\mathbf{K}_{\mathbf{c}}$ Módulo de rigidez de referência para o concreto

$\mathbf{K}_{\mathbf{c n}}$ Rigidez à compressão da almofada de elastômero (neoprene)

$\mathbf{K}_{\mathbf{E}}$ Rigidez à flexão secante de uma ligação

$\mathbf{K}_{\mathbf{s}}$ Rigidez equivalente de uma ligação

$\mathbf{K}_{\phi}$ Rigidez à flexão tangente de uma ligação

M Momento fletor

$\mathbf{M}_{\mathbf{d}}$ Momento fletor de cálculo

$\mathbf{M}_{\text {lig }}$ Momento fletor na ligação

Mp Momento de engastamento perfeito

N Força normal de compressão

a Comprimento da almofada de elastômero, flecha

$\boldsymbol{b}$ Largura da almofada de elastômero, largura de uma viga

d Altura útil de uma viga de concreto armado

$\boldsymbol{e}$ Excentricidade 
$f_{\mathbf{c}}$ Resistência à compressão cilíndrica do concreto

$f_{\mathbf{c c}}$ Resistência à compressão cúbica do concreto

$f_{\text {cj }}$ Resistência média de compressão cilíndrica do concreto na idade j

$f_{\text {ck }}$ Resistência de compressão característica do concreto

$f_{\text {tk }}$ Resistência de tração característica do aço

$\boldsymbol{f}_{\text {sy }}$ Tensão de escoamento do aço

$\boldsymbol{f}_{\text {sy,red }}$ Tensão reduzida do aço

$\mathbf{h}_{\mathbf{n}}$ Espessura da almofada de elastômero

$\mathbf{h}_{\ell}$ Altura livre

k Constante de proporciaonalidade

$\ell$ Comprimento

$\ell_{\mathbf{a}}$ Distância entre as ancoragens em uma barra lisa

$\ell_{\mathbf{b}}$ Comprimento de ancoragem

$\ell_{\mathbf{e}}$ Comprimento efetivo de ancoragem de uma barra na zona da ligação

$\ell_{\mathbf{s}}$ Comprimento efetivo de uma barra de aço

n Número de barras

q Carga distribuída

$\mathbf{x}$ Altura da linha neutra

z Braço de alavanca

$\Delta \mathbf{h}_{\mathbf{n}} \quad$ Afundamento em uma almofada de elastômero

$\Delta_{\mathbf{n}} \quad$ Alongamento de uma barra

$\alpha_{1} \alpha_{2}$ Fator que relaciona a rigidez da barra do chumbador com o módulo de rigidez de referência do concreto

$\alpha_{\text {crit }}$ Deformação angular crítica da barra do chumbador

$\beta_{\mathbf{i}} \quad \beta_{\mathbf{j}} \quad$ Fator de restrição ao deslocamento axial na extremidade de uma barra

$\varepsilon$ Deformação específica

$\varepsilon_{\mathbf{c}}$ Deformação do concreto

$\varepsilon_{\mathbf{s}}$ Deformação do Aço

$\phi_{\text {lig }}$ Rotação específica de uma ligação / Diâmetro de uma barra

$\phi_{\mathbf{b}} \quad$ Diâmetro de uma barra

$\gamma_{\mathbf{i}} \gamma_{\mathbf{j}} \quad$ Fator de restrição à rotação em uma ligação

$\lambda_{\text {cn }}$ Deformabilidade à compressão em uma almofada de elastômero (neoprene)

$\lambda_{\text {tb }}$ Deformabilidade à tração em uma barra

$\lambda_{\phi \text {,lig }}$ Deformabilidade à flexão de uma ligação

$\lambda_{\tau, \text { lig }}$ Deformabilidade ao cisalhamento de uma ligação

$\lambda_{\sigma, \text { lig }}$ Deformabilidade à compressão de uma ligação

$\mu$ Coeficiente de atrito

$v$ Coeficiente de Poisson

$\theta$ Rotação na extremidade de uma barra

$\theta_{\text {rot }}$ Rotação em uma rótula

$\sigma_{\mathbf{m}}$ Tensão média de compressão

$\sigma_{\text {sm }}$ Tensão normal no aço 


\section{Lista de Abreviaturas e Siglas}

$\begin{array}{lll}\text { ACI } & - & \text { American Concrete Institute } \\ \text { CEB } & - & \text { Comité Euro-International du Betón } \\ \text { COST 1 } & - & \text { European Cooperation in the Field of Scientific and Thecnical } \\ & - & \text { Research } \\ \text { EUROCODE } & - & \text { European Commitee for Standardization } \\ \text { LVDT } & - & \text { Linear Variable Differencial Transformer } \\ \text { NBR } & - & \text { Norma Brasileira Registrada } \\ \text { NBIF } & - & \text { The Norwegian Precast Concrete Federation } \\ \text { PCI } & - & \text { Precast/Prestressed Concrete Institute }\end{array}$




\section{RESUMO}

FERREIRA, M. A ., (1999). Deformabilidade de ligações viga-pilar de concreto pré-moldado. São Carlos, 231 p. Tese (Doutorado) - Escola de Engenharia de São Carlos, Universidade de São Paulo.

No presente trabalho é abordada uma metodologia analítica para o cálculo de deformabilidades de ligações típicas de concreto pré-moldado, levando-se em conta os mecanismos básicos de deformação na ligação.

Foram estudas duas ligações típicas viga-pilar de concreto pré-moldado. A primeira ligação é uma ligação com almofada de elastômero e chumbador. É apresentado um desenvolvimento analítico para o cálculo da deformabilidade ao cisalhamento da ligação. Também, é abordado um procedimento para a determinação da resistência ao cisalhamento. Foram realizados ensaios de cisalhamento, de flexão e torção nessa ligação, onde foram variados a geometria da almofada e o diâmetro do chumbador. A segunda ligação é uma ligação resistente à flexão com chapas soldadas. É apresentado um desenvolvimento para o cálculo da deformabilidade à flexão da ligação. Foram realizados dois ensaios de flexão alternada em um protótipo com ligações soldadas e um protótipo monolítico, o qual serviu de referência para avaliar a rigidez da ligação.

Os valores calculados da deformabilidade ao cisalhamento, para os protótipos com almofada de elastômero e chumbador, foram, em média, 23 \% superiores aos valores experimentais. Todavia, este equacionamento não se aplica ao caso de uma ligação com almofada com um fator de forma maior do que 5. As resistências ao cisalhamento calculadas corresponderam a valores entre 96 a $100 \%$ em relação aos valores experimentais. A ligação com chapas soldadas apresentou uma rigidez à flexão da ordem $83 \%$ da rigidez da ligação monolítica. $\mathrm{O}$ valor calculado para a rigidez à flexão secante foi $5 \%$ superior à rigidez apresentada pela ligação ensaiada. O momento máximo de cálculo da ligação, estimado com base na rigidez calculada, foi $6 \%$ superior ao momento de ruptura.

A partir dos resultados experimentais, demonstrou-se que, através da utilização de procedimentos analíticos para a determinação das deformabilidades, pode-se obter uma boa estimativa para os valores experimentais, constituindo-se assim em uma alternativa viável e em uma ferramenta de grande potencial a ser explorado para o projeto das ligações de concreto pré-moldado.

\section{Palavras Chave:}

Concreto Pré-Moldado; Ligações Típicas; Ligações Semi-Rígidas; Deformabilidades de Ligações; Mecanismos de Deformação. 


\begin{abstract}
FERREIRA, M. A ., (1999). Deformability of beam-column connections in precast concrete structures. São Carlos, 231 p. Tese (Doutorado) - Escola de Engenharia de São Carlos, Universidade de São Paulo.
\end{abstract}

This thesis discusses an analytical methodology to determine the deformability of beam-column connections for precast concrete structures, considering the basic mechanisms of deformation in these connections.

Two typical beam-column connections it was studied. For the first one, which consists of a connection with bearing pad and dowel bars, is presented an analytical development to determine its shear deformability. In addition, it is discussed a procedure to determine its shear resistance and some tests, which include shear, bending moment and sprain about beam axis, are also reported, where it were used different parameters to the bearing pad geometry and to the dowel bar diameter in the connections. For the second connection, which consists of a moment resistant connection with welded plates, is presented an analytical development to determine the connection flexibility. In order to evaluate the flexibility behaviour of the connection, two tests are reported. In the first one was used a rigid connection, which was used as a stiffness reference.

As a result, the theoretical shear deformability, calculated to the prototypes with bearing pad and dowel bars, presented $23 \%$ more than the experimental results. Therefore, this calculus was not applied for pads with shape factor bigger than 5 . The predicted shear resistance suited to values between 96 and $100 \%$ in relation to experimental values. The stiffness response of the resistant moment connection suited about $83 \%$ of the rigid connection stiffness. The theoretical secant stiffness of the connection it was $5 \%$ bigger than the experimental response. The predicted ultimate bending moment it was $6 \%$ bigger than moment crack of connection.

Based on the analysis of the results, it was demonstrated that, the employ of analytical developments to determine deformabilities in the precast concrete connections is viable and provides good estimated values. In other way, the use of those analytical developments together with available procedures consist on important design tools to be applied for the precast concrete connections.

\title{
Keywords:
}

Precast Concrete; Typical Connections; Semi-rigid Connections; Deformability of Connections; Deformation Mechanism. 


\section{Capítulo 1}

\section{Introdução}

\subsection{Preliminares}

$\mathrm{Na}$ constante preocupação com o desenvolvimento da qualidade e da economia na indústria das construções pré-moldadas, tem-se a questão da pesquisa e do desenvolvimento técnico. Neste sentido, o estudo do comportamento estrutural possui uma grande importância, sendo uma condição básica para o desenvolvimento das inovações tecnológicas futuras. Dentre as prioridades de pesquisa, no estudo das estruturas de concreto pré-moldado, as ligações entre os elementos estruturais são de grande interesse de estudo.

A importância do estudo das ligações está amplamente difundida na literatura técnica. Em ORDÓÑEZ et al. (1974), argumenta-se que a influência das ligações na construção pré-moldada é tal, que alguns especialistas chegaram a afirmar que as questões técnicas relacionadas com as ligações é que têm impedido a superação dos métodos construtivos convencionais pelos pré-moldados. Em CHEOK \& LEW (1991), faz-se referência à uma consulta realizada no APPLIED TECHNOLOGY COUNCIL, em Berckley em 1981, onde no início de uma lista com 40 prioridades de pesquisa, para as estruturas de concreto pré-moldado, estava a necessidade do desenvolvimento de recomendações práticas para o projeto de ligações típicas. Em JOHAL et al. (1991) é apresentado o resultado de um outro levantamento sobre as prioridades para direcionamentos de futuras pesquisas, realizado pelo PCI COMMITEE ON RESEARCH AND DEVELOPMENT, onde o estudo das ligações aparece novamente em lugar de destaque. Em BALLARIN (1993), comenta-se que, embora alguns países venham realizando estudos sistemáticos sobre determinados tipos de ligações nas últimas décadas, tal investigação não tem acompanhado a expansão na utilização das estruturas de concreto pré-moldado. 
Do ponto de vista do comportamento estrutural, a presença das ligações é o que diferencia basicamente uma estrutura de concreto pré-moldado de uma estrutura convencional.

As ligações são regiões particulares na estrutura pré-moldada, onde ocorrem concentrações das tensões. Também, as ligações apresentam-se como regiões de descontinuidade que podem ou não mobilizar deslocamentos e esforços decorrentes dos elementos por elas ligados, fazendo com que haja uma redistribuição desses esforços ao longo da estrutura, interferindo no comportamento da mesma. Desta forma, o desempenho de um sistema estrutural e, consequentemente, o êxito nas suas aplicações, está diretamente relacionado com o desempenho das suas ligações.

O grau de conhecimento que se possui sobre o comportamento de um sistema estrutural é um fator determinante para a garantia da segurança no cálculo estrutural. Entretanto, em muitos casos das estruturas pré-moldadas, o comportamento estrutural ainda não pode ser inteiramente determinado devido à falta de conhecimento que se tem quanto ao comportamento da rigidez nas suas ligações.

Ao contrário do que ocorre na análise das estruturas monolíticas de concreto, tradicionalmente, as estruturas de concreto pré-moldado são concebidas e projetadas a partir da hipótese de que as suas ligações viga-pilar se comportam como articulações perfeitas. De fato, isto ocorre em função de que a maior parte das estruturas pré-moldadas são empregadas em edificações com poucos pavimentos, tendo-se uma tendência maior para o emprego das ligações consideradas como articuladas.

Entretanto, existe também uma necessidade do desenvolvimento de ligações resistentes à flexão, que apresentem um bom desempenho estrutural, a partir das quais poderão ser viabilizados sistemas estruturais em concreto pré-moldado para edificações de múltiplos pavimentos. Quando se pretende formar um pórtico com elementos prémoldados, torna-se de grande importância o desempenho apresentado pelas ligações empregadas, dependendo delas o desempenho de toda a estrutura. No caso das ligações resistentes à flexão, o desempenho destas ligações dependem da resistência, da rigidez, da ductilidade, da simplicidade na execução e da durabilidade.

CHEOK \& LEW (1991) comentam que, pela falta de uma base de dados sobre a rigidez das ligações viga-pilar com resistência à flexão, as estruturas pré-moldadas tendem 
a ser presumidas como muito menos dúcteis e muito menos estáveis do que as estruturas monolíticas. SUCUOGLU (1995) realizou um estudo experimental sobre a influência da rigidez de ligações resistentes à flexão na rigidez de um pórtico em estrutura de concreto pré-moldado. Segundo esse autor, o desempenho da rigidez da estrutura com ligações correspondeu a cerca de $80 \%$ da rigidez de uma estrutura monolítica, sendo considerada satisfatória para aplicação em regiões sísmicas.

No que diz respeito ao projeto estrutural das ligações, o desenvolvimento de critérios de dimensionamento e de detalhamento da ligação dependem do conhecimento dos fatores que interferem no comportamento desta ligação.

As ligações apresentam um comportamento semi-rígido, que é um comportamento intermediário entre os nós rígidos e as articulações, podendo-se aproximar de uma destas situações. A consideração das deformabilidades das ligações nas extremidades dos elementos de viga na estrutura faz com que haja uma modificação na rigidez desses elementos, promovendo uma redistribuição dos esforços e deslocamentos ao longo da estrutura.

O termo "ligações semi-rígidas" foi utilizado inicialmente no estudo de estruturas metálicas, na década de 30, sendo incorporado recentemente ao estudo das estruturas prémoldadas. Esta notação, a princípio, está relacionada com a rigidez à flexão da ligação, ou a sua relação inversa, a deformabilidade à flexão, também denominada flexibilidade. Este conceito já vem sendo utilizado na análise estrutural de pórticos com nós semi-rígidos, aplicada ao caso de estruturas metálicas.

Todavia, no caso das ligações em estruturas de concreto pré-moldado, o conceito da rigidez, ou da deformabilidade da ligação está relacionado também com outros esforços que não a flexão, como é o caso da deformabilidade ao cisalhamento, que é um importante parâmetro no estudo das ligações com almofadas de elastômero e chumbador, e da deformabilidade à compressão em almofadas de elastômero.

Assim, no presente trabalho, optou-se por utilizar o termo "ligações semi-rígidas" quando se está tratando da análise estrutural de pórticos com nós semi-rígidos, acompanhando-se uma notação já aceita internacionalmente.

No entanto, com o objetivo de se ter maior clareza dentro de um assunto que está no início do seu estudo, optou-se por empregar o termo "deformabilidade da ligação" 
(associada a um determinado esforço) para tratar do comportamento dos mecanismos de deformação das ligações.

Utilizando-se esta terminologia, a análise estrutural das estruturas pré-moldadas deveria, então, ser feita por meio de sistemas de cálculo que levem em consideração as deformabilidades das ligações, conduzindo a um cálculo mais realístico das estruturas de concreto pré-moldado.

A análise estrutural de pórticos com nós semi-rígidos está amplamente divulgada na literatura técnica. Em MONFORTON \& WU (1963), BRUN \& PICARD (1976) e em FAFARD et al. (1990), encontram-se desenvolvimentos matemáticos, onde são apresentadas modificações para as matrizes de rigidez e para os esforços de bloqueio dos elementos da estrutura, para se levar em conta as deformabilidades das ligações. Estes desenvolvimentos estão apresentados de forma detalhada em FERREIRA (1993), onde também foram incorporadas deformabilidades axiais nas extremidades dos elementos de barra, além da flexão. Esses procedimentos de análise podem ser aplicados diretamente na modificação de rotinas, que se utilizem do processo dos deslocamentos, para transformálas em programas computacionais para o cálculo de pórticos com nós semi-rígidos. Por outro lado, atualmente existem vários programas comerciais para o cálculo estrutural, os quais já têm incorporado em suas rotinas modelos para a consideração da rigidez das ligações nas extremidades dos elementos estruturais, com a utilização de molas segundo os graus de liberdade na ligação.

Todavia, todo este conhecimento e mesmo os recursos computacionais atuais não são aplicados na prática para a análise das estruturas pré-moldadas, devido à falta do conhecimento que se tem sobre as deformabilidades das ligações típicas que compõem as estruturas pré-moldadas. Neste contexto, a questão da determinação das deformabilidades nas ligações constitui-se num caminho crítico para a aplicação dessa teoria na análise das estruturas pré-moldadas.

A obtenção dos valores das deformabilidades das ligações entre os elementos de estruturas de concreto pré-moldada tem sido feita, geralmente, através de resultados experimentais e, raramente, por meio de modelos analíticos que representem 0 comportamento da rigidez e da resistência da ligação. 
As metodologias que se baseiam somente nos procedimentos experimentais são muito caras e possuem o inconveniente de que os resultados quantitativos obtidos nos ensaios, a rigor, tenham aplicação apenas para as ligações com mesmo detalhamento, materiais e dimensões da ligação ensaiada, tendo-se assim uma aplicação restrita do ponto de vista prático.

Por outro lado, em vários trabalhos experimentais, onde se estudou 0 comportamento da rigidez de ligações, tinha-se a preocupação apenas com a determinação do valor global da rigidez da ligação, ou seja, com a medida da relação existente entre a força aplicada em uma ligação e o seu deslocamento associado. Por esta razão, não se formou uma base de dados suficiente sobre o comportamento qualitativo da rigidez, nem se dispõe de critérios e diretrizes, para o projeto de ligações típicas, que levem em conta a rigidez.

Em alternativa à uma metodologia puramente experimental, tem-se a possibilidade da modelagem analítica da ligação. Todavia, devido ao fato de que as ligações constituemse em regiões de comportamento complexo, com concentração de tensões e com a interferência de uma série de parâmetros interrelacionados entre si, no caso dos desenvolvimentos analíticos para as ligações, são necessárias verificações e comprovações experimentais para que se possa ajustar os modelos analíticos.

Com relação ao desenvolvimento de equacionamentos analíticos para o cálculo da deformabilidade de ligações, em FERREIRA (1993) iniciou-se um estudo sobre a associação analítica de mecanismos básicos de deformação que compõem uma ligação, onde se buscou sistematizar uma metodologia que levasse em conta estes aspectos. Neste sentido, foram desenvolvidos modelos para o cálculo de deformabilidades em várias ligações típicas de estruturas de concreto pré-moldado. Todavia, pela falta de uma base de dados experimentais sobre as ligações ali estudadas, não se pôde consolidar esta linha metodológica, pela falta de comprovações práticas.

Uma terceira alternativa para a determinação da deformabilidade em ligações é através da utilização de procedimentos numéricos. A distretização numérica de ligações é, atualmente, um recurso com grande potencial. Existem programas comerciais que possuem nas suas rotinas alguns modelos com molas que permitem a discretização dos componentes de uma ligação. Todavia, para que se tenha uma boa discretização da ligação 
por meio destas ferramentas, é necessário o conhecimento prévio dos parâmetros internos relacionados com o comportamento da ligação.

Na intenção de modelar o mecanismo de deformação de uma barra inserida em um elemento de concreto, inicialmente nesta pesquisa, foram feitas tentativas para discretizar uma ligação viga-pilar resistente à flexão com chapas metálicas soldadas, utilizando-se um programa para a análise linear de barras dentro de um meio elástico bi-dimensional, através da combinação do MEC e do MEF, disponível no Departamento de Estruturas da EESC. Todavia, naquele momento, não se obteve uma modelagem que conseguisse representar adequadamente o comportamento real da ligação.

Acredita-se que isto se deu, não em função da limitação da ferramenta numérica, mas sim pela falta de dados experimentais e de parâmetros sobre o comportamento da rigidez da ligação discretizada. Naquele momento, ainda não se dispunha de uma bibliografia específica sobre os mecanismos básicos de deformação, como são os casos dos mecanismos de deformação por cisalhamento e por tração em barras inseridas no concreto. Desta forma, embora já existissem as ferramentas para solucionar os problemas, ainda não se podia compreender adequadamente os parâmetros que estavam envolvidos dentro desses problemas.

Num outro lado da questão, está o fato de que a discretização numérica também apresenta limitações para a modelagem de alguns mecanismos de deformação. Durante este trabalho, quando não se dispunha na literatura de uma expressão para a determinação da deformabilidade por compressão simples de uma almofada de elastômero simples, buscou-se um modelo para representar o comportamento uma placa elástica, com uma grande deformação transversal (da mesma ordem da sua espessura). Busca-se analisar o efeito do atrito na superfície de contato comprimida da almofada, a qual não poderia ser ser aplicada à Teoria da Elasticidade, dificultanto o desenvolvimento de um modelo analítico. Entretanto, nem o LUSAS e nem o ANSYS, softwares disponíveis no SETEESC-USP, possuíam um modelo que pudesse representar o comportamento da almofada de elastômero simples.

De fato, não se encontram na literatura técnica internacional procedimentos referentes à discretização numérica de ligações pré-moldadas, com aplicação prática de projeto. $\mathrm{O}$ que se encontra, correntemente, são procedimentos numéricos para a análise de 
estruturas, considerando as deformabilidades das ligações, as quais se pressupõe serem conhecidas.

Assim, em função de, num momento inicial, não se dispor de um embasamento teórico suficiente que possibilitassem as condições necessárias para garantir modelagens numéricas consistentes, optou-se, na presente pesquisa, por abordar o problema da determinação da rigidez de uma ligação através da utilização de desenvolvimentos analíticos, baseados na associação dos mecanismos de deformação presentes na ligação, retomando uma linha metodológica já iniciada durante a pesquisa de mestrado. Cercando a questão, decidiu-se fazer um estudo de caso para duas ligações viga-pilar típicas, onde foram realizados ensaios com o objetivo de levantar dados que possibitassem 0 entendimento do comportamento dessas ligações, possibilitando ajustar os desenvolvimentos analíticos e adequar os conhecimentos teóricos existentes na literatura.

O critério para a escolha dessas ligações foi baseado no interesse de suas aplicações e também na existência de trabalhos na literatura sobre as mesmas, o que possibilitaria um maior balizamento para estudo e comparação dos resultados.

O primeiro tipo de ligação escolhida foi uma ligação viga-pilar com almofada de elastômero não fretado e chumbador. O interesse de estudo sobre este tipo de ligação está na sua grande utilização no Brasil, com aplicação nas estruturas de galpões de uso múltiplo e também nas edificações de andares múltiplos de pequena altura.

O chumbador, utilizado no detalhamento dessa ligação, a princípio, possui apenas a função de garantir a estabilidade lateral do elemento, e não a de resistir aos esforços horizontais. Todavia, em virtude do detalhamento construtivo corrente, onde os nichos da viga para o encaixe dos chumbadores são preenchidos com graute não retrátil, tem-se a solidarização do chumbador com o elemento de viga. Desta forma, a ligação apresenta uma restrição parcial aos deslocamentos horizontais na extremidade do elemento de viga. Entender este mecanismo é de grande importância para que se possa estimar os esforços de restrição, como os causados pela retração da viga ou mesmo para se determinar a distribuição dos esforços horizontais transmitidos para os pilares, no caso das ações horizontais na estrutura.

Em GARCIA et al. (1993), realizou-se um ensaio com uma ligação viga-pilar com almofada de elastômero e chumbador, onde se estudou o efeito de aplicação de forças de 
cisalhamento alternadas na ligação. Alguns trabalhos, onde não se estudou a ligação em si, apresentam estudos importantes para a compreensão dos mecanismos de deformação presentes nesse tipo de ligação. Em LIN (1991) foram estudados os parâmetros que interferem no desempenho ao cisalhamento de uma barra inserida em dois elementos de concreto. Também em DEI POLI et al. (1992), estudou-se o comportamento de uma barra inserida em um elemento de concreto submetida ao esforço cortante. Em FERREIRA (1993) são apresentados equacionamentos para a modelagem do mecanismo de deformação por cisalhamento da ligação.

$\mathrm{Na}$ literatura técnica corrente não são encontrados muitos trabalhos específicos sobre este tipo de ligação. Isto se dá em razão de que, nos países desenvolvidos, a maior preocupação atual é o com o desempenho de ligações viga-pilar resistentes à flexão para a composição de sistemas estruturais localizados em regiões sísmicas.

Entretanto, já em fase avançada no presente trabalho, teve-se acesso às informações existentes em um amplo programa de pesquisa, conduzido pelo EUROPEAN COOPERATION IN THE FIELD OF SCIENTIFIC AND TECHNICAL RESEARCH, através de uma comissão específica denominada COST PROJECT C1 - "SEMI-RIGID BEHAVIOUR". Este programa de pesquisa reuniu os principais pesquisadores europeus na área de ligações em estruturas de concreto pré-moldado, onde foram realizados vários trabalhos dentro de um estudo temático sobre o comportamento semi-rígido das ligações. As informações dos trabalhos ali desenvolvidos encontram-se nos anais das conferências do COST 1, em 1992 e 1996, sendo que as principais sínteses e a conclusão dessa pesquisa temática foi apresentada na última conferência do $\operatorname{COST} 1$, realizada na Bélgica, em Setembro de 1998.

Cabe aqui destacar que o acesso a esse material bibliográfico, no final do ano de 1997, foi de grande contribuição para o andamento e conclusão da presente pesquisa. Também, que isto foi possível graças ao intercâmbio e à colaboração do Professor Kim Elliott, da Universidade de Nottingham (UK) e um dos pesquisadores membros do COST 1, o qual também contribuiu com sugestões e comentários relativos especificamente a esta pesquisa. Neste sentido, faz-se o reconhecimento e o agradecimento pela colaboração prestada pelo Prof. Elliott para a realização desta pesquisa. 
Em ENGSTRÖM (1992.a) são apresentados desenvolvimentos teóricos e resultados experimentais a respeito da resistência ao cisalhamento de uma ligação vigapilar com almofada de elastômero e chumbador. $\mathrm{O}$ interesse deste estudo nesse trabalho foi, além do dimensionamento da ligação, o de fornecer subsídios para o estudo da estrutura pré-moldada para grandes deslocamentos e as reservas de resistência das ligações para estas situações.

Em LINDBERG (1987), LINDBERG (1992), KERONEN (1984) e KERONEN (1996), são apresentados os trabalhos experimentais realizados na Tampere University of Technology, na Finlândia. Trata-se de um grupo de pesquisa na área de ligações viga-pilar em estruturas de concreto pré-moldado, onde se tem estudado experimentalmente a interação do comportamento da rigidez da ligação no comportamento global da estrutura. Foram realizados ensaios de traves planas, onde o desempenho da estrutura foi avaliado em função da variação de parâmetros na ligação.

O segundo tipo de ligação escolhido para estudo nesta pesquisa é uma ligação viga-pilar resistente à flexão por meio de chapas soldadas. Estas chapas são soldadas nas bordas superior e inferior da viga. O interesse nessa ligação está relacionado ao fato de ser uma alternativa de ligação resistente à flexão para a composição de pórticos em estruturas de múltiplos pavimentos, sendo bastante utilizada nos EUA. Além deste fato, existem na literatura técnica alguns trabalhos que estudaram este tipo de ligação, nos quais esta ligação é apontada como sendo de grande potencial para utilização. As principais referências sobre estudos experimentais realizados com esse tipo de ligação são STANTON et al. (1986) e DOLAN et al. (1987). Também, em DOLAN \& PESSIKI (1989) são apresentados os resultados de ensaios de flexão em modelos em escala reduzida (1/4) para este tipo de ligação.

Em FERREIRA (1993) é apresentado um desenvolvimento analítico para o cálculo da deformabilidade à flexão nesse tipo de ligação. Como aplicação deste cálculo, também foi apresentado um exemplo de simulação numérica para a análise dos deslocamentos de uma estrutura com múltiplos pavimentos, considerando-se as deformabilidades calculadas para as suas ligações. A partir dos resultados de deslocamentos nessa estrutura, fez-se uma comparação, através do parâmetro de instabilidade " $\alpha$ ", com uma estrutura monolítica 
convencional, onde a estrutura pré-moldada apresentou um bom desempenho com relação à sua rigidez global.

\subsection{Objetivos}

O objetivo geral no presente trabalho consiste em consolidar uma proposta metodológica para o cálculo da deformabilidade em ligações de estruturas pré-moldadas, por meio da associação dos mecanismos básicos de deformação, mediante comprovações experimentais, com vistas na sua aplicação na análise estrutural.

Entre os objetivos específicos estão:

a) sistematizar conhecimentos teóricos existentes sobre procedimentos de análise para estruturas com nós semi-rígidos;

b) sistematizar conhecimentos teóricos existentes sobre a deformabilidade de ligações em estruturas de concreto pré-moldado;

c) alargar a base de dados sobre o comportamento da rigidez e da resistência das duas ligações viga-pilar escolhidas para objeto de estudo nesta pesquisa, analisando os mecanismos de deformação presentes nessas ligações e a sua influência no comportamento global da ligação;

d) fazer comparações dos resultados experimentais com os valores teóricos a fim de calibrar os modelos analíticos;

e) propor procedimentos e critérios de projeto das ligações, levando em conta critérios de rigidez e de resistência, visando sua aplicação na análise das estruturas com a consideração da deformabilidade das ligações.

\subsection{Apresentação do Trabalho}

No Capítulo 2 é apresentada de forma resumida a formulação matricial para a análise de pórticos com nós semi-rígidos, a qual foi apresentada de forma extensa no trabalho de mestrado em FERREIRA (1993). As aplicações da análise numérica das estruturas com nós semi-rígidos são de grande potencial. Também, nesse capítulo são apresentados procedimentos simplificados para a análise estrutural e para a estimativa da resistência de uma ligação viga-pilar resistente à flexão, com base na sua rigidez. 
No Capítulo 3 são apresentados os mecanismos básicos de deformação importantes para a compreensão do comportamento das ligações estudadas no presente trabalho, como são os casos dos mecanismos de tração e de cisalhamento de um chumbador inserido em um elemento de concreto. Nesse capítulo são apresentadas a conceituação e a caracterização de almofadas de elastômero não fretado, com atenção especial no mecanismo de deformação por compressão da almofada. Dentro desse enfoque, nesse capítulo são apresentados os resultados dos ensaios de compressão simples com deformação controlada para almofadas de elastômero não fretado, realizados nesta pesquisa, onde foram alteradas a geometria e a tensão média na almofada. Também, com base nesses ensaios, é proposto um equacionamento para o cálculo do módulo de elasticidade de uma almofada de elastômero não fretado.

No Capítulo 4 é apresentado um estudo do comportamento da ligação viga-pilar com almofada de elastômero simples e chumbador, com base na sua resistência e na sua rigidez, onde se tem um enfoque na deformabilidade ao cisalhamento da ligação. Dentro da abordagem teórica, é apresentada uma revisão sobre o estudo da resistência ao cisalhamento da ligação. Também, é apresentada uma proposta de desenvolvimento analítico para o cálculo da deformabilidade ao cisalhamento da ligação, com base na associação dos mecanismos básicos na ligação. Dentro da abordagem experimental, são apresentados os resultados dos ensaios em ligações viga-pilar com almofadada de elastômero simples realizados nesta pesquisa, onde, além dos ensaios de cisalhamento na ligação, foram realizados ensaios complementares de flexão e torção, para avaliar o comportamento da ligação. No final desse capítulo, são apresentadas comparações dos resultados experimentais com os valores da deformabilidade ao cisalhamento, obtidos por meio do equacionamento analítico proposto nesse capítulo, e com os valores das resistências de cisalhamento da ligação, obtidos por meio dos procedimentos teóricos da revisão teórica.

Finalmente, no Capítulo 5 é apresentado um estudo do comportamento da ligação viga-pilar resistente à flexão por meio de chapas soldadas, com base na sua resistência e na sua rigidez à flexão. Dentro da abordagem teórica, é apresentada uma revisão com as informações na literatura técnica sobre esta ligação. Também, é apresentada uma proposta de desenvolvimento analítico para o cálculo da deformabilidade à flexão da ligação, com 
base na associação dos mecanismos básicos na ligação. Dentro da abordagem experimental, são apresentados os resultados dos ensaios de flexão com carregamento alternado e cíclico, realizados para um protótipo monolítico e um protótipo com ligações soldadas. No final deste capítulo, são apresentadas comparações dos valores da deformabilidade à flexão, obtidos por meio do equacionamento analítico proposto nesse capítulo, e da estimativa da resistência da ligação, com base na sua rigidez, com os resultados experimentais obtidos nos ensaios de flexão. 


\section{Capítulo 2}

\section{Estruturas com Ligações Semi-Rígidas}

\subsection{Preliminares}

O termo "ligações semi-rígidas" vem do Inglês e foi utilizado inicialmente no estudo das estruturas metálicas, na década de 30, sendo incorporado recentemente ao estudo das estruturas de concreto pré-moldado. Esta notação, a princípio, tem sido empregada para relacionar a ligação com a sua deformabilidade à flexão, ou à sua flexibilidade. Todavia, este conceito pode ser estendido para outras formas de deformabilidades nas ligações, como por exemplo a deformabilidade ao cisalhamento, que é um importante parâmetro no estudo das ligações com apoio sobre almofada de elastômero e chumbador.

Quando se diz que as ligações possuem um comportamento semi-rígido, tem-se em mente um comportamento intermediário, em termos da flexão, entre a articulação e o engastamento perfeito, tendendo a se aproximar de uma das duas situações em função da flexibilidade da ligação.

A consideração das deformabilidades das ligações nas extremidades dos elementos da estrutura, promove uma modificação na rigidez dos elementos, gerando uma redistribuição dos esforços e deslocamentos ao longo de toda a estrutura.

\subsection{Parâmetros Relacionados à Rigidez da Ligação}

As principais propriedades de uma ligação são: resistência, rigidez e ductilidade. A resistência da ligação é uma função da resistência dos materiais que compõem a ligação. Entretanto, no caso de uma ligação ser super-armada, a geometria passa a ter uma influência maior sobre a resistência. A geometria é, por sua vez, o principal fator 
interveniente na rigidez inicial de uma ligação, $\mathrm{K}_{\phi}$. A rigidez inicial também é afetada pelas condições impostas à ligação no momento da sua execução, por exemplo, como as folgas e tolerâncias deixadas para os preenchimentos de juntas no local. Segundo GÖRGUN (1997), isto é particularmente relevante no caso das ligações grauteadas ou com chumbadores, onde para baixas ações iniciais pode-se ter a impressão de uma baixa rigidez, a qual tem o seu valor incrementado na medida em que as folgas vão diminuindo.

As ligações são caracterizadas em relação à sua rigidez em função do comportamento do seu diagrama $\mathrm{M}-\phi$, conforme apresentado na figura 2.1, onde a rigidez $\mathrm{K}_{\phi}$ da ligação é obtida pelo gradiente da curva $\mathrm{M}-\phi$, dado por:

$$
K_{\phi}=M / \phi
$$

onde:

M - Momento fletor interno à ligação

$\phi$ - Rotação da ligação associada ao momento $\mathrm{M}$

A relação inversa da rigidez rotacional da ligação é denominada de flexibilidade, $\lambda_{\phi}$, tendo-se portanto a relação

$$
\lambda_{\phi}=\phi / M
$$

A rigidez pode ser expressa em termos adimensionais, como sendo a razão entre a rigidez da ligação pela rigidez do elemento de viga à qual esta conectada, sendo:

$$
K_{s}=\frac{K_{\phi} \cdot \ell}{4 E_{c} I}
$$

onde:

$\mathrm{E}_{\mathrm{C}}-$ Módulo de Elasticidade do Concreto

I - Momento de Inércia da viga

$\ell$ - Vão efetivo da viga. 


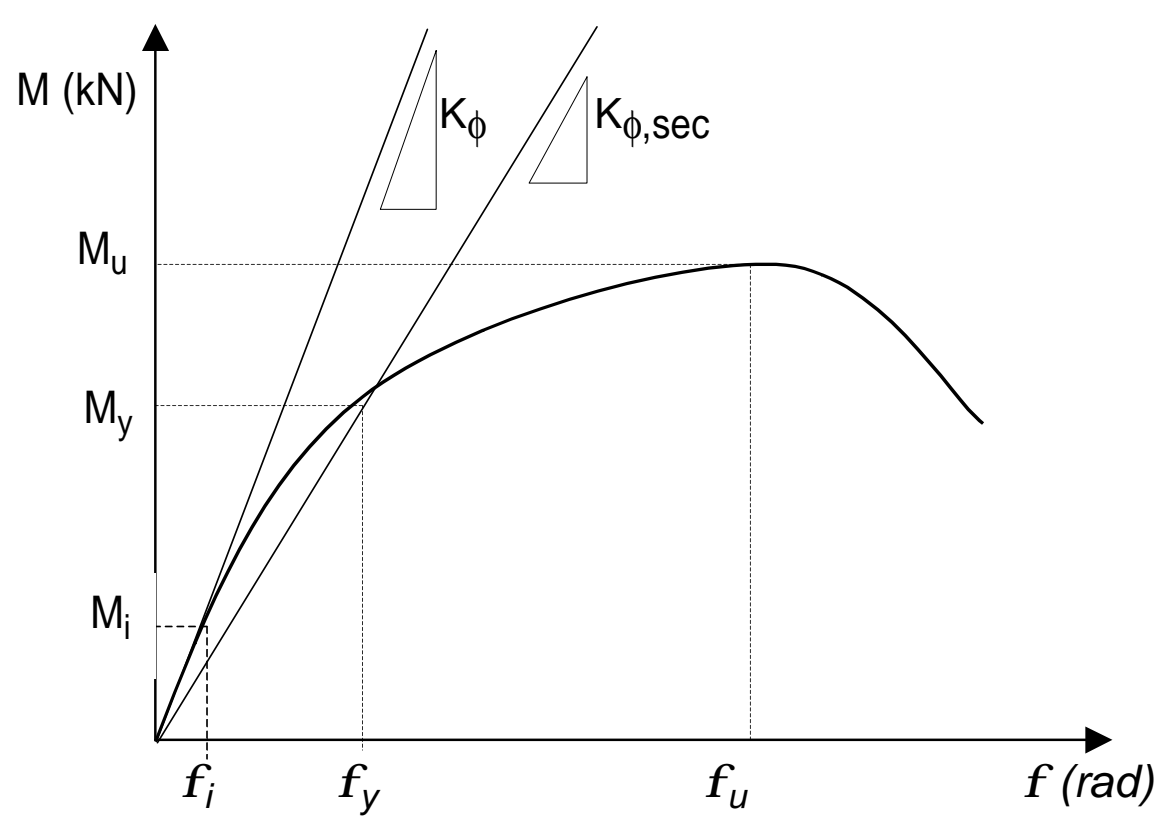

Figura 2.1 - Curva momento-rotação para uma ligação

As ligações podem ser classificadas em função da sua rigidez em três classes:

Classe 1: Ligações rígidas, com resistência total à flexão;

Classe 2: Ligações semi-rígidas, com resistência total ou parcial à flexão;

Classe 3: Ligações articuladas

Existem diferentes sistemas de classificação que estabeleceram limites de separação entre essas classes de rigidez para ligações semi-rígidas. BJORHOVDE et al. (1990) propôs um sistema baseado em diagramas M- $\theta$ bi-lineares, para os momentos e as rotações normalizados, conforme apresentado na figura 2.2. O EUROCODE 3 (1992) adota um sistema de classificação um pouco diferente que está baseado em diagramas M- $\phi$ normalizados tri-lineares, o qual faz uma diferenciação, no caso das ligações rígidas, entre as estruturas contraventadas e não contraventadas, conforme apresentado na figura 2.3. Na Tabela 2.1 são apresentados os limites de rigidez entre as três categorias de ligações, segundo Bjorhovde e o EUROCODE 3. 


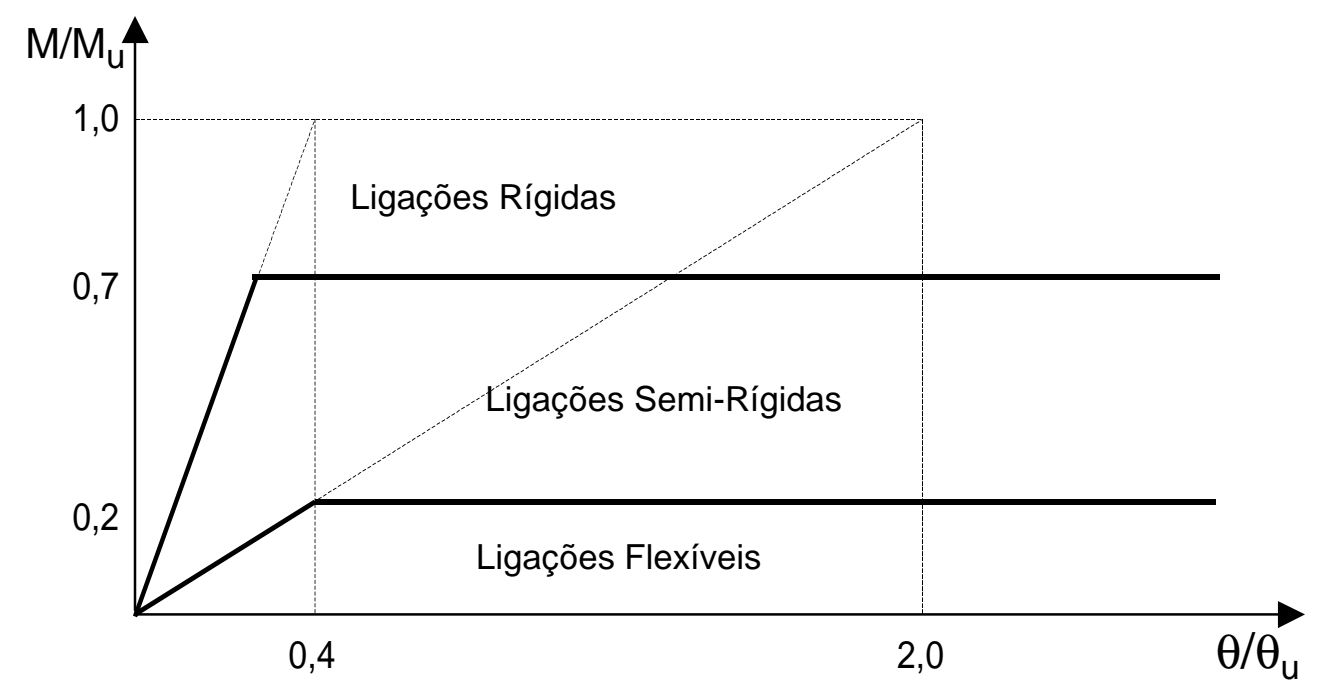

Figura 2.2 - Sistema de classificação para ligações semi-rígidas. [BJORHOVDE et al. (1990)]

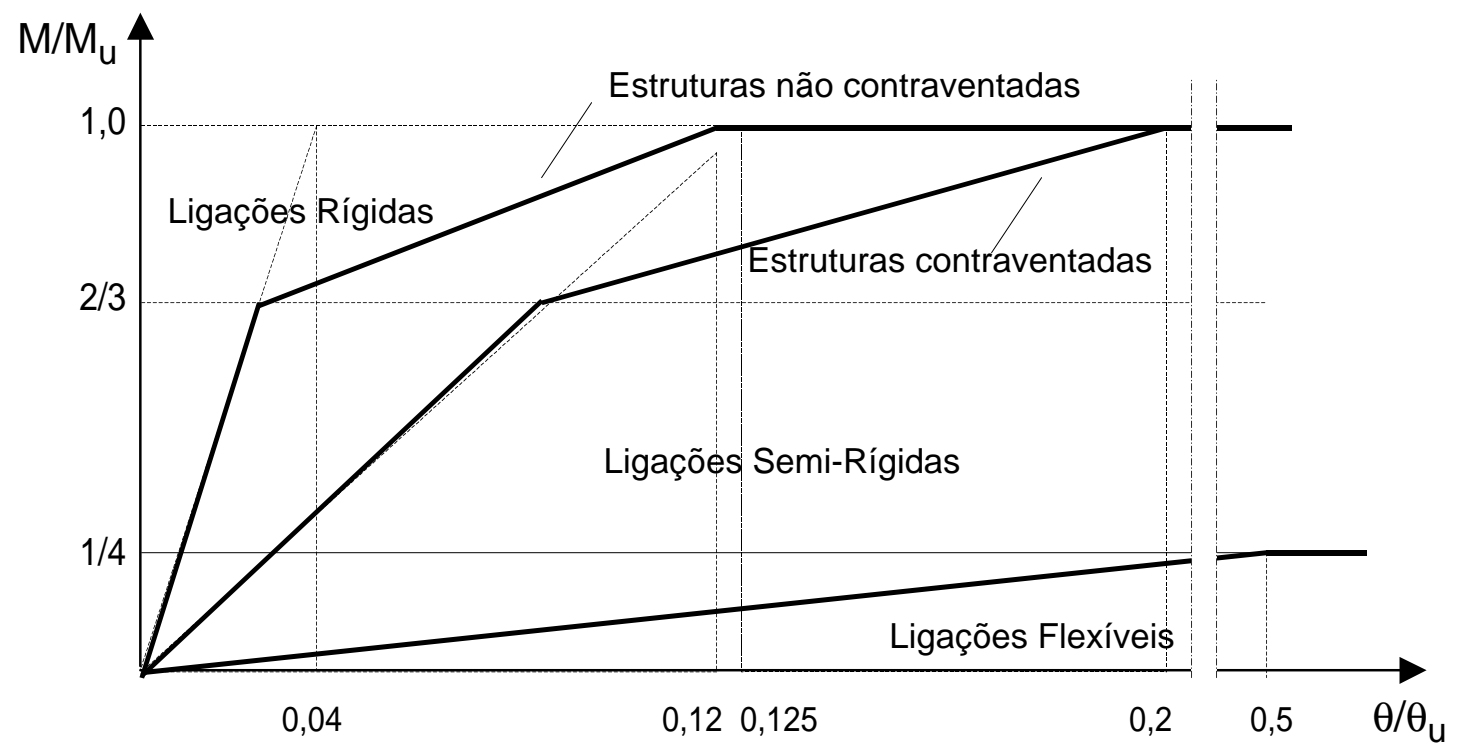

Figura 2.3 - Sistema de classificação para ligações semi-rígidas. [EUROCODE 3 (1992)]

Os momentos e rotações normalizados são dados por:

$$
\bar{M}=M / M_{\text {ultimo }} \quad \bar{\phi}=\phi / \phi_{\text {ulltimo }}
$$


Tabela 2.1: Limites entre as classes de rigidez.

\begin{tabular}{|c|c|c|c|}
\hline Rigidez inicial da ligação & EUROCOD & (1992) & BJ ORDHODVE \\
\hline $\mathrm{K}_{\phi}$ & $\begin{array}{c}\text { Estruturas não } \\
\text { contraventadas }\end{array}$ & $\begin{array}{c}\text { Estruturas } \\
\text { contraventadas }\end{array}$ & (1990) \\
\hline $\begin{array}{l}\text { Mínimo valor de } \mathrm{K}_{\phi} \text { para ligações } \\
\text { rígidas ou } \\
\text { Máximo valor de } \mathrm{K}_{\phi} \text { para ligações } \\
\text { semi-rígidas. }\end{array}$ & $\mathrm{K}_{\phi}=25 \mathrm{El} / \ell$ & $\mathrm{K}_{\phi}=8 \mathrm{El} / \ell$ & $\mathrm{K}_{\phi}=\mathrm{El} / 2 \mathrm{~d}$ \\
\hline $\begin{array}{l}\text { Mínimo valor de } k_{\phi} \text { para ligações semi- } \\
\text { rígidas ou } \\
\text { Máximo valor de } k_{\phi} \text { para ligações } \\
\text { flexíveis. }\end{array}$ & $\mathrm{K}_{\phi}=0,5 \mathrm{EI} / \ell$ & $\mathrm{K}_{\phi}=0,5 \mathrm{E} \mathrm{I} / \ell$ & $\mathrm{K}_{\phi}=\mathrm{El} / 10 \mathrm{~d}$ \\
\hline
\end{tabular}

(OBS: $d$ - altura da viga)

No caso de um elemento isolado de uma viga com duas ligações nas suas extremidades, tendo as duas a mesma rigidez $\mathrm{K}_{\phi}$, a solução para esta viga se aproxima de uma viga bi-apoiada para a rigidez da ligação tendendo à zero. Por outro lado, quando a rigidez da ligação tende ao infinito, então a solução para a viga se aproxima de uma viga bi-engastada. Na figura 2.4 são apresentadas as configurações de um elemento de viga, para um carregamento uniforme q, com ligações flexíveis, semi-rígidas e rígidas.

A rigidez das ligações viga-pilar influi na estabilidade das estruturas aporticadas com pilares contínuos, conforme ilustrado na figura 2.5. Neste caso, a consideração das ligações semi-rígidas faz com que haja uma modificação dos efeitos de segunda ordem sobre a estrutura. Em MAHDI (1992), ELLIOTT (1992) e ELLIOTT (1998a) são apresentados estudos sobre a influência da rigidez das ligações na estabilidade das estruturas pré-moldadas.

Uma ligação em uma estrutura pré-moldada não pode ser entendida como sendo apenas um nó da estrutura, mas sim como sendo uma região da estrutura. A região da ligação se distingue dos outros elementos estruturais por ser uma região com comportamento singular, com concentração de tensões, onde as deformações e deslocamentos podem não ser desprezíveis, mesmo para a ações de serviço. De fato, este é um dos motivos que dificulta a modelagem matemática desta região. Desta forma, a ligação pode ser definida como mais um elemento intermediário que faz a ponte entre dois elementos estruturais, como no caso da viga e do pilar. 


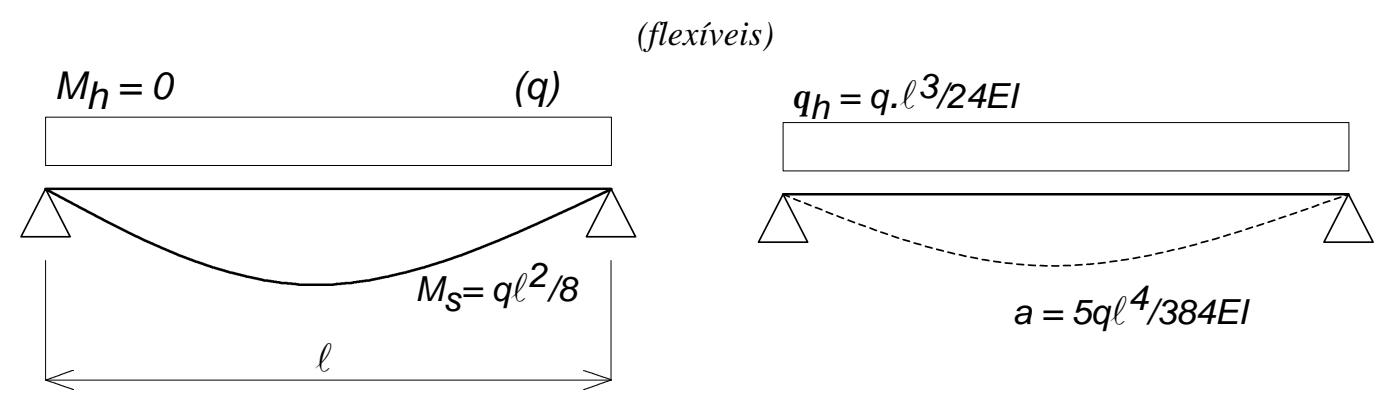

(rígidas)
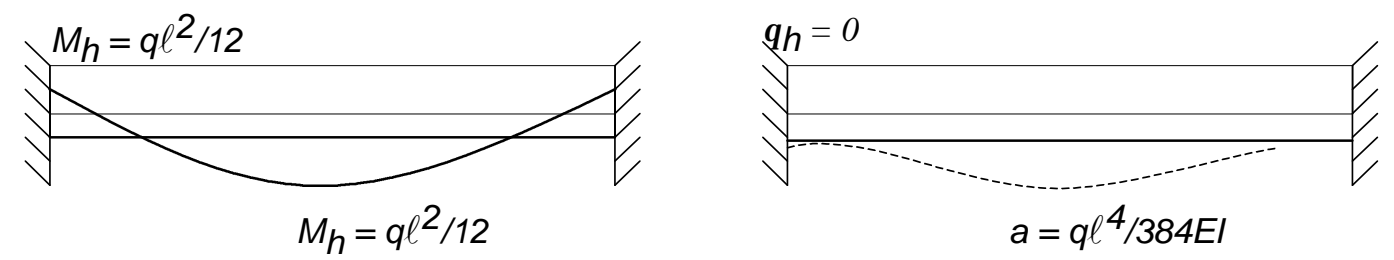

(semi-rígidas)
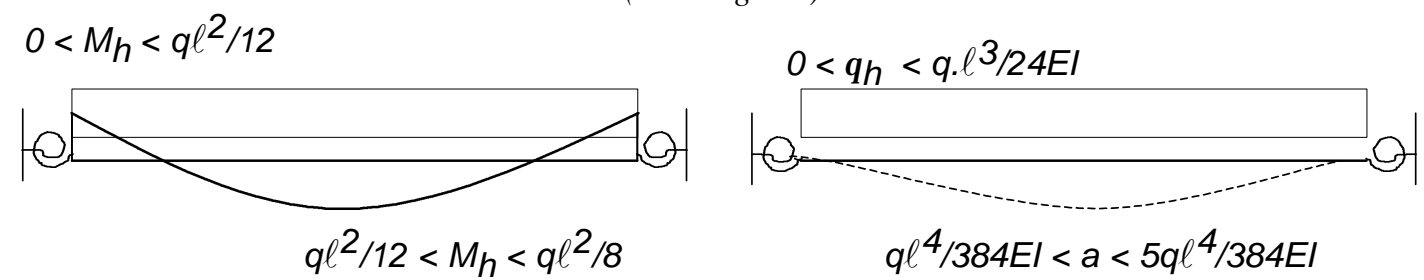

Figura 2.4 - Influência da deformabilidade da ligação no comportamento da viga.

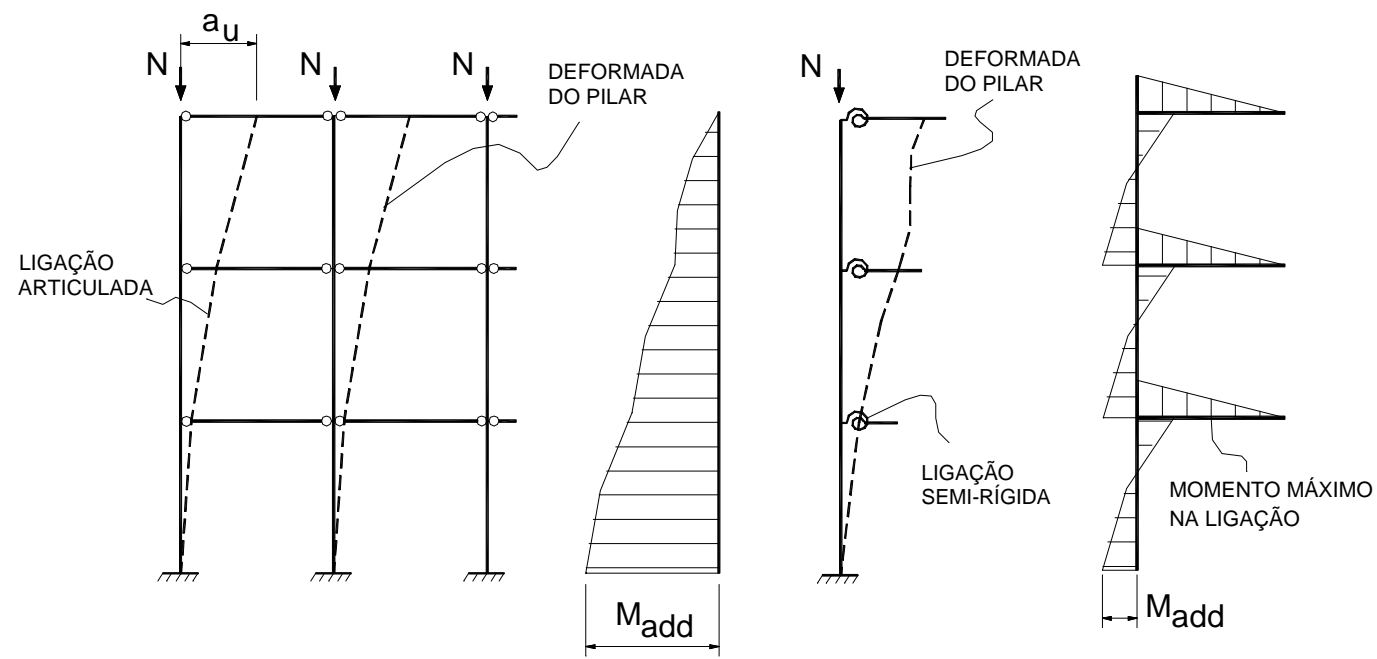

Figura 2.5 - Influência da deformabilidade da ligação na estabilidade da estrutura. [ELLIOTT (1992)] 


\subsection{Método para Análise Linear de Pórticos com Nós Semi-Rígidos.}

A teoria para a análise estrutural de pórticos com nós semi-rígidos está amplamente divulgada na literatura técnica. MONFORTON \& WU (1963) desenvolveram um método para a análise linear de estruturas com nós semi-rígidos que tem servido de base para vários outros trabalhos, como BRUN \& PICARD (1976), FAFARD \& PICARD (1990), FERREIRA (1993), CHIKHO \& KIRBY (1995), GIBBONS et al. (1996) entre outros.

No método dos deslocamentos, as incógnitas a considerar são os deslocamentos nodais da estrutura. $\mathrm{Na}$ resolução do problema utiliza-se a estrutura restringida, que é cinematicamente determinada, de modo que os deslocamentos desconhecidos sejam nulos. Ao se restringir os nós, associa-se os esforços de bloqueio aos deslocamentos nodais. Nos pórticos com nós rígidos, os deslocamentos de extremidades dos elementos são os mesmos que os deslocamentos nodais, sendo o número de incógnitas o mesmo que o número de deslocabilidades internas. Ao se trabalhar com um pórtico com ligações semi-rígidas estáse, a princípio, aumentando o número de deslocabilidades internas, aumentando o número de incógnitas, mas permanecendo o mesmo número de equações.

Os momentos nas extremidades elasticamente restritas de uma barra carregada resultam de três origens:

a) dos esforços de bloqueio;

b) dos deslocamentos das extremidades dos elementos;

c) dos deslocamentos relativos das extremidades dos elementos.

Ao se introduzir as deformabilidades das ligações, estas contribuirão para os momentos nas extremidades dos elementos. A deformabilidade da ligação está relacionada de forma interdependente ao três fatores citados acima. Segundo Monforton, por esta razão não é possível se obter a relação força-deslocamento pela aplicação da superposição, como é feito no caso das ligações rígidas.

No processo proposto por MONFORTON \& WU (1963), utiliza-se o mesmo modelo matemático do método dos deslocamentos para pórticos com nós rígidos, mantendo-se a indeterminação cinemática, mas corrigindo-se a matriz de rigidez dos elementos e ainda os esforços de bloqueio em função das deformabilidades em suas extremidades. Desta forma, não se adiciona novas condições de vinculações aos nós da 
estrutura. Por outro lado, corrige-se os parâmetros ligados aos elementos, utilizando-se da notação de rigidez equivalente. Na montagem da matriz de correção são consideradas apenas as deformabilidades nas extremidades das barras relativas aos esforços de flexão. Em FERREIRA (1993), foram acrescentadas molas horizontais nas extremidades das barras relativas à deformabilidade axial. Na figura 2.6 é apresentado um elemento de barra com as respectivas deformabilidades nas extremidades da barra.

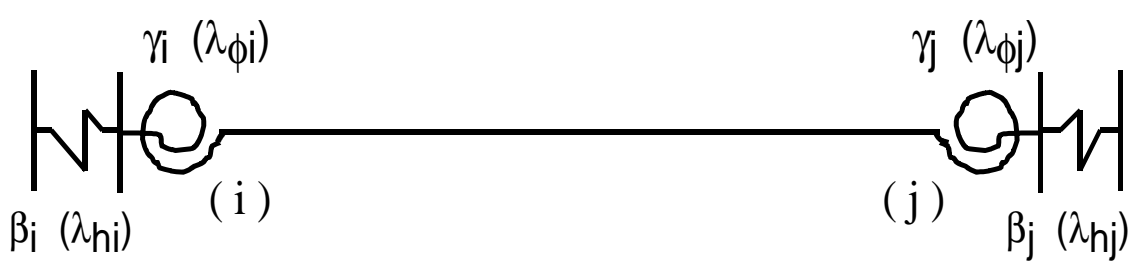

Figura 2.6 - Esquema com "molas” para representação das deformabilidades nas extremidades de uma barra [FERREIRA (1993)]

A matriz de rigidez do elemento modificada, $\mathrm{K}$, pode ser escrita na forma:

$$
K=C \cdot S
$$

onde:

$S$ - matriz de rigidez elástica de um elemento

$C$ - matriz de correção da rigidez aplicada à matriz $\mathrm{S}$

Os esforços internos dos elementos são dados por:

$$
\begin{aligned}
& F_{i}=K_{i i} \cdot D_{i}+K_{i j} \cdot D_{j} \\
& F_{j}=K_{j i} \cdot D_{i}+K_{j j} \cdot D_{j}
\end{aligned}
$$

Podendo ser escritos na forma:

$$
\begin{aligned}
& F_{i}=S_{i i} \cdot C_{i i} \cdot D_{i}+S_{i j} \cdot C_{i j} \cdot D_{j} \\
& F_{j}=S_{j i} \cdot C_{j i} \cdot D_{i}+S_{j j} \cdot C_{j j} \cdot D_{j}
\end{aligned}
$$

onde: 
$F$ - forças internas

$D$ - deslocamentos locais de extremidade

A matriz de correção, $\mathrm{C}$, para a modificação das matrizes de rigidez dos elementos é dada por:

$$
\begin{gathered}
c_{i i}=c_{j i}=\left[\begin{array}{ccc}
\beta_{i} & 0 & 0 \\
0 & \frac{4 \gamma_{j}-2 \gamma_{i}+\gamma_{i} \gamma_{j}}{\left(4-\gamma_{i} \gamma_{j}\right)} & \frac{-2 \ell \gamma_{i}\left(1-\gamma_{j}\right)}{\left(4-\gamma_{i} \gamma_{j}\right)} \\
0 & \frac{6}{\ell} \frac{\gamma_{j}-\gamma_{i}}{\left(4-\gamma_{i} \gamma_{j}\right)} & \frac{3 \gamma_{i}\left(2-\gamma_{j}\right)}{\left(4-\gamma_{i} \gamma_{j}\right)}
\end{array}\right] \\
c_{i i}=c_{j j}=\left[\begin{array}{ccc}
\beta_{j} & \frac{4 \gamma_{i}-2 \gamma_{j}+\gamma_{i} \gamma_{j}}{\left(4-\gamma_{i} \gamma_{j}\right)} & \frac{2 \ell \gamma_{j}\left(1-\gamma_{i}\right)}{\left(4-\gamma_{i} \gamma_{j}\right)} \\
0 & \frac{6}{\ell} \frac{\gamma_{i}-\gamma_{j}}{\left(4-\gamma_{i} \gamma_{j}\right)} & \frac{3 \gamma_{j}\left(2-\gamma_{j}\right)}{\left(4-\gamma_{i} \gamma_{j}\right)}
\end{array}\right]
\end{gathered}
$$

sendo:

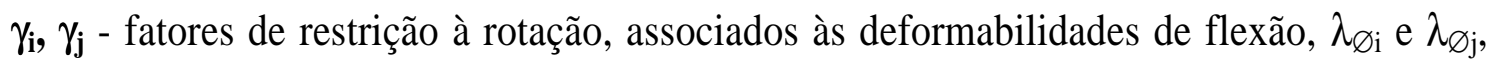
dados por:

$$
\gamma_{i}=\left(1+\frac{3 \mathrm{EI}_{z} \lambda_{\phi i}}{\ell}\right)^{-1} \quad \gamma_{j}=\left(1+\frac{3 \mathrm{El}_{z} \lambda_{\phi j}}{\ell}\right)^{-1}
$$

$\beta_{\mathbf{i}}, \beta_{\mathbf{j}}$ - fatores de restrição ao deslocamento axial na extremidade de uma barra, associados às deformabilidades nas ligações na direção axial ao elemento de barra, $\lambda_{\text {hi }}$ e $\lambda_{\text {hj }}$, dador por:

$$
\beta_{\mathrm{i}}=\beta_{\mathrm{j}}=\frac{\ell}{\mathrm{EA}}\left(\lambda_{\mathrm{hi}}+\lambda_{\mathrm{hj}}+\frac{\ell}{\mathrm{EA}}\right)^{-1}
$$


Segundo FAFARD (1990), a matriz de correção para os esforços de engastamento, escrita em função dos parâmetros $\gamma_{\mathbf{i}} \mathrm{e} \gamma_{\mathbf{j}}$ pode ser escrita por:

$$
\left\{\begin{array}{l}
M_{i} \\
M_{j}
\end{array}\right\}=\left[C_{f}\right] \cdot\left\{\begin{array}{l}
M_{i}^{p} \\
M_{j}^{p}
\end{array}\right\}
$$

sendo:

$$
\left[C_{f}\right]=\frac{1}{\left(4-\gamma_{i} \gamma_{j}\right)}\left[\begin{array}{cc}
\gamma_{i}\left(4-\gamma_{j}\right) & 2 \gamma_{i}\left(\gamma_{j}-1\right) \\
2 \gamma_{j}\left(\gamma_{i}-1\right) & \gamma_{j}\left(4-\gamma_{i}\right)
\end{array}\right]
$$

onde:

$M^{p}$ - momento de engastamento perfeito

$C_{f}$ - matriz de correção para os esforços de bloqueio

A partir desta expressão pode-se obter as equações para os esforços de engastamento corrigidos para cada tipo de carregamento. Em FERREIRA (1993) estão desenvolvidos os equacionamentos para os carregamentos mais freqüentes.

Utilizando-se o método dos deslocamentos, a equação dos esforços internos na extremidade de uma barra é dada pela soma dos esforços associados aos deslocamentos locais aos esforços de bloqueio. Tendo-se assim:

$$
\begin{aligned}
& P_{i}=F_{i}+P_{i} \\
& P_{j}=F_{j}+P_{j}
\end{aligned}
$$

onde:

$P_{i}$ - esforços de extremidade das barras

$F_{i}$ - esforços devido aos deslocamentos locais

$P_{i}$ - esforços de bloqueio

$\mathrm{Na}$ forma geral, estas expressões podem ser escritas por:

$$
P_{m}=S_{m} \cdot C_{m} \cdot D_{m}+P_{m}
$$


Sendo D' os k deslocamentos nodais desconhecidos referidos ao sistema global e U a matriz de ordem 6n.k, composta de matrizes de transformação T, relacionados a cada elemento por:

$$
D=U \cdot D^{\prime}
$$

A equação para $P_{m}$ pode ser escrita por:

$$
P_{m}=S_{m} \cdot C_{m} \cdot U_{m} \cdot D_{m}^{\prime}+P_{m}
$$

No desenvolvimento de Monforton e $\mathrm{Wu}$, os deslocamentos de extremidades das barras ainda estão associados aos deslocamentos nodais, não levando em conta os deslocamentos das ligações. Os deslocamentos finais nas extremidades das barras da estrutura podem ser obtidos pela soma dos deslocamentos nas extremidades das barras, com rigidez modificada, com os deslocamentos das ligações em suas extremidades, o que também está ilustrado na figura 2.7.

$$
\phi_{\text {barra }}=\theta_{\text {nodal }}+\phi_{\text {lig }}
$$

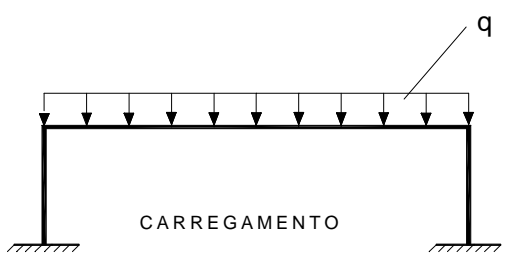

q
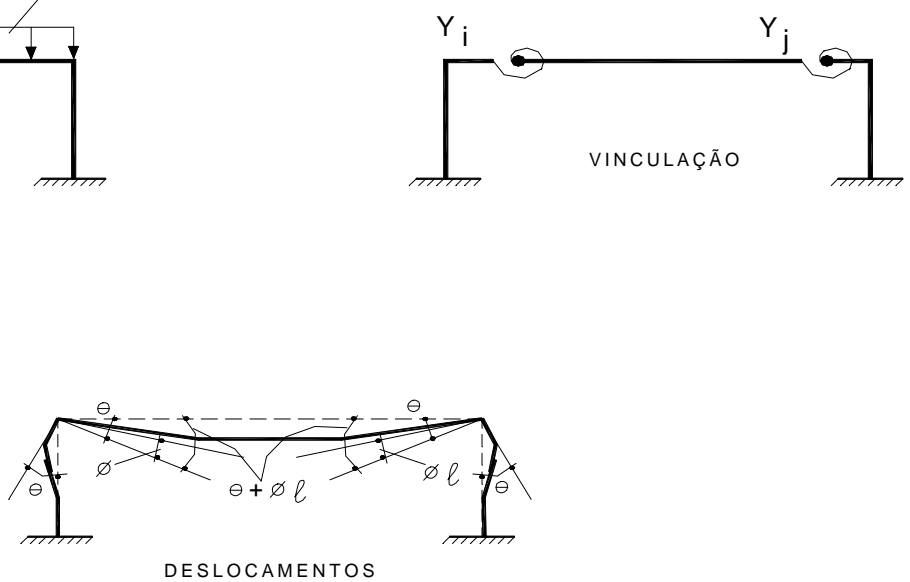

Figura 2.7 - Representação das rotações nas extremidades dos elementos com rigidez modificada $(\theta)$, nas ligações $\left(\phi_{l}\right)$ e nas extremidades das barras com rigidez modificada $\left(\theta+\phi_{l}\right)$. 


\subsection{Validade da aproximação linear para a Análise Estrutural}

No desenvolvimento proposto por Monforton e Wu, a relação momento-rotação da ligação foi considerada como sendo linear. Segundo FAFARD (1990), vários autores têm proposto métodos aproximados com a consideração da linearidade. GIBBONS et al. (1996) propuseram um procedimento para a análise de pórticos com nós semi-rígidos, assumindo um comportamento linear para o pórtico e aproximando o comportamento nãolinear da ligação, através da utilização da rigidez secante da ligação. Segundo estes autores, uma análise com consideração da não linearidade não seria muito apropriada para rotinas de cálculo dos escritórios de projeto. CHIKHO \& KIRBY (1995) apresentam um método aproximado para o cálculo dos esforços em pórticos com nós semi-rígidos. Eles partiram das mesmas equações básicas desenvolvidas por MONFORTON \& WU (1963) e também propuseram um método interativo para a obtenção de uma rigidez secante, a partir da rigidez inicial, para contornar o problema da não linearidade na ligação.

Outros autores, como BRUN e PICARD (1976), consideraram a não linearidade da relação momento-rotação nas ligações através de processos interativos. RAGUPATHY (1990) estudou o comportamento não linear em estruturas pré-moldadas de concreto.

Assim, a rigidez inicial, tangente da curva momento-rotação, tem sido bastante utilizada por vários pesquisadores na análise de pórticos com nós semi-rígidos por causa da relativa facilidade para a sua determinação por meio de gráficos ou meios analíticos. Através do procedimento ilustrado na figura 2.8, pode-se observar que o momento da ligação aparente, M'lig, obtido pela aproximação linear, está superestimado em relação ao

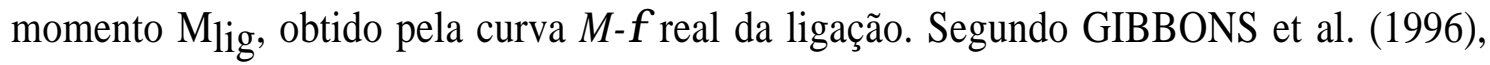
esta superestimativa da rigidez inicial produz um pequeno decréscimo nos deslocamentos da estrutura, desde que dentro de um limite para as rotações. Quanto ao valor referencial para esse limite de rotação, BJORHOVDE (1984) concluiu que para rotações da ordem de até $0,01 \mathrm{rad}$, o valor de $\mathrm{M}^{\prime}$ lig se aproxima de $\mathrm{M}_{\mathrm{lig}}$, sendo que para valores maiores que este limite, as características não lineares das ligações são bastante significantes. Segundo GIBBONS et al. (1996), a maior parte dos momentos de projetos em ligações, no caso das estruturas metálicas, são atingidos para rotações menores que 0,01 rad. Entretanto, esse autor sugere uma aproximação mais conservativa através da consideração da rigidez 
secante linear. Todavia, para o caso de ligações com curvas $M-\phi$ mais abatidas, Gibbons sugere que se considere a rigidez secante correspondente ao momento resistente de projeto da ligação.

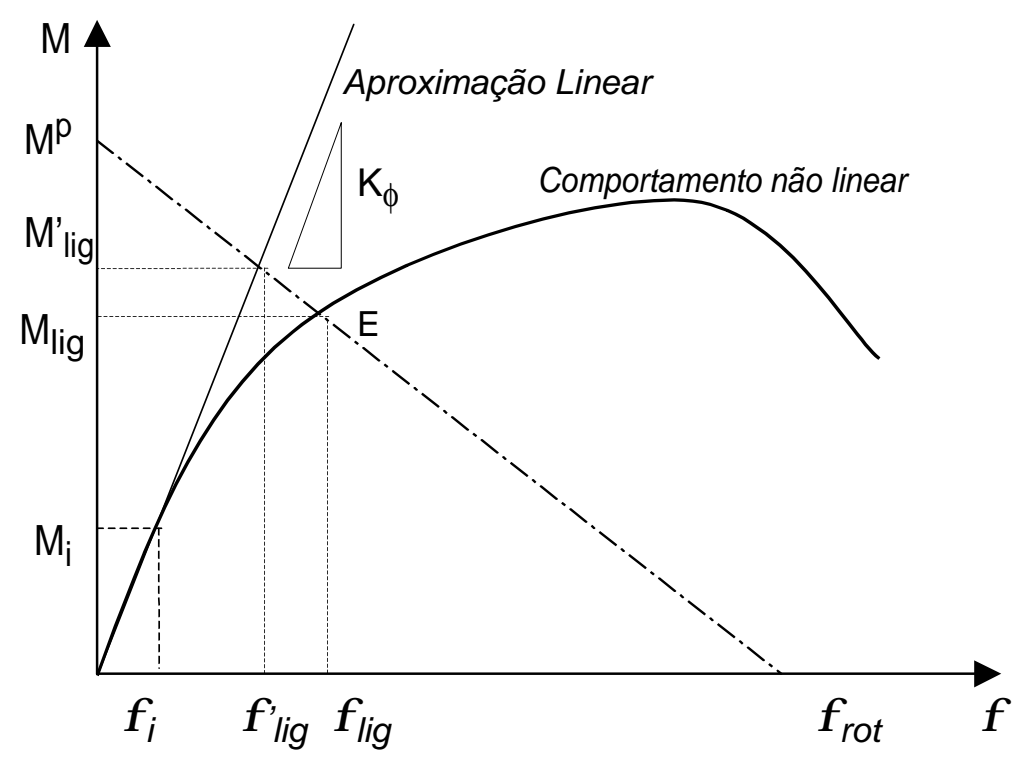

Figura 2.8 - Comparação entre os pontos de interseção da rigidez inicial da ligação, $K \phi$, e da curva M- $\phi$ da ligação com a reta "Beam-Line".

RAGUPATHY \& VIRDI (1996) realizaram um estudo comparativo entre a análise de uma estrutura com nós semi-rígidos, baseado num processo simplificado com aproximação linear para a rigidez da ligação, e a utilização de um método de análise não linear, por meio de um programa computacional. Estes autores concluíram que, desde que os momentos nas ligações não ultrapassem a sua capacidade máxima, as ligações podem ser consideradas com um comportamento linear. Eles também concluíram que o método de análise com aproximação linear apresentou uma boa correlação com o método de análise não linear, dentro de um limite para os valores da rigidez da ligação tais que:

$$
K_{\phi} \geq 0,5 . \frac{E . I}{\ell}
$$

Este limite coincide com o limite inferior para ligações semi-rígidas definido pelo EUROCODE-3, conforme já apresentado no Quadro 2.1. Desta forma, pode-se concluir que a utilização de aproximações lineares é bastante razoável para aplicações usuais de projeto. 


\subsection{Influência da Deformabilidade da Ligação na Rigidez de um Elemento de Viga}

\subsubsection{Influência do Fator de Restrição da Ligação, $\gamma$}

$\mathrm{O}$ fator de restrição, $\gamma$, proposto por Monforton e Wu representa a relação entre a rotação da extremidade da viga devida à aplicação de um momento unitário, $\theta_{m l}$, e a rotação devida a este mesmo momento acrescida da rotação devido à própria ligação $\phi_{\text {lig. }}$.

$$
\gamma=\frac{\theta_{m 1}}{\theta_{m 1}+\phi_{\text {lig }}}
$$

A relação entre o momento na ligação, $M$, pelo momento de engastamento perfeito, $M^{p}$, escrita em função do fator de restrição, pode ser escrita como:

$$
\frac{M}{M^{p}}=\frac{3 \cdot \gamma}{(2+\gamma)}
$$

A presença das ligações semi-rígidas faz com que haja uma redistribuição entre os momentos nas extremidades, $M_{\text {ext }}$, e no meio do vão da viga, $M_{v a \tilde{o}}$. Na figura 2.9 é apresentada a variação dos momentos normalizados nas extremidades e no vão de uma viga com carregamento uniforme e com ligações iguais, em função do fator de rigidez, $\gamma$, correspondente às ligações.

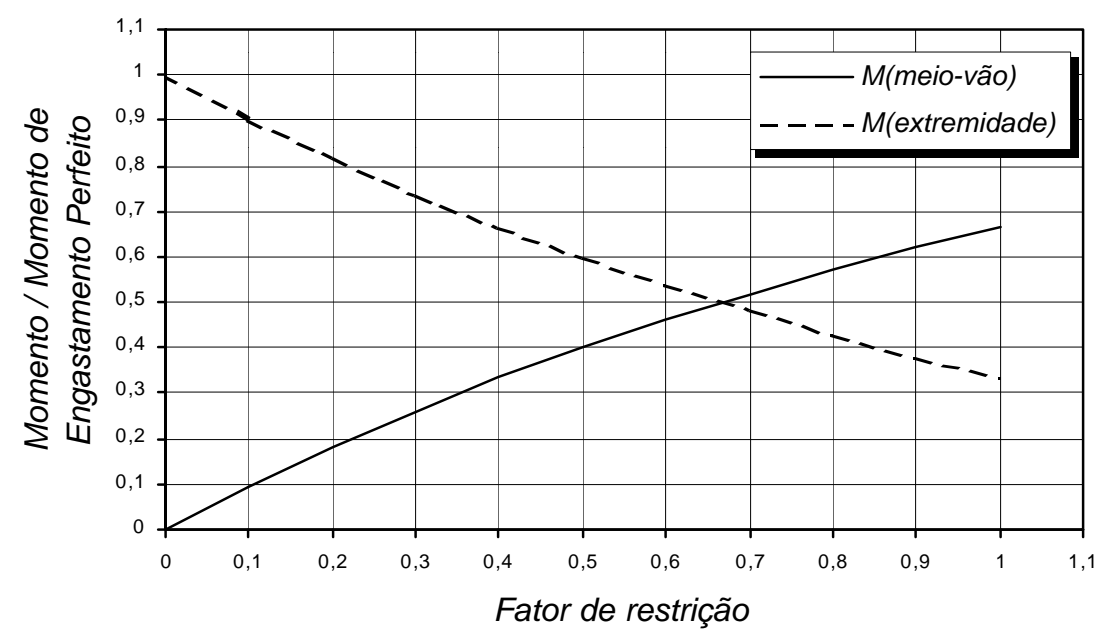

Figura 2.9 - Variação dos momentos normalizados nas extremidades e no meio do vão de uma viga em função do fator de rigidez, $\gamma$. 
A relação existente entre o fator de restrição, $\gamma$, e a rigidez equivalente da ligação, $K_{S}$, é dada por:

$$
K_{s}=\frac{3 \cdot \gamma}{4 \cdot(1-\gamma)}=0,75 \cdot \frac{\gamma}{(1-\gamma)}
$$

onde:

$$
\text { para } \gamma \rightarrow 1 \text {, tem-se: } K_{S} \rightarrow \infty
$$

\subsubsection{Influência da Rigidez Equivalente da Ligação, $K_{\mathrm{S}}$ •}

A partir da figura 2.10, onde é apresentada a variação dos momentos normalizados nas extremidades e no meio do vão da viga em função da rigidez equivalente da ligação $\left(K_{S}\right)$, tem-se as seguintes relações:

$$
\begin{array}{ll}
K_{S}=1,50 & M_{\text {ext }}=M_{v \tilde{a} o} \\
K_{S}>1,50 & M_{\text {ext }}>M_{v \tilde{a} o} \\
K_{S}<1,50 & M_{\text {ext }}<M_{v \tilde{a} o}
\end{array}
$$
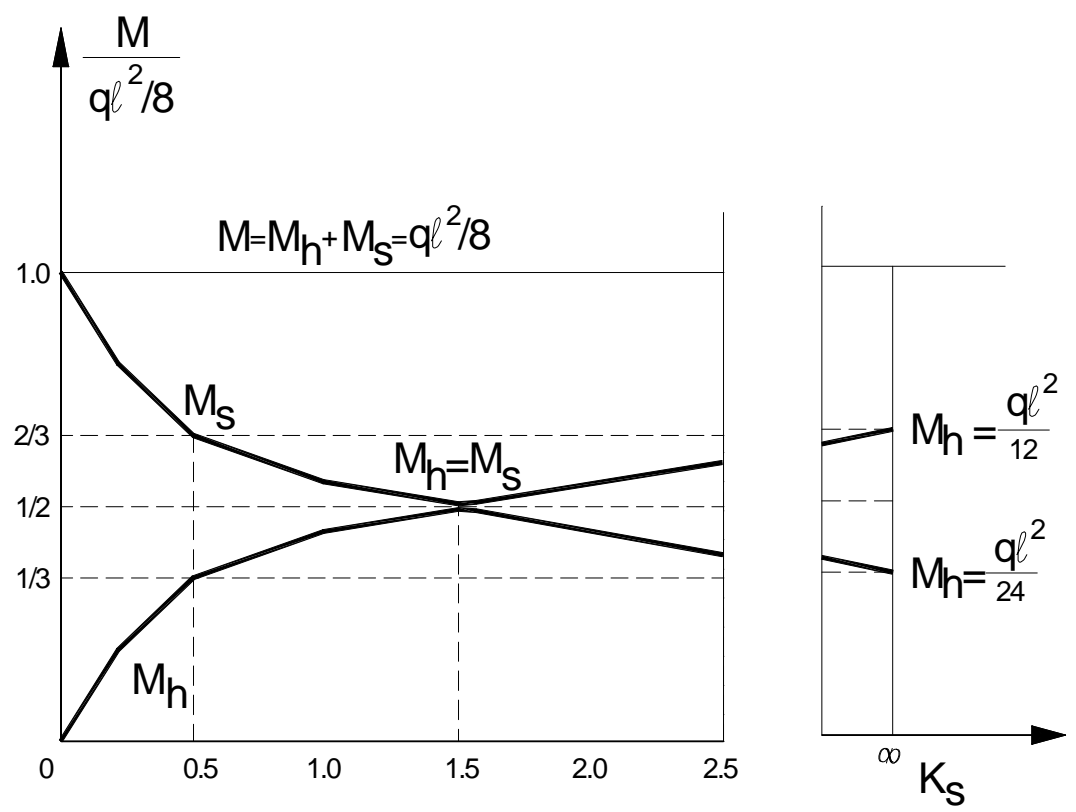

Figura 2.10 - Variação dos momentos normalizados nas extremidades e no meio do vão de uma viga em função da rigidez equivalente, $K_{S}$. 
A flecha no meio do vão de uma viga bi-apoiada com carregamento uniforme é dada por:

$$
a_{1}=\frac{5 \cdot q \cdot \ell^{4}}{384 \cdot E \cdot I}
$$

A flecha no meio do vão de uma viga bi-engastada com carregamento uniforme é dada por:

$$
\begin{aligned}
& a_{2}=\frac{q \cdot \ell^{4}}{384 \cdot E \cdot I} \\
& a_{2}=0,2 \cdot a_{1}
\end{aligned}
$$

Na Tabela 2.2 são apresentados alguns intervalos intermediários para a variação da flecha no meio do vão em função da rigidez equivalente da ligação, $K_{S}$.

Tabela 2.2 - Variação da flecha em função da rigidez equivalente, $K_{S}$.

\begin{tabular}{|c|c|}
\hline $\mathrm{K}_{\mathrm{S}}=0$ & $\mathrm{a}_{1}=5 . q . \mathrm{L}^{4} /(384 \mathrm{EI})$ \\
\hline $0<\mathrm{K}_{\mathrm{S}}<0,5$ & $\mathrm{a}_{1}>\mathrm{a}>0,6 . \mathrm{a}_{1}$ \\
\hline $0,5<\mathrm{K}_{\mathrm{S}}<1,5$ & $0,6 . \mathrm{a}_{1}>\mathrm{a}>0,4 \cdot \mathrm{a}_{1}$ \\
\hline $1,5<\mathrm{K}_{\mathrm{S}}<\infty$ & $0,4 . \mathrm{a}_{1}>\mathrm{a}>0,2 \cdot \mathrm{a}_{1}$ \\
\hline $\mathrm{K}_{\mathrm{S}}=\infty$ & $\mathrm{a}_{2}=0,2 \cdot \mathrm{a}_{1}$ \\
\hline
\end{tabular}

Pode observar-se que a flecha, $a$, possui uma taxa de variação maior dentro do intervalo $0<K_{S}<0,5$, possui uma taxa de variação média dentro do intervalo $0,5<K_{S}<$ 1,5 , e possui uma taxa de variação baixa dentro do intervalo $1,5<K_{s}<\infty$. Desta forma, a partir de valores para a rigidez equivalente $K_{s}<1,5$, tem-se uma pequena variação da influência da rigidez da ligação sobre a rigidez do elemento de viga. Assim, também dentro deste intervalo a aproximação linear é bastante razoável. 


\subsection{Procedimentos Simplificados para a Análise de Vigas com Ligações Semi-rígidas}

\subsubsection{Método "Beam-Line" para Avaliação da Rigidez de Ligações Semi-rígidas}

O método "Beam-Line", válido para pórticos contraventados, foi desenvolvido inicialmente por Batho \& Rowan (1934) para a aplicação no estudo de ligações semirígidas em estruturas metálicas.

Este método consiste em um processo simplificado para estimar a resistência da ligação a partir da consideração da rigidez da ligação, sendo esta resistência compatível com o comportamento elástico da viga e com a rigidez da ligação.

A reta denominada "Beam-Line" é definida a partir dos pontos que unem as situações de engastamento perfeito e de articulação perfeita nas extremidades da viga, com $\mathrm{M}=\mathrm{M}^{\mathrm{p}}$ e $\mathrm{M}=0$ respectivamente, conforme apresentada na figura 2.11.

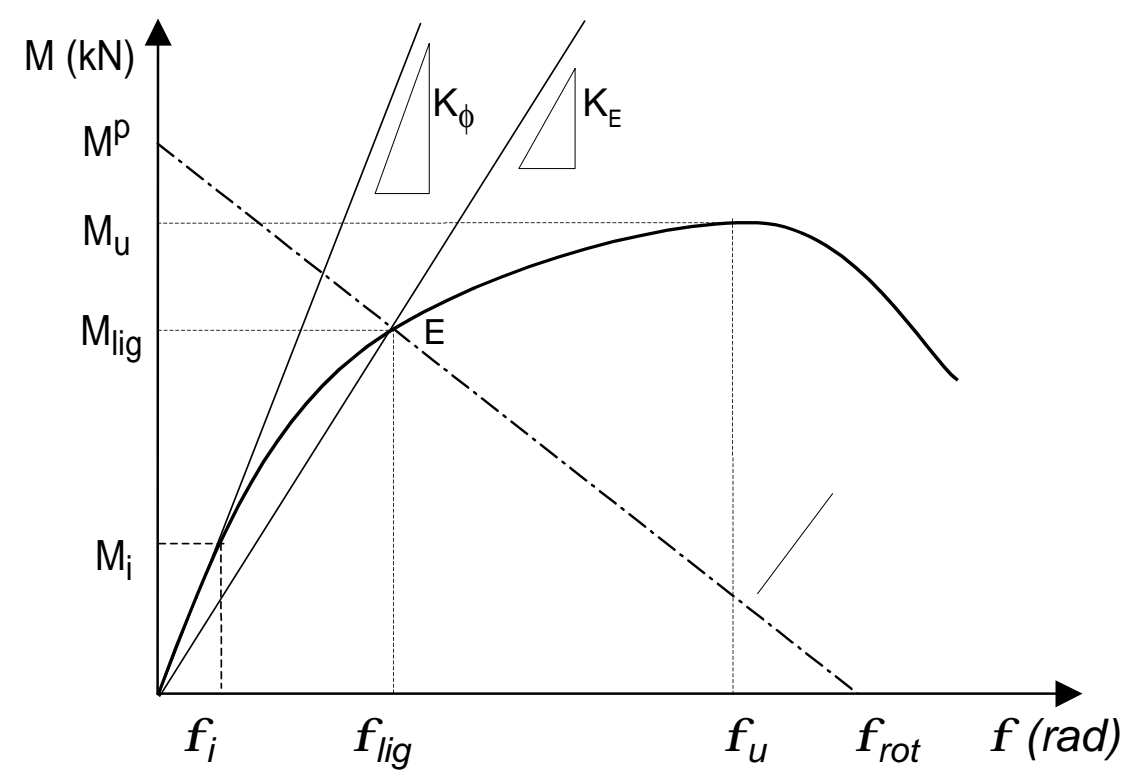

Figura 2.11 - Reta Beam-Line com a curva M- $\phi$ da ligação.

O trecho da curva M- $\phi$ da ligação que se encontra na região abaixo da reta "BeamLine", corresponde ao trecho de trabalho efetivo da ligação. O ponto limite para o trabalho da ligação, definido pelo ponto $E$, é corresponde à interseção da curva M- $\phi$ da ligação com a reta "Beam-line", conforme a figura 2.11. Em outras palavras, se a ruptura ocorrer no trecho abaixo da interseção da curva M- $\phi$ com a reta "Beam-Line", isto significa que a 
ruptura deverá ocorrer na ligação. Por outro lado, se a ruptura ocorrer após a interseção com a reta "Beam-Line", a ruptura deverá acontecer na região da viga.

A rotação na ligação, correspondente ao ponto $E$, é dada por:

$$
\phi_{E}=\frac{M_{E}}{K_{E}}
$$

ou:

$$
\phi_{E}=\frac{M_{E} \cdot l}{K_{s} \cdot 4 \cdot E \cdot I}
$$

onde:

$M_{E}-$ Momento Limite para a ligação

$\phi_{E}-$ Rotação da ligação no ponto de trabalho E.

$K_{E}-$ Rigidez secante para a ligação, correspondente ao ponto E.

$K_{S}$ - Rigidez equivalente da ligação em relação à rigidez à flexão da viga.

A equação para a Beam-Line, para uma viga com ligações semi-rígidas iguais nas duas extremidades, com carregamento simétrico, será dada por:

$$
\phi=\frac{\ell}{2 . E . I}\left(M^{p}-M\right)
$$

No caso de uma viga com carregamento uniformemente distribuído, para $\mathrm{M}=0$, tem-se:

$$
\phi_{\text {rot }}=\frac{\ell}{2 \cdot E \cdot I}\left(\frac{q \cdot \ell^{2}}{12}\right)=\frac{q \cdot \ell^{3}}{24 \cdot E \cdot I}
$$

Para uma viga com ligações semi-rígidas iguais nas duas extremidades, com carregamento anti-simétrico, a equação para a Beam-Line será dada por:

$$
\phi=\frac{\ell}{6 . E . I}\left(M^{p}-M\right)
$$

No caso das ações horizontais decorrentes do vento, seria:

$$
\phi=\frac{\ell}{6 . E . I}\left(M^{\text {vento }}-M\right)
$$


A relação entre o momento da ligação correspondente ao momento $M_{E}$ e o momento de engastamento perfeito $M^{p}$, escrita em função da rigidez equivalente $K_{S}$ pode ser escrita segundo a expressão:

$$
\frac{M_{E}}{M^{p}}=\left[\frac{K_{\phi}}{K_{\phi}+2 \cdot E \cdot I / \ell}\right]
$$

Substituindo-se a rigidez rotacional $K_{\phi}$ pela rigidez equivalente $K_{S}$, tem-se:

$$
\begin{aligned}
& \frac{M_{E}}{M^{p}}=\left[\frac{4 \cdot E \cdot I \cdot K_{s} / \ell}{4 \cdot E \cdot I \cdot K_{s} / \ell+2 \cdot E \cdot I / \ell}\right] \\
& \frac{M_{E}}{M^{p}}=\left[\frac{2 \cdot K_{s}}{2 \cdot K_{s}+1}\right]
\end{aligned}
$$

O Momento da ligação $M_{E}$, obtido pelo método Beam-Line, corresponde ao momento de engastamento perfeito corrigido, $M_{\text {corr }}^{p}$ para levar em conta a deformabilidade da ligação na rigidez da viga, apresentado no procedimento desenvolvido por MONFORTON \& WU (1963), conforme apresentado no ítem 2.2. Assim, o momento na ligação deverá ser sempre menor que o momento correspondente à interseção da curva M- $\phi$ da ligação com a reta Beam-line, dado por $M_{E}$. A partir desta definição, pode-se construir um diagrama bi-linear para a ligação, conforme a figura 2.12.

$$
M_{\text {lig }} \leq M_{E}=M_{\text {corr }}^{p}
$$

Baseados em estudos anteriores, como RAGUPATHY \& VIRDI (1996) e GÖRGUN (1997), onde foram analisados diferentes tipos de ligações, ELLIOTT et al. (1998b) propõem equações empíricas para as relações entre o momento máximo na ligação, dado por $M_{u}$, e o momento de engastamento perfeito $M^{p}$, escrita em função da rigidez equivalente $K_{S}$, para o caso da ligação em apenas um lado da coluna e para o caso de duas ligações opostas sobre a coluna, as quais são dadas por: 


$$
\begin{array}{ll}
\frac{M_{u}}{M^{p}}=0,87 \cdot \sqrt{K_{s}} & \text { (Ligação em um lado da coluna) } \\
\frac{M_{u}}{M^{p}}=0,62 \cdot \sqrt{K_{s}} & \text { (Ligação em dois lados da coluna) }
\end{array}
$$

Analisando-se estas expressões, pode-se concluir que o efeito da rigidez das ligações é maior nos casos onde se têm duas vigas adjacentes conectadas a pilares centrais, onde há uma maior restrição aos giros nodais, e menor para as situações de vigas conectadas a pilares de extremidade, com uma maior liberdade aos giros nodais.

Uma vez conhecidos $M_{u}$ e $M^{p}$, pode-se obter uma rigidez equivalente $K_{S}$ e, assim, obter o momento de projeto $M_{E}$, através das expressões anteriores.

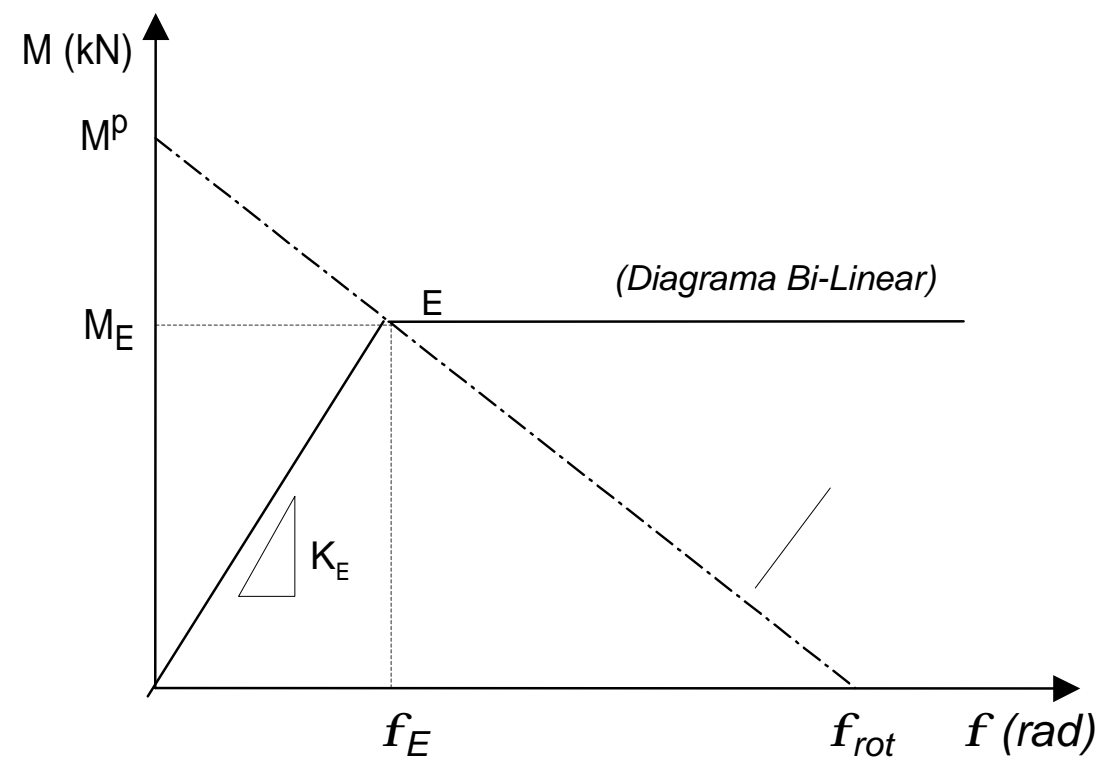

Figura 2.12 - Diagrama Bi-linear para uma ligação, construído a partir do método Beam-Line. 


\title{
2.6.2 Procedimento Proposto pelo Precast/Prestressed Concrete Institute (1988)
}

\author{
No DESIGN AND TYPICAL DETAILS OF CONNECTIONS FOR PRECAST \\ AND PRESTRESSED CONCRETE, PCI (1988), é apresentado um procedimento \\ simplificado, o qual está baseado no método "Beam-Line", para a avaliação da resistência \\ e da curvatura de uma ligação semi-rígida, com resistência à flexão, com vistas na \\ aplicação à prática de projeto de ligações de estruturas de concreto pré-moldado. \\ Esse procedimento consiste nos seguintes passos:
}

Passo 1: Traçar duas retas "Beam-Line" (M vs. $\left.\theta_{\text {rot }}\right)$ e $\left(\mathrm{M}_{\mathrm{u}}\right.$ vs. $\left.\theta_{\text {rot }}\right)$ para os momentos nas extremidades da viga, para as ações de serviço e as ações últimas:

Momento de engastamento perfeito na extremidade da viga, para ações de serviço:

$$
M=p \cdot \ell^{2} / 12, \text { onde }: \mathrm{p}=\mathrm{q}+\mathrm{g}
$$

Momento de engastamento perfeito, para as ações de projeto:

$$
M_{u}=p_{u} \cdot \ell^{2} / 12, \text { onde }: \mathrm{p}_{\mathrm{u}}=1,4 \mathrm{~g}+1,7 \mathrm{q}
$$

Rotação máxima na extremidade da viga, com ligações rotuladas, dada por:

$$
\theta_{r o t}=p \cdot \ell^{3} / 24 E_{c} I \quad \text { para } \mathrm{M}=0
$$

Passo 2: Traçar um diagrama momento-curvatura da ligação bi-linear, para:

Momento resistente da ligação, relativo ao escoamento das barras (negativas) na ligação:

$$
\phi \cdot M_{n}=\phi \cdot\left(A_{s} \cdot f_{y} \cdot d\right), \quad \operatorname{para} \phi=0,9
$$


Rotação na ligação correspondente ao momento $\phi \mathrm{M}_{\mathrm{n}}$ :

$$
\theta_{y}=\Delta h / d=\frac{f_{y} \cdot \ell}{E_{s} \cdot d}
$$

Passo 3: Obter graficamente os momentos permitidos na ligação e as suas correspondentes rotações através das interseções entre as retas $\left(\mathrm{M}\right.$ vs $\left.\theta_{\text {rot }}\right)$ e $\left(\mathrm{M}_{\mathbf{u}}\right.$ vs $\left.\theta_{\text {rot }}\right)$ com o diagrama momento-curvatura da ligação, obtidos nos passos 1 e 2, ou através das expressões (2.40) e (2.41).

Momento de Serviço permitido na ligação:

$$
M_{(i g)}=\theta_{r o t}\left(\frac{\theta_{y}}{\phi M_{n}}+\frac{\theta_{r o t}}{M}\right)
$$

Momento Último permitido na ligação:

$$
M_{u(l i g)}=\theta_{r o t} \prime\left(\frac{\theta_{y}}{\phi M_{n}}+\frac{\theta_{\text {rot }}}{M_{u}}\right)
$$

Passo 4: A capacidade de momento permitido obtido no passo 3 deve ser maior do que o momento da ligação calculado da análise estrutural, $M_{(\text {ext.) }}$, mas deve ser menor que a resistência de momento fletor da extremidade da viga, $M$. Esta verificação deve ser feita para as ações de serviço e para as ações últimas na ligação.

$$
\begin{aligned}
& M_{(e x t .)}<M_{(\text {lig. })}<M \\
& M_{u(\text { ext. })}<M_{u(\text { lig. })}<M_{u}
\end{aligned}
$$


Na figura 2.13 é apresentado um esquema do diagrama M- $\theta$ que foi construído a partir do procedimento proposto pelo PCI (1988).

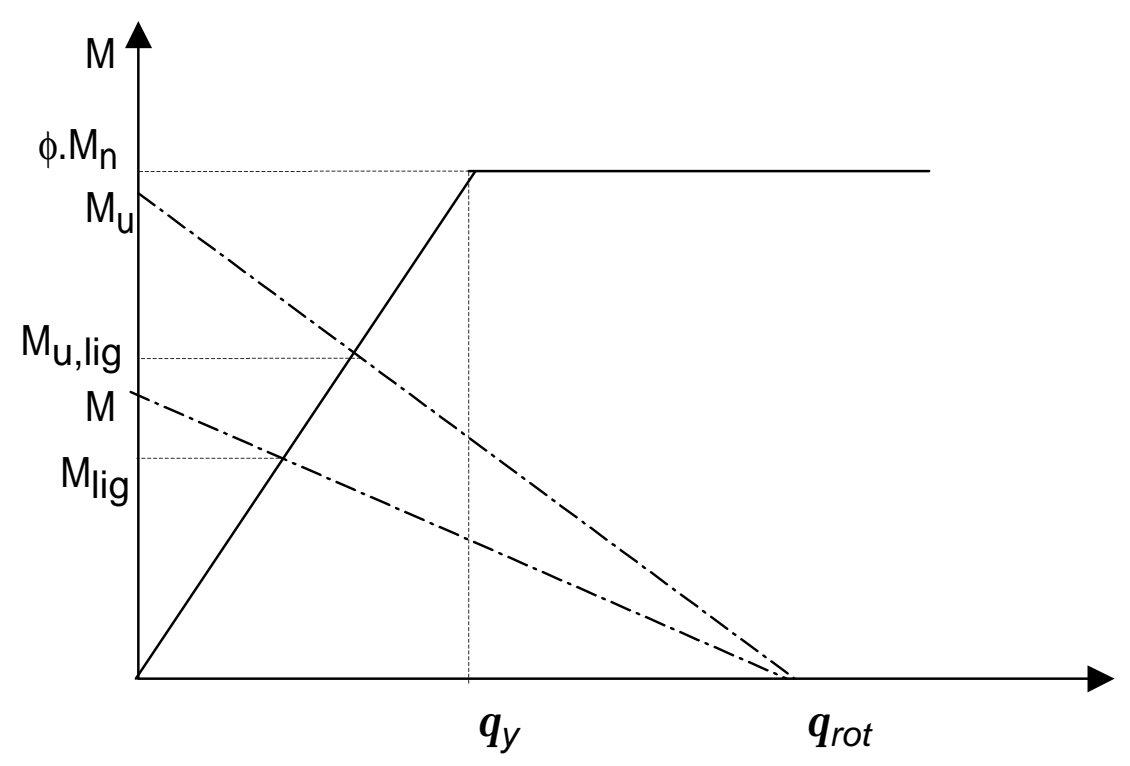

Figura 2.13- Procedimento de Projeto proposto pelo PCI (1988)

Sendo uma extensão do Método "Beam-Line", o procedimento proposto pelo PCI (1988) é uma indicação de uma preocupação atual em levar para os escritórios de projeto, por meio de procedimentos simplificados, ferramentas práticas para o projeto de ligações e de estruturas de concreto pré-moldado, com a considerando das deformabilidades em suas ligações.

Todavia, ainda a maior limitação para a aplicação prática destes procedimentos simplificados, e mesmo de toda a teoria aplicada ao estudo das estruturas com nós semirígidas, está no fato de que não se dispõe de uma base de dados experimentais, nem tão pouco de equacionamentos analíticos que possibilitem a determinação da rigidez das ligações, parâmetro fundamental dentro da teoria exposta no presente capítulo.

Assim, a aplicação do estudo das estruturas com nós semi-rígidos no projeto das estruturas de concreto pré-moldado deverá passar necessariamente pelo estudo das deformabilidades das ligações típicas utilizadas neste tipo de estrutura. 


\section{Capítulo 3}

\section{Mecanismos Básicos de Deformação Presentes nas Ligações}

\subsection{Preliminares}

O estudo das deformabilidades de ligações em estruturas de concreto pré-moldado, utilizando procedimentos analíticos que levem em conta os mecanismos de deformação existentes na ligação, tem sido definido como uma tendência metodológica somente a partir da última década.

Todavia, ainda hoje não existe uma bibliografia específica sobre este assunto. Alguns dos autores que tratam parcialmente deste assunto são MARTIN (1980) e BLJUGER (1988). Em MARTIN (1980) é apresentado um desenvolvimento para o equacionamento da deformabilidade à flexão de uma ligação com chapa parafusada na base de uma coluna. BLJUGER (1988) caracterizou alguns mecanismos de deformação presentes nas juntas dos sistemas estruturais em painéis pré-moldados, não tratando das deformabilidades de ligações em estruturas pré-moldadas. Todavia, esse trabalho contribuiu para a formação do conceito de que deformabilidade da ligação pode ser estudada a partir dos mecanismos de deformação dos elementos que compõe esta ligação.

Em FERREIRA (1993), iniciou-se na EESC-USP uma primeira tentativa de teorizar e sistematizar o estudo das deformabilidades nas ligações entre elementos de concreto pré-moldado, levando-se em conta os parâmetros internos que interferem na deformabilidade da ligação dentro de um único equacionamento, onde foram desenvolvidos os equacionamentos para as deformabilidades de diferentes ligações.

Os parâmetros internos, os quais estão relacionados às deformações dos elementos que compõem a ligação, foram denominados como "mecanismos básicos de deformação". O modelo analítico desenvolvido a partir deste método procura obter a deformabilidade de uma determinada ligação através de um equacionamento que represente o comportamento 
em conjunto dos mecanismos básicos de deformação presentes na ligação. Assim, este método consiste na avaliação de três fatores interdependentes:

a) os sistemas de vinculação adotados na ligação (modelo cinemático);

b) os esforços a serem transmitidos;

c) os mecanismos básicos de deformação a serem considerados.

A consideração dos esforços a serem transmitidos pela ligação depende da função estrutural a qual se pretende destinar a ligação, tendo-se em vista a distribuição dos esforços ao longo dos elementos estruturais e a estabilidade global da estrutura.

A escolha do sistema de vinculação em uma ligação depende dos esforços a serem transmitidos e também das condições de execução e de montagem da ligação.

Definido o sistema de vinculação, identificam-se os mecanismos básicos de deformação.

O cálculo é desenvolvido a partir da montagem do sistema de forças para a configuração deformada da ligação, associando-se a cada força uma deformação correspondente a um dado mecanismo de deformação (representada por uma mola). A expressão final, para a deformabilidade da ligação, resulta da associação das deformabilidades dos elementos da ligação.

Mais à frente, nos Capítulos 4 e 5, são apresentados dois equacionamentos analíticos desenvolvidos a partir desta metodologia, um equacionamento para o cálculo da deformabilidade ao cisalhamento de uma ligação viga-pilar com almofada de elastômero não fretado e chumbador e um equacionamento para o cálculo da deformabilidade à flexão de uma ligação viga-pilar resistente à flexão por com chapas soldadas, respectivamente.

No presente capítulo, o assunto tratado está limitado à apresentação da revisão teórica de alguns mecanismos básicos de deformação, os quais foram considerados de grande importância para o estudo das ligações escolhidas como objeto de estudo na presente pesquisa. Dentro deste assunto, também são apresentados neste capítulo os resultados de ensaios de compressão simples realizados em almofadas de elastômero não fretado, a partir dos quais foi proposta uma equação para a determinação do módulo de elasticidade da almofada de elastômero. 


\subsection{Mecanismos de Deformação de uma Barra Inserida em um Elemento de Concreto}

\subsubsection{Mecanismo de Deformação por Tração em uma Barra Inserida em um Elemento de Concreto (Comportamento Linear)}

Este mecanismo é muito freqüente nas ligações pré-moldadas. No presente trabalho, preocupou-se apenas com a definição do comprimento efetivo da barra a ser considerado no mecanismo deformação por tração de uma barra inserida em um elemento de concreto, considerando-se apenas a sua fase linear. Em ENGSTRÖM (1992.b) é apresentado um estudo sobre a ancoragem de barras após o seu escoamento.

Para o desenvolvimento analítico do mecanismo de deformação à tração na fase linear, considerou-se a deformação axial de uma barra tracionada de comprimento $\ell_{S}$, conforme indicado na figura 3.1.

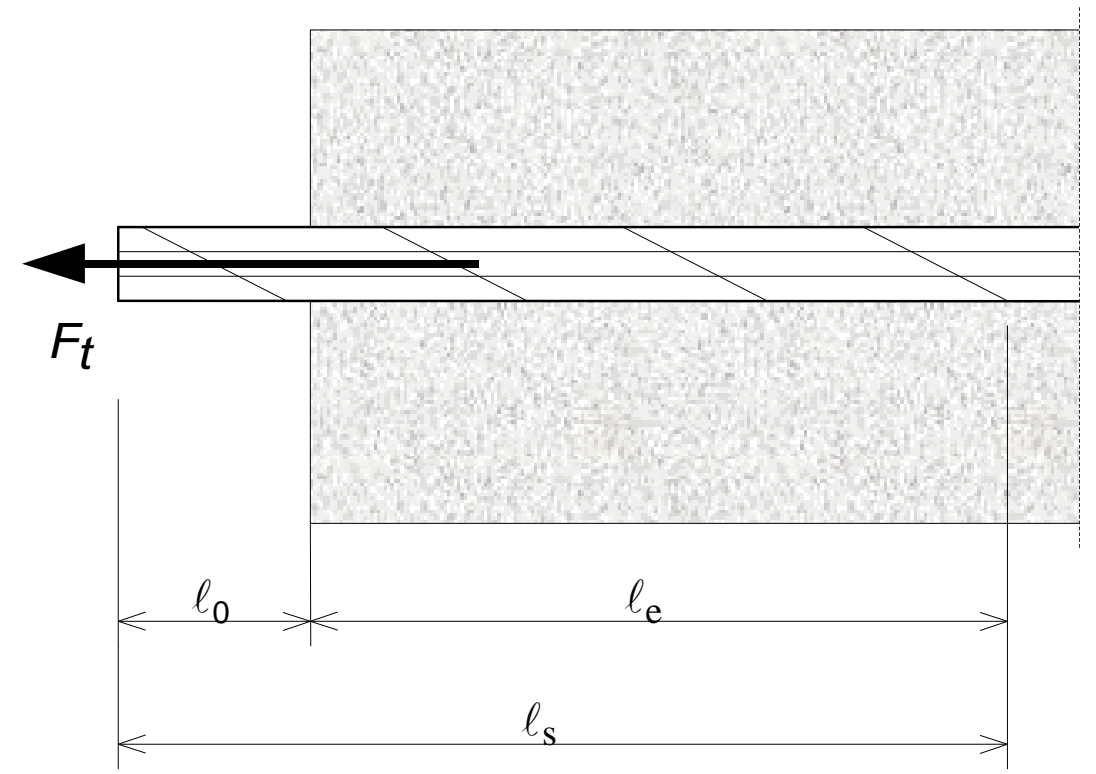

Figura 3.1 - Comprimento efetivo de uma barra inserida em um elemento de concreto.

A deformabilidade por alongamento da barra é definida por:

$$
\lambda_{t b}=\frac{\ell_{s}}{A_{s} \cdot E_{s}}
$$


sendo:

$$
\ell_{s}=\ell_{0}+\ell_{e}
$$

onde:

$\lambda_{\mathrm{tb}}-$ deformabilidade à tração da barra

$\ell_{\mathrm{S}}$ - comprimento da barra considerado para o cálculo da deformabilidade à tração.

$\ell_{0}$ - distância da face do elemento de concreto ao ponto considerado para o cálculo.

$\ell_{\mathrm{e}}$-comprimento de ancoragem efetivo da barra no elemento de concreto.

Em FERREIRA (1993), foi sugerido que o comprimento efetivo para o cálculo da deformação à tração de uma barra, dado por $\ell_{\mathrm{e}}$, fosse tomado como sendo a metade do comprimento de ancoragem $\ell_{\mathrm{b}}$. Na figura 3.2 é apresentado o desenvolvimento da força de tração ao longo do comprimento da barra.

$$
\ell_{e} \cong 0,5 \cdot \ell_{b}
$$

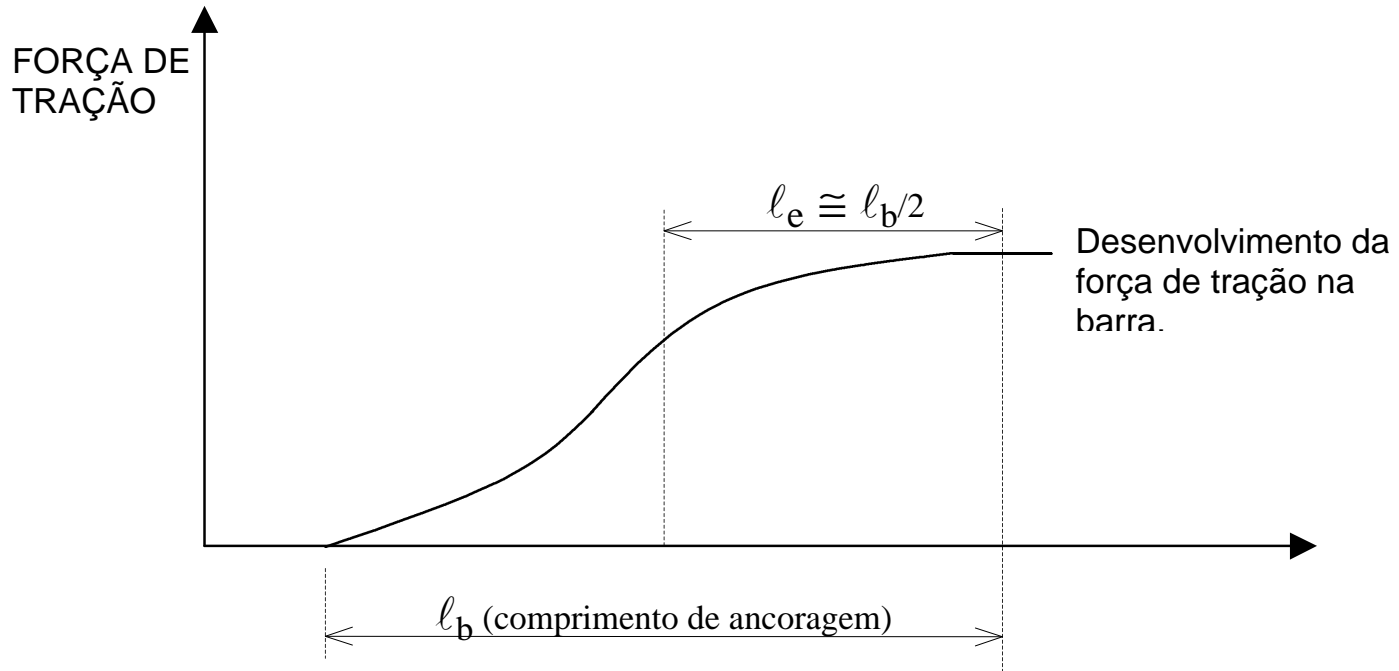

Figura 3.2 - Comprimento efetivo de ancoragem. [FERREIRA (1993)]

Tal recomendação pode ser confirmada a partir dos resultados experimentais apresentados em GÖRGUN (1997) e ELLIOTT et al. (1996). Para a determinação do comprimento efetivo de ancoragem, a ser considerado na deformação da barra, foi realizado um ensaio conforme o esquema apresentado na figuras 3.3. Na figura 3.4 é 
apresentada a curva Força de Tração vs. Abertura de Fissuras, apresentada em ELLIOTT et al. (1996). Para a fase elástica, com deformações até a ordem de $0,5 \mathrm{~mm}$, a rigidez à tração da barra foi de aproximadamente de $\mathrm{K}_{\mathrm{tb}}=360 \mathrm{kN} / \mathrm{mm}$.

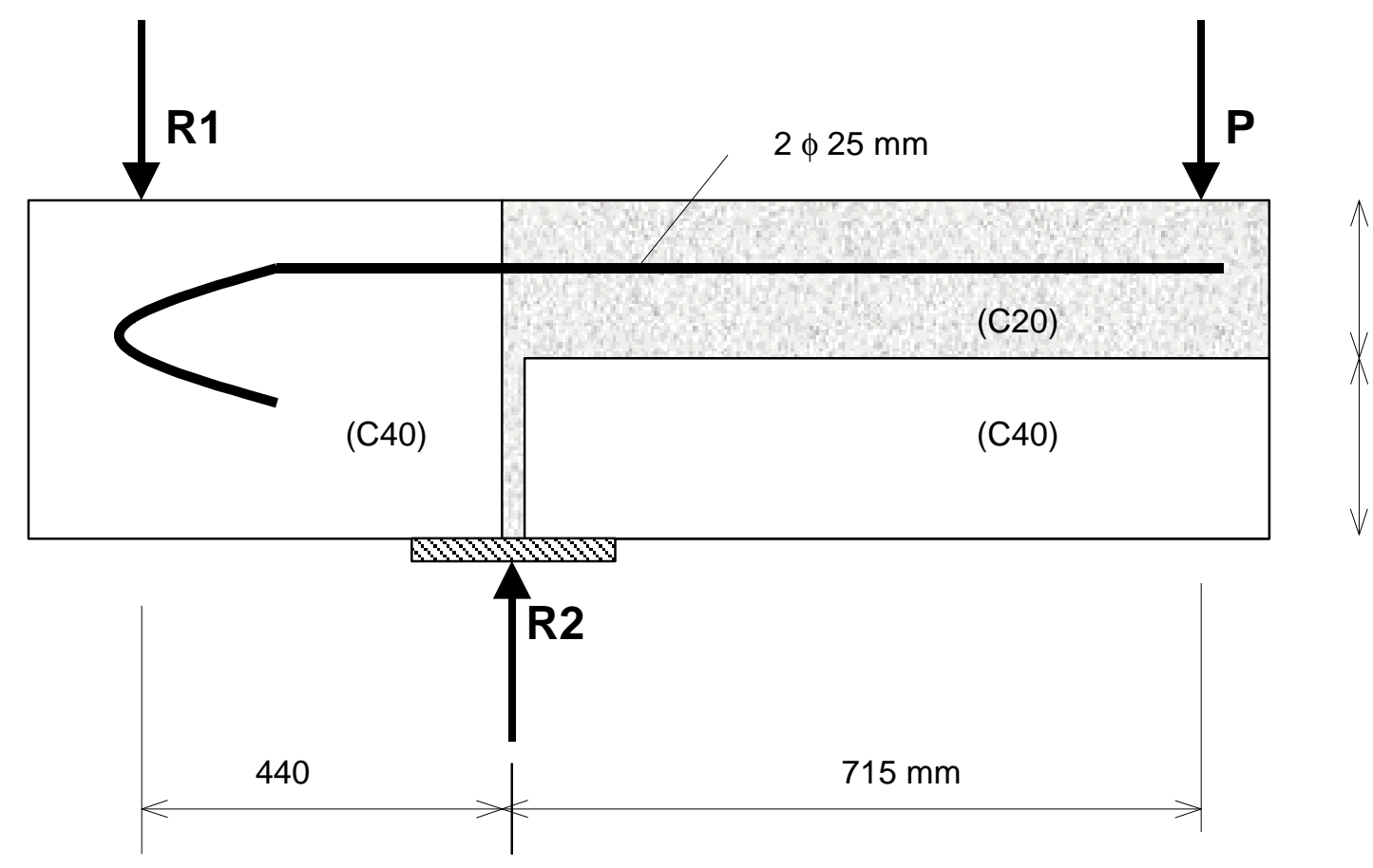

Figura 3.3 - Arranjo geral do ensaio [ELLIOTT et al. (1996)]

A rigidez à tração da barra, que é o valor inverso da deformabilidade, é dada por:

$$
K_{t b}=\frac{1}{\lambda_{t b}}=\frac{F_{t}}{\Delta \ell}=\frac{E_{s} \cdot A_{s}}{\ell_{e}}
$$

Assim, o comprimento efetivo da barra é dado por:

$$
\ell_{e}=\frac{E_{s} \cdot A_{s}}{K_{t b}}
$$

Para os valores obtidos em GÖRGUN (1997), com $\mathrm{K}_{\mathrm{tb}}=360000 \mathrm{kN} / \mathrm{m} \mathrm{e}_{\mathrm{s}}=$ $9,82 \times 10^{-4} \mathrm{~m}^{2}$, tem-se:

$$
\ell_{e}=\frac{200 \cdot 10^{6} \cdot 9,82 \cdot 10^{-4}}{360000}=0,54 \mathrm{~m}
$$



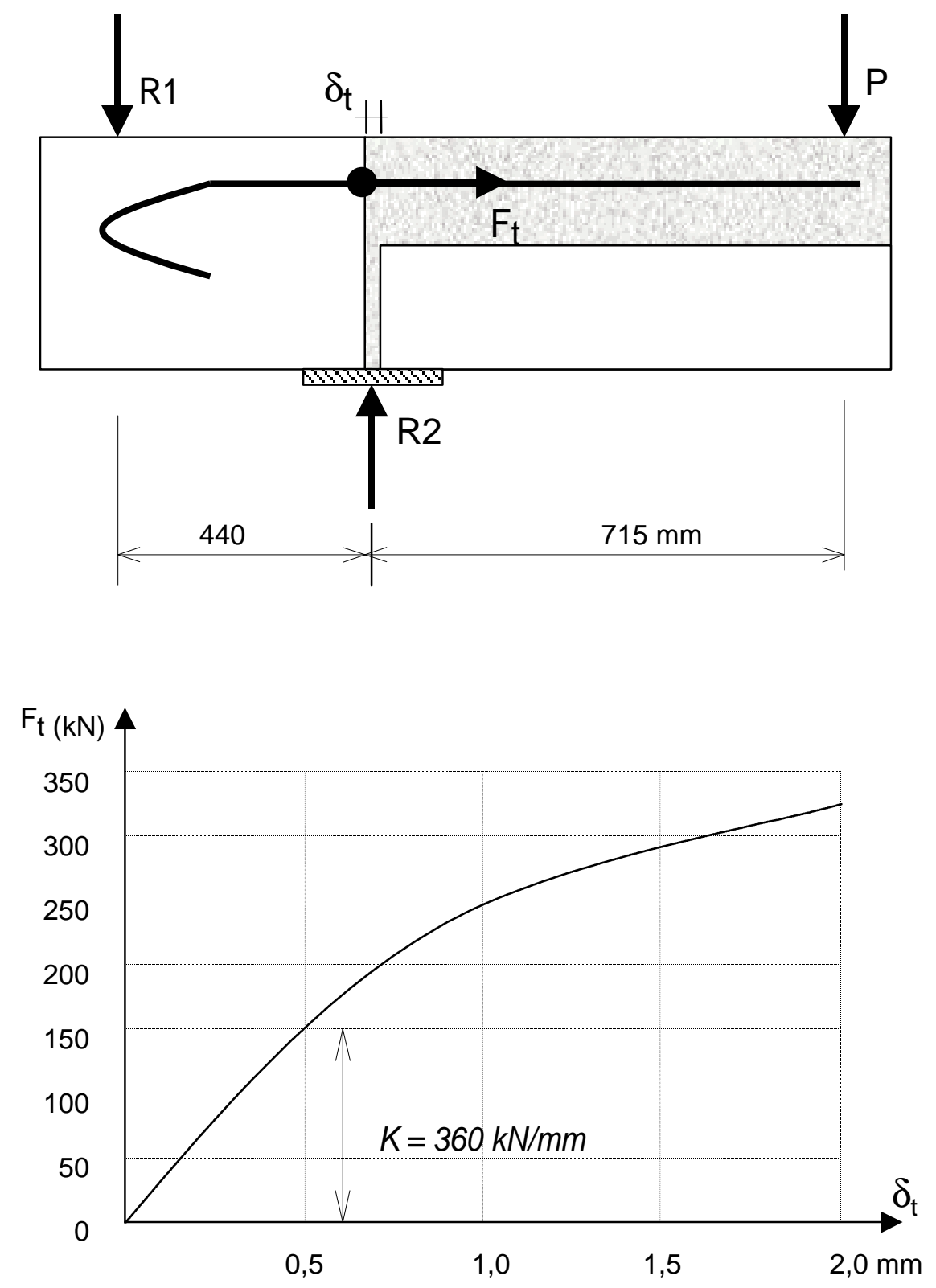

Figura 3.4 - Curva Força de Tração vs. Abertura de Fissuras [ELLIOTT et al. (1996)]

Por outro lado, o comprimento de ancoragem para esta mesma barra é dado por:

$$
\ell_{b}=\frac{f_{y d} \cdot \phi_{b}}{\tau_{b u} \cdot 4}
$$

onde:

$$
\begin{aligned}
& \phi_{b}=25 \mathrm{~mm} \\
& \mathrm{f}_{\mathrm{yd}}=500 / 1,15 \mathrm{MPa}
\end{aligned}
$$


$\tau_{\mathrm{bu}}=2,46 \mathrm{MPa}($ para fck $=20 \mathrm{MPa})$

Assim, tem-se que:

$$
\begin{aligned}
& \ell_{b}=\frac{(500 / 1,15) \cdot \phi_{b}}{(2,46) \cdot 4}=44,2 \cdot \phi_{b}=110,5 \mathrm{~cm} \\
& \ell_{e}=\frac{54}{110,5} \cong 0,5 \cdot \ell_{b}
\end{aligned}
$$

Portanto, pode-se verificar que o comprimento efetivo, dado por $\ell_{\mathrm{e}}$, neste caso, foi da ordem da metade do comprimento de ancoragem $\ell_{\mathrm{b}}$, como proposto inicialmente na expressão (3.3).

\subsubsection{Mecanismo de Deformação por Cisalhamento de uma Barra Inserida em um Elemento de Concreto}

O mecanismo de cisalhamento em um chumbador inserido em um elemento de concreto pode ser modelado por diferentes aproximações, dependendo do tipo de análise a ser realizada. Segundo DEI POLI et al. (1978) e DEI POLI et al. (1992), para esforços da ordem de até $40 \%$ da capacidade última do chumbador, resultados experimentais demonstraram que a consideração da linearidade se aproxima adequadamente do comportamento real.

Em geral, para a obtenção dos chamados "modelos lineares", tem-se utilizado a analogia de uma viga (elástica ou rígida) sob apoio elástico aplicada à teoria de reação do solo. Em conjunto com esta teoria, utiliza-se a notação de Módulo de Reação do Material, o qual possibilita uma relação direta entre as forças e os deslocamentos transversais à barra. O parâmetro do módulo de reação do material eqüivale a uma constante de rigidez elástica, dada em $\left(\mathrm{F} / \mathrm{L}^{3}\right)$.

Em relação ao mecanismo de cisalhamento na barra do chumbador, DEI POLI et al. (1992) apresenta dois estudos importantes. O primeiro é quanto ao comportamento do 
chumbador na fase elástica, para o qual foi utilizada a analogia já mencionada, conforme ilustrada na figura 3.5. O segundo é o estudo do chumbador na sua configuração crítica, com a formação de uma rótula plástica na seção da máxima flexão e com a plastificação do concreto na face do elemento, conforme ilustrado na figura 3.6. Para a modelagem do chumbador para esse estado, os dois parâmetros mais importantes são a resistência à compressão do concreto e a localização da rótula plástica no chumbador, definida por $\ell_{y}$, conforme indicado na figura 3.6.

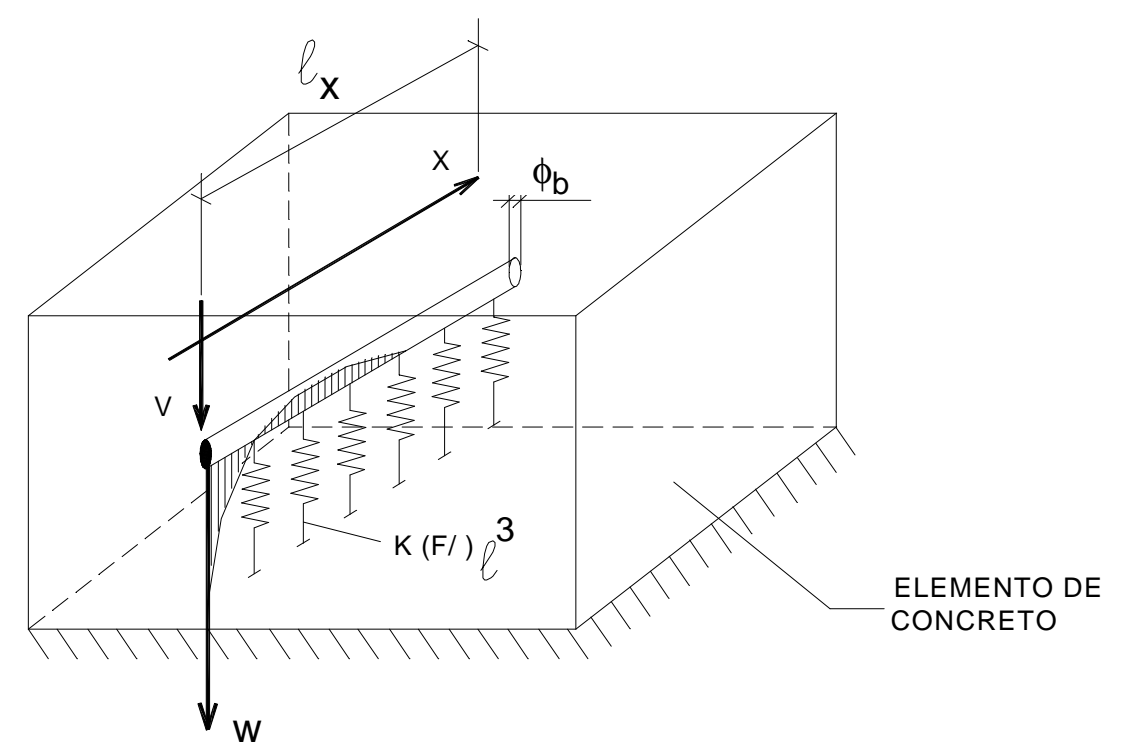

Figura 3.5 -Analogia de viga sobre apoio elástico para a barra do chumbador inserida em um elemento de concreto [DEI POLI et al. (1992)]

A partir dos resultados experimentais, para uma barra de chumbador inserida em apenas um elemento de concreto, DEI POLI et al. (1992) estabeleceu uma relação para a distância $\ell_{\mathrm{y}}$ dada por:

$$
\ell_{y}=(1,6 \text { a } 1,7) \cdot \phi_{b}
$$

$\ell_{\mathrm{y}}$ - distância da borda do concreto até a seção de máximo momento no chumbador

$\phi_{\mathrm{b}}$ - diâmetro da barra do chumbador 


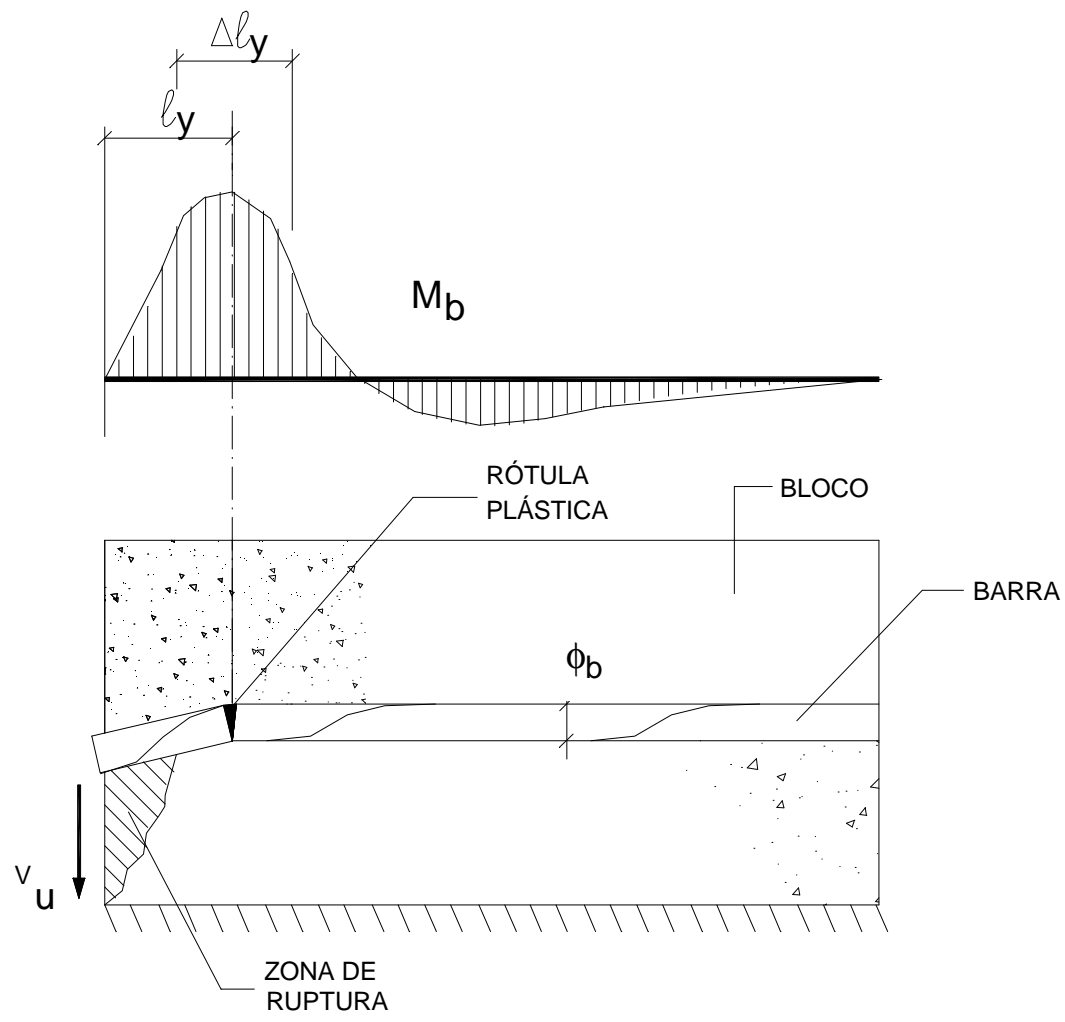

Figura 3.6 - Formação da rótula plástica na barra do chumbador e zona de ruptura na borda do concreto [DEI POLI et al. (1992)]

A espessura da zona de ruptura na borda do concreto, dada por $e_{z r}$, indicada na figura 3.7, varia inversamente ao diâmetro da barra do chumbador.

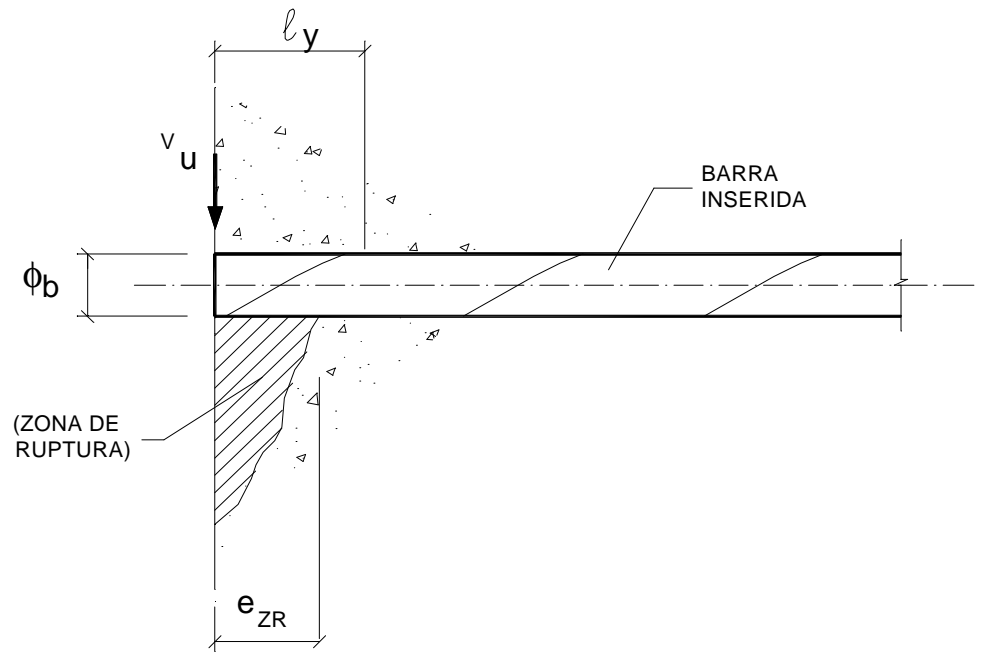

Figura 3.7 - Mecanismo de ruptura, indicando $e_{z r} e \ell_{y}$. 
Em DEI POLI et al. (1992), sugere-se as seguintes relações para $e_{z r}$ :

$$
\begin{array}{ll}
e_{z r} / \phi_{b}=0,6 & \text { Para } \phi_{b}=12 \mathrm{~mm} \\
e_{z r} / \phi_{b}=0,4 & \text { Para } \phi_{b}=25 \mathrm{~mm}
\end{array}
$$

Baseando-se na analogia da viga sobre apoio elástico, DEI POLI et al. (1992) apresentou o seguinte equacionamento para o cálculo do deslocamento transversal do chumbador na borda do elemento de concreto:

$$
w=\frac{V}{\left(2 \cdot \alpha^{3} \cdot E_{s} \cdot I_{b}\right)}
$$

sendo:

$$
\begin{aligned}
& \alpha=\sqrt[4]{\frac{K_{c} \cdot \phi_{b}}{4 \cdot E_{s} \cdot I_{b}}} \\
& K_{c}=127 \cdot \sqrt{f_{c}} /\left(\phi_{b}\right)^{2 / 3}
\end{aligned}
$$

(Obs: $K_{C}$ dado em $M P a / m m$ e $\phi_{b}$ dado em $m m$ )

onde:

W - deslocamento transversal na barra do chumbador

$\mathrm{V}$ - força cortante aplicada à barra do chumbador

$K_{C}$ - módulo de rigidez de referência para o concreto [DEI POLI et al. (1992)]

$f_{C}$ - resistência à compressão do concreto

$\phi_{b}$ - diâmetro da barra do chumbador

$E_{S}$ - módulo elástico do aço

$I_{b}$ - momento de inércia da barra do chumbador

Por extensão a este desenvolvimento, a deformabilidade ao cisalhamento na barra do chumbador, inserido em apenas um elemento de concreto, será dada por:

$$
\lambda_{\tau b}=\left(2 \cdot \alpha^{3} \cdot E_{s} \cdot I_{b}\right)^{-1}
$$




\subsubsection{Mecanismo de Deformação por Cisalhamento em uma Barra Bi-Engastada em Dois Elementos de Concreto com Altura Livre}

A deformabilidade da barra de um chumbador, com uma altura livre do elastômero entre os dois elementos de concreto, conforme a hipótese de deformação apresentada na figura 3.8, é dada por:

$$
\lambda_{\tau b}=\frac{\ell_{e}^{3}}{12 \cdot E_{s} \cdot I_{b}}
$$
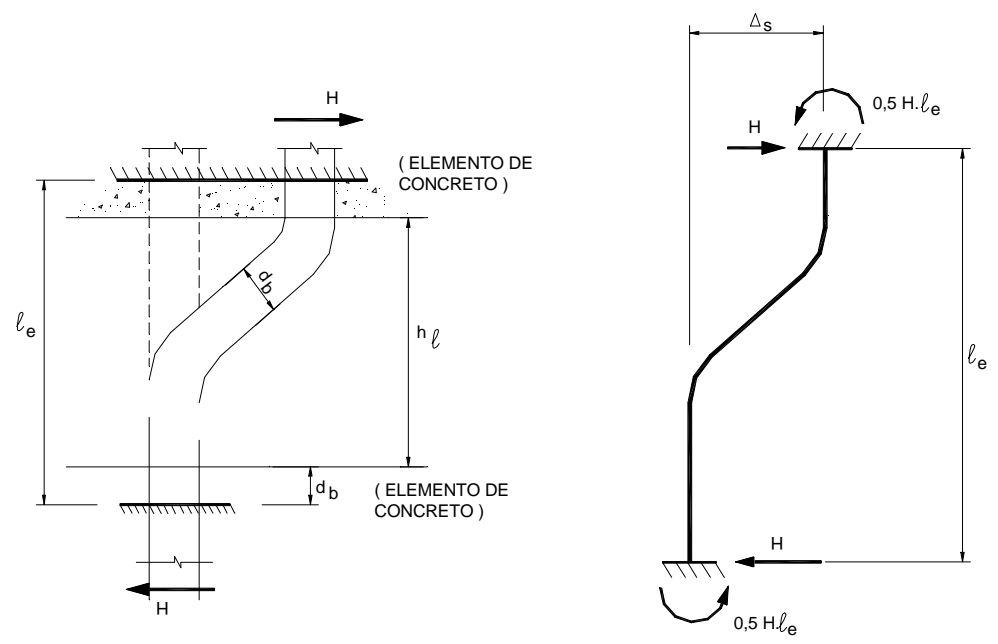

Figura 3.8 - Deformação da barra do chumbador devido à força horizontal [BLJUGER (1988)]

Segundo BLJUGER (1988), a altura livre efetiva na barra do chumbador, definida por $\ell_{e}$, pode ser expressa pela seguinte relação:

$$
\ell_{e}=h_{\ell}+2 \cdot \phi_{b}
$$

onde:

$h_{\ell}-$ altura livre entre os elementos de concreto

$\phi_{b}$ - diâmetro da barra do chumbador

Neste caso, na deformação ao cisalhamento é considerada uma parcela da barra que está inserida dentro do concreto à uma profundidade igual ao diâmetro da barra. 
O momento de inércia da barra do chumbador é dado por:

$$
I_{b}=\frac{\pi \cdot \phi_{b}^{4}}{64}
$$

Substituindo-se as relações (3.14) e (3.15) na expressão (3.13) tem-se, a nova expressão para a deformabilidade ao cisalhamento, dada por:

$$
\lambda_{\tau b}=\frac{16 \cdot\left(h_{\ell}+2 \cdot \phi_{b}\right)^{3}}{3 \cdot \pi \cdot E_{s} \cdot \phi_{b}^{4}}
$$

\subsection{Mecanismo de Deformação por Compressão em Almofadas de Elastômero Simples}

\subsubsection{Preliminares}

As almofadas de elastômeros são extensamente utilizadas nas construções prémoldadas, como apoio para vigas, lajes e elementos pré-moldados em geral.

O elastômero utilizado na Construção Civil é conhecido comercialmente como neoprene, nome do produto fabricado pela Du Pont deste a década de 30. O termo "elastômero simples" é utilizado pela NBR-9062/85 para designar um produto derivado da borracha sintética que apresenta um bom desempenho quanto à durabilidade e à conservação das suas características físicas ao longo do tempo e quando submetidas à interpéries. Estudos realizados na Alemanha na década de 60 demonstraram que o elastômero é resistente à ataques de ácidos inorgânicos e bases, mas não contra ataques de óleos. Posteriormente, descobriu-se que o elastômero também é atacado pelo ozona atmosférico. As almofadas de elastômero simples são utilizadas para cargas pequenas e médias, enquanto para as cargas maiores, como nas pontes, são empregadas almofadas de elastômero cintadas que são compostas por placas de borracha intercaladas com chapas de aço unidas por meio de vulcanização. 


\subsubsection{Propriedades dos Almofadas de Elastômero Simples}

\subsubsection{Características Físicas}

\subsection{Dureza}

A dureza é uma das principais características físicas do elastômero simples. A dureza de um elastômero é medida geralmente na escala Shore, que é baseada em um ensaio de penetração padronizado. Comercialmente, utiliza-se três classes de dureza, visando atender a diferentes campos de aplicação, conforme apresentadas na tabela 3.1.

Tabela 3.1: Classes de Dureza Shore A:

\begin{tabular}{|c|c|c|c|}
\hline Dureza Shore A & 50 & 60 & 70 \\
\hline Aplicações & Cargasleves & Estruturas sem geral & Estruturas pesadas \\
\hline
\end{tabular}

A dureza do elastômero é um fator determinante no valor do módulo de deformação transversal $\mathrm{G}$, sendo que deste depende basicamente a resistência da almofada tanto para ações normais quanto para ações de cisalhamento.

\subsection{Módulo de Deformação Transversal}

A NBR-9785/86 apresenta um método para o ensaio de distorção na almofada provocada por ações de aplicação lenta, consideradas como estáticas. Vários trabalhos experimentais realizados na Alemanha na década de 70, para elastômeros com dureza shore $60 \mathrm{~A}$, apresentaram valores para o módulo $\mathrm{G}$ que variavam entre 0,8 à 2,2 $\mathrm{MPa}$ (para $\tan \gamma<1)$.

$\mathrm{Na}$ falta de ensaios conclusivos, a NBR-9062/85 orienta que se sejam adotados os valores de correspondência para o módulo G em função da dureza Shore A, conforme apresentados na tabela 3.2 .

Tabela 3.2: Módulo G em função da dureza Shore A $\left(a^{\circ} 20^{\circ} \mathrm{C}\right)$, segundo a NBR-9062/85:

\begin{tabular}{|c|c|c|c|}
\hline Dureza Shore A & 50 & 60 & 70 \\
\hline Módulo G (MPa) & 0,8 & 1,0 & 1,2 \\
\hline
\end{tabular}


O módulo G é afetado pela variação de temperatura. A NBR-9062/85, orienta que para temperaturas inferiores a $0{ }^{\circ} \mathrm{C}$ deve-se considerar o dobro do valor do módulo transversal G (a $\left.20^{\circ} \mathrm{C}\right)$.

O módulo G está sujeito à alteração em função do tipo do carregamento, estático ou dinâmico, e ainda por influência da deformação lenta. Segundo Braga (1985), sob efeito de ações dinâmicas o módulo transversal G tem o seu valor dobrado. Para cargas estáticas de longa duração, considerando o efeito da deformação lenta, a NBR-9062/85 recomenda que se adote o valor para o $\mathrm{G}$ (final) como sendo a metade do valor do módulo G(inicial). A este respeito, em seus estudos na Alemanha na década de 60, Topaloff propôs que se adota-se um valor para o $\mathrm{G}$ (final) como sendo igual a $70 \%$ do valor inicial. $\mathrm{Na}$ figura 3.9 é apresentada a variação do módulo $\mathrm{G}$ em função do tipo e duração do carregamento, segundo Topaloff e a NBR-9062/85.

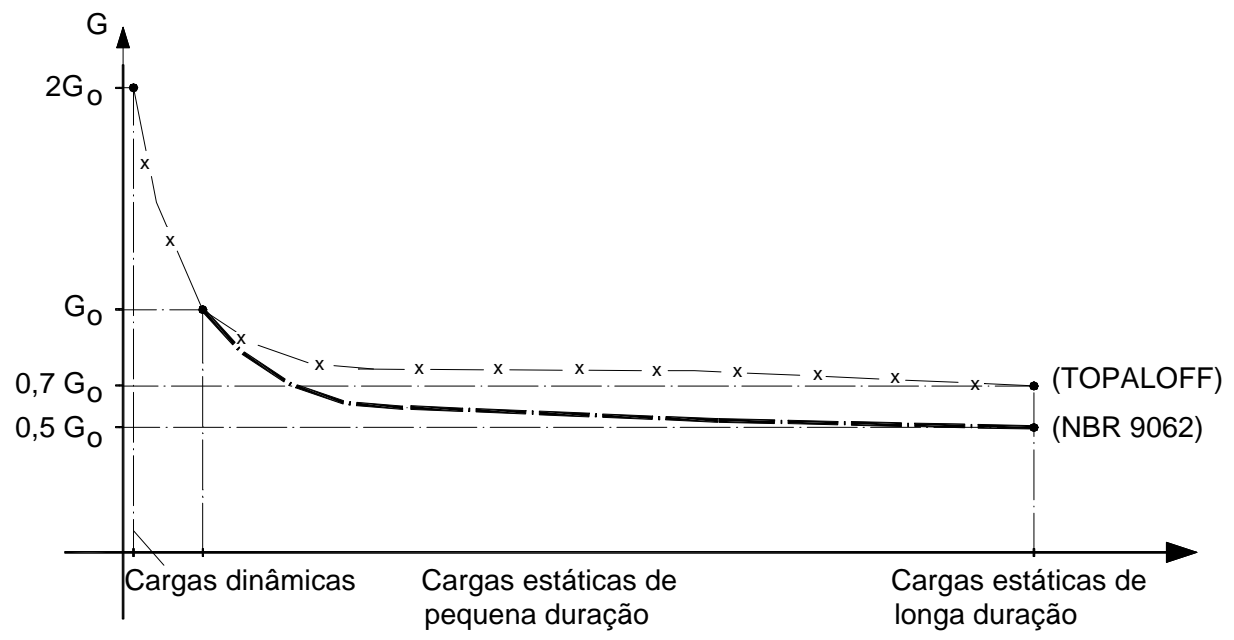

Figura 3.9 - Variação do módulo G em função do tipo e da duração do carregamento.

\subsection{Coeficiente de Poisson}

Segundo CATÂNIA \& MENDITTO (1978), o coeficiente de Poisson para o elastômero, $\mu_{n}$, é assumido como sendo:

$$
\mu_{n}=0,5
$$




\subsection{Deformação Lenta}

TOPALOFF (1964) estudou os efeitos da deformação lenta sobre a almofada de elastômero. A deformação final, considerando a deformação lenta, será dada por:

$$
\varepsilon_{t}=[1+\varphi(t)] . \varepsilon_{0}
$$

onde:

$\varepsilon_{t}-$ deformação final no elastômero no tempo $\mathrm{t}$

$\varepsilon_{0}-$ deformação inicial

$\varphi(t)$ - coeficiente que leva em conta a dureza

O coeficiente $\varphi(t)$ evolui rapidamente com a idade, atingindo a metade do seu valor a 10 dias e o seu valor total em 180 dias (ver tabela 3.3).

Tabela 3.3 - Coeficiente $\varphi(t)$ em função da dureza Shore

\begin{tabular}{|c|c|c|}
\hline Dureza Shore $A$ & $\varphi(10$ dias $)$ & $\varphi(180$ dias $)$ \\
\hline 50 & 0,25 & 0,45 \\
60 & 0,18 & 0,35 \\
70 & 0,13 & 0,25 \\
\hline
\end{tabular}

O valor final de $\mathrm{G}$, considerando a deformação lenta, para um elastômero de dureza Shore 60 A, será:

$$
G_{t}=0,7 \cdot G_{0}
$$

Onde:

$G_{t}$ - módulo de elasticidade transversal considerando a deformação lenta.

$G_{0}-$ módulo de elasticidade transversal inicial

\subsection{Efeito da Temperatura}

Como já foi citado anteriormente, a diminuição da temperatura provoca um aumento do módulo transversal $\mathrm{G}$, fazendo com que a almofada se torne menos deformável. Para temperaturas muito baixas, à cerca de - $50 \mathrm{C}$, o elastômero se torna frágil. 
Como as almofadas de elastômero são vulcanizadas a mais ou menos $150{ }^{\circ} \mathrm{C}$, elas poderiam chegar a ser expostas até $100{ }^{\circ} \mathrm{C}$, por um curto período de tempo, sem que isto comprometesse a sua integridade. Segundo KERONEN (1996), para temperaturas da ordem de 60 a $70{ }^{\circ} \mathrm{C}$, uma almofada de elastômero poderia ficar exposta por meses sem que sua integridade fosse afetada. Por outro lado, o aumento da temperatura acelera o processo de envelhecimento da almofada de elastômero simples. Com o envelhecimento, a almofada torna-se mais rígida, mas também menos resistente.

O elastômero não é combustível. Se o material for afetado por fogo, ele não propaga chamas. O coeficiente de expansão térmica do elastômero é adotada usualmente entre $\alpha_{n}=50$ a $200 \times 10^{6} /{ }^{\circ} \mathrm{C}$

\subsubsection{Características Geométricas}

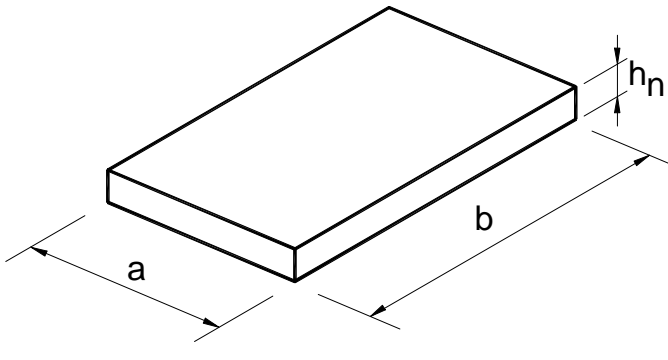

(a) almofada retangular

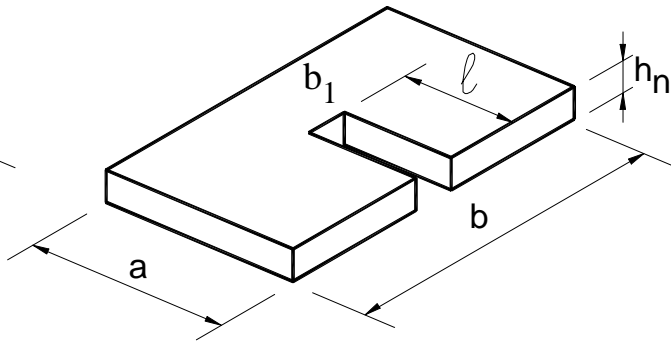

(b) almofada com rasgo

Figura 3.10 - Geometria da almofada de elastômero.

Uma almofada de elastômero é caracterizada também pela sua geometria, em função do fato de que o tamanho e a forma da almofada têm efeitos sobre outras propriedades da almofada de elastômero. As dimensões de uma almofada de elastômeros são definidas conforme indicado na figura 3.10. A caracterização geométrica é expressa por meio de um fator de forma, denominado pela letra B, que relaciona a superfície de apoio carregada (superfície que possui restrição à sua deformação) e a superfície lateral da almofada (superfície sem restrição à sua deformação), dado pela expressão: 


$$
B=\frac{a \cdot b}{2 \cdot h_{n} \cdot(a+b)}
$$

No caso da almofada ter um rasgo para a colocação do chumbador, a expressão acima fica:

$$
B=\frac{\left(a \cdot b-\ell \cdot b_{1}\right)}{2 \cdot h_{n} \cdot(a+b+\ell)}
$$

A geometria da almofada influi no mecanismo de deformação por compressão da almofada de elastômero. $\mathrm{O}$ aumento do fator de forma faz com que haja uma diminuição da deformação por compressão da almofada. Todavia, almofadas com mesmo fator de forma, não têm necessariamente um comportamento igual na compressão. Almofadas de menor espessura tendem a ter maior rigidez à deformação por compressão. VINJE (1985), através de estudos experimentais, concluiu que a deformação por compressão de uma almofada de elastômero simples é inversamente proporcional ao seu fator de forma B (o mesmo fator de forma indicado pela NBR-9062). Segundo este autor, além do fator de forma, a deformação por compressão depende de $\sigma_{m}$ e do tipo de elastômero. Ensaios realizados por KERONEN (1996) confirmaram esta hipótese, onde para maiores fatores de forma, obteve-se menores deformações em almofadas de mesma altura.

\subsubsection{Expansão Lateral}

A expansão lateral de uma almofada de elastômero ocorre conforme ilustrado na figura 3.11. O principal fator que influi na deformação lateral é a espessura da almofada. Aumentando-se a espessura, está-se aumentando também a área lateral, a qual está livre para a deformação lateral. A expansão é diretamente proporcional à espessura da almofada, sendo uma função do fator de forma, e da tensão média no elastômero. Segundo VINJE (1985), a expansão lateral é "menos" afetada pela dureza do elastômero. Segundo esse mesmo autor, as almofadas de elastômero com espessura de $15 \mathrm{~mm}$ apresentam tamanha expansão lateral que se tornam inadequadas para o seu uso em aplicações estruturais correntes. 

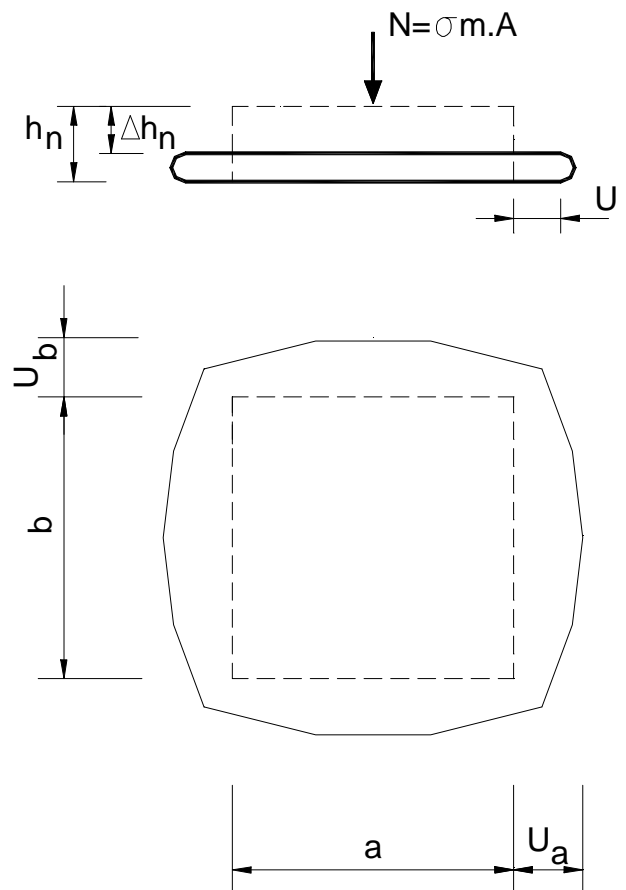

Figura 3.11 - Expansão lateral na almofada de elastômero [VINJE (1985)]

Na escolha das dimensões para os lados a e b da almofada, deve-se levar em conta as expansões laterais $U_{a}$ e $U_{b}$, de modo a se evitar apareçam saliências na almofada entre os elementos de concreto, conforme indicado na figura 3.12.

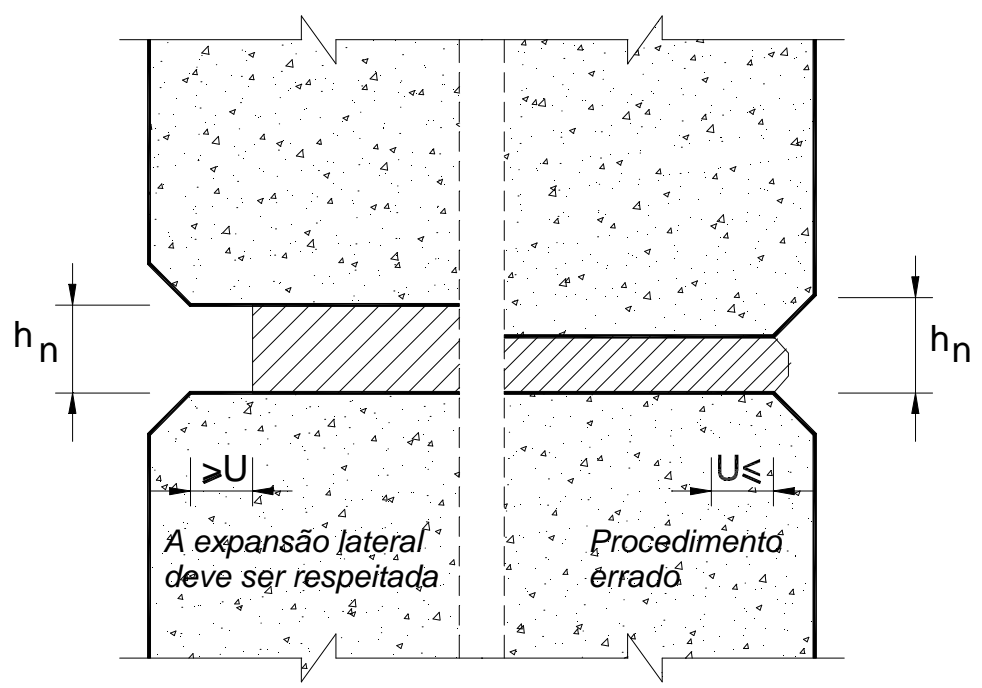

Figura 3.12 - Limitações para a largura da almofada entre elementos de concreto [VINJE (1985)] 


\subsubsection{Deformação por Compressão na Almofada de Elastômero Simples}

Considerando uma placa elástica comprimida por dois elementos de rigidez muito maior que a sua própria, para a compressão em serviço, o elastômero apresenta uma configuração de deformações conforme a indicada na figura 3.13a. Nesta configuração, a almofada de elastômero apresenta pouca resistência às deformações transversais próximo às extremidades da almofada, fazendo com que as tensões normais sejam praticamente nulas nestas regiões. Na região central da almofada tem-se um estado triplo de tensões, o que confere resistência às deformações.

Com o aumento das deformações transversais, para grandes tensões e deformações normais na almofada, tem-se uma nova configuração de deformações conforme indicada na figura 3.13b. Para estas situação, os elastômeros podem sofrer tanto deslocamentos quanto deformações que chegam a ser da mesma ordem de grandeza das dimensões da almofada.

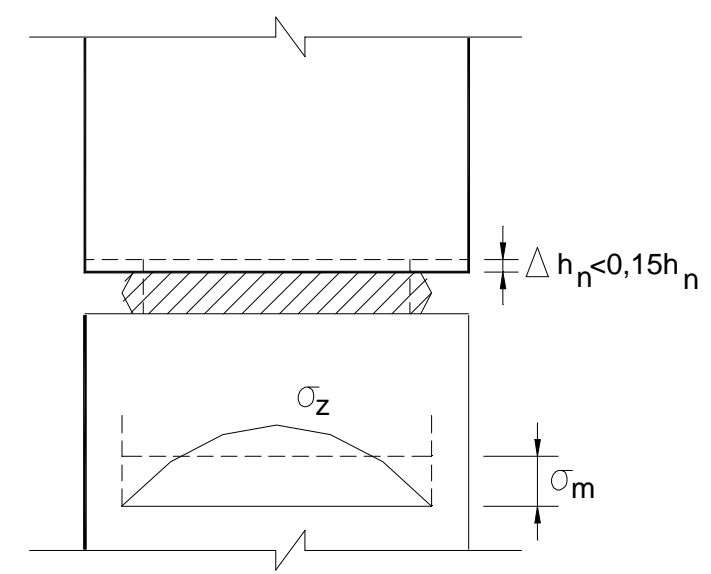

(a)

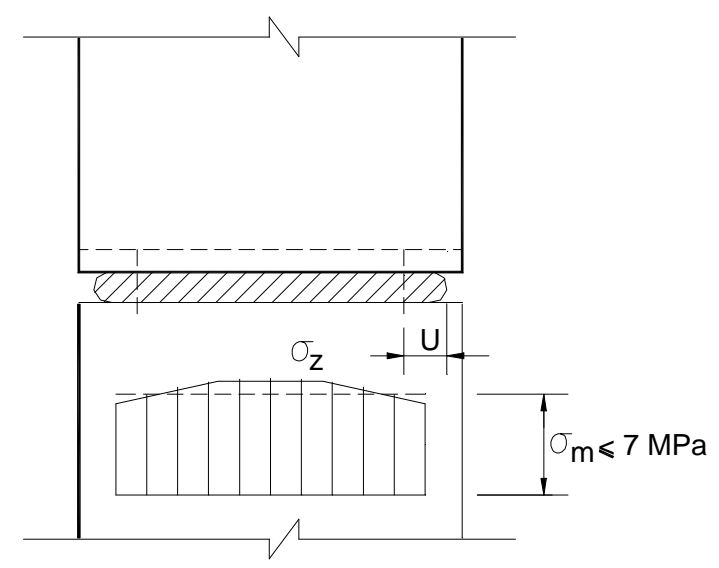

(b)

Figura 3.13 - Configurações de deformação para uma almofada comprimida.

No Brasil, ainda não se tem uma padronização para os ensaios de compressão simples para almofadas de elastômeros simples. A NBR-9784/86 estabelece o método para o ensaio de compressão simples para almofadas de elastômero fretado. 
A NBR-9062/85 estabelece que a deformação por compressão da almofada simples deve estar limitada a $15 \%$, para a compressão em serviço. Os limites máximos para as pressões de contato das almofadas simples e cintadas são $7 \mathrm{MPa}$ e $11 \mathrm{MPa}$, respectivamente.

Segundo o Design Manual da NBIF (The Norwegian Precast Concrete Federation), a tensão média no elastômero, $\sigma_{\mathrm{m}}$, também é limitada pela resistência de compressão dos elementos de concreto, conforme apresentado na tabela 3.4.

Tabela 3.4: Limites para $\sigma_{m}$ segundo a resistência do concreto segundo o NBIF-Design Manual

\begin{tabular}{|c|c|}
\hline Concreto C30 (30 MPa) & $\sigma_{\mathrm{m}}=11,4 \mathrm{MPa}$ \\
\hline Concreto C40 (40 Mpa) & $\sigma_{\mathrm{m}}=13,7 \mathrm{MPa}$ \\
\hline Concreto C50 (50 MPa) & $\sigma_{\mathrm{m}}=16,0 \mathrm{MPa}$ \\
\hline
\end{tabular}

Segundo KERONEN (1996), após ensaios de compressão rápida, com uma pressão de $125 \mathrm{MPa}$ entre chapas metálicas grossas e lisas, a almofada ainda estava utilizável após o ensaio. KERONEN (1996) apresenta resultados de ensaios com deformações normais que chegaram a 85\% e valores de tensões de compressão que ultrapassaram $200 \mathrm{MPa}$. Já no caso de elastômero com dureza Shore $50 \mathrm{~A}$, as almofadas ensaiadas apresentaram danos significantes para tensões da ordem de $70 \mathrm{MPa}$, e tiveram sua integridade destruída para tensões da ordem de $110 \mathrm{MPa}$. Desta forma, os valores limites para almofadas de elasômero simples e cintada atribuídos pela NBR-9062 estão muito abaixo da capacidade máxima da almofada. De fato, estes valores de limites de deformação e tensão foram fixados com base a garantir que se tenha uma boa distribuição das tensões ao longo de toda almofada, fornecendo uma boa condição de contato em toda a superfície do apoio.

Entretanto, a questão da determinação da deformação por compressão em almofadas de elastômero simples ainda não está bem definida na literatura. Não se dispõe de equacionamentos confiáveis para que se consiga fazer uma estimativa segura. A razão para isto é a dificuldade que se tem para a determinação do módulo de elasticidade fictício de almofadas de elastômero simples. 


\subsubsection{Elasticidade da Almofada de Elastômero}

\subsubsection{Equacionamentos para Obtenção do Módulo de Elasticidade Fictício $\mathbf{E}_{\mathbf{n}}$}

Da Teoria da Elasticidade, a deformabilidade à compressão é dada por:

$$
\lambda_{n c}=\frac{h_{n}}{E_{n} \cdot A_{n}}
$$

Uma almofada de elastômero comprimida possui grandes deformações, possuindo um estado triplo de tensões para uma Teoria de Terceira Ordem. Todavia, como forma de simplificação para o problema, muitos autores têm adotado uma relação b>>a, onde haveria um maior impedimento às deformações transversais na direção do lado maior, "b". Desta forma, o problema ficaria restrito ao Estado Plano de Deformações no plano paralelo ao lado menor, "a". Neste caso, o equacionamento no Estado Plano de Tensões pode ser utilizado desde que se faça uma correção do módulo elástico através de um módulo fictício dado por:

$$
E_{f}=E /\left(1-\mu_{n}\right)
$$

A relação entre o módulo longitudinal e o módulo transversal, para uma simplificação no Estado Plano de Tensões, é dada por:

$$
E_{f}=2 \cdot G \cdot\left(1+\mu_{n}\right)
$$

Para $\mu_{\mathrm{n}}=0.5$, o módulo fictício $\mathrm{E}_{\mathrm{f}}$ pode ser escrito por:

$$
E_{f}=4 . G
$$

Todavia, este equacionamento não é suficiente para representar o comportamento de uma almofada de elastômero simples comprimida. A partir dos estudos experimentais existentes, descobriu-se que o módulo elástico fictício de uma almofada de elastômero simples, $\mathrm{E}_{\mathrm{n}}$, não depende apenas das propriedades físicas da almofada, mas também da sua geometria, da rugosidade entre as superfícies de contato, da tensão normal, da velocidade do carregamento e da temperatura. Em seu trabalho experimental, VINJE 
(1985) concluiu que o módulo $\mathrm{E}_{\mathrm{n}}$ é diretamente proporcional ao fator de forma da almofada. Segundo KERONEN (1996), o módulo $\mathrm{E}_{\mathrm{n}}$, além de estar relacionado com o fator de forma, também é uma função da tensão média de compressão, $\sigma_{m}$, sobre a almofada.

O módulo de elasticidade do elastômero depende do atrito entre as superfícies de contato. A tensão de atrito, por sua vez depende do coeficiente de atrito e da tensão de compressão. VINJE (1985) observou que o coeficiente de atrito diminui rapidamente quando a tensão de compressão é aumentada. Também, que o coeficiente de atrito é menor para almofadas de dureza menor. Como exemplo, o coeficiente de atrito é $50 \%$ menor para elastômeros com dureza Shore 50 A do que para elastômeros com dureza Shore 60 A.

Na literatura técnica existem vários trabalhos, como em TOPALOFF (1964), CATÂNIA \& MENDITTO (1978), ROEDER et al. (1987), BRAGA (1985), que apresentam equacionamentos para a determinação do módulo elástico de elastômeros fretados, baseados em estudos teóricos e experimentais, mas o mesmo não ocorre no caso das almofadas de elastômero simples.

Segundo BRAGA (1985), importantes trabalhos experimentais conduzidos na França nos anos 60, serviram como base para várias normas européias, como na França, na Inglaterra e na Itália, sendo que estes trabalhos apresentaram expressões para a determinação os módulos de elasticidade fictício de elastômeros como funções, além do módulo $G$, do fator de forma $B$ e da tensão média $\sigma_{\mathrm{m}}$.

No caso dos elastômeros fretados, o módulo $\mathrm{E}_{\mathrm{n}}$ é dado pela expressão:

$$
E_{n, f}=K_{1} \cdot G \cdot B^{2}+K_{2} \cdot \sigma_{m}
$$

Os coeficientes $\mathrm{K}_{1}$ e $\mathrm{K}_{2}$, adotados pela norma francesa (UIC), são iguais a 4 e 3 respectivamente. Já no caso da norma italiana (CNR), adota-se os valores 8 e 3. No item 7.2.1.5.22 da NBR-9062, tem-se uma expressão idêntica à expressão (3.25), com os mesmos valores de $\mathrm{K}_{1}$ e $\mathrm{K}_{2}$ utilizados pela norma francesa, sendo 4 e 3 respectivamente.

Assim, a expressão para o módulo de elasticidade fictício de uma almofada de elastômero fretado, em conformidade com a NBR-9062, seria dada por: 


$$
\left.E_{n, f}=4 . G \cdot B^{2}+3 . \sigma_{m} \quad \text { (Elatômero Fretado }\right)
$$

De forma análoga, a partir do ítem 7.2.1.5.22 da NBR-9062, pode-se reduzir uma expressão para o módulo de elasticidade fictício de uma almofada de elastômero simples, dada pela seguinte expressão:

$$
E_{n}=K_{3} \cdot G \cdot B+K_{4} \cdot \sigma_{m}
$$

onde os coeficientes $\mathrm{K}_{3}$ e $\mathrm{K}_{4}$, em conformidade com a NBR-9062, são dados por 10 e 2, respectivamente, sendo que a expressão final para o módulo $\mathrm{E}_{\mathrm{n}}$ de uma almofada de elastômero simples seria dada por:

$$
E_{n}=10 \cdot G \cdot B+2 \cdot \sigma_{m} \quad(\text { Elastômero Näo-Fretado })
$$

As relações na expressão (3.28) confirmam as relações observadas nos trabalhos, já citados, de VINJE (1985) e KERONEN (1996). Todavia, outros fatores, como a rugosidade das superfícies de contato e a velocidade de carregamento, também afetam a deformabilidade da almofada. O módulo elástico é maior, por exemplo, para almofadas entre elementos com superfícies rugosas do que entre elementos de superfície lisa. Assim, os valores dos coeficientes $\mathrm{K}_{3}$ e $\mathrm{K}_{4}$ podem ser ajustados para levar em conta outras condições externas à almofada, como as diferentes superfícies de contato.

Com o objetivo de se levantar mais dados sobre assunto, sem a pretensão de esgotá-lo, foram realizados ensaios de compressão simples com deformação controlada, variando-se a geometria e a tensão de compressão em elastômeros simples. Posterior aos ensaios, fez-se uma comparação dos resultados experimentais obtidos nesta pesquisa e também de outros trabalhos apresentados na literatura, com a finalidade de ajustar valores para os coeficientes $\mathrm{K}_{3}$ e $\mathrm{K}_{4}$, na expressão (3.27), que possibilitem uma estimativa adequada para o valor do módulo de elasticidade de almofadas de elastômero simples. 


\subsubsection{Ensaios de Compressão Simples em Almofadas de Elastômeros}

Com o objetivo de se levantar mais dados para o estudo da determinação do módulo de elasticidade de uma almofada de elastômero simples, $\mathrm{E}_{\mathrm{n}}$, foram realizados ensaios de compressão simples com deformação controlada em uma série de almofadas, onde foram variadas as suas características geométricas e também os limites para as tensões médias de compressão na almofada.

Em meados de 1997, nesta pesquisa ainda não se tinha acesso aos relatos mais detalhados na bibliografia com respeito de ensaios em almofadas de elastômeros simples. Posteriormente, recebeu-se do Departamento de Engenharia Civil da Universidade de Tampere, na Finlândia, o trabalho realizado por KERONEN (1996), que além de ter feito vários ensaios em elastômeros, também apresenta uma ampla abordagem sobre o assunto. Embora a geometria das almofadas ali ensaiadas não sejam as mesmas utilizadas no presente trabalho, esse trabalho foi de grande valia para a comparação com os resultados aqui obtidos, tanto para confirmações quanto para reorientação dos ensaios durante o andamento da pesquisa.

\subsubsection{Ensaio Piloto}

Inicialmente, ainda não se dispunha no Laboratório de Estruturas do SET-EESC um equipamento com deformação controlada para grandes capacidades de cargas. Assim, utilizou-se um equipamento de deformação controlada com capacidade para $100 \mathrm{kN}$, DARTEC, do Laboratório de Madeiras do SET. Como o que se pretendia avaliar eram as relações geométricas da almofada, caracterizadas pelo fator de forma, os corpos de prova não poderiam ter a sua área reduzida, pois isto afetaria a relação área/espessura da almofada, desta forma as tensões atingidas nas almofadas foram baixas.

Foram realizados inicialmente dois ensaios pilotos de compressão simples em duas almofadas, conforme resumo na tabela 3.5 , com o objetivo de se ter uma primeira idéia sobre o comportamento do elastômero neste tipo de ensaio. A Almofada 1 foi ensaiada repetidamente, estando os resultados registrados nos gráficos 3.1 e 3.2. Os resultados do ensaio da Almofada 2 estão registrados no gráfico 3.3. 
Tabela 3.5: Almofadas ensaiadas em ensaio piloto

\begin{tabular}{|l|c|c|c|c|c|}
\hline & $a(\mathrm{~mm})$ & $b(\mathrm{~mm})$ & $h_{\mathrm{n}}(\mathrm{mm})$ & $A_{\mathrm{n}}\left(\mathrm{m}^{2}\right)$ & $B$ \\
\hline Almofada 1 & 150 & 300 & 10 & 0,045 & 5 \\
\hline Almofada 2 & 200 & 300 & 15 & 0,060 & 4 \\
\hline
\end{tabular}

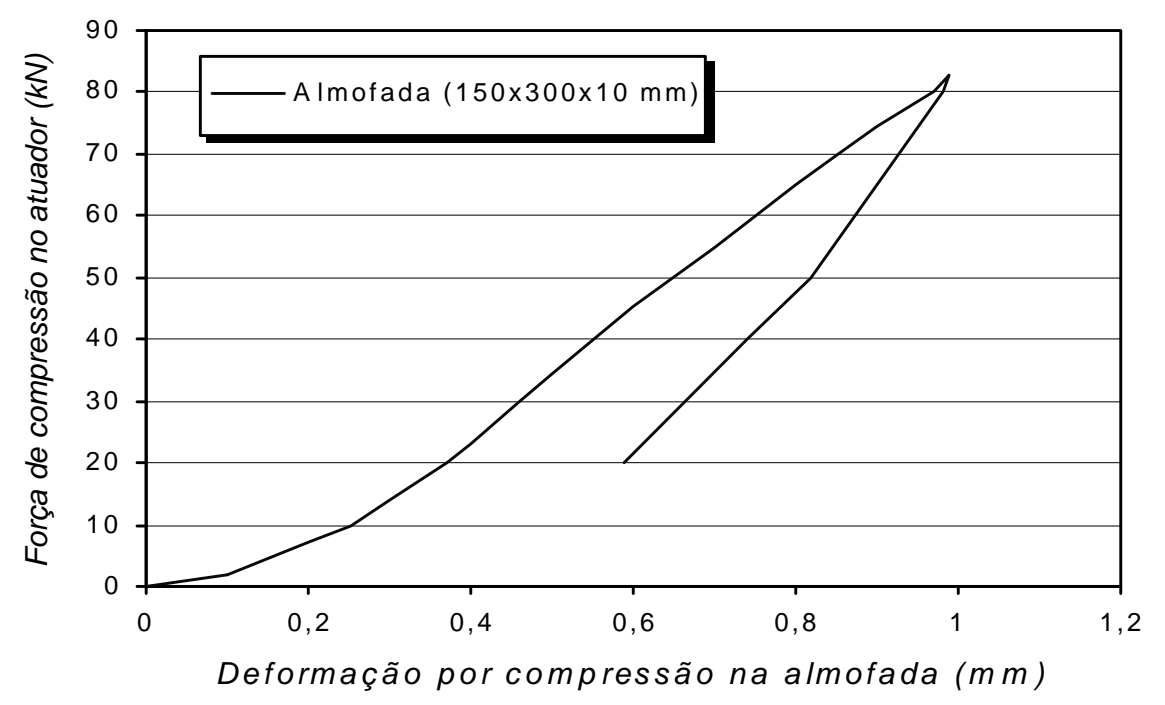

Gráfico 3.1 - Ensaio Piloto de Compressão Simples da Almofada 1 - Etapa 1

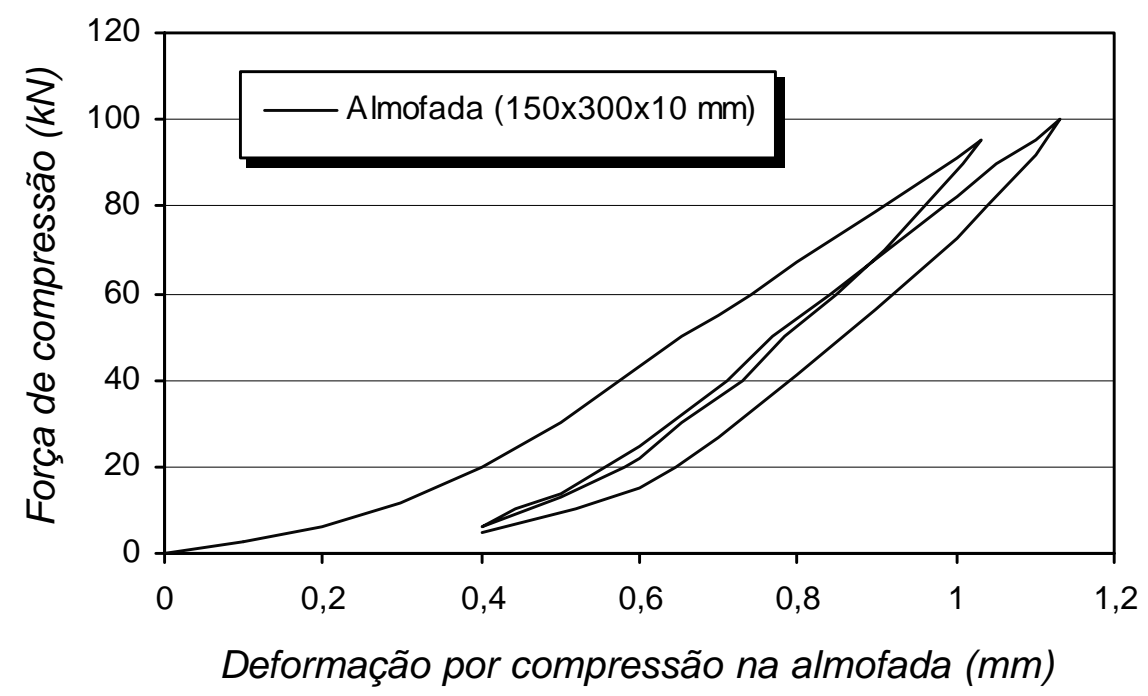

Gráfico 3.2 - Ensaio Piloto de Compressão Simples na Almofada 1 - Etapa 2 


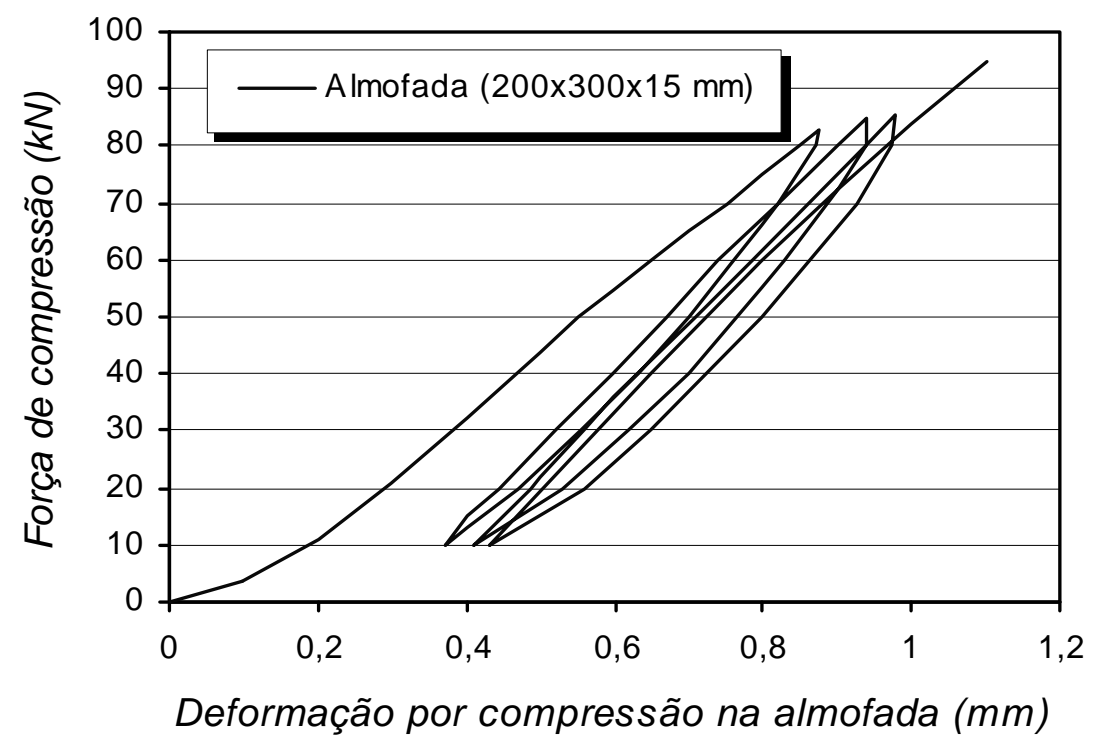

Gráfico 3.3 - Ensaio Piloto de Compressão Simples na Almofada 2

O módulo de elasticidade $E_{n}$ pode ser obtido a partir das inclinações das curvas experimentais da força de compressão $(\mathrm{N})$ vs. afundamento da almofada $\left(\Delta \mathrm{h}_{\mathrm{n}}\right)$. Essas inclinações correspondem à rigidez à compressão da almofada, $\mathrm{K}_{\mathrm{cn}}(\mathrm{kN} / \mathrm{mm})$, que é a relação inversa da deformabilidade à compressão, $\lambda_{\mathrm{nc}}$, que é dada por:

$$
\lambda_{n c}=\frac{h_{n}}{E_{n} \cdot A_{n}}=\frac{\Delta h_{n}}{N}
$$

Assim, o módulo En pode ser obtido pela expressão:

$$
E_{n}=\frac{N \cdot h_{n}}{\Delta h_{n} \cdot A_{n}}=K_{n c} \cdot \frac{h_{n}}{A_{n}}
$$

$\mathrm{Na}$ tabela 3.6 estão apresentados os módulos $\mathrm{E}_{\mathrm{n}}$ que foram calculados para cada ciclo de carregamento nas almofadas $\left(150 \times 300 \times 10 \mathrm{~mm}^{3}\right)$ e $\left(200 \times 300 \times 15 \mathrm{~mm}^{3}\right)$. 
Tabela 3.6: Obtenção do módulo $E_{n}$ a partir dos resultados experimentais para ensaio piloto.

\begin{tabular}{|c|c|c|c|c|c|}
\hline $\begin{array}{l}\text { Almofadas } \\
\text { (Dimensões) }\end{array}$ & Ciclo & $\mathrm{K}_{\mathrm{Cn}}(\mathrm{kN} / \mathrm{m})$ & $\begin{array}{l}\mathrm{E}_{\mathrm{n}}(\mathrm{MPa}) \\
\text { (porciclo) }\end{array}$ & $\sigma_{\mathrm{n}}(\mathrm{MPa})$ & $\begin{array}{c}\mathrm{E}_{\mathrm{n}}(\mathrm{MPa}) \\
\text { (final) }\end{array}$ \\
\hline $\begin{array}{l}\text { Almofada } 1 \\
(150 \times 300 \times 10)\end{array}$ & Ciclo 1 & 101134 & 22,47 & 1,89 & \\
\hline Etapa 2 & Ciclo 1 & 119613 & 26,58 & 1,89 & \\
\hline \multirow{5}{*}{$\begin{array}{l}\text { Àlmofada } 2 \\
(200 \times 300 \times 15)\end{array}$} & Ciclo 2 & 143700 & 31,93 & 1,89 & 31,93 \\
\hline & Ciclo 1 & 106738 & 26,68 & 1,41 & \\
\hline & Ciclo 2 & 132957 & 33,24 & 1,41 & \\
\hline & Ciclo 3 & 131970 & 32,99 & 1,41 & \\
\hline & Ciclo 4 & 130562 & 32,64 & 1,41 & 32,96 \\
\hline
\end{tabular}

Observou-se nestes ensaios, que após o primeiro ciclo de carregamento, sem retirar a carga totalmente para iniciar o segundo ciclo, houve um aumento e uma estabilização da rigidez à compressão na almofada e, por consequiência, também do módulo de elasticidade. O módulo elástico final da almofada foi tomado pelo valor médio dos módulos obtidos a partir do segundo ciclo de carregamento.

No início da realização dos ensaios, verificou-se que uma das chapas de aço grossas, que estavam sendo utilizadas para aplicar a compressão na almofada, não estava perfeitamente plana, mas um pouco empenada. Observou-se então, que a rigidez à compressão da almofada caiu sensivelmente quando a chapa foi posicionada com a sua concavidade voltada para a superfície de contato com a almofada. Isto fez com que as bordas da almofada se deformassem primeiro do que a região central. A rigidez à compressão da almofada sob estas condições chegou a atingir a cerca de $57 \%$ da rigidez obtida com uma chapa plana, onde a deformação vertical se deu uniforme na almofada. Desta forma, é importante ressaltar a importância de se garantir superfícies de contato regularizadas, mesmo com a utilização de argamassas de alta resistência para a colocação da almofada de elastômero, para que não ocorra grandes alterações na deformabilidade da almofada. 


\subsubsection{Ensaios de Compressão Simples com Deformação Controlada (Série A)}

Com a aquisição pelo Laboratório de Estruturas do SET-EESC de um novo equipamento para ensaios com deformação controlada, um atuador INSTRON Série 8506 com capacidade para $3000 \mathrm{kN}$, a partir do primeiro trimestre de 1998, foi possível realizar uma nova série de ensaios de compressão onde as almofadas foram comprimidas para altas pressões de contato, com deformações que atingiram $40 \%$. Nesta série de ensaios, denominada Série A, foram ensaiadas 6 almofadas de elastômero, com dureza Shore 60 A, as quais tiveram a sua geometria variada, conforme indicado na tabela 3.7. Os dados foram registrados continuamente, 1 registro por segundo, através de um sistema de aquisição de dados (K-5000). As cargas foram aplicadas a uma velocidade da ordem de $0,005 \mathrm{~mm} /$ segundo até que a deformação da almofada atingisse um limite da ordem de 40 $\%$ da espessura da almofada. As curvas força de compressão x afundamento na almofada estão apresentadas nos gráficos 3.4 a 3.9. Na tabela 3.8 estão apresentados os módulos de elasticidade $\mathrm{E}_{\mathrm{n}}$ que foram calculados a partir das curvas obtidas nos gráficos 3.4 a 3.9.

Tabela 3.7 - Ensaios de compressão simples em elastômeros. (Série A)

\begin{tabular}{|c|c|c|c|c|c|}
\hline Almofada & $\begin{array}{c}a \\
(\mathrm{~mm})\end{array}$ & $\begin{array}{c}\mathrm{B} \\
(\mathrm{mm})\end{array}$ & $\begin{array}{c}\mathrm{h}_{\mathrm{n}} \\
(\mathrm{mm})\end{array}$ & $\begin{array}{c}\mathrm{A}_{\mathrm{n}} \\
\left(\mathrm{m}^{2}\right)\end{array}$ & $\mathrm{B}$ \\
\hline CP 1 & 150 & 300 & 10 & 0,045 & 5 \\
\hline CP 2 & 60 & 300 & 10 & 0,018 & 2,5 \\
\hline CP 3 & 150 & 150 & 15 & 0,0225 & 2,5 \\
\hline CP 4 & 150 & 300 & 15 & 0,045 & 3,33 \\
\hline CP 5 & 200 & 300 & 15 & 0,06 & 4 \\
\hline CP 6 & 250 & 300 & 10 & 0,075 & 6,81 \\
\hline
\end{tabular}




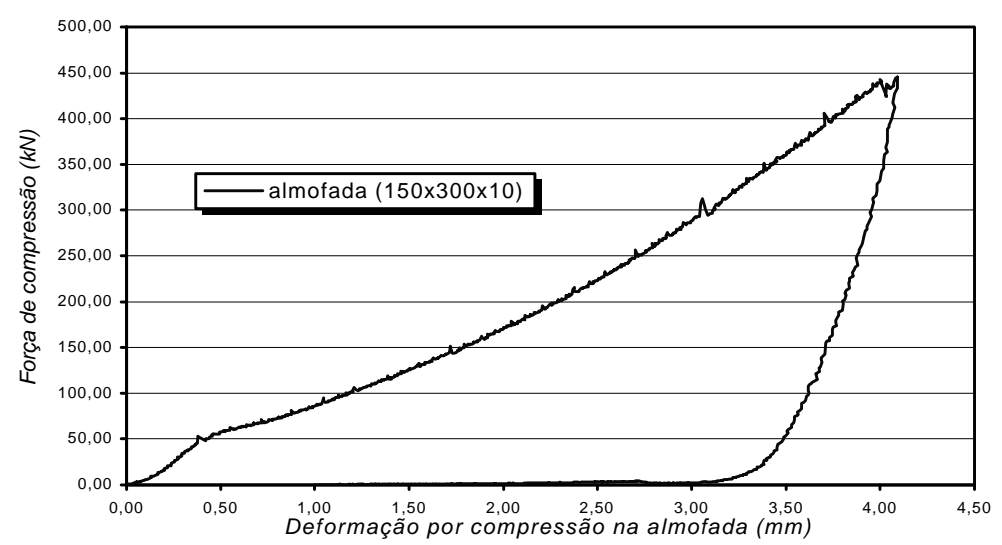

Gráfico 3.4 - Ensaio Compressão Simples em Almofada de Elastômero (CP-1)

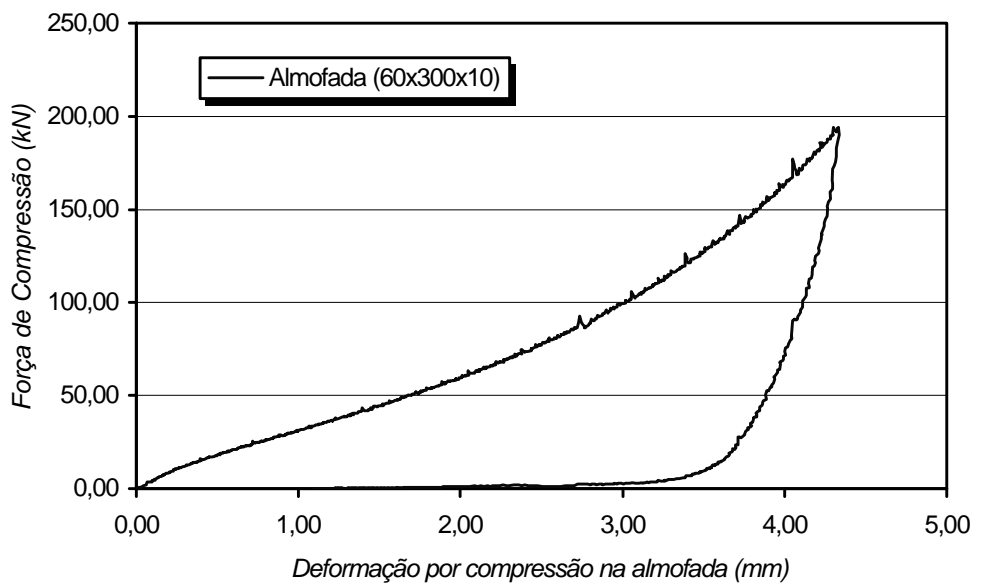

Gráfico 3.5 - Ensaio Compressão Simples em Almofada de Elastômero (CP-2)

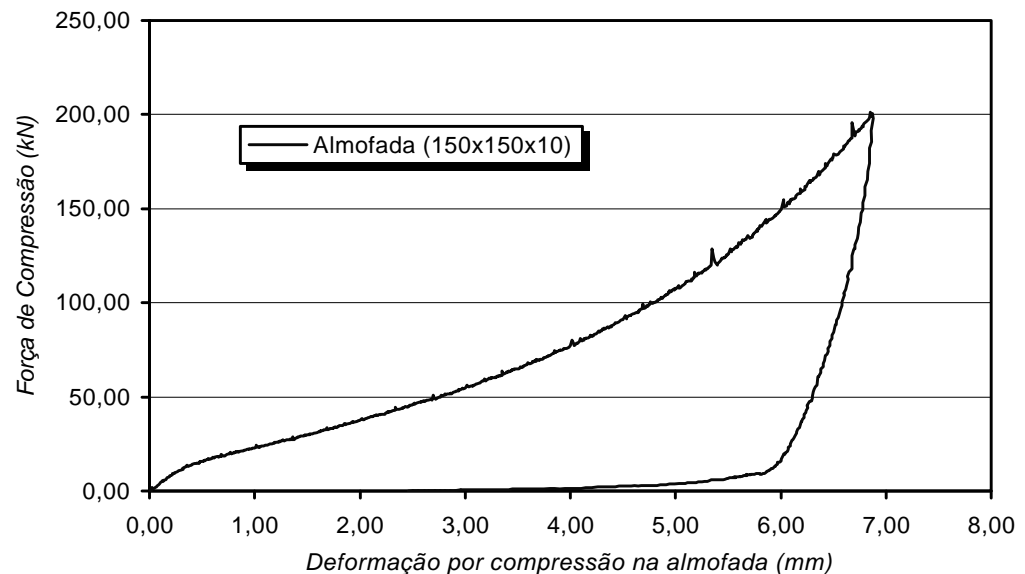

Gráfico 3.6 - Ensaio Compressão Simples em Almofada de Elastômero (CP-3) 


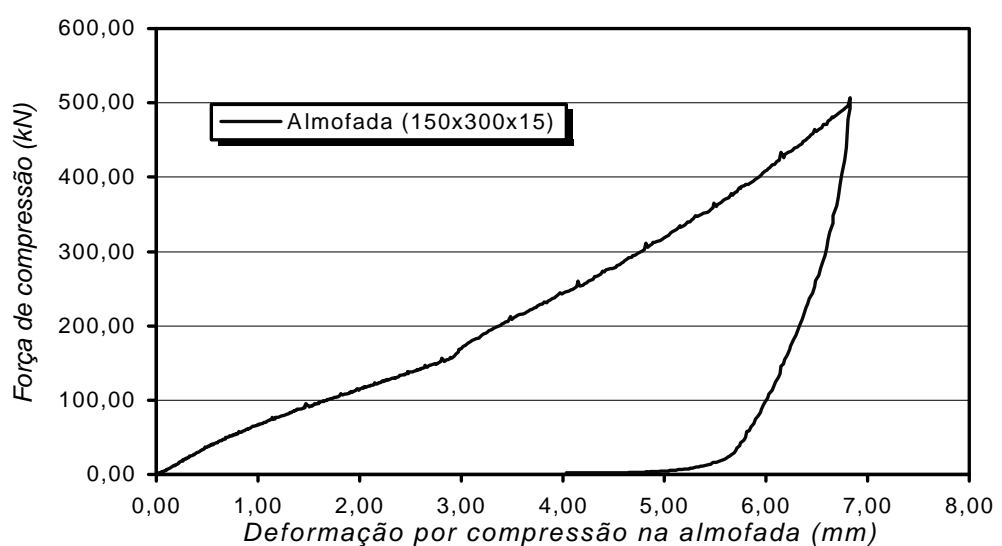

Gráfico 3.7 - Ensaio Compressão Simples em Almofada de Elastômero (CP-4)

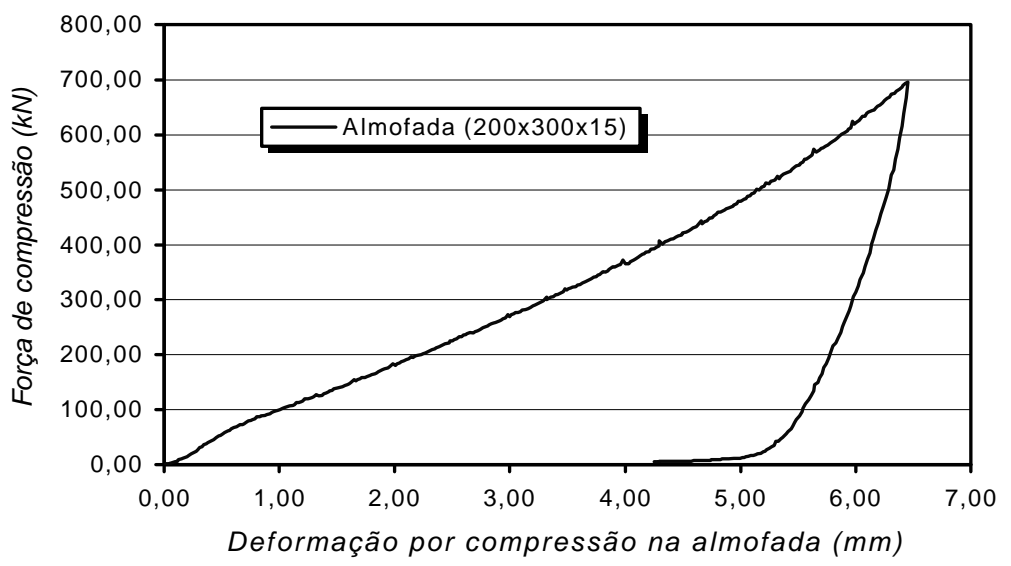

Gráfico 3.8 - Ensaio Compressão Simples em Almofada de Elastômero (CP-5)

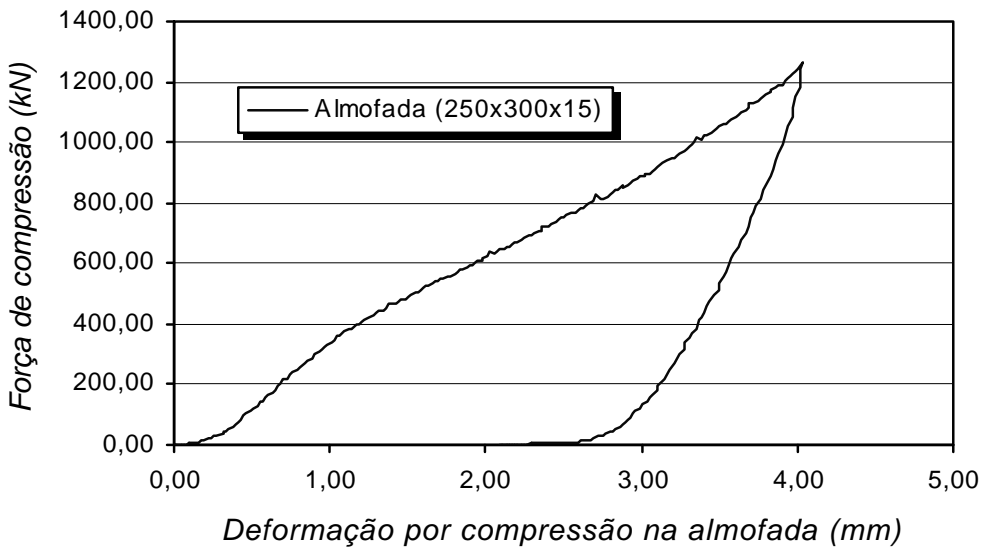

Gráfico 3.9 - Ensaio Compressão Simples em Almofada de Elastômero (CP-6) 
Na tabela 3.8 são apresentados os módulos de elasticidade obtidos a partir dos resultados experimentais dos ensaios da Série A. Para uma deformação máxima nas almofadas da ordem de $40 \%$, as tensões médias de compressão nas almofadas corresponderam a valores que variaram entre 8,9 e 16,8 MPa. Paras estas situações de afundamento máximo, as almofadas apresentaram uma grande expansão lateral $U_{a}$, na direção do lado "a", que chegou a ser maior que a espessura da almofada. Desta forma, à medida em que a tensão na almofada aumentou, a expansão lateral também aumentou, alterando assim a rigidez e o módulo de elasticidade da almofada. Por esta razão, na tabela 3.8, os módulos de elasticidade das almofada foram calculados para tensões de compressão $\sigma_{\mathrm{m}}<5 \mathrm{MPa}$ e para $\sigma_{\mathrm{m}}>5 \mathrm{MPa}$.

Tabela 3.8 - Obtenção do módulo $E_{n}$ a partir dos resultados experimentais.

\begin{tabular}{|c|c|c|c|c|c|c|c|c|}
\hline Almofadas & $B$ & $\begin{array}{c}\mathrm{N}_{\text {máx }} \\
(\mathrm{kN})\end{array}$ & $\begin{array}{l}\sigma_{\mathrm{m}, \text { máx }} \\
(\mathrm{MPa})\end{array}$ & $\begin{array}{c}\Delta \mathrm{h}_{\text {máx }} \\
(\mathrm{mm})\end{array}$ & $\begin{array}{l}a+U_{a} \\
(m m)\end{array}$ & $\begin{array}{c}\sigma_{\mathrm{m}} \\
(\mathrm{MPa})\end{array}$ & $\begin{array}{c}\mathrm{K}_{\mathrm{Cn}} \\
(\mathrm{kN} / \mathrm{m})\end{array}$ & $\begin{array}{c}\mathrm{E}_{\mathrm{n}} \\
(\mathrm{MPa})\end{array}$ \\
\hline $150 \times 300 \times 10$ & 5 & 445 & 9,88 & $\begin{array}{c}4,09 \\
(41 \%)\end{array}$ & 210 & $\begin{array}{l}\sigma_{n}<5 \\
\sigma_{n}>5\end{array}$ & $\begin{array}{c}83751 \\
143897\end{array}$ & $\begin{array}{l}18,6 \\
32,0\end{array}$ \\
\hline $60 \times 300 \times 10$ & 2,5 & 194 & 10,78 & $\begin{array}{c}4,33 \\
(43 \%)\end{array}$ & 97 & $\begin{array}{l}\sigma_{n}<5 \\
\sigma_{n}>5\end{array}$ & $\begin{array}{l}30240 \\
68502\end{array}$ & $\begin{array}{l}16,8 \\
38,1\end{array}$ \\
\hline $150 \times 150 \times 15$ & 2,5 & 200 & 8,89 & $\begin{array}{c}6,87 \\
(46 \%)\end{array}$ & 198 & $\begin{array}{l}\sigma_{n}<5 \\
\sigma_{n}>5\end{array}$ & $\begin{array}{l}19456 \\
50841\end{array}$ & $\begin{array}{l}13,0 \\
33,9\end{array}$ \\
\hline $150 \times 300 \times 15$ & 3,33 & 507 & 11,27 & $\begin{array}{c}6,83 \\
(46 \%)\end{array}$ & 215 & $\begin{array}{l}\sigma_{n}<5 \\
\sigma_{n}>5\end{array}$ & $\begin{array}{l}54838 \\
88131\end{array}$ & $\begin{array}{l}18,3 \\
29,4\end{array}$ \\
\hline $200 \times 300 \times 15$ & 4 & 696,5 & 11,61 & $\begin{array}{c}6,45 \\
(43 \%)\end{array}$ & 275 & $\begin{array}{l}\sigma_{n}<5 \\
\sigma_{n}>5\end{array}$ & $\begin{array}{c}88157 \\
124442\end{array}$ & $\begin{array}{l}22,0 \\
31,1\end{array}$ \\
\hline $250 \times 300 \times 10$ & 6,81 & $\begin{array}{c}1261 \\
5\end{array}$ & 16,82 & $\begin{array}{c}4,03 \\
(40 \%)\end{array}$ & 318 & $\begin{array}{l}\sigma_{n}<5 \\
\sigma_{n}>5\end{array}$ & $\begin{array}{l}372841 \\
286951\end{array}$ & $\begin{array}{l}49,7 \\
38,2\end{array}$ \\
\hline
\end{tabular}

Comparando-se os resultados dos módulos $\mathrm{E}_{\mathrm{n}}$ com os módulos obtidos nos ensaios pilotos, onde as almofadas $\left(150 \times 300 \times 10 \mathrm{~mm}^{3}\right)$ e $\left(200 \times 300 \times 15 \mathrm{~mm}^{3}\right)$ foram 
submetidas a tensões bem inferiores, na Série A foram obtidos valores inferiores para os módulos $\mathrm{E}_{\mathrm{n}}$. Acredita-se que isto tenha ocorrido em função da velocidade de carregamento, de 0,005 a 0,010 mm/segundo, adotada para a Série A deve ter sido suficiente baixa para permitir que a almofada fosse se expandindo lateralmente à medida em que era carregada, fazendo com que os resultados do módulo $\mathrm{E}_{\mathrm{n}}$ da almofada fossem bastante afetados.

Como o módulo $\mathrm{E}_{\mathrm{n}}$ sofre influência tensão média $\sigma_{\mathrm{m}}$, e de seus efeitos, verificouse que as almofadas não podem ser comparadas para mesmos níveis de deformação, sendo necessário que as mesmas sejam comparadas para os mesmos níveis de tensão. Por esta razão decidiu-se fazer uma nova série de ensaios, Série B.

\subsubsection{Ensaios de Compressão Simples com Deformação Controlada, para Limites de Tensões Fixos (Série B)}

Os ensaios na Série B foram realizados para os mesmos corpos de prova utilizados na Série A, onde cada almofada foi ensaiada para três limites de tensões médias nas almofadas: $\sigma_{\mathrm{m}}=3 \mathrm{MPa} ; \sigma_{\mathrm{m}}=7 \mathrm{MPa}$ e $\sigma_{\mathrm{m}}=10 \mathrm{MPa}$, conforme indicado na tabela 3.9. Para diminuir o efeito da expansão lateral, a velocidade de carregamento foi aumentada para cerca de 0,02 a $0,05 \mathrm{~mm} /$ segundos. Os resultados obtidos nas séries de ensaios de compressão estão apresentados nos gráficos 3.10 a 3.15. Na tabela 3.10 estão apresentados os módulos $\mathrm{E}_{\mathrm{n}}$ obtidos a partir dos resultados experimentais.

Tabela 3.9 - Ensaios de compressão simples em elastômeros. (Série B)

\begin{tabular}{|c|c|c|c|c|c|}
\hline Almofada & $\begin{array}{c}\mathrm{a} \\
(\mathrm{mm})\end{array}$ & $\begin{array}{c}\mathrm{b} \\
(\mathrm{mm})\end{array}$ & $\begin{array}{c}\mathrm{h}_{\mathrm{n}} \\
(\mathrm{mm})\end{array}$ & $\mathrm{B}$ & $\begin{array}{c}\sigma_{\mathrm{n}} \\
(\mathrm{MPa})\end{array}$ \\
\hline CP 1 & 150 & 300 & 10 & 5 & 3,7 e 10 \\
\hline CP 2 & 60 & 300 & 10 & 2,5 & 3,7 e 10 \\
\hline CP 3 & 150 & 150 & 15 & 2,5 & 3,7 e 10 \\
\hline CP 4 & 150 & 300 & 15 & 3,33 & 3,7 e 10 \\
\hline CP 5 & 200 & 300 & 15 & 4 & 3,7 e 10 \\
\hline CP 6 & 250 & 300 & 10 & 6,81 & 3,7 e 10 \\
\hline
\end{tabular}



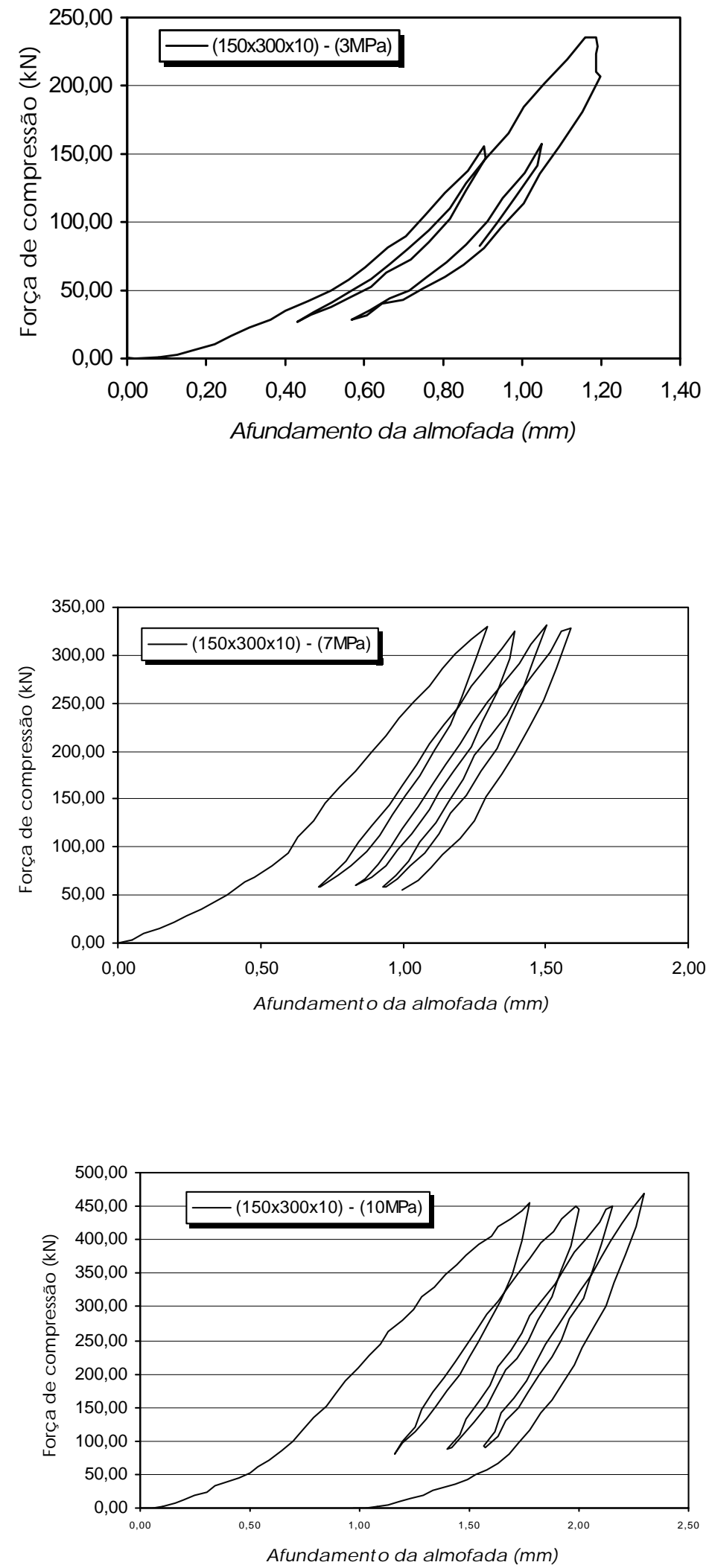

Gráfico 3.10 - Série B: Ensaios de Compressão Simples em Almofada de Elastômero (CP-1) 

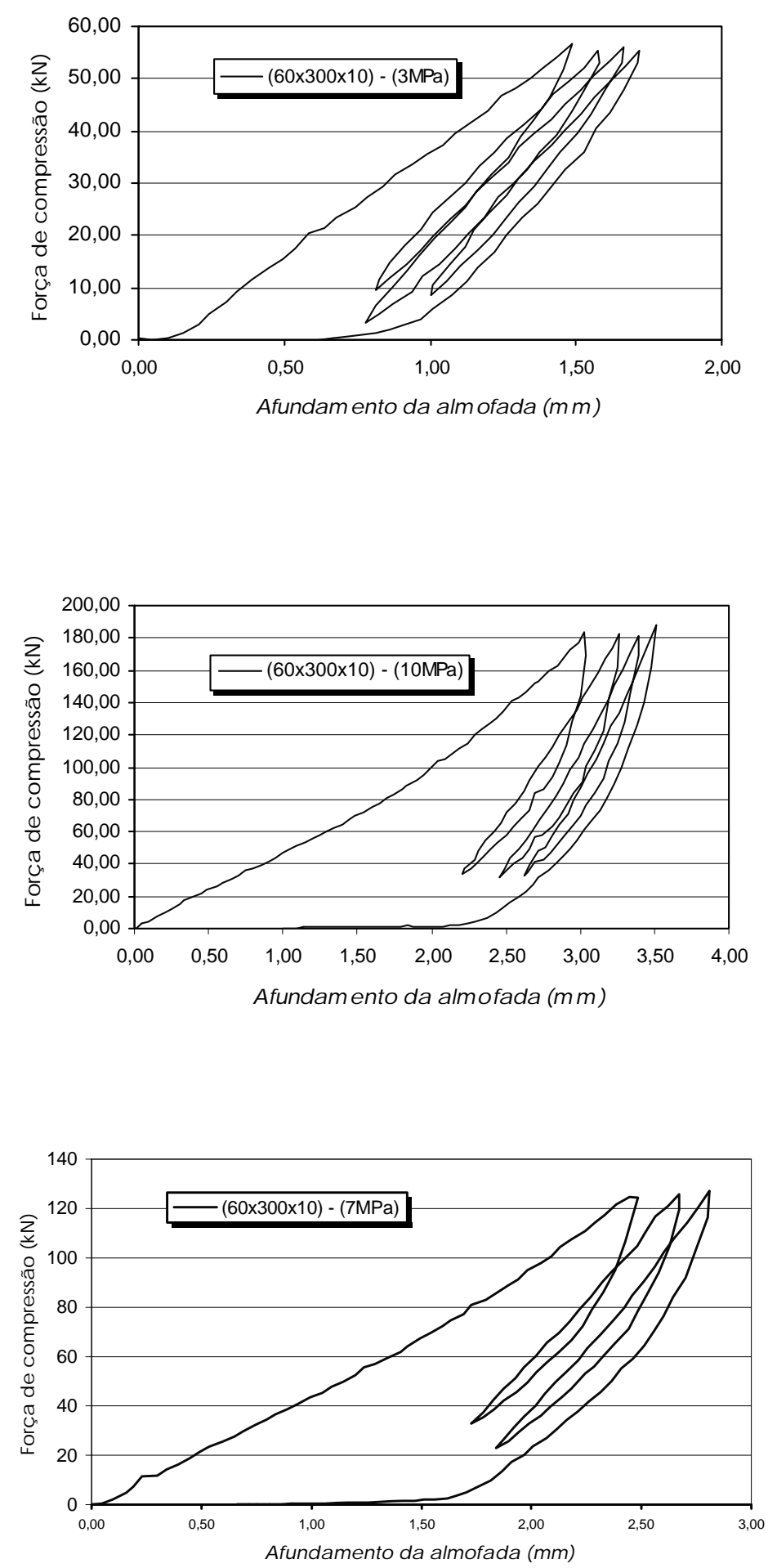

Gráfico 3.11 - Série B: Ensaios de Compressão Simples em Almofada de Elastômero (CP-2) 

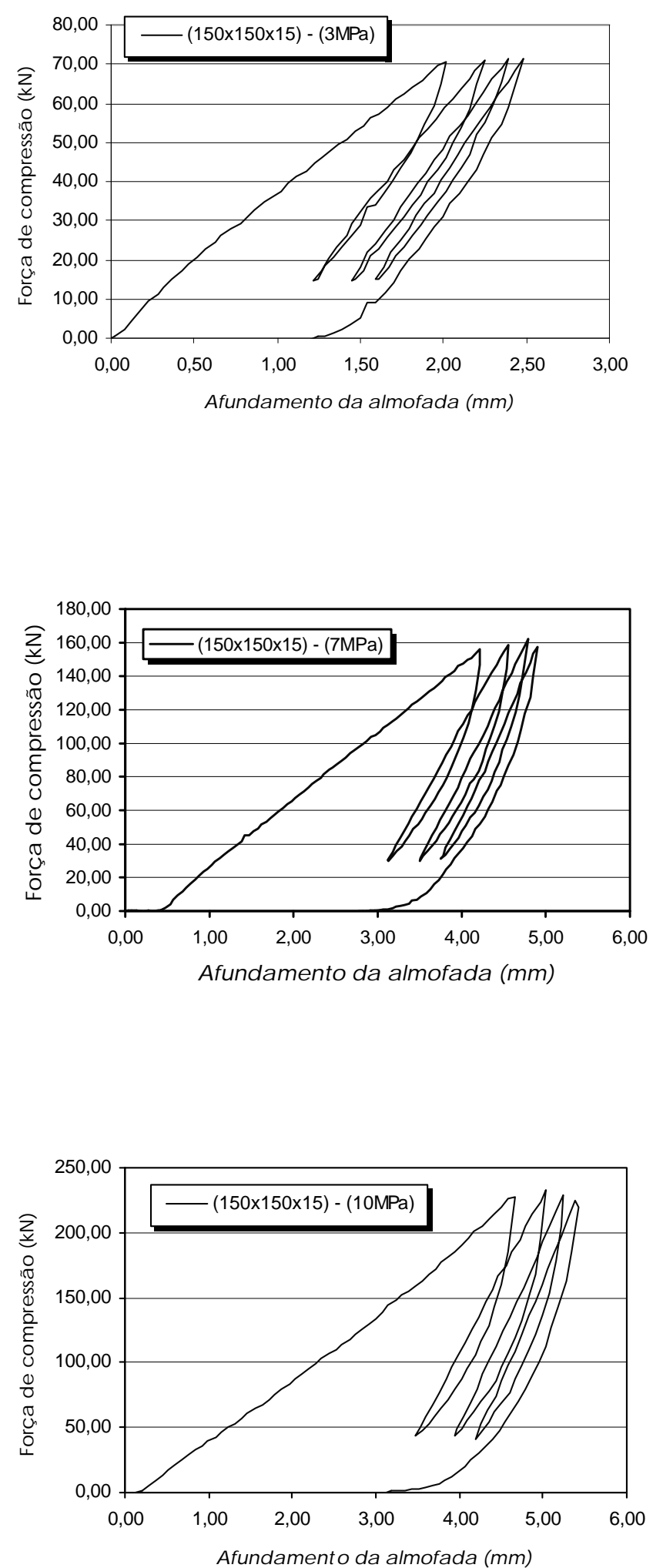

Gráfico 3.12 - Série B: de Ensaios de Compressão Simples em Almofada de Elastômero (CP-3) 

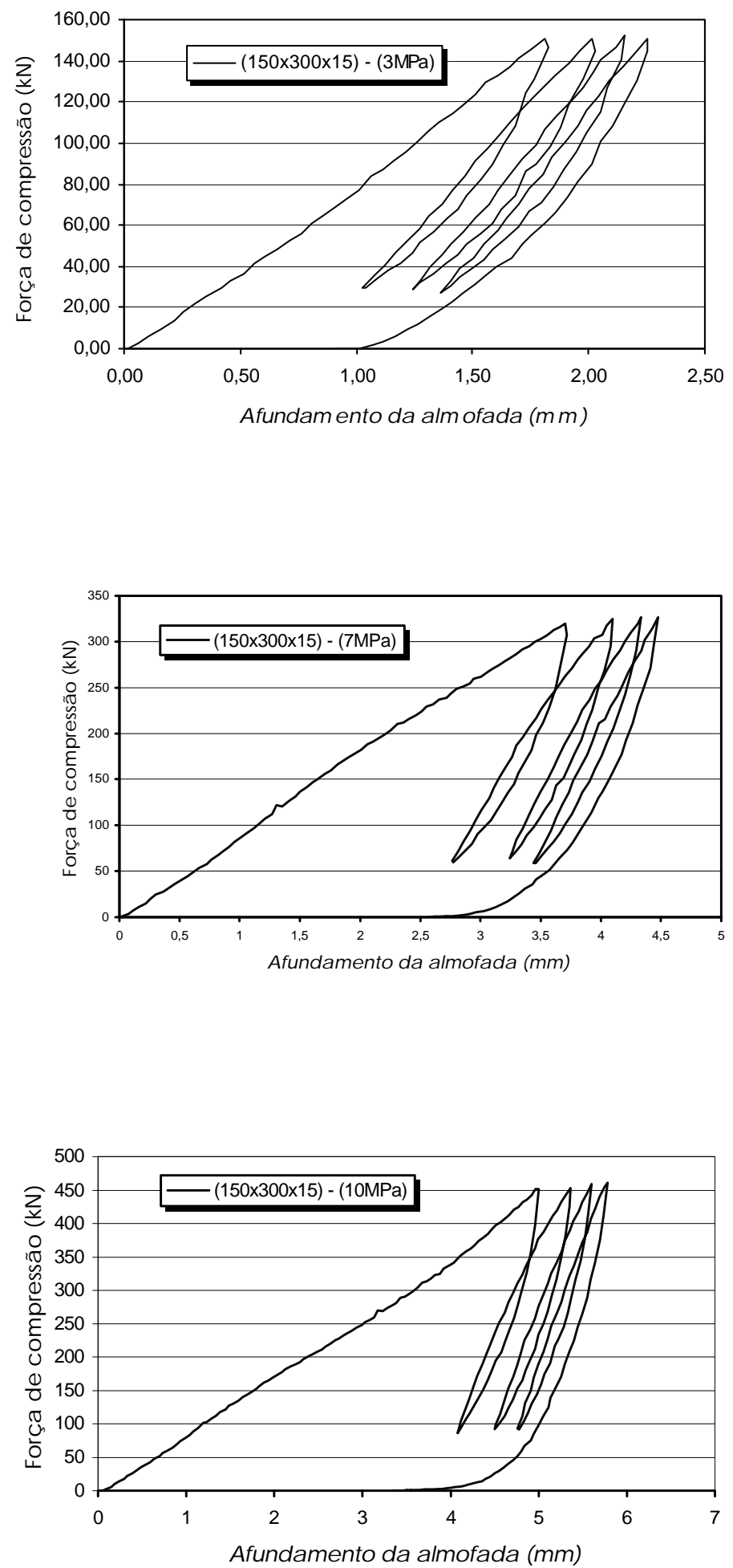

Gráfico 3.13- Série B: Ensaios de Compressão Simples em Almofada de Elastômero (CP-4) 

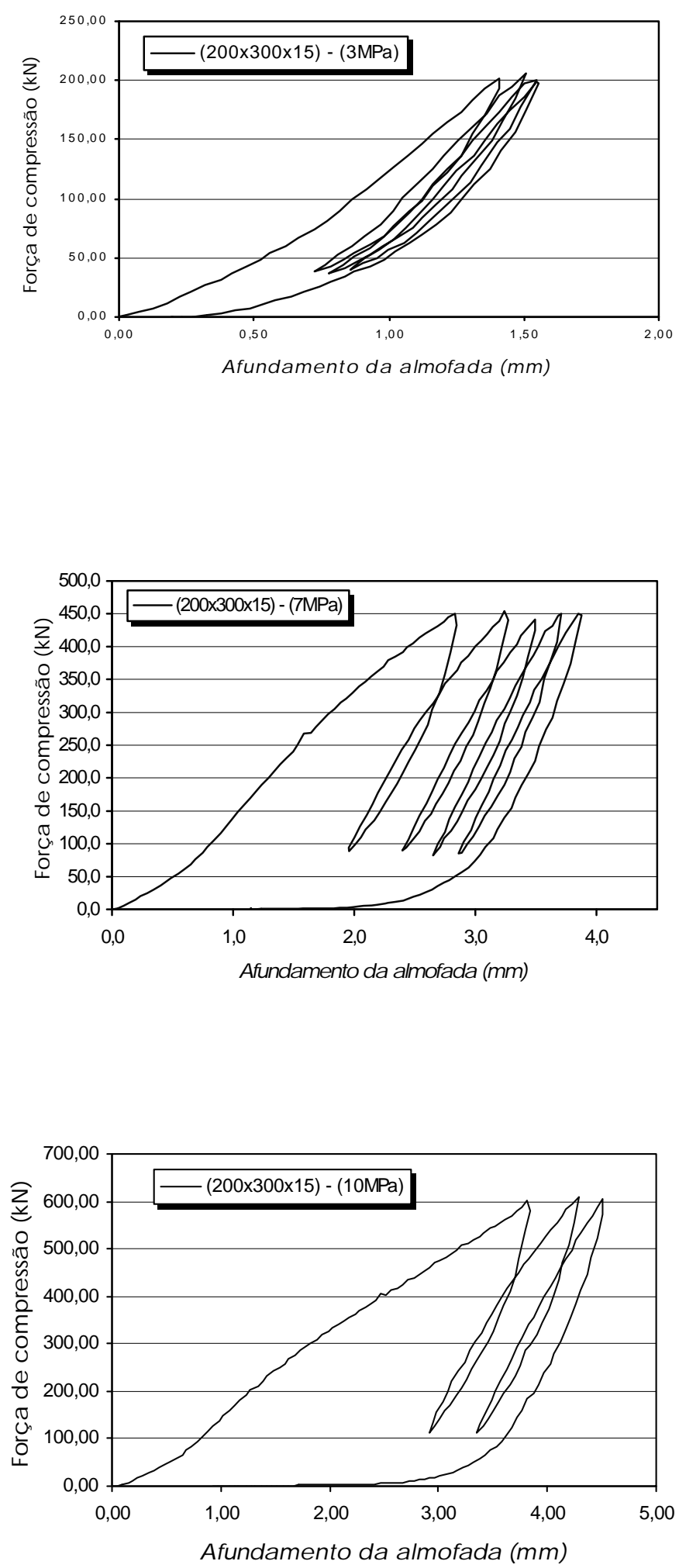

Gráfico 3.14 - Série B: Ensaios de Compressão Simples em Almofada de Elastômero (CP-5) 

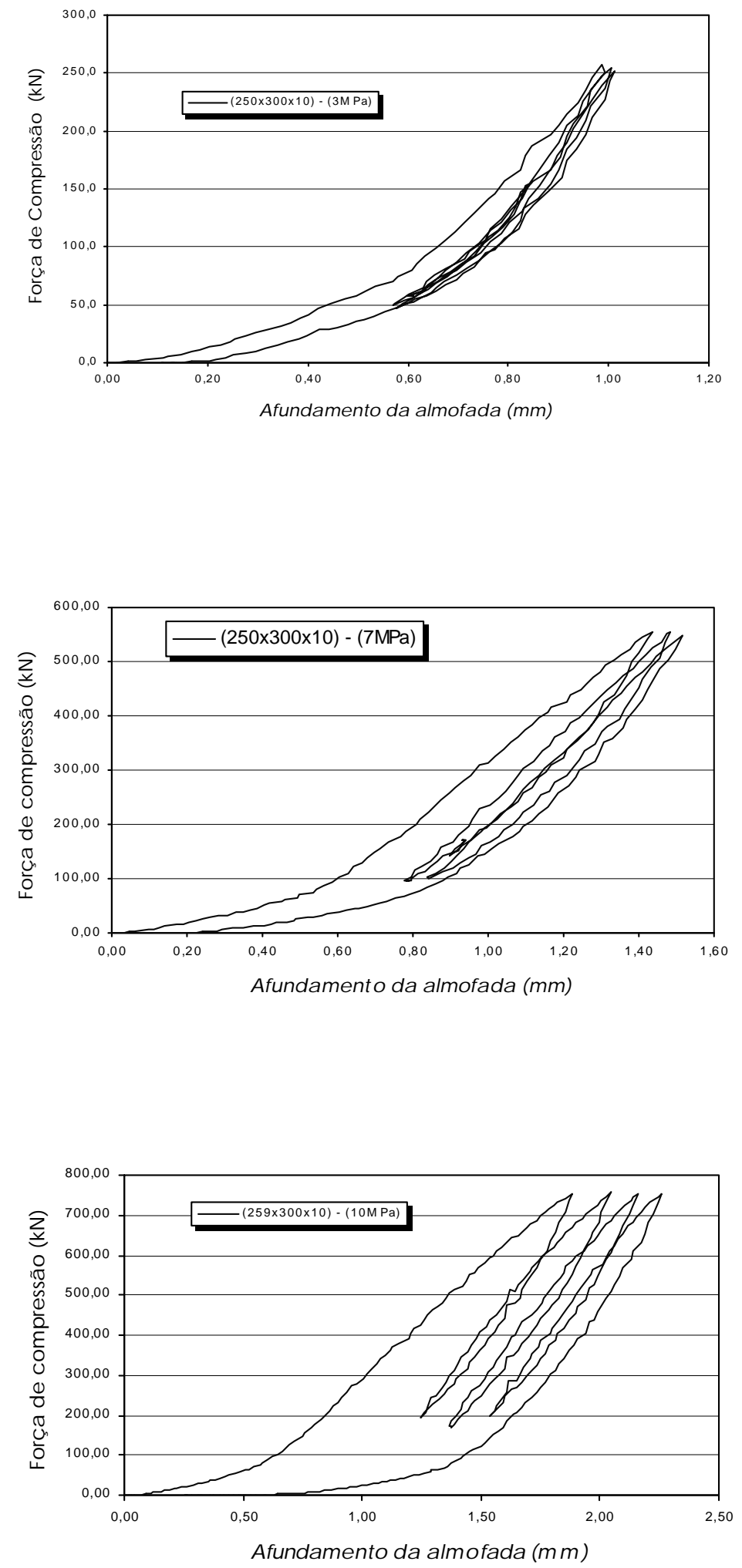

Gráfico 3.15 - Série B: Ensaios de Compressão Simples em Almofada de Elastômero (CP-6) 
Tabela 3.10 - Obtenção do módulo $E_{n}$ a partir dos resultados experimentais.

\begin{tabular}{|c|c|c|c|c|c|}
\hline Almofadas & $B$ (forma) & $\mathrm{N}(\mathrm{kN})$ & $\sigma_{\mathrm{m}}(\mathrm{MPa})$ & $\mathrm{K}_{\mathrm{cn}}(\mathrm{kN} / \mathrm{m})$ & $\mathrm{E}_{\mathrm{n}}(\mathrm{MPa})$ \\
\hline$(150 \times 300 \times 10)$ & 5 & $\begin{array}{l}150 \\
320 \\
450\end{array}$ & $\begin{array}{c}3 \\
7 \\
10\end{array}$ & $\begin{array}{c}307,18 \\
(342,27)^{1} \\
333,11 \\
(406,49) \\
332,11 \\
(451,87)\end{array}$ & $\begin{array}{c}68 \\
(72)^{2} \\
74 \\
(82) \\
73,8 \\
(87)\end{array}$ \\
\hline$(60 \times 300 \times 10)$ & 2,5 & $\begin{array}{r}55 \\
125 \\
180\end{array}$ & $\begin{array}{c}3 \\
7 \\
10\end{array}$ & $\begin{array}{c}41,84 \\
(54,84) \\
59,45 \\
(101,89) \\
79,76 \\
(150,28)\end{array}$ & $\begin{array}{c}23 \\
(26,9) \\
33 \\
(44,8) \\
44,3 \\
(63,9)\end{array}$ \\
\hline$(150 \times 150 \times 15)$ & 2,5 & $\begin{array}{r}70 \\
155 \\
225\end{array}$ & $\begin{array}{c}3 \\
7 \\
10\end{array}$ & $\begin{array}{c}33,10 \\
(52,85) \\
40,05 \\
(90,28) \\
54,50 \\
(121,46)\end{array}$ & $\begin{array}{c}22 \\
(28,7) \\
26,7 \\
(43,4) \\
36,3 \\
(58,7)\end{array}$ \\
\hline$(150 \times 300 \times 15)$ & 3,33 & $\begin{array}{l}150 \\
320 \\
450\end{array}$ & $\begin{array}{c}3 \\
7 \\
10\end{array}$ & $\begin{array}{c}90,65 \\
(125,46) \\
79,60 \\
(169,60) \\
101,54 \\
(251,20)\end{array}$ & $\begin{array}{c}30,2 \\
(35,4) \\
26,5 \\
(41,5) \\
33,8 \\
(58,8)\end{array}$ \\
\hline$(200 \times 300 \times 15)$ & 4 & $\begin{array}{l}200 \\
450 \\
600\end{array}$ & $\begin{array}{c}3 \\
7 \\
10\end{array}$ & $\begin{array}{c}192,99 \\
(236,32) \\
161,25 \\
(253,41) \\
145,44 \\
(319,78)\end{array}$ & $\begin{array}{c}48 \\
(53,7) \\
40,3 \\
(51,8) \\
36,4 \\
(58)\end{array}$ \\
\hline$(250 \times 300 \times 10)$ & 6,81 & $\begin{array}{r}250 \\
550 \\
750\end{array}$ & $\begin{array}{c}3 \\
7 \\
10\end{array}$ & $\begin{array}{c}471,06 \\
(493,94) \\
557,38 \\
(659,79) \\
541,71 \\
(706,45)\end{array}$ & $\begin{array}{c}62,8 \\
(64,3) \\
74,3 \\
(81) \\
72 \\
(83,2)\end{array}$ \\
\hline
\end{tabular}

\footnotetext{
${ }^{1}$ Correspondente ao segundo ciclo de carregamento.

${ }^{2}$ Calculado para o valor médio de $K_{c n}$ no primeiro e segundo ciclo.
} 
$\mathrm{Na}$ tabela 3.11 pode-se verificar que as almofadas $\left(60 \times 300 \times 10 \mathrm{~mm}^{3}\right)$ e (150x150x15 mm³), com o mesmo fator de forma $B=2,5$, apresentam valores compatíveis para o módulo $\mathrm{E}_{\mathrm{n}}$, quando submetidas às mesmas tensões.

Tabela 3.11 - Comparação entre almofadas com mesmo fator de forma $B$

\begin{tabular}{|c|c|c|c|c|}
\hline (valor fixo) & (va riável) & $(60 \times 300 \times 10)$ & $(150 \times 150 \times 15)$ & \\
\hline$B$ (forma) & $\sigma_{\mathrm{n}}(\mathrm{MPa})$ & $\mathrm{E}_{\mathrm{n} 1}(\mathrm{MPa})$ & $\mathrm{E}_{\mathrm{n} 2}(\mathrm{MPa})$ & $\mathrm{E}_{\mathrm{n} 1} / \mathrm{E}_{\mathrm{n} 2}$ \\
\hline 2,5 & 3 & 23 & 22 & 1,05 \\
\hline 2,5 & 7 & 33 & 26,7 & 1,24 \\
\hline 2,5 & 10 & 44,3 & 36,3 & 1,22 \\
\hline
\end{tabular}

\subsubsection{Ajuste do Equacionamento Teórico para o Cálculo do Módulo $\mathrm{E}_{\mathbf{n}}$ a partir dos Resultados Experimentais}

Na tabela 3.12 são comparados os resultados experimentais com os valores teóricos obtidos a partir da expressão para o cálculo do módulo elástico, $\mathrm{E}_{\mathrm{n}}$, dada por:

$$
E_{n}=10 \cdot G \cdot B+2 \cdot \sigma_{m}
$$

A partir destas comparações, verificou-se que a expressão acima forneceu uma boa estimativa para o módulo $\mathrm{E}_{\mathrm{n}}$. Assim, baseando-se na análise dos resultados dos ensaios aqui realizados, concluiu-se que a equação para o cálculo do módulo $\mathrm{E}_{\mathrm{n}}$ para o elastômero não fretado pode ser escrita na sua forma geral dada por:

$$
E_{n}=K_{1} \cdot G \cdot B+K_{2} \cdot \sigma_{m}
$$

Entretanto, cabe ressaltar que os resultados para o módulo $\mathrm{E}_{\mathrm{n}}$ foram obtidos para a situação em que o elastômero estava entre duas chapas metálicas lisas (não polidas), o que se diferencia um pouco da situação onde se tem o elastômero entre duas superfícies de concreto. Desta forma, para esta última situação, a equação acima pode sofrer um novo ajuste para os valores dos coeficientes $\mathrm{K}_{1}$ e $\mathrm{K}_{2}$. 
Tabela 3.12 - Obtenção do módulo $E_{n}$ a partir dos resultados experimentais.

\begin{tabular}{|c|c|c|c|c|c|}
\hline Almofadas & $\begin{array}{c}\text { B } \\
\text { (forma) }\end{array}$ & $\begin{array}{c}\sigma_{\mathrm{m}} \\
(\mathrm{MPa})\end{array}$ & $\begin{array}{r}E_{n, \exp } . \\
(\mathrm{MPa})\end{array}$ & $\begin{array}{r}E_{n, \text { calc. }} \\
(\mathrm{MPa})\end{array}$ & $E_{n, \text { calc }} / E_{n, \exp }$ \\
\hline$(150 \times 300 \times 10)$ & 5 & $\begin{array}{c}3 \\
7 \\
10\end{array}$ & $\begin{array}{c}68 \\
(72)^{3} \\
74 \\
(82) \\
73,8 \\
(87)\end{array}$ & $\begin{array}{l}56 \\
64 \\
70\end{array}$ & $\begin{array}{c}0,82 \\
(0,78) \\
0,86 \\
(0,78) \\
0,95 \\
(0,80)\end{array}$ \\
\hline$(60 \times 300 \times 10)$ & 2,5 & $\begin{array}{c}3 \\
7 \\
10\end{array}$ & $\begin{array}{c}23 \\
(26,9) \\
33 \\
(44,8) \\
44,3 \\
(63,9)\end{array}$ & $\begin{array}{l}31 \\
39 \\
45\end{array}$ & $\begin{array}{c}1,35 \\
(1,15) \\
1,18 \\
(0,88) \\
1,02 \\
(0,70)\end{array}$ \\
\hline$(150 \times 150 \times 15)$ & 2,5 & $\begin{array}{c}3 \\
7 \\
10\end{array}$ & $\begin{array}{c}22 \\
(28,7) \\
26,7 \\
(43,4) \\
36,3 \\
(58,7)\end{array}$ & $\begin{array}{l}31 \\
39 \\
45\end{array}$ & $\begin{array}{c}1,4 \\
(1,08) \\
1,46 \\
(0,90) \\
1,24 \\
(0,77)\end{array}$ \\
\hline$(150 \times 300 \times 15)$ & 3,33 & $\begin{array}{c}3 \\
7 \\
10\end{array}$ & $\begin{array}{c}30,2 \\
(35,4) \\
26,5 \\
(41,5) \\
33,8 \\
(58,8)\end{array}$ & $\begin{array}{r}39,3 \\
47,3 \\
53,3\end{array}$ & $\begin{array}{c}1,30 \\
(1,11) \\
1,78 \\
(1,13) \\
1,58 \\
(0,90)\end{array}$ \\
\hline$(200 \times 300 \times 15)$ & 4 & $\begin{array}{c}3 \\
7 \\
10\end{array}$ & $\begin{array}{c}48 \\
(53,7) \\
40,3 \\
(51,8) \\
36,4 \\
(58)\end{array}$ & $\begin{array}{l}46 \\
54 \\
60\end{array}$ & $\begin{array}{c}0,96 \\
(0,86) \\
1,34 \\
(1,04) \\
1,65 \\
(1,03)\end{array}$ \\
\hline$(250 \times 300 \times 10)$ & 6,81 & $\begin{array}{c}3 \\
7 \\
10\end{array}$ & $\begin{array}{c}62,8 \\
(64,3) \\
74,3 \\
(81) \\
72 \\
(83,2)\end{array}$ & $\begin{array}{l}74,1 \\
82,1 \\
88,1\end{array}$ & $\begin{array}{c}1,18 \\
(1,15) \\
1,10 \\
(1,01) \\
1,22 \\
(1,06)\end{array}$ \\
\hline
\end{tabular}

\footnotetext{
${ }^{3}$ Correspondente ao segundo ciclo de carregamento
} 
Para a nova calibração dos coeficientes $\mathrm{K}_{1}$ e $\mathrm{K}_{2}$, optou-se, ao invés da realização de uma nova série de ensaios, por utilizar os resultados experimentais apresentados em KERONEN (1996), para almofadas de elastômero comprimidas entre dois elementos de concreto (executados com formas metálicas).

Na tabela 3.13 são apresentadas comparações entre os resultados experimentais apresentados em KERONEN (1996), com valores teóricos obtidos para $\mathrm{K}_{1}=10$ e $\mathrm{K}_{2}=2$.

Tabela 3.13 - Resultados experimentais para $E_{n}$, em KERONEN (1996), comparados com valores teóricos calculados para $\mathrm{Kl}=10$ e $\mathrm{K} 2=2$.

\begin{tabular}{|c|c|c|c|c|c|}
\hline Almofadas & $\begin{array}{c}\mathrm{B} \\
\text { (foma) }\end{array}$ & $\begin{array}{c}\sigma_{\mathrm{m}} \\
(\mathrm{MPa})\end{array}$ & $\begin{array}{c}\mathrm{E}_{\mathrm{n}, \mathrm{exp}} \\
(\mathrm{MPa})\end{array}$ & $\begin{array}{c}\mathrm{E}_{\mathrm{n}, \text { calc. }} \\
(\mathrm{MPa})\end{array}$ & $\mathrm{E}_{\mathrm{n}, \text { calc }} / \mathrm{E}_{\mathrm{n}, \mathrm{exp}}$ \\
\hline & \multirow{3}{*}{$(150 \times 150 \times 8)$} & 1,8 & 30 & 36,6 & 1,22 \\
& & 4,6 & 60 & 42,2 & 0,70 \\
& & 7,1 & 80 & 47,2 & 0,59 \\
\hline & 2,8 & 4,1 & 40 & 36,2 & 0,91 \\
& & 10,8 & 80 & 49,6 & 0,62 \\
& & 16,4 & 125 & 60,8 & 0,48 \\
\hline
\end{tabular}

(Obs: superfície de contato Concreto-Neoprene-Concreto)

A partir da tabela 3.13, pode-se observar que os valores teóricos se aproximaram dos resultados experimentais apenas para baixos valores de tensões, sendo que na medida em que a tensão foi aumentando os valores teóricos foram se distanciando, para valores inferiores, dos resultados experimentais.

É intuitivo que, no caso das superfícies de concreto, onde existe um aumento do atrito nas superfícies de contato, tendo-se um aumento na influência da tensão média no elastômero, $\sigma_{\mathrm{n}}$. Partindo deste princípio, os coeficientes devem ser ajustados para valores:

$$
\mathrm{K}_{1}<10 \text { e } \mathrm{K}_{2}>2
$$

A partir da resolução de um sistema de equações com os valores experimentais apresentados na tabela 3.13, fez-se um novo ajuste dos coeficientes $\mathrm{K}_{1}$ e $\mathrm{K}_{2}$, onde se encontrou uma nova expressão para o módulo $\mathrm{E}_{\mathrm{n}}$, dada por: 


$$
E_{n}=7 \cdot G \cdot B+6 \cdot \sigma_{n}
$$

Sendo: $K_{1}=7<10$ e $\quad K_{2}=6>2$

Na tabela 3.14 é apresentada uma nova comparação com os valores obtidos a partir da expressão (3.31) com os resultados experimentais apresentados em KERONEN (1996), onde se observa uma boa estimativa para os valores de cálculo, mesmo para as tensões maiores.

Tabela 3.14 - Resultados experimentais para $E_{n}$, a partir de KERONEN (1996), comparados com valores teóricos calculados para $K_{1}=7$ e $K_{2}=6$.

\begin{tabular}{|c|c|c|c|c|c|}
\hline Almofadas & $\begin{array}{c}B \\
\text { (forma) }\end{array}$ & $\begin{array}{c}\sigma_{\mathrm{n}} \\
(\mathrm{MPa})\end{array}$ & $\begin{array}{l}E_{n, \exp } . \\
(\mathrm{MPa})\end{array}$ & $\begin{array}{r}E_{n, \text { calc. }} \\
(\mathrm{MPa})\end{array}$ & $\mathrm{E}_{\mathrm{n}, \mathrm{calc}} / \mathrm{E}_{\mathrm{n}, \exp }$ \\
\hline (150x150x8) & 3,3 & $\begin{array}{l}1,8 \\
4,6 \\
7,1\end{array}$ & $\begin{array}{l}30 \\
60 \\
80\end{array}$ & $\begin{array}{l}33,9 \\
50,7 \\
65,7\end{array}$ & $\begin{array}{l}1,13 \\
0,85 \\
0,82\end{array}$ \\
\hline$(65 \times 150 \times 8)$ & 2,8 & $\begin{array}{c}4,1 \\
10,8 \\
16,4\end{array}$ & $\begin{array}{c}40 \\
80 \\
125\end{array}$ & $\begin{array}{l}44,0 \\
84,4 \\
118\end{array}$ & $\begin{array}{l}1,10 \\
1,06 \\
0,94\end{array}$ \\
\hline
\end{tabular}

(Obs: superfície de contato Concreto-Neoprene-Concreto)

Conclui-se portanto, que o módulo elástico de uma almofada de elastômero $\mathrm{E}_{\mathrm{n}}$ pode ser determinado, com uma boa estimativa do seu valor real, por uma expressão dada na forma geral:

$$
E_{n}=K_{1} \cdot G \cdot B+K_{2} \cdot \sigma_{n}
$$

Para superfícies de contato aço-neoprente-aço (não polidas):

$$
K_{1}=10 \text { e } K_{2}=2
$$

Para superfícies de contato concreto-neoprene-concreto (não rugosas)

$$
K_{1}=7 \quad \text { e } K_{2}=6
$$




\section{Capítulo 4}

\section{Ligação Viga-Pilar com Almofada de Elastômero e Chumbador}

\subsection{Preliminares}

As ligações viga-pilar com almofada de elastômero simples e chumbador têm sido largamente empregadas no Brasil, com aplicações em estruturas para galpões de uso múltiplo e também para edificações de mais de um pavimento com pequena altura, em razão do seu baixo custo e da sua simplicidade construtiva.

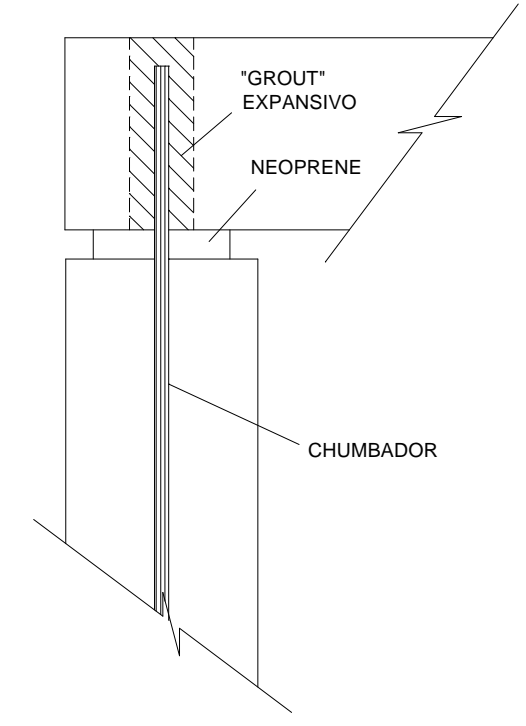

a) Preenchimento do nicho com "grout"expansivo.

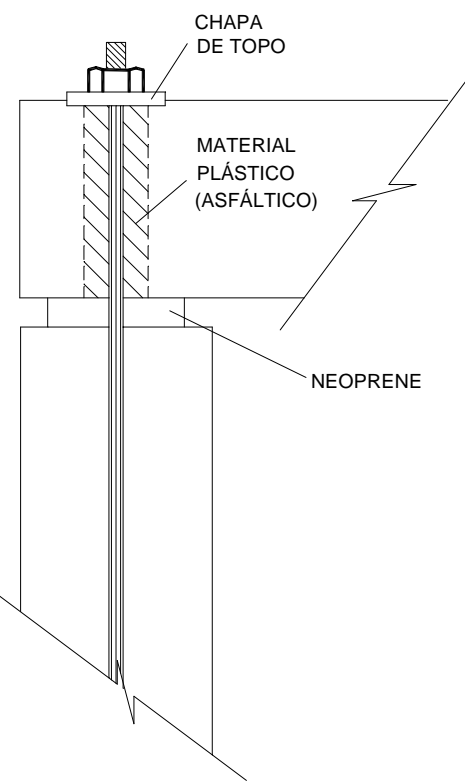

b) Preenchimento do nicho com material plástico.[CATANIA e MENDITTO (1981)]

Figura 4.1 - Exemplo de uma ligação viga-pilar com almofada de elastômero e chumbador

Tradicionalmente, considera-se que o chumbador possui apenas a função de garantir a estabilidade lateral do elemento de viga, não se levando em conta os esforços transmitidos pela ligação. Todavia, em razão do detalhamento construtivo corrente, conforme figura 4.1a, onde o nicho do chumbador é preenchido com graute não retrátil, tem-se a solidarização do chumbador com ambos os elementos. Desta forma, a ligação oferece uma restrição parcial aos deslocamentos horizontais relativos, fazendo com que o chumbador transmita esforços horizontais da viga para a coluna. Compreender o 
funcionamento deste mecanismo é de suma importância para que se possa estimar os esforços de restrição na ligação.

Freqüentemente, utiliza-se na ligação uma almofada de elastômero não fretado na interface entre os elementos de concreto, com o objetivo de prevenir concentrações de tensões normais na superfície de contato da ligação e evitar a formação de fissuras nas extremidades dos elementos de viga e pilar, causadas por restrições aos deslocamentos relativos.

A almofada de elastômero apresenta uma baixa restrição aos deslocamentos horizontais por cisalhamento, devido à sua distorção e ao seu deslizamento em relação aos elementos de concreto, sendo que a distorção aumenta em função da espessura da almofada. Para solicitações de cisalhamento na ligação, a presença da almofada na interface da ligação proporciona uma altura livre entre os elementos, fazendo com que haja uma excentricidade entre as forças de cisalhamento horizontais nos elementos, gerando assim solicitações combinadas de cortante e flexão no chumbador. Este fenômeno depende da relação existente entre o diâmetro do chumbador e da espessura da almofada na interface da ligação.

Em GARCIA et al. (1993) realizou-se um ensaio com este tipo de ligação, onde foram aplicadas ações alternadas de cisalhamento para simular o efeito das ações sísmicas sobre a ligação. Para o ensaio, foi utilizado um chumbador com diâmetro da mesma ordem de grandeza da altura da almofada de elastômero. Relacionado a este fato, os autores observaram que o efeito da flexão localizada na barra do chumbador foi maior do que o efeito do cisalhamento, fazendo com que a ligação apresentasse uma deformabilidade acentuada, atingido o escoamento bem antes do esperado.

LIN (1991) realizou um estudo sobre este tipo de ligação onde foi analisado o efeito do atrito na interface entre os elementos na ligação. O coeficiente de atrito, $\mu_{f}$, também é uma função inversa da espessura da almofada, sendo assim uma função da deformabilidade ao cisalhamento. Nos ensaios, a ligação com uma almofada espessa apresentou um coeficiente de $\mu_{f}=0,27$, enquanto a ligação com uma almofada fina apresentou um coeficiente de $\mu_{f}=0,30$. No caso de ligações que não possuíam nenhum 
componente na interface entre os elementos de concreto, os coeficientes foram da ordem de $\mu_{f}=0,60$ a 0,94 .

Em ENGSTRÖM (1985) e ENGSTRÖM (1992a) são apresentados os resultados de uma pesquisa experimental em uma série de ligações viga-pilar com almofadas de elastômero e chumbador. Para os ensaios, foram empregados modelos em escala 1:1, com o objetivo de examinar o comportamento da ligação quando submetida ao cisalhamento, para grandes deslocamentos relativos. O autor analisou a influência dos parâmetros internos da ligação na sua resistência ao cisalhamento e na sua capacidade de deformação. Com base nesses estudos, ENGSTRÖM (1992a) propôs um modelo para o cálculo da resistência ao cisalhamento da ligação, considerando a contribuição do efeito do atrito na resistência da ligação. Num segundo plano, Engström pesquisou indicações para melhorias no detalhamento da ligação, visando incrementar a sua ductilidade e a sua resistência residual, para situações de grandes deslocamentos na estrutura. Embora esta ligação seja considerada como flexível, foram também realizados ensaios de flexão, onde os chumbadores foram parafusados nas suas extremidades superiores acima da viga. $\mathrm{O}$ objetivo com este detalhamento é que, para grandes deslocamentos da estrutura, os chumbadores atuem como tirantes, conferindo uma resistência residual para a estrutura. Este detalhe é empregado na Suécia e Finlândia, sendo conhecido como "tie connections". Nos ensaios de flexão, os elementos de viga giraram sobre um bloco suporte como se fossem corpos rígidos. Os modos de falha ocorreram pela ruptura do chumbador ou pela perda da ancoragem do chumbador no bloco suporte. $\mathrm{O}$ mecanismo de funcionamento da ligação se distinguiu em três fases distintas. Inicialmente, o centro de giro coincidiu com o chumbador. Conforme o momento fletor foi sendo aplicado na ligação, o centro de giro caminhou em direção da borda do apoio, ficando posicionado no trecho comprimido da almofada. Para rotações maiores, o centro de giro foi a própria borda do suporte de apoio.

O sistema "tie connections", também foi analisado em LINDBERG (1992), onde foi ensaiada uma trave plana, com ligações viga-pilar com almofada de elastômero, submetida à forças horizontais. $\mathrm{O}$ autor verificou que, para grandes deslocamentos, a ligação apresenta uma restrição às rotações relativas entre a viga e a coluna, havendo uma força de reação entre as extremidades da viga e da coluna, a qual tem o seu ponto de aplicação modificado em função das forças horizontais aplicadas na trave plana. 


\subsection{Modelo Clássico de uma Barra Inserida num Elemento de Concreto Submetida à Ação de Cisalhamento [ENGSTRÖM (1992a)]}

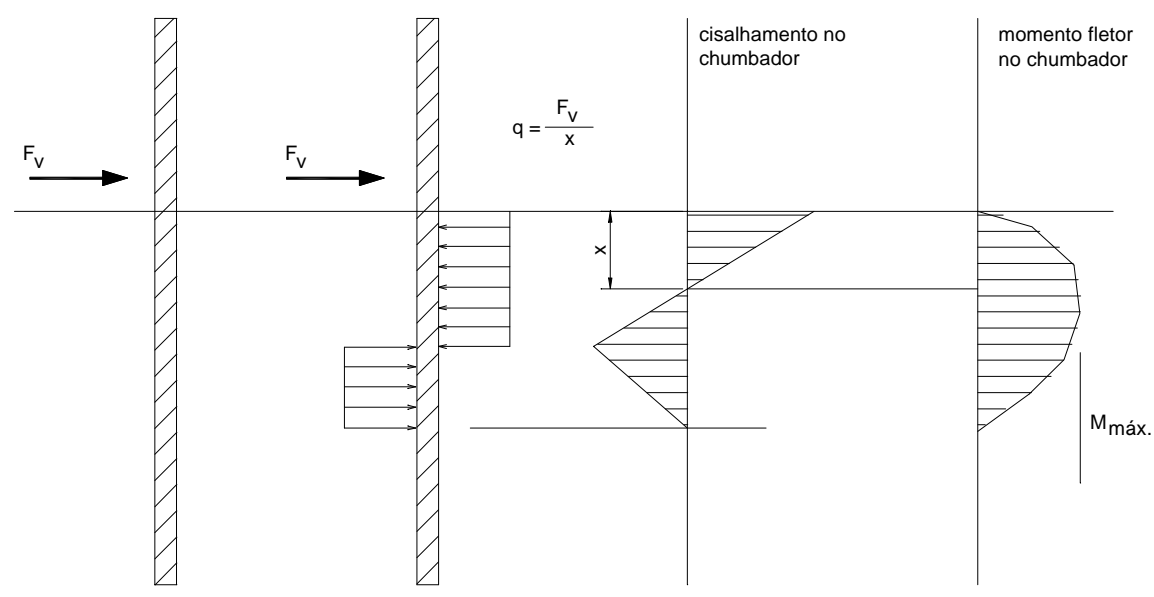

Figura 4.2 - Modelo para o cálculo da capacidade ao cisalhamento em uma barra inserida em um elemento de concreto. [ENGSTRÖM (1992a)

O modelo para o cálculo da resistência ao cisalhamento em um chumbador inserido em um elemento de concreto, submetido à uma ação transversal, foi proposto originalmente por Höjlund e Rasmussem em 1963, sendo aperfeiçoado posteriormente por DULASKA (1972). Neste modelo, conforme ilustrado na figura 4.2, ao longo do chumbador é desenvolvida uma reação distribuída "q". Para o estado em que o concreto desenvolve deformações "plásticas", a reação "q" é proporcional ao produto $\phi_{\mathrm{b}} \cdot f_{\mathrm{cc}}$. Assim, a condição de equilíbrio no estado em que o concreto está completamente plastificado, para a seção de momento máximo $\mathrm{M}_{\text {máx }}$, fornece a expressão para o cálculo da capacidade ao cisalhamento, dada por:

$$
F_{v y}=C_{1} \cdot \phi_{b}^{2} \cdot \sqrt{f_{c c} \cdot f_{s y}}
$$

sendo:

$$
\begin{gathered}
C_{1}=\sqrt{(K / 3)} \\
K=q /\left(\phi_{b} \cdot f_{c c}\right)
\end{gathered}
$$

onde:

$\mathrm{K}$ - constante de proporcionalidade

$\phi_{\mathrm{b}}$ - diâmetro da barra do chumbador 
$f_{\mathrm{cc}}-$ resistência do concreto (corpo de prova cúbico, $150 \mathrm{~mm}$ )

$f_{\text {sy }}$ - resistência do aço

A partir dos resultados experimentais obtidos por Höjlund-Rasmussen, onde chegou-se a um valor de $C_{1}=1,29$, para chumbadores variando entre 16 à $26 \mathrm{~mm}$ e resistências cilíndricas, $f_{c}$, do concreto variando entre 10 à 45 MPa, ENGSTRÖM (1992a) sugeriu que o fator $\mathrm{C}_{1}$ deveria variar entre 1,15 a 1,25 para os casos de concretos com resistências cúbicas, $f_{\mathrm{cc}}$, entre 20 a $60 \mathrm{MPa}$. Assim, a partir destas informações, elaborouse a tabela 4.1, com valores para $\mathrm{C}_{1}$ em função da resistência do concreto.

Tabela 4.1 - Valores para o fator $C_{1}$ em função de $f_{c c}$ e $f_{c}$

\begin{tabular}{|cc|cc|}
\hline$f_{c c}(\mathrm{MPa})$ & $\mathrm{C}_{1}$ & $f_{c}(\mathrm{MPa})$ & $\mathrm{C}_{1}$ \\
\hline 20 & 1,15 & $15-20$ & 1,19 \\
30 & 1,18 & $25-30$ & 1,22 \\
40 & 1,21 & $35-40$ & 1,25 \\
50 & 1,23 & $45-50$ & 1,27 \\
60 & 1,25 & $55-60$ & 1,29 \\
\hline
\end{tabular}

A equação (4.1) fornece uma boa estimativa para a força cortante que produz a plastificação na seção de máximo momento fletor no chumbador. Todavia, este modelo foi desenvolvido somente para uma barra imersa em apenas um elemento de concreto. Para um chumbador que está imerso em dois elementos de concreto, em ambos os seus lados, o escoamento da ligação é atingido quando as rótulas plásticas no chumbador são atingidas em ambos os trechos nos elementos de concreto. Quando as resistências dos concretos dos dois elementos não são as mesmas, as duas rótulas serão formadas para diferentes valores da força de cisalhamento na ligação. No elemento com concreto de menor resistência a rótula plástica será formada primeiro, mas a capacidade ao cisalhamento da ligação é atingida quando a rótula plástica se formar também no outro lado do chumbador. De fato, como na maior parte das aplicações tem-se um chumbador imerso em dois elementos de concreto, faz-se necessário adotar algumas correções na equação (4.1). 
Em situações correntes, a resistência ao cisalhamento da ligação é afetada pelo efeito da força de atrito na interface da ligação. Segundo ENGSTRÖM (1992a), a contribuição do atrito na capacidade ao cisalhamento da ligação é proporcional à normal que atua no chumbador, expressa por:

$$
\Delta F_{v}=C_{f} \cdot \phi_{b}^{2} \cdot f_{s}
$$

Como a contribuição do atrito na capacidade da ligação é proporcional ao quadrado do diâmetro do chumbador, $\phi_{\mathrm{b}}$. Então, no cálculo de $\mathrm{F}_{\mathrm{v}}$ pela equação (4.1), bastaria aumentar o coeficiente $\mathrm{C}_{1}$ para se levar em conta o efeito do atrito.

No caso de haver uma restrição ao giro do chumbador na região da interface da ligação, tem-se a modificação no comportamento do chumbador, no trecho inserido no concreto, formando-se um novo modelo conforme ilustrado na figura 4.3.a. Esta restrição pode ser causada pelas restrições aos giros relativos entre os elementos, ou ainda por uma restrição proposital através da utilização de uma chapa metálica presa ao chumbador na face do elemento de concreto.

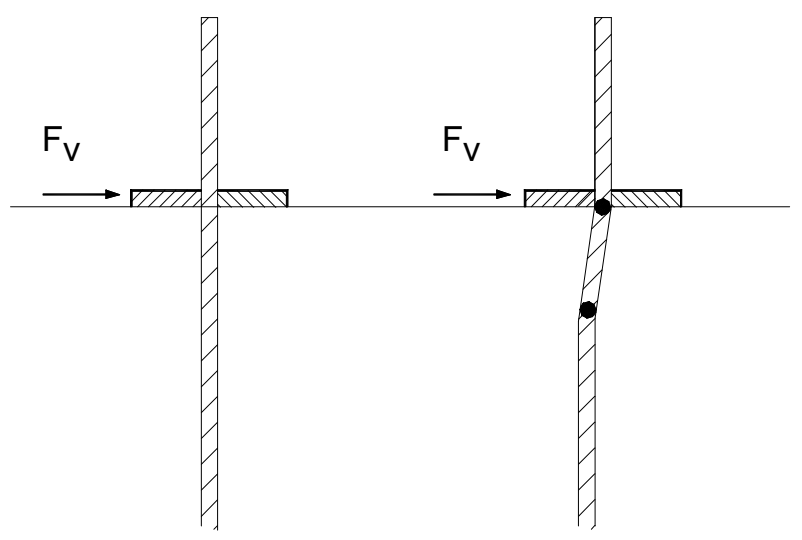

(a)

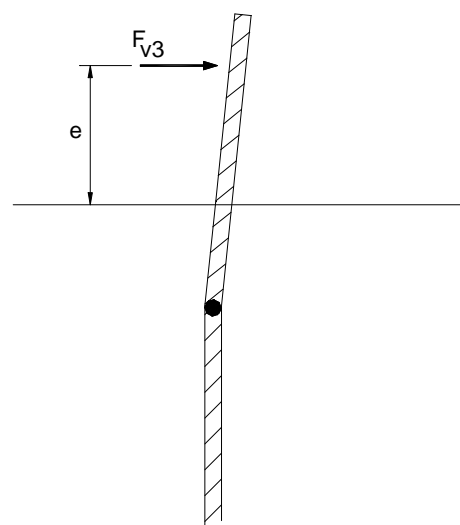

(b)

Figura 4.3 - Modificação do modelo para a determinação da capacidade de cisalhamento.

a) restrição ao giro do chumbador na interface da ligação

b) excentricidade da aplicação da força de cisalhamento [ENGSTRÖM (1992)]

Em razão desta restrição aos giros, são formados em cada lado do chumbador, próximo à interface da ligação, dois momentos fletores com sinais contrários. O 
mecanismo plástico da ligação ocorrerá quando forem formadas rótulas plásticas em ambos os lados restritos do chumbador. A condição de equilíbrio para tal mecanismo, fornece a força de escoamento da ligação, expressa por:

$$
F_{v}=C_{r} \cdot C_{1} \cdot \phi_{b}^{2} \cdot \sqrt{f_{c c} \cdot f_{s y}}
$$

onde:

$\mathrm{C}_{\mathrm{r}}-$ fator de restrição

Segundo ENGSTRÖM (1992a), para o caso onde se tem uma grande restrição ao giro no chumbador, próximo à face do concreto, o fator de restrição $C_{r}$ pode ser adotado como sendo $C_{r}=1,42$. Também, para o caso de uma restrição parcial ao giro no chumbador, o fator de restrição deve variar em torno de $1<\mathrm{C}_{\mathrm{r}}<1,42$.

Quando existe uma altura livre entre os dois elementos, devido à presença de uma almofada de elastômero ou de outro aparelho de apoio, haverá uma excentricidade vertical entre as solicitações horizontais de cisalhamento no chumbador, nos trechos imersos. Assim, no cálculo da força de escoamento da ligação deverá ser incorporada uma redução através de um fator de excentricidade, $\mathrm{C}_{\mathrm{e}}$, ficando a expressão para $\mathrm{F}_{\mathrm{vy}}$ dada por:

$$
F_{v y}=C_{e} \cdot C_{1} \cdot \phi_{b}^{2} \cdot \sqrt{f_{c c} \cdot f_{s y}}
$$

sendo:

$$
\begin{aligned}
& C_{e}=\sqrt{1+\left(\varepsilon \cdot C_{1}\right)^{2}}-\varepsilon \cdot C_{1} \\
& \varepsilon=\frac{3 \cdot e}{\phi_{b}} \sqrt{f_{c c} / f_{s y}}
\end{aligned}
$$

onde:

$\mathrm{C}_{\mathrm{e}}$ - fator de excentricidade

No caso de uma altura livre ocasionada pela presença de uma almofada de elastômero entre dois elementos de concreto, a excentricidade "e" deverá ser tomada como sendo a metade da altura livre entre os dois elementos, sendo $\mathrm{e} \cong \mathrm{h}_{\mathrm{n}} / 2$, onde $\mathrm{h}_{\mathrm{n}}$ é a espessura da almofada de elastômero. 


\subsection{Modelo Modificado para um Chumbador Inserido em Elementos de Concreto, Considerando o Efeito do Atrito no seu Comportamento. [ENGSTRÖM (1992a)]}

\subsubsection{Cálculo Modificado para a Capacidade Total de Cisalhamento da Ligação}

ENGSTRÖM (1992a) propôs um modelo mais geral para o caso de ligações com chumbadores, o qual pode ser utilizado para estimar os efeitos combinados da ação de pino dentro do concreto e também dos efeitos do atrito na interface da ligação.

Nos ensaios realizados em ENGSTRÖM (1992a), observou-se que o atrito na interface da ligação atua positivamente, aumentando a resistência ao cisalhamento da ligação. Baseado neste fato, assumiu-se que a capacidade da ligação deve-se em parte pela ação de pino e em parte pelo ação do atrito na interface da ligação. A força de atrito depende da força normal atuante no chumbador $\mathrm{N}_{\mathrm{s}}$, sendo que a tensão normal no chumbador, dada por $\sigma_{\text {sm }}$, depende de dois fatores:

$$
\sigma_{s m}=\sigma_{p}+\sigma_{s e}
$$

sendo:

$$
\sigma_{s e}=\Delta \varepsilon_{s} \cdot E_{s}
$$

onde:

$\sigma_{\mathrm{p}}$ - pretensão no chumbador.

$\sigma_{\mathrm{se}}-$ tensão causada por um alongamento imposto no chumbador.

Parte da capacidade da tensão de tração no chumbador será utilizada para balancear a força normal $\mathrm{N}_{\mathrm{S}}$, que está relacionada com a força de atrito. A parcela restante, dada pela tensão $\mathrm{f}_{\text {sy,red, }}$ estará relacionada com o comportamento de pino do chumbador. Assim, a capacidade total de cisalhamento da ligação será dada pela expressão:

$$
F_{v, t o t}=C_{1} \cdot \phi_{b}^{2} \cdot \sqrt{f_{c c, \text { máx }} \cdot f_{s y, r e d}}+\mu_{f} \cdot \sigma_{s m} \cdot A_{s}
$$

sendo:

$$
f_{s y, r e d}=f_{s y}-\sigma_{s m}
$$

onde: 
$\mathrm{C}_{1}=1,03$ (para o caso de $f_{\mathrm{cc}}$ ) ou $\mathrm{C}_{1}=1,07$ (para o caso de $f_{\mathrm{c}}$ )

$\mu_{f}$ - coeficiente de atrito na interface da ligação dada na tabela 4.2

Tabela 4.2 - Valores para o Coeficiente de Atrito $\mu_{f}$ [ENGSTRÖM (1992a)]

\begin{tabular}{|c|c|}
\hline Superfícies de Conta to na Interface da Ligação & $\mu_{f}$ \\
\hline Concreto-concreto & 0,6 \\
Aço-concreto & 0,4 \\
Concreto-neoprene & $0,3-0,4$ \\
\hline
\end{tabular}

\subsubsection{Estudo da Configuração Deformada do Chumbador [ENGSTRÖM (1992a)]}
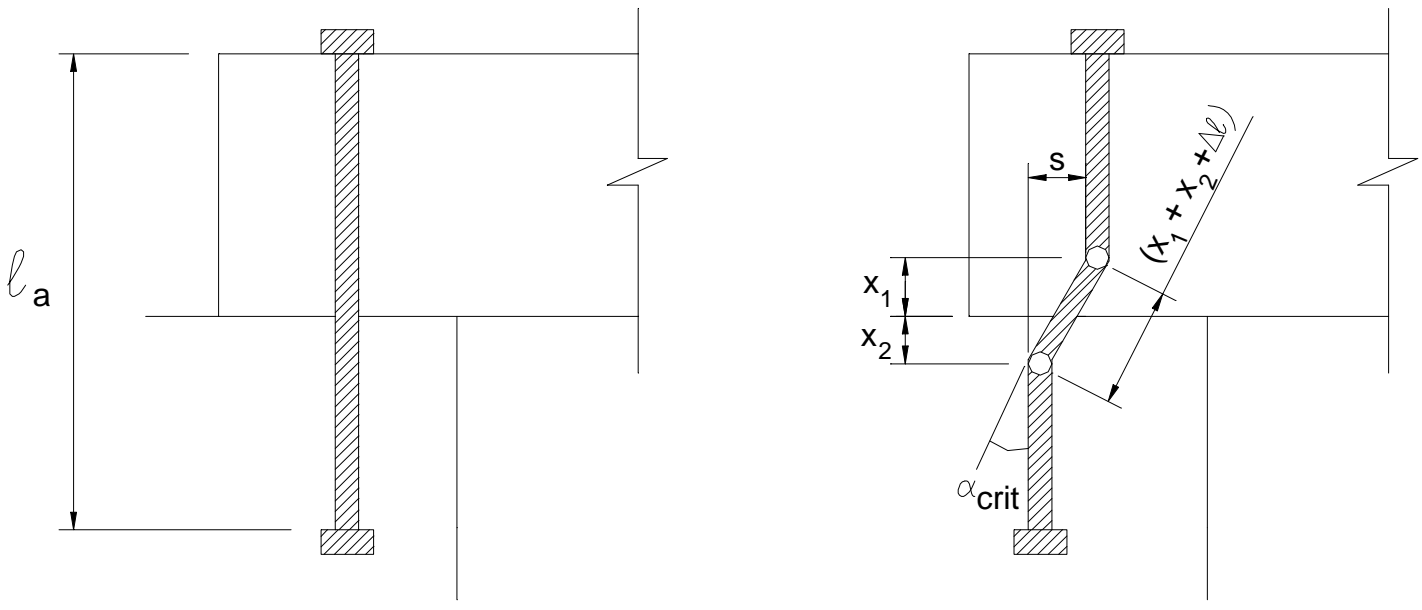

Figura 4.4 - Estado simplificado de deformação para o chumbador inserido em dois elementos de concreto. [ENGSTRÖM (1992)]

Na figura 4.4 é apresentado um estado de deformação simplificado para um chumbador inserido em dois elementos de concreto, no momento em que ocorre o mecanismo da formação das rótulas plásticas nos dois lados das seções solicitadas do chumbador. Segundo ENGSTRÖM (1992a), o mecanismo da formação das rótulas plásticas ocorre quando o chumbador atinge uma deformação angular crítica, definida como $\alpha_{\text {crit }}$, expressa por:

$$
\alpha_{c r i t}=k \cdot \frac{f_{\text {sy,red }}}{\phi_{b} \cdot E_{s}}
$$


Baseado nos resultados experimentais, ENGSTRÖM (1992a) sugeriu um valor médio para $\mathrm{k}=1,75 \mathrm{~m}$, para ser utilizado diretamente na equação (4.7). Também, a título de simplificação, definiu-se a deformação angular como estando dentro do trecho no chumbador delimitado pelas seções de momentos máximos, conforme indicado na figura 4.4 .

A distância "x", da face do concreto até à seção de máximo momento no chumbador, pode ser calculada por meio de uma condição de equilíbrio. Todavia, somente

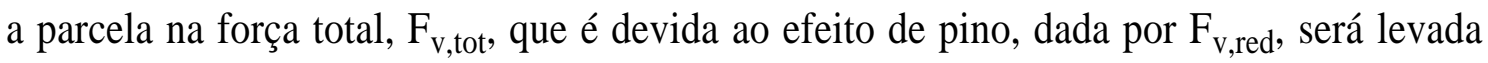
em conta no equilíbrio.

$$
x=\frac{F_{v, \text { red }}}{q}=\frac{\sqrt{f_{s y, r e d} / f_{c c}}}{3 \cdot C_{1}} \cdot \phi_{b}
$$

sendo:

$$
q=3 \cdot\left(C_{1}\right)^{2} \cdot f_{c c} \cdot \phi_{b}
$$

onde:

q - reação distribuída do concreto sobre o chumbador

Caso seja o indicado, o valor da distância "x" pode ser ajustado pelos fatores $\mathrm{C}_{\mathrm{r}} \mathrm{e}$ $\mathrm{C}_{\mathrm{e}}$, para se levar em conta os efeitos da restrição ao giro e da excentricidade das ações horizontais. Para chumbadores que estão inseridos em dois elementos de concreto, a distância "x" deve ser calculada separadamente para cada lado, utilizando-se os valores da resistência do concreto para cada elemento.

A partir da deformação angular crítica $\alpha_{\text {crit }}$ o deslocamento horizontal relativo na ligação $\mathrm{a}_{\mathrm{vy}}$, que está associado ao momento da formação das rótulas plásticas no chumbador, pode ser obtido pelas seguintes expressões:

$$
\begin{array}{ll}
\alpha_{c r i t}=\frac{a_{v y}}{\ell_{p}} & \begin{array}{l}
\text { (Para chumbador inserido } \\
\text { em dois elementos de concreto) }
\end{array} \\
\alpha_{\text {crit }}=\frac{a_{v y}}{x} & \begin{array}{l}
\text { (Para chumbador inserido } \\
\text { em um elemento de concreto) }
\end{array}
\end{array}
$$


No caso de ligações sem altura livre entre os elementos, o comprimento $\ell_{\mathrm{p}}$ é dado pela expressão:

$$
\ell_{p}=x_{1}+x_{2}
$$

No caso de ligações com almofada de elastômero, com uma altura livre entre os elementos da ordem da espessura da almofada $h_{n}$, o comprimento $\ell_{p}$ é dado pela expressão:

$$
\ell_{p}=x_{1}+x_{2}+h_{n}
$$

\subsubsection{Cálculo da Tensão Normal $\sigma_{\mathrm{sm}}$ no Chumbador [ENGSTRÖM (1992a)]}

Para o caso de um chumbador com elementos em ambos os lados, o alongamento no chumbador pode ser determinado pela expressão:

$$
\Delta_{n}=\sqrt{\left(\ell_{p}\right)^{2}+\left(\alpha_{c r i t} \cdot \ell_{p}\right)^{2}}-\left(\ell_{p}\right)
$$

Para o caso de um chumbador com um lado inserido em um elemento de concreto, o alongamento no chumbador pode ser determinado pela expressão:

$$
\Delta_{n}=\sqrt{(x)^{2}+\left(\alpha_{c r i t} \cdot x\right)^{2}}-(x)
$$

Para o caso de barras lisas com extremidades ancoradas, assume-se que o alongamento é igualmente distribuído ao longo do comprimento do chumbador. Assim, o acréscimo na deformação por alongamento do chumbador, definido por $\Delta \varepsilon_{\mathrm{s}}$, pode ser calculado pela expressão:

$$
\Delta \varepsilon_{s}=\Delta_{n} / \ell_{a}
$$

onde:

$\ell_{\mathrm{a}}$ - distância entre as ancoragens no chumbador de barra lisa 


\subsection{Deformabilidade ao Cisalhamento da Ligação}

Como já foi comentado anteriormente, com o emprego de graute nos nichos dos chumbadores, tem-se a solidarização do chumbador com o elemento da viga, fazendo com que a ligação apresente restrição aos deslocamentos horizontais da viga. $\mathrm{O}$ conhecimento da deformabilidade ao cisalhamento da ligação possibilitaria o cálculo dos esforços horizontais transmitidos da viga para os pilares através da ligação, tais como os esforços devido à retração da viga, das ações devidas ao vento ou das ações horizontais nas vigas de rolamento.

Em FERREIRA (1993), desenvolveu-se um modelo analítico para o cálculo da deformabilidade ao cisalhamento, conforme apresentado a seguir.

Para o cálculo da deformabilidade ao cisalhamento da ligação em estudo, considerou-se a ocorrência de três mecanismos de deformação presentes na ligação, sendo:

1. Mecanismo de Deformação ao Cisalhamento no Elastômero Não fretado, (MDCI-EN), associado à deformabilidade $\lambda_{\tau n}$;

2. Mecanismo de Deformação ao Cisalhamento de uma Barra Inserida no concreto, (MDCI-BI), associado à deformabilidade $\lambda_{\text {tbi }}$;

3. Mecanismo de Deformação ao Cisalhamento de uma Barra bi-engastada em dois elementos de concreto com altura Livre entre si, (MDCI-BL), associado à deformabilidade $\lambda_{\tau b b}$.

$\mathrm{Na}$ figura 4.5 é apresentada uma esquematização por meio de molas, as quais representam os mecanismos de deformação presentes na ligação. As deformabilidades $\lambda_{\text {rbi }}$ e $\lambda_{\text {tbl }}$ estão associadas em série entre si. Estas, por sua vez, estão associadas em paralelo à deformabilidade ao cisalhamento do elastômero não fretado, $\lambda_{\text {tn }}$. A partir destas associações entre os mecanismos básicos de deformação a deformabilidade total de cisalhamento na ligação, $\lambda_{\text {tlig, }}$ pode ser escrita por:

$$
\lambda_{\tau i i g}=\left(\frac{1}{\lambda_{\tau n}}+\frac{1}{\lambda_{\tau b \ell}+\lambda_{\tau b i}}\right)^{-1}
$$




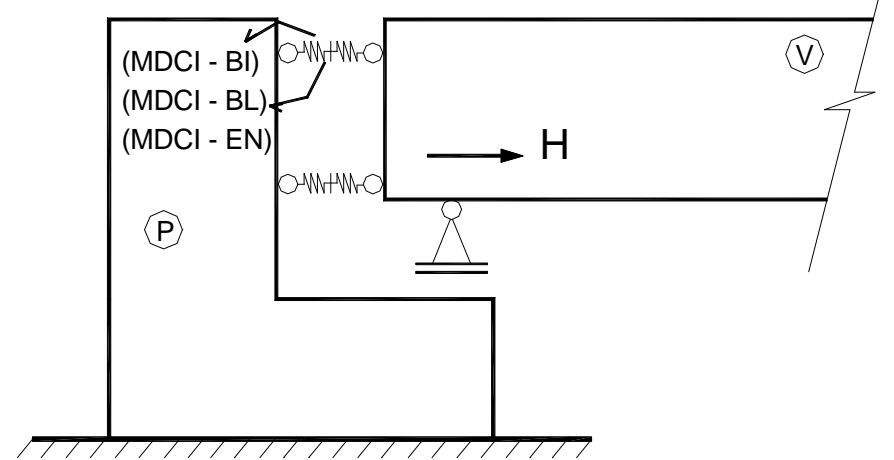

Figura 4.5 - Esquematização por meio de molas para o mecanismo de deformação ao cisalhamento em ligação viga-pilar articulada em apoio sobre consolo com almofada de elastômero não fretado e chumbador.

A deformabilidade ao cisalhamento da almofada de elastômero não fretado, $\lambda_{\tau n}$, é dada por:

$$
\lambda_{\tau n}=\frac{h_{n}}{G A_{o}}
$$

onde:

$\mathrm{h}_{\mathrm{n}}$ - espessura da almofada de elastômero

$\mathrm{A}_{\mathrm{o}}$ - área da superfície de apoio efetiva do elastômero

G - módulo de deformação transversal

A deformabilidade ao cisalhamento da barra do chumbador na altura livre entre os elementos de concreto, correspondente à espessura da almofada de elastômero, $\lambda_{\tau b \ell}$, é dada por:

$$
\lambda_{\tau b \ell}=\frac{16 \cdot h_{n}^{3}}{3 \cdot \pi \cdot E_{s} \cdot \phi_{b}^{4}}
$$

onde:

$\mathrm{E}_{\mathrm{S}}$ - módulo de elasticidade da barra do chumbador

$\varnothing_{\mathrm{b}}$ - diâmetro da barra do chumbador 
A deformabilidade ao cisalhamento de uma barra inserida em um elemento de concreto, $\lambda_{\tau \mathrm{bi}}$, a qual foi discutida no item (3.3.2) do presente trabalho, pode ser determinada através da expressão:

$$
\lambda_{\tau b i}=\left(2 \cdot \alpha^{3} \cdot E_{s} \cdot I_{b}\right)^{-1}
$$

A expressão (4.15) é derivada do modelo para o cálculo dos deslocamentos transversais em uma barra de chumbador proposto por DEI POLI et al. (1992), a partir de resultados experimentais. Admite-se que o mecanismo de deformação do chumbador dentro do elemento de concreto apresente um comportamento linear para forças transversais no chumbador inferiores a $40 \%$ da sua capacidade ao cisalhamento. Entretanto, tal expressão é aplicada ao caso particular de uma barra de chumbador solicitada por cisalhamento puro, estando inserida em apenas um elemento de concreto.

No caso de uma barra inserida em dois elementos de concreto com uma almofada de elastômero na interface da ligação, tem-se a excentricidade entre as solicitações horizontais nos elementos de concreto, havendo com isso uma alteração no mecanismo de deformação da barra do chumbador. Na tentativa de levar em conta esses efeitos, com base nas informações existentes na literatura e nos resultados experimentais obtidos na presente pesquisa, a expressão (4.15) foi ajustada para uma nova expressão dada por:

$$
\lambda_{\tau b i}=\left[3,5 \cdot \alpha^{3} \cdot E_{s} \cdot I_{b}\right]^{-1}
$$

O fator " $\alpha$ " apresentado em DEI POLI et al. (1992), relaciona o módulo de rigidez do concreto com a rigidez da barra do chumbador, sendo dado pela expressão:

$$
\begin{aligned}
& \alpha=\sqrt[4]{\frac{k_{c} \phi_{b}}{4 E_{s} I_{b}}} \\
& k_{c}=127 \sqrt{f_{c}^{\prime}} /\left(\phi_{b}\right)^{2 / 3}[\mathrm{MPa} / \mathrm{mm}]
\end{aligned}
$$

onde 
$\mathrm{K}_{\mathrm{c}}$ - módulo de rigidez de referência do concreto (em $\mathrm{MPa} / \mathrm{mm}$ )

$\varnothing_{\mathrm{b}}$ - diâmetro da barra $(\mathrm{em} \mathrm{mm})$

$\mathrm{I}_{\mathrm{b}}$ - momento de inércia da barra

$f_{c}^{\prime}$ - resistência à compressão do concreto (em $\left.M P a\right)$

Para "n" barras dispostas em uma mesma linha da ligação, estando as mesmas inseridas em dois elementos de concreto com resistências diferentes, das quais derivam-se respectivamente os fatores " $\alpha_{1}$ " e " $\alpha_{2}$ ", a deformabilidade total de cisalhamento da ligação, $\lambda_{\tau \text { lig }}$, pode ser obtida pela expressão:

$$
\lambda_{\tau \ell i g}=\left[\frac{G \cdot A_{o}}{h_{n}}+\left(n \cdot E_{s} \cdot I_{b}\right) \cdot\left(\frac{h_{n}^{3}}{12}+\frac{1}{3,5 \cdot \alpha_{1}^{3}}+\frac{1}{3,5 \cdot \alpha_{2}^{3}}\right)^{-1}\right]^{-1}
$$

\subsection{Proposta de um Procedimento Gráfico para Representar o Comportamento da Ligação Submetida ao Cisalhamento}

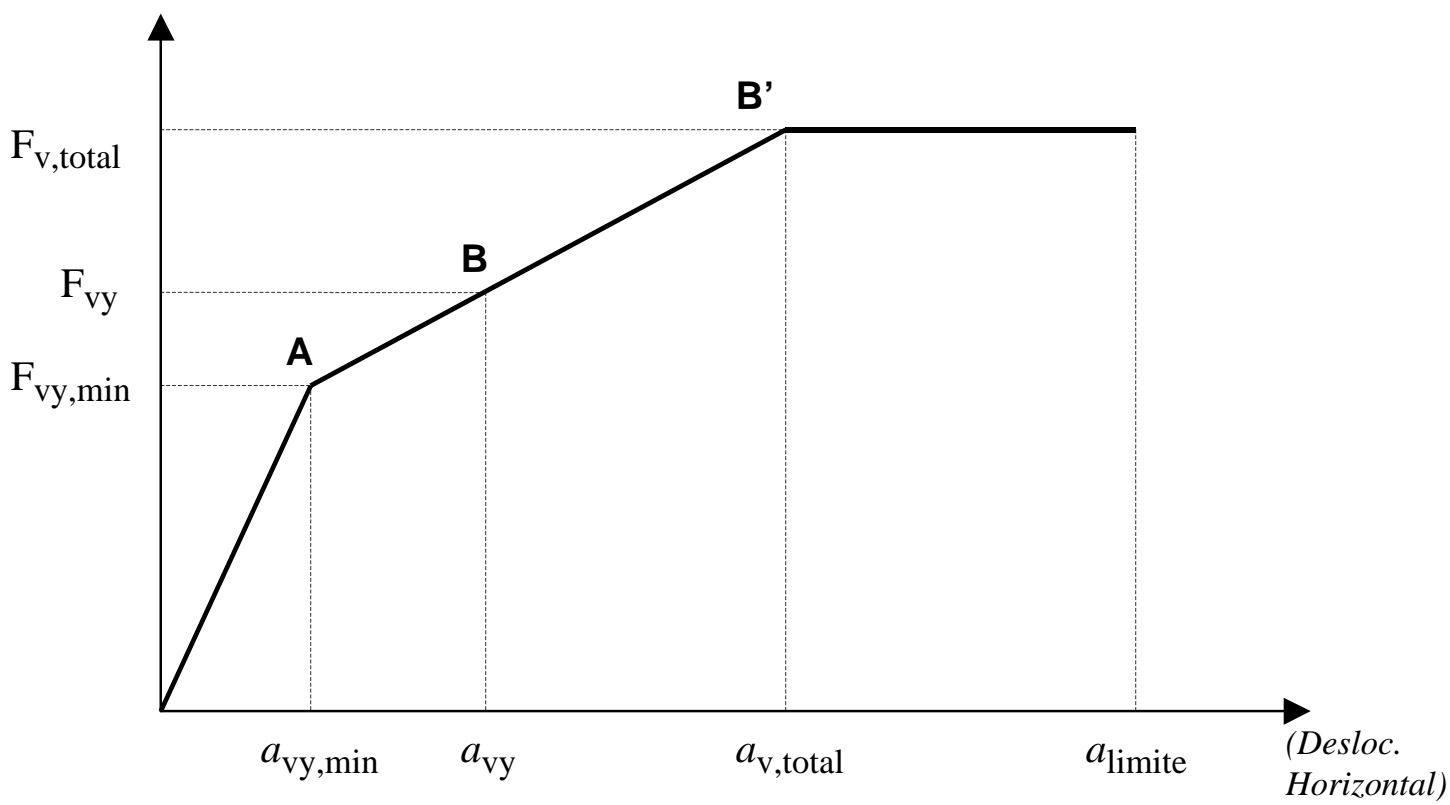

Figura 4.6 - Diagrama Simplificado Tri-linear da Força de Cisalhamento X Deslocamento Horizontal na Ligação 
A partir da teoria exposta nos itens 4.3 e 4.4, propõe-se neste trabalho a construção de um Diagrama Simplificado Tri-Linear, relacionando a força de cisalhamento com o deslocamento horizontal da ligação, conforme indicado na figura 4.6, com vistas à sua aplicação no cálculo prático e, também, fornecer uma representação gráfica do comportamento da ligação.

A seguir é apresentado o procedimento a ser utilizado para a obtenção do diagrama:

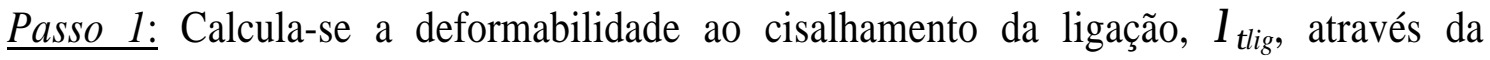
equação (4.19). A relação inversa de $\lambda_{\tau l i g}$, dada por $K_{\tau l i g}$, corresponde à inclinação da reta tangente inicial da curva Força de Cisalhamento vs. Deslocamento Horizontal da ligação.

Passo 2: $\mathrm{O}$ ponto A é definido por $\left(a_{v y, \text { min }} ; F_{v y, \text { min }}\right)$ no diagrama da figura 4.6. A força $F_{v y, \text { mín }}$, relativa ao concreto de menor resistência, é obtida através das equações (4.1) à (4.4), levando-se em conta os fatores $C_{l}, C_{e}$ e $C_{r}$. A partir dos valores $\lambda_{\text {clig }}$ e $F_{v y, m i ́ n}$, calcula-se $\mathrm{a}_{\mathrm{vy} \text {,mín }}$ que corresponde ao deslocamento horizontal da ligação associada a força $F_{v y, \min }$, dada por:

$$
a_{v y, \min }=\lambda_{\tau l i g} \cdot F_{v y, \min }
$$

Passo 3: O ponto B é definido por $\left(a_{v y} ; F_{v y}\right)$ no diagrama da figura 4.6. A força $F_{v y}$, relativa ao concreto de maior resistência, é obtida através das equações (4.1) à (4.4), levando-se em conta os fatores $C_{l}, C_{e}$ e $C_{r}$.

Passo 4: Calcula-se a distância " $x$ ", que é o comprimento no chumbador que vai da face do elemento de concreto na interface da ligação até à seção de momento máximo da barra, através da equação (4.8), onde também os fatores $C_{1}, C_{e}$ e $C_{r}$ deverão ser levados em conta. Quando não se conhece o valor da tensão reduzida $f_{\text {sy,red, }}$, recomenda-se adotar $f_{\text {sy,red }}=0,7 . f_{\text {sy }}$ para o cálculo de " $\mathrm{x}$ ". 
Obs: Uma outra alternativa para estimar a tensão reduzida $f_{\text {sy,red }}$, seria utilizar um roteiro interativo, proposto em ENGSTRÖM (1992a), que consiste em:

a) adotar um valor inicial para a tensão $f_{s y, r e d}$;

b) calcular "x" pela equação (4.8);

c) calcular $\alpha_{\text {crit }}$ através da equação (4.7), para k=1,75;

d) calcular o alongamento imposto $\Delta$ n através da equação (4.10.1) ou (4.10.2);

e) calcular $\Delta \varepsilon_{\mathrm{s}}$ através da equação (4.11) e $\sigma_{\mathrm{sm}}$ através da equação (4.5);

f) calcular $f_{\text {sy,red }}$ pela equação (4.6.1) e verificar com o valor adotado inicialmente (se estiver razoável prosseguir);

g) após a determinação de $f_{\text {sy,red }}$, calcular finalmente a distância "x", através da expressão (4.8).

Passo 5: Calcula-se $\alpha_{\text {crit }}$ através da equação (4.7), para k=1,75.

Passo 6: O deslocamento horizontal $\mathrm{a}_{\mathrm{vy}}$ é obtido a partir dos valores de $\alpha_{\text {crit }} \mathrm{e}$ "x", através da expressão:

$$
a_{v y}=\alpha_{c r i t} \cdot \ell_{p}=\alpha_{c r i t} \cdot\left(x_{1}+x_{2}+h_{n}\right)
$$

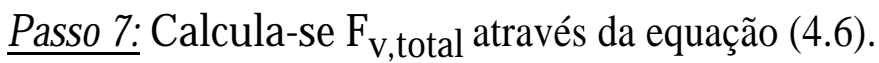

Passo 8: O ponto B', que é definido pelas coordenadas $\left(a_{v, \text { total }} ; F_{v, \text { total }}\right)$ no diagrama da figura 4.6, é obtido pela interseção do prolongamento da reta A-B com a reta $F_{v}$ $=F_{v, \text { total }}$ O valor limite para deslocamento horizontal na ligação, dado por $a_{\text {lim }}$, foi aqui definido como sendo um valor inferior ao da ordem do diâmetro da barra do chumbador. 


\subsection{Ensaios em Ligações Viga-Pilar com Almofada de Elastômero e Chumbador}

\subsubsection{Protótipos e Propriedades dos Materiais}

Os protótipos foram executados em escala 1:1, onde se procurou caracterizar a região da ligação entre as extremidades de elementos de viga e de coluna. Para tal, utilizou-se um elemento de viga, com $120 \mathrm{~cm}$ de comprimento e seção 30x50 cm², e um elemento de bloco suporte, com $50 \mathrm{~cm}$ de altura e seção $40 \times 40 \mathrm{~cm}^{2}$, simulando o apoio sobre uma coluna, conforme indicadas na figura 4.7, tendo-se essas mesmas dimensões para todos os protótipos.
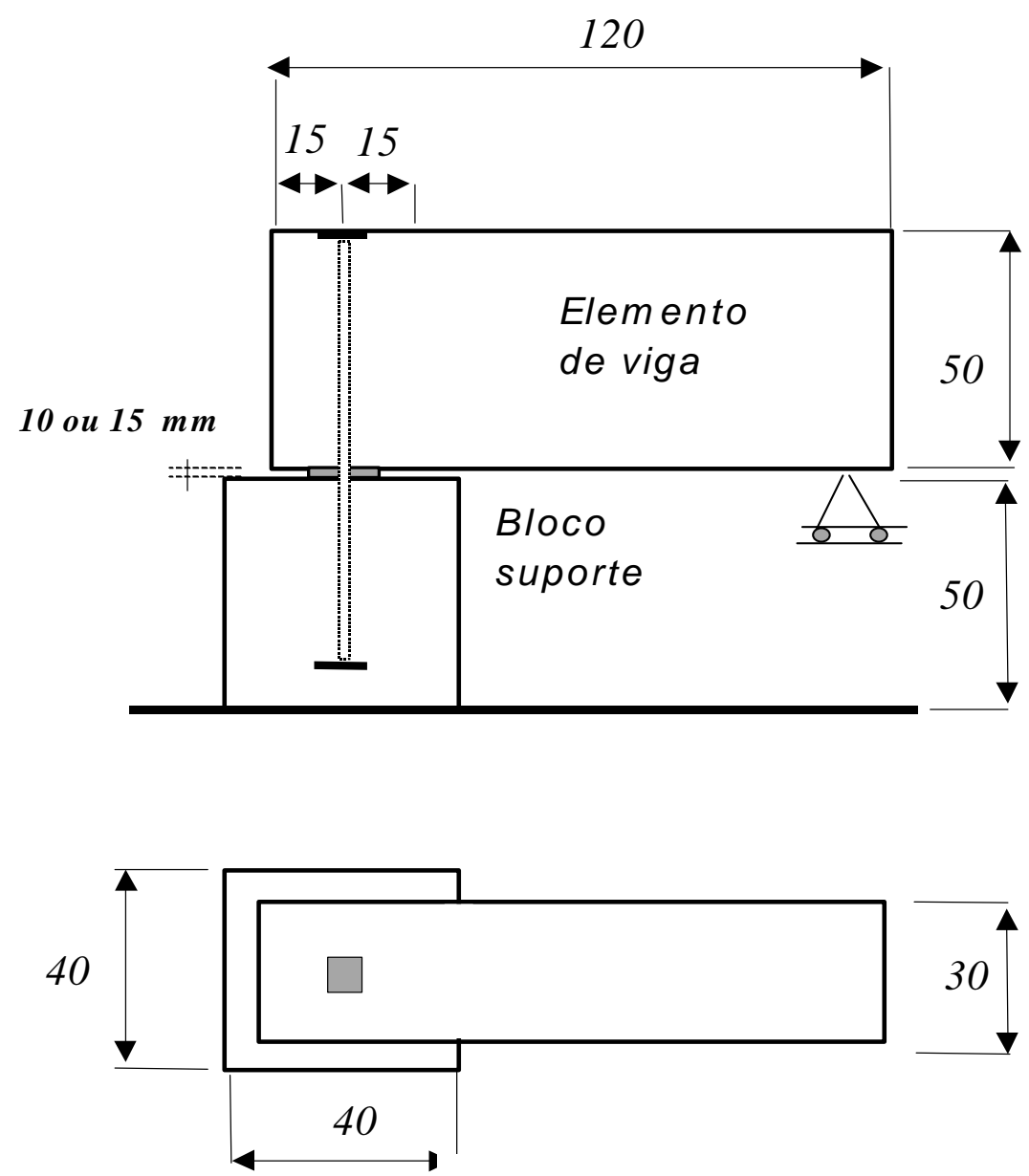

Figura 4.7 - Dimensões básicas utilizadas nos protótipos das ligações 
Para a série de ensaios das ligações foram utilizados 4 protótipos, sendo que 0 primeiro protótipo foi utilizado na realização de um ensaio piloto preliminar. Nesses protótipos foram variados os diâmetros das barras dos chumbadores e as dimensões das almofadas de elastômeros. Tais parâmetros estão relacionados com os mecanismos de deformação da barra do chumbador, na região da interface na ligação e internamente aos elementos de concreto, e com os mecanismos de deformação da almofada de elastômero. Na tabela 4.3 tem-se um resumo com os parâmetros que foram variados nos protótipos.

Tabela 4.3 - Parâmetros variados nos protótipos ensaiados

\begin{tabular}{|c|c|c|c|c|}
\hline Protótipos & \multirow{2}{*}{$\begin{array}{c}\text { Chumbador } \\
\text { (aço 1020) }\end{array}$} & \multicolumn{3}{|c|}{ Almofada de Ela stômero } \\
\cline { 3 - 5 } & $1 \phi 16 \mathrm{~mm}$ & 150 & $\mathrm{~b}(\mathrm{~mm})$ & $\mathrm{h}_{\mathrm{n}}(\mathrm{mm})$ \\
\hline Piloto & $1 \phi \mathrm{mm})$ & 300 & 10 \\
\hline Protótipo A & $2 \phi 16 \mathrm{~mm}$ & 150 & 300 & 10 \\
\hline Protótipo B & $2 \phi 25 \mathrm{~mm}$ & 250 & 300 & 10 \\
\hline Protótipo C & $2 \phi 25 \mathrm{~mm}$ & 200 & 300 & 15 \\
\hline
\end{tabular}

Para os aparelhos de apoio nos protótipos, foram utilizadas almofadas de elastômero simples, com dureza Shore 60 A, módulo transversal G $=1000 \mathrm{kN} / \mathrm{m}^{2}$ e coeficiente de Poisson $v=0,5$.

Devido às grandes deformações previstas para os chumbadores, foram utilizadas barras lisas de aço 1020, com $f_{\mathrm{yk}}=250 \mathrm{MPa}$. Para o protótipo piloto utilizou-se apenas 1 barra de chumbador, sendo que para os demais protótipos foram utilizadas duas barras de chumbadores. A ancoragem foi conseguida por meio de uma chapa soldada na extremidade inferior e por meio de chapas parafusadas na extremidade superior do chumbador, conforme ilustrado na figura 4.8 .

Em geral, a prática da ancoragem na extremidade superior do chumbador por meio de chapas parafusadas é utilizada para esse tipo de ligação com o objetivo de garantir a estabilidade lateral do elemento de viga, para evitar o seu tombamento. Por esta razão, para os ensaios de cisalhamento da ligação não se pretendia inicialmente contar com a ancoragem na extremidade superior do chumbador. Esta ancoragem serviria apenas para o 
travamento da extremidade do elemento de viga durante os ensaios de flexão e de torção e, também, para auxiliar no transporte do protótipo durante a montagem.

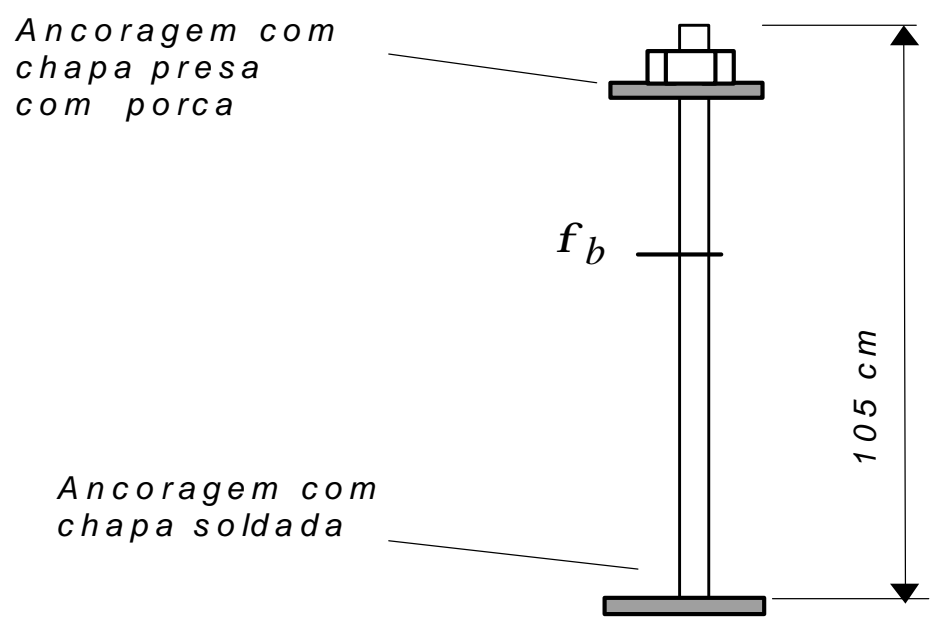

Figura 4.8 - Esquema da barra do chumbador

Entretanto, durante a realização do ensaio de cisalhamento no Protótipo A, onde os esforços internos da barra do chumbador estavam sendo monitorados, observou-se a formação de um mecanismo de tirante da barra do chumbador quando a ligação apresentava grandes deformações. Por esta razão, para os Protótipos B e C, as barras dos chumbadores foram travadas com porcas, sem uma pré-tração inicial, para garantir a segurança dos protótipos nesses ensaios.

Após o término dos ensaios nesta pesquisa, teve-se acesso a ENGSTRÖM (1992a), onde se verificou que este detalhamento na ancoragem superior do chumbador foi utilizado também para os ensaios de cisalhamento, com a finalidade de estudar o efeito do atrito na ligação, causado por uma força de tração na barra do chumbador, conforme a teoria apresentada no item 4.3 do presente trabalho.

O traço básico do concreto que foi utilizado para todos os protótipos ensaiados, encontra-se indicado na tabela 4.4. Este traço foi preparado para atingir uma resistência média em torno de $50 \mathrm{MPa}$, onde se procurou obter resistências da mesma ordem de grandeza das resistências utilizadas nos ensaios realizados por ENGSTRÖM (1985). 
Tabela 4.4 - Traço básico utilizado para o concreto

Traço em peso:

$1: 1,70: 2,60$

$\mathrm{a} / \mathrm{c}=0,43(\mathrm{com} 0,8 \%$ de SP $1000 \mathrm{~A})$

Cimento $A R I=450 \mathrm{~kg} / \mathrm{m} 3$

Brita 1

Materiais por Protótipo (com volume de $\mathbf{3 0 0}$ litros):

Cimento: $135 \mathrm{~kg}$;

Areia: $230 \mathrm{~kg}$;

Brita 1: $351 \mathrm{~kg}$;

Água: $56,4 \mathrm{~kg}$;

SP $1000 \mathrm{~A}: 1,08 \mathrm{~kg}$

Com o emprego de cimento ARI, a desmoldagem dos protótipos foi feita no dia posterior à concretagem e os ensaios em torno de 7 dias após a concretagem. Os corpos de prova para controle da resistência do concreto, foram rompidos nas mesmas datas dos ensaios. As resistências médias, para corpos de prova cilíndricos de $10 \times 20 \mathrm{~cm}$, de cada protótipo estão indicadas no tabela 4.5.

Tabela 4.5 - Valores médios das resistências dos concretos nas datas dos ensaios

\begin{tabular}{|c|c|c|}
\hline Protótipos & $f_{\text {cj(ensaio })}(\mathrm{MPa})$ & $f_{\text {ck(adotado })}(\mathrm{MPa})$ \\
\hline Piloto & 55,00 & 51,50 \\
\hline Protótipo A & $62,80^{*}$ & 59,30 \\
\hline Protótipo B & 53,70 & 50,20 \\
\hline Protótipo C & 52,70 & 49,20 \\
\hline
\end{tabular}

*. O ensaio teve um atraso de 3 dias.

O graute utilizado para o preenchimento dos nichos nos elementos de viga para os chumbadores, com seção $5 \times 5 \mathrm{~cm}$, foi o EUCOGROUT, doado pela HOLDERCIM DO BRASIL. Trata-se de um produto pré-misturado que requer acréscimo de água (11\% em peso). $\mathrm{O}$ rompimento dos corpos de prova cilíndricos para argamassa, com $5 \times 5 \mathrm{~cm}$, foi realizado no dia posterior ao preenchimento dos nichos, que coincidiam com as datas de ensaios, onde se obteve uma variabilidade muito baixa para as resistências. Por esta razão, foi adotado um valor médio para a resistência característica do graute de 30,0 MPa. Mesmo em se tratando de um produto auto adensável, foi utilizado um vibrador de agulha para retirar o excesso de ar presente no nicho. 
Nas figuras 4.9 e 4.11, são apresentados os detalhamentos das armaduras utilizadas nos elementos de viga e do bloco suporte, respectivamente.
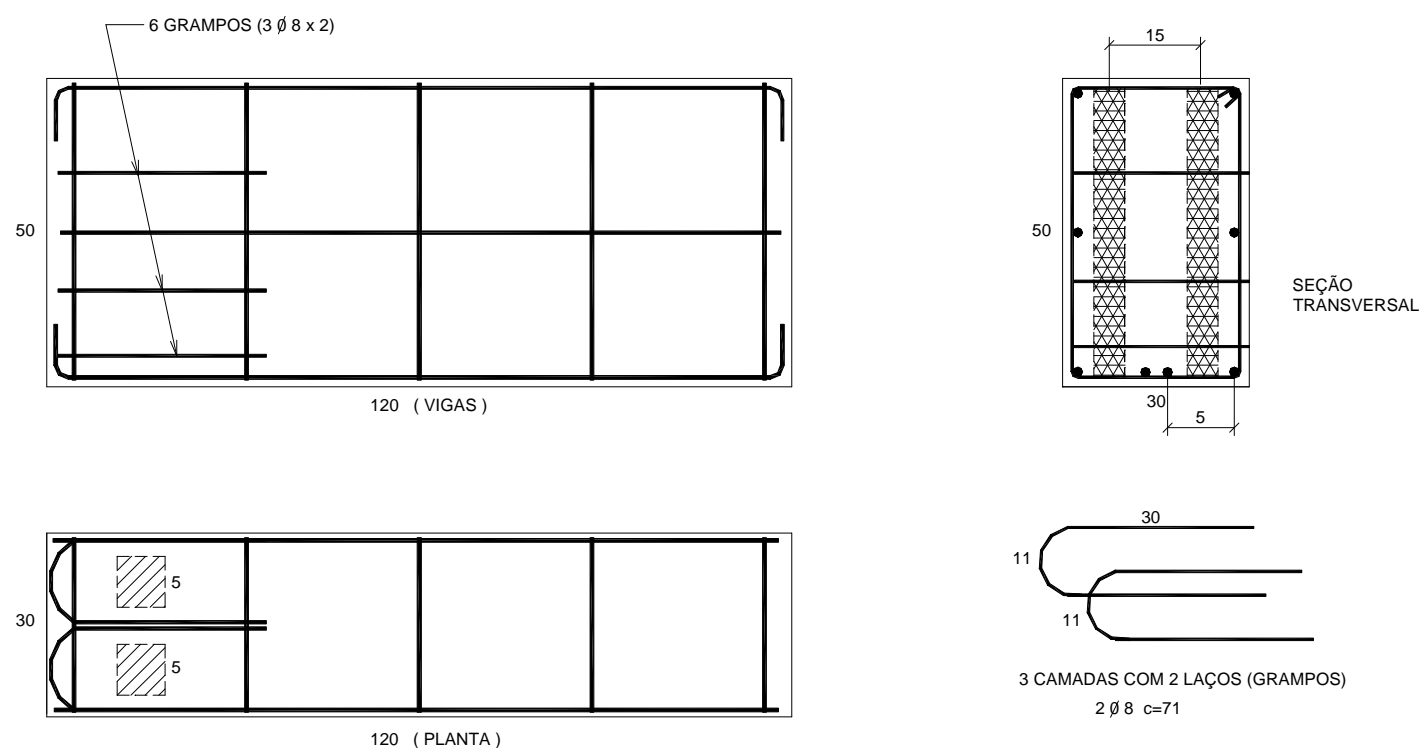

3 CAMADAS COM 2 LAÇOS (GRAMPOS) $2 \emptyset 8 \mathrm{c}=71$
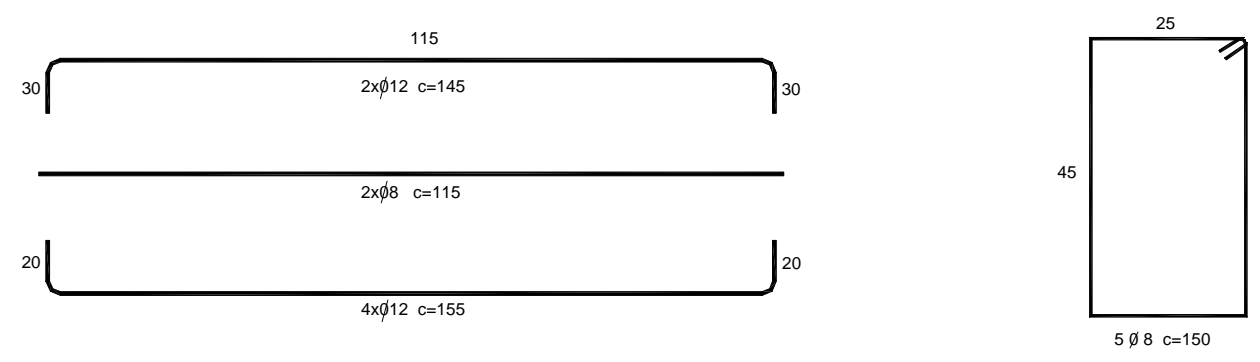

Figura 4.9 - Detalhamento da armadura do elemento de viga
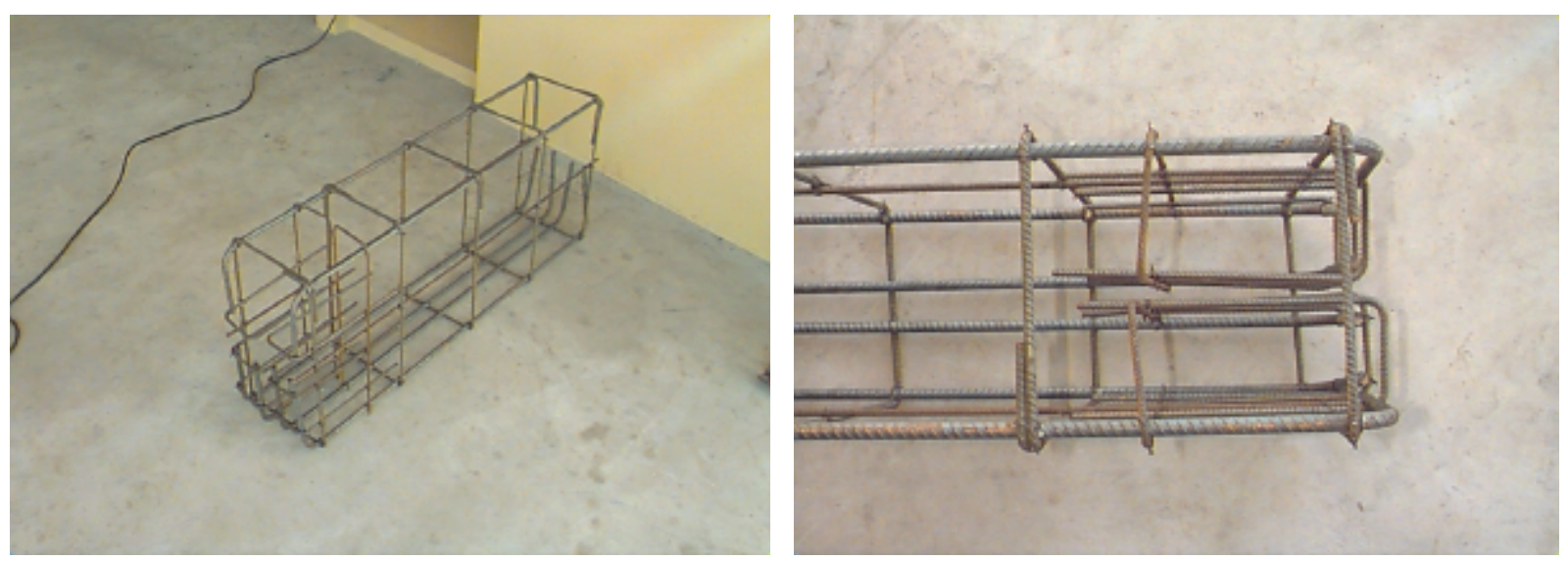

Figura 4.10 - Foto da armadura utilizada no elemento de viga 


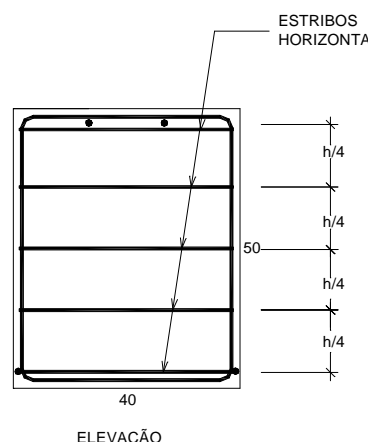

(1)

ESTRIBOS

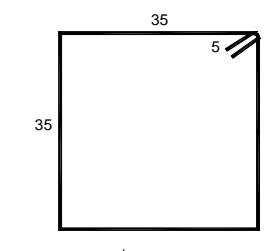

$5 \varnothing 8 \mathrm{c}=150$

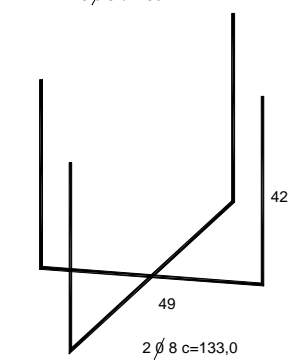

$2 \varnothing 8 \mathrm{c}=133,0$

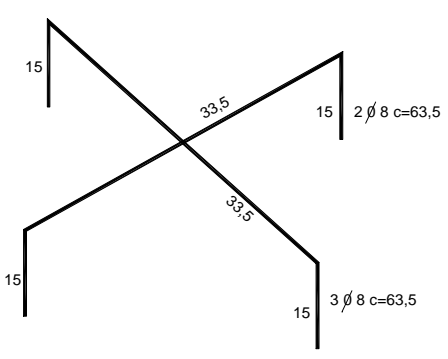

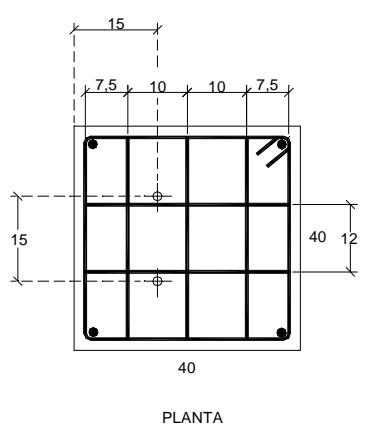

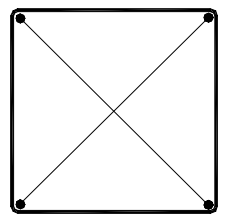

PLANTA - FUNDO

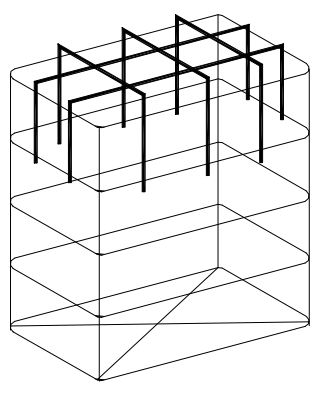

ESQUEMA DA GAIOLA

Figura 4.11 - Detalhamento da armadura do elemento do bloco suporte

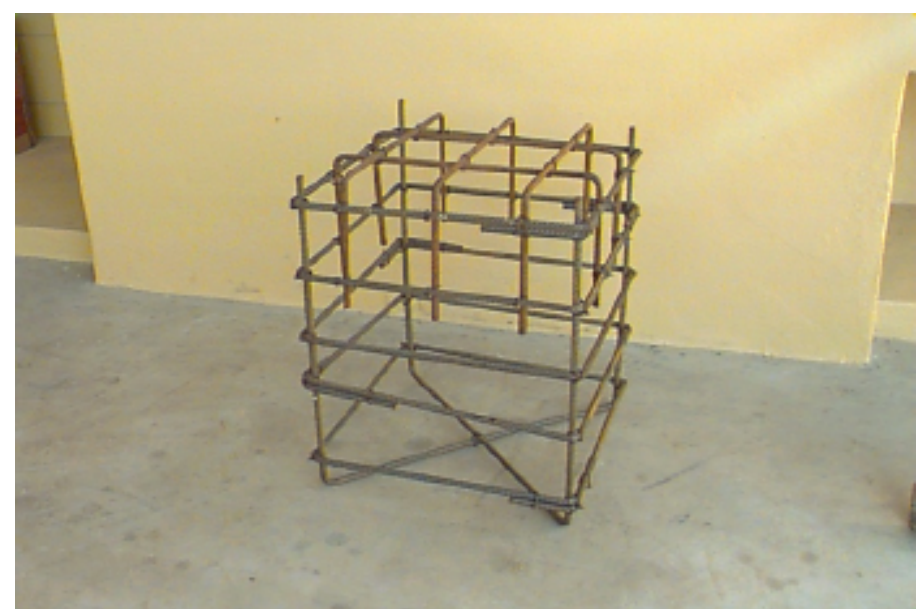

Figura 4.12 - Foto da armadura do elemento de bloco 


\subsubsection{Sistema de Travamento do Bloco Suporte para Aplicação das Ações}

Durante a realização dos ensaios, foram feitas algumas modificações nos sistemas de travamento dos protótipos ensaiados, em função das observações que foram sendo feitas com relação ao comportamento das ligações durante os ensaios.

Inicialmente, o travamento do bloco suporte no ensaio piloto foi feito por meio de bases metálicas, com chapas grossas enrijecidas, presas na laje de reação, conforme apresentado na figura 4.13 .

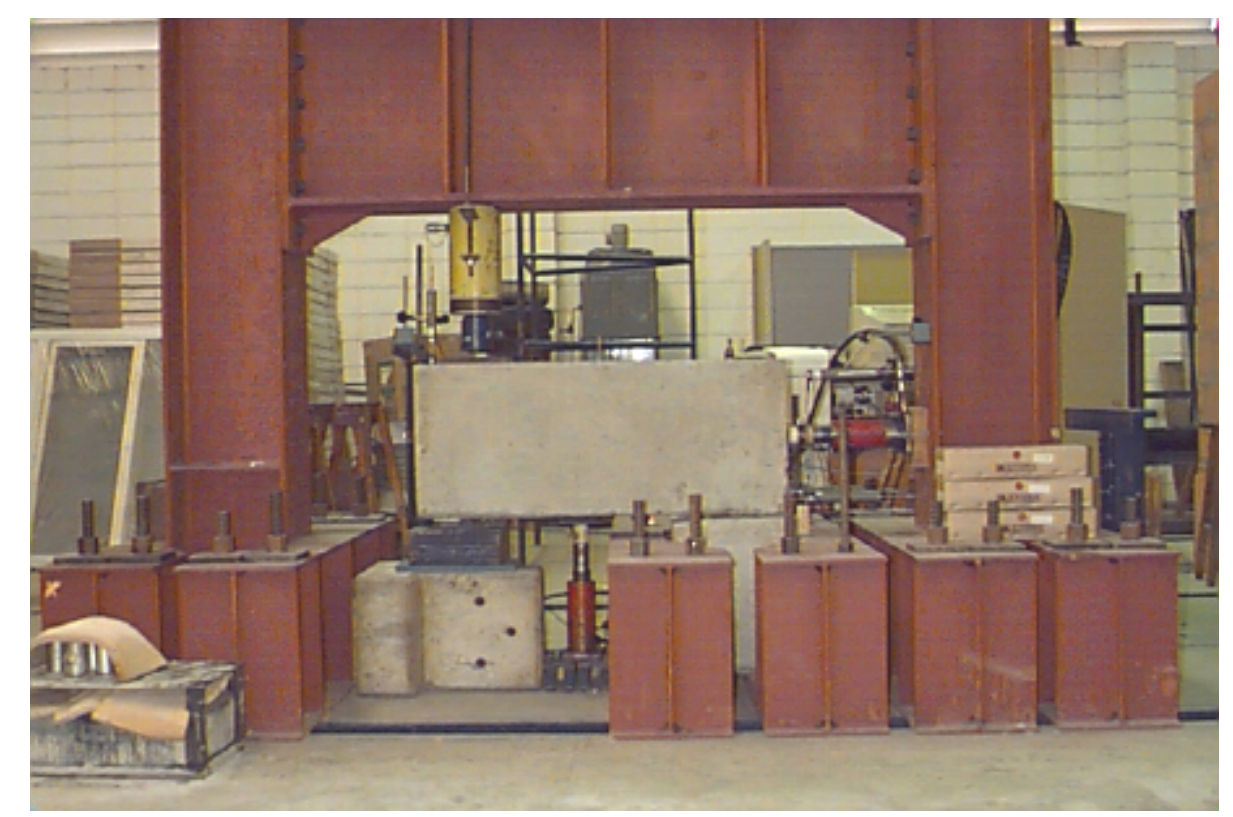

Figura 4.13 - Montagem do sistema de reação para o ensaio piloto

Após a realização do ensaio piloto, decidiu-se fazer algumas modificações:

a) optou-se por utilizar dois chumbadores na ligação, ao invés de apenas um, com o propósito de minorar a rotação horizontal do elemento de viga sobre o bloco suporte;

b) o travamento do bloco suporte passou a ser feito por meio um sistema de tirantes pré tensionados, com 4 barras de $25 \mathrm{~mm}$, conforme a figura 4.14. Neste sistema, diminuíram sensivelmente os deslocamentos causados pelas acomodações iniciais no bloco suporte. A área dos tirantes foi o suficiente para que os mesmos trabalhassem com tensões e deformações axiais baixas. Desta forma, o sistema de travamento mostrou-se eficiente para restringir os deslocamentos horizontais do bloco e também para resistir às forças de cisalhamento nos protótipos. Esse sistema de travamento foi utilizado para os ensaios dos Protótipos A e B. 


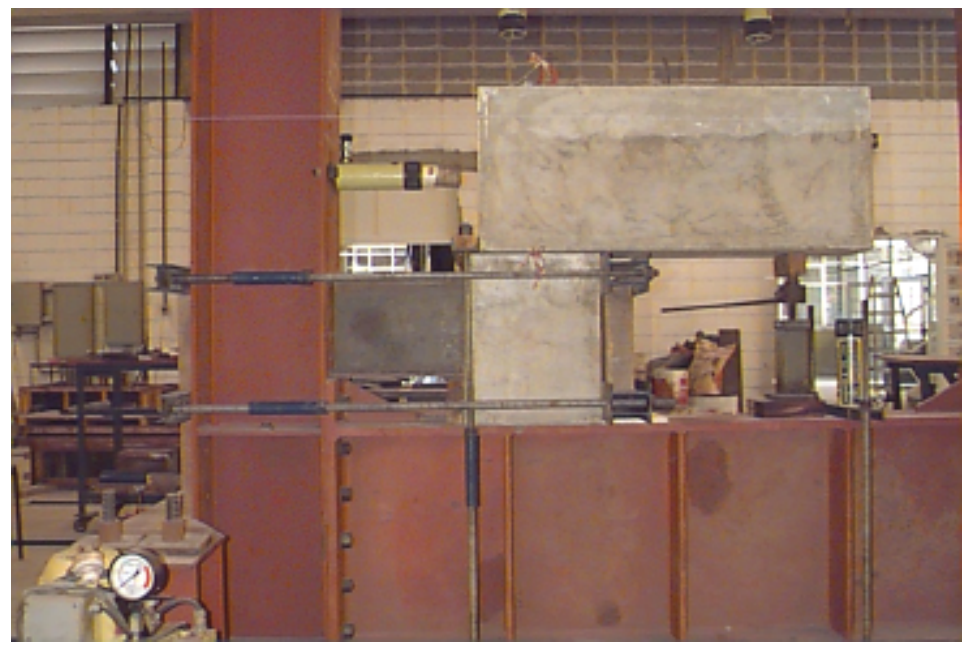

a) Protótipo $A$

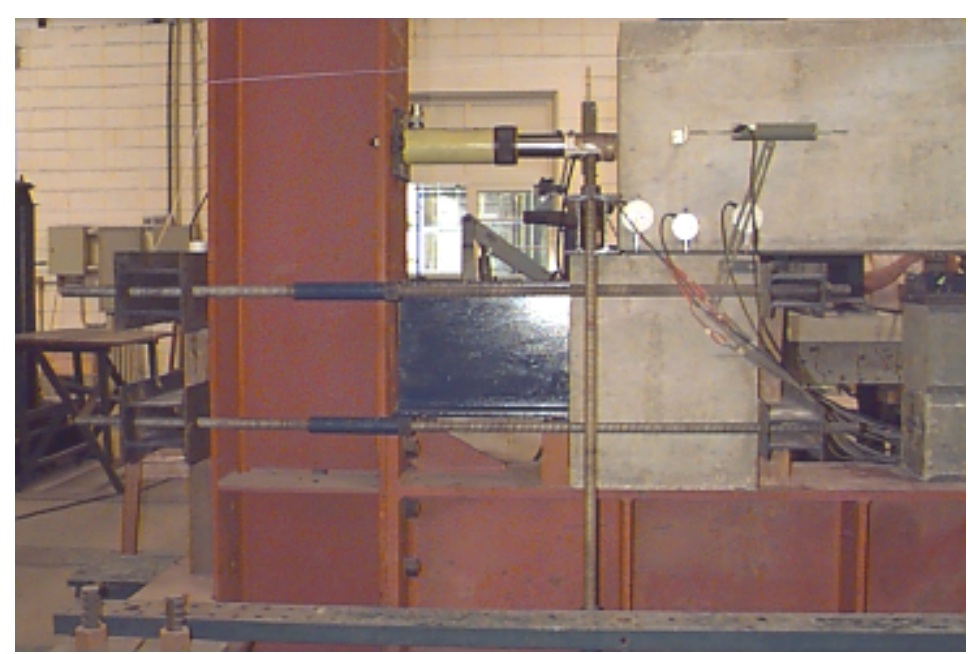

b) Protótipo $B$

Figura 4.14 - Sistema de travamento do bloco suporte por meio de barras atirantadas

No sistema de travamento indicado na figura 4.14, ainda não se conseguiu evitar totalmente as pequenas rotações no elemento do bloco suporte. Como se acreditava que a ligação fosse bastante flexível, este efeito não seria muito importante. Todavia, durante os ensaios de cisalhamento no Protótipo B, onde foi utilizada uma almofada larga, percebeuse que pequenas rotações relativas entre o bloco e a viga geraram esforços de flexão na barra do chumbador não desprezíveis. Assim, para o ensaio do Protótipo $\mathrm{C}$ foi acrescentado um quadro de reação vertical, fixo ao pórtico de reação, o qual forneceu um pré travamento do bloco através de um dispositivo de ajuste com barras rosqueadas, conforme indicado na figura 4.15. Também, para melhorar as condições na superfície do apoio da base do bloco suporte sobre o quadro de reação, foram colocadas almofadas de 
elastômero de $10 \mathrm{~mm}$, conforme apresentado na figura 4.16. A partir destas medidas, conseguiu-se eliminar mesmo as pequenas rotações no bloco suporte.
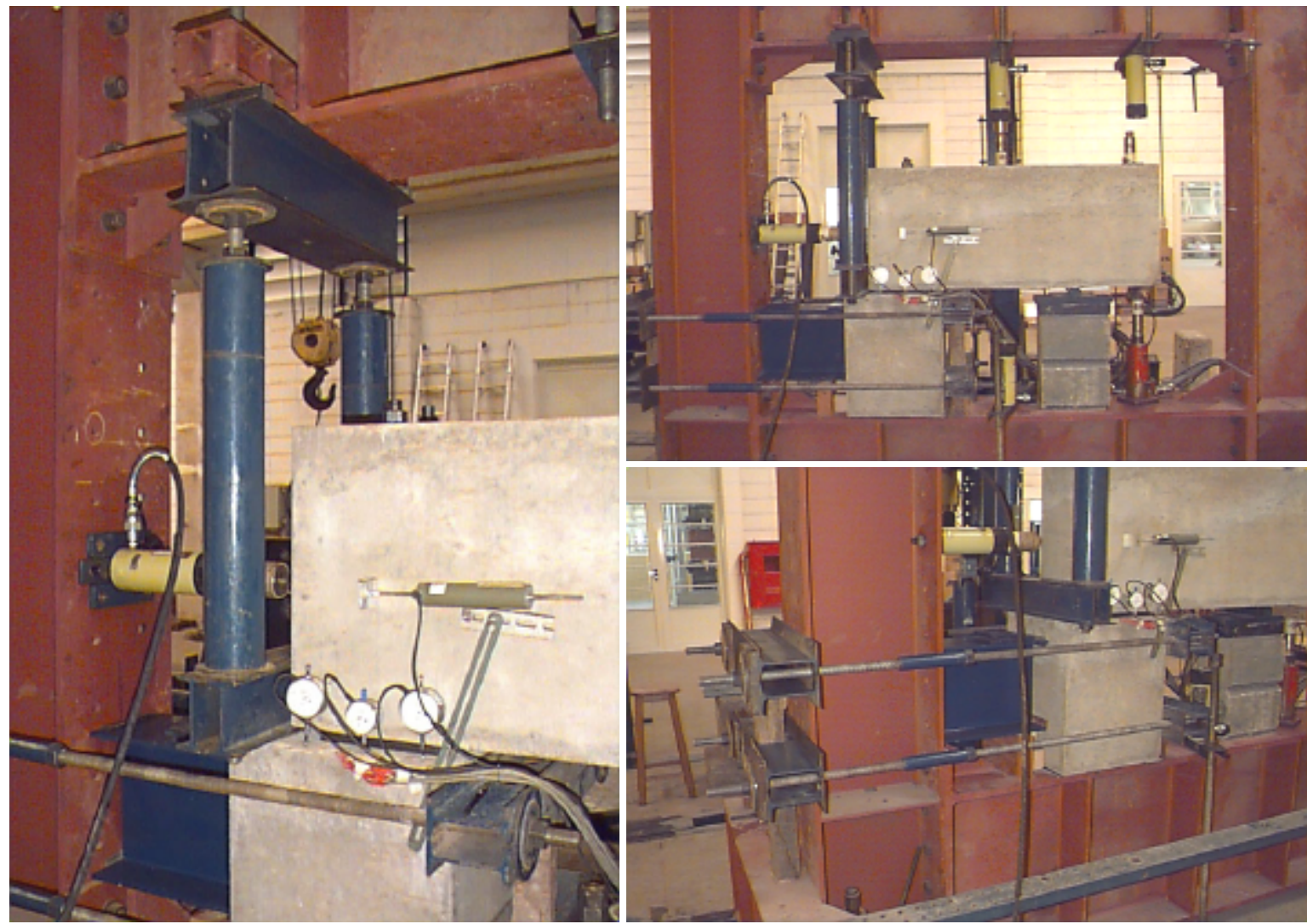

Figura 4.15 - Sistema de travamento do bloco suporte utilizado no Protótipo C

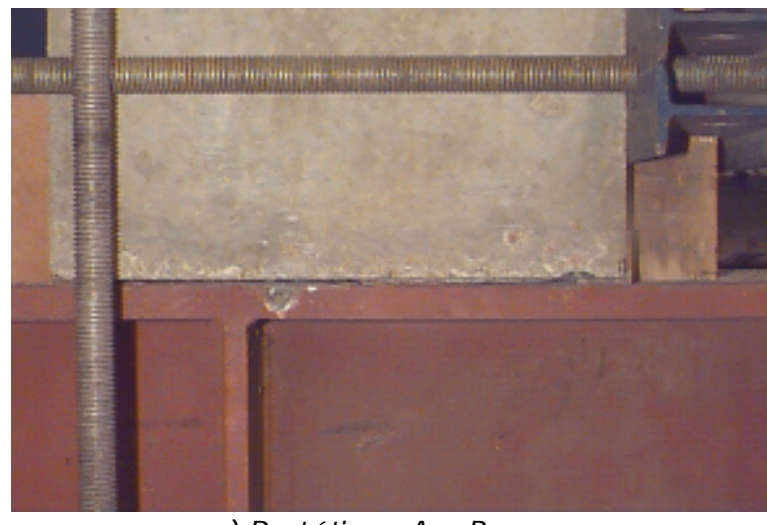

a) Protótipos A e B

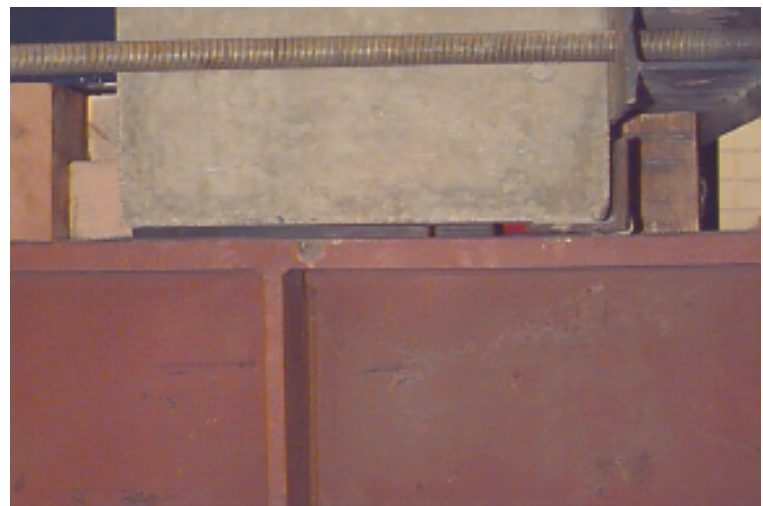

b) Protótipo C

Figura 4.16 - Colocação de almofadas de elastômero na base do Bloco Suporte. 


\subsubsection{Instrumentação}

A medição dos deslocamentos relativos entre o elemento de viga e o elemento do bloco suporte foi feita por meio de transdutores de deslocamento elétricos (LVDT) ligados a um sistema de aquisição de dados. Nas figuras 4.17 e 4.18 apresentam-se os posicionamentos dos transdutores utilizados para os ensaios do Protótipo Piloto. Nas figuras 4.19 e 4.20 apresentam-se os posicionamentos dos transdutores utilizados para os ensaios do Protótipo A. Nas figuras 4.21 e 4.22 apresentam-se os posicionamentos dos transdutores utilizados para os ensaios dos protótipos B e C, onde foram utilizados 3 transdutores verticais em cada lateral da almofada de elastômero, os quais foram utilizados para a leitura das rotações relativas entre o elemento de viga e do bloco suporte, conforme indicado na figura 4.22 .

Para a medição das tensões internas foram utilizados extensômetros elétricos distribuídos ao longo das barras dos chumbadores. Para uma dada seção da barra do chumbador, foram posicionados dois extensômetros nas fibras opostas, com objetivo de medir tensões normais decorrentes da tração e da flexão na barra, causadas pela aplicação da força de cisalhamento na ligação.

No ensaio do protótipo piloto a barra do chumbador não foi instrumentada, mas somente foram feitas medidas externas de deslocamentos. Para o ensaio do protótipo A, as barras dos chumbadores foram instrumentadas tanto na parte da barra inserida no bloco suporte, quanto na parte inserida no elemento de viga, conforme apresentado nas figuras 4.23 e 4.24. Nos Protótipos B e C, as barras dos chumbadores foram instrumentadas apenas na parte da barra que estava inserida dentro do bloco suporte, conforme apresentado nas figuras 4.25 e 4.26. Tal procedimento foi adotado, devido à preocupação com que a instrumentação não causasse maiores perturbações na região em que as barras estavam grauteadas dentro dos nichos do elemento de viga. Tal preocupação se deu, nos casos dos Protótipos B e C, em razão de que as barras dos chumbadores passaram a ter 25 $\mathrm{mm}$ de diâmetro, sendo que os nichos possuíam $50 \mathrm{~mm}$, e também devido ao aumento da força máxima de cisalhamento nos Protótipos B e C, prevista para a ordem de $160 \mathrm{kN}$.

Também, para medir as forças nos atuadores foram utilizadas células de carga de $250 \mathrm{kN}$. Todas as leituras foram registradas para cada incremento das ações através de sistema de aquisição de dados K4000 (com leitura de 80 canais por segundo) 

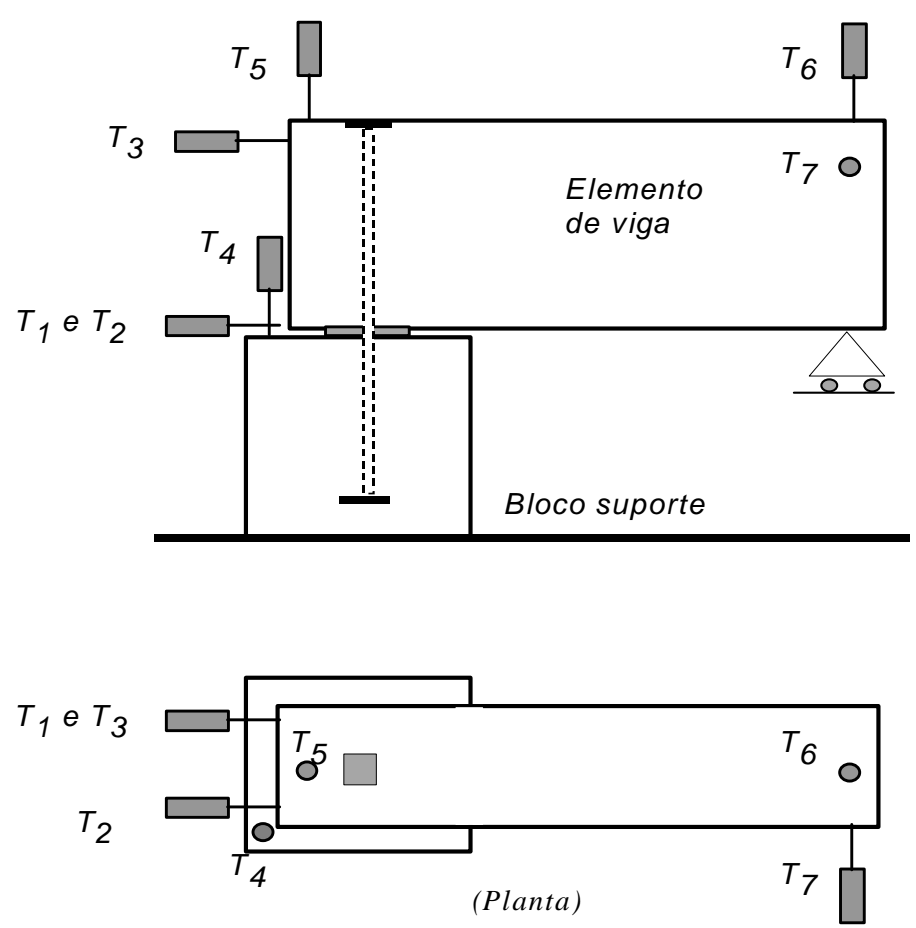

Figura 4.17 - Esquema dos transdutores no Ensaio Piloto
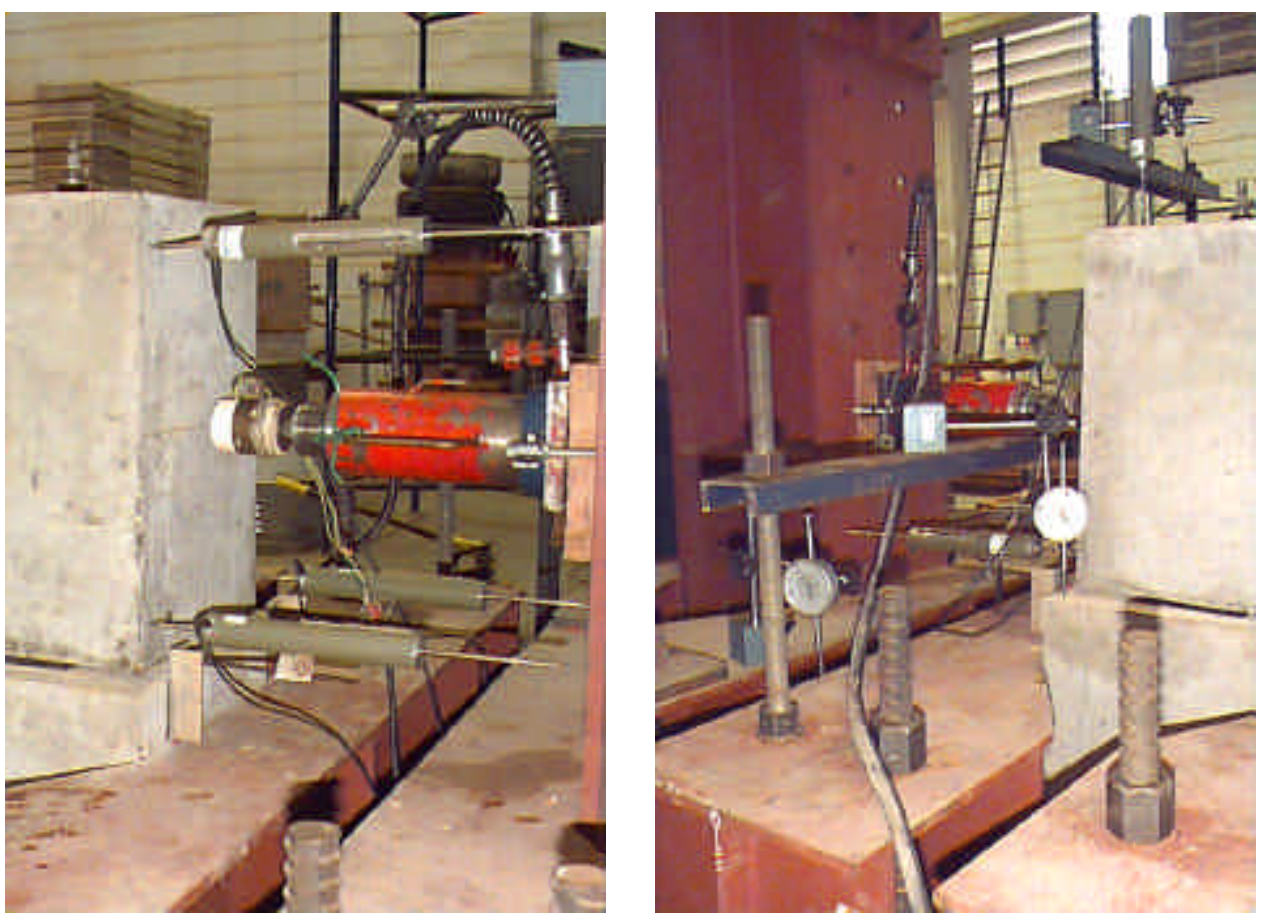

Figura 4.18 - Vista dos transdutores no ensaio piloto 

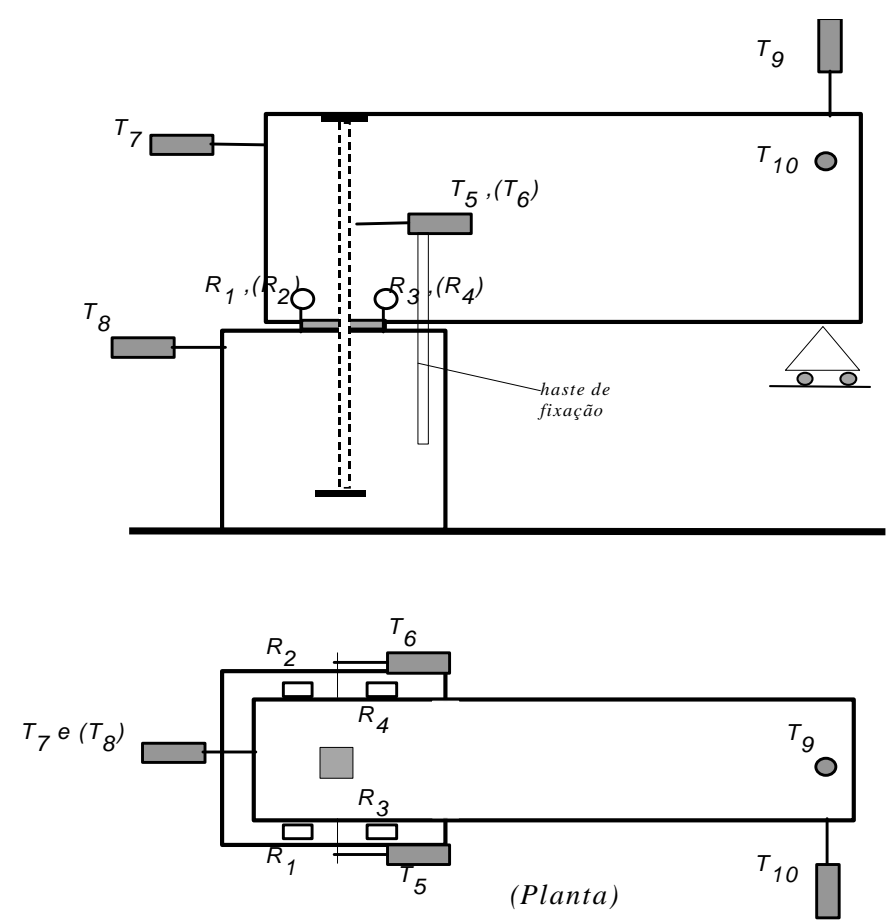

Figura 4.19 - Esquema dos transdutores e relógios no Ensaio do Protótipo A

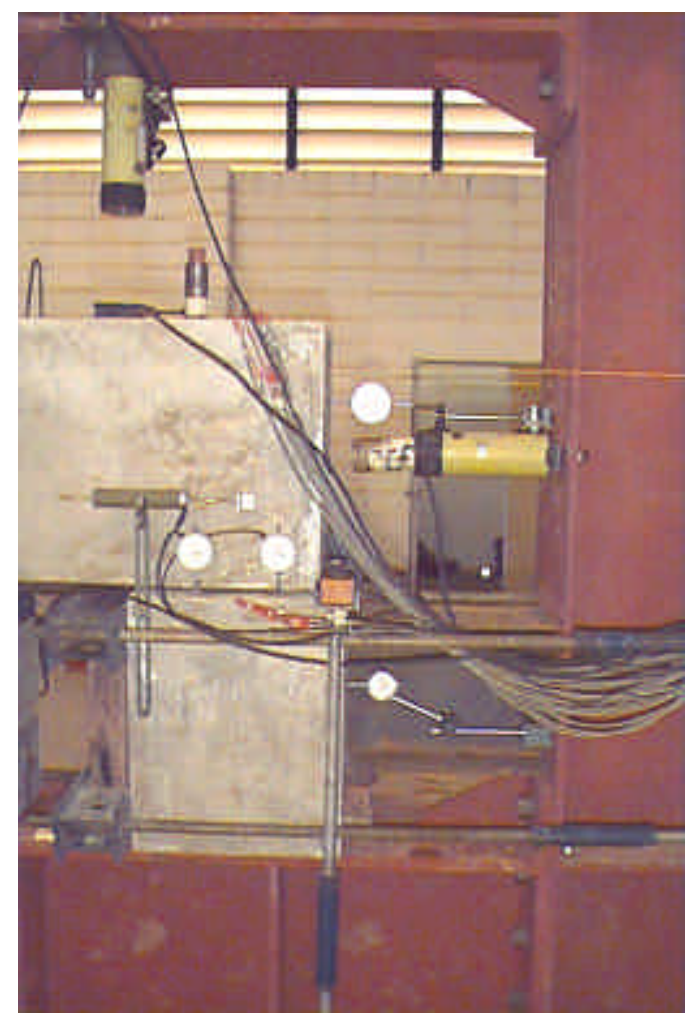

a) Vista Geral dos Transdutores e Relógios no Protótipo A

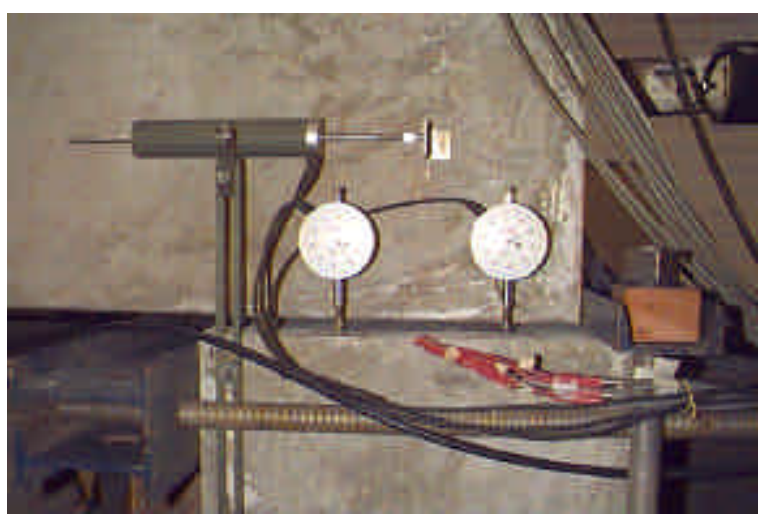

b) Detalhe dos relógios para medição das rotações relativas

Figura 4.20 - Medição dos deslocamentos relativos no Protótipo A 

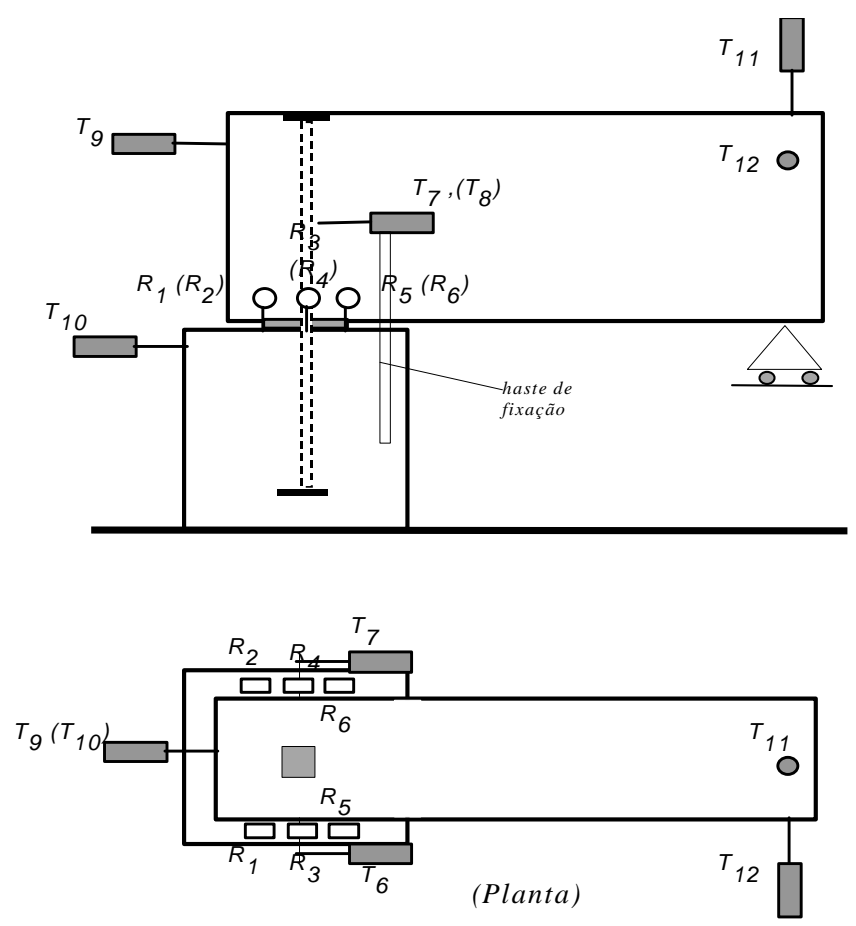

Figura 4.21 - Esquema dos transdutores e relógios nos Protótipos $B$ e $C$

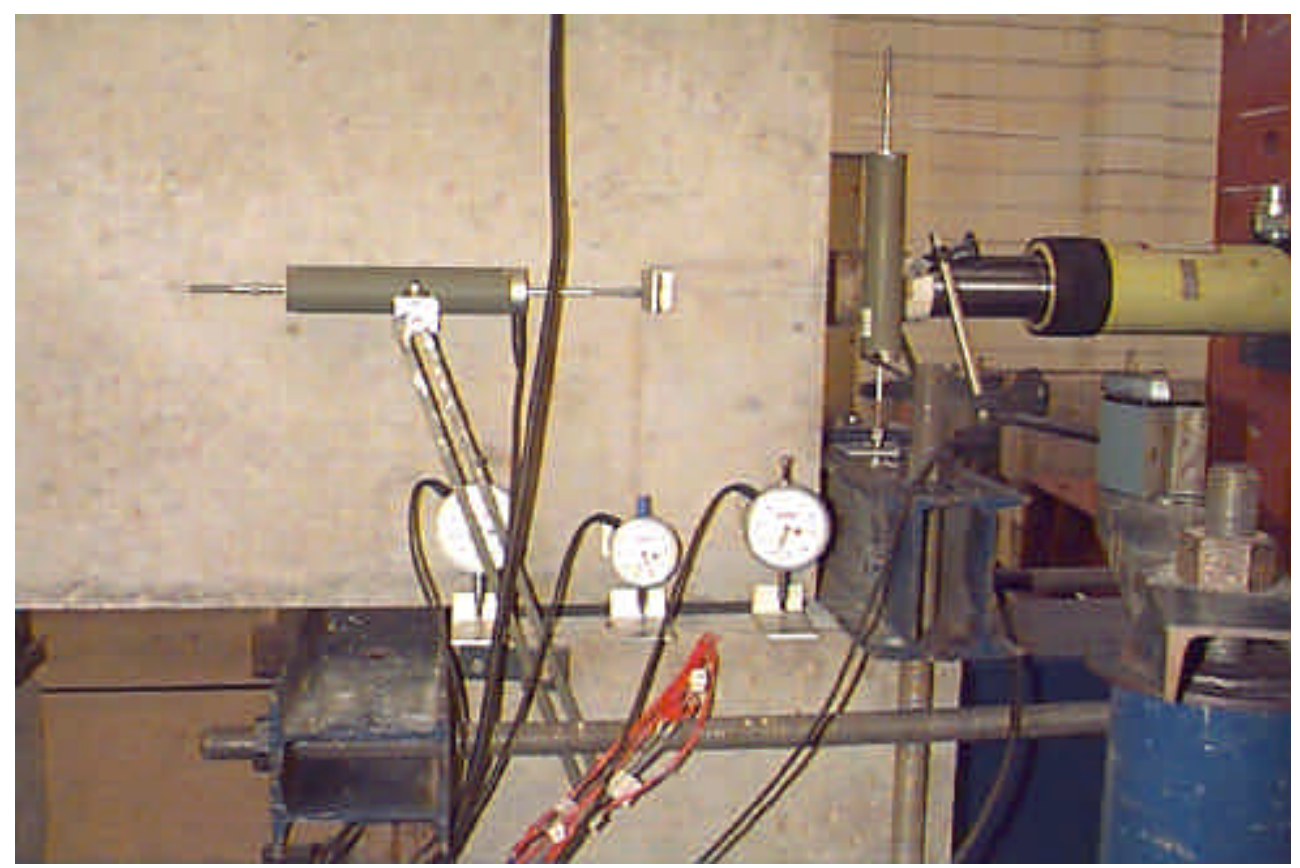

Figura 4.22 - Medidas dos deslocamentos relativos nos protótipos $B$ e $C$. 

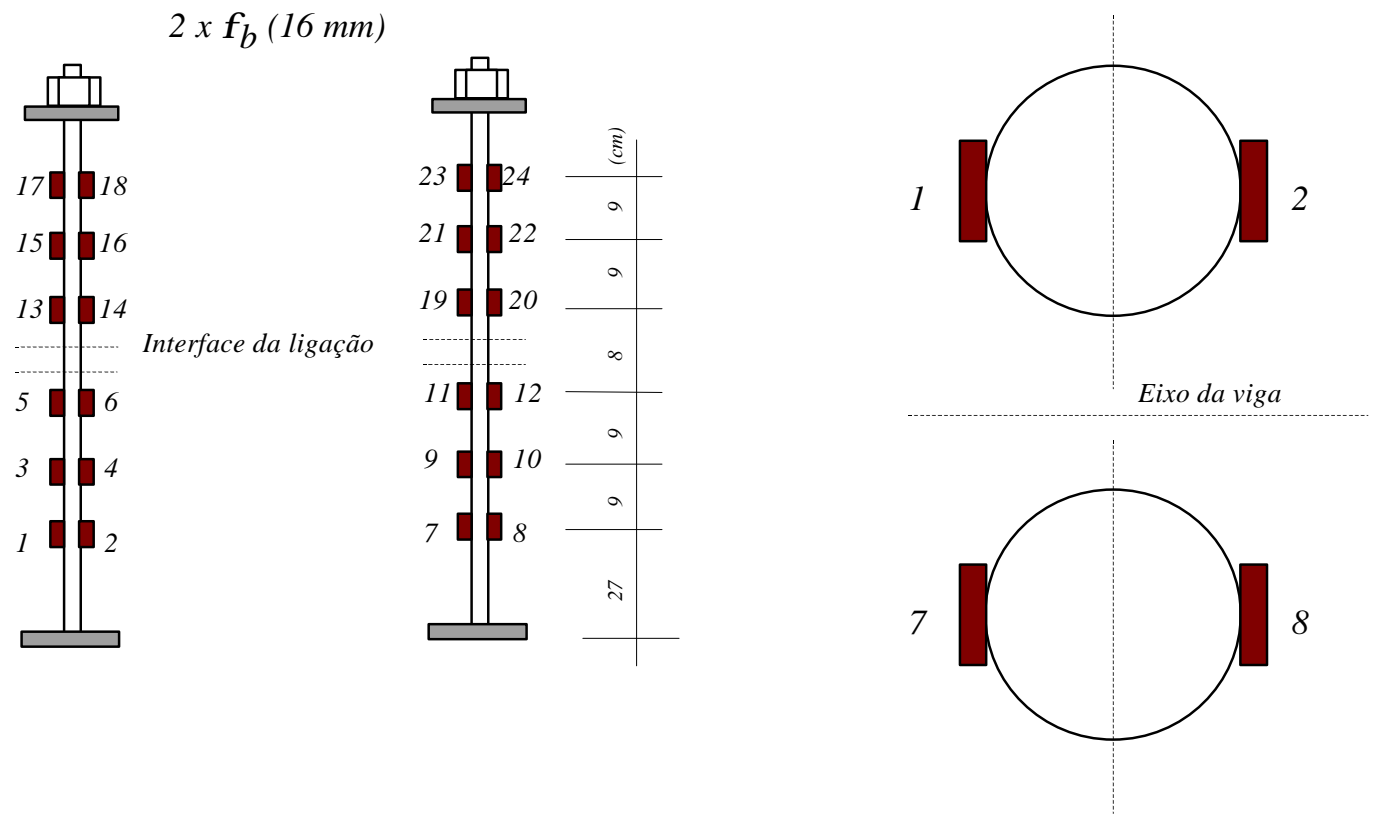

Figura 4.23 - Extensômetros elétricos nos chumbadores do Protótipo A

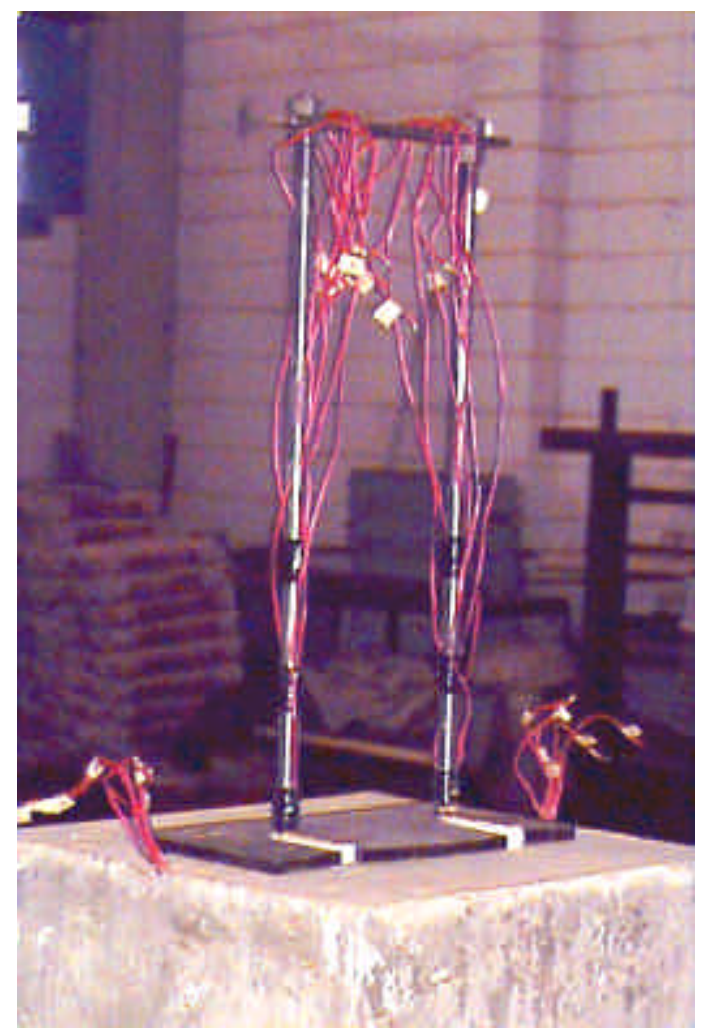

Figura 4.24 - Vista da instrumentação nos chumbadores no Protótipo A 

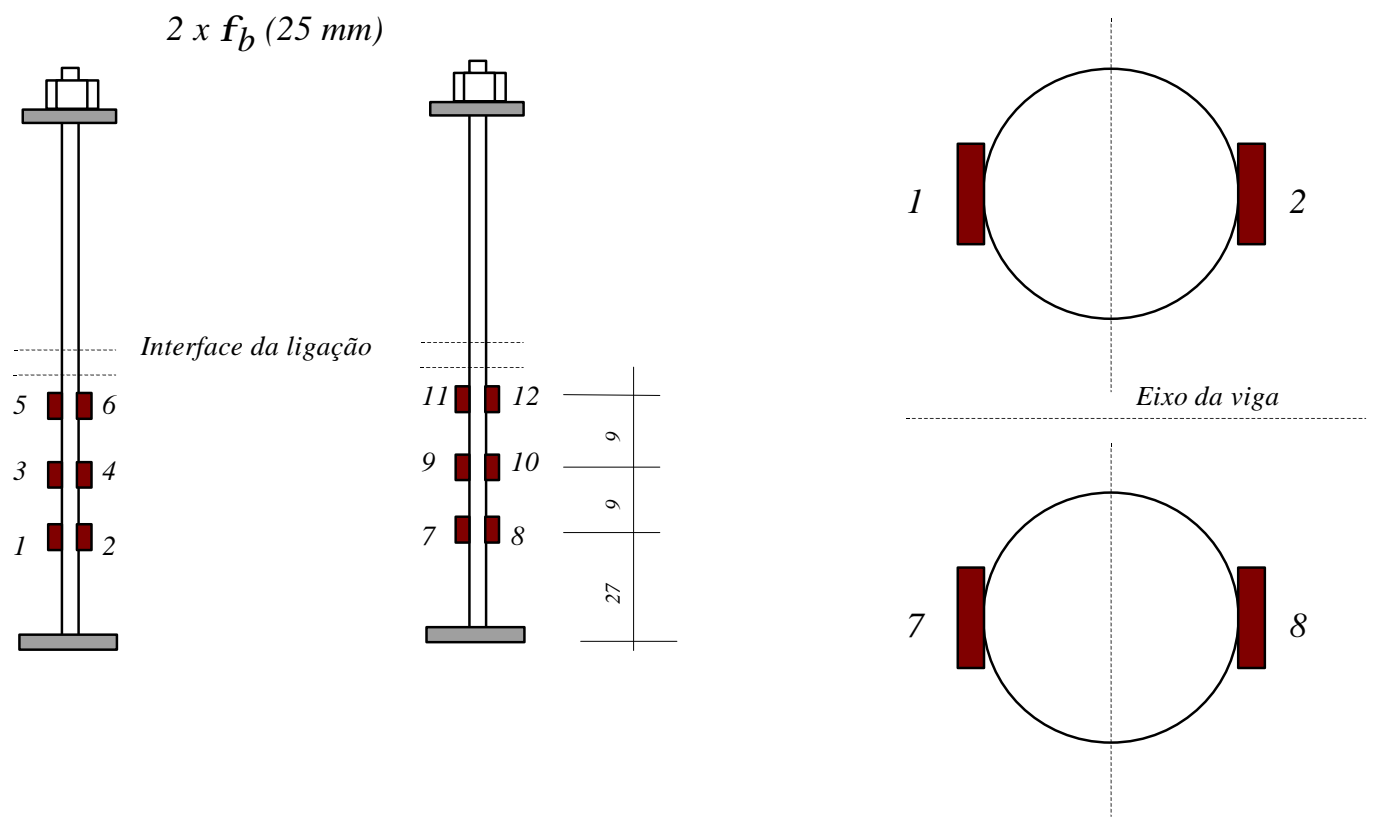

Figura 4.25 - Extensômetros elétricos nos chumbadores dos Protótipos B e C

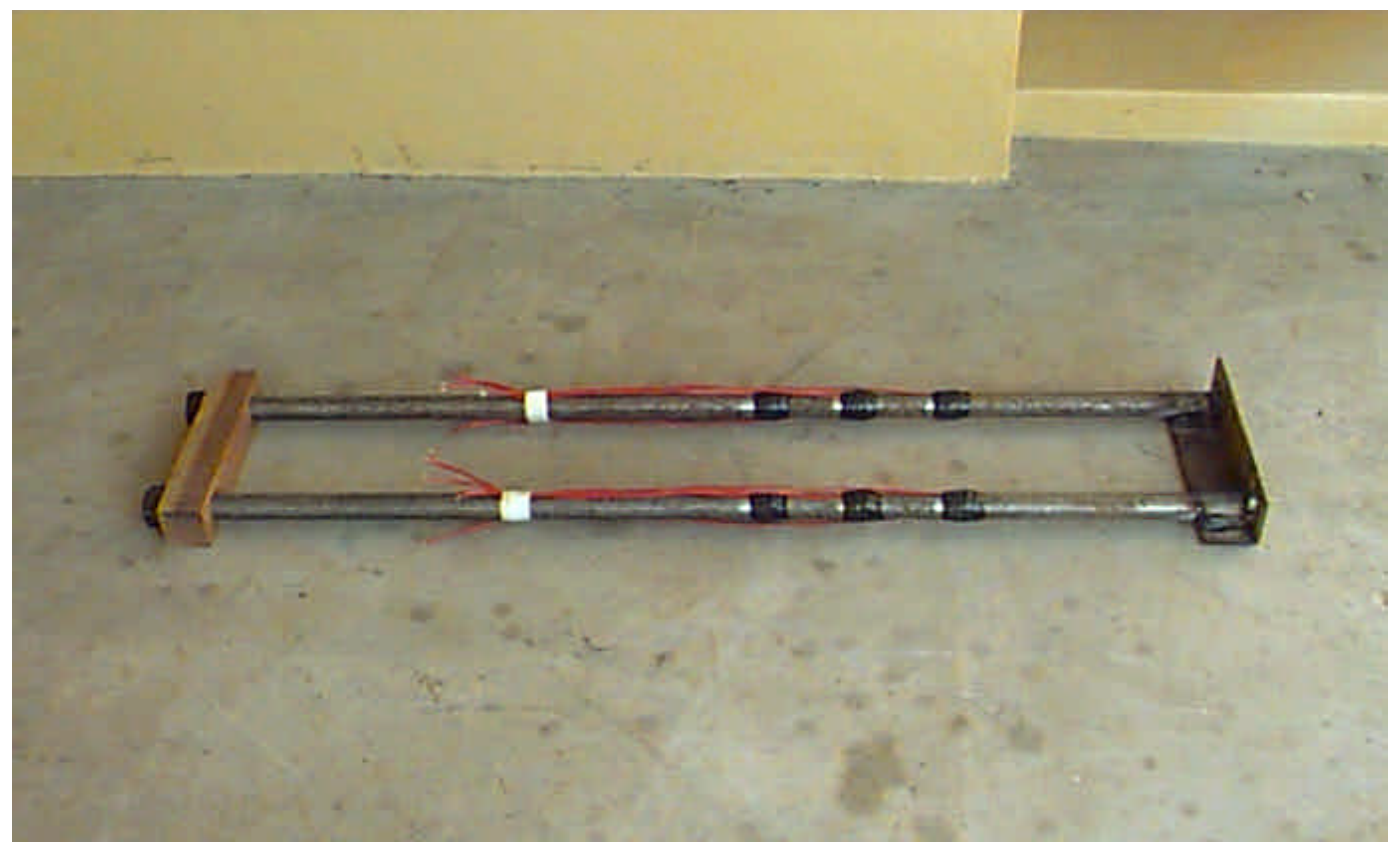

Figura 4.26 - Vista da instrumentação nos chumbadores para os Protótipos B e C 


\subsubsection{Aplicações das Ações}

O objetivo principal nesta pesquisa foi o de avaliar a deformabilidade e o comportamento da ligação quando submetida ao esforço de cisalhamento. Porém, como contribuição ao estudo do comportamento global da ligação, foram aplicadas na ligação ações normais, de flexão e de torção, para situações de serviço. Na tabela 4.6 estão apresentadas as ações que foram aplicadas em cada protótipo.

Tabela 4.6 - Resumo das aplicações das ações nos ensaios

\begin{tabular}{|c|c|c|}
\hline Protótipo & Ensa ios de C isa lha mento & Ensa ios Complementa res \\
\hline $\begin{array}{c}\text { Piloto } \\
1 \phi 16 \mathrm{~mm} \\
(150 \times 300 \times 10)\end{array}$ & $\begin{array}{l}\text { - Cisa lhamento na fase elástic a e após } \\
\text { o escoamento }\end{array}$ & - Flexão (ligação muito flexível) \\
\hline $\begin{array}{c}\text { Protótipo A } \\
2 \phi 16 \mathrm{~mm} \\
(150 \times 300 \times 10)\end{array}$ & $\begin{array}{l}\text { - Cisa lhamento na fase elástica, a póso } \\
\text { escoamento, com esgotamento da } \\
\text { resistência da ligação }\end{array}$ & $\begin{array}{l}\text { - Flexão } \\
\text { - Torção na fase elástica } \\
\text { - Influência da força Normal }\end{array}$ \\
\hline $\begin{array}{l}\text { Protótipo B } \\
2 \phi 25 \mathrm{~mm} \\
(250 \times 300 \times 10)\end{array}$ & $\begin{array}{l}\text { - Cisa lhamento na fase elástica, a póso } \\
\text { escoamento, com esgotamento da } \\
\text { resistência da ligação }\end{array}$ & $\begin{array}{l}\text { - Flexão com ca rregamento } \\
\text { altemado na fase elástica. } \\
\text { - Torção na fase elástica }\end{array}$ \\
\hline $\begin{array}{c}\text { Protótipo A } \\
2 \phi 25 \mathrm{~mm} \\
(200 \times 300 \times 15)\end{array}$ & $\begin{array}{l}\text { - Cisa lhamento na fase elástica, apóso } \\
\text { escoamento, com esgotamento da } \\
\text { resistência da ligação }\end{array}$ & $\begin{array}{l}\text { - Flexão com carregamento } \\
\text { altemado na fase elástica. } \\
\text { - Torção na fase elástica }\end{array}$ \\
\hline
\end{tabular}

\subsubsection{Ações de Cisalhamento na Ligação}

Nos ensaios de cisalhamento, a ação foi aplicada no elemento de viga por meio de um atuador comprimido entre uma coluna do pórtico de reação e a extremidade do elemento de viga que estava conectada sobre o bloco suporte, conforme as figuras $4.27 \mathrm{e}$ 4.28. Em função desse arranjo, teve-se um sistema de forças desestabilizantes, onde surgiram deslocamentos laterais na extremidade livre do elemento de viga, com rotações no plano horizontal do elemento de viga sobre o bloco suporte. Para atenuar este comportamento, optou-se pela colocação de dois chumbadores nos Protótipos A, B e C.

Para o estudo da deformabilidade elástica ao cisalhamento da ligação, foram aplicadas inicialmente ações da ordem de 30 a $40 \%$ da força prevista para a resistência da ligação. Estas ações foram repetidas de dois a três ciclos, com incrementos da ordem de 1/10 do valor da máxima ação em cada ciclo. Após esses ciclos iniciais de carregamento, a ligação foi solicitada até ultrapassar o escoamento e atingir a sua resistência. 


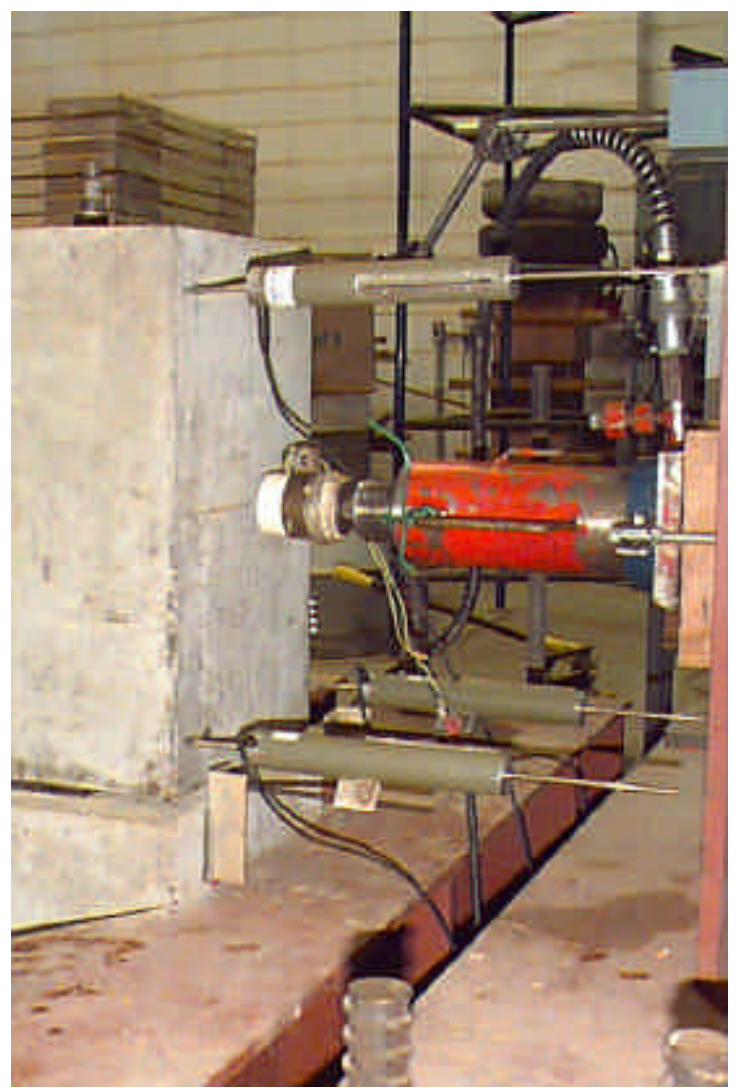

a) Protótipo Piloto

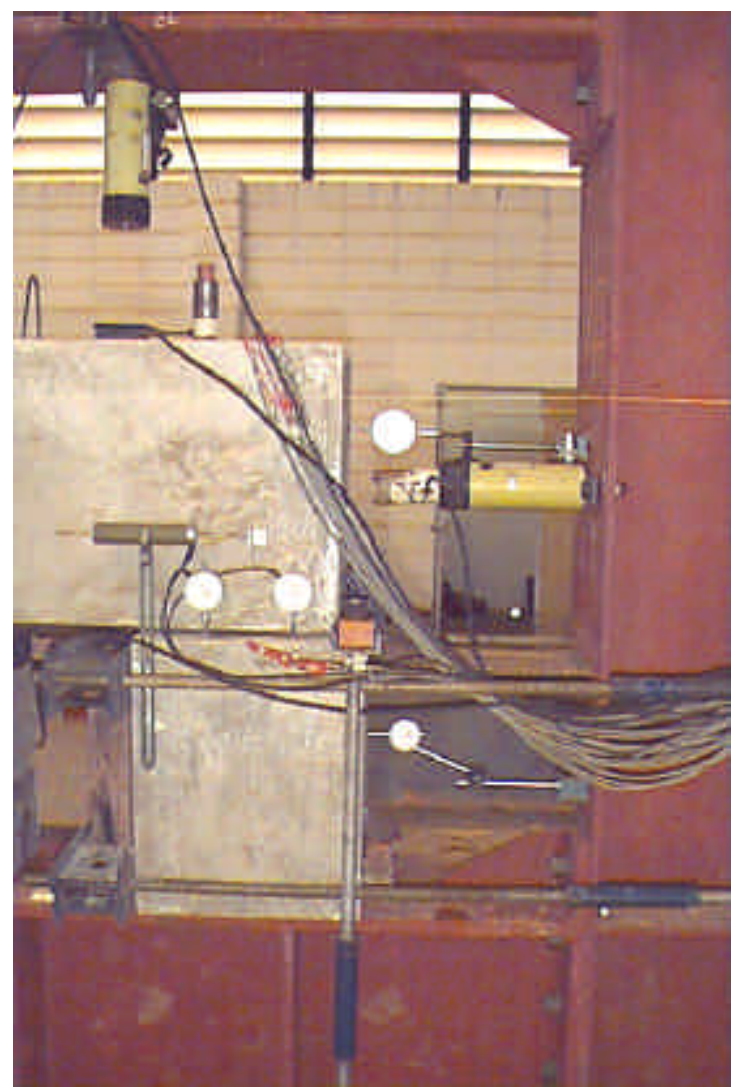

b) Protótipo A

Figura 4.27 - Aplicação da força de cisalhamento nos ensaios piloto e protótipo A

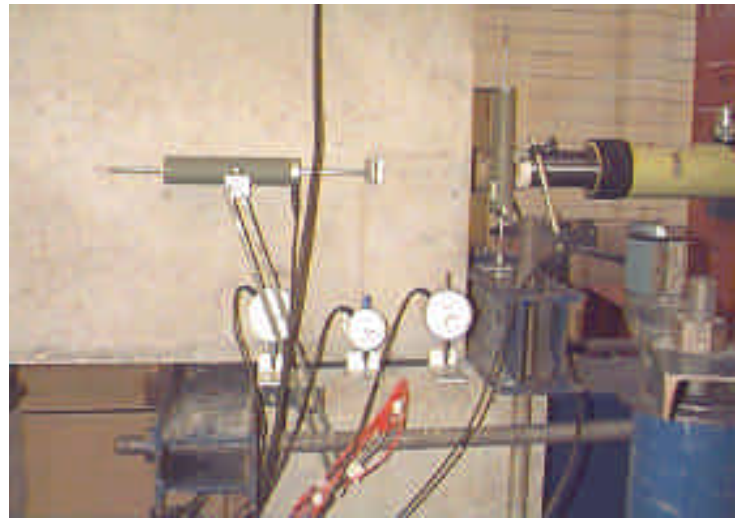

a) Protótipo B

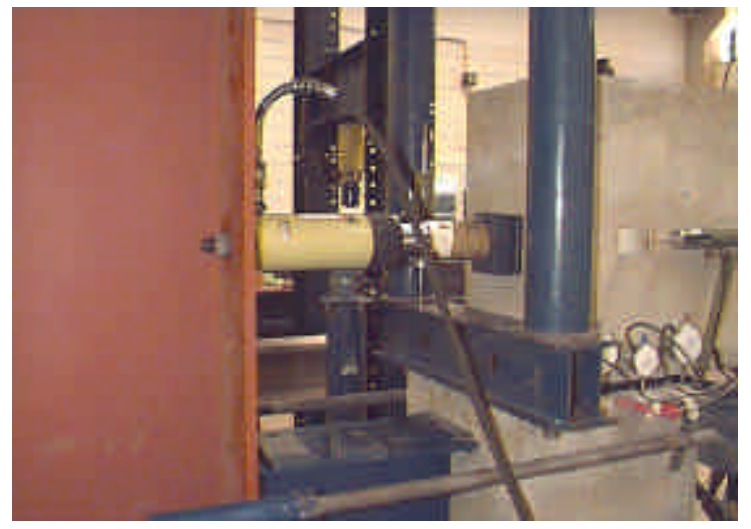

b) Protótipo C

Figura 4.28 - Aplicação da força de cisalhamento nos ensaios dos protótipo $B$ e $C$ 


\subsubsection{Ações de Torção na ligação}

As ações de torção foram aplicadas na ligação através da utilização de dois atuadores dispostos na direção vertical, descentralizados em relação ao eixo vertical da seção transversal do elemento de viga, conforme apresentados nas figuras 4.29a e 4.29b.

Inicialmente, o elemento de viga foi colocado na posição nivelada com o auxílio de um "macaco" com ajuste manual, conforme figura 4.29b. Em seguida, o atuador superior foi acionado até a ordem de $2 \mathrm{kN}$. O binário torçor foi conseguido, mantendo o atuador superior fixo, como um ponto de apoio, e acionando o atuador inferior.

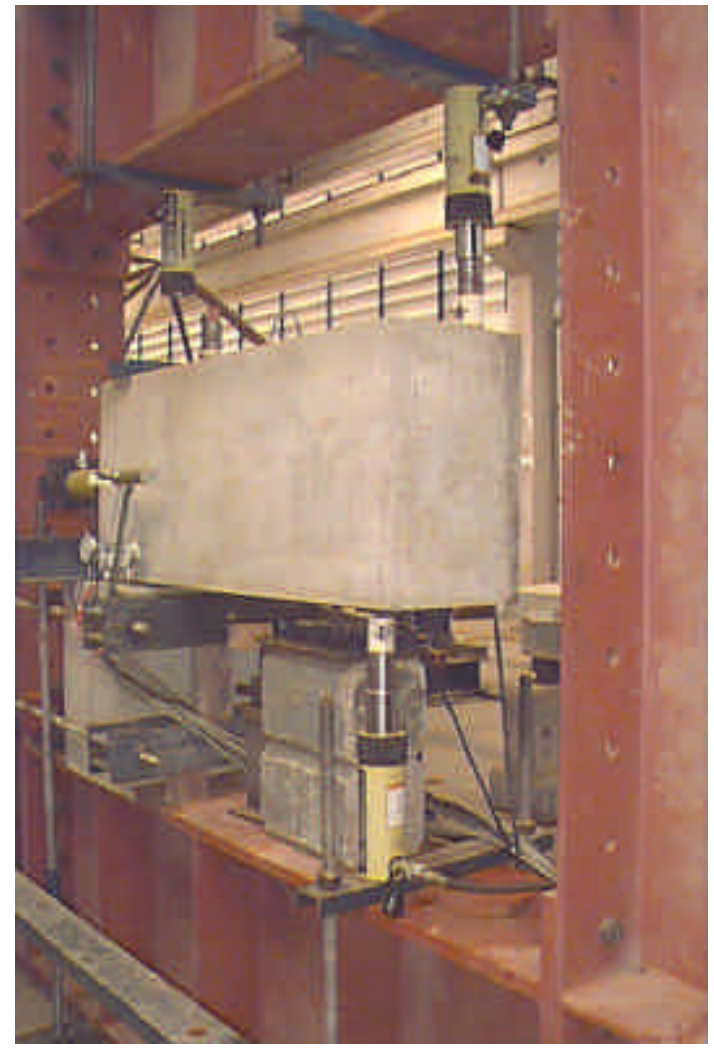

(a)

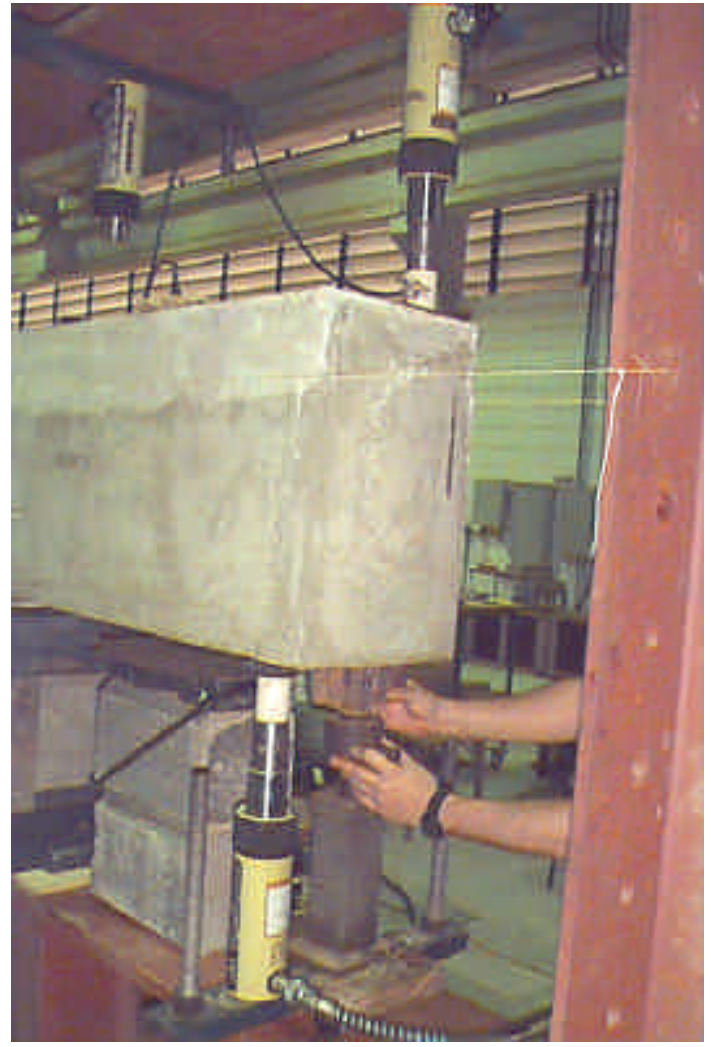

(b)

Figura 4.29 - Disposição dos atuadores para aplicação da ação de torção na ligação

As forças descentradas foram previstas para promover baixas tensões nos chumbadores, para não danificar a ligação que ainda seria solicitada por outras ações, antes da última ação de cisalhamento. Deste modo, foi observado somente o comportamento inicial da deformabilidade à torção da ligação. 


\subsubsection{Ações de Flexão na ligação}

A ação de flexão foi aplicada na ligação através de atuadores verticais posicionados na extremidade livre da viga, conforme indicado na figura 4.30. Os atuadores foram acionados de forma alternada, fazendo com que houvesse inversão dos momentos na ligação. Esta alternância de forças foi repetida de duas a três vezes. Também no caso dos ensaios de flexão, as ações foram limitadas em função das rotações na ligação e das tensões no chumbador, para não danificar a ligação. $\mathrm{O}$ objetivo de estudo foi o de estudar possíveis restrições ao giro por parte da ligação e, se possível, relacionar estas restrições com parâmetros internos da ligação.
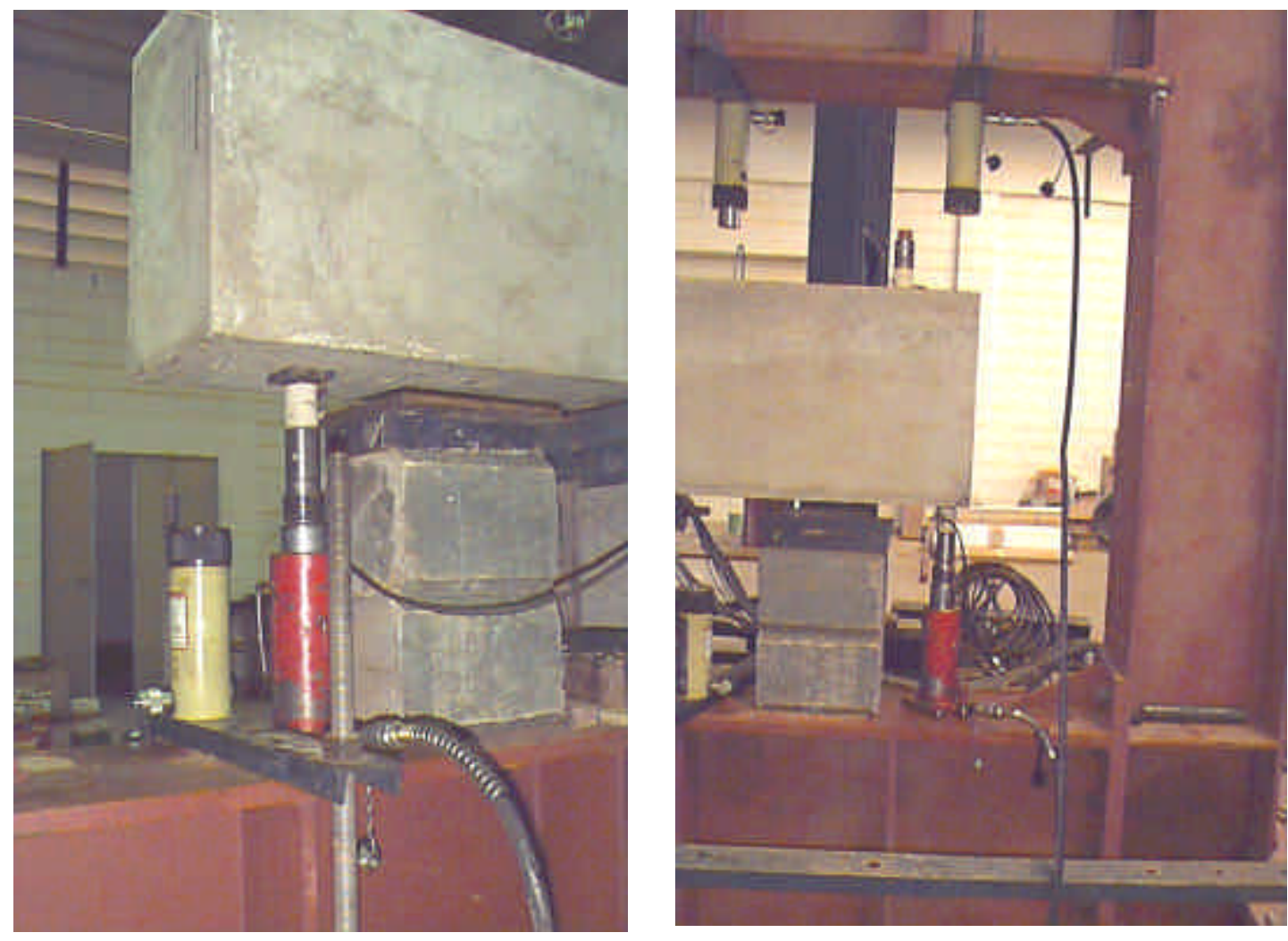

Figura 4.30 - Atuadores para aplicação de flexão na ligação

Devido à grande flexibilidade na ligação, nos casos do protótipo piloto e do protótipo A, não foi possível a alternância do carregamento na extremidade da viga, tendo sido utilizado apenas o atuador inferior, trabalhando contra o peso próprio do elemento de 
viga, conforme a figura 4.30a. Já para os Protótipos B e C, em virtude destes apresentarem uma restrição parcial aos giros iniciais, foram aplicadas ações alternadas, pelo atuador inferior e superior, conforme figura 4.30b.

Para que a ligação pudesse desenvolver um mecanismo resistente à flexão, foram colocadas porcas com arruelas nas extremidades rosqueadas dos chumbadores, conforme ilustrado na figura 4.31 .

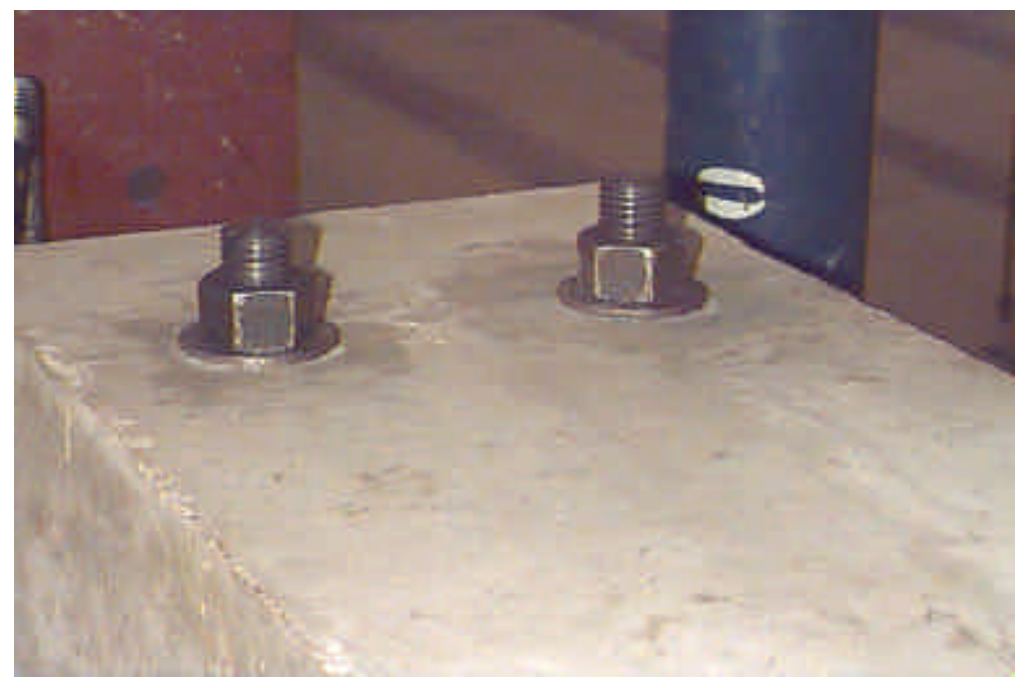

Figura 4.31 - Travamento dos chumbadores com porcas e arruelas

\subsubsection{3 - Ações Normais na ligação}

As deformações devidas à ação da força de compressão neste tipo de ligação ainda são pouco conhecidas. $\mathrm{O}$ estudo da deformabilidade à compressão em almofadas de elastômero simples está apresentado no item 3.3 do presente trabalho. Para a análise da deformabilidade à compressão do conjunto da ligação, utilizou-se um atuador posicionado entre os dois chumbadores, conforme figura 4.32. Também, relacionado com a influência da força normal na ligação, durante os ciclos de cisalhamento 2 e 3 para o ensaio do Protótipo A foram aplicadas, simultaneamente às forças de cisalhamento, forças normais de $10 \mathrm{kN}$ e $30 \mathrm{kN}$, respectivamente. Para tal, foi utilizado um apoio móvel entre o atuador e o elemento de viga, conforme indicado na figura 4.33. 


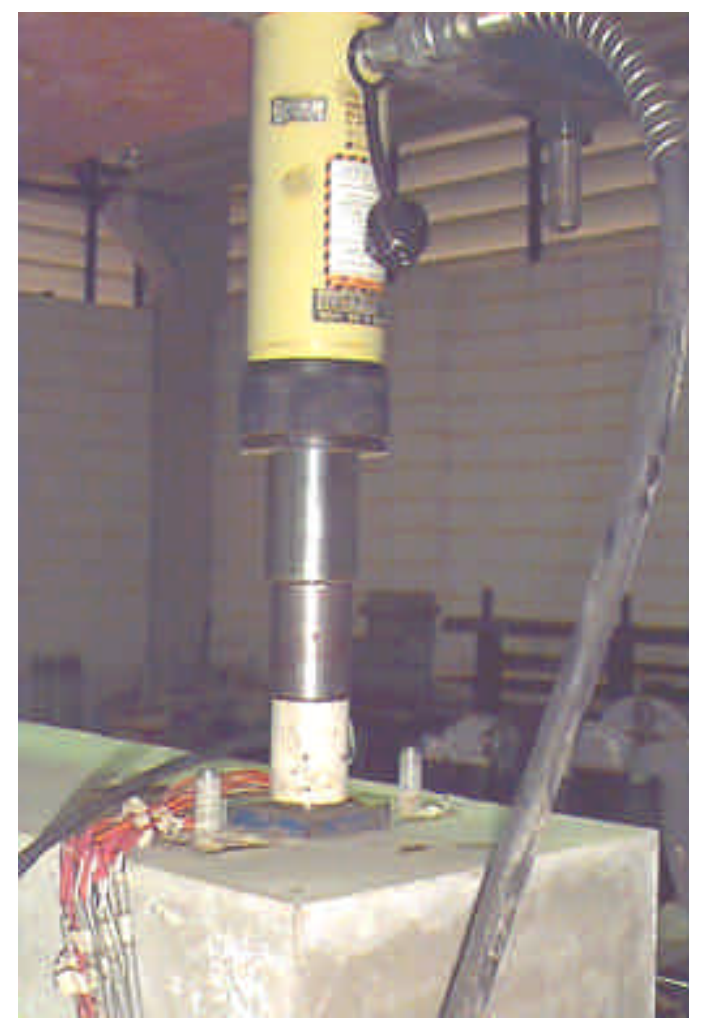

Figura 4.32- Atuador para aplicação da força normal na ligação.

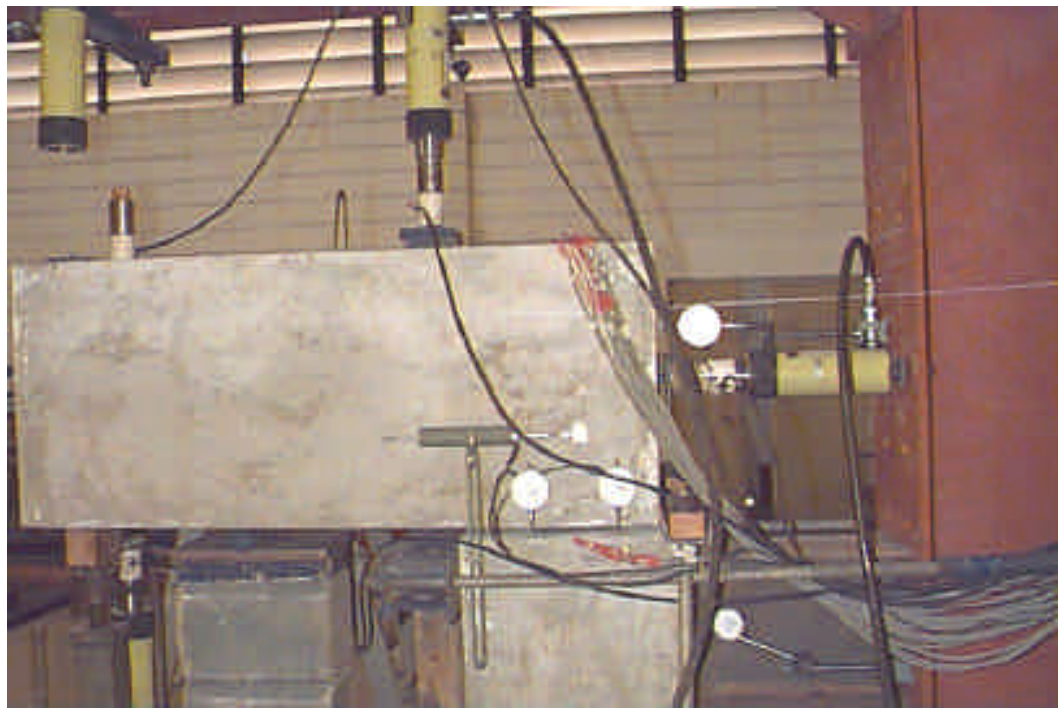

Figura 4.33 - Atuador sobre apoio móvel para aplicação da força normal durante o ensaio de cisalhamento. 


\subsubsection{Resultados Experimentais}

\subsubsection{Ensaios de Cisalhamento}

\subsection{Protótipo Piloto}

O Protótipo Piloto contou com um chumbador de $16 \mathrm{~mm}$ e uma almofada de elastômero não fretado $\left(150 \times 300 \times 10 \mathrm{~mm}^{3}\right)$. Durante o ensaio de cisalhamento, foram aplicados 3 ciclos de carregamento, cujas curvas força de cisalhamento vs. deslocamento horizontal da ligação encontram-se registrados nos gráficos 4.1 e 4.2, sendo também apresentados simultaneamente nos gráficos 4.3 e 4.4. Na tabela 4.7 é apresentado um resumo com os 3 ciclos de carregamento de cisalhamento no Protótipo Piloto.

No primeiro ciclo foi aplicada uma força de $10 \mathrm{kN}$, que representa cerca de $30 \%$ da capacidade ao cisalhamento da ligação, onde se pretendeu que a ligação estivesse apenas no regime elástico. No segundo e terceiro ciclos, os limites de escoamento da ligação, definidos pelas forças $\mathrm{F}_{\mathrm{vy} \text {,min }}$ e $\mathrm{F}_{\mathrm{vy}}$, foram ultrapassados.

Tabela 4.7 - Resumo dos ciclos de cisalhamento no Protótipo Piloto

\begin{tabular}{|c|c|c|c|}
\hline $\begin{array}{l}\text { Ciclosde } \\
\text { carregamento }\end{array}$ & $\begin{array}{c}\mathrm{F}_{\mathrm{V}} \\
(\mathrm{kN})\end{array}$ & $\begin{array}{l}\Delta_{\text {hor }} \\
(\mathrm{mm})\end{array}$ & Observações: \\
\hline Ciclo 1 & 9,10 & 0,20 & $\begin{array}{l}\checkmark \text { O ca rregamento atingiu cerca de } 30 \% \text { da capacidade } \\
\text { prevista para a ligação. (Regime elástico). }\end{array}$ \\
\hline Ciclo 2 & $\begin{array}{c}10,0 \\
17,80 \\
30,10 \\
28,70\end{array}$ & $\begin{array}{l}0,22 \\
0,41 \\
2,10 \\
3,43\end{array}$ & $\begin{array}{l}\checkmark \text { Comportamento na fase elástica semelhante ao do ciclo } 1 . \\
\checkmark \text { Trecho linearinicial para Fv }<17,8 \mathrm{kN} \text {. } \\
\checkmark \text { A resistência da ligação foi alcançada, entrando no regime } \\
\text { plástico, para } \Delta_{\text {hor }}<4 \mathrm{~mm} \text {. }\end{array}$ \\
\hline Ciclo 3 & $\begin{array}{c}9,80 \\
34,10 \\
28,70\end{array}$ & $\begin{array}{l}0,88 \\
5,34 \\
5,80\end{array}$ & $\begin{array}{l}\checkmark \text { Aumento da deformabilida de na ligação, a inda com } \\
\text { comportamento linear para } 5<\mathrm{Fv}<25 \mathrm{kN} \text {. } \\
\checkmark \text { Atingiu-se a resistência da ligação, entrando no regime } \\
\text { plástico, para } \Delta_{\text {hor }}>5 \mathrm{~mm} \text { ( } \Delta_{\text {hor,efet }}>7 \mathrm{~mm} \text { ). }\end{array}$ \\
\hline
\end{tabular}

As inclinações das retas tangentes às curvas força de cisalhamento vs. deslocamento horizontal da ligação, estão apresentadas na tabela 4.8. Nos ciclos 1 e 2, a ligação apresentou inclinações semelhantes das retas tangentes iniciais, para $\mathrm{F}_{\mathrm{V}}<10 \mathrm{kN}$, onde se verificou que a deformabilidade ao cisalhamento da ligação foi mantida, sendo mantidos assim os mecanismos de deformação. 


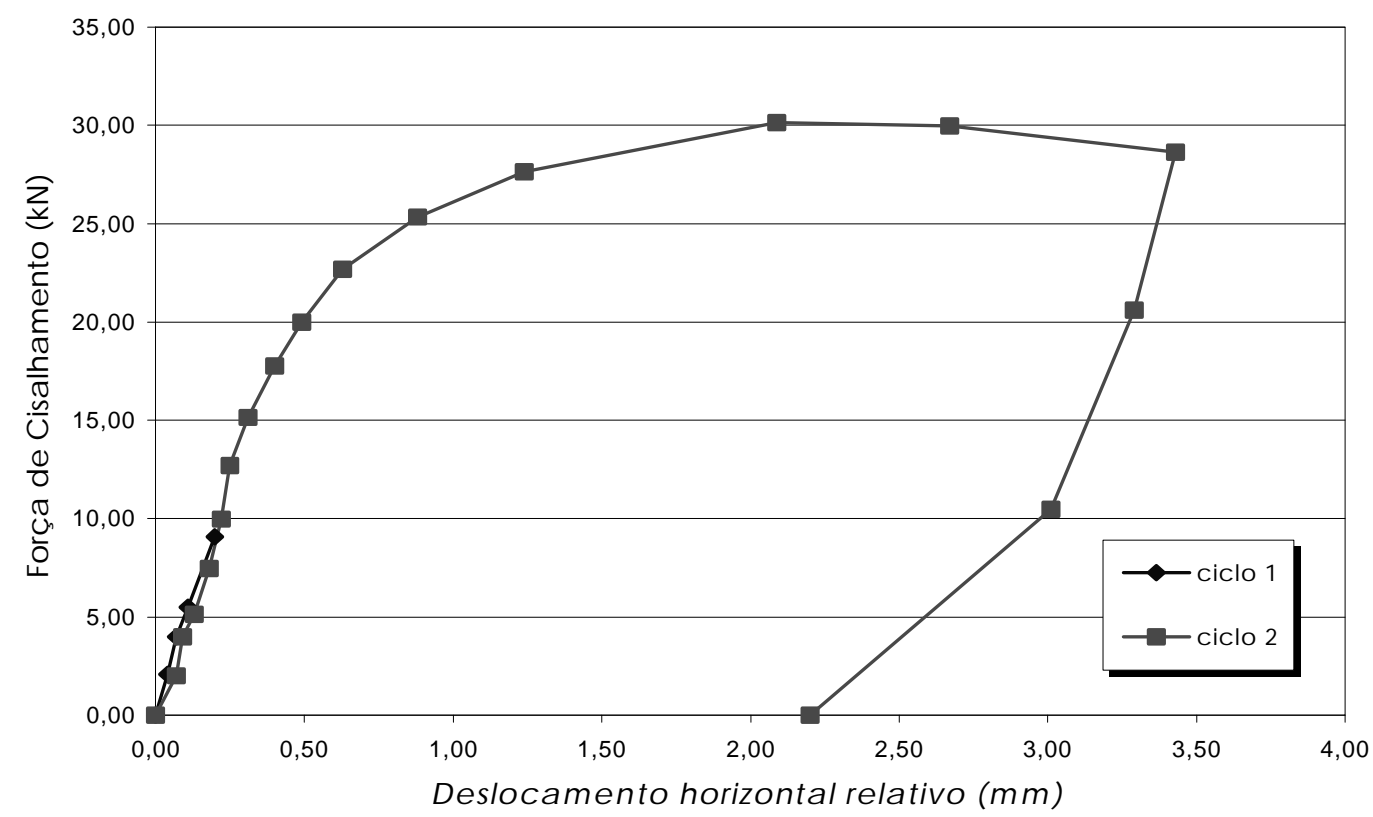

Gráfico 4.1 - Ensaio de cisalhamento - protótipo piloto (ciclos 1 e 2)

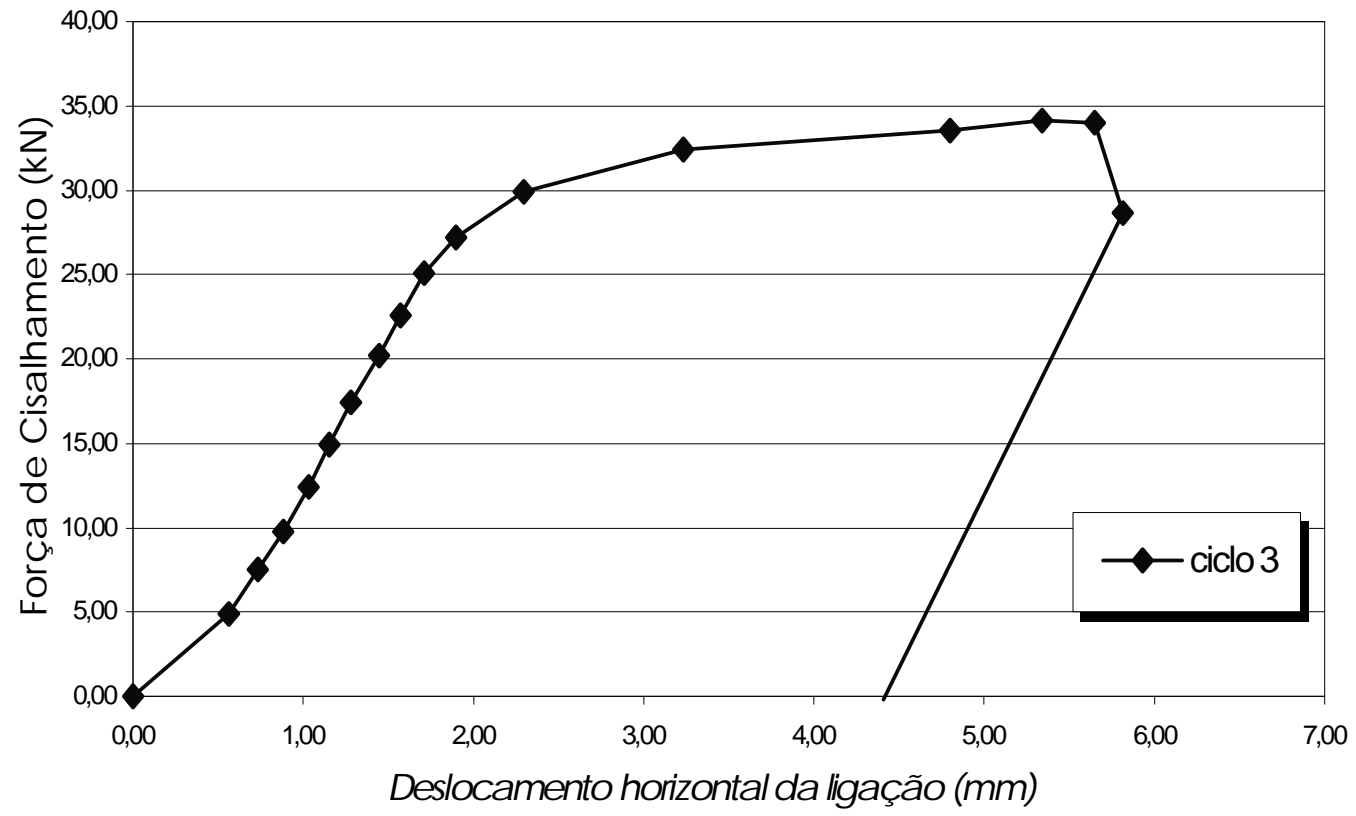

Gráfico 4.2 - Ensaio de cisalhamento - protótipo piloto (ciclo 3) 


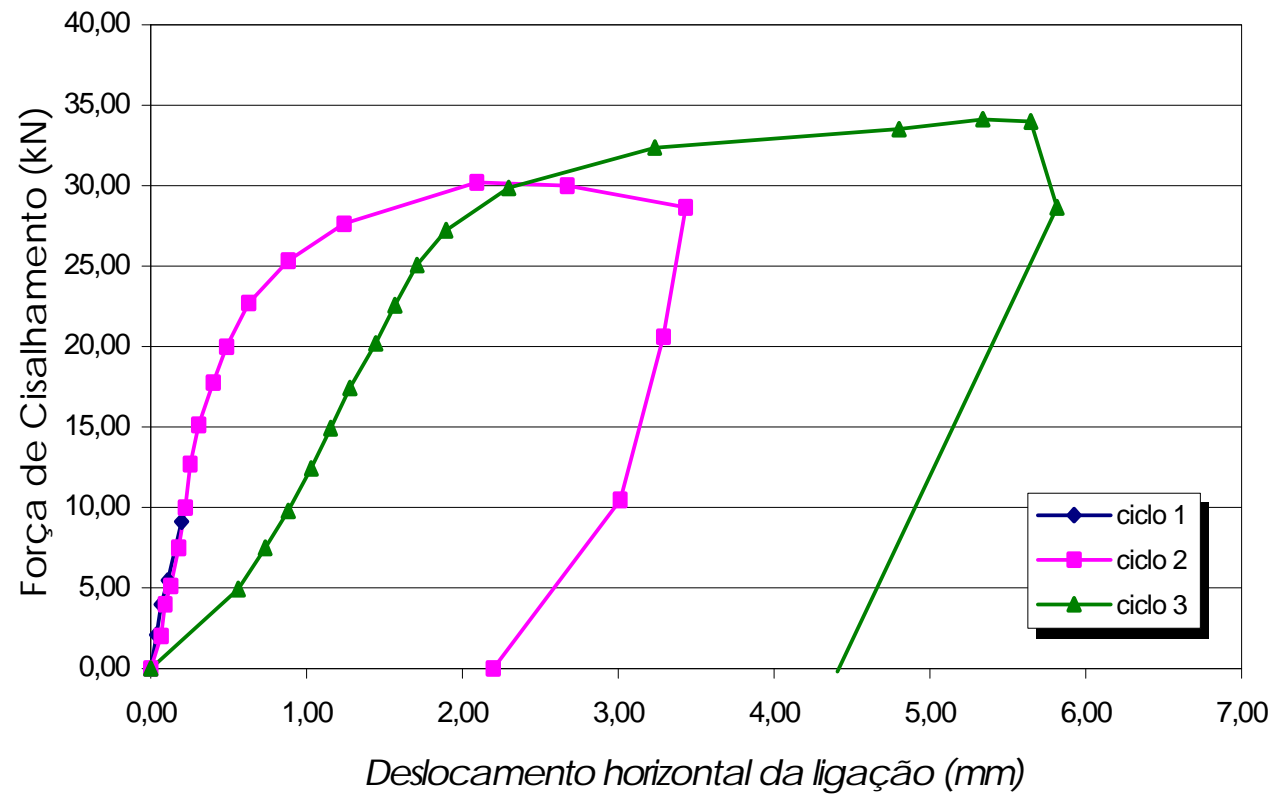

Gráfico 4.3 - Ciclos de Cisalhamento - Protótipo Piloto (partindo da origem)

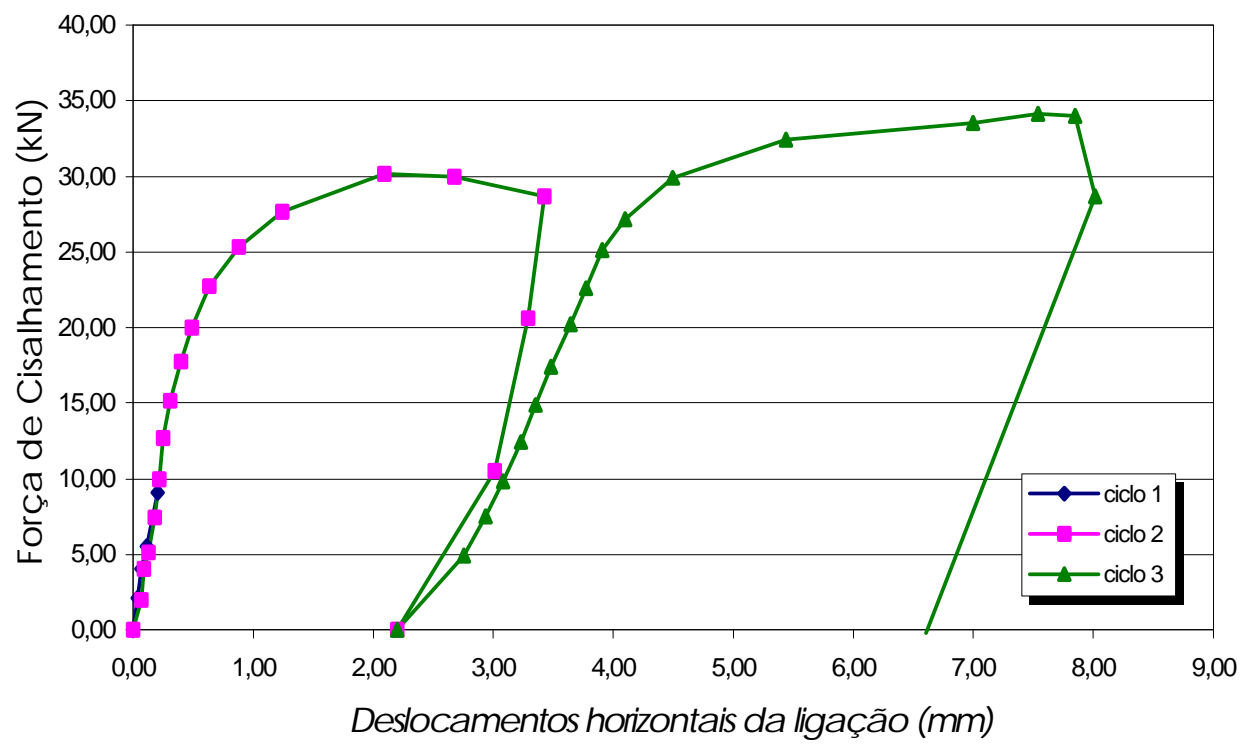

Gráfico 4.4 - Ciclos de Cisalhamento - Protótipo Piloto

(Considerando as deformações residuais) 
Tabela 4.8 - Inclinações nos trechos retos dos ciclos de carregamento no protótipo Piloto.

\begin{tabular}{|c|c|c|c|c|}
\hline $\begin{array}{c}\text { Ciclosde } \\
\text { carga }\end{array}$ & $\begin{array}{l}F_{V} \\
(k N)\end{array}$ & $\begin{array}{l}\text { Fatorde } \\
\text { Correlação }\end{array}$ & $\begin{array}{c}\text { Inc linação } \\
(\mathrm{kN} / \mathrm{mm})\end{array}$ & Observações: \\
\hline Ciclo 1 & $0-9,10$ & 0,955 & 45,8 & $\begin{array}{l}\text { A curva apresentou acomodações inicia is, } \\
\text { fazendo com que a correlação não fosse } \\
\text { muito alta. }\end{array}$ \\
\hline Ciclo 2 & $\begin{array}{c}0-9,90 \\
0-17,8 \\
17,8-22,5\end{array}$ & $\begin{array}{l}0,990 \\
0,991 \\
0,998\end{array}$ & $\begin{array}{l}45,4 \\
47,9 \\
21,3\end{array}$ & $\begin{array}{l}\checkmark \text { O comportamento na fase linear se ajustou } \\
\text { à do ciclo anterior. } \\
\checkmark \text { início do esc oamento da ligação se deu } \\
\text { para uma força da ordem de } 17,8 \mathrm{kN} \\
\checkmark \text { Apósa fase linear inicial, a ligação } \\
\text { a presentou um segundo trecho reto, } \\
\text { compreendido entre } 17,8 \text { à } 22,5 \mathrm{kN}, \text { com } \\
40 \% \text { da inclinação inicial }\end{array}$ \\
\hline Ciclo 3 & $4,9-25,0$ & 0,999 & 17,9 & $\begin{array}{l}\text { Após uma acomodação inicial da ligação, } \\
\text { para } \mathrm{Fv}<4,9 \mathrm{kN} \text {, a ligação a presentou } \\
\text { novamente um comportamento linear até } \\
\text { atingir } 25 \mathrm{kN} \text {. }\end{array}$ \\
\hline
\end{tabular}

Para a obtenção da força $F_{v y, m i n}$ (força de cisalhamento no início do escoamento da ligação) no Protótipo Piloto, tomou-se como base o trecho linear inicial com inclinação da reta tangente igual a 45,6 kN/mm, a qual representou a média das duas inclinações obtidas nos trechos iniciais dos ciclos 1 e 2, para $F_{V}<10 \mathrm{kN}$. Em seguida, fez-se a interseção desta reta com a curva experimental do ciclo 2, conforme indicado no gráfico 4.5, obtendo-se graficamente $\mathrm{F}_{\mathrm{vy}, \min }=17,8 \mathrm{kN}$. O valor da força $\mathrm{F}_{\mathrm{vy}}$ (força de cisalhamento máximo para o escoamento da ligação) foi obtido a partir do próximo ponto de inflexão na curva experimental, para $F_{V}>17,8 \mathrm{kN}$, que correspondeu a uma força da ordem de $\mathrm{F}_{\mathrm{vy}}=22,5 \mathrm{kN}$. O trecho reto compreendido entre $17,8<\mathrm{F}_{\mathrm{V}}<22,5 \mathrm{kN}$ possuiu uma inclinação de 21,3 kN/mm (correlação $=0,999$ ), correspondente a $40 \%$ da inclinação inicial.

No início do ciclo 3 , para $\mathrm{F}_{\mathrm{V}}<5 \mathrm{kN}$, a ligação apresentou um trecho com inclinação muito baixa, indicando a ocorrência de deformações residuais que foram produzidas no ciclo anterior. Ao se deformar, a barra do chumbador impõe deformações no concreto. Quando o chumbador deixa de ser solicitado, este tende a retornar à sua posição inicial, deixando vazios entre a barra e o concreto. Estes vazios, por sua vez, promovem uma acomodação da ligação no início de um novo carregamento, aumentando a 
deformabilidade inicial da ligação. Entretanto, após a acomodação inicial, a ligação voltou a apresentar um comportamento linear para o trecho compreendido entre 5 a $25 \mathrm{kN}$, tendose um limite de escoamento efetivo da ordem de $20 \mathrm{kN}$, para uma inclinação da ordem de $18 \mathrm{kN} / \mathrm{mm}$.

Observou-se que houve uma modificação no mecanismo de deformação da barra do chumbador do segundo para o terceiro ciclo, após os limites de escoamento da ligação terem sido ultrapassados no segundo ciclo. Todavia, com relação à resistência da ligação, no ciclo 3 a ligação atingiu uma resistência da ordem de $34,1 \mathrm{kN}$, superando os $30,1 \mathrm{kN}$ do ciclo anterior. Desta forma, pode-se verificar que apesar de a deformabilidade da ligação ter sido modificada, após ter sido atingido o limite de escoamento da ligação, a resistência da ligação foi mantida.

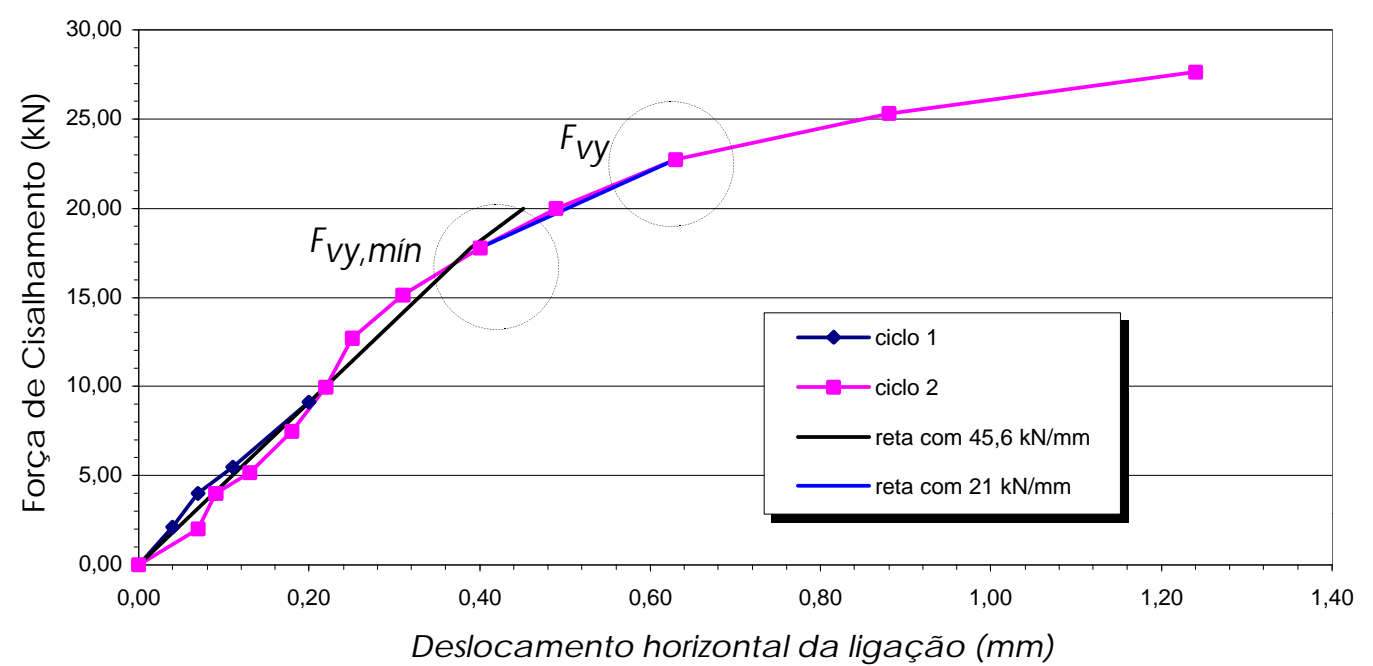

Gráfico 4.5 - Obtenção Gráfica de $F_{v y, \min }$ e $F_{v y}$ no Protótipo Piloto 


\subsection{Cisalhamento no Protótipo A}

Para o protótipo A foram aplicados 5 ciclos da força de cisalhamento. Na tabela 4.9 é apresentado um resumo das forças e deslocamentos para cada ciclo de cisalhamento.

Tabela 4.9 - Resumo dos ciclos de cisalhamento no Protótipo A

\begin{tabular}{|c|c|c|c|}
\hline $\begin{array}{l}\text { Ciclosde } \\
\text { carga }\end{array}$ & $\begin{array}{l}\mathrm{F}_{\mathrm{V}} \\
(\mathrm{kN})\end{array}$ & $\begin{array}{l}\Delta \text { hor } \\
(\mathrm{mm})\end{array}$ & Observações: \\
\hline Ciclo 1 & 20,59 & 0,29 & $\begin{array}{l}\checkmark \text { A força Fv atingiu cerca de } 30 \% \text { de } \mathrm{F}_{\mathrm{vu}} \text {, capacidade prevista } \\
\text { para a ligação. Regime elástico linear. }\end{array}$ \\
\hline $\begin{array}{c}\text { Ciclo } 2 \\
\text { Com Nomal } \\
\mathrm{N}=10 \mathrm{kN}\end{array}$ & 20,35 & 0,27 & $\begin{array}{l}\checkmark \text { A força Fv atingiu cerca de } 30 \% \text { de } \mathrm{F}_{\mathrm{vu}} \text {. Regime elástico linear. } \\
\checkmark \text { Com a presença da força nomal, } \mathrm{N}=10 \mathrm{kN} \text {, não houve } \\
\text { alterações significativas no comportamento da ligação. }\end{array}$ \\
\hline $\begin{array}{l}\text { Ciclo } 3 \\
\text { Com Nomal } \\
\mathrm{N}=30 \mathrm{kN}\end{array}$ & 20,70 & 0,27 & $\begin{array}{l}\checkmark \text { A força Fv atingiu cerca de } 30 \% \text { de } \mathrm{F}_{\mathrm{vu}} \text {. Regime elástico linear. } \\
\checkmark \text { Com a presença da força nomal, } \mathrm{N}=30 \mathrm{kN} \text {, não houve } \\
\text { alterações significativas no comportamento da ligação }\end{array}$ \\
\hline Ciclo 4 & $\begin{array}{l}20,5 \\
30,5 \\
40,0 \\
31,8 \\
\\
20,7 \\
40,0 \\
48,7\end{array}$ & $\begin{array}{l}0,40 \\
0,70 \\
1,15 \\
1,92 \\
\\
1,05 \\
1,56 \\
4,20\end{array}$ & $\begin{array}{l}\checkmark \text { A ligação apresentou um a créscimo na sua deformabilidade } \\
\text { já na fase inicial, para } F_{v}<20,47 \mathrm{kN} \text {. } \\
\checkmark \quad \text { No ponto de } F_{v u}=40 \mathrm{kN} \text {, ocorreu uma falha no tirante de } \\
\text { fixação do bloco suporte, permitindo-o girar, produzindo um } \\
\text { salto ainda maiorna deformabilidade da ligação. } \\
\checkmark \quad \text { Após ajustes de trava mento no sistema de fixação do bloco } \\
\text { suporte, o ciclo } 4 \text { foi reiniciado (ciclo } 4 \mathrm{~B} \text { ), ating indo } 48 \mathrm{kN}, \\
\text { quando a ligação a presentou } \Delta_{\mathrm{hor}}>4 \mathrm{~mm} \text {. }\end{array}$ \\
\hline Ciclo 5 & $\begin{array}{c}19,80 \\
39,58 \\
56,50 \\
59,0 \\
60,0 \\
60,0 \\
50,0\end{array}$ & $\begin{array}{c}1,41 \\
2,4 \\
\\
5,4 \\
7,5 \\
10,5 \\
20,0 \\
25,0\end{array}$ & $\begin{array}{l}\checkmark \text { Após novos ajustes no sistema de fixação do bloco suporte, o } \\
\text { ciclo } 5 \text { foi iniciado. } \\
\checkmark \quad \text { A ligação foi carregada a té a sua máxima resistência, a qual } \\
\text { foi mantida, fazendo com que a liga ção plastificasse, } \\
\text { atingindo grandes deforma ções. } \\
\checkmark \quad \text { Na marca de } \Delta_{\text {hor }}=20 \mathrm{~mm} \text {, ocorreu um salto brusco para } \\
\Delta_{\text {hor }}=25 \mathrm{~mm} \text {, ocorrendo ao mesmo tempo um levantamento } \\
\text { vertical de } 5 \mathrm{~mm} \text { na interface da ligação. }\end{array}$ \\
\hline
\end{tabular}

Nos três primeiros ciclos, a ligação foi solicitada por uma força de cisalhamento da ordem de $20 \mathrm{kN}$, que correspondeu a cerca de $30 \%$ da $\mathrm{F}_{\mathrm{vu}}$ estimada. Nos ciclos 2 e 3, além da força de cisalhamento, foram aplicadas na ligação forças normais de $10 \mathrm{kN}$ e 30 $\mathrm{kN}$, respectivamente.

A aplicação da força normal em conjunto com a força de cisalhamento foi feita, inicialmente, para evitar que houvessem espaços vazios na interface entre os elementos de concreto e o aparelho de apoio, promovendo uma maior distribuição das tensões na superfície do apoio. Num segundo momento, houve a intenção de observar se a presença da força normal ocasionaria alguma perturbação expressiva na deformabilidade da ligação. 
$\mathrm{Na}$ tabela 4.10 são apresentadas as inclinações dos trechos retos das curvas força de cisalhamento vs. deslocamento horizontal da ligação para cada ciclo de carregamento. Com relação às inclinações nos trechos iniciais de cada ciclo, as quais estão associadas às deformabilidades ao cisalhamento, observou-se valores muito próximos para os três primeiros ciclos, sendo $69 \mathrm{kN} / \mathrm{mm}$ para o ciclo $1,72 \mathrm{kN} / \mathrm{mm}$ para o ciclo 2 e $70 \mathrm{kN} / \mathrm{mm}$ para o ciclo 3. Desta forma, pode-se verificar que, para os casos observados, a presença da força normal na ligação não afetou a deformabilidade inicial ao cisalhamento da ligação.

Tabela 4.10 - Inclinações nos trechos retos dos ciclos de carregamento no Protótipo A.

\begin{tabular}{|c|c|c|c|c|}
\hline $\begin{array}{c}\text { Ciclos de } \\
\text { carga }\end{array}$ & $\begin{array}{c}F_{V} \\
(k N)\end{array}$ & $\begin{array}{c}\text { Fator de } \\
\text { Correlação }\end{array}$ & $\begin{array}{c}\text { Inclinação } \\
(\mathrm{kN} / \mathrm{mm})\end{array}$ & Observações: \\
\hline Ciclo 1 & $0-20,6$ & 0,965 & 69,0 & $\begin{array}{l}\text { A ligação a presentou acomodações } \\
\text { iniciais, fazendo com que o fator de } \\
\text { correlação não fosse muito alto. } \\
\text { Acredita-se que isto tenha ocorrido } \\
\text { por deficiência no contato entre as } \\
\text { superfícies no apoio. }\end{array}$ \\
\hline $\begin{array}{c}\text { Ciclo } 2 \\
\text { Com Nomal } \\
\mathrm{N}=10 \mathrm{kN} \\
\end{array}$ & $0-20,4$ & 0,997 & 72,0 & $\begin{array}{l}\text { O trecho reto inicial apresentou uma } \\
\text { inclinação semelhante à obtida no } \\
\text { ciclo } 1 .\end{array}$ \\
\hline $\begin{array}{c}\text { Ciclo } 3 \\
\text { Com Nomal } \\
\mathrm{N}=30 \mathrm{kN}\end{array}$ & $0-20,7$ & 0,992 & 70,0 & $\begin{array}{l}\text { O trecho reto inicial apresentou uma } \\
\text { inclinação semelhante às obtidas nos } \\
\text { ciclos } 1 \text { e } 2 \text {. }\end{array}$ \\
\hline Ciclo 4 & $\begin{array}{c}0-20,5 \\
0-30,5 \\
30,5-40,0 \\
0-20,7 \\
0-40,0 \\
\end{array}$ & $\begin{array}{l}0,992 \\
0,987 \\
0,997 \\
\\
(1,0) \\
0,997\end{array}$ & $\begin{array}{l}51,2 \\
47,0 \\
21,0 \\
21,0 \\
26,0\end{array}$ & $\begin{array}{l}\text { Deformabilidade acrescida em } 37 \% \\
\text { com relação aos cic los anteriores } \\
\text { para Fv <20 kN. } \\
\text { A ligação começou escoar para Fv = } \\
30,5 \mathrm{kN} \text {. }\end{array}$ \\
\hline Ciclo 5 & $\begin{array}{c}0-19,80 \\
0-39,60 \\
39,6-50,8\end{array}$ & $\begin{array}{l}0,992 \\
0,992 \\
0,995\end{array}$ & $\begin{array}{c}14,1 \\
16,4 \\
10,32\end{array}$ & $\begin{array}{l}\text { A ligação iniciou o cic lo } 5 \text { já com } \\
\text { uma deformabilidade alta, mas } \\
\text { apresentando um comporta mento } \\
\text { linear para } \mathrm{Fv}<39,6 \mathrm{kN}\end{array}$ \\
\hline
\end{tabular}

As curvas força de cisalhamento vs. deslocamento horizontal da ligação, para os 5 ciclos de carregamento, encontram-se registradas nos gráficos 4.6 ao 4.10, respectivamente. No gráfico 4.11 são apresentados de forma simultânea os 3 primeiros ciclos. No gráfico 4.12 estão apresentados de forma simultânea os 5 ciclos de cisalhamento. 


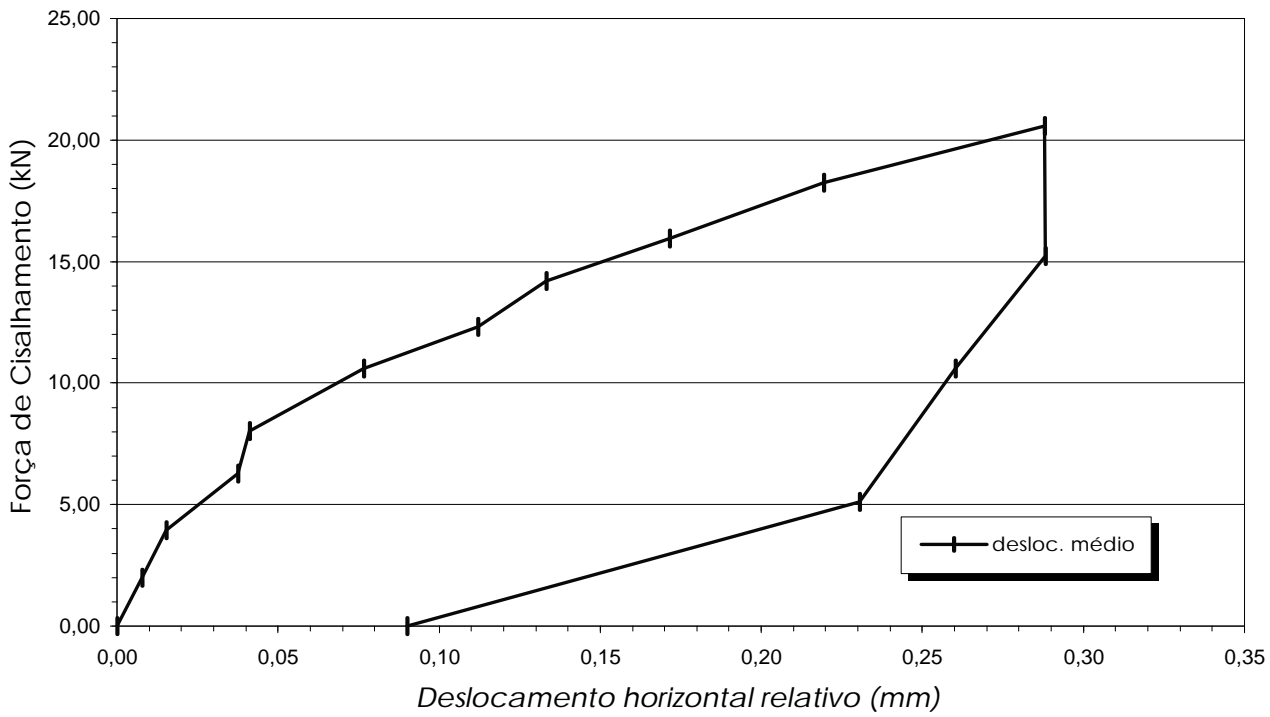

Gráfico 4.6 - Ensaio de Cisalhamento - Protótipo A (Ciclo 1)

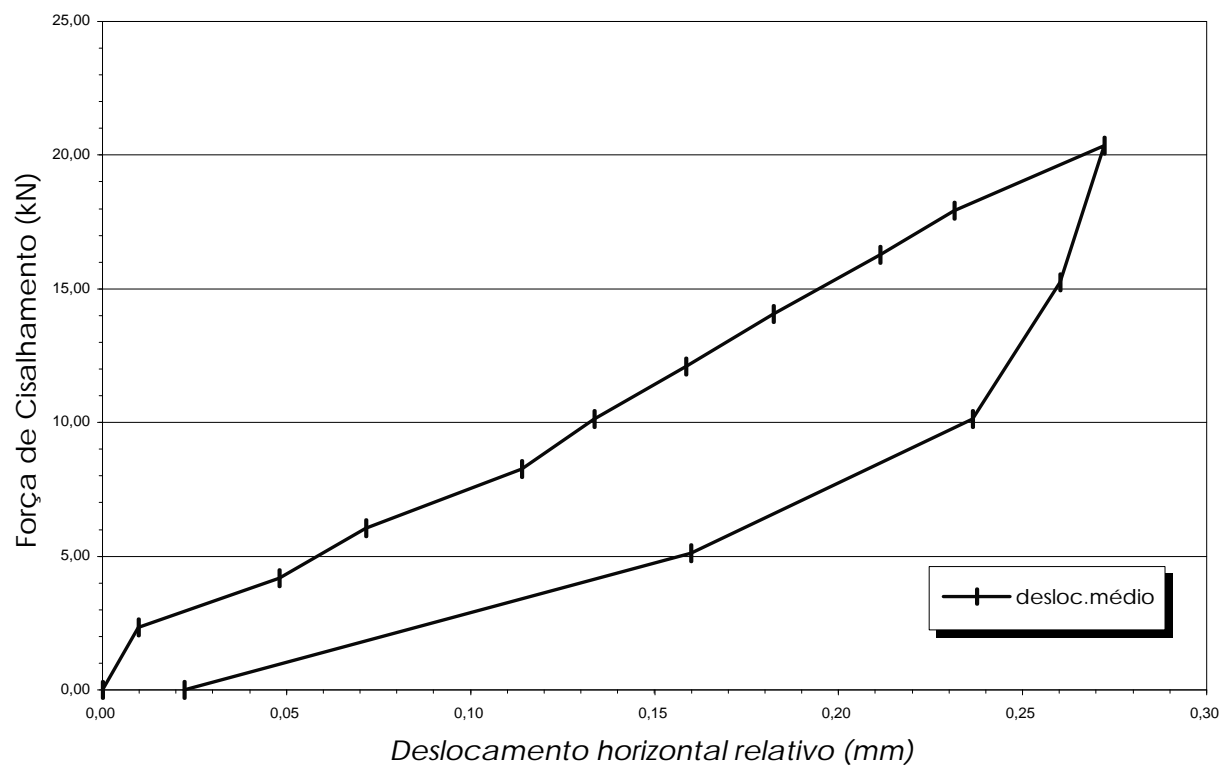

Gráfico 4.7 - Ensaio de Cisalhamento - Protótipo A

(Ciclo 2; $\operatorname{com} N=10 \mathrm{kN}$ ) 


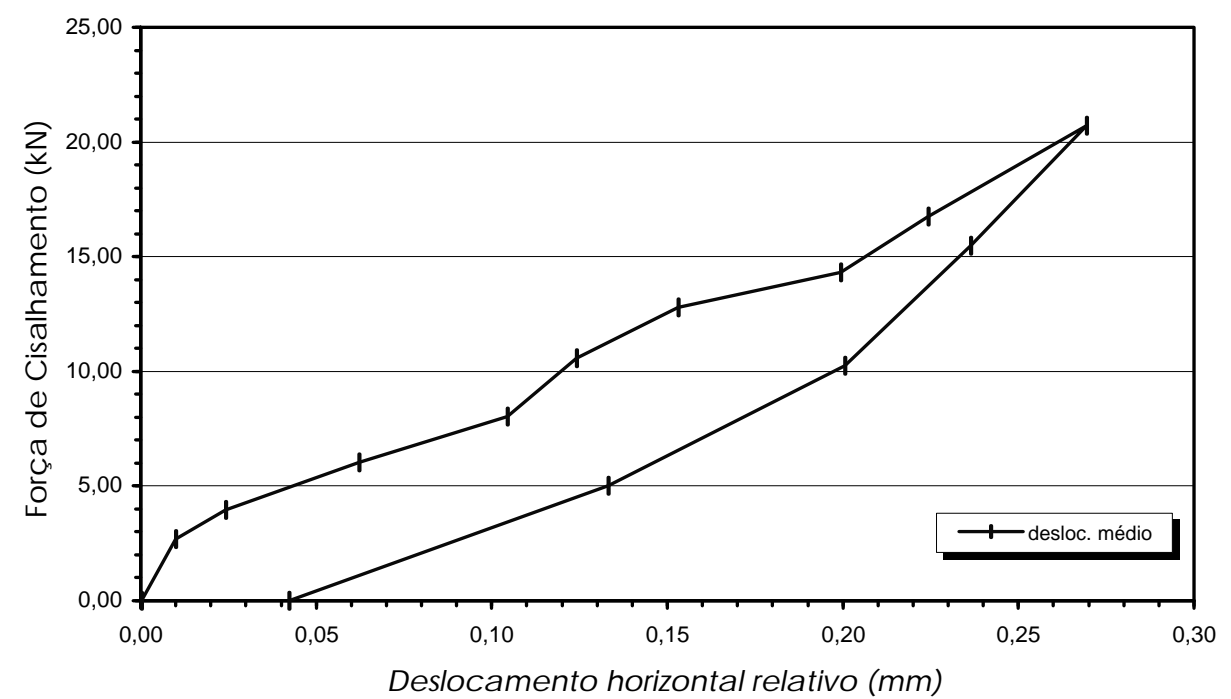

Gráfico 4.8 - Ensaio de Cisalhamento - Protótipo A

(Ciclo 3; $\operatorname{com} N=30 \mathrm{kN}$ )

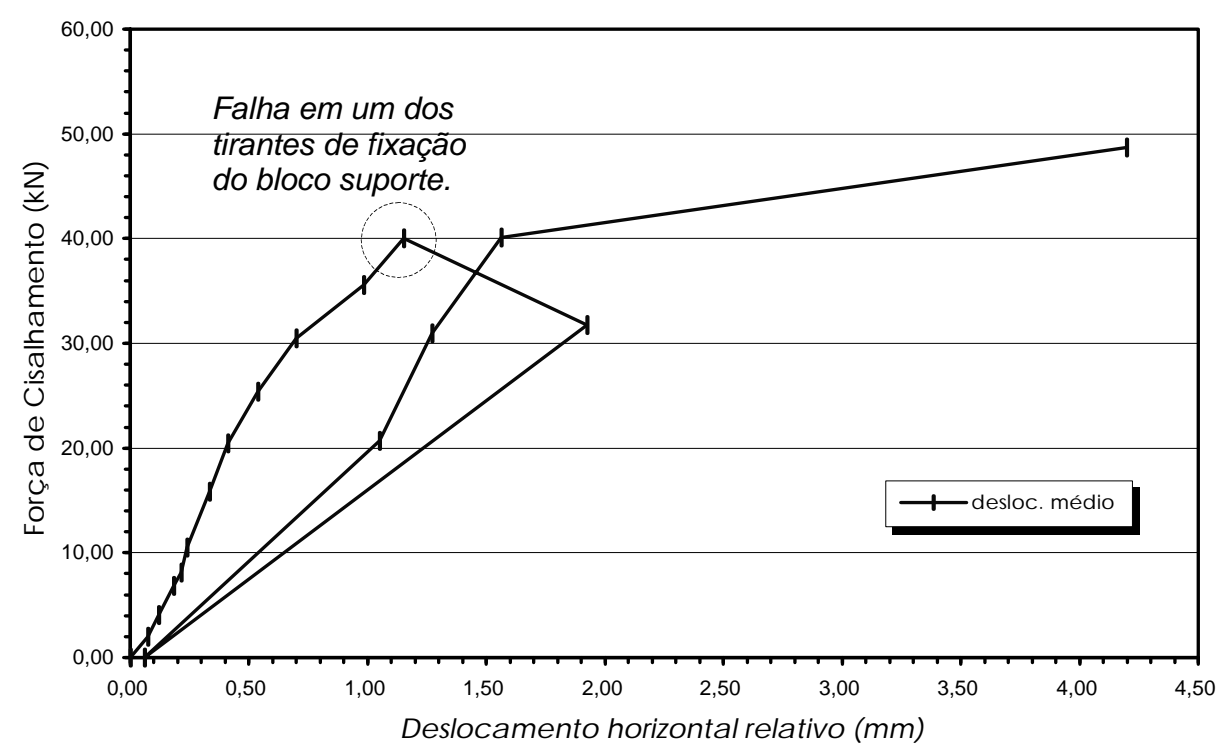

Gráfico 4.9 - Ensaio de Cisalhamento - Protótipo A - (Ciclo 4) 


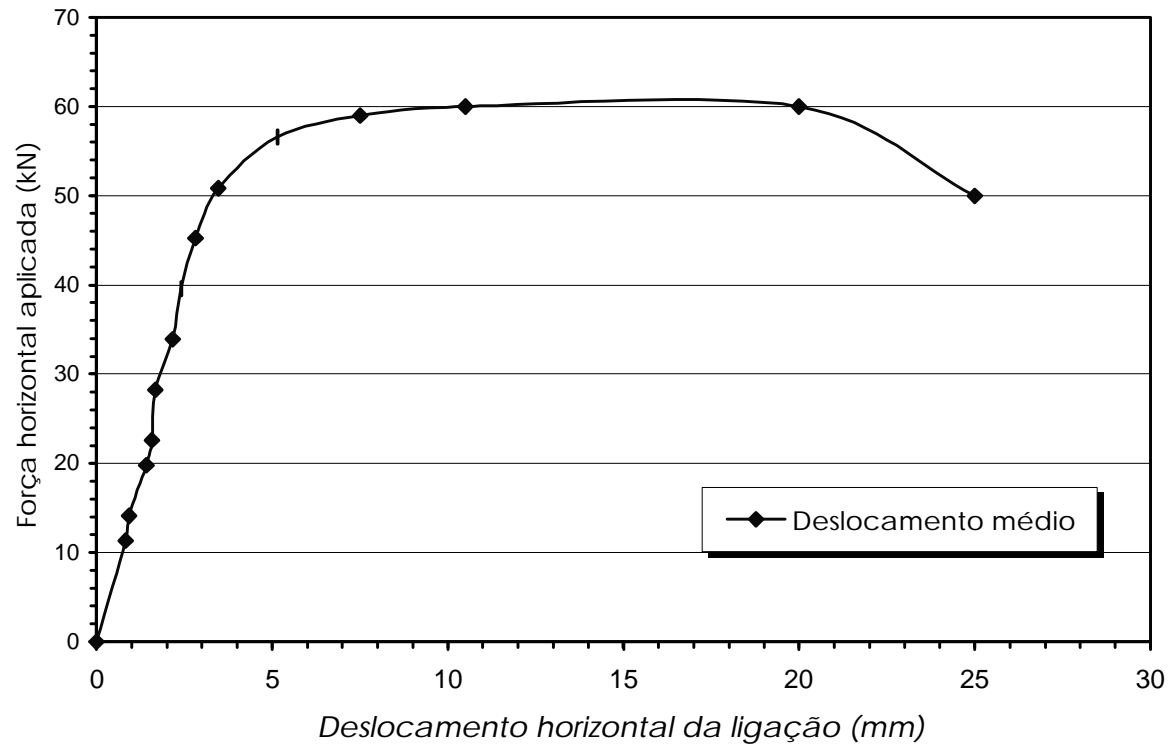

Gráfico 4.10 - Ensaio de Cisalhamento - Protótipo A - (Etapa 5)

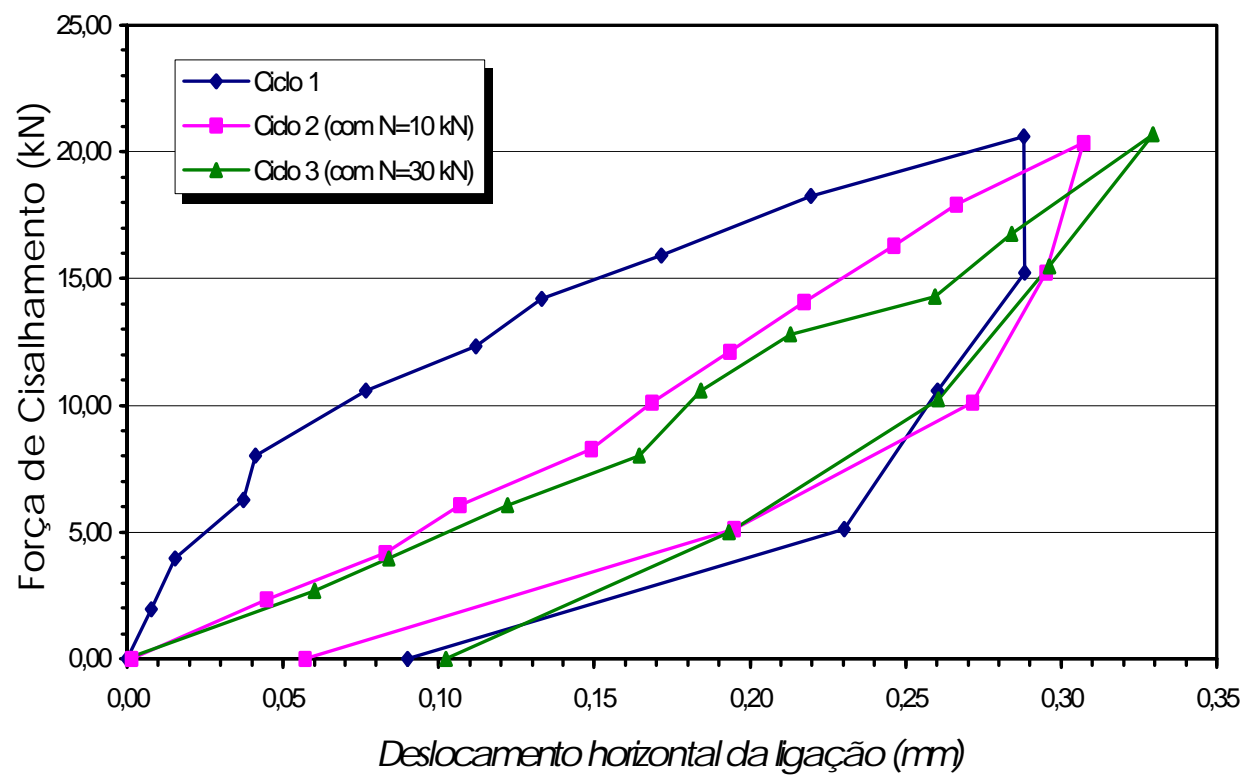

Gráfico 4.11 - Ensaio de Cisalhamento - Protótipo A (Avaliação da interferência da força normal) 


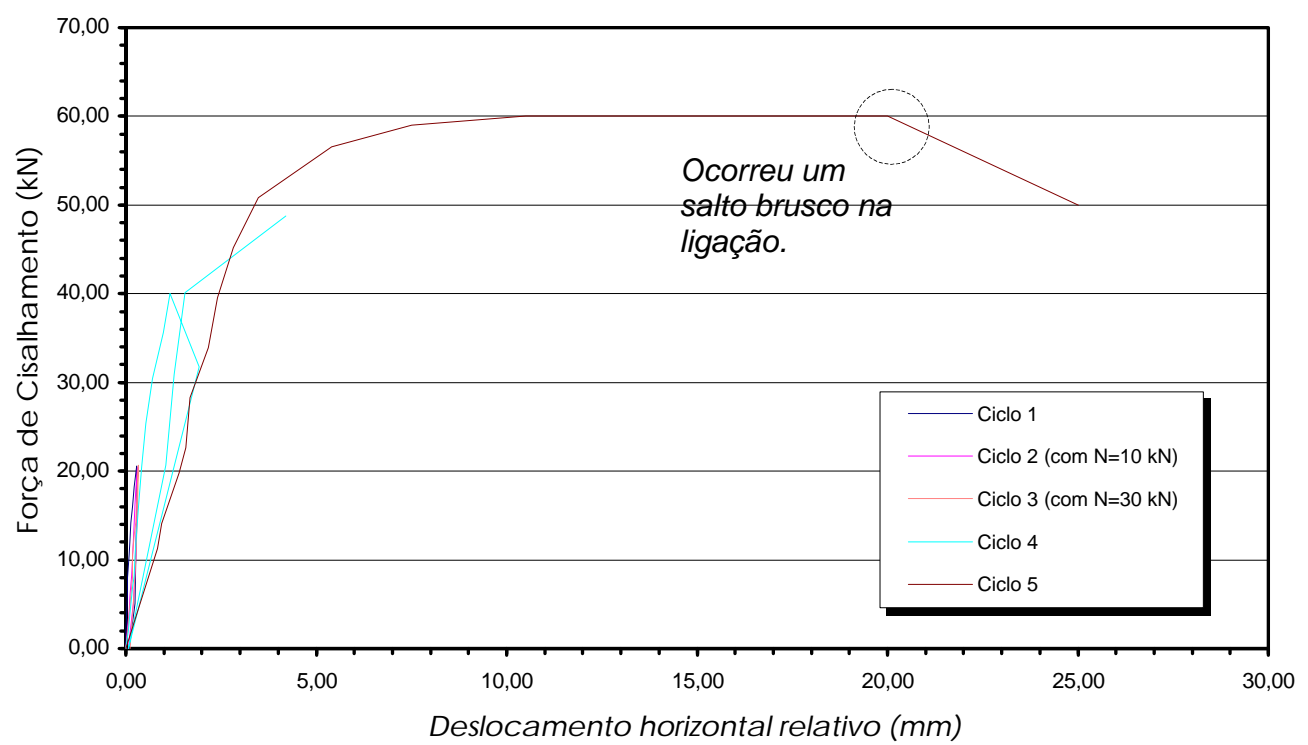

Gráfico 4.12 - Ciclos da Força de Cisalhamento no Protótipo A

Nas tabelas 4.11 e 4.12 são apresentados os valores das forças e das tensões normais de compressão nas barras de chumbador para as forças normais na ligação de 10 $\mathrm{kN}$ e $30 \mathrm{kN}$. $\mathrm{O}$ valores nas barras 1 e 2 foram medidos nos pontos da barra próximos à interface da ligação, dentro dos elementos do bloco suporte e da viga, os quais foram instrumentados com extensômetros elétricos conforme indicados na figura (4.28).

Tabela 4.11 - Força de Compressão nos chumbadores, próximo à interface da ligação.

\begin{tabular}{|c|cc|cc|c|c|}
\hline $\begin{array}{c}\mathrm{N} \\
(\mathrm{kN})\end{array}$ & $\begin{array}{c}\text { Barra 1: } \\
\text { Pontos } \\
(5 \mathrm{e}) \\
(\mathrm{kN})\end{array}$ & $\begin{array}{c}\text { Barra 1: } \\
\text { Pontos } \\
(13 \text { e 14) } \\
(\mathrm{kN})\end{array}$ & $\begin{array}{c}\text { Barra 2: } \\
\text { Pontos } \\
(11 \text { e 12) } \\
(\mathrm{kN})\end{array}$ & $\begin{array}{c}\text { Barra 2: } \\
\text { Pontos } \\
(19 \text { e 20) } \\
(\mathrm{kN})\end{array}$ & $\begin{array}{c}1+2 \\
\text { Barras dentro } \\
\text { do bloco } \\
(\mathrm{kN})\end{array}$ & $\begin{array}{c}1+2 \\
\text { Ba mas dentro } \\
\text { da viga } \\
(\mathrm{kN})\end{array}$ \\
\hline 10 & 1,8 & 2,4 & 6,2 & 7,6 & 8,0 & 10,0 \\
\hline 30 & 7,1 & 8,3 & 18,6 & 20,2 & 25,7 & 28,5 \\
\hline
\end{tabular}

Tabela 4.12 - Tensões normais nos chumbadores, próximo à interface da ligação

\begin{tabular}{|c|c|c|c|c|}
\hline $\begin{array}{c}\mathrm{N} \\
(\mathrm{KN})\end{array}$ & $\begin{array}{c}\text { Barra 1: } \\
(\text { Pontos 5 e 6) } \\
(\mathrm{MPa})\end{array}$ & $\begin{array}{c}\text { Barra 1: } \\
\left(\begin{array}{c}\text { Pontos 13 e 14) } \\
(\mathrm{MPa})\end{array}\right.\end{array}$ & $\begin{array}{c}\text { Barra 2: } \\
(\text { Pontos 11 e 12) } \\
(\mathrm{MPa})\end{array}$ & $\begin{array}{c}\text { Ba ra 2: } \\
(\text { Pontos 19 e 20) } \\
(\mathrm{MPa})\end{array}$ \\
\hline 10 & 9 & 12 & 31 & 38 \\
\hline 30 & 35 & 42 & 92 & 100 \\
\hline
\end{tabular}


Acredita-se que o aumento da deformabilidade no início do ciclo 4, com a inclinação da curva diminuindo para $51 \mathrm{kN} / \mathrm{mm}$, tenha ocorrido em decorrência de alguma falha no reajuste do sistema de travamento do bloco suporte (para eliminar as folgas residuais deixadas após o ciclo 3), liberando assim o bloco suporte para deslocamentos de rotação que, embora sejam relativamente pequenos, provocaram acréscimos na flexão localizada nas barras do chumbador, aumentando assim a deformabilidade da ligação.

A partir do monitoramento por extensômetros nas barras dos chumbadores, nos pontos $5,6,11$ e 12 conforme indicados na figura 4.29, estando estes posicionados próximo à interface da ligação, sabe-se que as barras atingiram a tensão de escoamento no ciclo 4 para uma força de cisalhamento da ordem de $\mathrm{Fv}=30,5 \mathrm{kN}$.

Durante o ciclo 4, ocorreu uma falha inesperada em um dos tirantes verticais de fixação que prendiam o bloco suporte. Isto se deu quando a ligação estava sendo solicitada por uma força de $40 \mathrm{kN}$. A ruptura aconteceu pela falta de rosqueamento da barra dentro de uma luva de prolongamento, estando essa barra presa apenas por uma porca que estava soldada na extremidade da luva. Desta forma, houve uma ruptura frágil na solda que prendia a porca à luva. Com o rompimento desse tirante, o bloco suporte foi liberado ao giro, aumentando a deformabilidade da ligação repentinamente. O ensaio foi interrompido, o tirante foi rosqueado novamente dentro da luva, procedeu-se um novo ajuste de todo o sistema de tirantes, e o ciclo 4 foi então repetido como ciclo 4B.

No ciclo 5, a ligação teve um acréscimo na sua deformabilidade inicial. Todavia, ainda foi observado um trecho linear, com inclinação média da ordem de $15 \mathrm{kN} / \mathrm{mm}$, até a altura de 39,6 kN. A ligação atingiu uma capacidade ao cisalhamento da ordem de $60 \mathrm{kN}$, a qual foi associada a um deslocamento horizontal na ligação da ordem de $10 \mathrm{~mm}$. Esta força foi mantida até que a ligação atingisse um deslocamento horizontal da ordem de 20 mm. Neste ponto, a ligação apresentou um salto brusco, onde foram ouvidos estalos internos ao elemento de viga. A configuração final da ligação foi caracterizada por um deslocamento horizontal final da ordem de $25 \mathrm{~mm}$ e por um deslocamento vertical (para cima) da ordem de $5 \mathrm{~mm}$. Não foram observadas fissuras nas superfícies do elemento de viga, nem no elemento do bloco suporte. Todavia, os chumbadores assumiram deformações plásticas internamente aos elementos do bloco e da viga. 


\subsection{Cisalhamento no Protótipo B}

Para o protótipo B, foram utilizados dois chumbadores de $25 \mathrm{~mm}$ de diâmetro e uma almofada de elastômero não fretado com dimensões 250x300x10 mm³ . Com estes novos parâmetros, buscou-se estudar o comportamento de uma barra "rígida" inserida em elementos de concreto e, também, estudar a interferência da largura da almofada no comportamento da ligação.

Foram aplicados 3 ciclos de carregamento para a força de cisalhamento sobre a ligação. Na tabela 4.13 é apresentado um resumo com os ciclos de carregamento no Protótipo B. No Ciclo 1 a ligação atingiu uma força de cisalhamento de $70 \mathrm{kN}$, equivalente a $40 \%$ da força última. No Ciclo 2, atingiu uma força de $167 \mathrm{kN}$ e, no Ciclo 3, atingiu uma força de $170 \mathrm{kN}$. As curvas força de cisalhamento vs. deslocamentos horizontais na ligação para os 3 ciclos estão apresentadas nos gráficos 4.13 à 4.15, respectivamente, estando também apresentados de forma simultânea no gráfico 4.16.

Tabela 4.13 - Resumo dos ciclos de carregamento de cisalhamento no Protótipo B

\begin{tabular}{|c|c|c|c|}
\hline $\begin{array}{l}\text { Ciclosde } \\
\text { carga }\end{array}$ & $\begin{array}{l}\mathrm{F}_{\mathrm{V}} \\
(\mathrm{kN})\end{array}$ & $\begin{array}{l}\Delta \text { hor } \\
\text { (mm) }\end{array}$ & Observações: \\
\hline Ciclo 1 & $\begin{array}{c}70,1 \\
0,0\end{array}$ & $\begin{array}{l}0,30 \\
0,01\end{array}$ & $\begin{array}{l}\checkmark \text { O efeito do giro relativo na ligação fez com aumentasse o } \\
\text { flexão loca lizada no chumbador, fazend o com que o mesmo } \\
\text { começasse a escoar para } F_{V}=15 \mathrm{kN} \text {. }\end{array}$ \\
\hline Ciclo 2 & $\begin{array}{c}70,7 \\
101,4 \\
139,7 \\
167,7 \\
0,0\end{array}$ & $\begin{array}{l}0,24 \\
0,39 \\
0,73 \\
2,10 \\
0,44\end{array}$ & $\begin{array}{l}\checkmark \text { Como o efeito do giro relativo minimizado, a barra do } \\
\text { chumbador começou a escoarpara } F_{v}=60 \mathrm{kN} \text {. }\end{array}$ \\
\hline Ciclo 3 & $\begin{array}{c}30,0 \\
131,0 \\
170,7 \\
170,1 \\
121,4 \\
0,0\end{array}$ & $\begin{array}{l}1,04 \\
2,49 \\
4,73 \\
5,14 \\
5,28 \\
2,02\end{array}$ & $\begin{array}{l}\checkmark \text { Apósuma acomodação inicial da ligação, para } F_{V}=30 \text { kN, a } \\
\text { ligação a presentou um comporta mento linear a té a ting ir } 130 \\
\text { kN. }\end{array}$ \\
\hline
\end{tabular}

Em razão do aumento do diâmetro dos chumbadores, diminuindo assim a deformabilidade da ligação, tomou-se um cuidado especial com relação às acomodações iniciais e aos giros relativos iniciais do bloco suporte e da ligação. Para tal, procederam-se dois escorvamentos da ligação até que se conseguiu ajustar convenientemente o sistema de travamento do bloco suporte. 
Entretanto, apesar deste cuidado, no Ciclo 1, para o intervalo da força de cisalhamento $\mathrm{F}_{\mathrm{V}}<70 \mathrm{kN}$, o elemento do bloco suporte atingiu uma rotação da ordem de 0,0025 rad (anti-horário), fazendo com que houvesse uma rotação relativa entre o elemento de viga e o elemento de bloco da ordem de 0,001 rad (horário). A partir deste giro relativo, teve-se um aumento significativo da flexão localizada na barra do chumbador, fazendo com que a mesma começasse a escoar, na fibra mais tracionada da seção de máximo momento na barra, para uma força da ordem de $\mathrm{F}_{\mathrm{v}}=15 \mathrm{kN}$. Por outro lado, no Ciclo 2, para o mesmo intervalo $\mathrm{F}_{\mathrm{V}}<70 \mathrm{kN}$, quando a rotação do bloco suporte foi minimizada para 0,0002 rad (anti-horário), fazendo com que a rotação relativa do elemento de viga em relação ao bloco fosse da ordem de 0,0013 rad (anti-horário), teve-se um efeito compensador da flexão localizada na barra do chumbador. Desta forma, a mesma barra do chumbador atingiu o escoamento para uma força $\mathrm{F}_{\mathrm{v}}=60 \mathrm{kN}$.

Nos gráficos 4.17 a 4.19 são apresentadas as deformações normais na seção de máxima flexão do chumbador para os ciclos 2,1 e 3, respectivamente.

Tabela 4.14 - Inclinações nos trechos retos dos ciclos de carregamento no Protótipo B.

\begin{tabular}{|c|c|c|c|c|}
\hline $\begin{array}{c}\text { Ciclosde } \\
\text { carga }\end{array}$ & $\begin{array}{c}\mathrm{F}_{\mathrm{V}} \\
(\mathrm{kN})\end{array}$ & $\begin{array}{c}\text { Fatorde } \\
\text { Correlação }\end{array}$ & $\begin{array}{c}\text { Inc linação } \\
\text { (kN/mm) }\end{array}$ & Observações: \\
\hline Ciclo 1 & 70,1 & 0,94 & 233,0 & $\begin{array}{l}\text { Devido ao efeito do giro relativo na ligação } \\
\text { sobre a flexão localiza da na barra do } \\
\text { chumbador, teve-se um aumentando da } \\
\text { deformabilidade da ligação. }\end{array}$ \\
\hline Ciclo 2 & $\begin{array}{c}70,7 \\
101,4 \\
101,4-139 \\
139-167,7\end{array}$ & $\begin{array}{c}0,994 \\
0,997 \\
0,98 \\
0,95\end{array}$ & $\begin{array}{c}271,7 \\
257,5 \\
112,7 \\
19,3\end{array}$ & $\begin{array}{l}\text { Minimizando-se o giro relativo na liga ção, } \\
\text { diminuiu-se a flexão localizada na barra do } \\
\text { chumbador, diminuindo a deformabilidade } \\
\text { da ligação. }\end{array}$ \\
\hline Ciclo 3 & $\begin{array}{c}0-30 \\
30-131 \\
131-170\end{array}$ & $\begin{array}{l}0,988 \\
0,999 \\
0,975\end{array}$ & $\begin{array}{l}29,0 \\
74,3 \\
16,7\end{array}$ & $\begin{array}{l}\text { Apóso escoamento da ligação ter sido } \\
\text { atingido no Ciclo 2, houve um sensível } \\
\text { aumento da deformabilidade da ligação. }\end{array}$ \\
\hline
\end{tabular}

Na tabela 4.14 são apresentadas as inclinações nos trechos retos das curvas experimentais de cada ciclo de carregamento, com os respectivos coeficientes de correlação. A partir desta tabela, pode observar-se que a inclinação do trecho reto inicial do Ciclo 1 foi inferior à do Ciclo 2. Portanto, a deformabilidade ao cisalhamento da 
ligação no Ciclo 1 foi inferior que à apresentada no Ciclo 2. A explicação para isto pode estar relacionada com o efeito do giro relativo da ligação sobre o mecanismo de deformação da barra do chumbador, tenha sido maior no Ciclo 1 do que no Ciclo 2, fazendo com que a deformabilidade da ligação fosse maior no Ciclo 1.

O escoamento da barra do chumbador não coincide com o escoamento da ligação. Isto se dá em razão de que o escoamento da ligação está relacionado à formação do mecanismo de rótula plástica na seção de máxima flexão na barra do chumbador, que corresponde a um valor bem acima do início do escoamento na barra.

Através destes ensaios, pode-se também observar que o que altera o mecanismo de deformação na ligação, de um ciclo anterior para um ciclo seguinte, não é quando o escoamento da barra do chumbador é atingido, mas sim quando o escoamento da ligação, caracterizado pela formação do mecanismo de rótula plástica na barra do chumbador, é atingido.

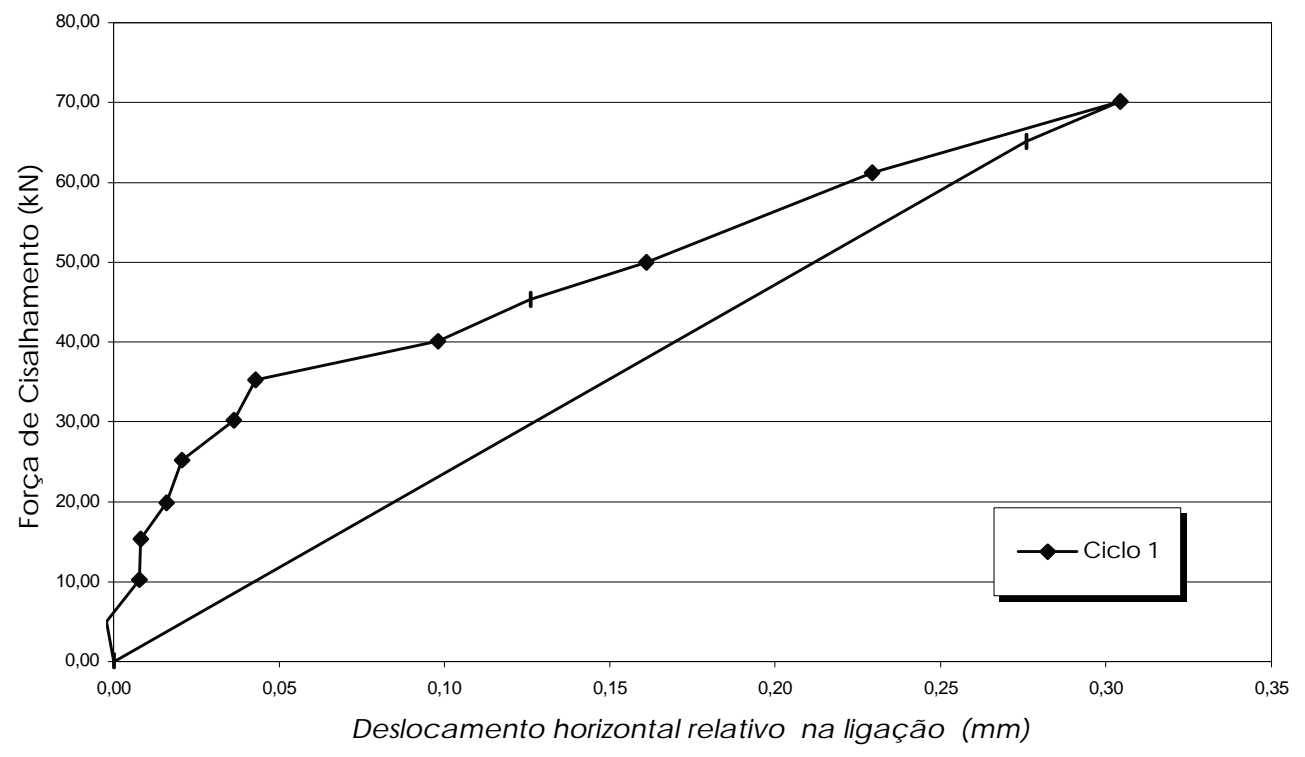

Gráfico 4.13 - Ensaio de Cisalhamento no Protótipo B - Ciclo 1 


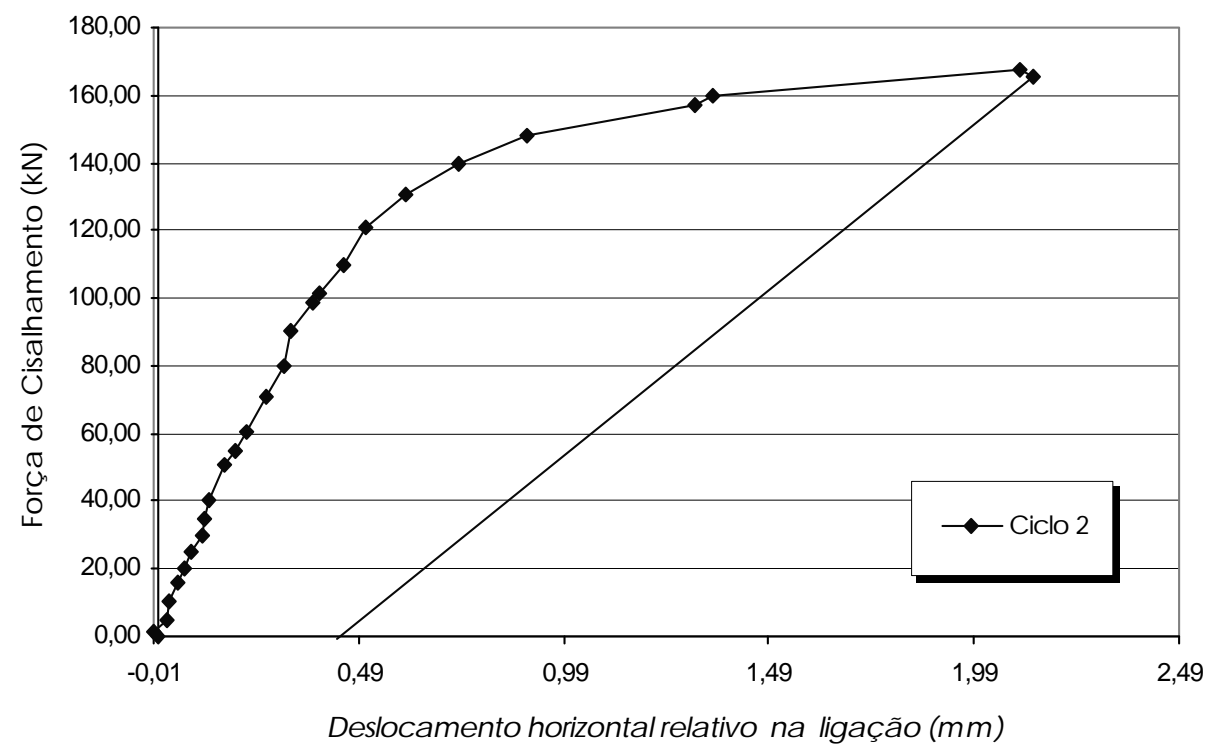

Gráfico 4.14 - Ensaio de Cisalhamento no Protótipo B - Ciclo 2

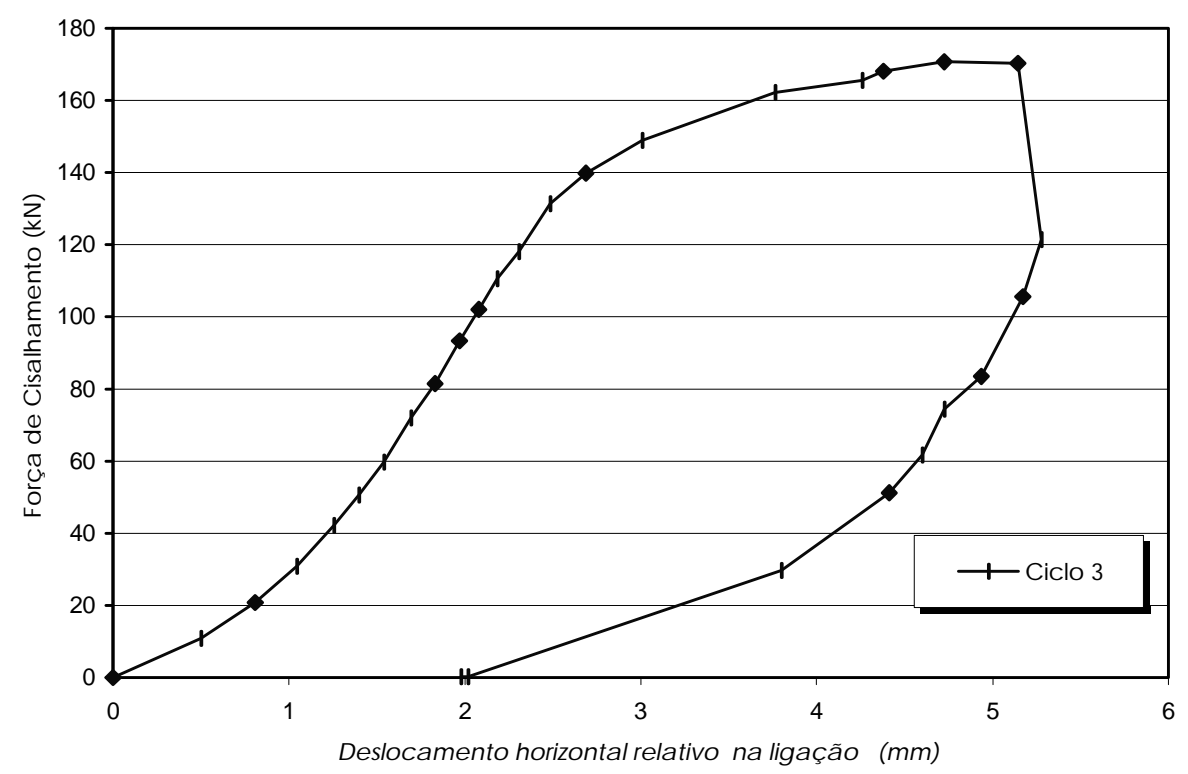

Gráfico 4.15 - Ensaio de Cisalhamento no Protótipo B - Ciclo 3 


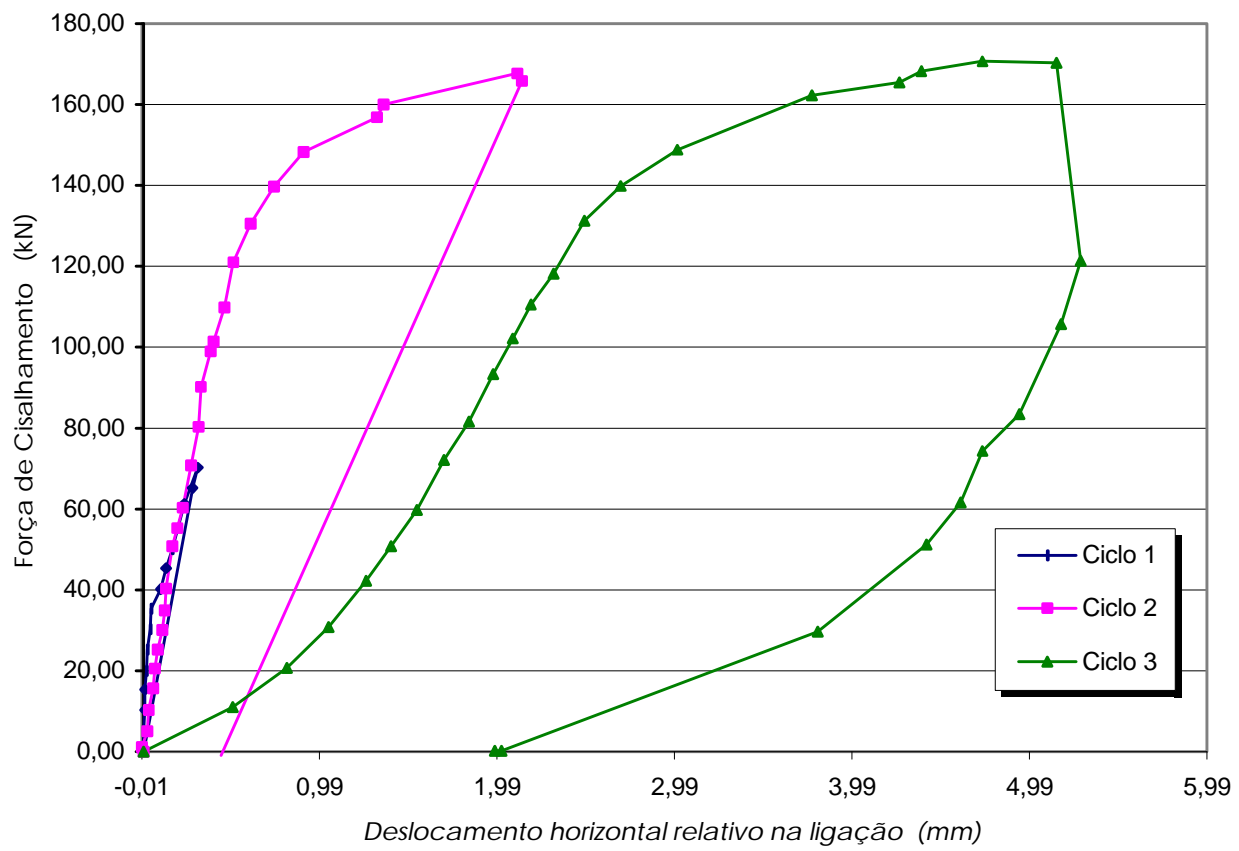

Gráfico 4.16 - Ensaio de Cisalhamento no Protótipo B - Ciclos 1,2 e 3

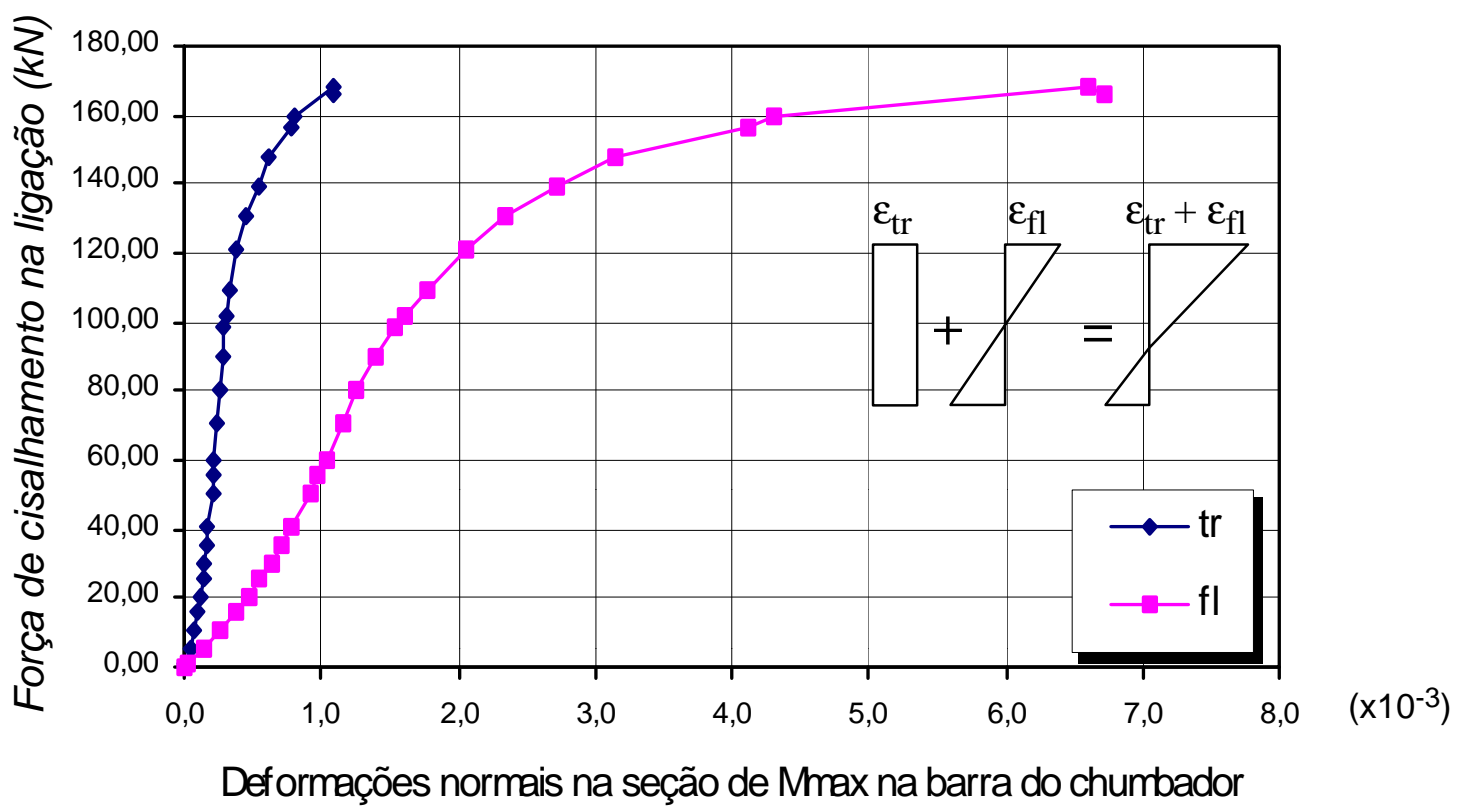

Gráfico 4.17 - Deformações normais na seção de máximo momento no chumbador. Ensaio de Cisalhamento do Protótipo B - (Ciclo 2) 


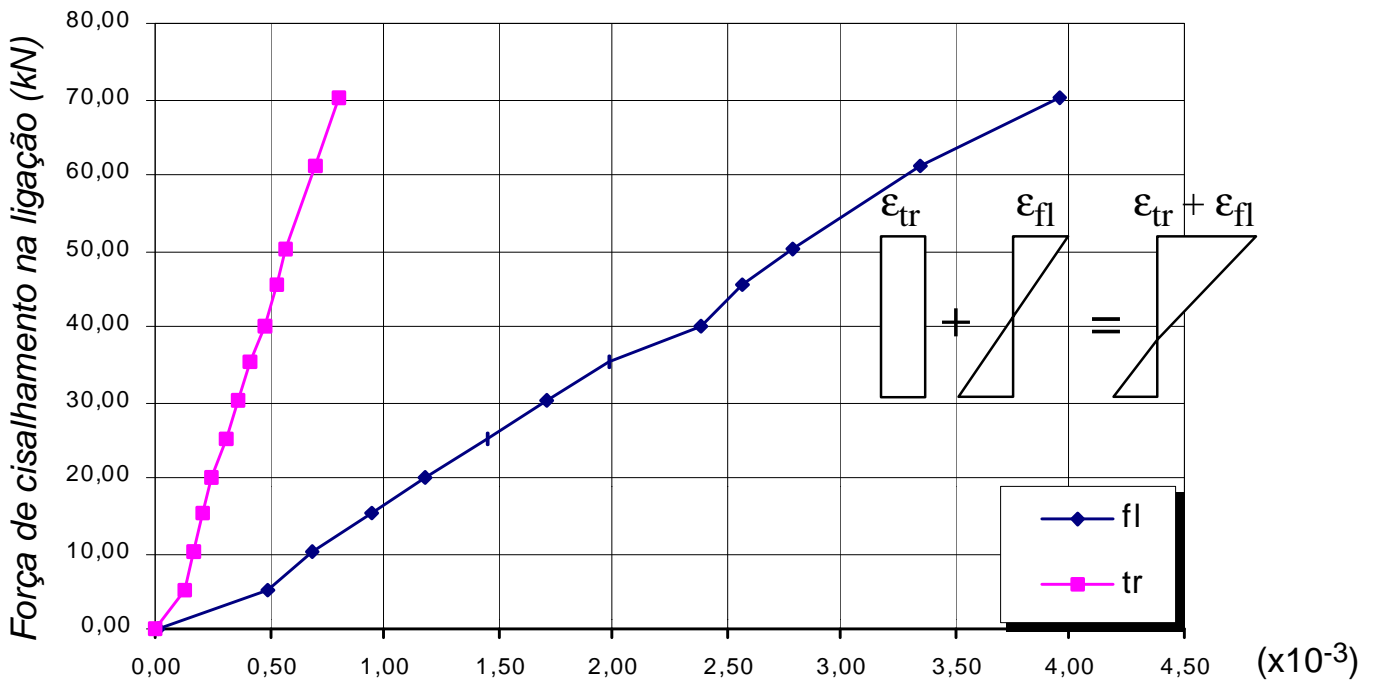

Deformações normais na seção de Mmax na barra do chumbador

Gráfico 4.18 - Deformações normais na seção de máximo momento no chumbador Ensaio de Cisalhamento no Protótipo B - (Ciclo 1)

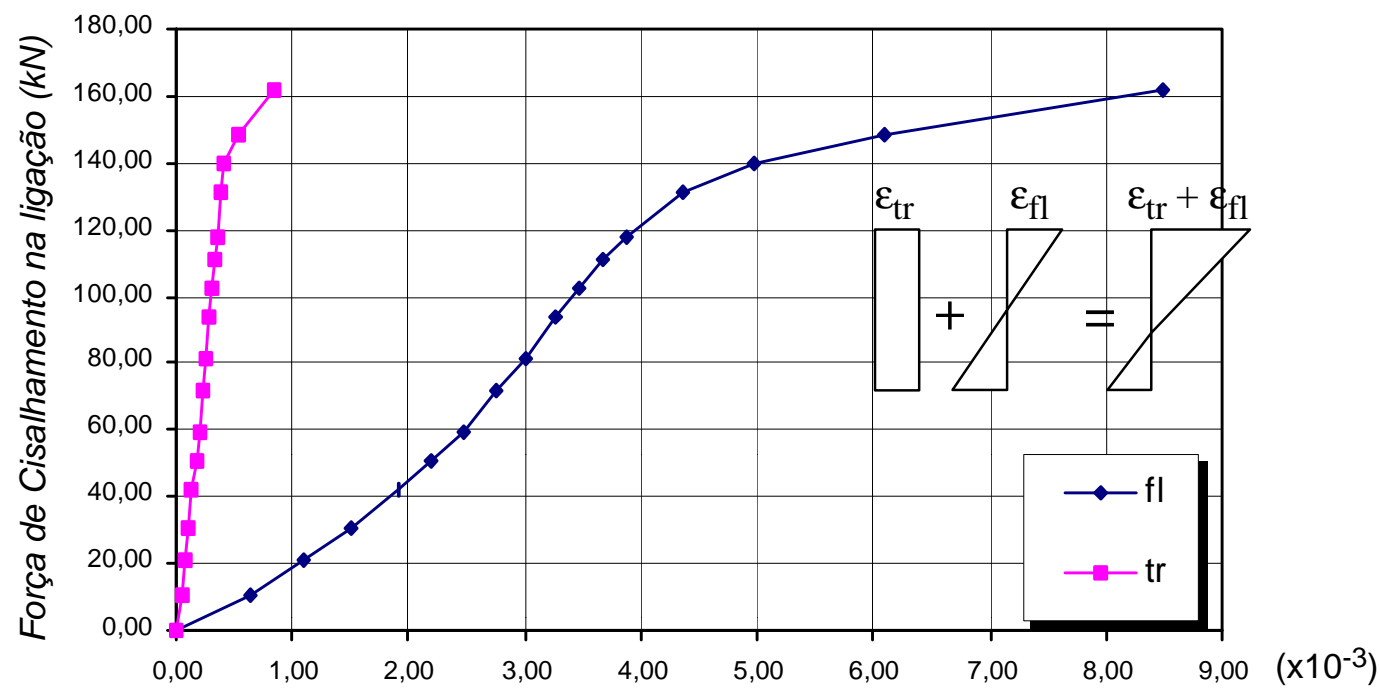

Deformações normais na seção de Mmax na barra do chumbador

Gráfico 4.19 - Deformações normais no chumbador na seção de máximo momento Ensaio de Cisalhamento do Protótipo B - (Ciclo 3) 


\subsection{Protótipo C}

Para o Protótipo C foram utilizados dois chumbadores de $25 \mathrm{~mm}$ de diâmetro e uma almofada com $15 \mathrm{~mm}$ de espessura e $200 \mathrm{~mm}$ de comprimento, com um fator de forma B equivalente aos das almofadas utilizadas no protótipo Piloto e no protótipo A. O objetivo foi avaliar o desempenho da ligação, mantendo o diâmetro do chumbador, para uma almofada mais espessa, aumentando-se assim a altura na interface da ligação.

Foram aplicados dois ciclos para a força de cisalhamento na ligação. No primeiro ciclo atingiu-se $\mathrm{F}_{\mathrm{v}}=30 \mathrm{kN}$, cerca de $25 \%$ da capacidade prevista para a ligação. No segundo ciclo a ligação atingiu $\mathrm{F}_{\mathrm{vu}}=156 \mathrm{kN}$, esgotando-se a sua capacidade. Na tabela 4.15 é apresentado um resumo com os ciclos de carregamento e na tabela 4.16 são apresentadas as inclinações obtidas para curvas experimentais no Protótipo C.

Tabela 4.15 - Resumo dos ciclos de cisalhamento no Protótipo C

\begin{tabular}{|c|c|c|c|}
\hline $\begin{array}{c}\text { Ciclosde } \\
\text { carga }\end{array}$ & $\begin{array}{c}\mathrm{F}_{\mathrm{V}} \\
(\mathrm{kN})\end{array}$ & $\begin{array}{l}\Delta_{\text {hor }} \\
\text { (mm) }\end{array}$ & Observações: \\
\hline Ciclo 1 & 30 & 0,28 & $\checkmark \quad$ Ligação se comportando no regime linear. \\
\hline Ciclo 2 & $\begin{array}{c}30 \\
65 \\
80 \\
100 \\
110 \\
150\end{array}$ & $\begin{array}{l}0,25 \\
0,67 \\
0,91 \\
1,48 \\
1,81 \\
7,81\end{array}$ & $\checkmark \quad$ Ligação se comportando no regime linear para ações da ordem de $100 \mathrm{kN}$. \\
\hline
\end{tabular}

Tabela 4.16 - Inclinações nos trechos retos das curvas experimentais no Protótipo C.

\begin{tabular}{|c|c|c|c|c|}
\hline $\begin{array}{c}\text { Ciclosde } \\
\text { carga }\end{array}$ & $\begin{array}{c}\mathrm{F}_{\mathrm{V}} \\
(\mathrm{kN})\end{array}$ & $\begin{array}{c}\text { Fatorde } \\
\text { Correlação }\end{array}$ & $\begin{array}{c}\text { Inclinação } \\
(\mathrm{kN} / \mathrm{mm})\end{array}$ & Observações: \\
\hline Ciclo 1 & 30 & 0,99 & 103,6 & \\
\hline Ciclo 2 & 30 & 0,98 & 134,4 & $\checkmark$ Em comparação com o Ciclo 2 do Prot. B, a inclinação foi \\
& 65 & 0,98 & 113,0 & de cerca de 50 \%, significando que, com o aumento da \\
& 70 & 0,98 & 108,0 & espessura da almofada, a deformabilidade da ligação foi \\
& 75 & 0,98 & 102,0 & dobrada para o Prot. Cem relação ao Prot. B. \\
\hline
\end{tabular}

As curvas experimentais obtidas nos ciclos de carregamento 1 e 2 estão apresentadas nos gráficos 4.20 e 4.21, e de forma simultânea no gráfico 4.22. No gráfico 4.23 é apresentado um diagrama do desenvolvimento das deformações normais de tração, para o Ciclo 2, na fibra mais tracionada na seção de momento máximo na barra do chumbador, distante à $3,5 \mathrm{~cm}$ da superfície do concreto na interface da ligação, dentro do bloco suporte. 


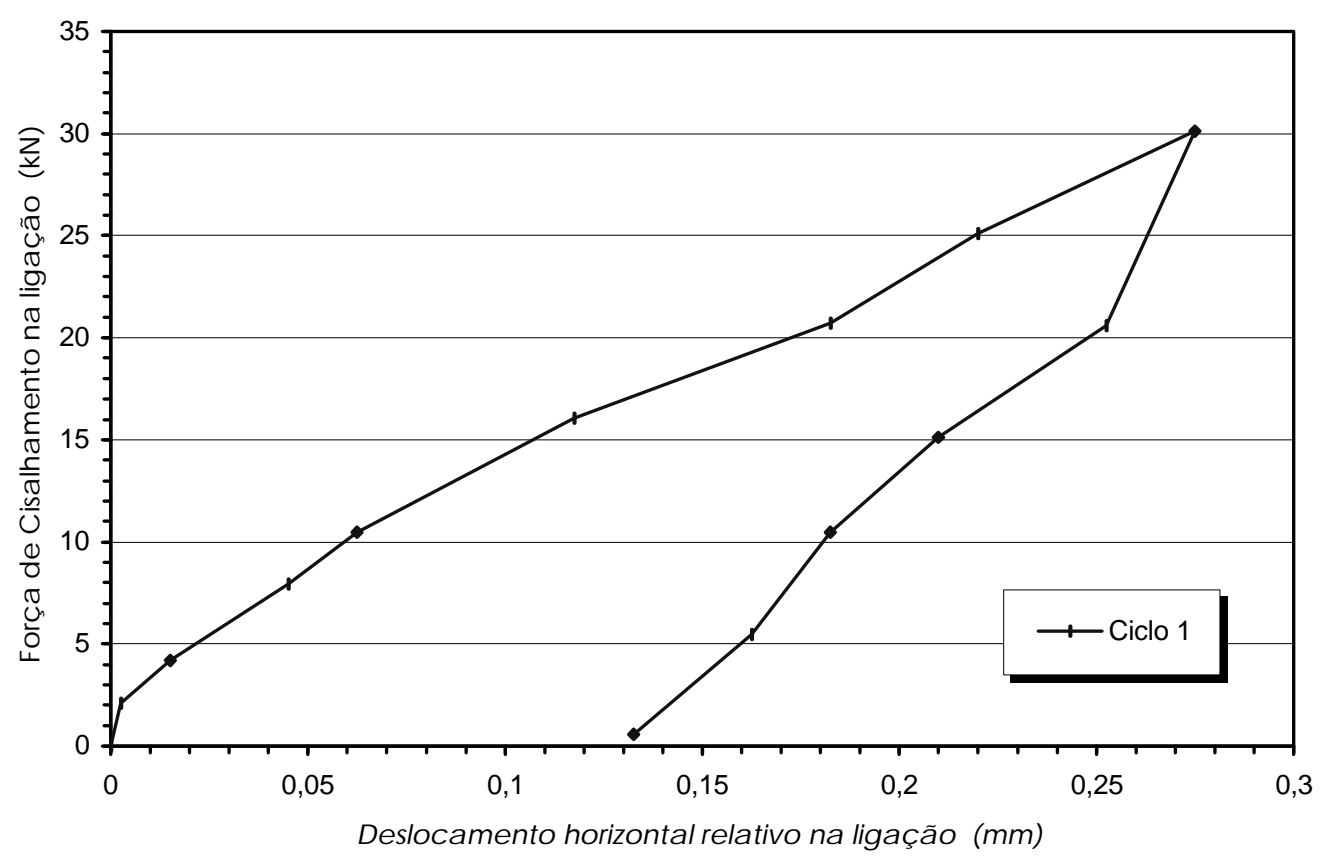

Gráfico 4.20 - Ensaio de Cisalhamento no Protótipo C - Ciclo 1

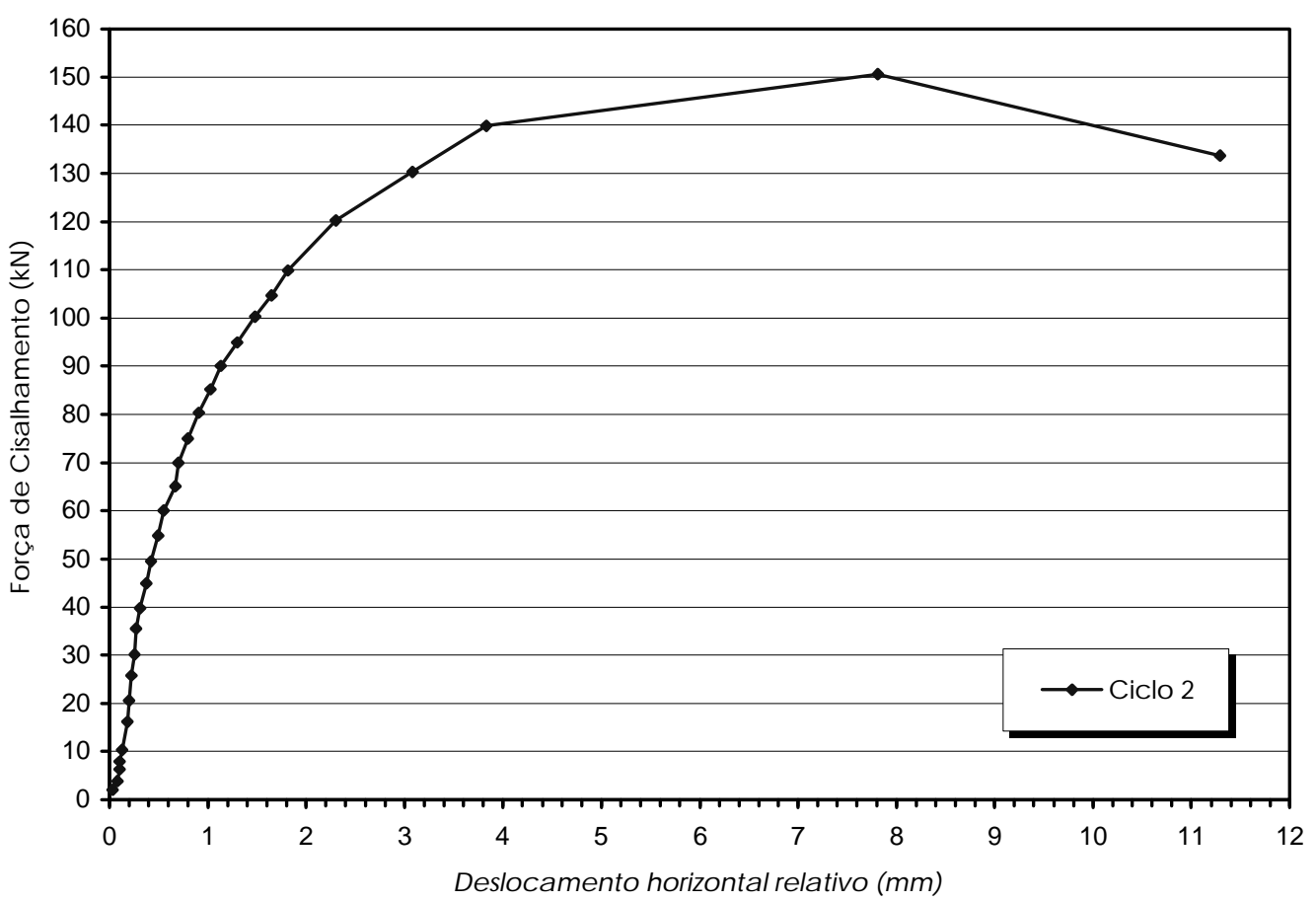

Gráfico 4.21-Ensaio de Cisalhamento no Protótipo C - Ciclo 2 


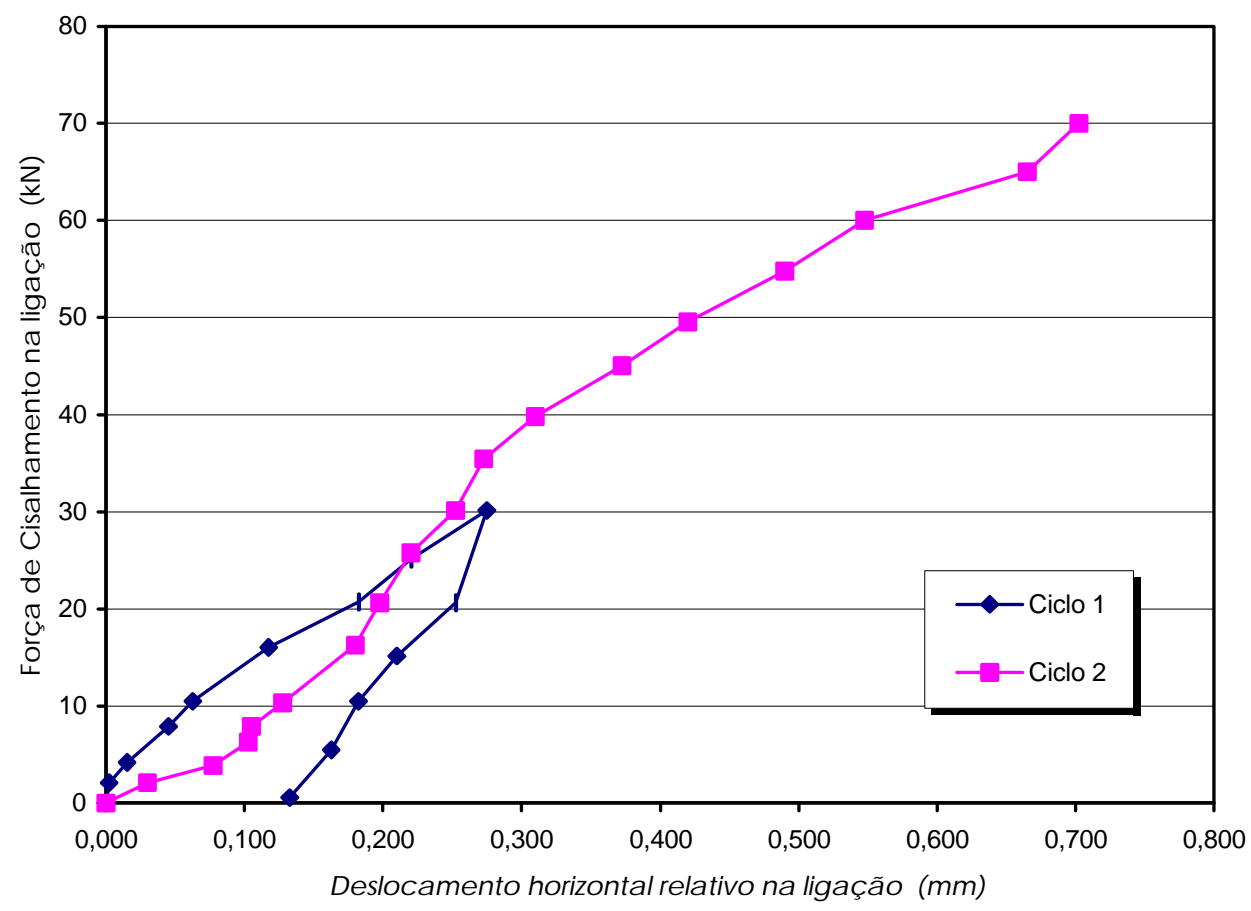

Gráfico 4.22-Ensaio de Cisalhamento no Protótipo C-Ciclos 1 e 2

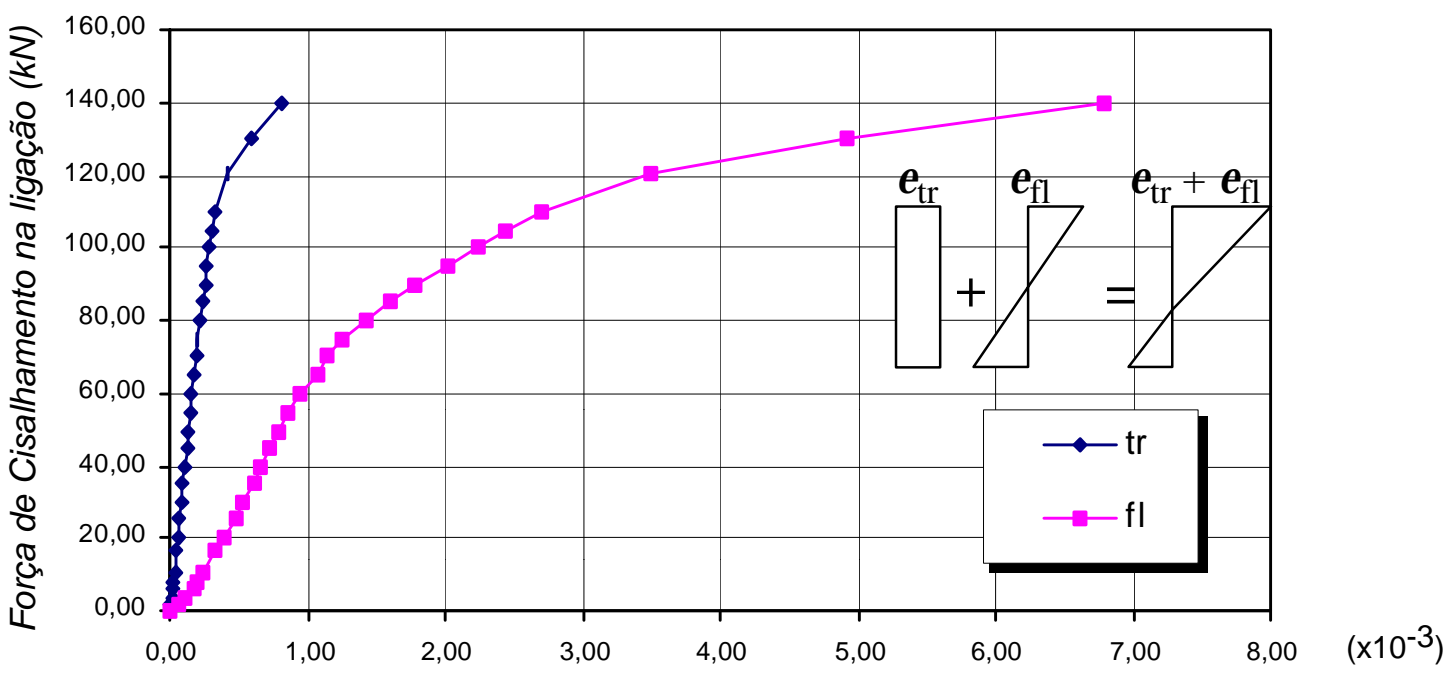

Deformações normais na seção de Mmax da barra do chumbador

Gráfico 4.23 - Deformações normais na barra do chumbador - Protótipo C 


\subsubsection{Ensaios de Flexão}

Os ensaios de flexão foram feitos para ações baixas, onde o objetivo principal foi o de estudar formação dos mecanismos resistentes à flexão na ligação para rotações iniciais.

No protótipo piloto, entretanto, não foi possível avaliar a sua deformabilidade inicial à flexão em função desse protótipo ter apresentado uma restrição muito baixa para as rotações iniciais, mesmo para as rotações causadas somente pelo peso próprio do elemento de viga. De fato, a ligação não chegou a mobilizar um mecanismo inicial para a restrição das rotações, tendo sido considerada como uma ligação bastante flexível.

Para o ensaio de flexão no Protótipo A, a força aplicada na extremidade livre do elemento de viga foi aplicada somente no sentido de baixo para cima, em apenas um ciclo de carregamento. A curva Momento vs. Rotação para o Protótipo A é apresentada no gráfico 4.24. A inclinação do trecho linear inicial dessa curva foi de $92,13 \mathrm{kN} . \mathrm{m} / \mathrm{rad}$, o que representa uma deformabilidade à flexão de $\lambda_{\phi l i g}=11,0 \times 10^{-3} \mathrm{rad} / \mathrm{kN}$.m. No gráfico 4.25 são apresentadas as tensões normais na fibra mais tracionada da seção de momento máximo na barra do chumbador, próxima à interface da ligação. A partir dos resultados, pode-se observar que o efeito de flexão localizada foi bem maior do que o efeito da tração na barra do chumbador. Assim, acredita-se que o mecanismo resistente à flexão da ligação, caracterizou-se (para essas rotações iniciais) muito mais pelo efeito da rigidez da barra do chumbador do que pela ação de binário, com compressão na borda da almofada de elastômero e com tração na barra do chumbador.

Para o ensaio do Protótipo B, foram aplicadas uma sequiência de forças verticais na extremidade livre do elemento de viga, no sentido de baixo para cima, intercaladas pela ação do peso próprio do elemento de viga sobre a ligação. No gráfico 4.26 é apresentada a curva Momento vs. Rotação para o Protótipo B, onde se obteve uma inclinação do trecho linear inicial da ordem de $421 \mathrm{kN} . \mathrm{m} / \mathrm{rad}$, que representa uma deformabilidade à flexão da ordem de $\lambda_{\phi l i g}=2,34 \times 10^{-3} \mathrm{rad} / \mathrm{kN}$.m. No gráfico 4.27 são apresentadas as tensões normais na fibra mais tracionada da seção de momento máximo na barra do chumbador, onde se observa novamente a predominância da rigidez da barra do chumbador sobre o mecanismo de binário, almofada e chumbador, atingindo-se tensões totais de tração superiores à $250 \mathrm{MPa}$. 
Para o ensaio do Protótipo $\mathrm{C}$, foi aplicada uma seqüência de forças verticais na extremidade livre do elemento de viga, no sentido de baixo para cima e de cima para baixo, através da utilização seqüencial de dois atuadores. No gráfico 4.28 é apresentada a curva Momento vs Rotação para o Protótipo C, onde se obteve uma inclinação do trecho linear inicial da ordem de $246,3 \mathrm{kN} . \mathrm{m} / \mathrm{rad}$, que representa à uma deformabilidade à flexão da ordem de $\lambda_{\phi l i g}=4,06 \times 10^{-3} \mathrm{rad} / \mathrm{kN}$.m. No gráfico 4.29 são apresentadas as tensões normais na fibra mais tracionada da barra do chumbador, na seção de momento máximo, onde também se observa a predominância do efeito da rigidez da barra do chumbador no mecanismo resistente da ligação, atingindo-se a tensões totais de tração superiores à 200 $\mathrm{MPa}$.

A partir de uma observação e da consideração dos resultados obtidos nos ensaios dos protótipos, pode-se dizer que, para as rotações iniciais, o mecanismo de deformação predominante na ligação foi o da flexão na barra do chumbador. Acredita-se que a explicação para este fenômeno esteja no fato de que, inicialmente, o centro de giro da ligação está posicionado sobre o chumbador, causando a flexão do mesmo. Na medida em que o centro de giro vai se deslocando em direção à borda comprimida da almofada, com o incremento das ações, o mecanismo resistente principal passa a ser fornecido pela ação de binário, com uma resultante de compressão num trecho da borda da almofada e com uma resultante de tração na barra do chumbador.

Todavia, a partir desta primeira análise, ainda não se conseguiu definir precisamente sobre a influência dos parâmetros internos da ligação sobre a sua deformabilidade à flexão. A rigidez da barra também é influenciada pela distância entre os dois elementos de concreto, a qual é definida pela espessura da almofada. Assim, quanto menor a espessura da almofada, maior será a restrição às rotações na ligação. Confirmando este fato, a ligação do protótipo $B$, com $h_{n}=10 \mathrm{~mm}$, apresentou uma rigidez 1,7 vezes maior do que a rigidez da ligação do protótipo $\mathrm{C}$, com $\mathrm{h}_{\mathrm{n}}=15 \mathrm{~mm}$. A espessura da almofada também influi na rigidez à compressão da mesma, onde para espessuras menores tem-se uma rigidez à compressão maior, oferecendo assim uma maior restrição aos giros iniciais (quando a almofada for solicitada). Sabe-se também, com relação ao impedimento aos giros iniciais, que uma almofada de comprimento maior, com um fator de forma alto, oferece maior restrição aos giros. 


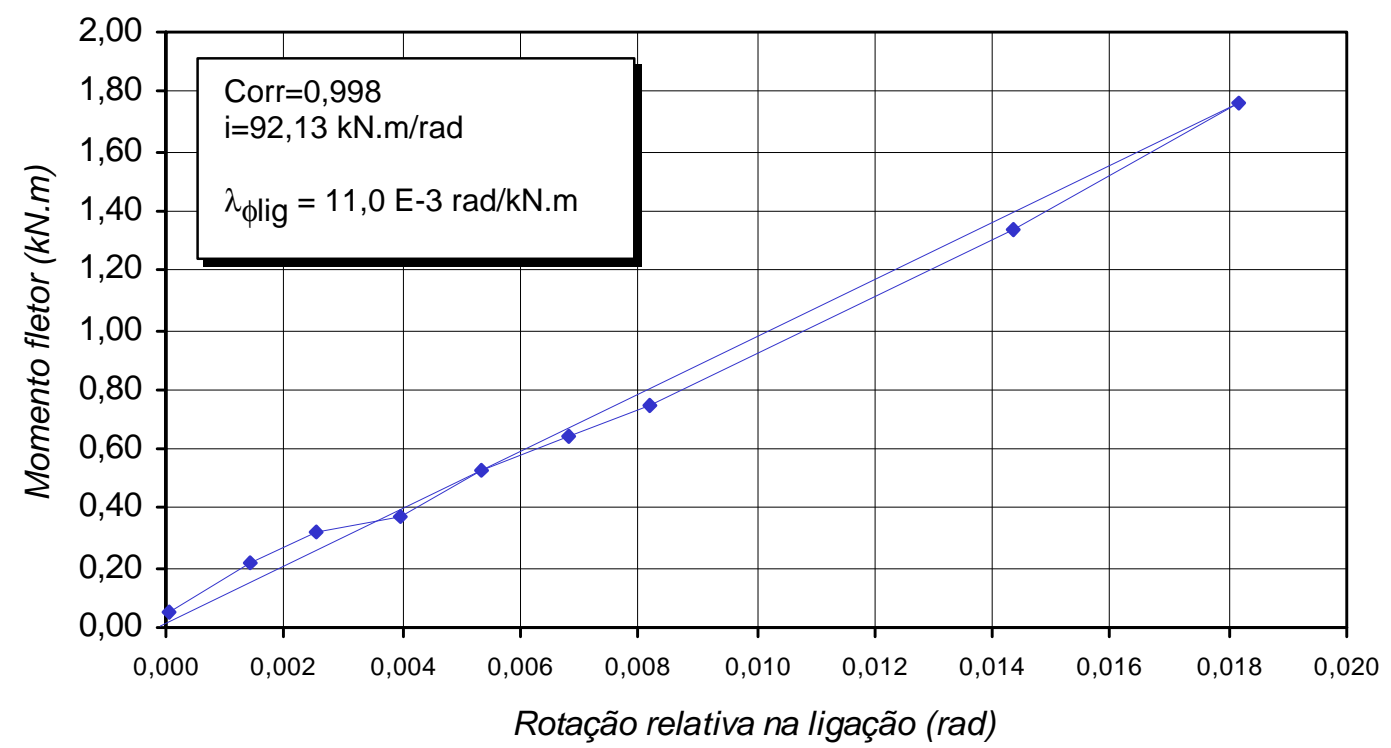

Gráfico 4.24 - Curva Momento-Rotação para a Ligação no Protótipo A

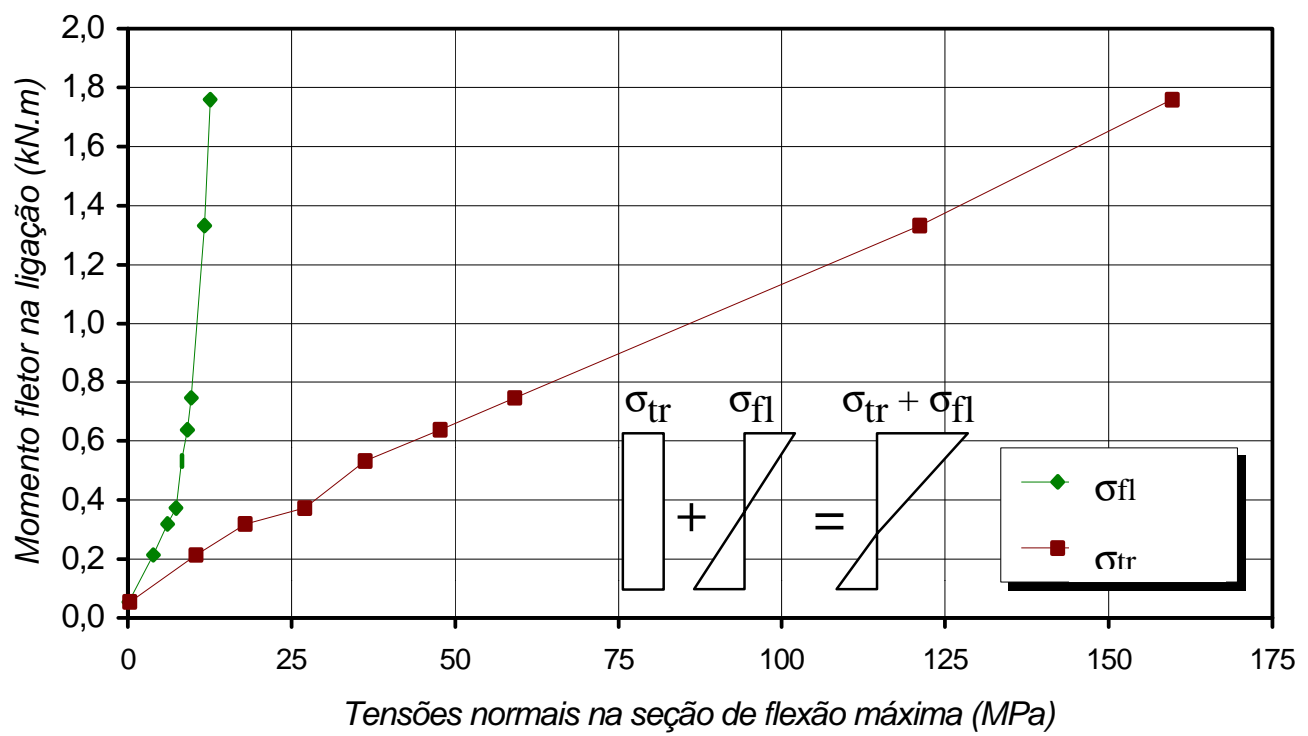

Gráfico 4.25 - Tensões Normais $\sigma_{f l}$ e $\sigma_{t r}$ na fibra mais tracionada da seçâo com momento máximo na barra do chumbador do Protótipo $A$ 


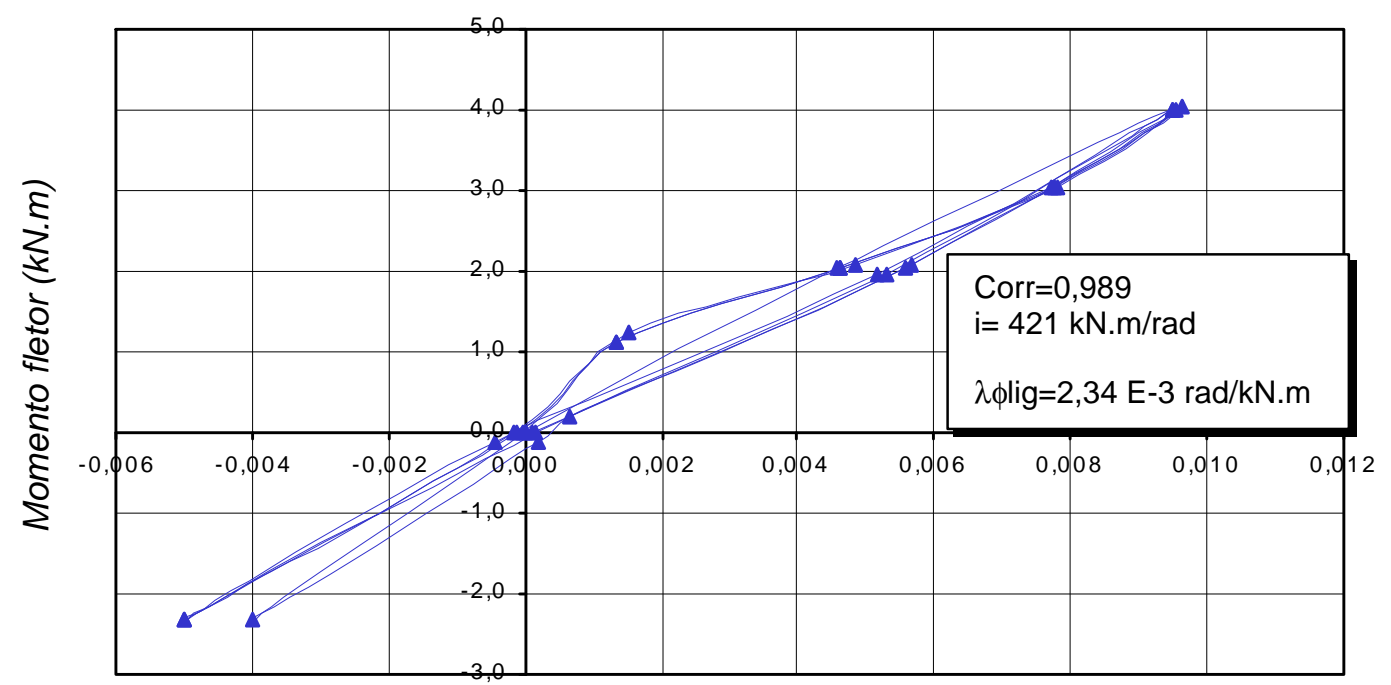

Rotação relativa na ligação ( $r a d)$

Gráfico 4.26 - Curva Momento-Rotação para a Ligação no Protótipo B

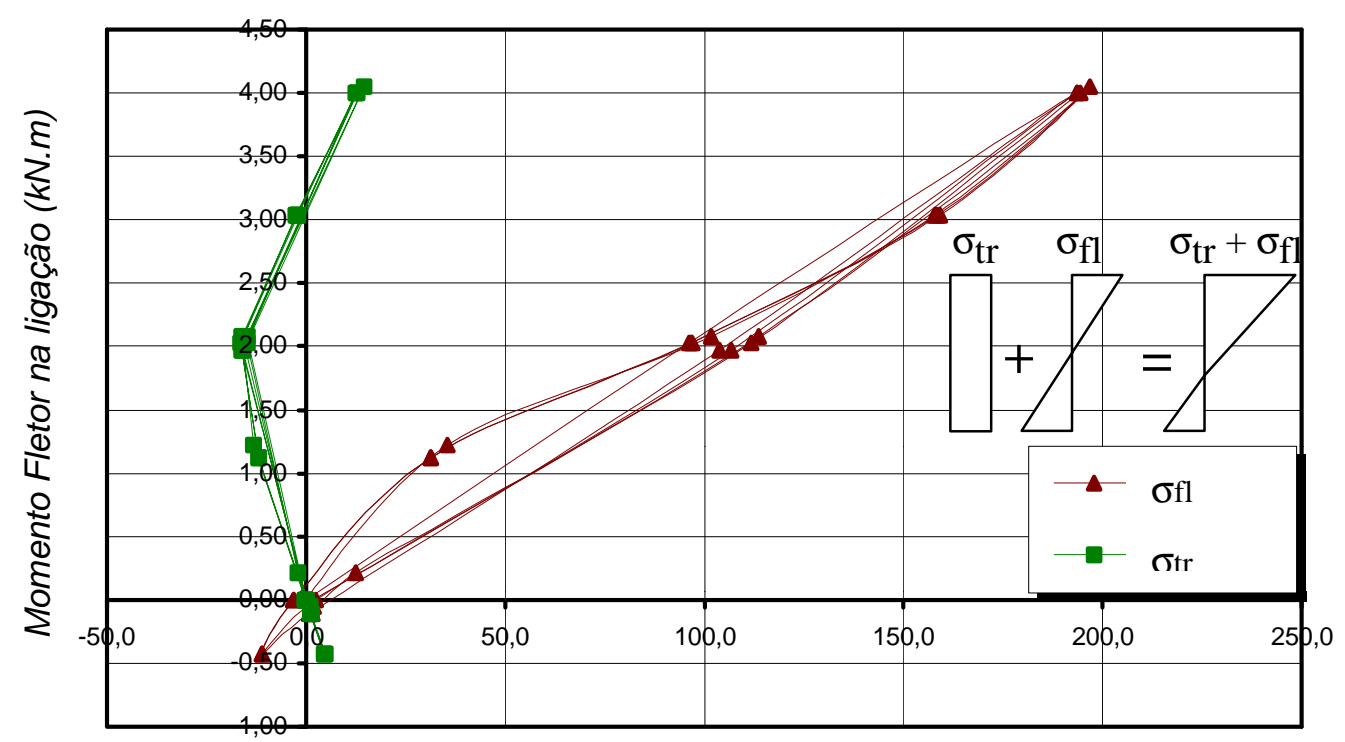

Tensões normais na seção de máxima flexão (composta) (MPa)

Gráfico 4.27 - Tensões Normais $\sigma_{f l}$ e $\sigma_{t r}$ na fibra mais tracionada da seçâo com momento máximo na barra do chumbador do Protótipo $B$ 


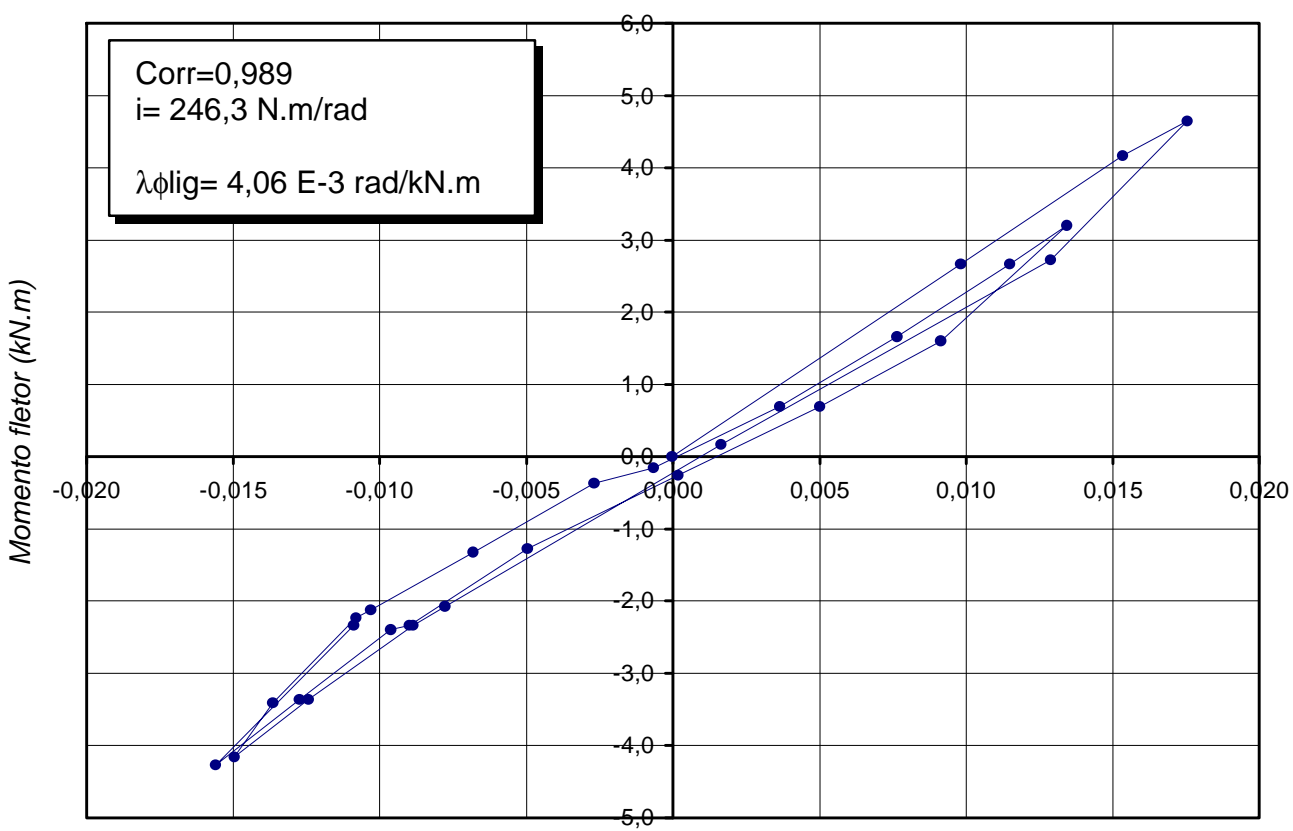

Rotação relativa na ligação (rad)

Gráfico 4.28 - Curva Momento-Rotação para a Ligação no Protótipo C

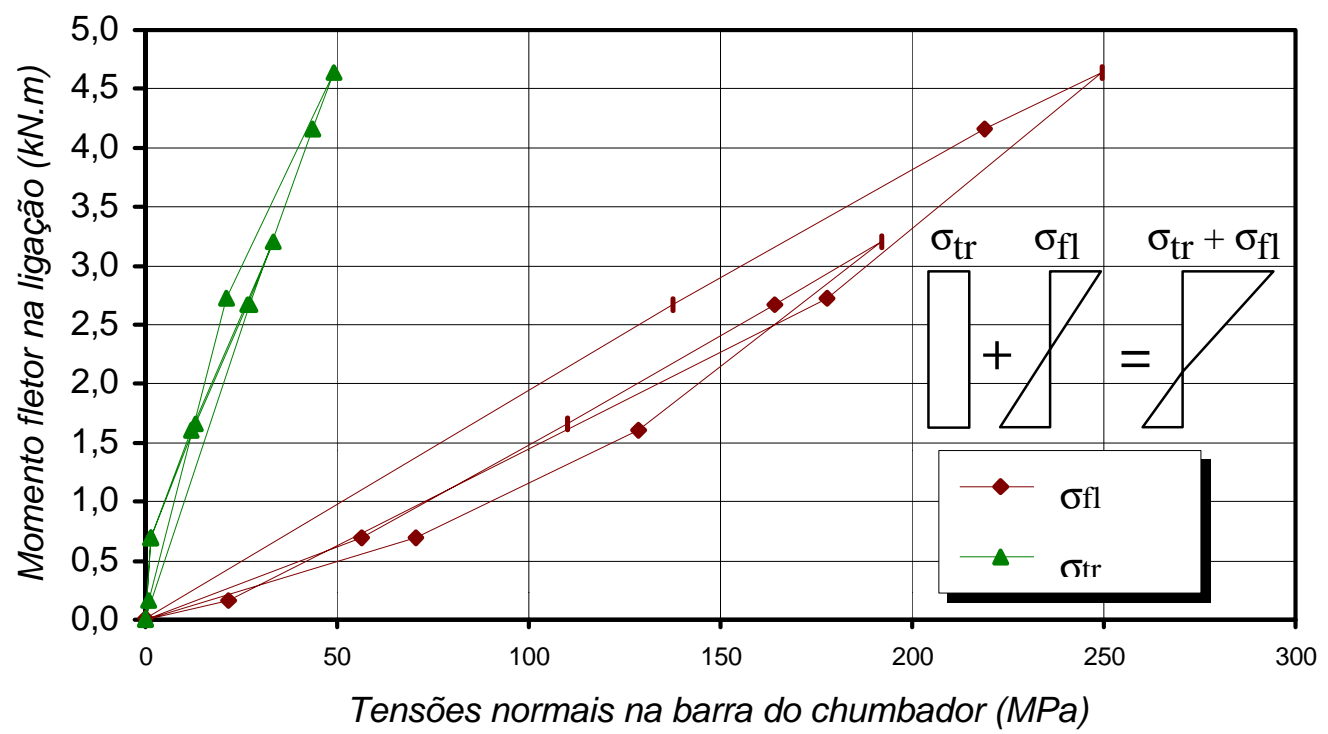

Gráfico 4.29 - Tensões Normais $\sigma_{f l}$ e $\sigma_{t r}$ na fibra mais tracionada da seçâo com momento máximo na barra do chumbador do Protótipo $C$ 


\subsubsection{Ensaios de Torção}

Os ensaios de torção foram feitos a partir da ação simultânea de dois atuadores, conforme explicado no item 4.6.4. As curvas Momento Torçor vs Rotação em torno do eixo da viga, para os protótipos A, B e C, estão apresentadas nos gráficos 4.30, 4.32 e 4.34 , respectivamente.

Para o Protótipo A, obteve-se uma deformabilidade à torção da ordem de $\lambda_{\theta \text { rot }}=$ $12,0 \times 10^{-4} \mathrm{rad} / \mathrm{kN}$. Para o Protótipo $\mathrm{B}$, obteve-se uma deformabilidade à torção da ordem de $\lambda_{\theta \text { rot }}=5,96 \times 10^{-4} \mathrm{rad} / \mathrm{kN}$. Já para o Protótipo $\mathrm{C}$, obteve-se a maior deformabilidade à torção entre os protótipos, da ordem de $\lambda_{\theta \mathrm{rot}}=61,1 \times 10^{-4} \mathrm{rad} / \mathrm{kN}$. Como os chumbadores utilizados no Protótipo A são inferiores aos que foram utilizados no Protótipo C, concluiuse então que a geometria da almofada de elastômero, acima do diâmetro do chumbador, foi o fator determinante para a deformabilidade à torção na ligação. Como no caso do Protótipo C, a largura da almofada $(\mathrm{a}=200 \mathrm{~mm})$ foi superior à largura da almofada no Protótipo A $(\mathrm{a}=150 \mathrm{~mm})$, concluiu-se também que a variável de maior influência na geometria foi a espessura na almofada. De fato, o protótipo C, com almofada mais espessa, com $h_{n}=15 \mathrm{~mm}$, apresentou uma deformabilidade bem maior que as dos protótipos A e B com almofadas mais finas, com $h_{n}=10 \mathrm{~mm}$. Assim, verificou-se mais uma vez que as almofadas de maior espessura, apresentam uma resistência menor às deformações por compressão, influindo assim de modo significativo na deformabilidade à torção da ligação.

Nos gráficos 4.31, 3.33 e 4.35 são apresentadas as forças normais resultantes aplicadas nas barras dos dois chumbadores e no trecho comprimido da almofada de elastômero para os Protótipos A, B e C, respectivamente. Observou-se, a partir desses gráficos, que o mecanismo resistente à torção da ligação foi promovido pela ação do binário composto por uma força de tração aplicada em uma das barras do chumbador e por uma força de compressão com uma componente aplicada na outra barra do chumbador e com uma componente aplicada em um trecho da almofada de elastômero.

A posição média para a Linha Neutra, medida para os três protótipos, esteve à uma distância de aproximadamente $9 \mathrm{~cm}$ da barra tracionada, dentro do trecho entre os dois chumbadores (os quais distavam de $15 \mathrm{~cm}$ entre si). 


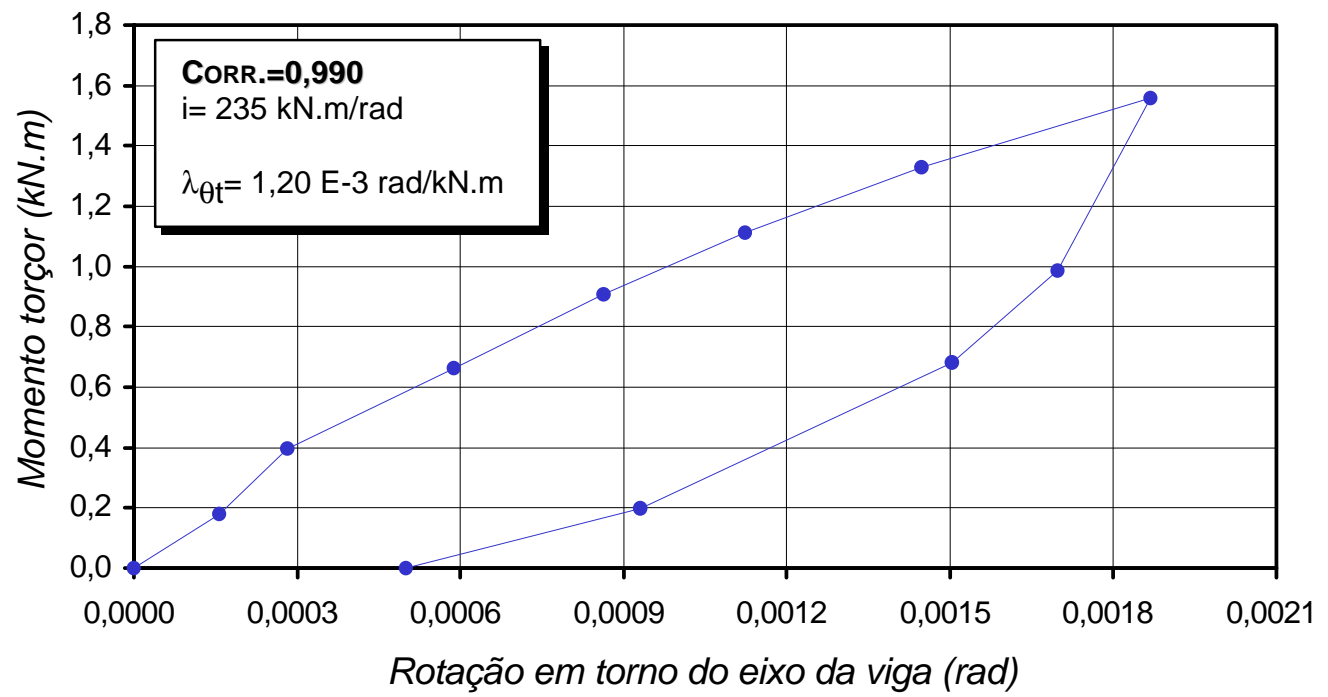

Gráfico 4.30 - Curva Momento Torçor - Rotação em torno do eixo da viga (Protótipo A)

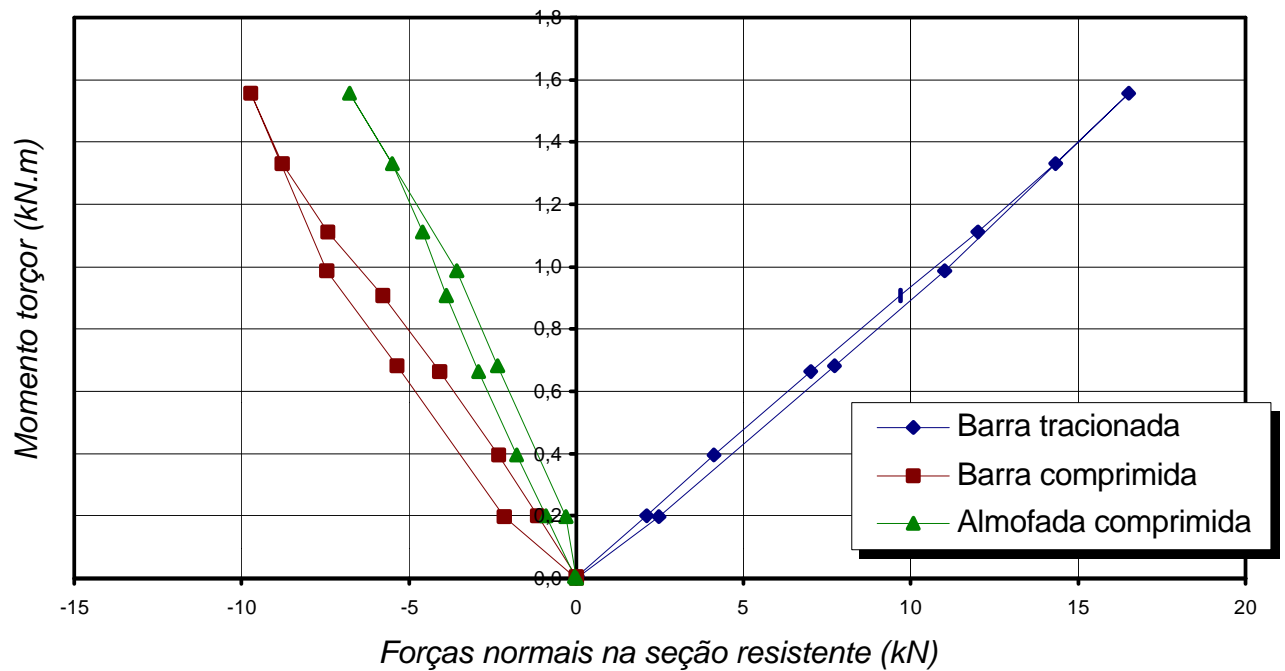

Gráfico 4.31 - Componentes Normais na Seção Resistente à Torção na Ligação. (Protótipo A) 


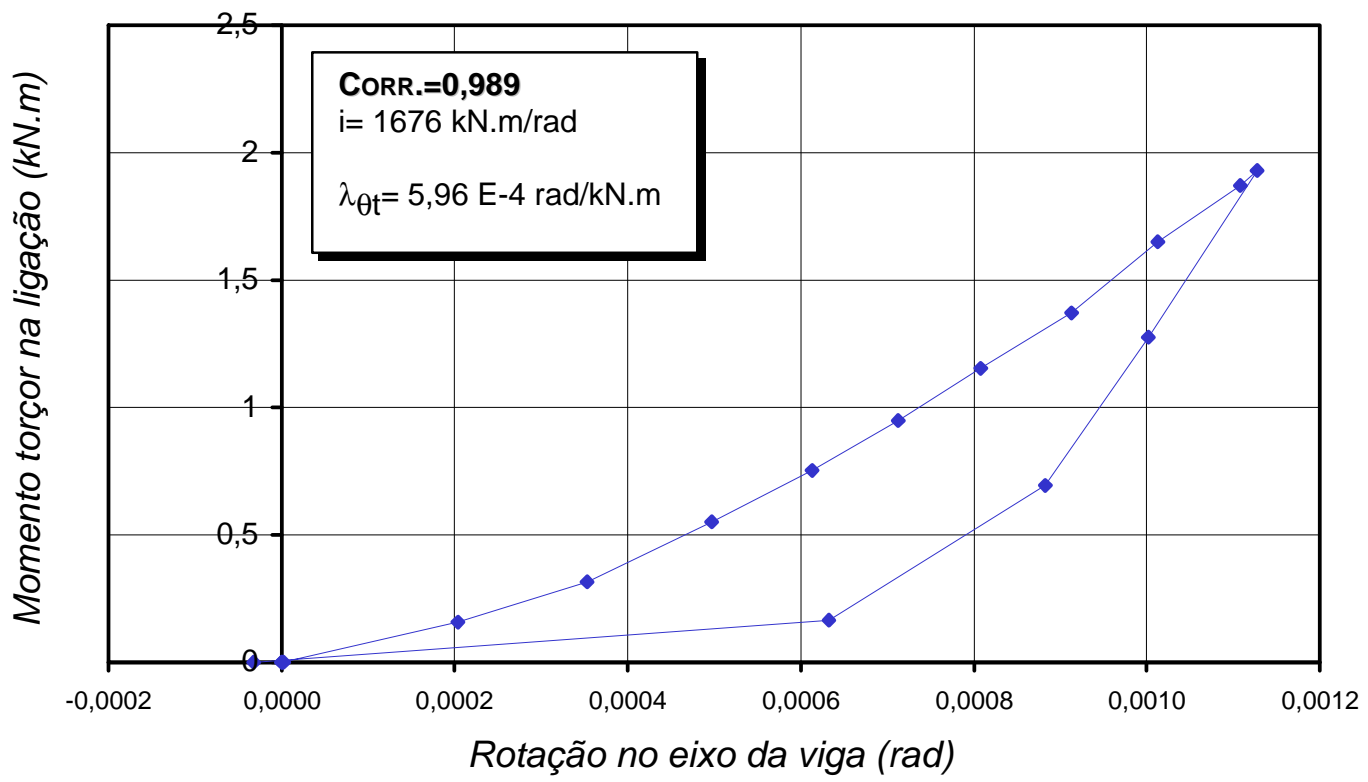

Gráfico 4.32 - Curva Momento Torçor - Rotação em torno do eixo da viga (Protótipo B)

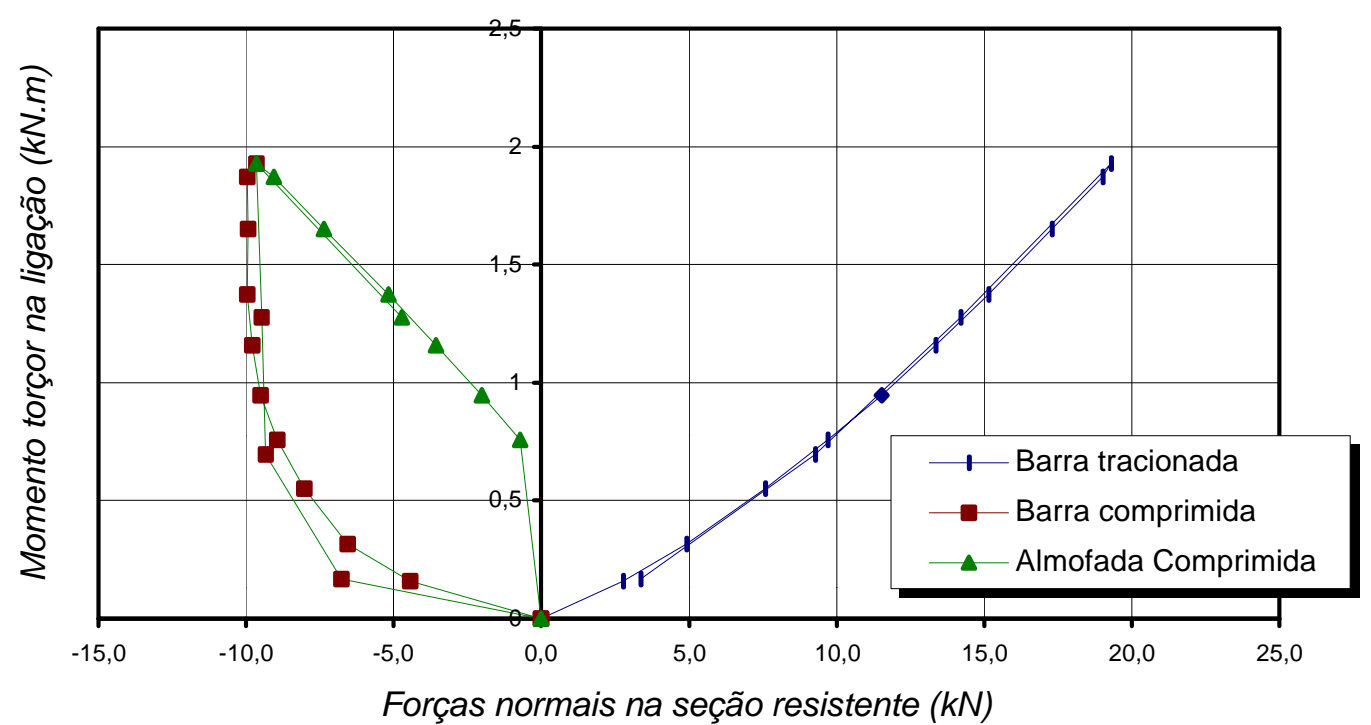

Gráfico 4.33 - Componentes Normais na Seção Resistente à Torção na Ligação. (Protótipo B) 


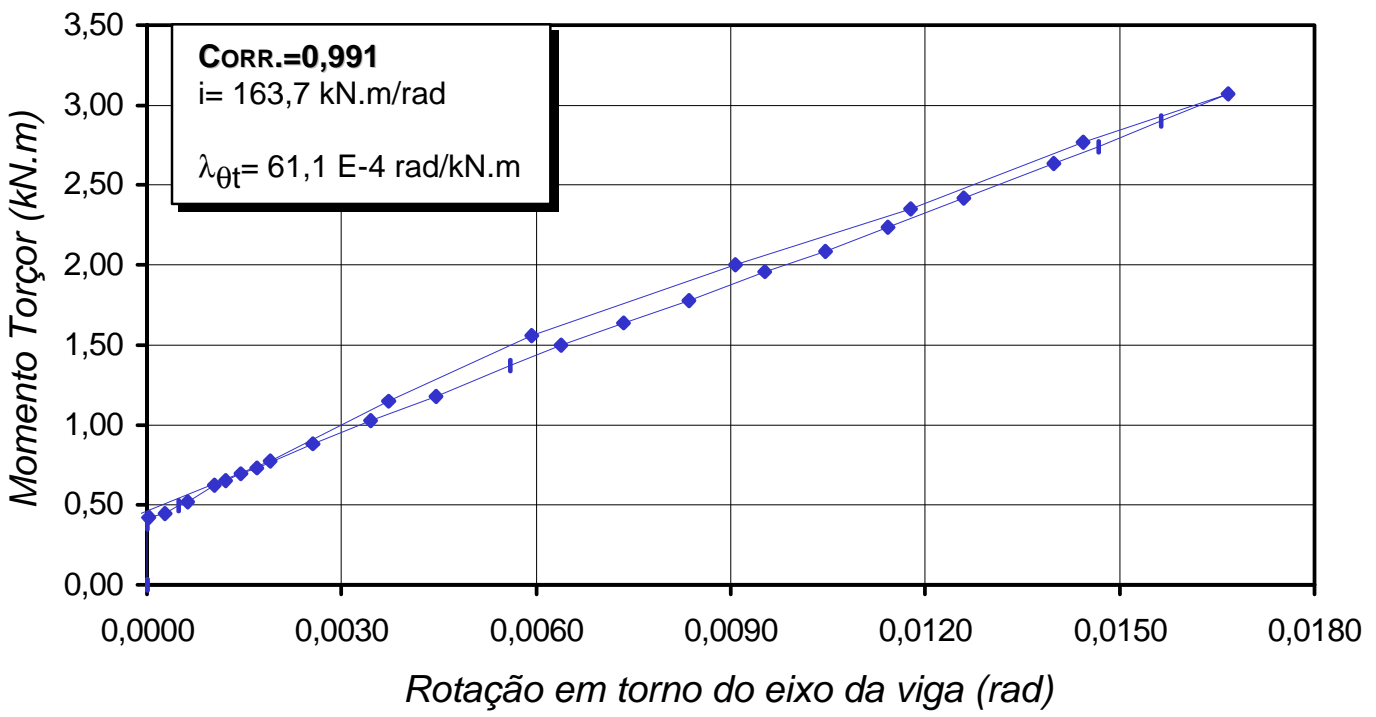

Gráfico 4.34 - Curva Momento Torçor - Rotação em torno do eixo da viga (Protótipo C)

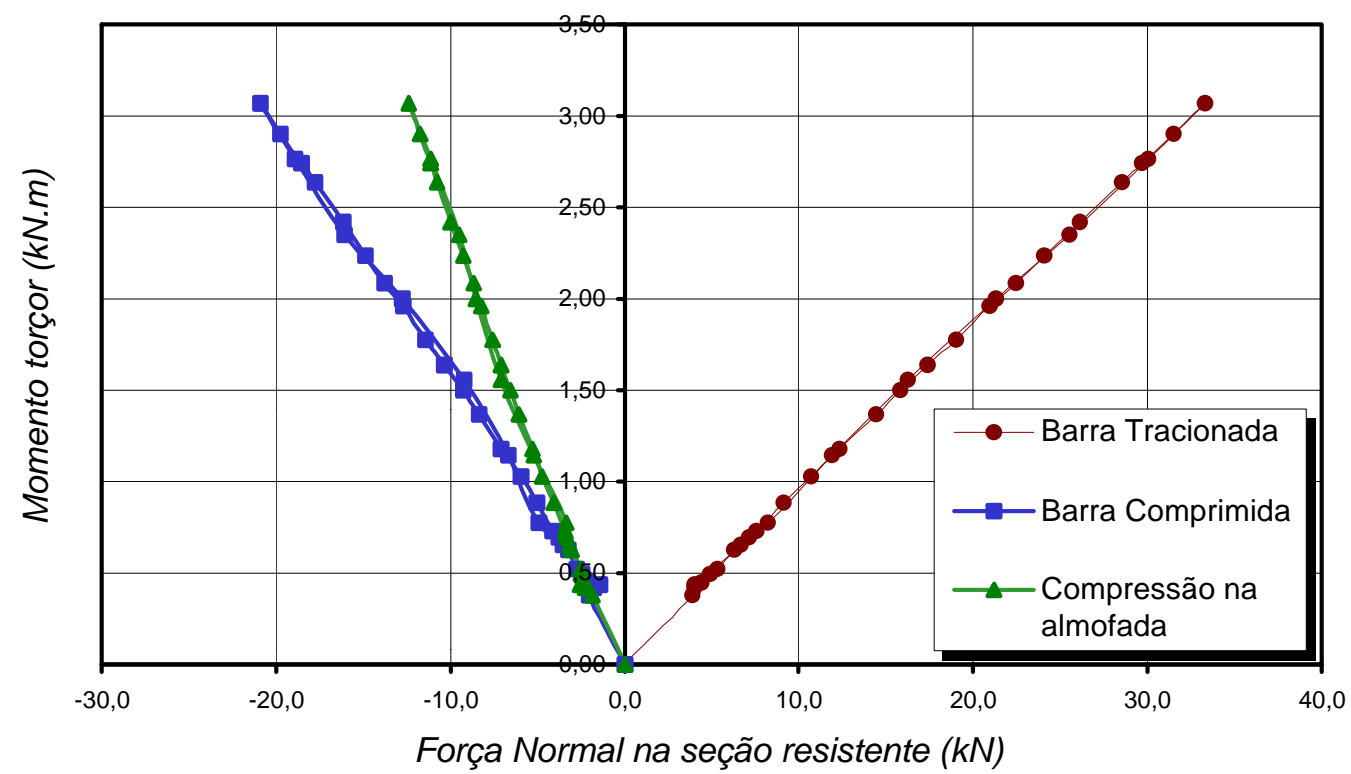

Gráfico 4.35 - Componentes Normais na Seção Resistente à Torção na Ligação. (Protótipo $C$ ) 


\subsection{Comparação dos Resultados Experimentais com os Valores Teóricos}

Os valores das forças $F_{v y, m i n}$ e $F_{v y}$ estão relacionados com a formação dos mecanismos de rótulas plásticas nos pontos de máximos momentos na barra do chumbador, segundo as resistências mínimas e máximas dos elementos de concreto. A formação destes mecanismos nas barras, por sua vez, coincidem com o escoamento da ligação. $\mathrm{A}$ força $\mathrm{F}_{\mathrm{vu}}$ corresponde à capacidade última ao cisalhamento da ligação. $\mathrm{Na}$ tabela 4.17 são apresentados os valores experimentais para $\mathrm{F}_{\mathrm{vy}, \min }, \mathrm{F}_{\mathrm{vy}}$ e $\mathrm{F}_{\mathrm{vu}}$

Tabela 4.17 - Valores Experimentais para $F_{v y, \text { min }}, F_{v y} e F_{v u}$

\begin{tabular}{|c|c|c|c|}
\hline & $\begin{array}{c}\text { Fvy,mín (exp) } \\
(\mathrm{kN})\end{array}$ & $\begin{array}{c}\text { Fvy (exp) } \\
(\mathrm{kN})\end{array}$ & $\begin{array}{c}\text { Fvu (exp) } \\
(\mathrm{kN})\end{array}$ \\
\hline Piloto & 17,5 & 22,5 & 34,0 \\
\hline Protótipo A & 40,0 & 50,0 & 60,0 \\
\hline Protótipo B & 100,0 & 140,0 & 170,0 \\
\hline Protótipo C & 80,0 & 110,0 & 156,0 \\
\hline
\end{tabular}

A deformabilidade ao cisalhamento da ligação, $\lambda_{\tau \text { lig }}$, é dada pelo valor inverso da inclinação obtida para os trechos lineares iniciais nas curvas força de cisalhamento vs deslocamento horizontal na ligação. Na tabela 4.18 são apresentados os valores das deformabilidades a partir dos ensaios nos protótipos.

Tabela 4.18 - Valores Experimentais para $\lambda_{\tau l i g}$

\begin{tabular}{|c|c|c|c|}
\hline & $\begin{array}{c}\text { Ciclo de } \\
\text { Referência }\end{array}$ & $\begin{array}{c}\text { Inc lina ção } \\
(\mathrm{kN} / \mathrm{mm})\end{array}$ & $\begin{array}{c}\lambda \tau l i g \\
(\mathrm{~mm} / \mathrm{kN})\end{array}$ \\
\hline Piloto & Ciclos 1 e 2 & 45,5 & $22,0 \times 10^{-3}$ \\
\hline Protótipo A & Cic $\operatorname{los} 1,2$ e 3 & 70,0 & $14,0 \times 10^{-3}$ \\
\hline Protótipo B & Ciclo 2 & 272,0 & $3,7 \times 10^{-3}$ \\
\hline Protótipo C & Ciclo 2 & 135,0 & $7,5 \times 10^{-3}$ \\
\hline
\end{tabular}

Na tabela 4.19 são apresentados os parâmetros de resistência dos protótipos que foram calculados a partir do desenvolvimento teórico apresentado no início deste capítulo. 
$\mathrm{Na}$ tabela 4.20 são comparados os valores teóricos e experimentais para as resistências ao cisalhamento das ligações.

Tabela 4.19 - Cálculo das Resistências ao Cisalhamento dos Protótipos

\begin{tabular}{|c|c|c|c|c|c|}
\hline Parâmetros & Obtenção & Piloto & Protótipo A & Protótipo $\mathrm{B}$ & Protótipo C \\
\hline$f_{c k, \min }(\mathrm{MPa})$ & Graute & 30,0 & 30,0 & 30,0 & 30,0 \\
\hline$f_{c k, m a ́ x}(\mathrm{MPa})$ & Concreto & 51,5 & 59,0 & 50,2 & 49,0 \\
\hline$F_{y k}(\mathrm{MPa})$ & Dado inicial & 250,0 & 250,0 & 250,0 & 250,0 \\
\hline $\mathrm{h}_{\mathrm{n}}(\mathrm{m})$ & Dado inicial & 0,01 & 0,01 & 0,01 & 0,015 \\
\hline$\phi_{\mathrm{b}}(\mathrm{m})$ & Dado inicial & 0,016 & $2 \times 0,016$ & $2 \times 0,025$ & $2 \times 0,025$ \\
\hline e (m) & Dado inicial & 0,005 & 0,005 & 0,005 & 0,0075 \\
\hline $\mathrm{C}_{1}$ & Tabela 4.1 & 1,24 & 1,24 & 1,24 & 1,24 \\
\hline $\mathrm{C}_{\mathrm{r}}$ & Adotado & 1 & 1 & 1,15 & 1,1 \\
\hline $\mathrm{C}_{\mathrm{e}}$ & Eq. (4.4.1) & 0,60 & 0,58 & 0,72 & 0,62 \\
\hline $\mathrm{F}_{\mathrm{vy}, \min }(\mathrm{kN})$ & Eq. (4.4) & 16,6 & 32,1 & 111,3 & 91,7 \\
\hline $\mathrm{F}_{\mathrm{vy}}(\mathrm{kN})$ & Eq. (4.4) & 21,7 & 45,0 & 143,9 & 117,4 \\
\hline$f_{s, r e d}(\mathrm{MPa})$ & $0,7 \cdot f_{s y}$ & 175,0 & 175,0 & 175,0 & 175,0 \\
\hline$\sigma_{\mathrm{sm}}(\mathrm{MPa})$ & Eq. (4.6.1) & $\begin{array}{c}\text { Não } \\
\text { considerado }\end{array}$ & $\begin{array}{c}\text { Não } \\
\text { considerado }\end{array}$ & 75,0 & 75,0 \\
\hline$\mu \cdot \sigma_{\mathrm{sm}} \cdot \mathrm{A}_{\mathrm{S}}(\mathrm{kN})$ & Eq. (4.6.b) & - & - & 36,83 & 29,46 \\
\hline $\mathrm{F}_{\mathrm{V}, \mathrm{red}}(\mathrm{kN})$ & Eq. (4.6.a) & - & - & 120,68 & 119,47 \\
\hline $\mathrm{F}_{\mathrm{v}, \text { total }}(\mathrm{kN})$ & Eq. (4.6) & 29,9 & 64,1 & 157,50 & 148,93 \\
\hline
\end{tabular}

Tabela 4.20 - Comparação das Resistências ao Cisalhamento Teóricas e Experimentais

\begin{tabular}{|c|c|c|c|c|}
\hline Pa râmetros & Piloto & Protótipo A & Protótipo B & Protótipo C \\
\hline $\mathrm{F}_{\mathrm{vy}, \text { min,calc }}(\mathrm{kN})$ & 16,6 & 32,1 & 111,3 & 91,7 \\
\hline $\mathrm{F}_{\mathrm{vy}, \text { min,exp }}(\mathrm{kN})$ & 17,5 & 40,0 & 100,0 & 80,0 \\
\hline Calc. / Experim. & 0,95 & 0,80 & 1,11 & 1,15 \\
\hline $\mathrm{F}_{\mathrm{vy}, \text { calc }}(\mathrm{kN})$ & 21,7 & 45,0 & 143,9 & 117,2 \\
\hline $\mathrm{F}_{\mathrm{vy}, \exp }(\mathrm{kN})$ & 22,5 & 50,0 & 140,0 & 110,0 \\
\hline Calc. / Experim. & 0,96 & 0,90 & 1,03 & 1,07 \\
\hline $\mathrm{F}_{\mathrm{vu}, \text { calc }}(\mathrm{kN})$ & 29,9 & 64,1 & 157,5 & 149,0 \\
\hline $\mathrm{F}_{\mathrm{vu}, \exp }(\mathrm{kN})$ & 34,0 & 60,0 & 170,0 & 150,0 \\
\hline Calc. / Experim. & 0,88 & 1,07 & 0,93 & 0,99 \\
\hline
\end{tabular}


Na tabela 4.21 são apresentados os parâmetros que foram utilizados para o cálculo da deformabilidade ao cisalhamento na ligação através da equação (4.19), apresentada no item 4.4 deste capítulo. Na tabela 4.22 são feitas comparações entre as deformabilidades teóricas e experimentais.

Tabela 4.21 - Cálculo das Deformabilidades ao Cisalhamento nos Protótipos

\begin{tabular}{|c|c|c|c|c|c|}
\hline Pa râmetros & Obtenção & Piloto & Protótipo A & Protótipo B & Protótipo C \\
\hline$f_{\text {ck,min }}(\mathrm{MPa})$ & Graute & 30,0 & 30,0 & 30,0 & 30,0 \\
\hline$f_{\text {ck,máx }}(\mathrm{MPa})$ & Concreto & 51,5 & 59,0 & 50,2 & 49,0 \\
\hline $\mathrm{K}_{\mathrm{c} 1}(\mathrm{MPa} / \mathrm{mm})$ & (Eq. 4.18) & 109,55 & 109,55 & 81,36 & 81,36 \\
\hline $\mathrm{K}_{\mathrm{c} 2}(\mathrm{MPa} / \mathrm{mm})$ & (Eq. 4.18) & 148,33 & 154,3 & 105,24 & 104,19 \\
\hline$\alpha_{1}\left(\mathrm{~m}^{-1}\right)$ & (Eq. 4.17) & 28,72 & 28,72 & 19,08 & 19,08 \\
\hline$\alpha_{2}\left(\mathrm{~m}^{-1}\right)$ & (Eq. 4.17) & 30,98 & 31,29 & 20,34 & 20,29 \\
\hline $\mathrm{E}_{\mathrm{S}}(\mathrm{MPa})$ & Adotado & 200.000 & 200.000 & 200.000 & 200.000 \\
\hline$\phi_{\mathrm{b}}(\mathrm{m})$ & Dado inicial & 0,016 & $2 \times 0,016$ & $2 \times 0,025$ & $2 \times 0,025$ \\
\hline $\mathrm{I}_{\mathrm{b}}\left(\mathrm{m}^{4}\right)$ & Dado inicial & $3,22 \times 10^{-9}$ & $3,22 \times 10^{-9}$ & $1,92 \times 10^{-8}$ & $1,92 \times 10^{-8}$ \\
\hline $\mathrm{G}_{(\mathrm{MPa})}$ & (Dureza 60 A) & 1,0 & 1,0 & 1,0 & 1,0 \\
\hline $\mathrm{A}_{\mathrm{n}}\left(\mathrm{m}^{2}\right)$ & Dado inicial & 0,045 & 0,045 & 0,075 & 0,06 \\
\hline $\mathrm{h}_{\mathrm{n}}(\mathrm{m})$ & Dado inicial & 0,01 & 0,01 & 0,01 & 0,015 \\
\hline$\lambda_{\tau, \text { lig }}(\mathrm{mm} / \mathrm{kN})$ & (Eq. 4.19) & $29,3 \times 10^{-3}$ & $15,5 \times 10^{-3}$ & $9,17 \times 10^{-3}$ & $9,49 \times 10^{-3}$ \\
\hline
\end{tabular}

Tabela 4.22 - Comparação das Deformabilidades ao Cisalhamento Teóricas e Experimentais

\begin{tabular}{|c|c|c|c|c|}
\hline & Piloto & Protótipo A & Protótipo B & Protótipo C \\
\hline $\begin{array}{c}\lambda_{\tau, \text { lig }}(\mathrm{mm} / \mathrm{kN}) \\
\text { (calculado) }\end{array}$ & $29,3 \times 10^{-3}$ & $15,5 \times 10^{-3}$ & $9,17 \times 10^{-3}$ & $9,49 \times 10^{-3}$ \\
\hline $\begin{array}{c}\lambda_{\tau, \text { lig }}(\mathrm{mm} / \mathrm{kN}) \\
(\text { experimentaP) }\end{array}$ & $22,0 \times 10^{-3}$ & $14,0 \times 10^{-3}$ & $3,7 \times 10^{-3}$ & $7,5 \times 10^{-3}$ \\
\hline $\begin{array}{c}\text { Calc. / Experim } \\
.\end{array}$ & 1,33 & 1,11 & 2,48 & 1,26 \\
\hline
\end{tabular}


$\mathrm{Na}$ tabela 4.23 são apresentados os deslocamentos horizontais na ligação que foram calculados com base no desenvolvimento teórico apresentado no item 4.3 do presente trabalho.

Tabela 4.23 - Cálculo dos deslocamentos horizontais nas ligações

\begin{tabular}{|c|c|c|c|c|c|}
\hline & Dados & Piloto & Protótipo A & Protótipo B & Protótipo C \\
\hline $\mathrm{F}_{\mathrm{vy}, \text { min }}(\mathrm{kN})$ & Eq. (4.4) & 16,6 & 32,1 & 111,3 & 91,7 \\
\hline$\lambda_{\tau, \text { lig }}(\mathrm{mm} / \mathrm{kN})$ & $($ Eq. 4.19) & $2,93 \times 10^{-2}$ & $1,55 \times 10^{-2}$ & $9,17 \times 10^{-2}$ & $9,49 \times 10^{-2}$ \\
\hline$A_{\mathrm{vy}, \min }(\mathrm{mm})$ & $($ Eq. 4.18) & 0,50 & 0,61 & 0,97 & 0,87 \\
\hline$f_{\text {ck,min }}(\mathrm{MPa})$ & Graute & 30,0 & 30,0 & 30,0 & 30,0 \\
\hline$f_{\text {ck,máx }}(\mathrm{MPa})$ & Concreto & 51,5 & 59,0 & 50,2 & 49,0 \\
\hline$\phi_{\mathrm{b}}(\mathrm{m})$ & Dado inicial & 0,016 & $2 \times 0,016$ & $2 \times 0,025$ & $2 \times 0,025$ \\
\hline $\mathrm{k}$ & ENGSTÖM (1992) & 1,75 & 1,75 & 1,75 & 1,75 \\
\hline$f_{s, \text { red }}(\mathrm{MPa})$ & $0,7 . \mathrm{f}_{\mathrm{Sy}}$ & 175,0 & 175,0 & 175,0 & 175,0 \\
\hline$\alpha_{\mathrm{crit}}(\mathrm{rad})$ & (Eq. 4.17) & 0,096 & 0,096 & 0,061 & 0,061 \\
\hline$\phi_{\mathrm{b}}(\mathrm{m})$ & Dado inicial & 0,016 & $2 \times 0,016$ & $2 \times 0,025$ & $2 \times 0,025$ \\
\hline $\mathrm{C}_{1}$ & Adotado & 1,24 & 1,24 & 1,24 & 1,24 \\
\hline $\mathrm{X}_{1}(\mathrm{~m})$ & Eq. (4.8) & 0,010 & 0,010 & 0,016 & 0,016 \\
\hline $\mathrm{X}_{2}(\mathrm{~m})$ & Eq. (4.8) & 0,008 & 0,007 & 0,013 & 0,013 \\
\hline $\mathrm{h}_{\mathrm{n}}(\mathrm{m})$ & Dado inicial & 0,01 & 0,01 & 0,01 & 0,015 \\
\hline$\ell_{\mathrm{a}}(\mathrm{m})$ & Eq. (4.9.4) & 0,028 & 0,028 & 0,039 & 0,044 \\
\hline$a_{\mathrm{vy}}(\mathrm{mm})$ & Eq. (4.9.1) & 2,71 & 2,66 & 2,38 & 2,69 \\
\hline$a_{\mathrm{v}, \text { toal }}(\mathrm{mm})$ & Extra pola ção & 5,45 & 5,78 & 4,96 & 3,00 \\
\hline
\end{tabular}

A partir das deformabilidades iniciais ao cisalhamento, das resistências de cisalhamento e dos deslocamentos associados foram construídos diagramas tri-lineares para representar o comportamento força de cisalhamento vs deslocamento horizontal nos protótipos, a partir do procedimento apresentado no item 4.5 deste trabalho. Nos gráficos 4.36 ao 4.39 são apresentadas as comparações entre as curvas experimentais e os diagramas teóricos. 


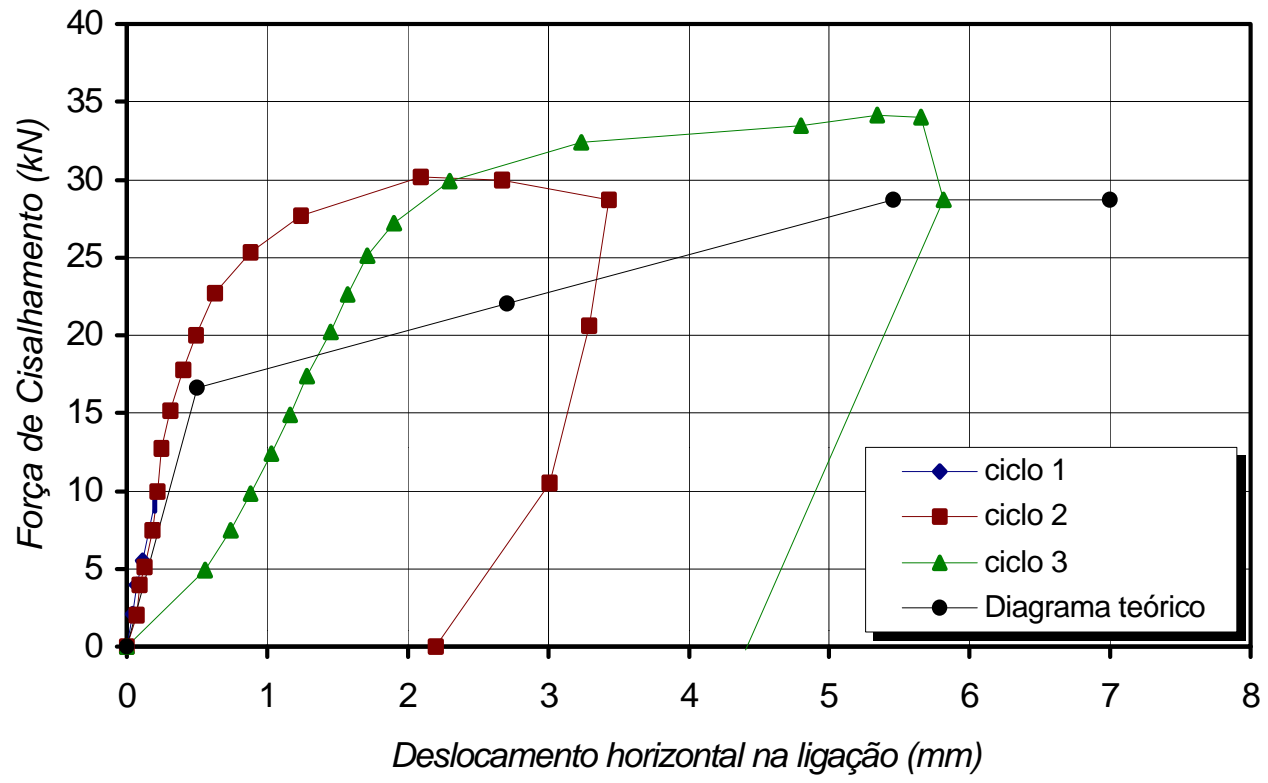

Gráfico 4.36 - Diagrama Teórico para o Protótipo Piloto

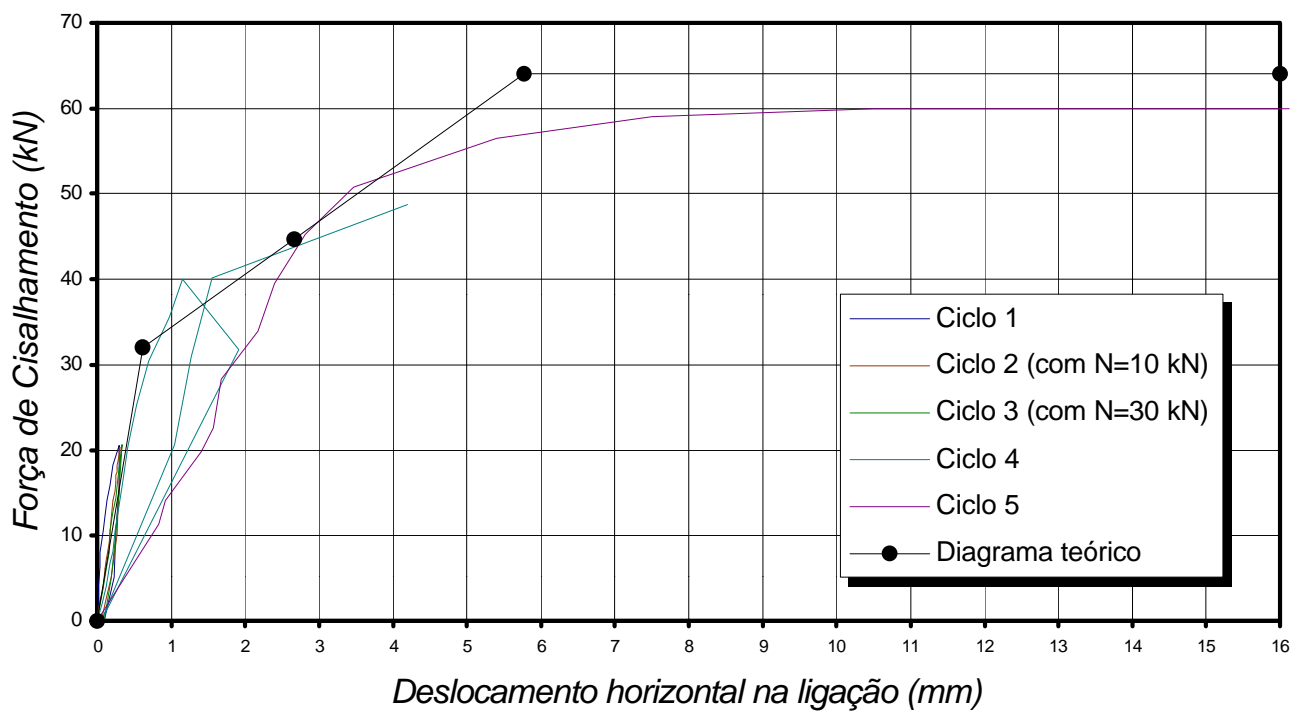

Gráfico 4.37 - Diagrama Teórico para o Protótipo A 


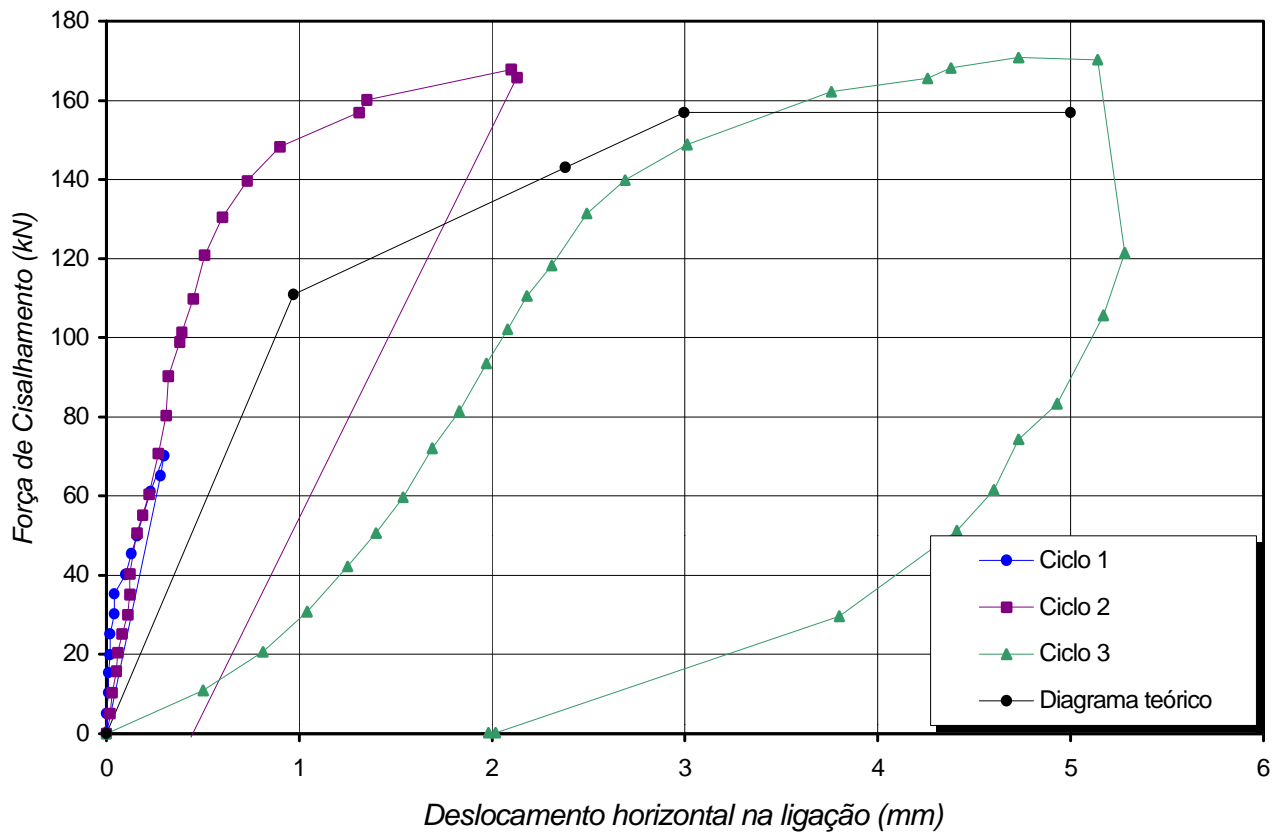

Gráfico 4.38 - Diagrama Teórico para o Protótipo B

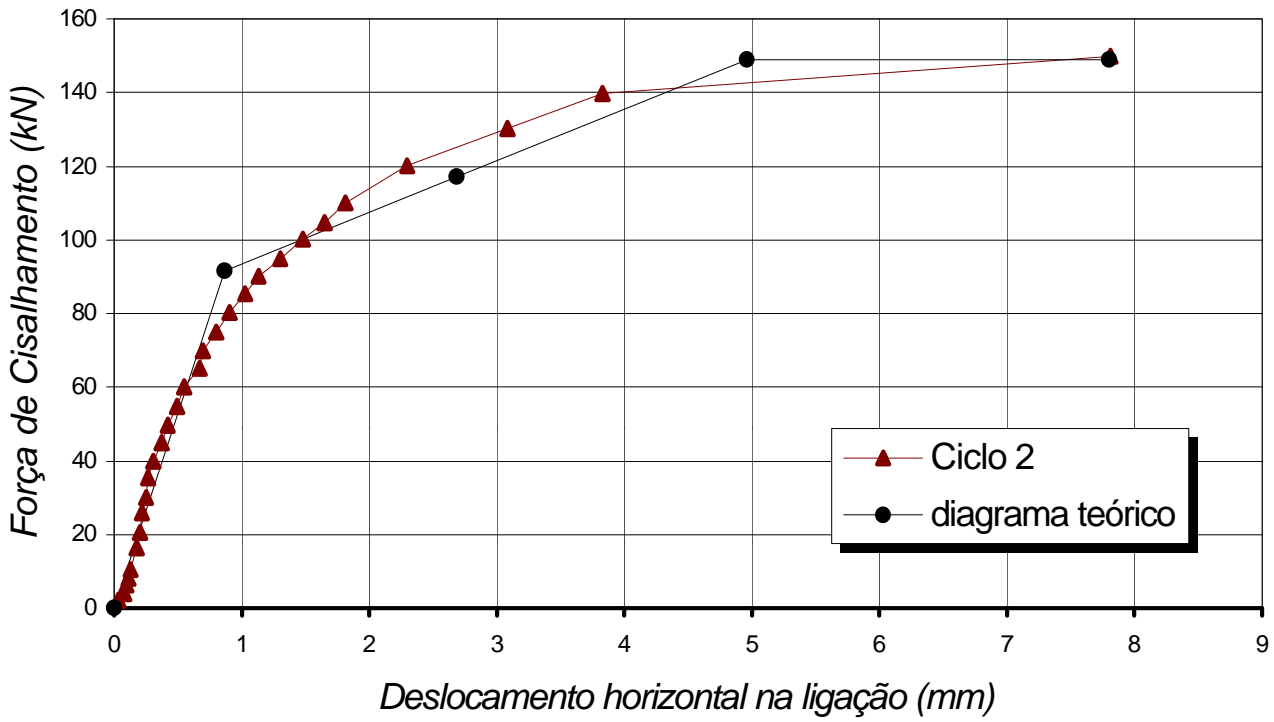

Gráfico 4.39 - Diagrama Teórico para o Protótipo C 
A seguir, são feitos alguns comentários com base nos resultados experimentais e nas comparações com os valores obtidos nos procedimentos teóricos.

A partir do procedimento teórico proposto por ENGSTRÖM (1992a), obteve-se boas estimativas para as resistências ao cisalhamento da ligação para os protótipos ensaiados (ver tabela 4.20).

$\mathrm{O}$ equacionamento desenvolvido com base nas associações dos mecanismos de deformação presentes na ligação, dado pela equação (4.19), forneceu uma boa estimativa para as deformabilidades ao cisalhamento da ligação para os protótipos Piloto, A e C (ver talela 4.22). Todavia, para o caso do protótipo B, a deformabilidade experimental foi quase 2,5 vezes menor do que a deformabilidade teórica, ou seja, a rigidez ao cisalhamento experimental foi 2,5 vezes maior do que a estimativa teórica.

No caso do protótipo $\mathrm{B}$, a resistência ao cisalhamento experimental, $\mathrm{F}_{\mathrm{vu}, \mathrm{exp}}=170$ $\mathrm{kN}$, também foi superior à resistência estimada teoricamente, $\mathrm{F}_{\mathrm{vu}, \mathrm{calc}}=157,5 \mathrm{kN}$. Desta forma, tanto do ponto de vista da rigidez quanto da resistência ao cisalhamento, o protótipo B apresentou um desempenho maior do que o desempenho esperado teoricamente.

O protótipo B também apresentou um desempenho elevado nos ensaios de flexão e de torção, onde a rigidez do protótipo $\mathrm{B}$ foi muito superior à rigidez dos demais protótipos, mesmo em se comparando com o protótipo $\mathrm{C}$, que possui chumbadores com os mesmos diâmetros do protótipo B.

A rigidez à flexão do protótipo $\mathrm{B}$ foi 1,7 vezes maior do que a rigidez à flexão do protótipo C. Por outro lado, a rigidez à torção do protótipo $\mathrm{B}$ foi 10 vezes maior do que a rigidez à torção do protótipo $\mathrm{C}$.

Acredita-se que a razão para que o protótipo B tenha apresentado um desempenho singular, em relação aos demais protótipos, está no fato de ter sido empregada uma almofada com um fator de forma alto, $\mathrm{B}=6,81$, com espessura de $10 \mathrm{~mm}$ e comprimento de $250 \mathrm{~mm}$. Mesmo para tensões baixas, em razão dessa geometria, a almofada de elastômero apresenta um módulo de elasticidade da ordem de $65 \mathrm{MPa}$, possuindo assim uma maior restrição às deformações por compressão. 
Por outro lado, devido ao seu comprimento, a almofada apresenta restrições parciais aos giros relativos entre os elementos. Isto foi comprovado durante os ensaios de flexão, onde a ligação apresentou uma rigidez á flexão da ordem de $K_{\phi l i g}=421 \mathrm{kN} . \mathrm{m} / \mathrm{rad}$.

Todavia, com base somente nos ensaios de flexão, não foi possível avaliar qual a parcela da influência da almofada de elastômero na restrição ao giro na ligação. Neste caso, a almofada de elastômero não foi o único parâmetro que afetou a rigidez da ligação, pois com o aumento da espessura da almofada, também aumentou a altura livre entre os dois elementos de concreto, de $10 \mathrm{~mm}$ para $15 \mathrm{~mm}$, aumentando o comprimento da barra do chumbador que está na interface da ligação. Desta forma, também a rigidez da barra foi afetada. Assim, tanto a rigidez do chumbador quanto a geometria da almofada está afetando a deformabilidade á flexão da ligação.

Todavia, a partir dos resultados dos ensaios de torção, pode-se concluir que a geometria da almofada teve uma parcela expressiva na restrição às rotações laterais, onde o principal fator foi a espessura da almofada. No caso do protótipo $\mathrm{C}$, com uma almofada de $15 \mathrm{~mm}$ de espessura, a deformabilidade à torção foi superior á deformabilidade apresentada pelo protótipo A, que possuiu chumbadores com diâmetros menores.

Assim, no caso da deformabilidade ao cisalhamento da ligação, acredita-se que tenha ocorrido algum mecanismo de restrição às rotações relativas entre os elementos, simultaneamente à aplicação da força de cisalhamento, diminuindo a deformabilidade ao cisalhamento da ligação.

No caso da resistência ao cisalhamento, com o aumento da almofada tem-se uma área de contato maior, aumentando o atrito na interface da ligação. Também, a restrição parcial às rotações, por parte da almofada de elastômero, faz com que haja um aumento da força de tração na barra do chumbador, aumentando assim a colaboração do efeito do atrito na capacidade ao cisalhamento da ligação.

Recomenda-se almofadas com fator de forma $\mathrm{B}<5$, para uma relação entre 0 comprimento e a espessura da almofada dada por a $/ \mathrm{h}_{\mathrm{n}}<20$. Também, um importante parâmetro a ser levado em conta seria a relação existente entre a altura da almofada em função do diâmetro, onde se recomenda que essa relação seja $\phi_{b} / h_{n}>1$ e, quando se deseja um desempenho maior para a rigidez da ligação, recomenda-se uma relação $\phi_{b} / h_{n}$ $>1,5$. 


\section{Capítulo 5}

\section{Ligação Viga-Pilar com Resistência à Flexão com Chapas Soldadas}

\subsection{Preliminares}

No início dos anos 80, houve nos EUA uma grande preocupação em se desenvolver ligações viga-pilar com resistência à flexão, com o objetivo de aplicá-las às estruturas de concreto pré-moldado destinadas às regiões sísmicas. Pretendia-se selecionar ligações típicas, dentre as ligações então existentes, que apresentassem um bom desempenho quanto à sua resistência à flexão, à sua rigidez e à sua ductilidade.

Com este objetivo, o Precast/Prestressed Concrete Institute (PCI) realizou um amplo programa de pesquisa, onde foram ensaiadas e comparadas várias tipologias de ligações vigapilar resistentes à flexão. Os resultados desta pesquisa estão registrados em STANTON et al. (1986), havendo também um resumo da mesma apresentado em DOLAN et al. (1987). Dentre as ligações estudadas, a ligação viga-pilar com resistência à flexão, com apoio sobre consolo e conexões por chapas soldadas, indicada na figura 5.1, foi uma das ligações selecionadas como sendo de grande interesse para estudos posteriores. Segundo aqueles autores, a ligação apresentou um bom desempenho quanto à sua resistência e à sua rigidez. Todavia, a ligação apresentou algumas deficiências em seu detalhamento inicial. A ruptura da ligação ocorreu por uma falha na solda de topo entre as barras da armadura da viga e as chapas metálicas. Este fenômeno foi agravado devido à rotação da extremidade da viga sobre a borda do consolo, provocando um efeito de alavanca da viga sobre à sua armadura, na região da ligação, aumentando a concentração das tensões nas regiões próximas à solda de topo, provocando assim uma ruptura não desejada. A partir deste direcionamento de pesquisa, DOLAN \& PESSIKI (1989) reestudaram a ligação, fazendo um estudo experimental com modelos em escala reduzida, dando seqüência ao trabalho de STANTON et al. (1986) e obtendo novas informações a respeito da ligação. Eles apresentaram propostas de melhorias no detalhamento da ligação, onde recomendaram que fossem utilizadas soldas de filete na ligação entre as barras da armadura e as chapas na ligação, em lugar das soldas de topo. 
Também, recomendaram que fossem minimizadas as excentricidades entre os eixos das armaduras na viga e os planos médios das chapas na ligação. Entretanto, as ligações por eles ensaiadas não apresentaram o desempenho desejado quanto à sua rigidez. Mesmo assim, segundo esses autores, esta ligação é uma alternativa interessante para a composição de pórticos com nós "rígidos" em estruturas de múltiplos pavimentos, tendo sido considerada com um grande potencial de utilização nos EUA. No Brasil ainda não se tem uma tradição da utilização de ligações resistentes à flexão, para a composição de estruturas pré-moldadas com múltiplos pavimentos, tendo-se poucas aplicações nesta área.

Assim, com base nestas informações preliminares, escolheu-se esta ligação, como representante tipo das ligações resistentes à flexão, para ser objeto do estudo analítico e experimental na presente pesquisa.

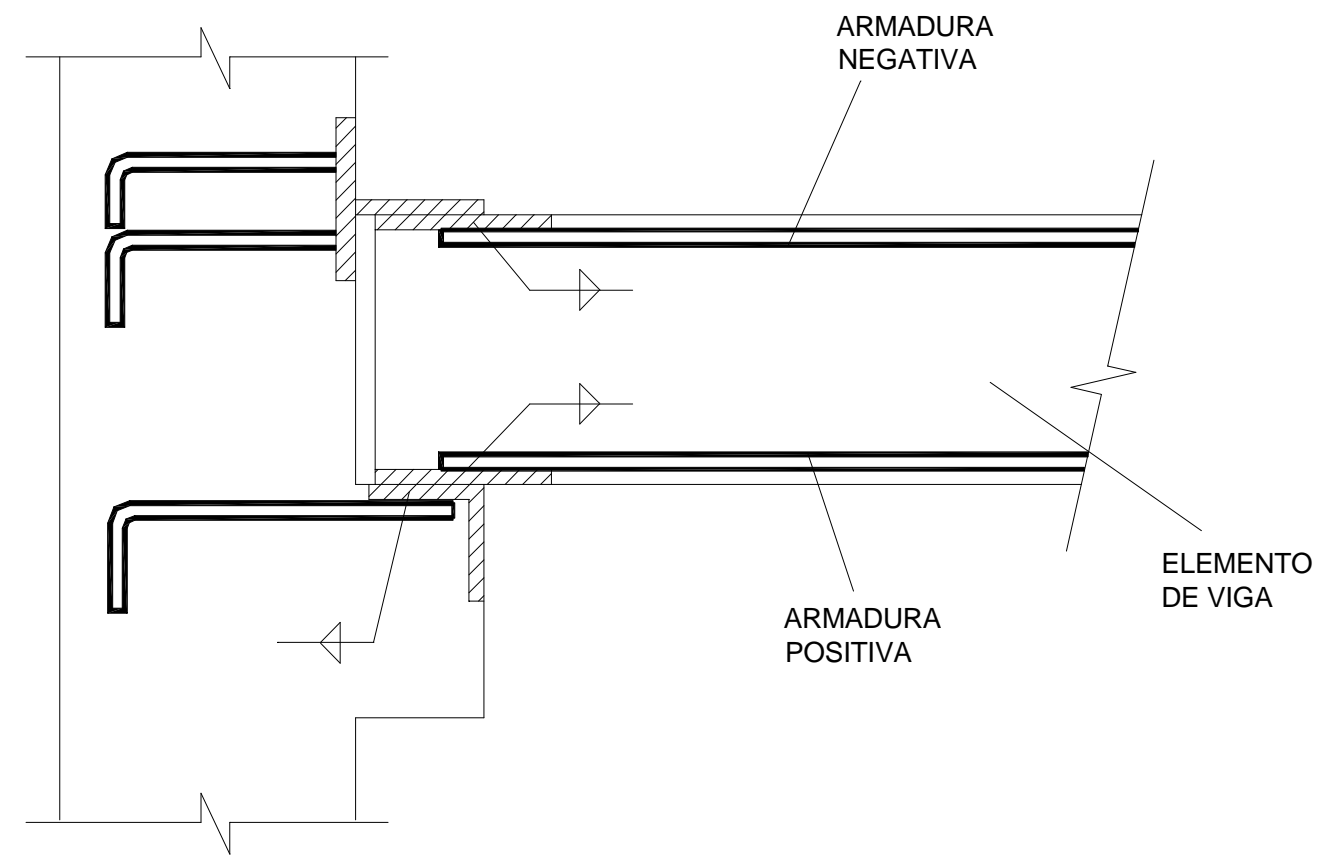

Figura 5.1 - Modelo da ligação viga-pilar resistente à flexão por meio de chapas soldadas. 


\subsection{Equacionamento para o cálculo da Deformabilidade à Flexão da Ligação}

Utilizando a metodologia dos mecanismos básicos de deformação, em FERREIRA (1993) desenvolveu-se um equacionamento para o cálculo da deformabilidade à flexão para uma rotação causada por um momento negativo na ligação. Na figura 5.2 é apresentada a ligação em sua configuração deformada. Nesta configuração, o consolo foi considerado como sendo um corpo rígido e sua excentricidade como centro de rotação da ligação. $\mathrm{O}$ trecho da extremidade da viga, sobre o consolo, também foi considerado como um elemento rígido.

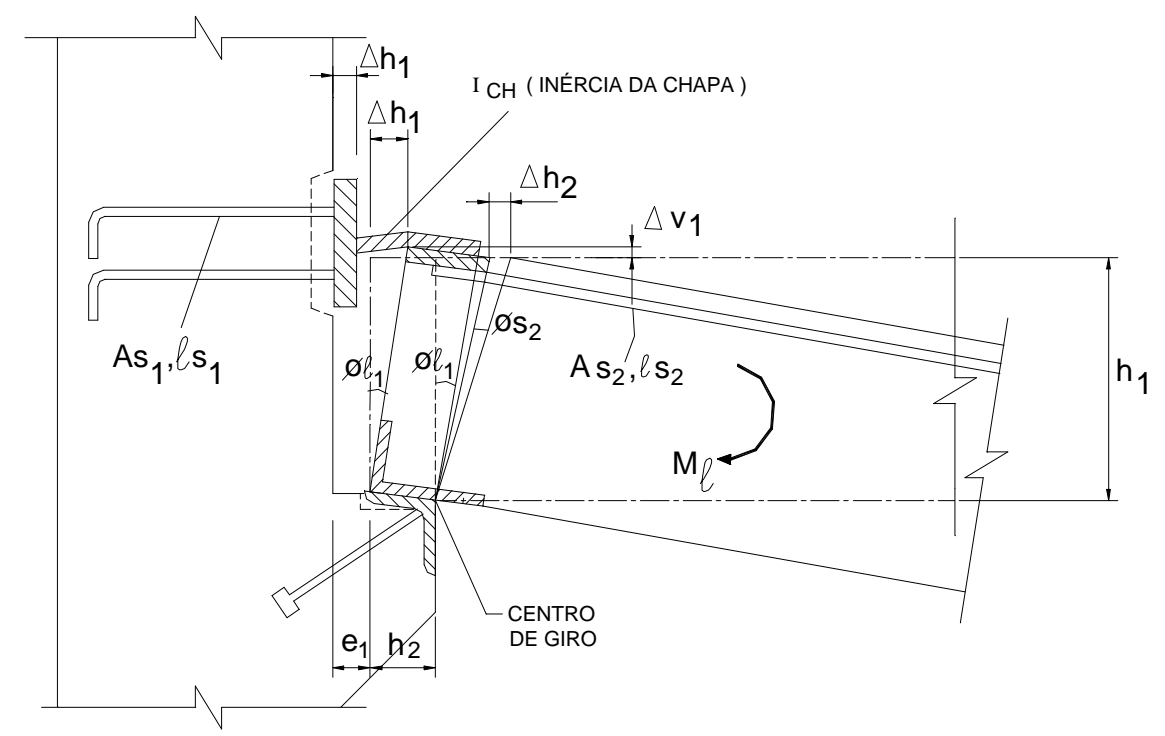

Figura 5.2 - Hipótese da configuração deformada da ligação [FERREIRA (1993)].

Foram considerados os seguintes mecanismos básicos de deformação:

- Mecanismo de Deformação por Tração nas barras de ancoragem, Inseridas no pilar, na extremidade superior da viga, (MDT-BI);

- Mecanismo de Deformação por Flexão nas Chapas soldadas na parte superior da ligação, (MDF-CH);

- Mecanismo de Deformação por Tração da armadura negativa da viga, Inserida na extremidade da viga, (MDT-BI). 
Na figura 5.3 é apresentada uma esquematização por meio de molas que representa a associação dos mecanismos de deformação considerados. Os esquemas das forças aplicadas na ligação e a relação entre os deslocamentos são apresentados na figura 5.4.

(MDF-CH)

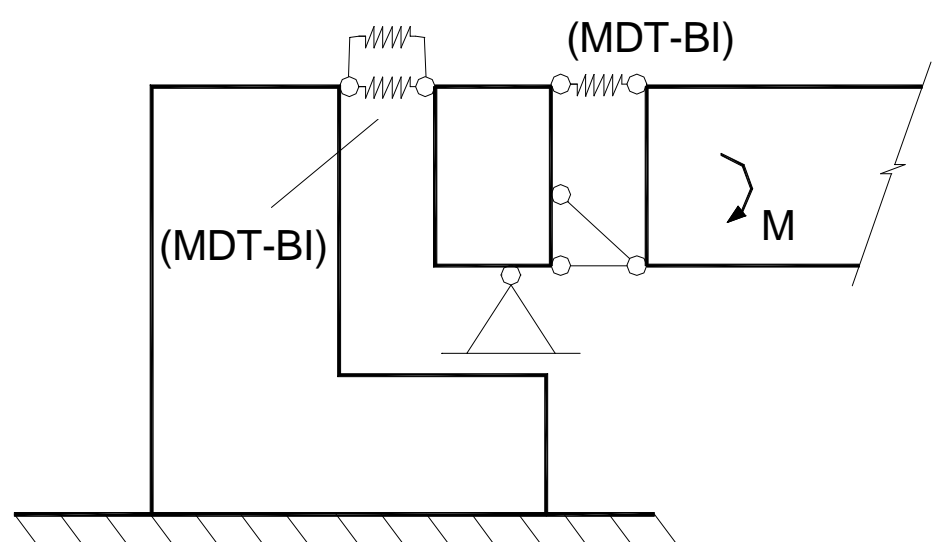

Figura 5.3 - Esquematização por meio de molas para representação da associação dos mecanismos de deformação presentes na ligação viga-pilar rígida.

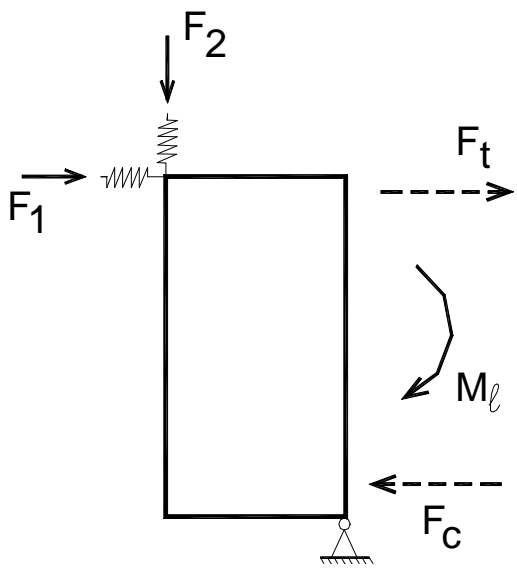

a)

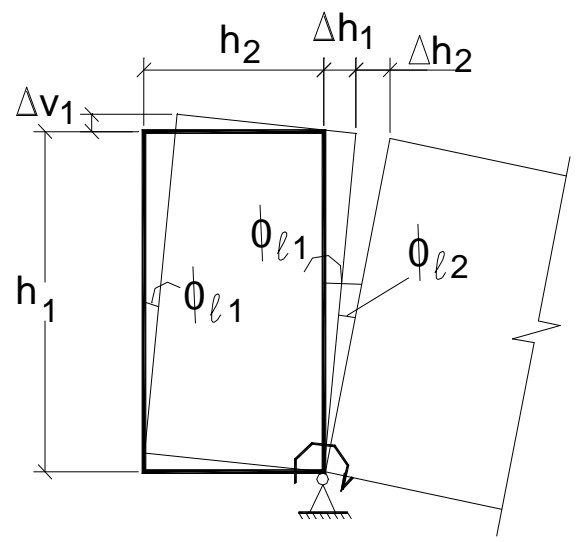

b)

Figura 5.4 - a) Esquema de forças aplicadas

b) Idealização de deslocamentos na extremidade da viga 
A equação de equilíbrio é dada por:

$$
F_{1} h_{1}+F_{2} h_{2}+F_{c}\left(h_{1}-z\right)-F_{t} h_{1}=0
$$

para $F_{c}=F_{t}$ tem-se:

$$
F_{1} h_{1}+F_{2} h_{2}-F_{t} z=0
$$

Da relação para o momento da ligação, dado por:

$$
M_{\text {lig }}=F_{c} \cdot z=F_{t} \cdot z
$$

a equação de equilíbrio fica:

$$
F_{1} h_{1}+F_{2} h_{2}=M_{\text {lig }}
$$

A deformabilidade à flexão é dada por

$$
\lambda_{\theta \text { lig }}=\theta_{\ell} / M_{\text {lig }}
$$

Para a rotação da ligação, $\theta_{\ell 1}$, considerou-se a contribuição de duas parcelas. A primeira, $\theta_{11}$, relativa ao giro da extremidade da viga sobre o consolo, causada pela deformação do vínculo viga-pilar (neg.). A segunda parcela, $\theta_{\ell 2}$, relativa ao giro da extremidade da viga sobre o consolo, causada pela deformação da armadura negativa na região da ligação. Pelas relações geométricas da figura 5.4, a expressão para a rotação da ligação é dada por:

$$
\theta_{\ell}=\theta_{\ell 1}+\theta_{\ell 2}=\frac{\Delta h_{1}}{h_{1}}+\frac{\Delta h_{2}}{h_{1}}
$$


Assim, a equação para a deformabilidade à flexão pode ser escrita na forma:

$$
\lambda_{\theta l i g}=\frac{\Delta h_{1}}{M_{\text {lig }} h_{1}}+\frac{\Delta h_{2}}{M_{\text {lig }} h_{1}}
$$

Os deslocamentos indicados na figura (5.4) são dados por:

$$
\begin{aligned}
& \Delta h_{1}=\frac{\ell_{s 1} \cdot F_{1}}{E_{s} \cdot A_{s 1}} \\
& \Delta h_{2}=\frac{\ell_{s 2} \cdot F_{t}}{E_{s} \cdot A_{s 2}} \\
& \Delta v_{1}=\frac{e_{1}^{3} \cdot F_{2}}{12 E_{s} \cdot I_{c h}}
\end{aligned}
$$

onde:

$\ell_{S 1}$ - comprimento considerado na deformação da barra ancorado no pilar

$\ell_{S 2}$ - comprimento considerado na deformação da armadura negativa na viga

$e_{1}$ - excentricidade entre a face do pilar e a força $\mathrm{F} 1$

$A_{S 1}$ - área da seção transversal das barras de ancoragem para a vinculação negativa no pilar

$A_{S 2}$ - área da seção transversal da armadura negativa da viga

$I_{c h}$ - momento de inércia da chapa da vinculação negativa viga-pilar

Das relações na figura (5.4), para pequenos deslocamentos, tem-se:

$$
\frac{\Delta v_{1}}{h_{2}}=\frac{\Delta h_{1}}{h_{1}}
$$

Substituindo-se as expressões (5.7) e (5.9) na expressão (5.10), tem-se:

$$
F_{1}=F_{2} \cdot\left(\frac{e_{1}^{3} \cdot A_{s 1} \cdot h_{1}}{12 \ell_{s 1} \cdot I_{c h} \cdot h_{2}}\right)
$$


Substituindo a relação da expressão (5.11) na equação de equilíbrio (5.3), tem-se:

$$
F_{2}=M_{l i g} \cdot\left(\frac{e_{1}^{3} \cdot A_{s 1} \cdot h_{1}^{2}}{12 \ell_{s 1} \cdot I_{c h} \cdot h_{2}}+h_{2}\right)^{-1}
$$

Escrevendo os deslocamentos $\Delta \mathrm{h}_{1}, \Delta \mathrm{h}_{2}$ e $\Delta \mathrm{v}_{1}$ em função das expressões para $\mathrm{F}_{1}$ e $\mathrm{F}_{2}$, tem-se:

$$
\begin{aligned}
& \Delta h_{1}=M_{l i g} \cdot\left(\frac{e_{1}^{3} \cdot \ell_{s 1} \cdot h_{1}}{E_{s} \cdot\left(e_{1}^{3} \cdot A_{s 1} \cdot h_{1}^{2}+12 \ell_{s 1} \cdot I_{c h} \cdot h_{2}^{2}\right)}\right) \\
& \Delta v_{1}=M_{l i g} \cdot\left(\frac{e_{1}^{3} \cdot \ell_{s 1} \cdot h_{2}}{E_{s} \cdot\left(e_{1}^{3} \cdot A_{s 1} \cdot h_{1}^{2}+12 \ell_{s 1} \cdot I_{c h} \cdot h_{2}^{2}\right)}\right) \\
& \Delta h_{2}=M_{l i g} \cdot\left(\frac{\ell_{s 2}}{E_{s} \cdot A_{s 2} \cdot z}\right)
\end{aligned}
$$

A parcela da deformabilidade à flexão associada à rotação $\theta_{\ell 1}$ é dada por:

$$
\lambda_{\theta_{\ell 1}}=\frac{e_{1}^{3}}{12 E_{s} \cdot I_{c h} \cdot h_{2}}\left(\frac{e_{1}^{3} \cdot A_{s 1} \cdot h_{1}^{2}}{12 \ell_{s 1} \cdot I_{c h} \cdot h_{2}}+h_{2}\right)^{-1}
$$

A parcela da deformabilidade à flexão associada à rotação $\theta_{\ell 2}$ é dada por:

$$
\lambda_{\theta_{\ell 2}}=\frac{\ell_{s 2}}{E_{s} \cdot A_{s 2} \cdot z \cdot h_{1}}
$$

Sendo, a deformabilidade total da ligação dada por:

$$
\lambda_{\theta_{\ell}}=\frac{e_{1}^{3}}{12 E_{s} \cdot I_{c h} \cdot h_{2}}\left(\frac{e_{1}^{3} \cdot A_{s 1} \cdot h_{1}^{2}}{12 \ell_{s 1} \cdot I_{c h} \cdot h_{2}}+h_{2}\right)^{-1}+\frac{\ell_{s 2}}{E_{s} \cdot A_{s 2} \cdot z \cdot h_{1}}
$$


Com relação ao termo associado à rotação $\theta_{\ell 2}$, correspondente à parcela da deformação da armadura negativa na extremidade da viga, no estudo experimental realizado por DOLAN \& PESSIKI (1989) considerou-se uma região na extremidade da viga como pertencente à região da ligação compreendida por um trecho de comprimento de $0,56 \mathrm{~h}$, sendo $\mathrm{h}$ a altura da viga. A escolha deste trecho para a avaliação da rigidez da ligação se deu em virtude do aparecimento de uma maior concentração das fissuras, fato que havia sido verificado nos estudos experimentais realizados por STANTON et al. (1986). Esta questão está relacionada principalmente com o comprimento da barra da armadura negativa que será considerado para o cálculo da deformabilidade à tração, conforme é tratado no item 3.3.1 do presente trabalho, onde o comprimento da barra $\ell_{s 2}$ é dado por:

$$
\ell_{s 2} \cong 0,5 \cdot \ell_{b}
$$




\subsection{Ensaios de Flexão com Carregamento Alternado e Cíclico}

\subsubsection{Metodologia Experimental}

No estudo experimental em questão, analisou-se a interação da extremidade de um elemento de viga com a sua ligação junto a um pilar, sendo o pilar um elemento contínuo. Com base nesta situação, adotou-se um modelo em disposição cruciforme, com duas vigas unidas a um pilar central, onde a ação vertical foi aplicada sobre o elemento de pilar, simplificando o problema para um ensaio de flexão em uma viga bi-apoiada, figura 5.5a. Tal arranjo possibilitou a simulação da situação real de uma região próxima a um nó central de uma estrutura de pórtico, conforme figura 5.6b.

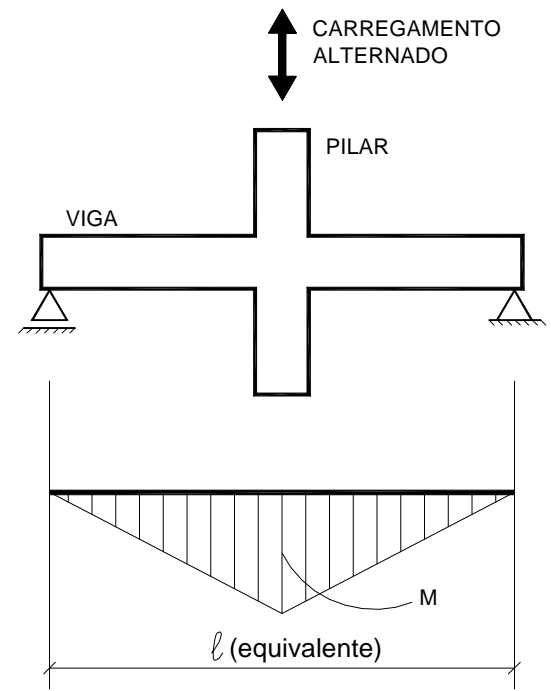

(a)

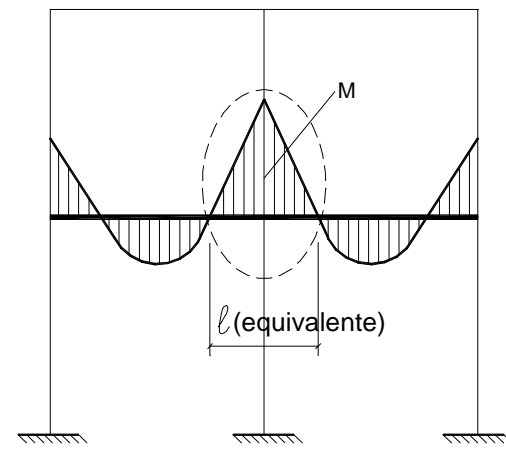

(b)

Figura 5.5 - Situação simulada de uma estrutura de pórtico.

Com a aquisição pelo LABORATÓRIO DE ESTRUTURAS (SET-EESC) de um atuador INSTRON-8506, que possibilita a aplicação de carregamento alternado com controle de deformação, decidiu-se fazer ensaios de flexão com carregamentos alternados e repetidos. Para isto, utilizou-se um pórtico de reação central, no qual o atuador foi fixado, e dois quadros de reação laterais que serviram para as reações nas extremidades livres dos elementos de viga, conforme indicados na seqüência de fotos na figura 5.6. 

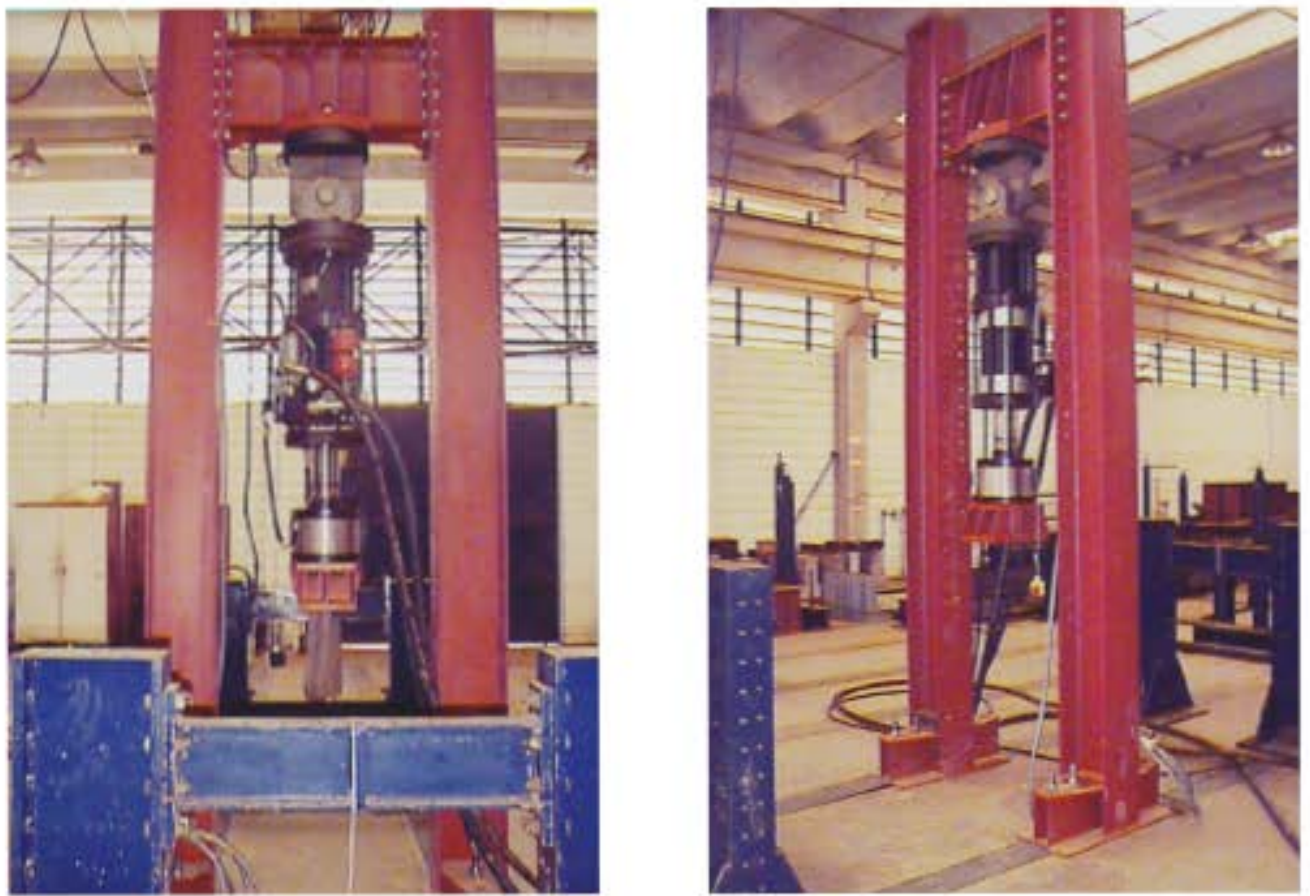

(a)
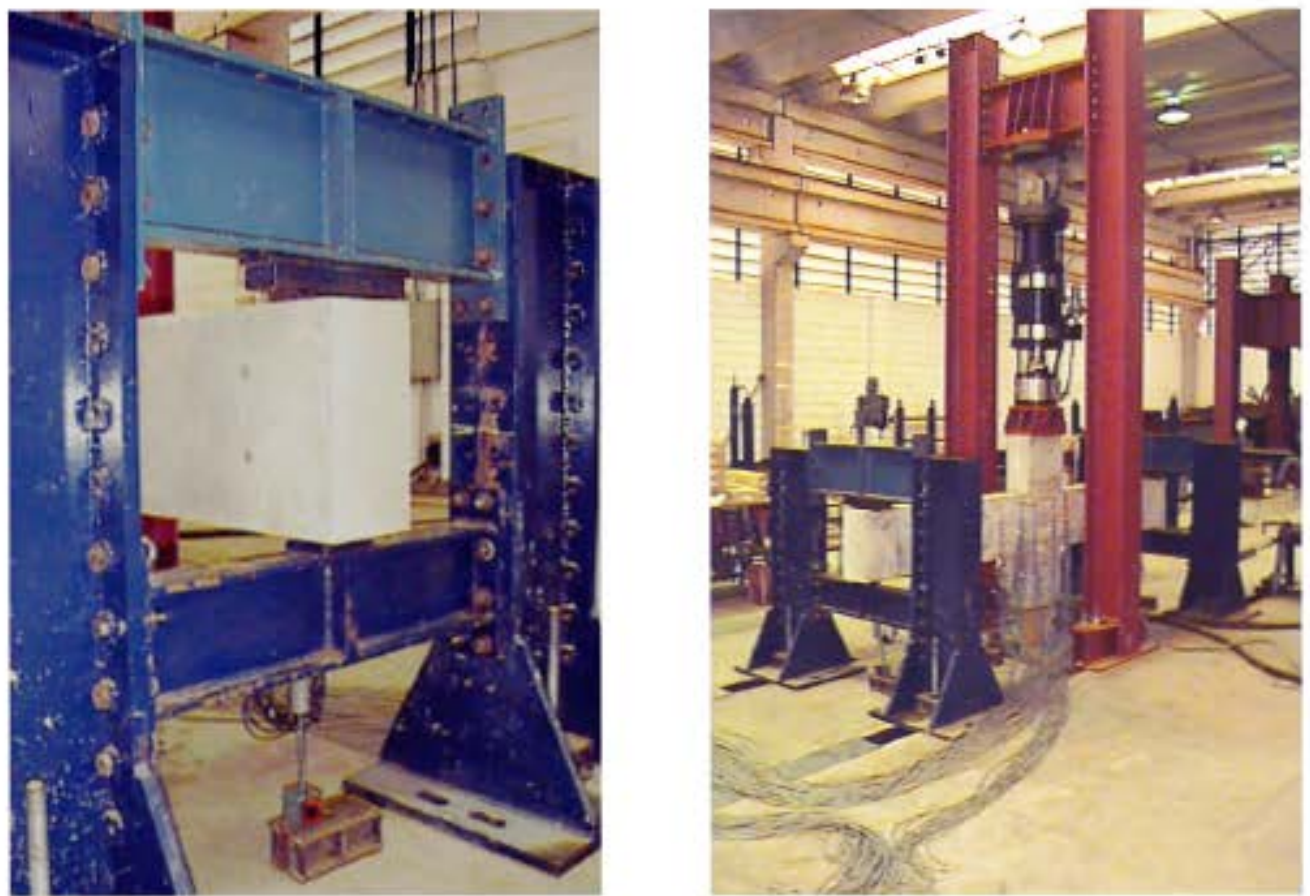

(b)

Figura 5.6 - a) Atuador INSTRON 8506 (ações alternadas e cíclicas, com controle de deformações). b) Disposição geral do modelo no pórtico de reação. 
Um dos problemas relativos aos ensaios para avaliação da rigidez à flexão de ligações resistentes à flexão é a questão da obtenção dos deslocamentos específicos da ligação, uma vez que nas medições dos deslocamentos externos, ou dos deslocamentos relativos entre os elementos estruturais, não se consegue garantir que estejam sendo medidos somente os deslocamentos específicos da ligação. Procurando minorar este problema, adotou-se o procedimento de ensaiar previamente um protótipo monolítico, compatível com o protótipo com ligações soldadas, onde alguns deslocamentos medidos no protótipo monolítico podem deduzidos ou comparados com os deslocamentos obtidos nos protótipos pré-moldados, conforme ilustrado na figura 5.8.

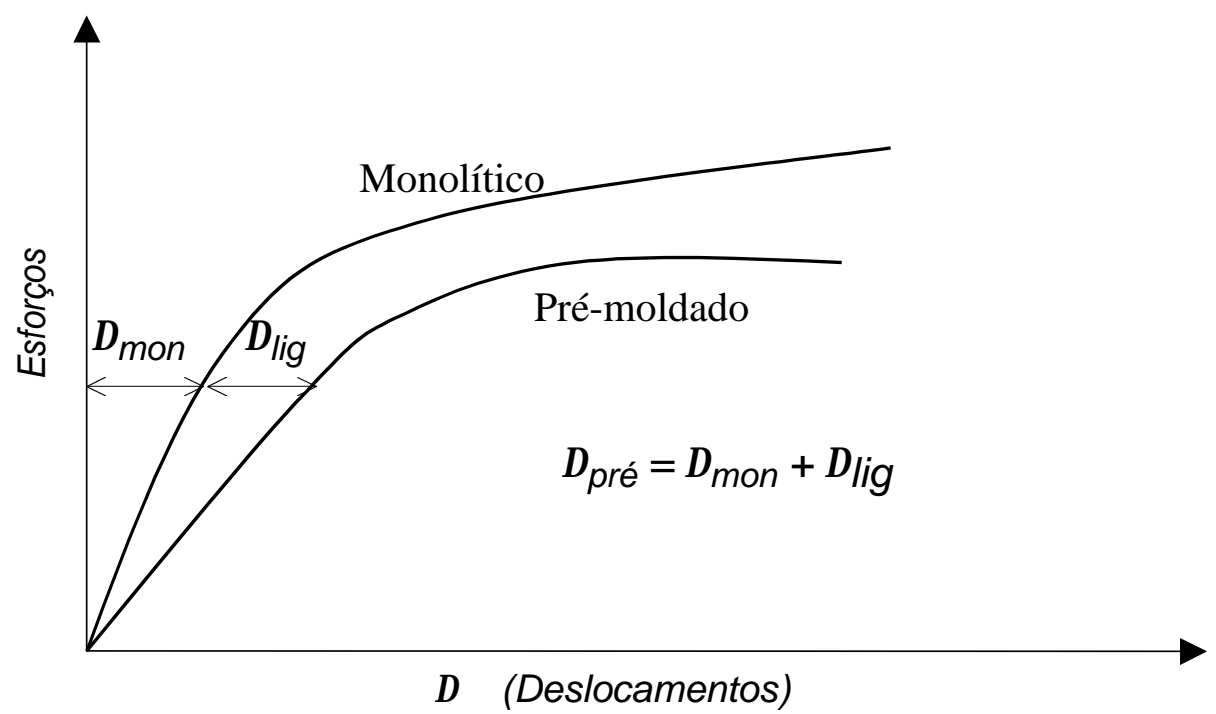

Figura 5.7 - Obtenção dos deslocamentos externos da ligação

\subsubsection{Protótipos e Propriedades dos Materiais}

Os protótipos foram executados em escala 1:1, onde se procurou caracterizar a região de ligação com dois elementos de viga unidos a um pilar central, sendo utilizados dois protótipos, um protótipo monolítico e um protótipo com ligações soldadas. O protótipo monolítico foi ensaiado primeiro e serviu como referência e controle dos deslocamentos específicos da ligação no protótipo com ligações soldadas. 


\subsubsection{Protótipo Monolítico}

Na figura 5.8 é apresentada a geometria para o protótipo monolítico, com uma seção para o elemento de viga com 40 × $20 \mathrm{~cm}^{2}$. Na figura 5.9 é apresentada uma vista do protótipo após a sua desforma.

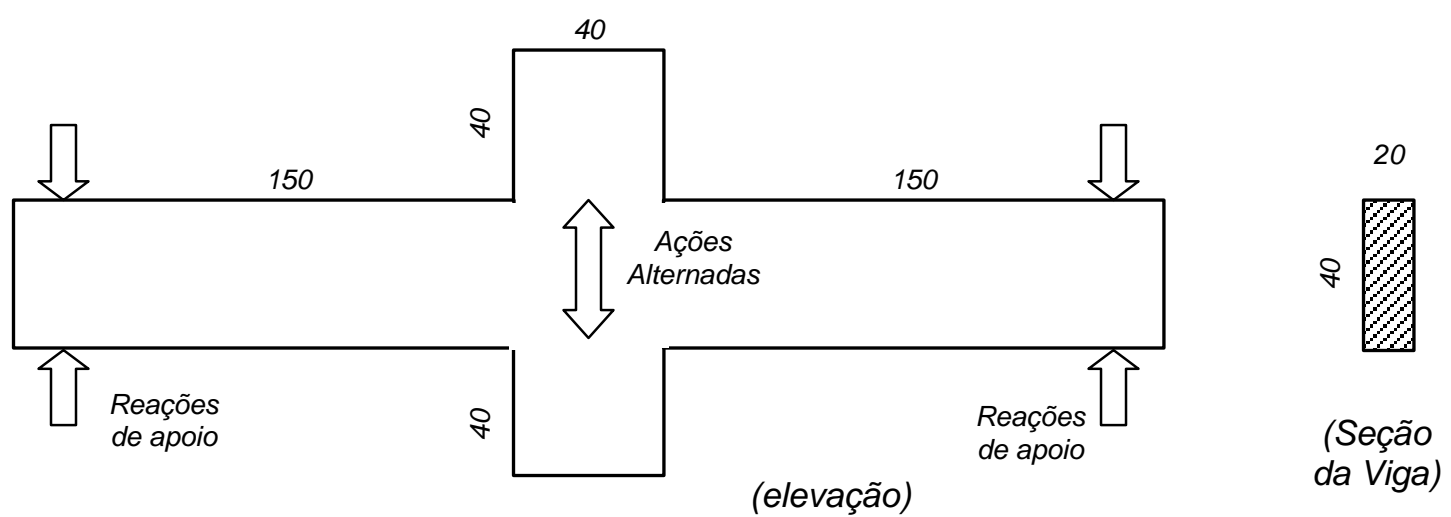

Figura 5.8 - Geometria do Protótipo Monolítico

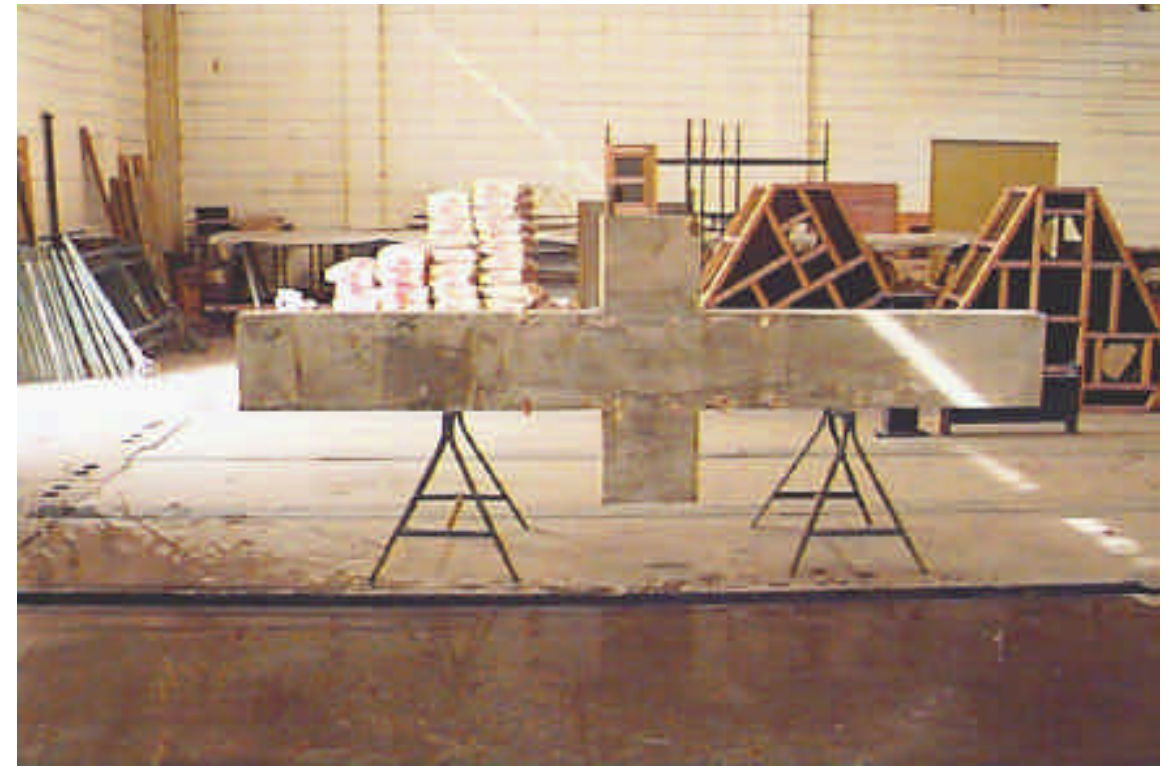

Figura 5.9 - Protótipo Monolítico após a desforma 
$\mathrm{Na}$ tabela 5.1 são apresentadas as propriedades do concreto utilizado no protótipo monolítico. O modelo foi concretado lateralmente, conforme indicado na figura 5.10. A desforma do modelo foi feita no terceiro dia e o ensaio foi programado para o sétimo dia. Em razão de problemas técnicos com o funcionamento do sistema do atuador, o ensaio teve inicio no oitavo dia. Também, como as leituras do painel do atuador tiveram de ser registradas manualmente, para uma série de ciclos de carregamento com deformação controlada, o ensaio estendeu-se por dois dias. Desta forma, houve uma variação das propriedades do concreto ao longo de todo o ensaio.

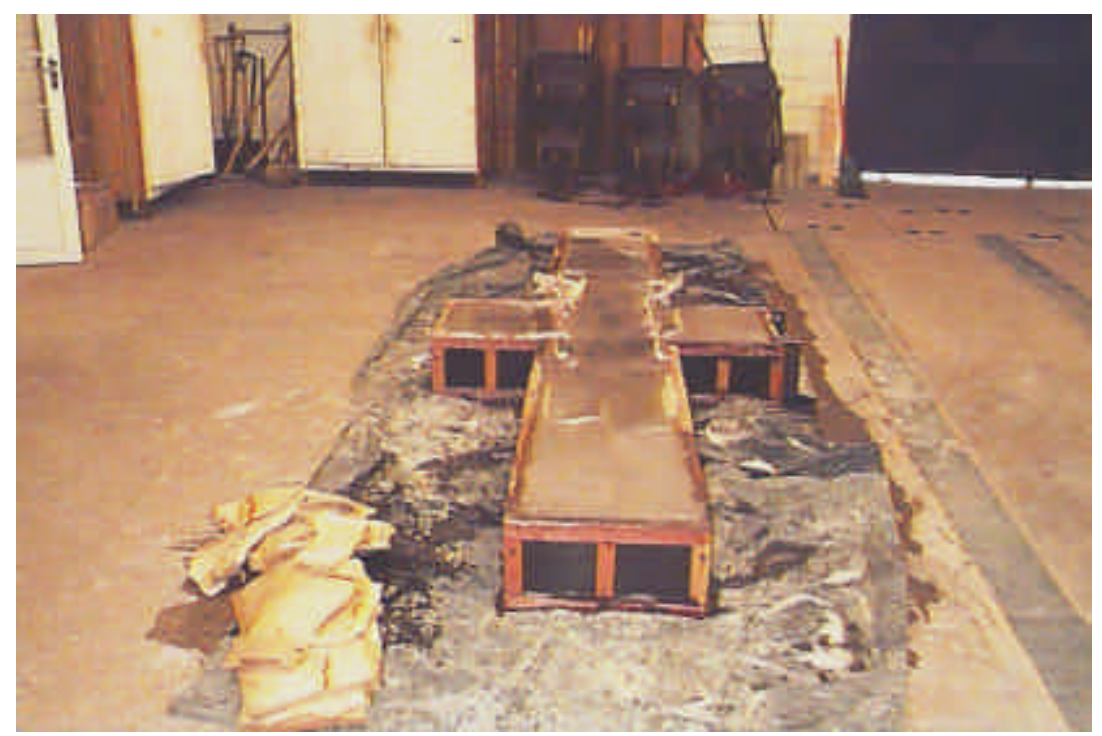

Figura 5.10 - Modelo concretado com a sua lateral na posição horizontal

Tabela 5.1 - Propriedades do Concreto para o protótipo monolítico

\begin{tabular}{|c|c|c|}
\hline \multicolumn{3}{|c|}{$\begin{array}{l}\text { Traço Básico (em peso): } \quad \text { 1:2,14:3,33 } \\
\mathrm{A} / \mathrm{C}=0,55 \text { (Cimento } \mathrm{ARI}=355 \mathrm{~kg} / \mathrm{m}^{3} \text { ) }\end{array}$} \\
\hline Volume do modelo: 330 litros & \multicolumn{2}{|c|}{ Peso total do modelo: $8,25 \mathrm{kN}$} \\
\hline Desforma & $f_{C j}(2$ dias) & $18,5 \mathrm{MPa}$ \\
\hline Início do Ensa io & $\mathrm{f}_{\mathrm{Cj}}$ (7 dias) & 40,5 MPa \\
\hline Fim do Ensaio & $f_{C j}(10$ dias) & 44,5 MPa \\
\hline \multicolumn{2}{|c|}{ Módulo de Elasticidade do Concreto, $\mathrm{E}_{\mathrm{C}}$ (a 10 dias) } & $34.700 \mathrm{MPa}$ \\
\hline
\end{tabular}


O módulo de elasticidade longitudinal, calculado segundo o CEB, é dado por:

Para $f_{\text {ck }}(7$ dias $)=40,5 M P a$ :

$$
E_{c m}=9,5 \cdot(40,5+8)^{1 / 3}=34 \cdot 644 M P a
$$

Para $f$ ck $(10$ dias $)=44,5 \mathrm{MPa}$

$$
E_{c m}=9,5 \cdot(44,5+8)^{1 / 3}=35 \cdot 572 M P a
$$

Na figura 5.11 é apresentado o detalhamento da armadura utilizada para o protótipo monolítico. O elemento de viga possuiu uma seção transversal de $20 x 40 \mathrm{cmxcm}^{2}$, com 150 $\mathrm{cm}$ de balanço em cada lado do elemento de pilar, sendo o comprimento total do protótipo de $340 \mathrm{~cm}$. A armadura negativa foi de 12,60 $\mathrm{cm}^{2}$, com 4 ф $20 \mathrm{~mm}$, sendo correspondente a um momento fletor resistente da ordem de $M_{d}=168$ kN.m. A armadura positiva foi de 8 $\mathrm{cm}^{2}$, com $4 \phi 16 \mathrm{~mm}$, o que correspondeu a um momento fletor resistente da ordem de $\mathrm{M}_{\mathrm{d}}=$ 127 kN.m.

O elemento de pilar teve a mesma seção transversal da viga, $20 \times 40 \mathrm{cmxcm}^{2}$, e comprimento de $120 \mathrm{~cm}$. A armadura sua longitudinal foi de 12,60 cm², com 4 ф $20 \mathrm{~mm}$, sendo que estas barras possuíram roscas em uma de suas extremidades, as quais foram deixadas no lado de fora da forma durante a concretagem. Estas extremidades rosqueadas foram utilizadas para a fixação por meio de parafusos do protótipo com o atuador, possibilitando a aplicação das ações alternadas. Esses tirantes foram projetados para uma resultante de tração no atuador da ordem de $\mathrm{F}_{\mathrm{d}}=200 \mathrm{kN}$, o que correspondeu a uma tensão na armadura de $f_{s}=160 \mathrm{MPa}$.

Na figura 5.11 é apresentado o detalhamento da armadura utilizada no protótipo monolítico. 


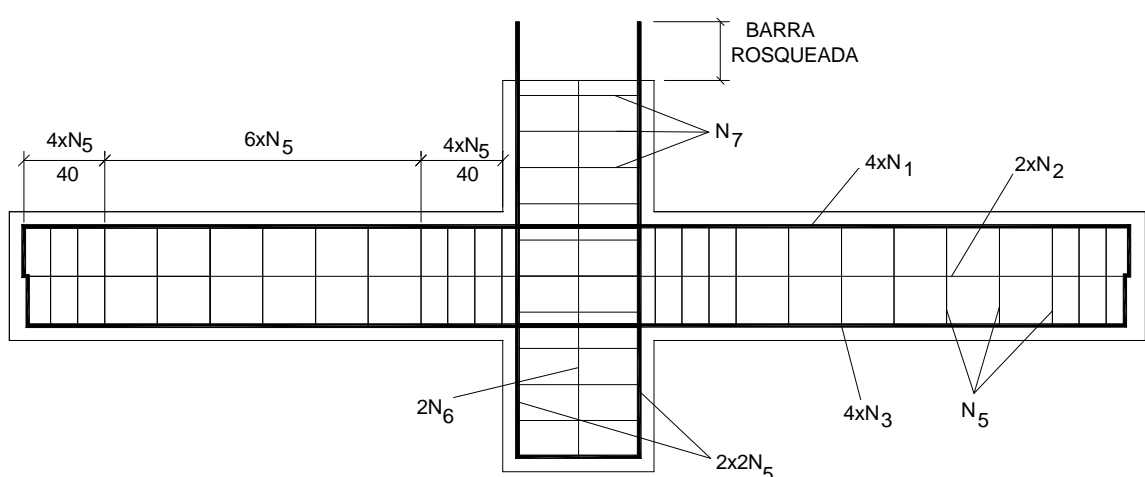

$2 5 \longdiv { 1 }$

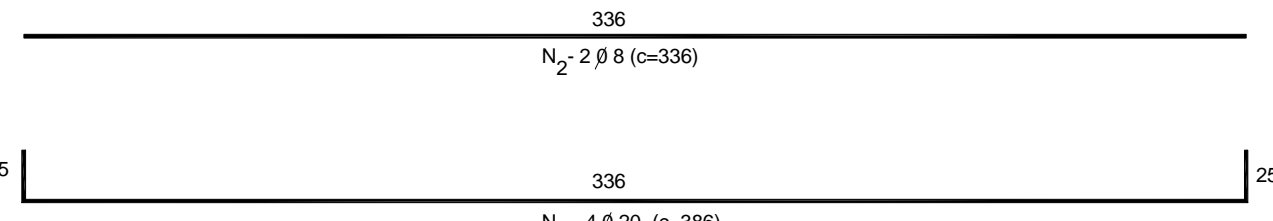

$\mathrm{N}_{3}-4020$ (c=386)

25

126

\section{$\mathrm{N}_{5}-4 \varnothing 20(\mathrm{c}=151)$}

TRECHO

115

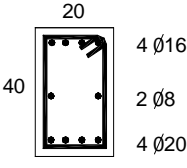

$3728 \times \mathrm{N}_{5}-(06,3 \mathrm{c}=114)$

$3612 \times \mathrm{N}_{7}^{-08,0(\mathrm{c}=116)}$

Figura 5.11 - Detalhamento da armadura do Protótipo Monolítico 


\subsubsection{Protótipo com Ligações de Chapas Soldadas}

O protótipo utilizado no estudo experimental contou com dois elementos de viga, unidos a um elemento de pilar central. Os elementos foram concretados em formas separadas e unidos posteriormente, antes da sua colocação no pórtico de reação, através de soldas nas chapas insertadas nas extremidades dos elementos. A geometria dos elementos que compõem o protótipo com ligações soldadas está apresentada na figura 5.12. Na figura 5.13 é apresentada uma vista do protótipo após a ligação com solda entre os elementos.

40

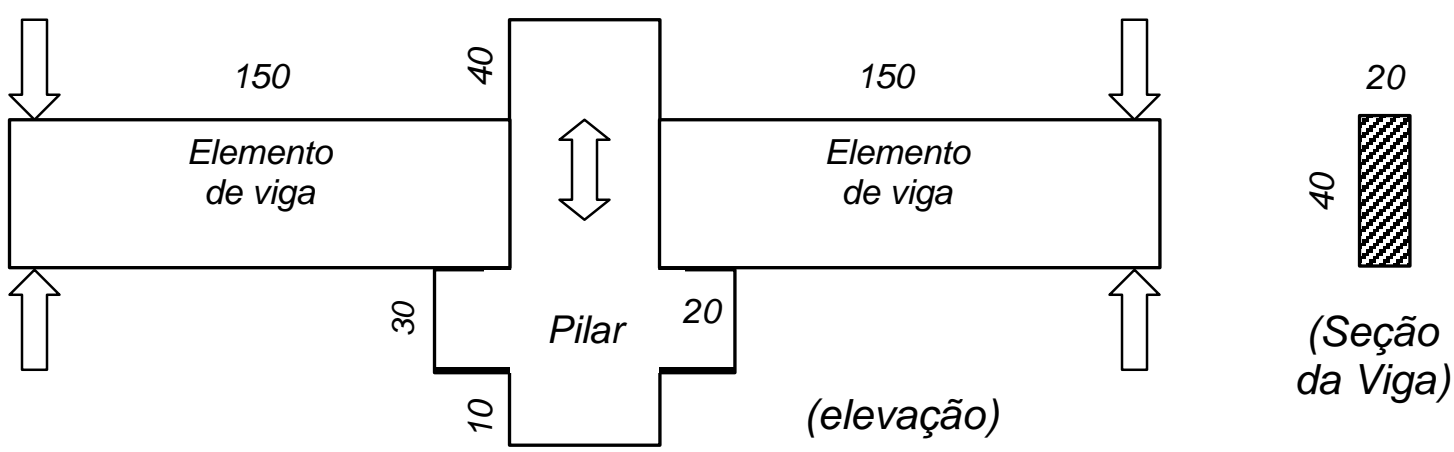

Figura 5.12 - Geometria do Protótipo com ligações por chapas soldadas.

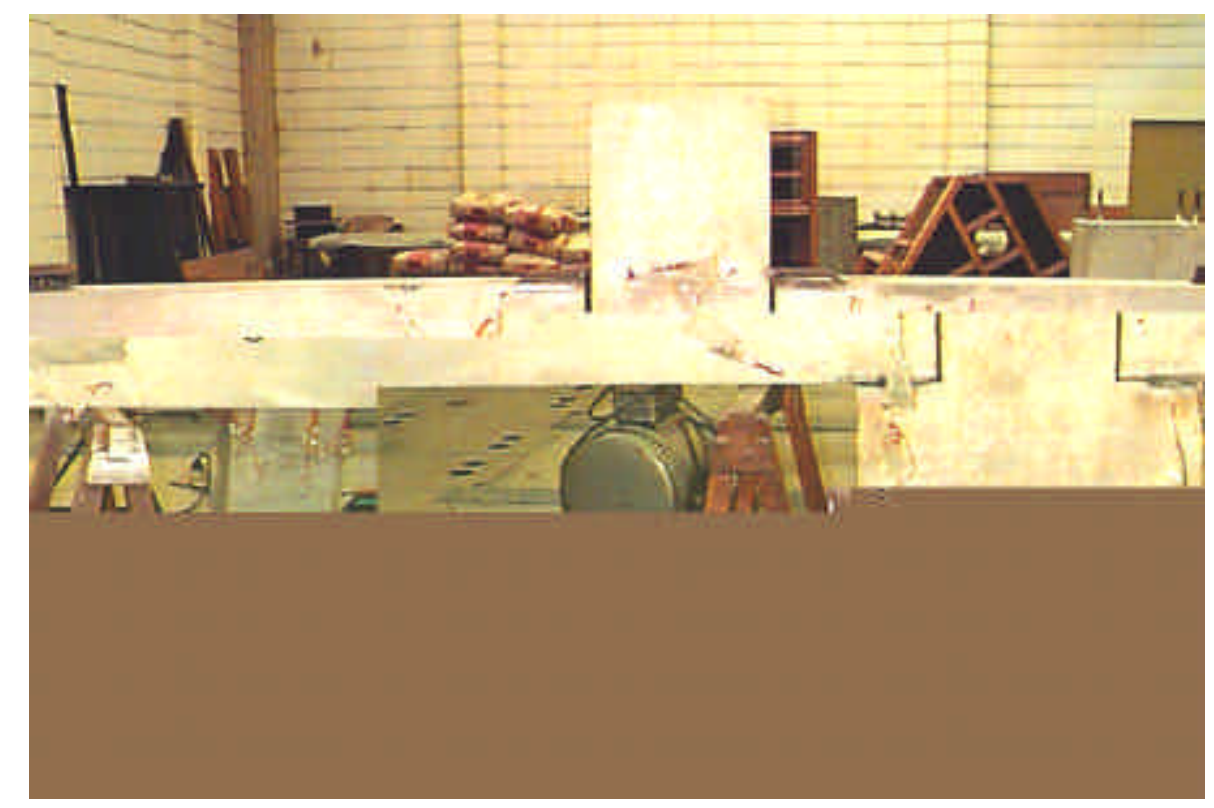

Figura 5.13 - Vista do protótipo com ligações por chapas soldadas, após a solda. 
Na tabela 5.2 são apresentadas as propriedades do concreto utilizado no protótipo com ligações soldadas, que possuiu o mesmo traço utilizado no protótipo monolítico. Os elementos de viga e de pilar foram concretado lateralmente, conforme ilustrado na figura 5.14. A desforma do modelo foi feita no terceiro dia e o ensaio foi realizado no nono dia.

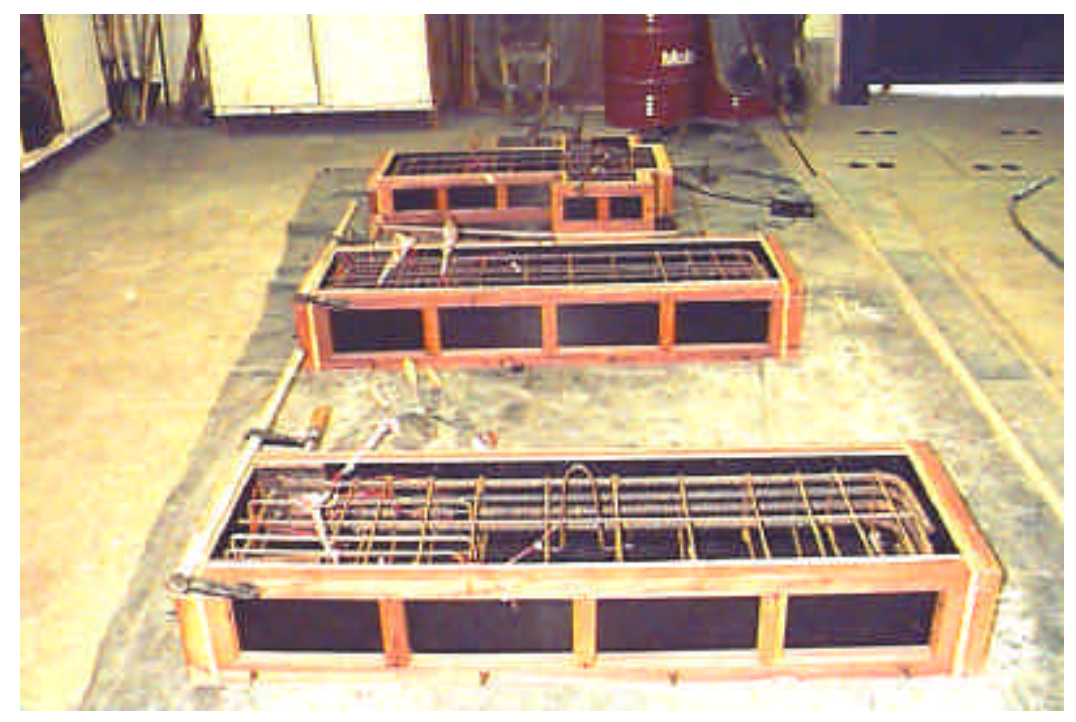

Figura 5.14 - Preparação para a concretagem dos elementos que compõem o protótipo com ligações soldadas.

Tabela 5.2 - Propriedades do Concreto para o Protótipo com Ligações Soldadas

\begin{tabular}{|c|c|c|}
\hline \multicolumn{3}{|c|}{$\begin{array}{l}\text { Traço Básico (em peso): } \quad \text { 1:2,14:3,33 } \\
\text { A/C =0,55 (Cimento ARI = } 355 \mathrm{~kg} / \mathrm{m}^{3} \text { ) }\end{array}$} \\
\hline Volume do modelo: 370 litros & \multicolumn{2}{|c|}{ Peso total do modelo: $9,25 \mathrm{kN}$} \\
\hline Desforma e Transporte & $f_{C j}$ (2 dias) & $34,3 \mathrm{MPa}$ \\
\hline Iníc io do Ensa io & $\mathrm{f}_{\mathrm{cj}}$ (9 dias) & 49,6 MPa \\
\hline Fim do Ensaio & $f_{C j}(12$ dias $)$ & $56,30 \mathrm{MPa}$ \\
\hline \multicolumn{2}{|c|}{ Módulo de Elasticidade do Concreto, $\mathrm{E}_{\mathrm{C}}$} & $36.800 \mathrm{MPa}$ \\
\hline
\end{tabular}

O módulo de elasticidade longitudinal, calculado segundo o CEB, é dado por:

$$
E_{c m}=9,5 \cdot(49,6+8)^{1 / 3}=36 \cdot 688 M P a
$$


Nas figuras 5.15 e 5.16 são apresentados os detalhamentos das armaduras dos elementos de viga e de coluna. O elemento de viga, com uma seção transversal de 20x40 $\mathrm{cm}^{2}$ e $150 \mathrm{~cm}$ de comprimento, possuiu a mesma armadura longitudinal do elemento de viga no protótipo monolítico, ou seja, armadura negativa com 4 ф $20 \mathrm{~mm}$ e armadura positiva com $4 \phi 16$ mm, o que corresponde à momentos fletores resistentes da ordem de 168 kN.m e 127 kN.m respectivamente.

Anteriormente à concretagem, as barras da armadura negativa foram soldadas por meio de soldas de filete em uma chapa metálica de aço 1020, com dimensões 200x160x16 $\mathrm{mm}^{3}$, conforme ilustrado na figura $5.17 \mathrm{~b}$. Esta chapa foi utilizada posteriormente para a ligação por meio de solda com uma chapa vertical insertada na face do pilar.

As barras da armadura positiva também foram soldadas à uma chapa lisa de aço 1020 de 200x220x12,5 mm³ , conforme figura 5.17a, a qual foi utilizada para a ligação por meio de solda com a cantoneira metálica insertada na borda do consolo.

O elemento de pilar contou uma armadura longitudinal com 4 ф $20 \mathrm{~mm}$, onde um lado dessas barras foi rosqueado e deixado para fora do elemento para a fixação do protótipo por meio de parafusos com o atuador. Os consolos no elemento de pilar possuíram altura de $30 \mathrm{~cm}$ com apoio de $20 \mathrm{~cm}$. A armadura de tirante no consolo contou com $2 \phi 25 \mathrm{~mm}+1 \phi$ $20 \mathrm{~mm}$, sendo que estas barras foram soldadas com solda de filete na aba interna da cantoneira posicionada no canto do consolo, conforme ilustrado na figura 5.18. Essa cantoneira foi utilizada para ligação por meio de solda com a chapa da extremidade inferior do elemento de viga. Como o modelo foi submetido à uma inversão dos esforços, utilizou-se uma armadura de suspensão no consolo com 2 ф $16 \mathrm{~mm}$ que foram soldadas na cantoneira da borda do consolo, conforme figura 5.18a. A transmissão dos esforços nas armaduras negativas entre os elementos de viga foi feita dentro do elemento de pilar por meio de 6 barras longitudinais de $20 \mathrm{~mm}$, o que corresponde a uma área $50 \%$ maior que a área da armadura negativa nos elementos de viga. Estas barras foram soldadas nas chapas verticais que facearam o elemento de pilar e foram utilizadas para a ligação com solda com a chapa no topo superior da extremidade do elemento de viga, conforme figura 5.18c. 

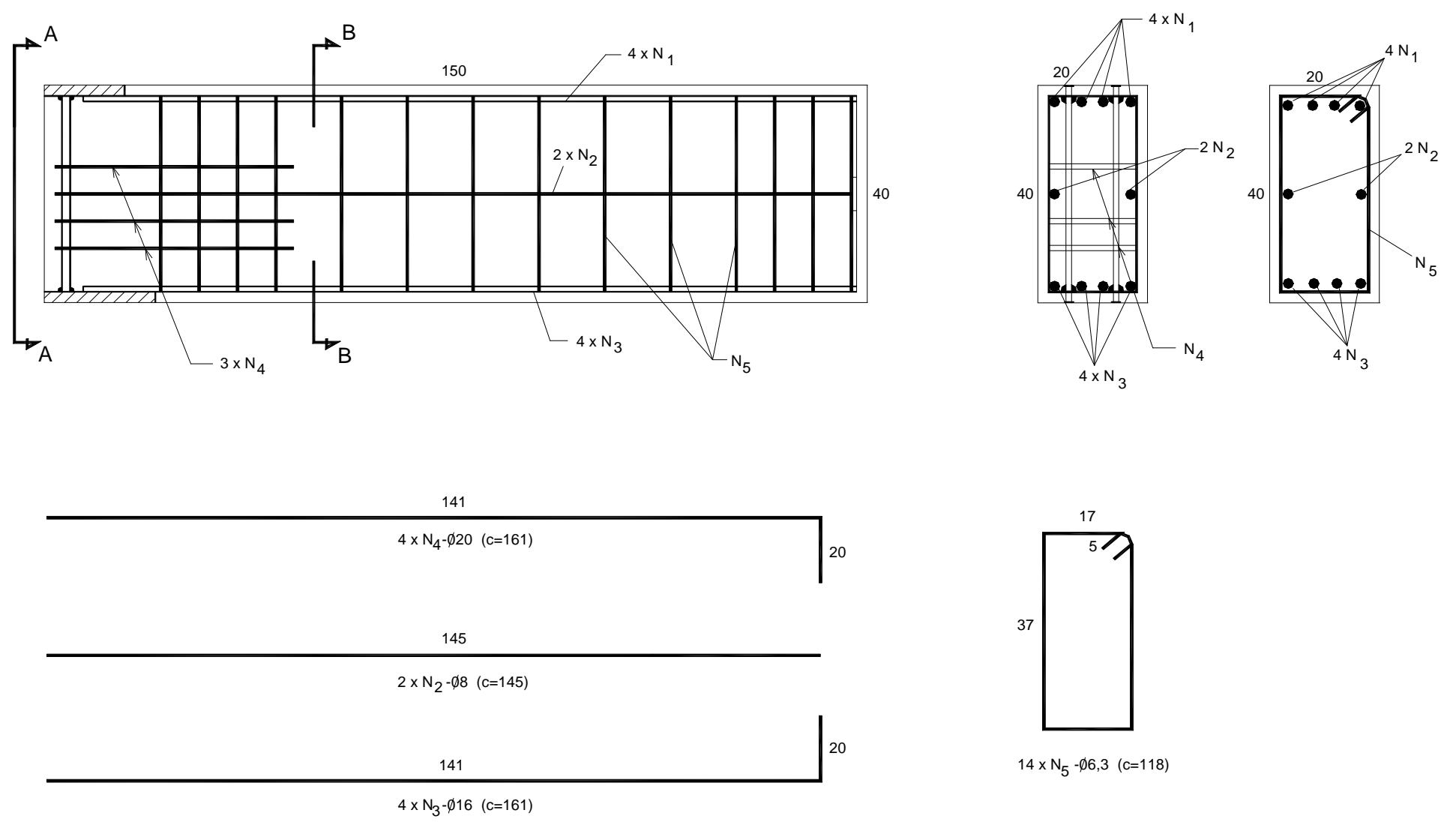

50

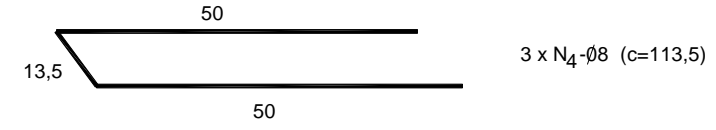

Detalhes das ligacõos:

Ver Anexo A

Figura 5.15- Detalhamento da armadura do elemento de viga do Protótipo com ligações soldadas 

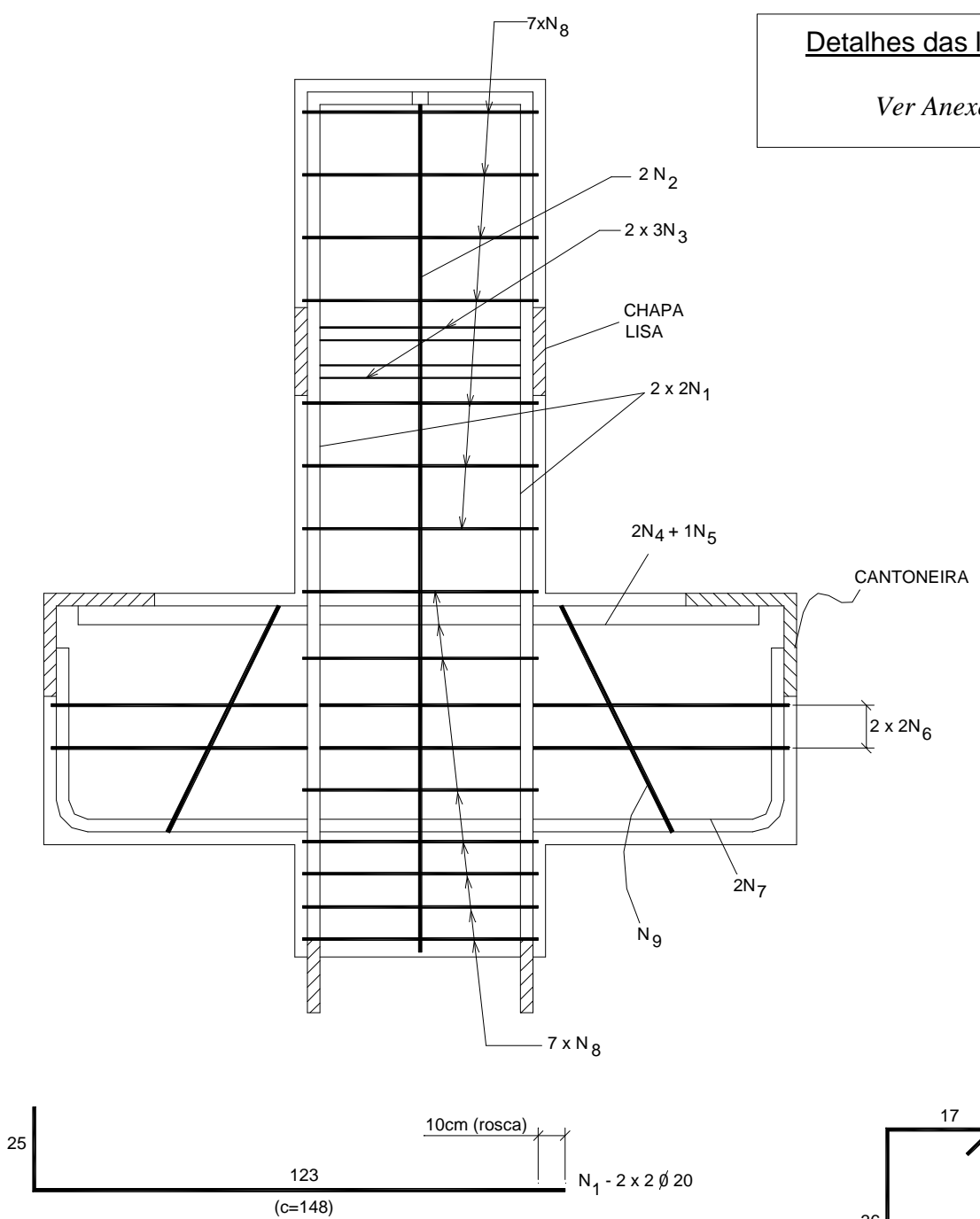

115

$N_{2}-2 \emptyset 8(c=115)$
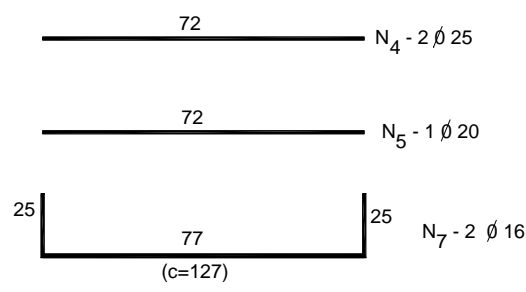

40

$N_{3}-2 \times 3 \emptyset 20$

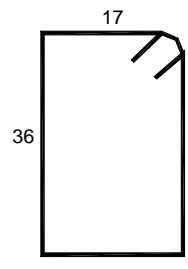

$14 \times \mathrm{N}_{8} \emptyset 6,3$ (c=116)

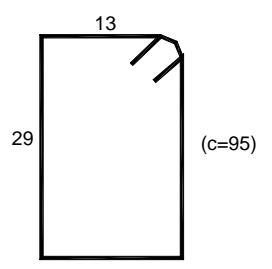

$2 \times \mathrm{N}_{9} \emptyset 8(\mathrm{c}=116)$

Figura 5.16 - Detalhamento da armadura do elemento de pilar do protótipo com ligações soldadas 

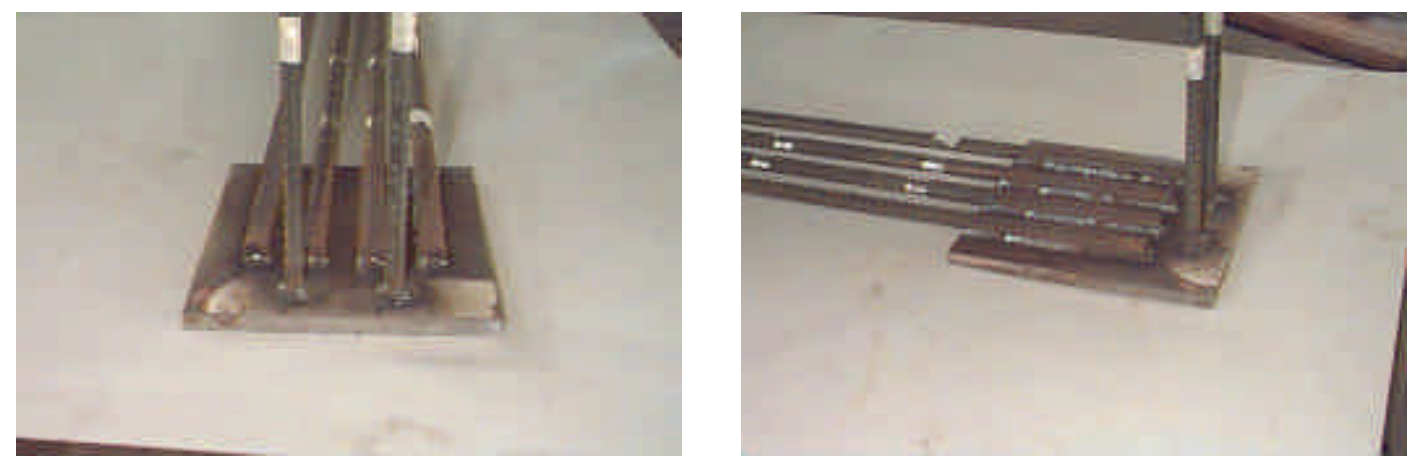

a) Detalhe da solda na armadura positiva da viga
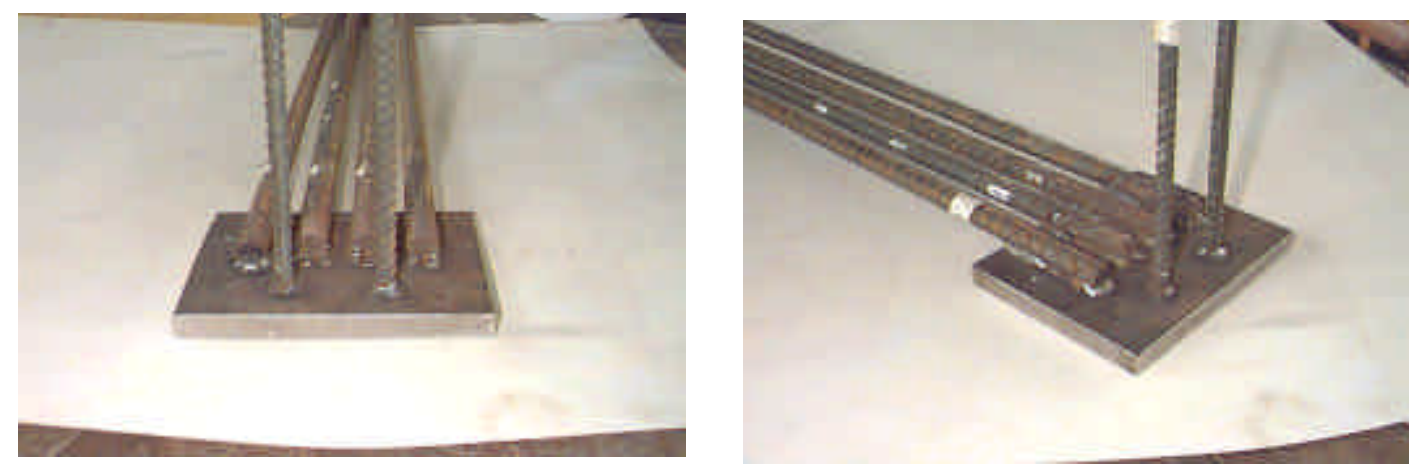

b) Detalhe da solda da armadura negativa da viga
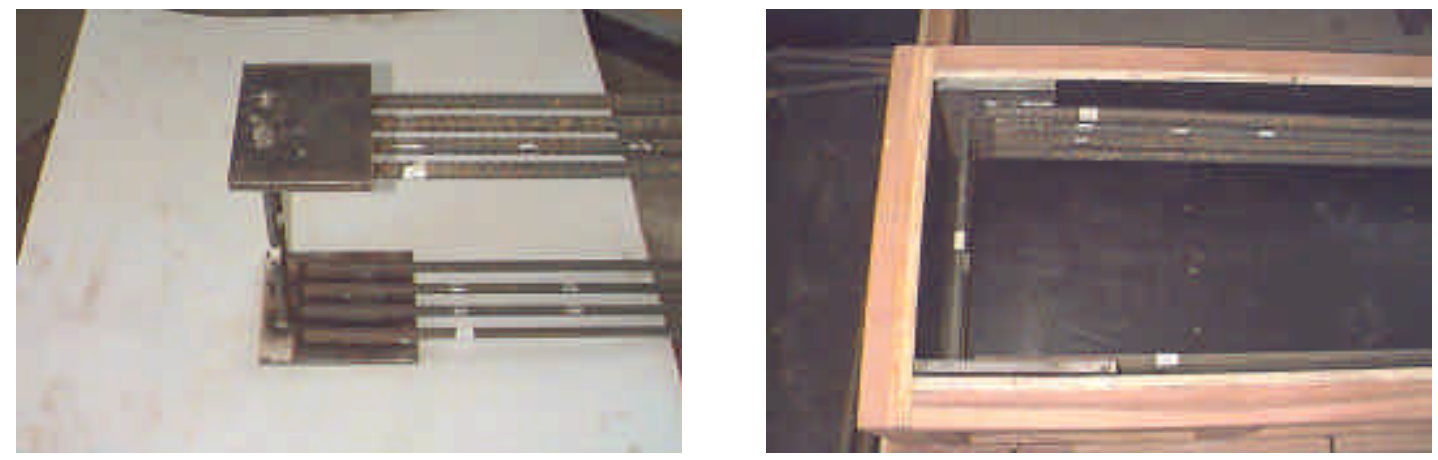

c) Solda das chapas metálicas com as armaduras da viga

Figura 5.17 - Ligação com solda na extremidade do elemento de viga 

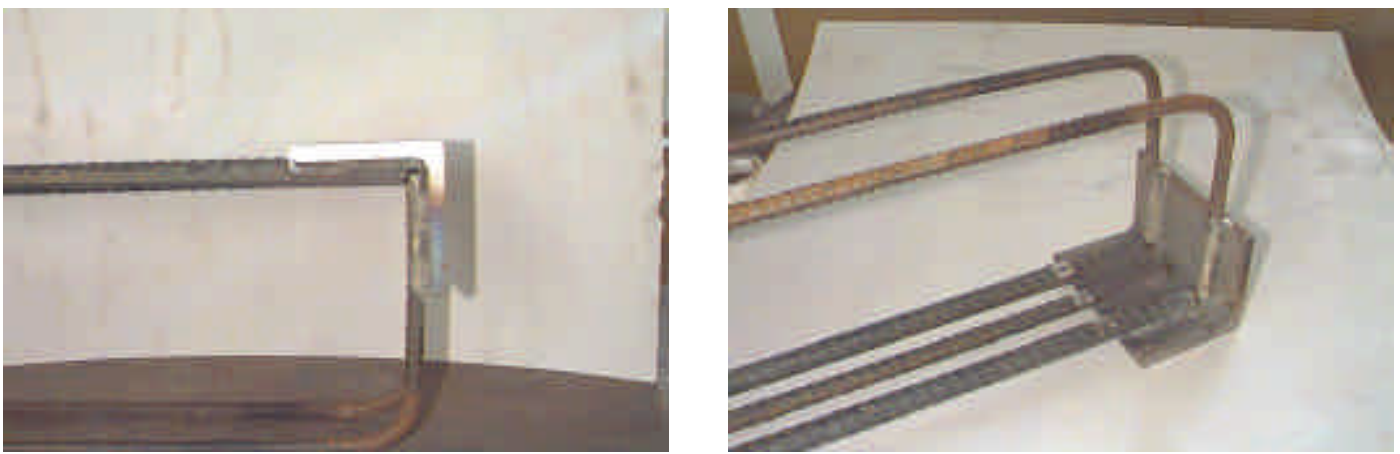

a) Detalhe da ligação com solda na armadura do consolo
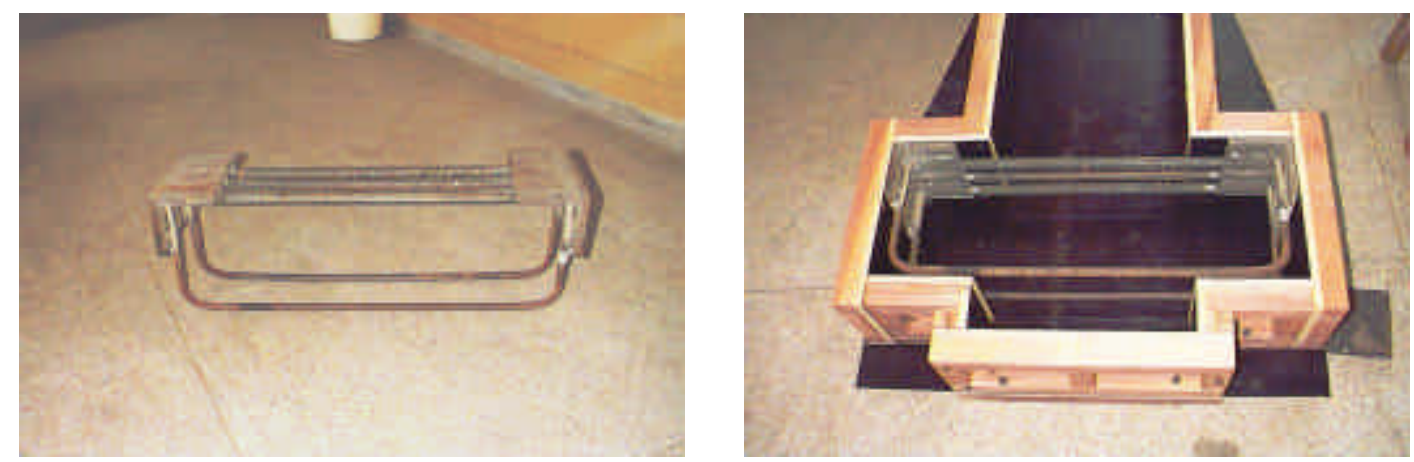

b) Posicionamento da armadura na forma
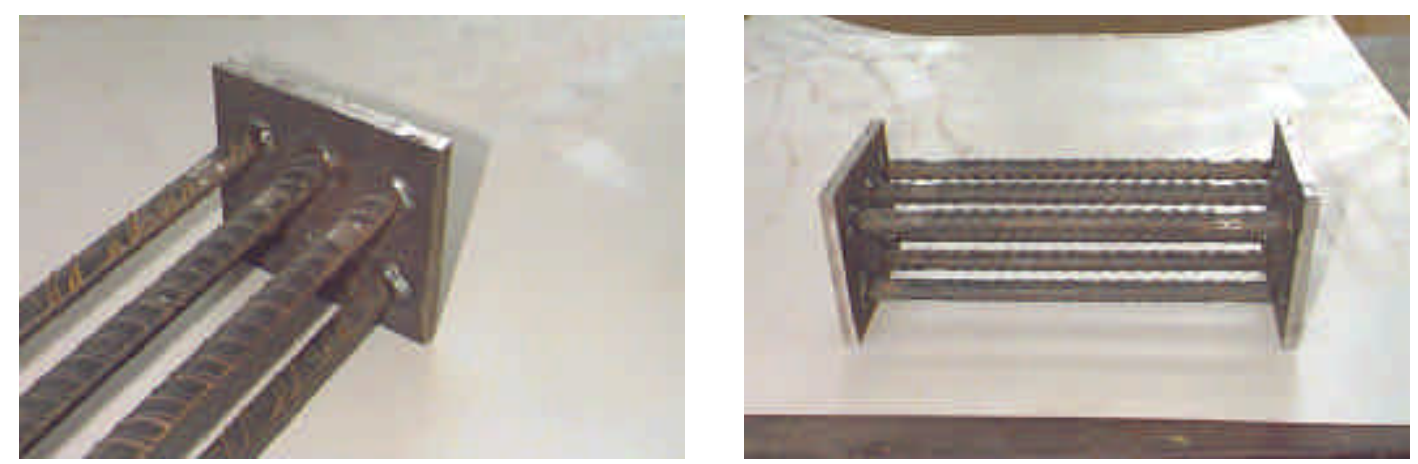

c) Detalhe do elemento de transição do esforço negativo, insertado no elemento de pilar

Figura 5.18 - Ligações com solda na armadura interna ao elemento de Pilar 


\subsubsection{Instrumentação}

Para a medição dos deslocamentos foram utilizados transdutores de deslocamentos elétricos (LVDT) que foram conectados a um sistema de aquisição de dados, K4000, onde os dados foram registrados e gravados para cada incremento no carregamento. Nas figuras 5.19 e 5.20 são apresentados os esquemas com o posicionamento dos transdutores utilizados para os protótipos monolítico e com ligação soldada, respectivamente. Nas tabelas 5.3 e 5.4 são apresentados os resumos com os transdutores utilizados no ensaio do protótipo monolítico e com ligação soldada, respectivamente. Nas figuras 5.21 e 5.22 são apresentadas fotografias com a disposição dos transdutores nos protótipos monolítico e com ligação soldada, respectivamente.

As tensões internas nas armaduras foram medidas e registradas por meio de extensômetros elétricos que foram conectados ao sistema de aquisição de dados K4000. Nas figuras 5.23 e 5.24 são apresentadas fotos dos extensômetros nas armaduras dos protótipos monolítico e com ligação soldada. Nas figuras 5.25 e 5.26 são apresentados os esquemas com o posicionamento para os extensômetros nos protótipos monolítico e com ligação soldada, respectivamente.

Por questões técnicas na instalação do equipamento, as leituras para as ações e deslocamentos no atuador tiveram que ser registradas manualmente a partir do painel de controle do atuador INSTRON 8506. Desta forma, foi necessária a colocação de um transdutor de deslocamento na cabeça do atuador e conectado com o sistema K4000, para servir de referência para os dados registrados manualmente. 


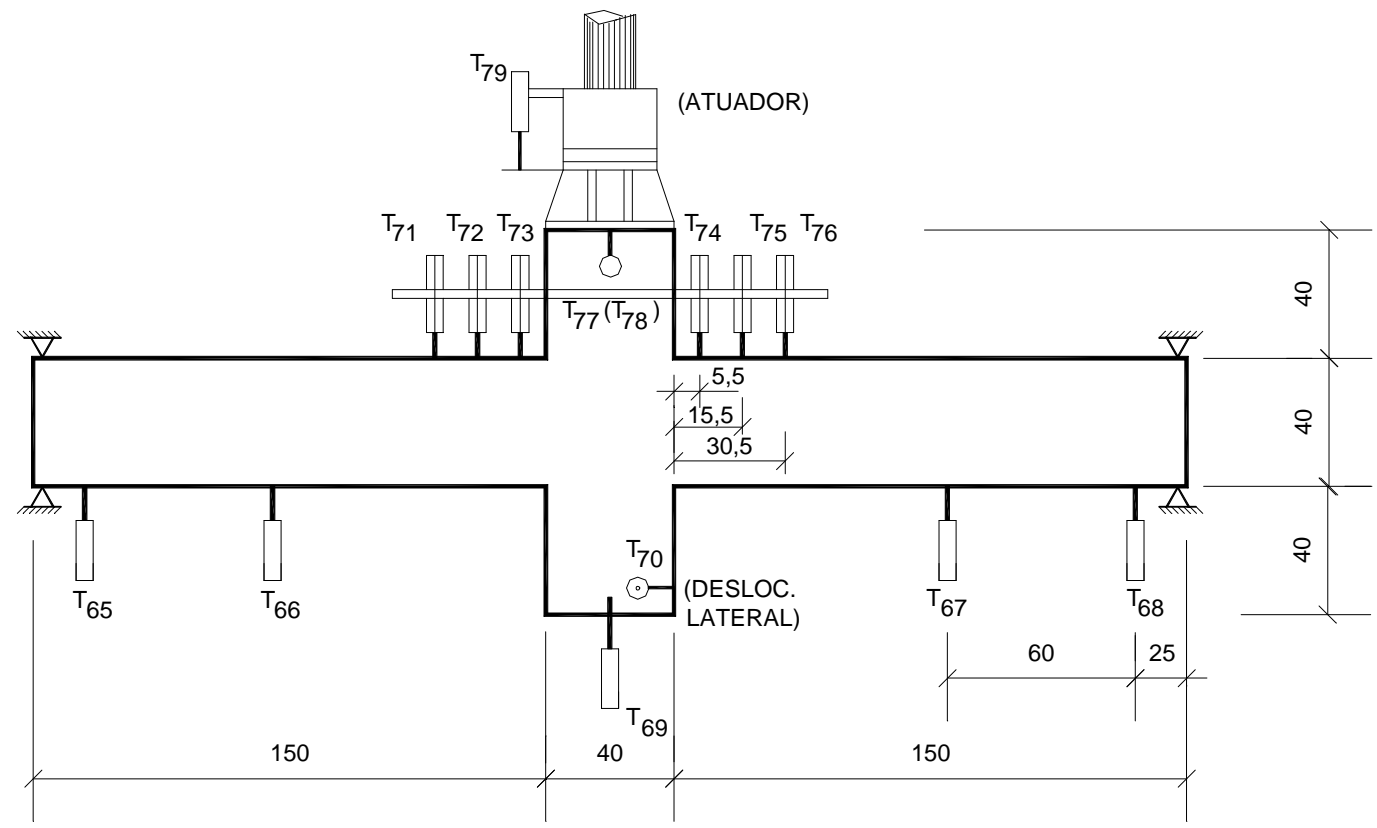

Figura 5.19 - Posicionamento dos transdutores no protótipo monolítico

Tabela 5.3 - Transdutores (LVDT) - Protótipo Monolítico

\begin{tabular}{|c|c|c|}
\hline Posição & Tipo do Instrumento de Leitura & Curso \\
\hline T65 - T68 & Transdutores (LVDT) & $100 \mathrm{~mm}$ \\
T69- T70 & Transdutores (LVDT) & $100 \mathrm{~mm}$ \\
T71- T76 & Transdutores (com relógio) & $10 \mathrm{~mm}$ \\
T77- T78 & Transdutores (LVDT) & $100 \mathrm{~mm}$ \\
T79 & Transdutores (LVDT) & $100 \mathrm{~mm}$ \\
\hline
\end{tabular}




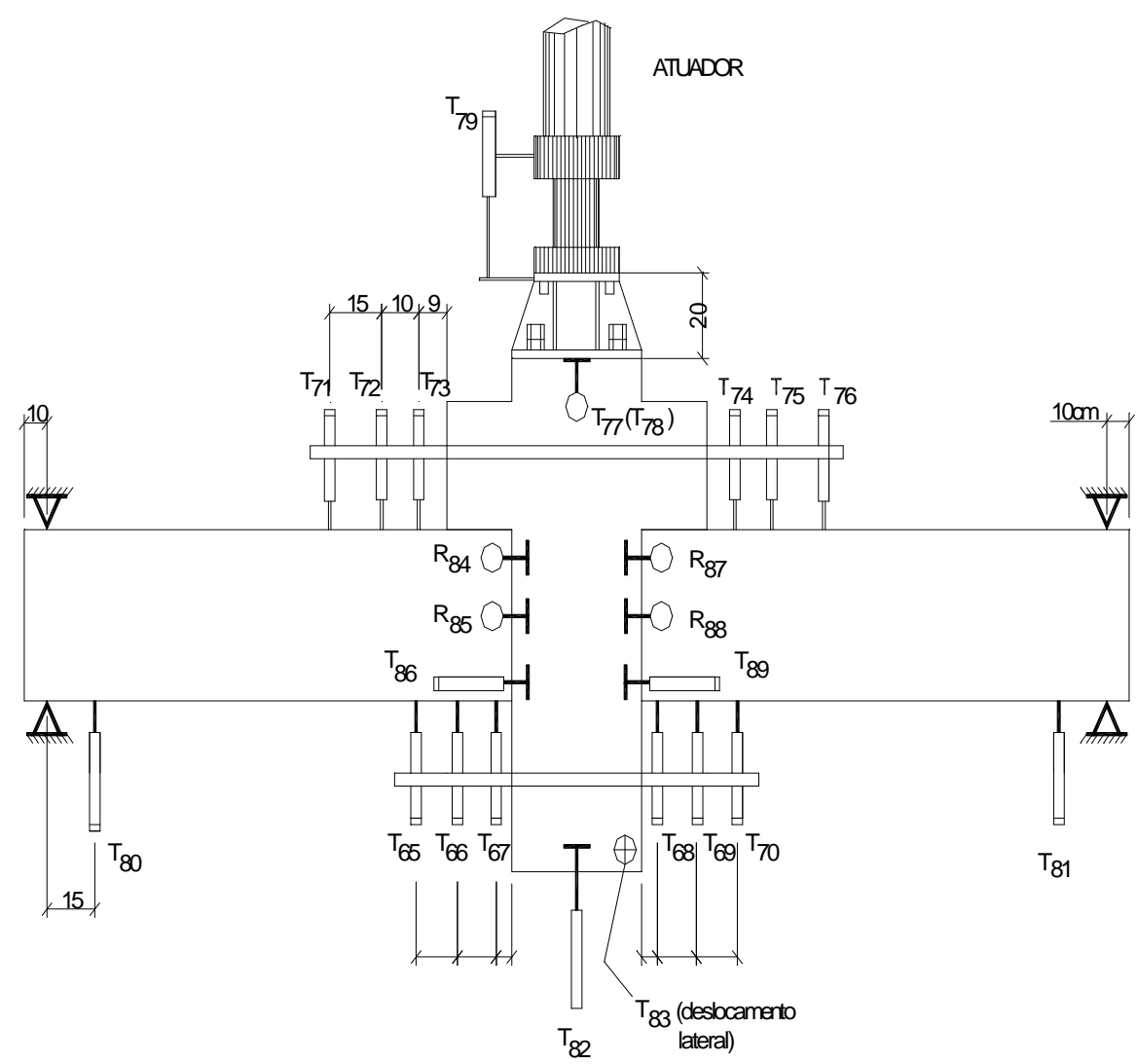

Figura 5.20 - Posicionamento dos transdutores no protótipo com ligações soldadas

Tabela 5.4 - Transdutores (LVDT) - Protótipo com ligação soldada

\begin{tabular}{|c|c|c|}
\hline Posição & Tipo do Instrumento de Leitura & Curso \\
\hline T65 à T70 & Transdutores (LVDT) & $100 \mathrm{~mm}$ \\
T71 à T76 & Transdutores (LVDT) & $100 \mathrm{~mm}$ \\
T77 à T78 & Transdutores (com relógio) & $10 \mathrm{~mm}$ \\
T79 & Transdutores (LVDT) & $100 \mathrm{~mm}$ \\
T80-T81 & Transdutores (LVDT) & $100 \mathrm{~mm}$ \\
T82-T83 & Transdutores (LVDT) & $100 \mathrm{~mm}$ \\
T84, T85, T87, T88 & Transdutores (com relógio) & $20 \mathrm{~mm}$ \\
T86, T89 & Transdutores (LVDT) & $50 \mathrm{~mm}$ \\
\hline
\end{tabular}



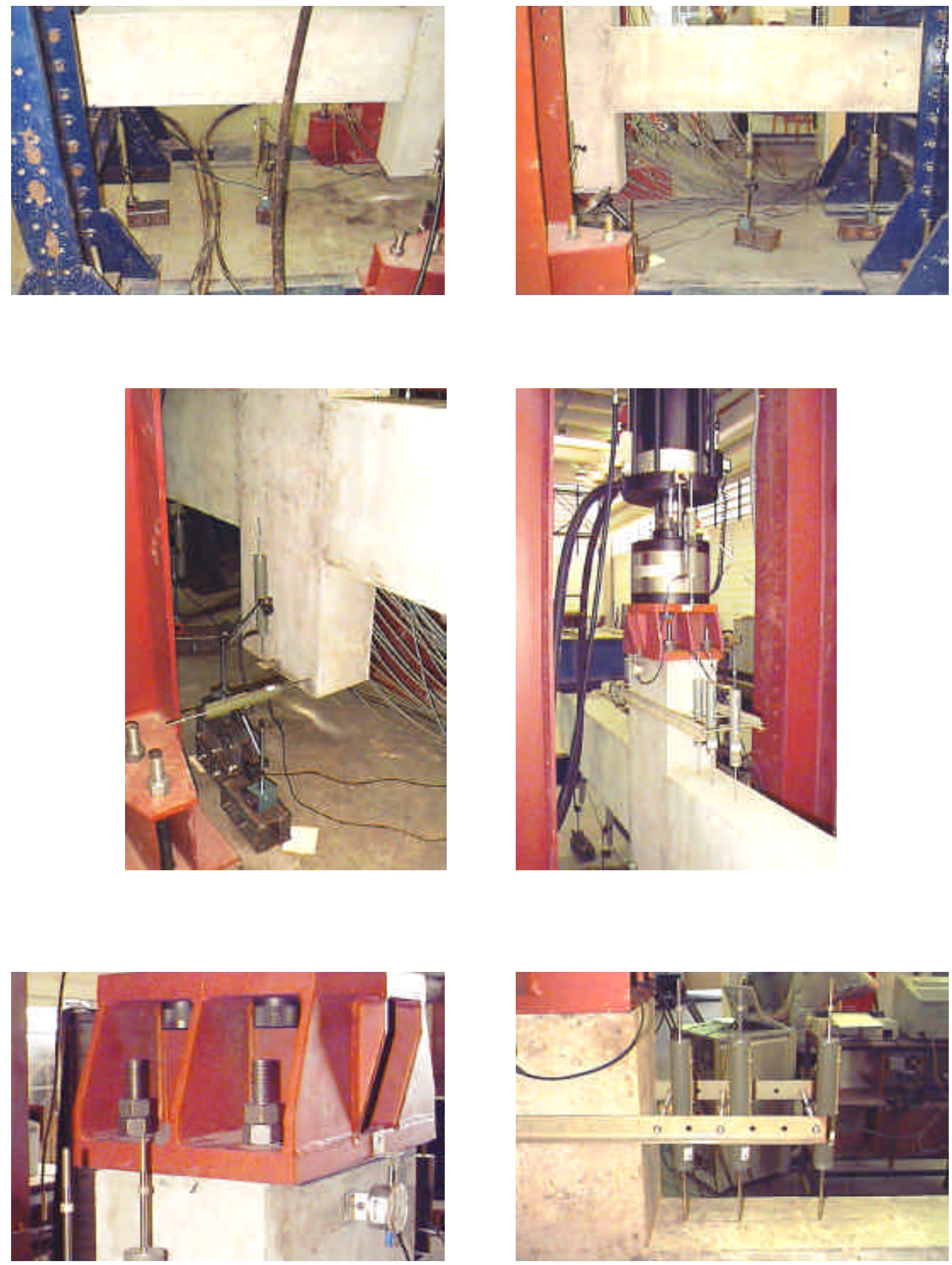

Figura 5.21 - Instrumentação para medição dos deslocamentos no protótipo monolítico 

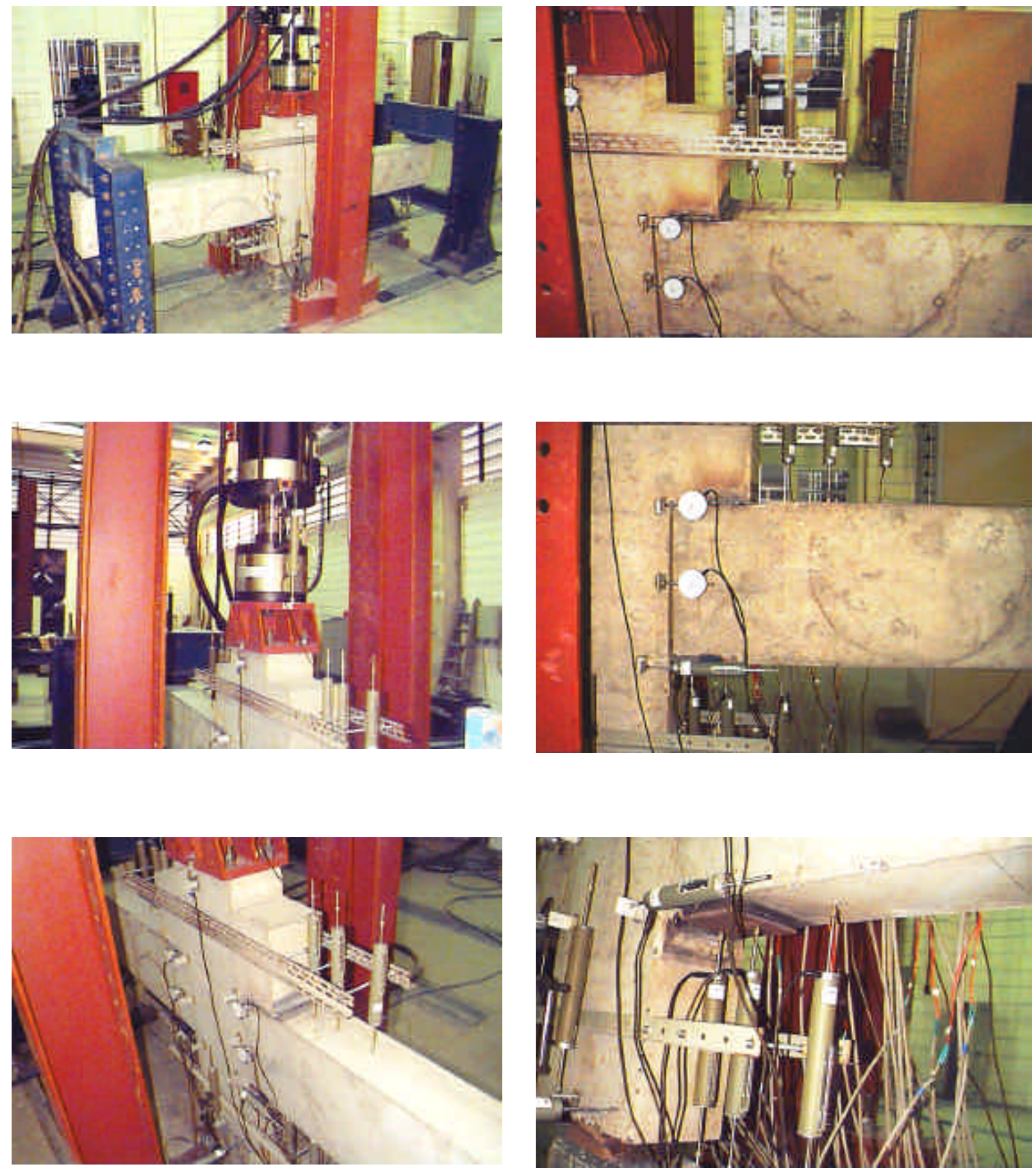

Figura 5.22 - Detalhes dos posicionamentos dos transdutores de deslocamento 

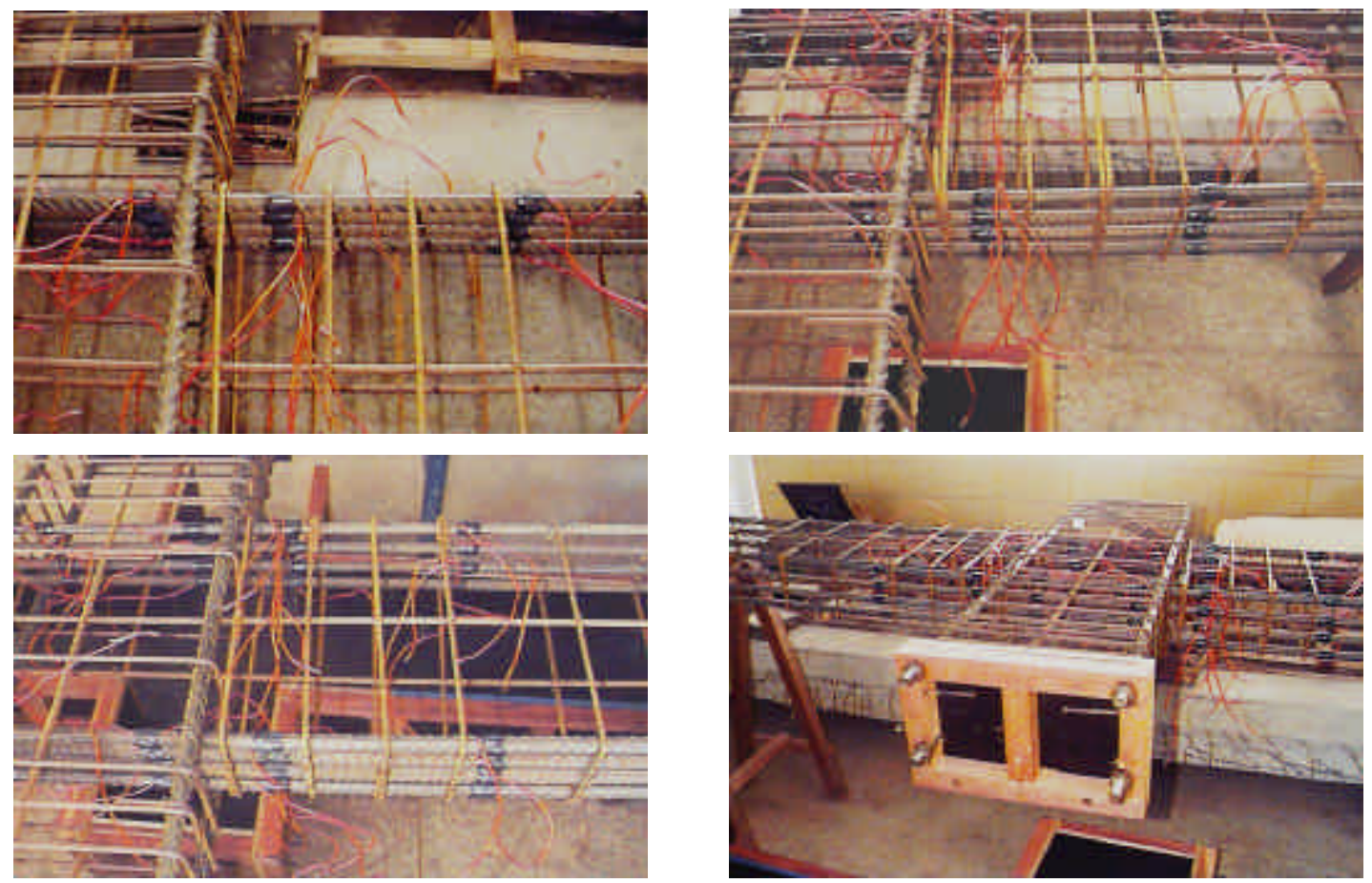

Figura 5.23- Instrumentação das armaduras do protótipo monolítico
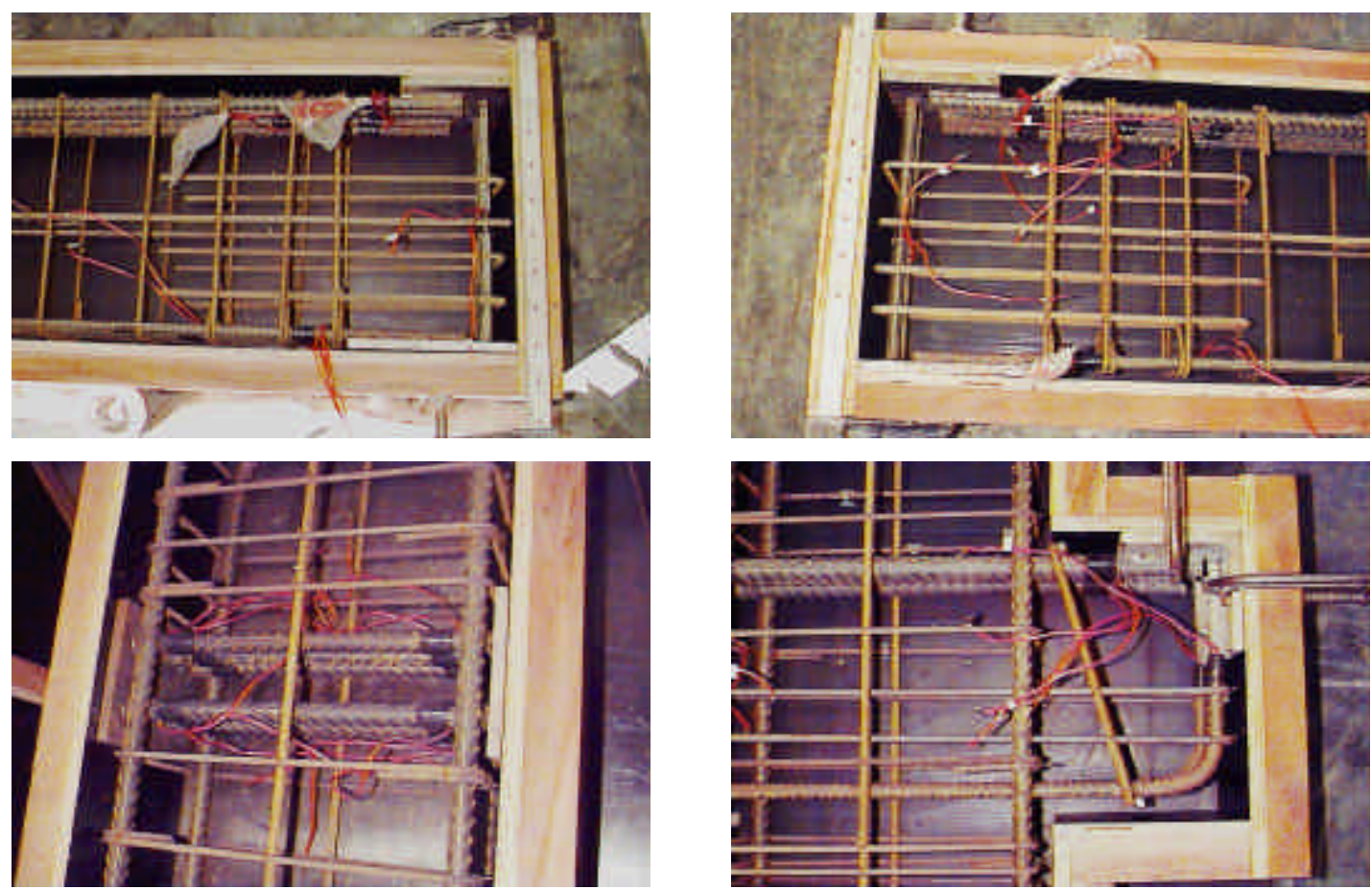

Figura 5.24 - Instrumentação das armaduras do protótipo com ligações soldadas. 


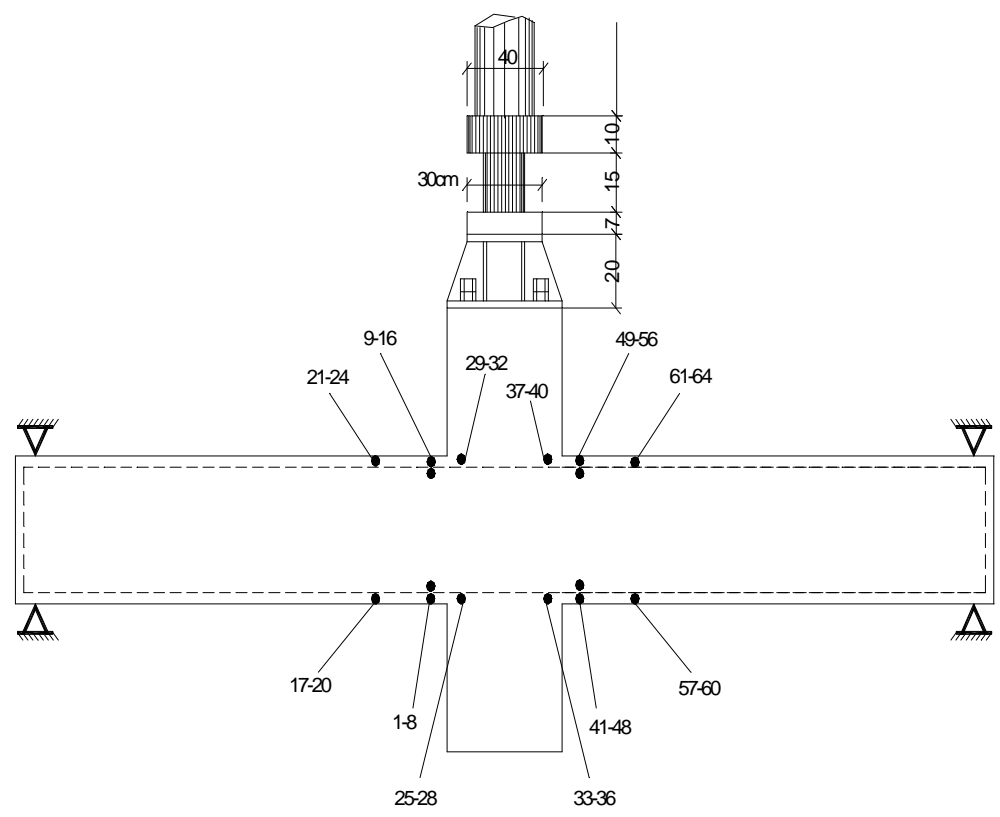

Figura 5.25 - Posicionameto dos extensômetros no protótipo monolítico

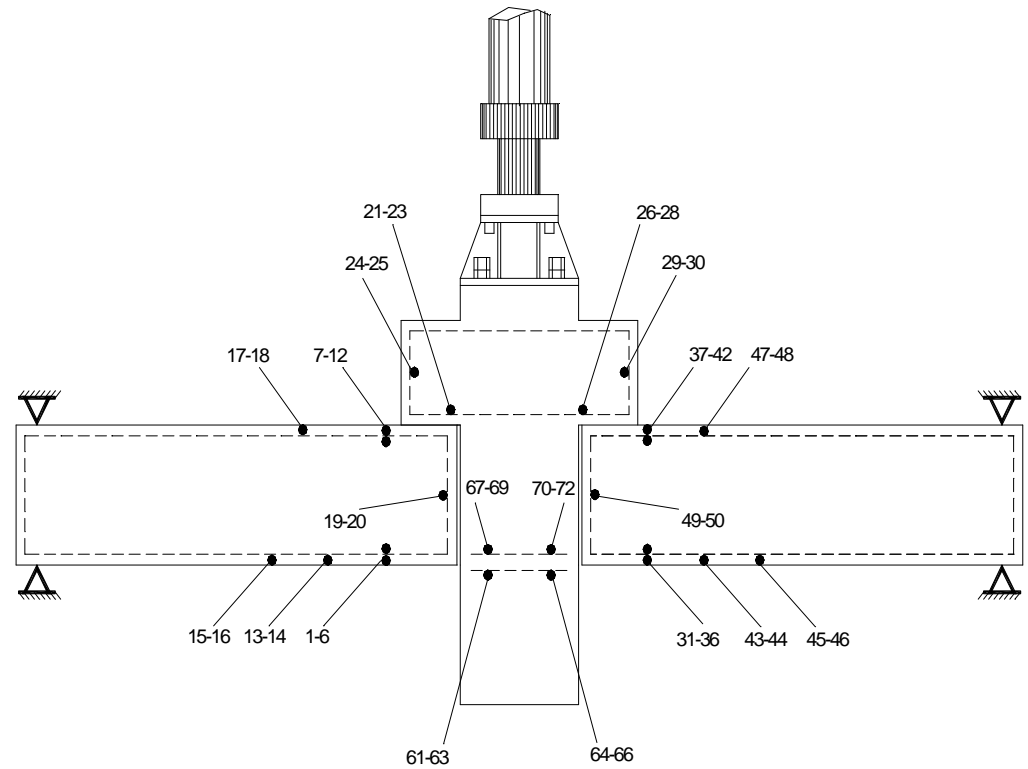

Figura 5.26 - Posicionamento dos extensômetros no protótipo com ligações soldadas. 


\subsubsection{Resultados Experimentais}

\subsubsection{Deslocamentos Verticais no Centro dos Protótipos}

Nos gráficos 5.1 ao 5.5 são apresentadas as curvas Força $x$ Deslocamento relacionadas com os deslocamentos verticais no centro do Protótipo Monolítico e do Protótipo com Ligações Soldadas, associados aos ciclos das ações alternadas no atuador.

As ações nos ciclos de carregamento de 1 a 6 corresponderam às ações de serviço para os dois protótipos ensaiados. O escoamento e a resistência dos protótipos foram atingidos a partir do ciclo 7 em diante.

No gráfico 5.6 são apresentados simultaneamente os deslocamentos verticais nos centros dos dois protótipos, para as ações de serviço. No gráfico 5.7, os deslocamentos verticais no Protótipo com Ligação Soldada foram relacionados com os deslocamentos no Protótipo Monolítico, para os ciclos de 1 a 7. A partir deste gráfico, na tabela 5.5 são apresentadas as inclinações obtidas para cada ciclo de carregamento, as quais representam a relação entre os deslocamentos no centro do Protótipo com Ligações Soldadas, representados na tabela por $D_{2}$, com os deslocamentos no centro do Protótipo Monolítico, representados por $D_{l}$.

Em média, os deslocamentos verticais no centro do Protótipo com Ligações Soldadas foram 37 \% superiores aos deslocamentos no Protótipo Monolítico, para o caso de momentos negativos nos elementos de viga (correspondentes às ações de compressão no atuador). Já para o caso dos momentos positivos (correspondentes às ações de tração no atuador), os deslocamentos foram cerca de $28 \%$ superiores aos deslocamentos no protótipo monolítico.

Tabela 5.5 - Inclinações das curvas obtidas no gráfico 6.7 para cada ciclo de carregamento

\begin{tabular}{|l|c|c|c|}
\hline \multicolumn{1}{|c|}{ Ciclos } & Inclinação $=\left(\mathrm{D}_{2} / \mathrm{D}_{1}\right)$ & Correlação & $\mathrm{F}_{\text {máx }}(\mathrm{kN})$ no atuador \\
\hline Esc orvamento & 1,37 & 0,999 & -35 \\
1 (M. Negativo) & 1,26 & 0,999 & -75 \\
2 (M. Positivo) & 1,28 & 0,993 & +75 \\
3 (M. Negativo) & 1,37 & 0,999 & -80 \\
4 (M. Positivo) & 1,28 & 0,990 & +75 \\
5 (M. Negativo) & 1,36 & 0,999 & -80 \\
6 (M. Positivo) & 1,31 & 0,991 & +75 \\
7 (M. Negativo) & 1,37 & 0,999 & -140 \\
\hline
\end{tabular}


Como simplificação para a comparação dos resultados dos deslocamentos verticais entre os dois protótipos, foram idealizadas duas "vigas-equivalentes" para cada protótipo, conforme apresentadas na figura 5.27. No caso do Protótipo Monolítico, a região do pilar com $40 \mathrm{~cm}$ de comprimento foi considerada como sendo um corpo rígido, ou seja, como uma região de descontinuidade na curvatura da "viga-equivalente" correspondente. No caso do Protótipo com Ligações Soldadas, devido à presença dos consolos e mesmo das chapas grossas soldadas, tem-se uma descontinuidade da curvatura também nas extremidades dos elementos de viga, modificando o comportamento da extremidade da viga em relação ao do protótipo monolítico. Assim, foram acrescentados à região de descontinuidade na "vigaequivalente" os comprimentos dos consolos, ficando um comprimento total de $80 \mathrm{~cm}$. Na prática, isto significa que o comprimento efetivo dos elementos de viga no protótipo com ligação soldada foram reduzidos em relação aos do protótipo monolítico. Por outro lado, para deslocamentos verticais iguais, os giros de corda nos elementos de viga são maiores no
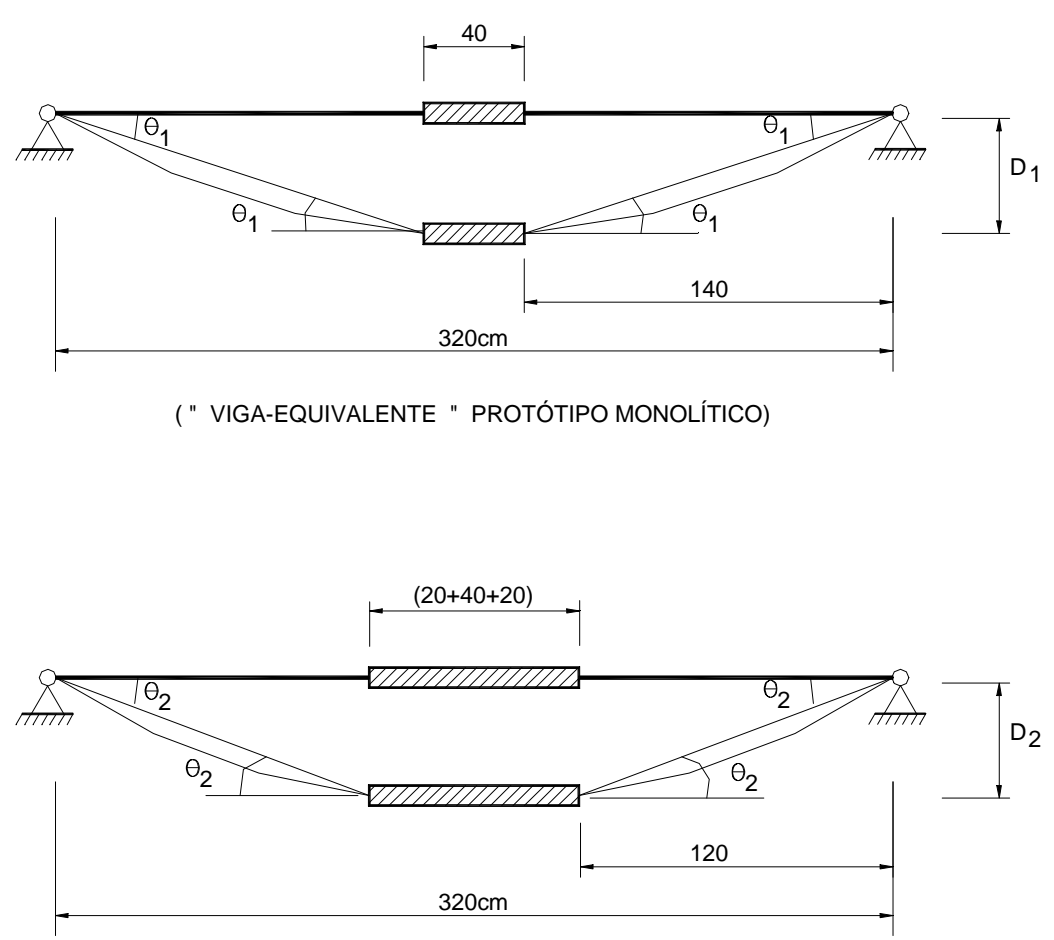

( " VIGA-EQUIVALENTE " PROTÓTIPO COM LIGAÇÃO SOLDADA)

caso do protótipo com ligação soldada.

Figura 5.27 - Esquematização das "Vigas-equivalentes" para os protótipos ensaiados 
A partir dos resultados apresentados na tabela 5.5, a "viga-equivalente" que representa o Protótipo com Ligação Soldada apresentou uma rigidez que correspondeu a cerca de $73 \%$ da rigidez da "viga-equivalente" do Protótipo Monolítico, para o caso de momentos negativos nos elementos de viga, e de cerca de $78 \%$, no caso dos momentos positivos.

A partir da figura 5.27, pode-se relacionar os deslocamentos verticais nos protótipos monolítico e com ligação soldada, representados por $D_{1}$ e $D_{2}$ respectivamente, com os giros de corda, representados por $\theta_{1}$ e $\theta_{2}$ respectivamente, para cada "viga-equivalente", dados

$$
\theta_{1}=D_{1} / 1,40 \quad \text { (segundo figura 5.27) }
$$

por:

$$
\begin{gathered}
\theta_{2}=D_{2} / 1,20 \\
D_{2}=1,37 . D_{1}
\end{gathered}
$$

Para o caso do momento negativo, com base no gráfico 5.7 e na tabela 5.5, a relação entre os deslocamentos verticais dos dois protótipos e dado gráfico 5.7 e tabela 5.5)

Substituindo-se a relação acima pelas relações entre os deslocamentos verticais e os giros de corda, para o caso do momento negativo nas extremidades das vigas, deriva-se a seguinte relação para os giros de corda entre os dois protótipos:

$$
\theta_{2}=1,59 \cdot \theta_{1}
$$

Cabe ressaltar que estas rotações de corda, ainda não estão diretamente associadas às rotações específicas das ligações, mas sim com as rotações nos trechos das extremidades dos elementos de viga, próximos à ligação.

No próximo item, são apresentadas as rotações obtidas para as extremidades dos elementos de viga nos dois protótipos, que foram obtidos a partir das leituras dos transdutores posicionados na face superior das extremidades dos elementos de viga, conforme indicados nas figuras 5.19 e 5.20 . 


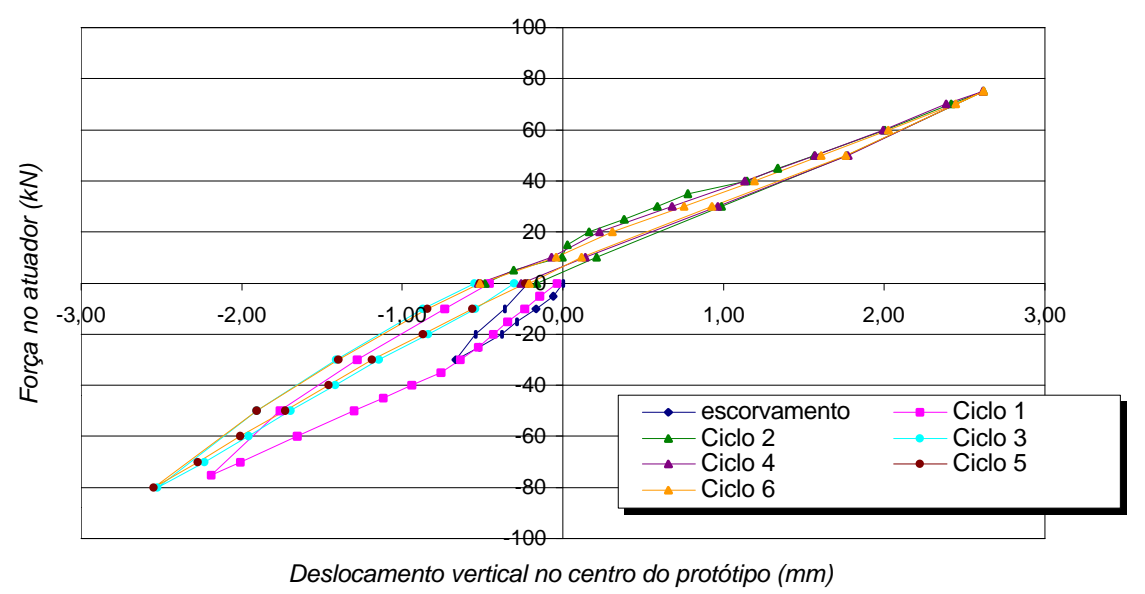

Gráfico 5.1 - Deslocamento vertical no centro do Protótipo Monolítico para os Ciclos 1 ao 6 (Solicitações de Serviço)

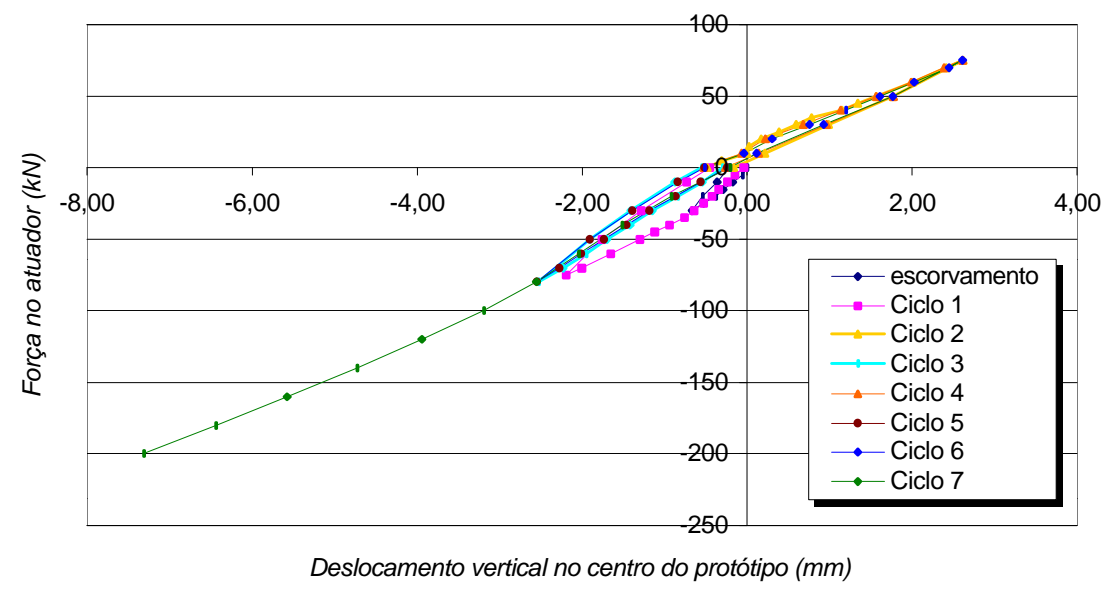

Gráficos 5.2 - Deslocamento vertical no centro do Protótipo Monolítico para os Ciclos 1 ao 7 (Solicitações de Serviço)

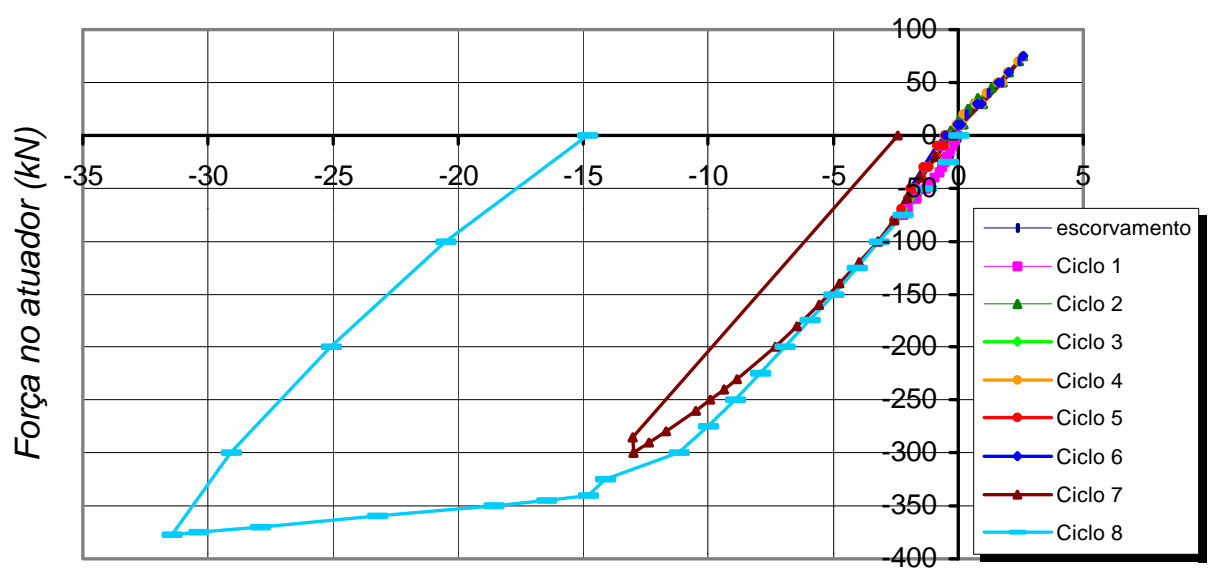

Deslocamento vertical no centro do protótipo $(\mathrm{mm})$

Gráfico 5.3 - Deslocamento vertical no centro do Protótipo Monolítico para os Ciclos 7 e 8 


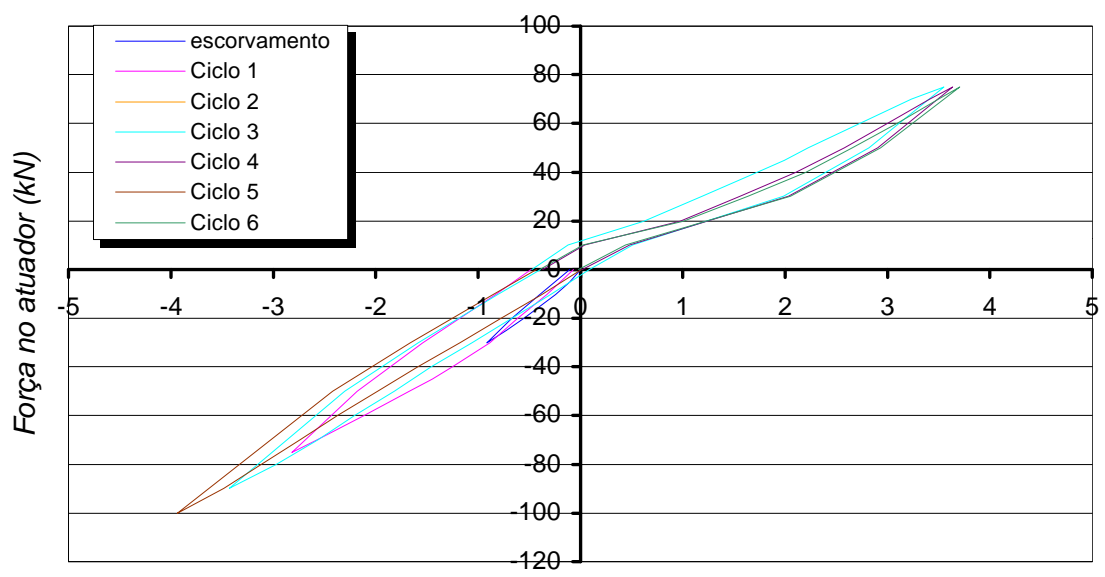

Deslocamento vertical no centro do protótipo $(\mathrm{mm})$

Gráfico 5.4 - Deslocamento vertical no centro do Protótipo com ligações soldadas para os Ciclos 1 ao 6 (Solicitações de Serviço)

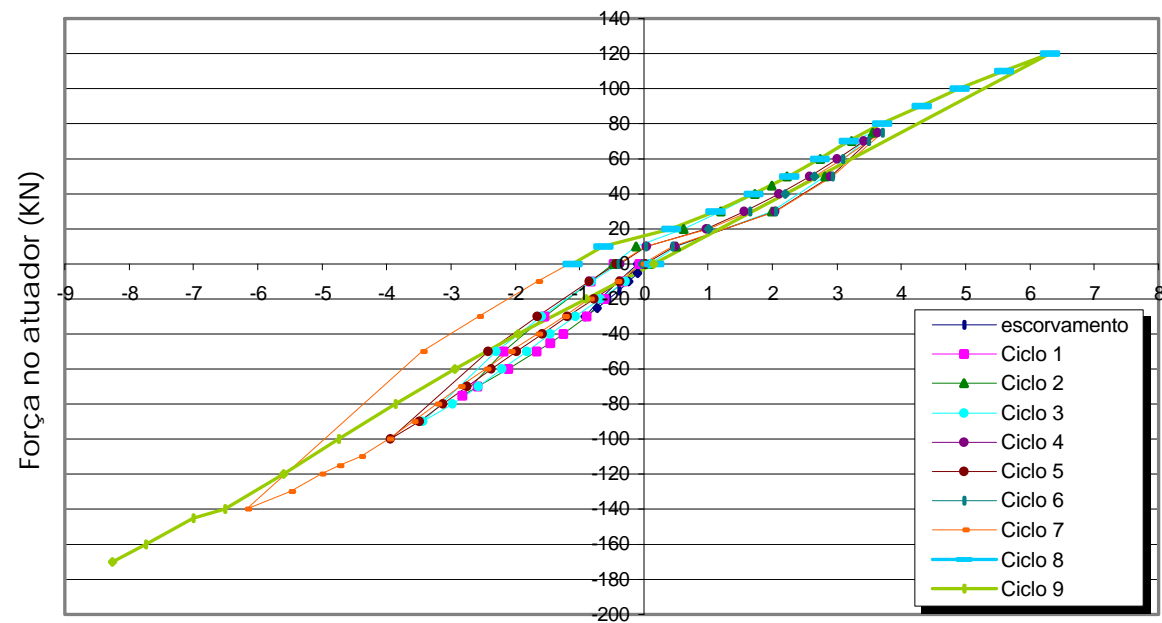

Deslocamento no atuador (mm)

Gráfico 5.5 - Deslocamento vertical no centro do Protótipo com ligações soldadas para os Ciclos 1 ao 9 (Até a falha na ligação) 
Gráfico 5.6 - Comparação das curvas Força Vertical x Deslocamento Vertical apresentadas

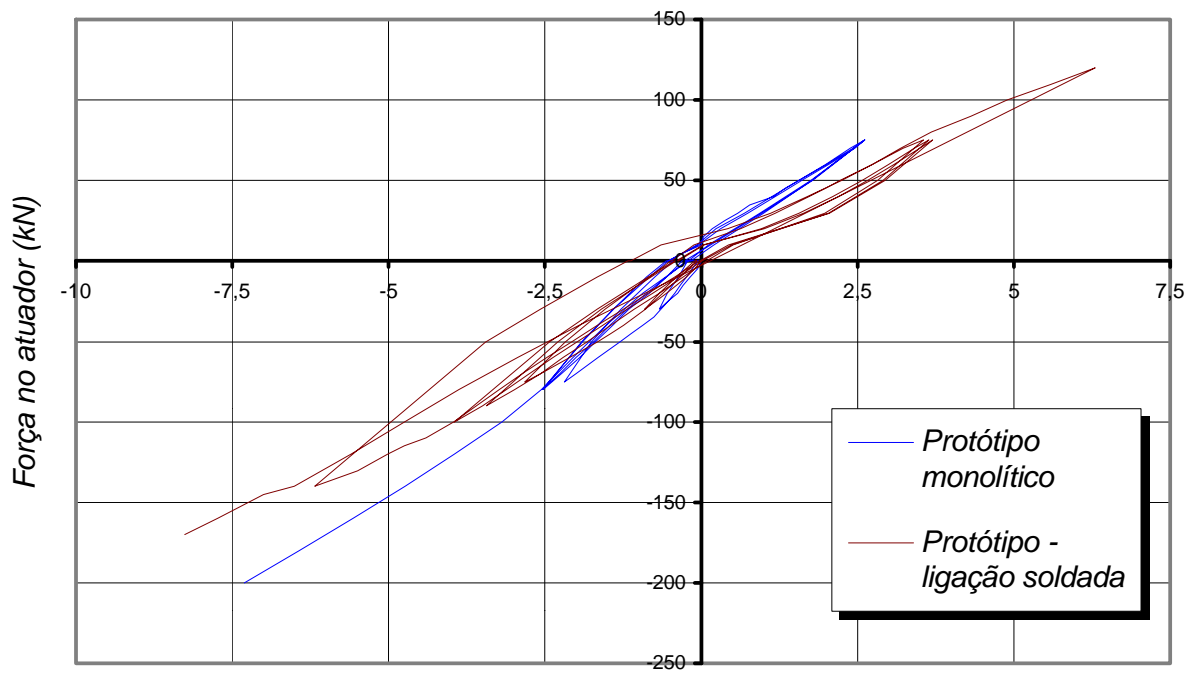

Deslocamento vertical no centro do protótipo $(\mathrm{mm})$

pelos

Protótipos Monolítico e Protótipo com Ligação Soldada para as ações de serviço

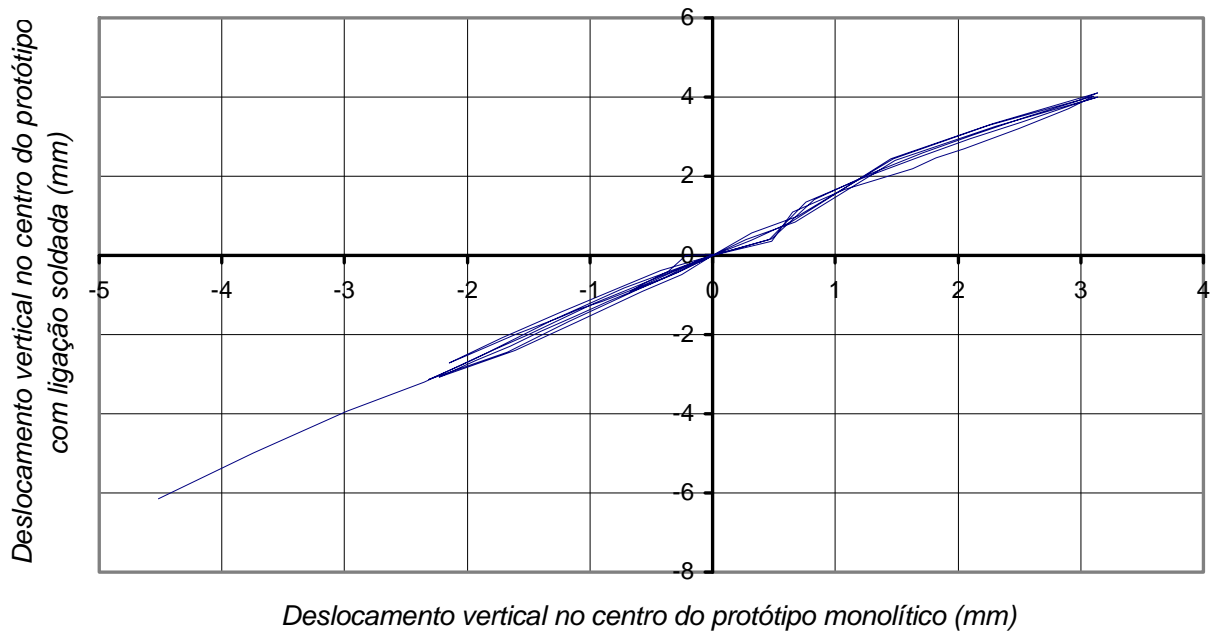

Gráfico 5.7 - Deslocamentos verticais no Protótipo com Ligações Soldadas escritos em função dos deslocamentos verticais no Protótipo Monolítico. 


\subsubsection{Rotações nas Extremidades dos Elementos de Viga para os Protótipos}

Nos gráficos 5.8 ao 5.10 são apresentadas as curvas Momento x Rotação (M- $\theta$ ) para as rotações nas extremidades dos elementos de viga no Protótipo Monolítico, as quais foram derivadas a partir de medidas internas de deformações e medidas externas de deslocamento no protótipo.

As medidas internas de deformações foram feitas através de extensômetros elétricos posicionados nas armaduras negativa e positiva de uma seção da extremidade da viga, próxima à interface entre os elementos de viga e o pilar, nas posições de 1 ao 16 e de 41 ao 56, conforme ilustrado na figura 5.25. As rotações nas extremidades dos elementos de viga que foram derivadas destas medidas estão apresentadas no gráfico 5.8.

As medidas externas de deslocamentos foram feitas a partir dos transdutores T-71 ao T-76, conforme indicado na figura 5.19, os quais foram posicionados na face superior das extremidades dos elementos de viga próximo ao pilar. As rotações nas extremidades dos elementos de viga que foram derivadas destas leituras estão apresentadas no gráfico 5.9.

No gráfico 5.10, são apresentadas simultaneamente as rotações que estão apresentadas nos gráficos 5.8 e 5.9. A partir deste gráfico, pode-se observar uma boa coerência entre os comportamentos das curvas, apesar de haver uma pequena dispersão entre os valores.

No gráfico 5.11 e 5.12 são apresentadas as curvas Momento $x$ Rotação $(M-\theta)$ referentes às rotações nas extremidades dos elementos de viga do Protótipo com Ligação Soldada. Estas rotações foram obtidas a partir das leituras dos transdutores T-71 ao T-76, posicionados na face superior dos elementos de viga, conforme indicado na figura 5.20.

No gráfico 5.13 são apresentadas simultaneamente as rotações nas extremidades dos elementos de viga nos casos do Protótipo Monolítico e do Protótipo com Ligações Soldadas.

No gráfico 5.14, as rotações nas extremidades dos elementos de viga no Protótipo com Ligação Soldada foram relacionadas em função das rotações obtidas para o Protótipo Monolítico. A partir deste gráfico foi organizada a tabela 5.6, onde estão apresentadas as inclinações e as correlações entre as duas rotações, representadas por $\operatorname{Rot}(2)$ e $\operatorname{Rot}(1)$, respectivamente, relativas aos ciclos de carregamento. 
Tabela 5.6 - Inclinação das curvas Rot(2) x Rot (1) no gráfico 5.14

\begin{tabular}{|c|c|c|c|}
\hline Ciclos & Inclinação $=[$ Rot(2) / Rot(1) & Correlação & $M_{\text {máx }}$ (kN.m) \\
\hline 1 (M. Negativo) & 1,38 & 0,950 & $-52,5$ \\
2 (M. Positivo) & 1,01 & 0,991 & $+52,5$ \\
3 (M. Negativo) & 1,62 & 0,974 & -56 \\
4 (M. Positivo) & 0,81 & 0,992 & $+52,5$ \\
5 (M. Negativo) & 1,40 & 0,976 & -56 \\
6 (M. Positivo) & 1,02 & 0,970 & $+52,5$ \\
7 (M. Negativo) & 1,85 & 0,985 & -98 \\
8 (Prot.1) =9 (Prot.2) & 1,89 & 0,970 & $-122,5$ \\
\hline
\end{tabular}

A partir dos valores apresentados na tabela 5.6, para o caso dos momentos negativos nos elementos de viga (com ação de compressão no atuador), obteve-se uma inclinação média entre as rotações nas extremidades dos elementos de viga no Protótipo com Ligações Soldadas, representadas por Rot(2), e as rotações no protótipo monolítico, representadas por Rot(1), da ordem de:

$$
\operatorname{Rot}(2)=1,63 \cdot \operatorname{Rot}(1)
$$

A partir desta relação, pode-se dizer que as rotações nas extremidades dos elementos de viga no Protótipo com Ligações Soldadas foram em média $63 \%$ maiores do que as rotações correspondentes no Protótipo Monolítico.

Também, esta relação para as rotações $\operatorname{Rot}(2)$ e $\operatorname{Rot}(1)$ vem a confirmar a relação já obtida para as rotações de corda, $\theta_{2}$ (correspondente à rotação Rot(2)) e $\theta_{1}$ (correspondente à rotação Rot(1)), para os elementos de viga nos dois protótipos, a qual foi estimada a partir dos resultados dos deslocamentos verticais no centro dos protótipos aplicados às relações geométricas das suas respectivas "vigas-equivalentes", onde:

$$
\theta_{2}=1,59 \cdot \theta_{1}
$$




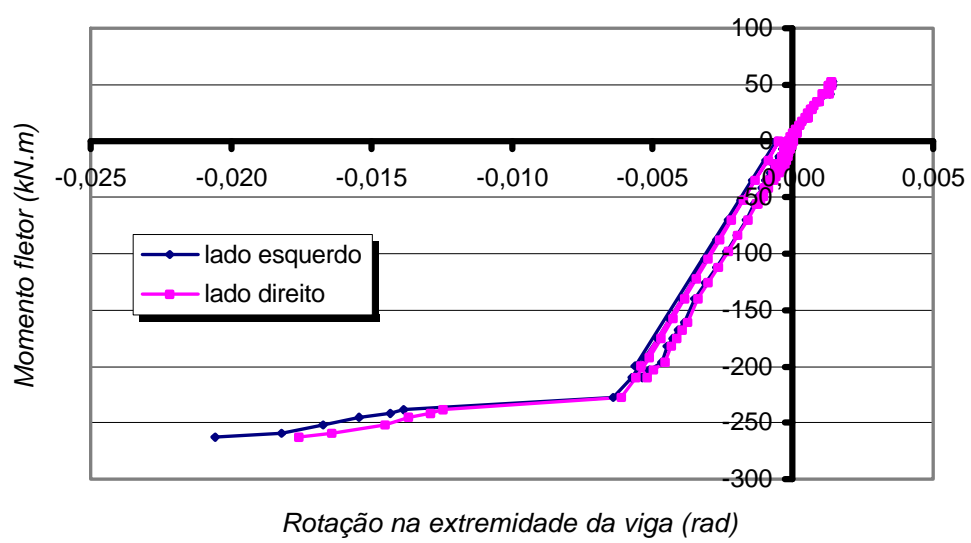

Gráfico 5.8 - Curva M- $\theta$ para o Protótipo Monolítico (a partir da leitura interna dos extensômetros elétricos).

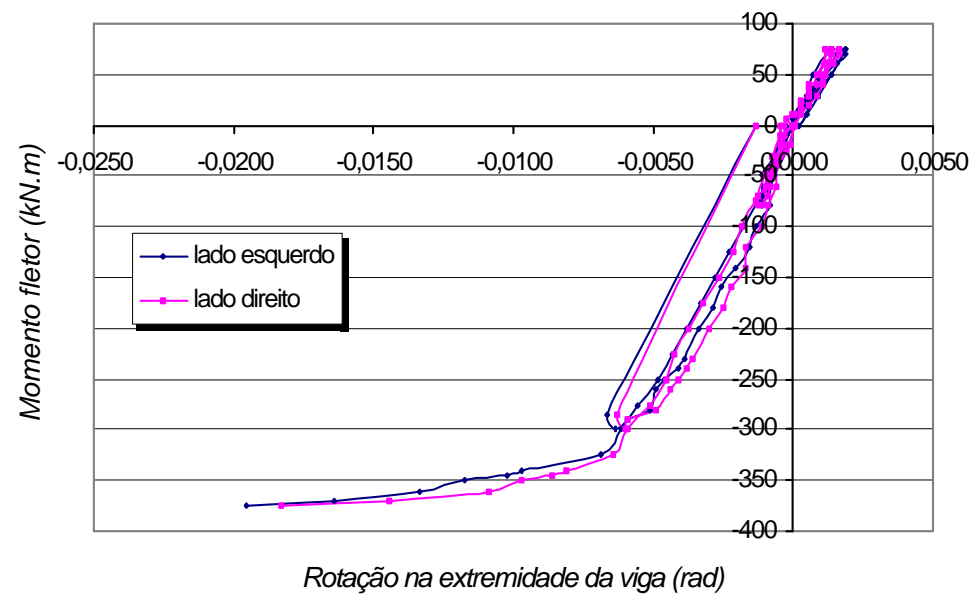

Gráfico 5.9 - Curva M- $\theta$ para o Protótipo Monolítico. (a partir da leitura externa por transdutores elétricos)

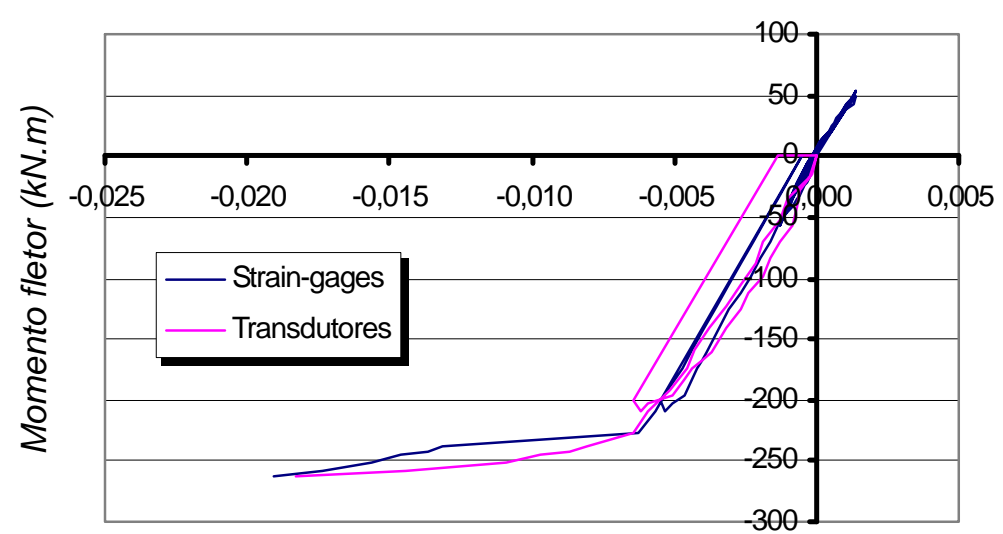

Rotação da extremidade da viga (rad)

Gráfico 5.10 - Comparação das curvas M- $\theta$, para o Protótipo Monolítico, obtidas a partir das leituras internas (extensômetros) e externas (transdutores). 


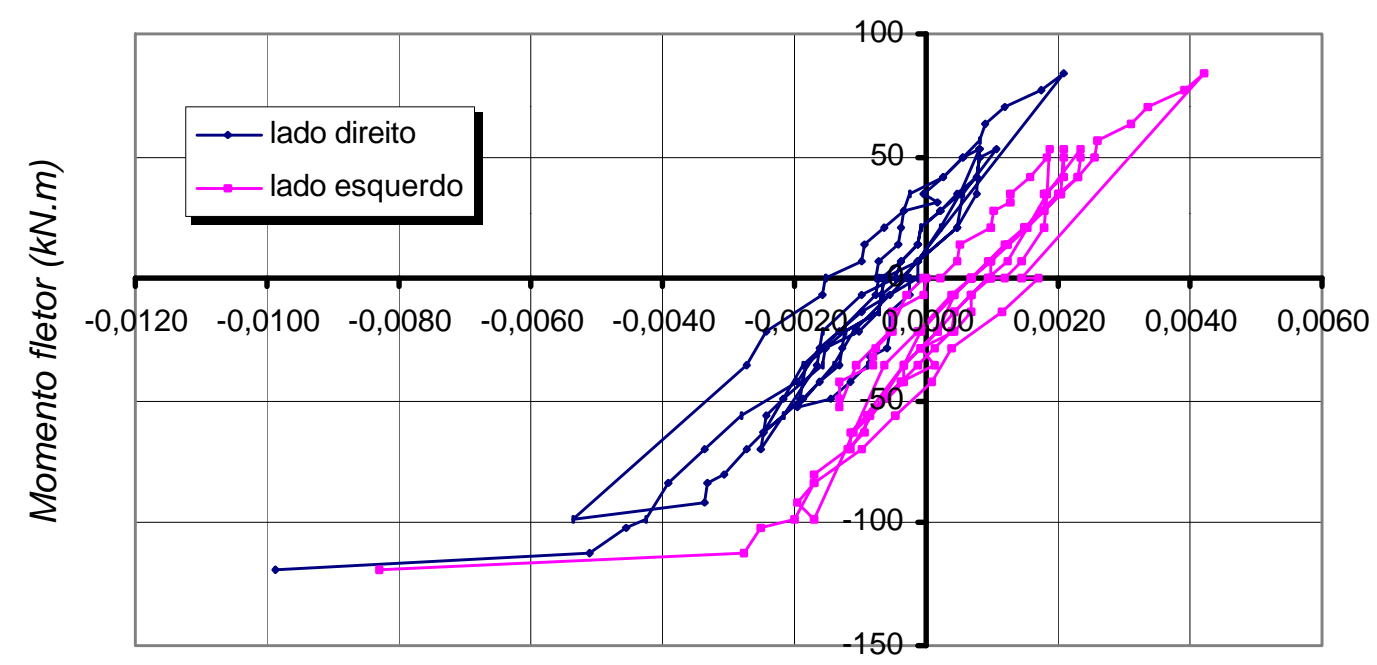

Rotação da extremidade da viga (rad)

Gráfico 5.11 - Curva M- $\theta$ para as rotações nas extremidades dos elementos de viga do Protótipo com Ligações Soldadas.

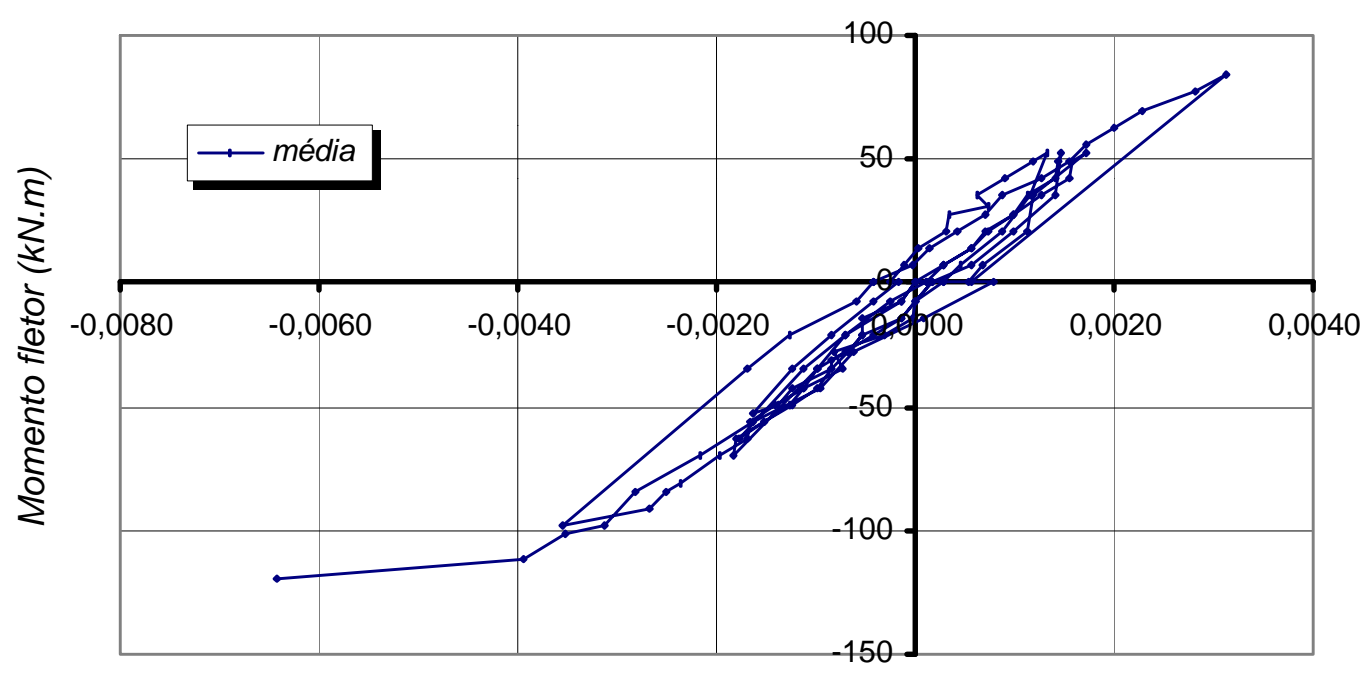

Rotação na extremidade da viga (rad)

Gráfico 5.12 - Curva M- $\theta$ para as rotações nas extremidades dos elementos de viga do Protótipo com Ligações Soldadas (Valores Médios). 


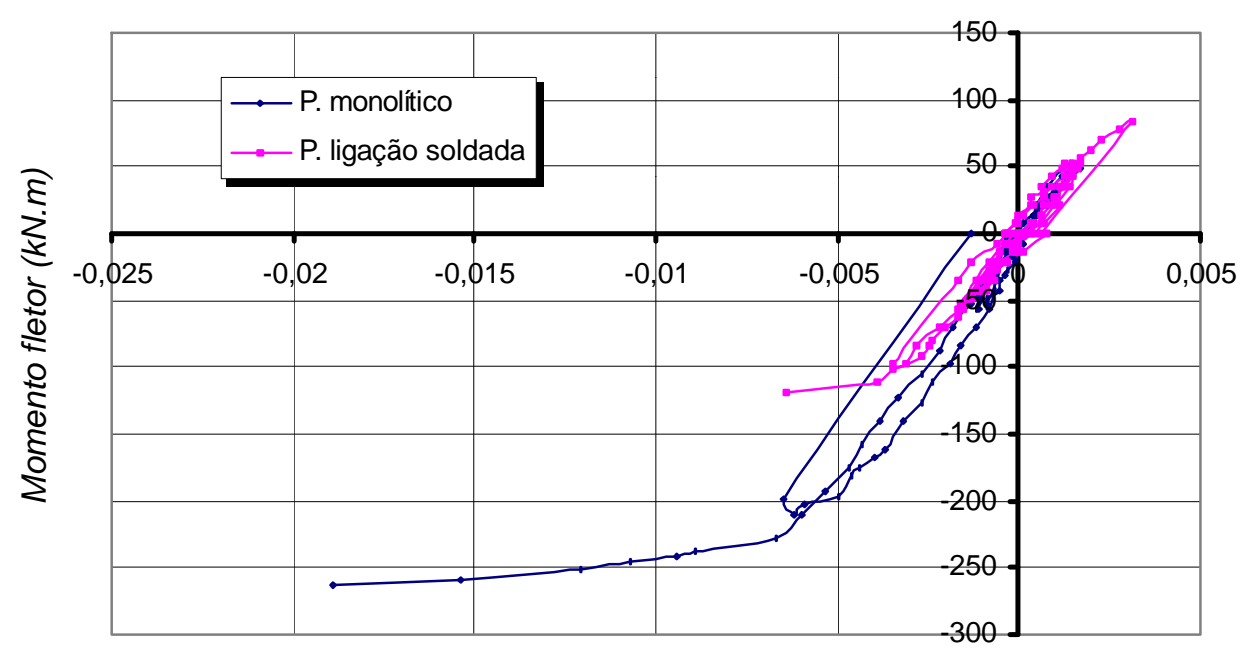

Rotação na extremidade da viga (rad)

Gráfico 5.13 - Comparação entre as rotações nas extremidades dos elementos de viga para os dois protótipos (Para todos os ciclos de carregamento).

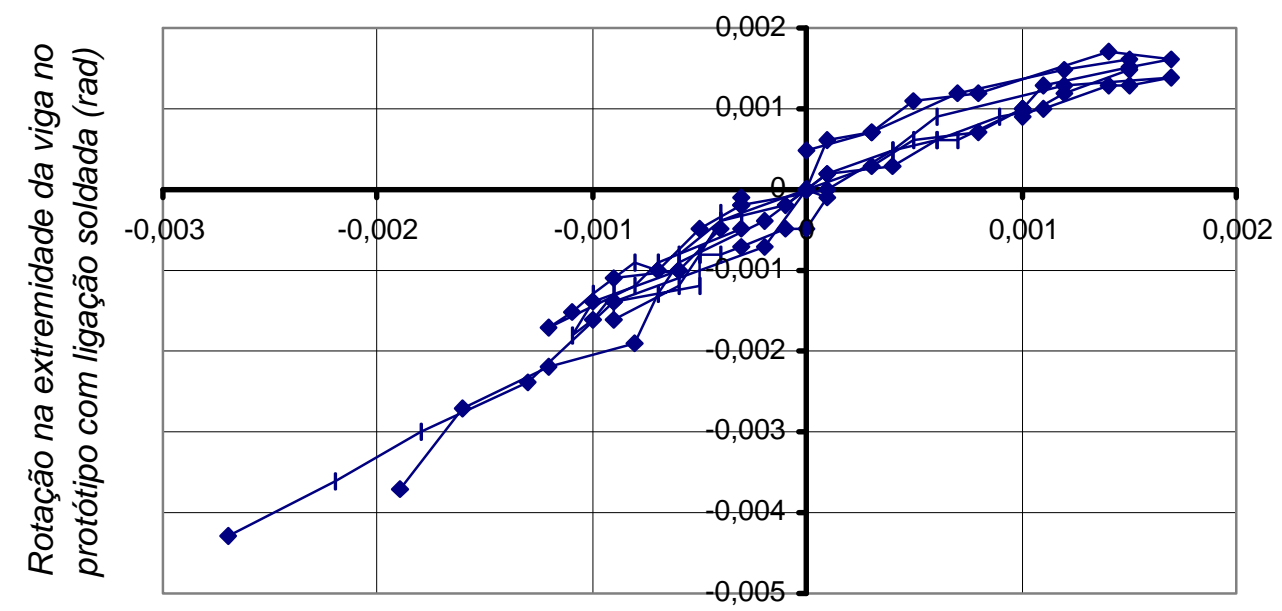

Rotação na extremidade da viga no protótipo monolítico (rad)

Gráfico 5.14 - Rotações nas extremidades dos elementos de viga no Protótipo com Ligações Soldadas em função das rotações no Protótipo Monolítico. (ver Tabela 5.6) 


\subsubsection{Rotações Relativas entre o Elemento de Viga e a face do Pilar no Protótipo com \\ Ligações Soldadas (Rotações da Ligação)}

A rotação relativa entre a face vertical do pilar e o elemento de viga constitui-se, no caso do Protótipo com Ligações Soldadas, como a única medida direta para a obtenção da rotação da ligação.

No caso do Protótipo Monolítico, como existe uma continuidade da curvatura ao longo da região na extremidade da viga, a rotação da extremidade do elemento de viga também corresponde à rotação relativa entre os elementos de viga e de pilar. Isto pode ser verificado a partir do gráfico 5.10, onde são apresentadas simultaneamente as curvas para as rotações obtidas a partir dos deslocamentos medidos nos transdutores dispostos na face superior de um trecho da extremidade da viga e as rotações obtidas para uma seção da extremidade da viga próxima à interface entre o elemento de viga e o elemento de pilar, instrumentada com extensômetros dispostos nas armaduras negativa e positiva.

Ao contrário, no caso do Protótipo com Ligações Soldadas, tem-se uma descontinuidade da curvatura na região da ligação, havendo uma concentração dos deslocamentos dentro de uma pequena região. Desta forma, as medidas das rotações nas extremidades dos elementos de viga, que foram medidas para um trecho na extremidade da viga, servem de comparação para os giros de corda entre os elementos de viga do Protótipo Monolítico e do Protótipo com Ligações Soldadas, mas não fornecem os deslocamentos diretos da ligação. Já as medidas para as rotações relativas entre os elementos do pilar e da viga são tomadas a partir das rotações na seção da interface vertical entre os dois elementos, fornecendo assim os deslocamentos diretos da ligação.

No gráfico 5.15 são apresentadas as curvas Momento $x$ Rotação para a rotação relativa entre a face vertical na extremidade da viga e a face do pilar para o Protótipo com Ligações Soldadas. Estas rotações foram obtidas a partir das leituras de deslocamento nos transdutores T-84 ao T-89, posicionados horizontalmente na interface entre as faces verticais do pilar e da extremidade da viga, conforme ilustrado na figura 5.19.

No gráfico 5.16, as curvas Momento x Rotação foram obtidas para os primeiros ciclos de carregamento, com momentos negativos máximos da ordem de - 60 kN.m e momentos positivos máximos da ordem de $45 \mathrm{kN.m}$. A partir deste gráfico, foram 
determinadas as inclinações dessas curvas para cada ciclo de carregamento, a partir das quais determinou-se a deformabilidade à flexão da ligação.

O valor médio da inclinação das curvas Momento x Rotação, no caso dos momentos $\underline{\text { negativos }}$, foi de $K_{\phi}=39.115 \mathrm{kN} . \mathrm{m} / \mathrm{rad}$, o que representou uma deformabilidade da ordem de $\lambda_{\phi, \text { lig }}=2,57 \times 10^{-5} \mathrm{rad} / \mathrm{kN} . \mathrm{m}$. Este valor para a inclinação correspondeu a cerca de $83 \%$ da inclinação média obtida para o Protótipo Monolítico $\left(K_{\phi}=47.297 \mathrm{kN} . \mathrm{m} / \mathrm{rad}\right.$ e $\lambda_{\phi \text {,lig }}=$ $\left.2,57 \times 10^{-5} \mathrm{rad} / \mathrm{kN} . \mathrm{m}\right)$.

Acredita-se que entre as causas, para a redução na rigidez inicial à flexão negativa da ligação, esteja à ação desfavorável do consolo sobre a extremidade da viga, a qual promove uma concentração da flexão localizada nas barras da armadura negativa próxima à ligação.

Do ponto de vista da resistência da ligação aos momentos negativos, este comportamento fez com que houvesse, além da flexão localizada na armadura negativa, uma concentração de tensões normais de tração na região da solda de filete na ligação da armadura negativa com a chapa metálica, criando uma situação desfavorável que contribui sensivelmente para a precipitação da falha na ligação.

A ruptura para o momento negativo no Protótipo com Ligação Soldada ocorreu na ligação por solda entre a armadura negativa e a chapa metálica. Inicialmente, ocorreu uma falha prematura na solda de uma das quatro barras da armadura negativa (em uma das barras de canto), ainda no ciclo 7, para uma ação de compressão no atuador da ordem de $120 \mathrm{kN}$. A ruptura completa, veio a acontecer no ciclo 9, por meio da ruptura frágil das soldas de mais duas barras da armadura negativa (uma de canto e outra central), para uma ação de compressão no atuador da ordem de $170 \mathrm{kN}$, que correspondeu a um momento negativo na ligação da ordem de 120 kN.m.

O valor médio da inclinação das curvas Momento x Rotação, no caso dos momentos positivos, foi de $K_{\phi}=48.585,6 \mathrm{kN} . \mathrm{m} / \mathrm{rad}$, o que representou uma deformabilidade da ordem de $\lambda_{\phi, l i g}=2,07 \times 10^{-5} \mathrm{rad} / \mathrm{kN} . \mathrm{m}$. Este valor para a inclinação correspondeu a cerca de $155 \%$ da inclinação média obtida para o Protótipo Monolítico $\left(K_{\phi}=31.358 \mathrm{kN} . \mathrm{m} / \mathrm{rad}\right.$ e $\lambda_{\phi \text {,lig }}=$

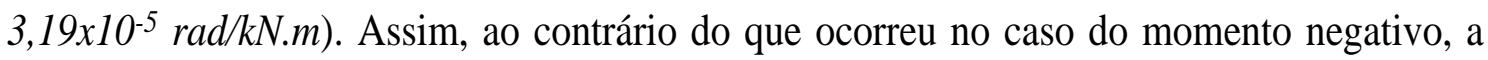
presença do consolo na ligação teve um efeito favorável para o aumento da rigidez à flexão positiva da ligação. 


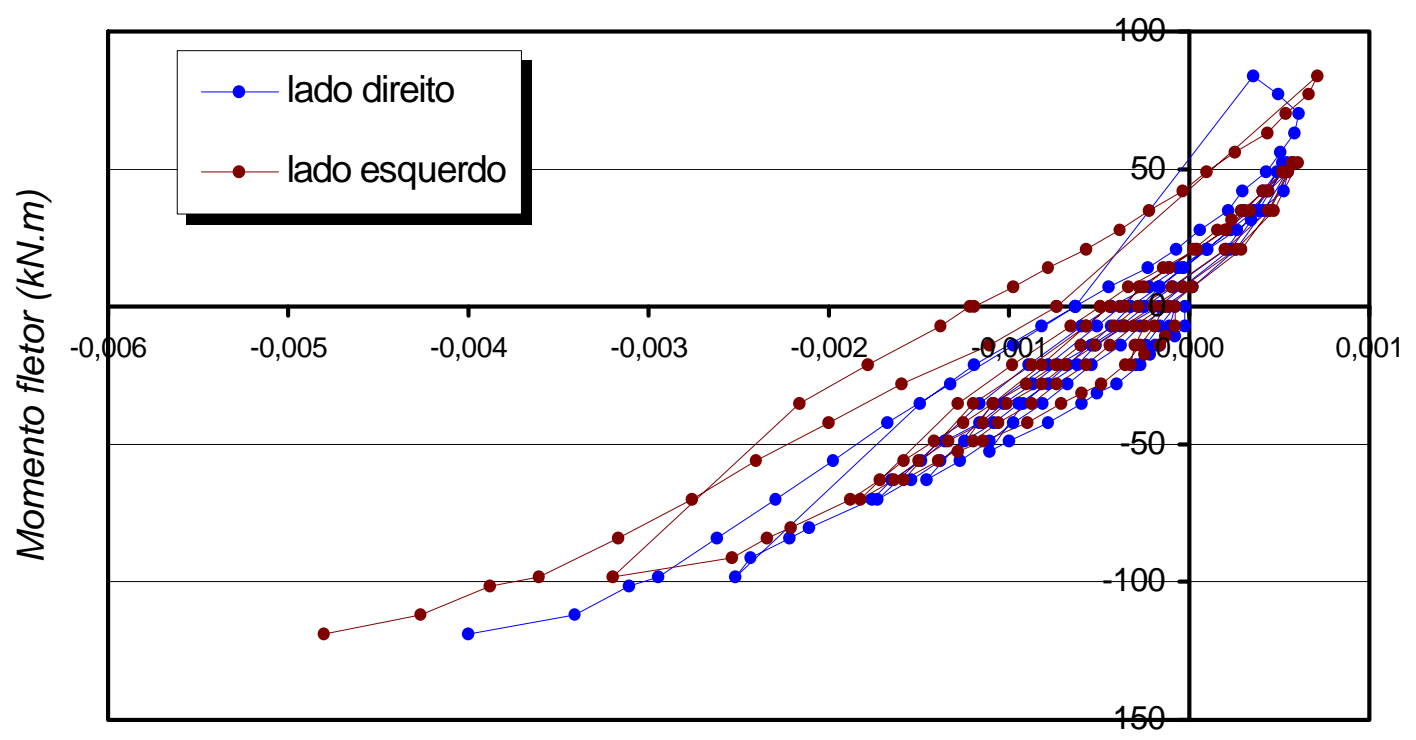

Rotação relativa entre a viga e a coluna (rad)

Gráfico 5.15 - Curva M- $\theta$ para as Rotações Relativas entre o elemento de viga e a face do pilar, para o Protótipo com Ligação Soldada. (Ciclos 1 ao 9)

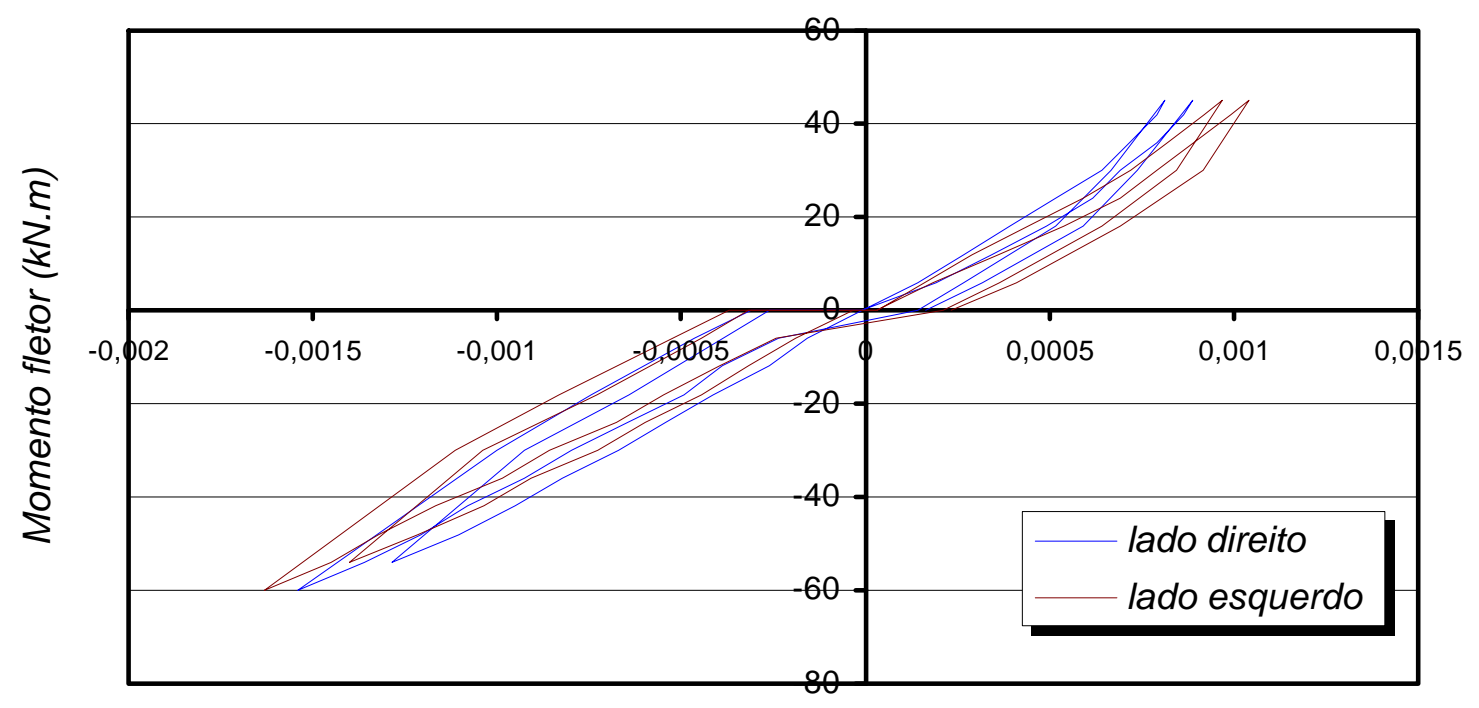

Rotação relativa entre a viga e o pilar (rad)

Gráfico 5.16 - Curva M- $\theta$ para as Rotações Relativas entre o elemento de viga e a face do pilar no Protótipo com Ligação Soldada. (Regime de Serviço) 


\subsubsection{Tensões nas Armaduras dos Elementos de Viga nos Protótipos}

Nos gráficos 5.17 e 5.18 são apresentadas as curvas da força de compressão no atuador, correspondente aos momentos negativos nas extremidades dos elementos de viga, em função das tensões máximas de tração nas armaduras negativas dos elementos de viga para o Protótipo Monolítico e Protótipo com Ligações Soldadas, respectivamente.

No gráfico 5.19 faz-se uma comparação das tensões desenvolvidas nas armaduras negativas dos dois protótipos. Observou-se que as armaduras negativa no Protótipo com Ligações Soldadas atingiram níveis de tensão da ordem de $500 \mathrm{MPa}$ para ações de compressão no atuador da ordem de $150 \mathrm{kN}$. Por outro lado, no caso do protótipo monolítico, estes mesmos níveis de tensões somente foram atingidos para ações de compressão no atuador acima de $300 \mathrm{kN}$.

Isto se deu em razão de que, no caso do Protótipo com Ligação Soldada, as barras da armadura negativa apresentaram uma flexão localizada próxima a região da ligação soldada. Esta flexão localizada na armadura foi causada pela ação alavancadora da extremidade da viga sobre o consolo.

A armadura negativa, por sua vez, atuou como uma alavanca que encontrou resistência ao giro, oferecida pelo momento de inércia da chapa metálica na ligação negativa. Tal fenômeno, fez com que essa chapa sofresse uma rotação inversa à rotação da extremidade do elemento de viga, surgindo assim um ponto de inflexão na seção de máxima flexão localizada na barra da armadura negativa, próximo à ligação com solda.

Nos gráficos 5.20 e 5.21 são apresentadas as curvas da força de tração no atuador, correspondente aos momentos positivos nos elementos de viga, como função das tensões máximas de tração nas armaduras positivas dos elementos de viga para o Protótipo Monolítico e Protótipo com Ligações Soldadas, respectivamente. No gráfico 5.22 é apresentada uma comparação das tensões desenvolvidas nas armaduras positivas das vigas nos dois protótipos, onde não foram observadas grandes diferenças entre as mesmas. 


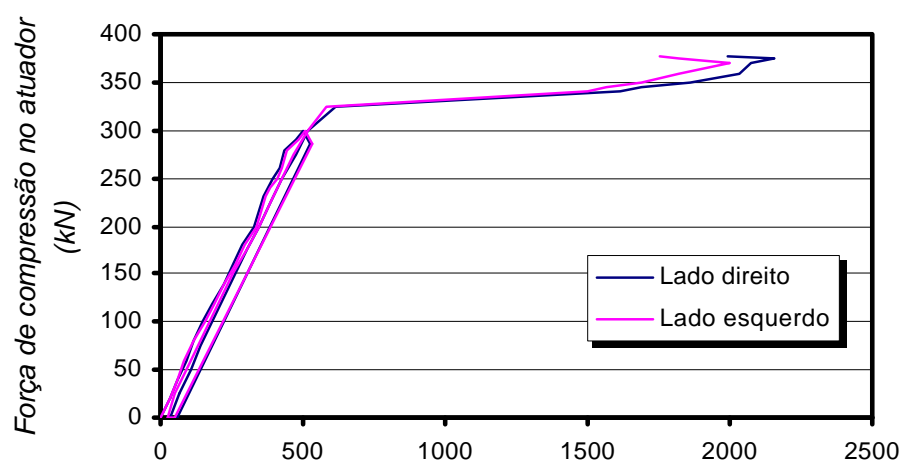

Tensão máxima de tração na armadura negativa da viga (MPa)

Gráfico 5.17 - Momento negativo no Protótipo Monolítico (Ciclos 7 e 8).

Tensão normal de tração na seção da armadura negativa da viga.

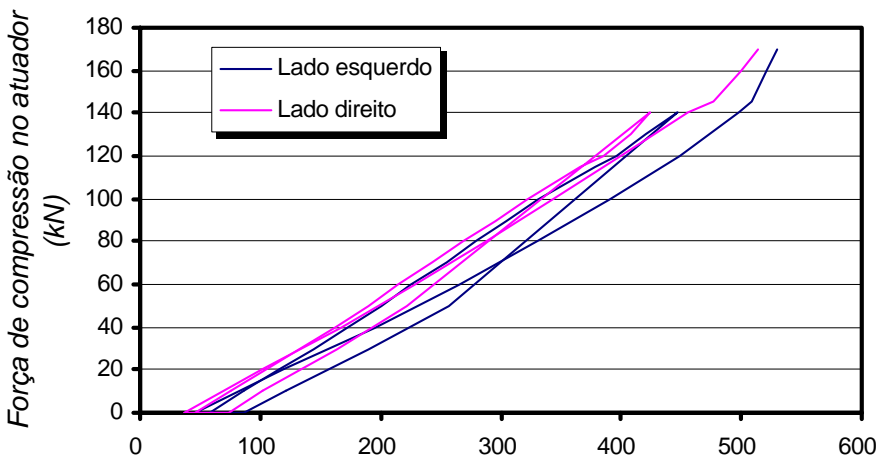

Tensão máxima de tração na armadura negativa da viga (MPa)

Gráfico 5.18 - Momento negativo no Protótipo com Ligação Soldada. (Ciclos 7 e 9).

Tensão de tração máxima na seção da armadura negativa da viga com flexão lnsal

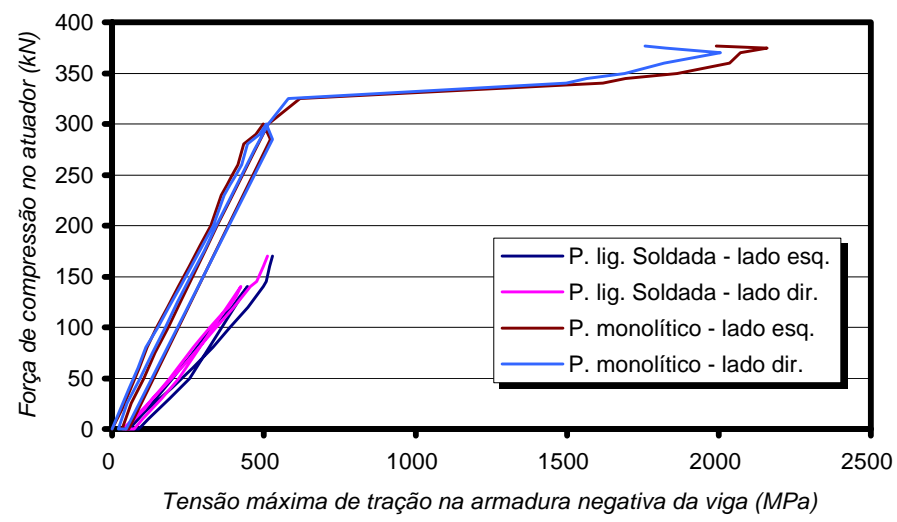

Gráfico 5.19 - Comparação dos níveis de tensões de tração nas seções das armaduras negativas para o Protótipo Monolíticos e o Protótipo com Ligação Soldada. 


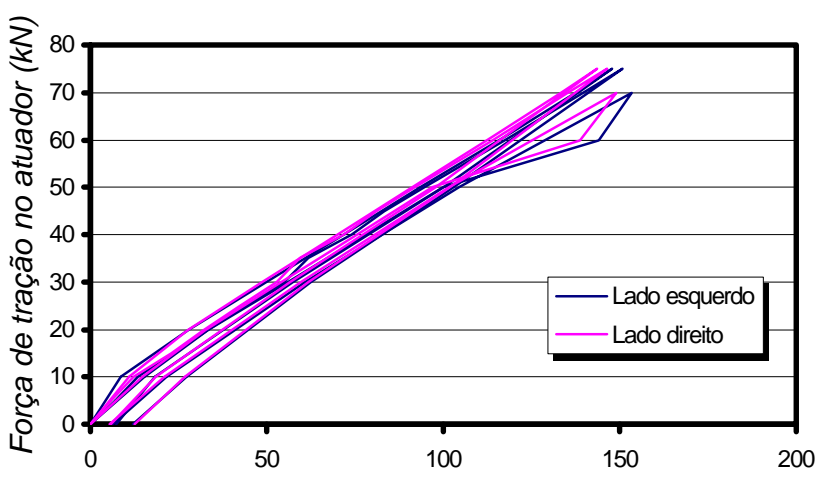

Tensão máxima de tração na armadura positiva de viga (MPa)

Gráfico 5.20 - Momento positivo no Protótipo Monolítico (Ciclos 2, 4 e 6)

Tensão normal de tração na seção da armadura positiva da viga.

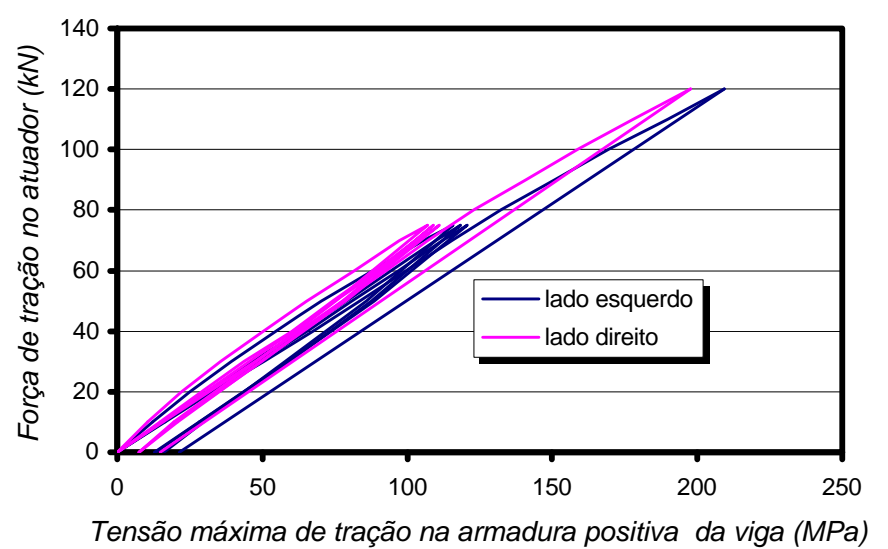

Gráfico 5.21-Momento positivo no Protótipo com Ligação Soldada. (Ciclos 6 e 8). Tensão de tração máxima na seção da armadura positiva da viga.

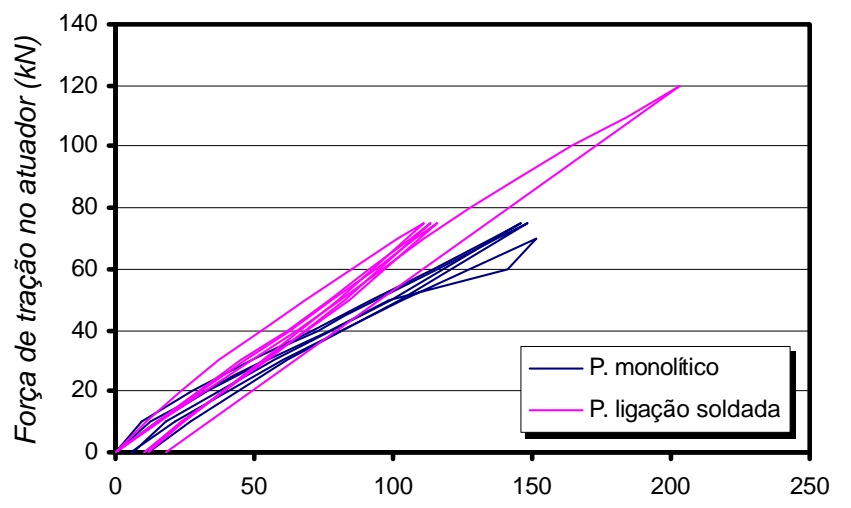

Tensão máxima de tração na armadura positiva da viga (MPa)

Gráfico 5.22 - Comparação dos níveis de tensões de tração nas seções das armaduras poitivas para o Protótipo Monolíticos e o Protótipo com Ligação Soldada. 


\subsubsection{Configurações das Fissuras nas Extremidades dos Elementos de Viga}

Nas figuras 5.28 e 5.29 são apresentadas as configurações das fissuras nas extremidades das vigas, junto ao pilar, do protótipo monolítico.

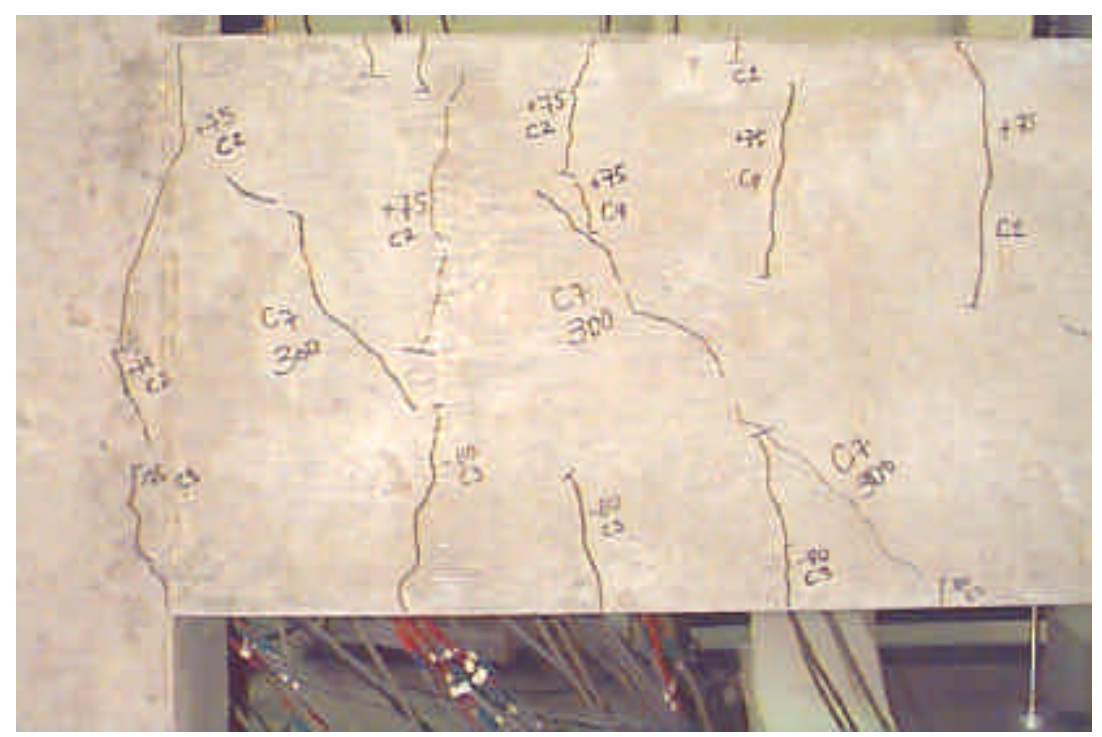

Figura 5.28 - Fissuras no lado direito do Protótipo Monolítico

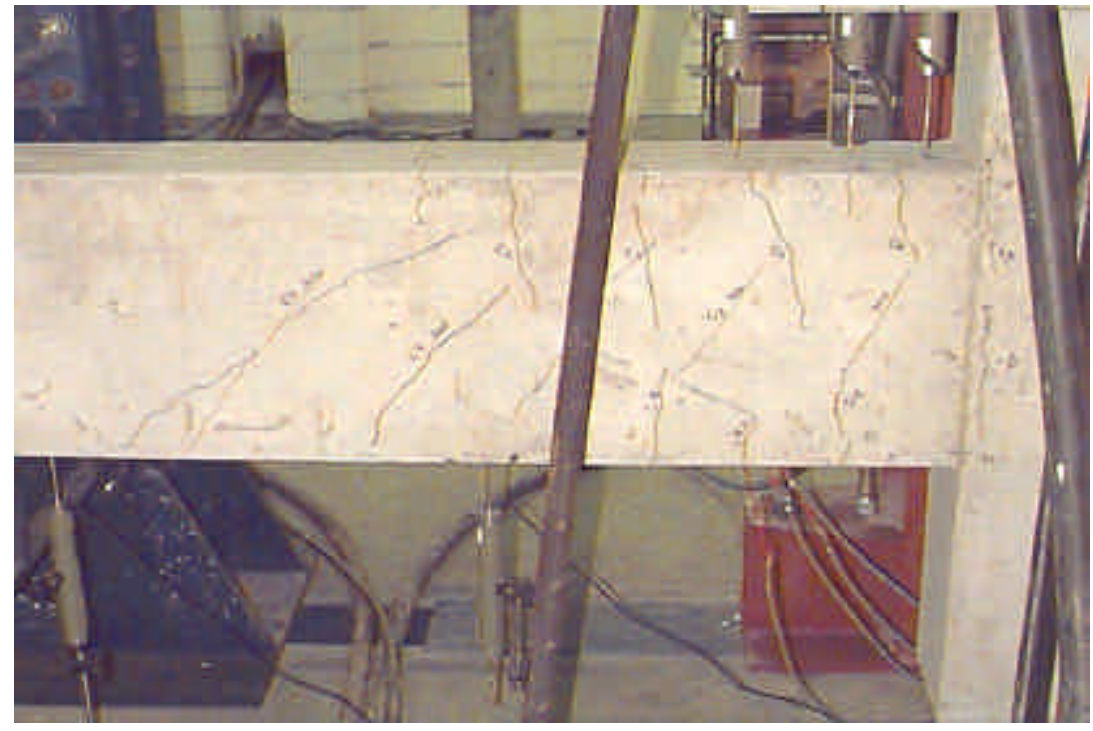

Figura 5.29 - Fissuras no lado esquerdo do Protótipo Monolítico 
Após a soldagem entre os elementos de viga e pilar, o protótipo com ligações soldadas apresentou pequenas fissuras junto às chapas metálicas, conforme indicadas nas fotos da figura 5.30.
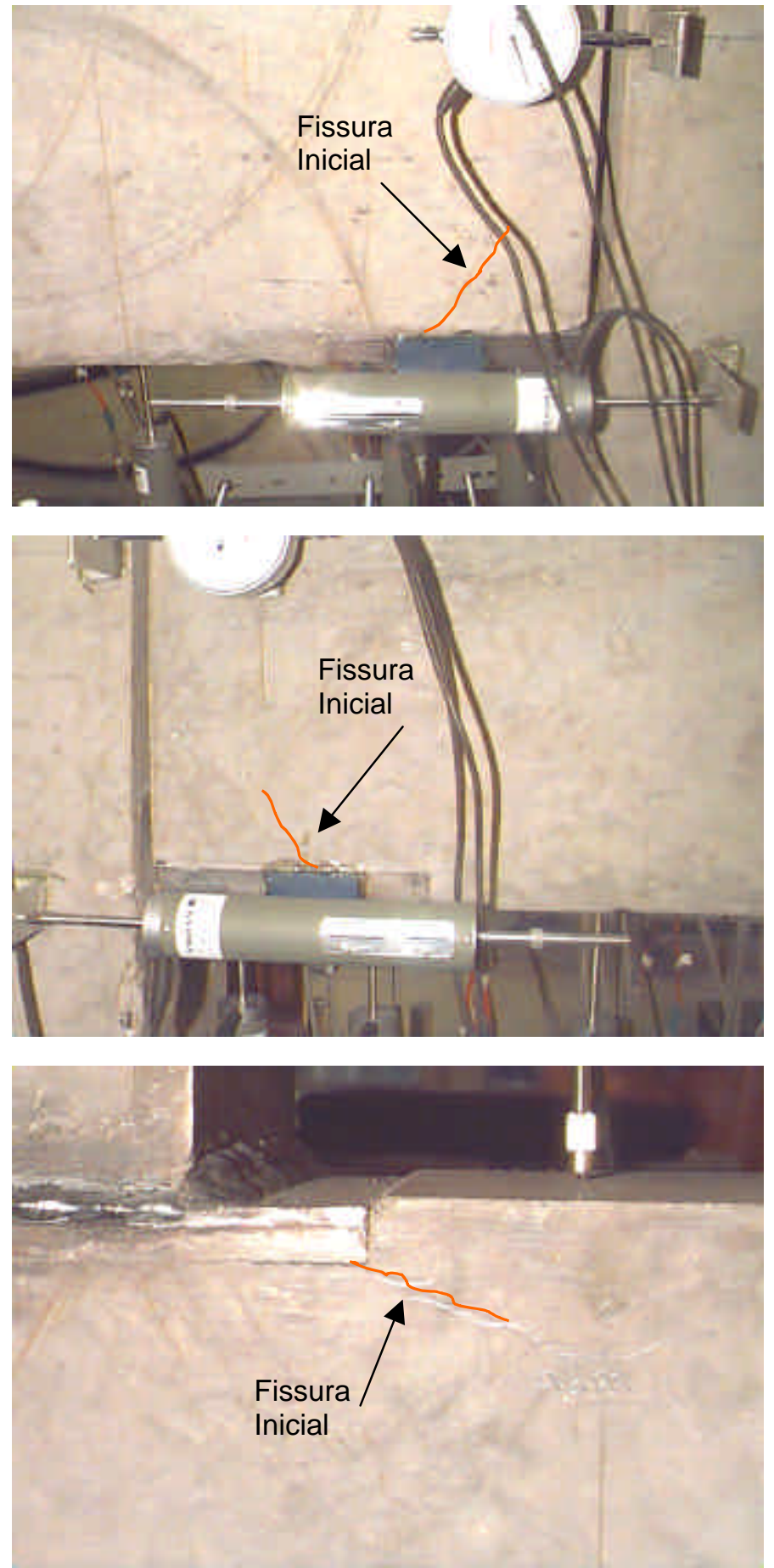

Figura 5.30 - Fissuras iniciais no Protótipo com Ligações Soldadas, decorrentes do efeito da temperatura durante o processo de solda entre os elementos 
Nas figuras 5.31 e 5.32 são apresentadas as configurações das fissuras nas extremidades dos elementos de viga no protótipo com ligações soldadas.

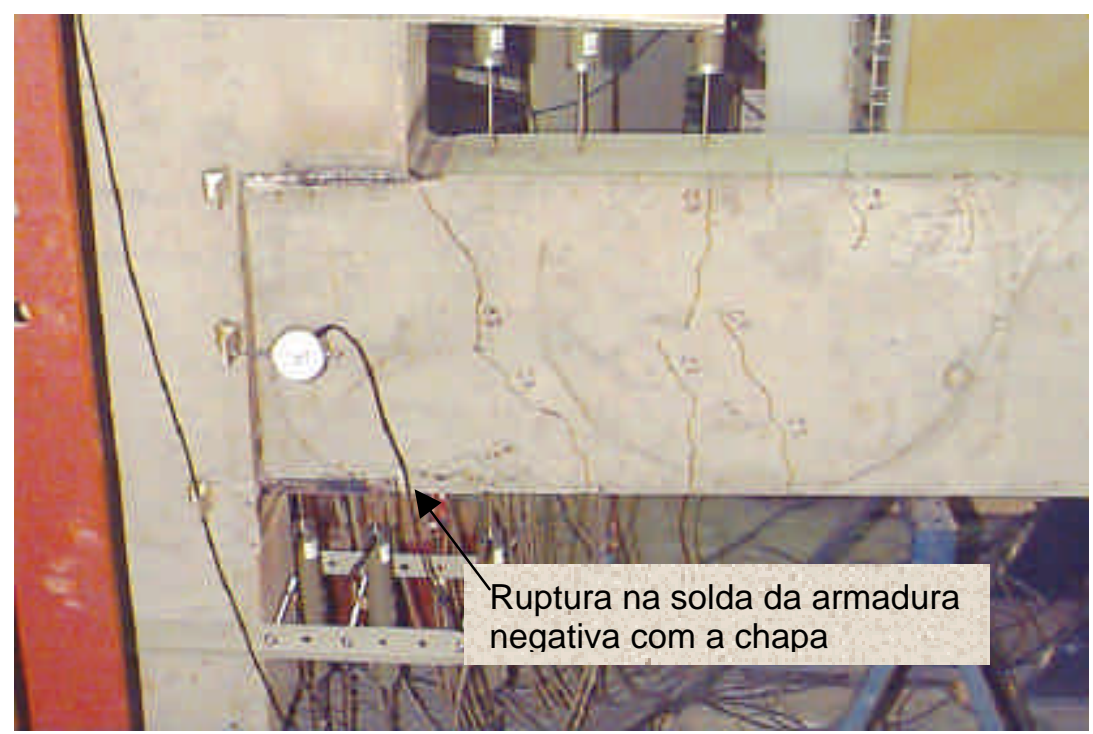

Figura 5.31 - Fissuras no lado direito do Protótipo com Ligações Soldadas.

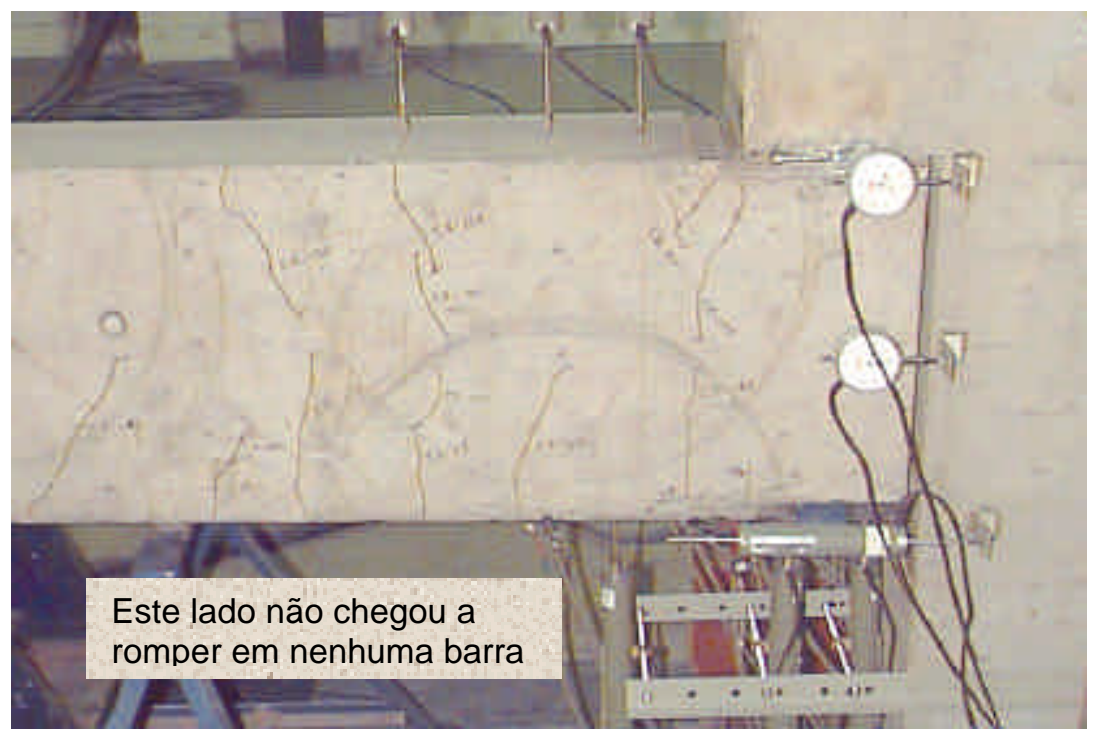

Figura 5.32 - Fissuras no lado esquerdo do Protótipo Monolítico 
As configurações das duas ligações negativas no protótipo, após a ruptura, são apresentadas nas figuras 5.33, com a ligação onde ocorreu a ruptura, e 5.34, com a ligação que não chegou a romper.

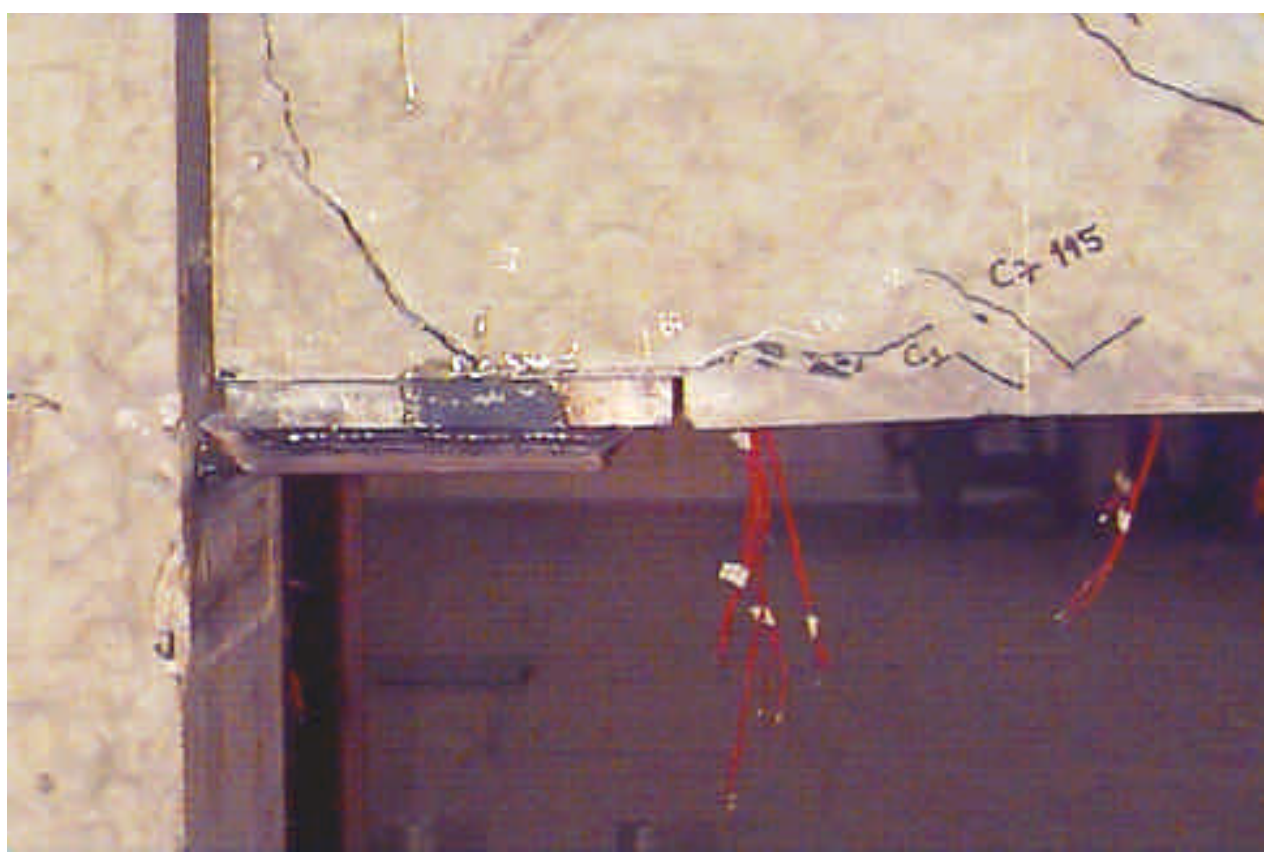

Figura 5.33 - Configuração da ligação negativa após a sua ruptura.

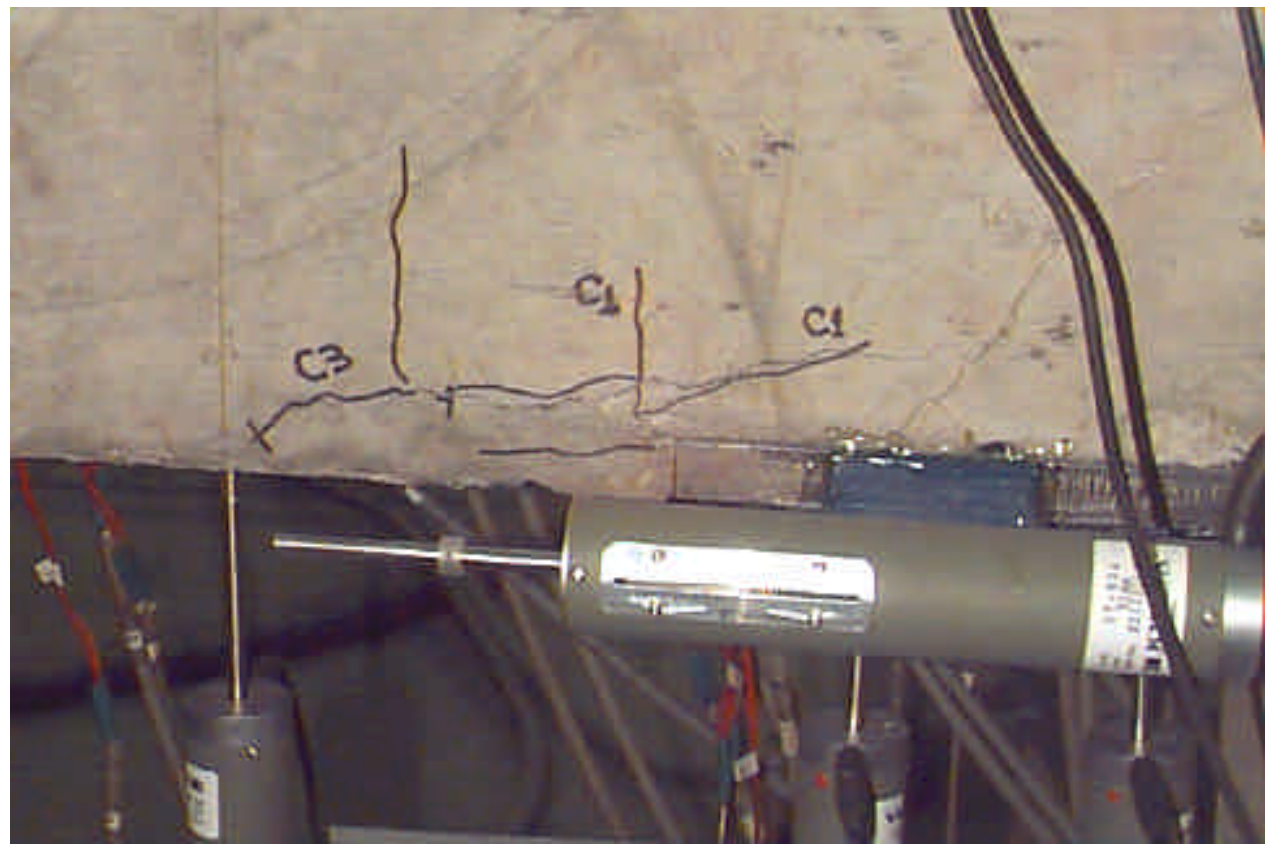

Figura 5.34 - Configuração da ligação negativa que não chegou a romper 


\subsection{Comparação dos Resultados Experimentais com os Procedimentos}

\section{Teóricos}

\subsubsection{Cálculo da Deformabilidade à Flexão da Ligação}

Na figura 5.35 é apresentada uma esquematização com a configuração da ligação deformada, conforme foi observada durante a realização do ensaio de flexão no protótipo com ligação soldada.

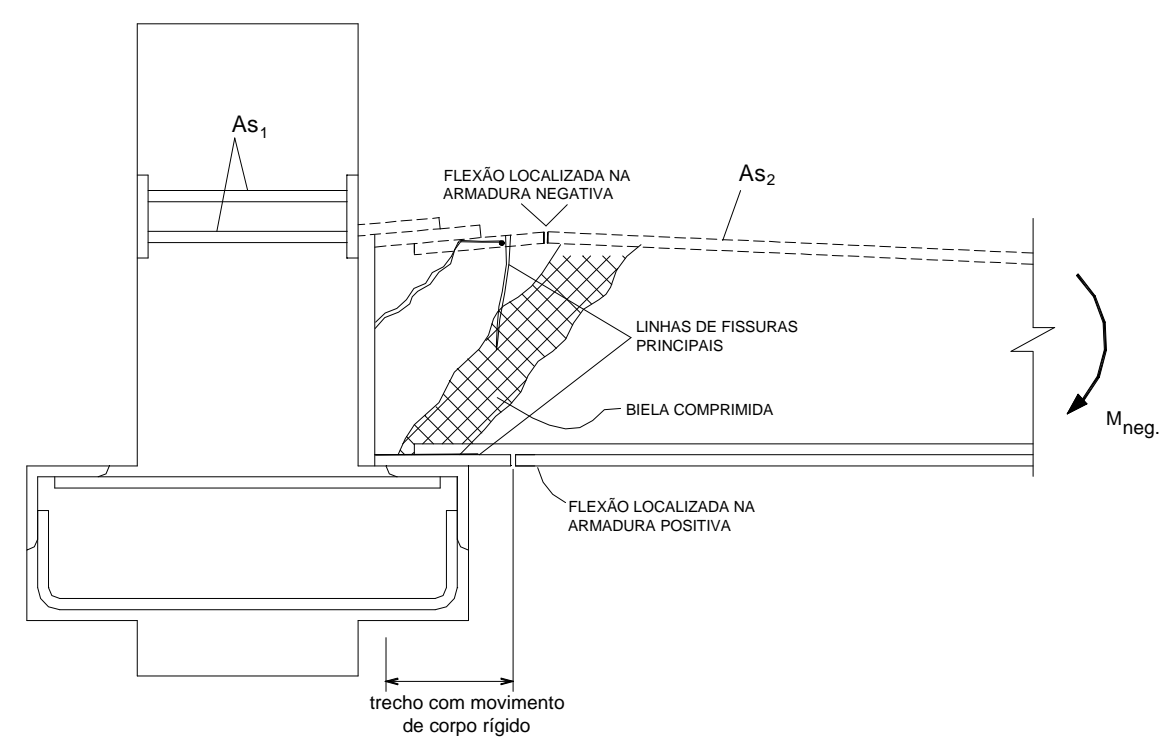

Figura 5.35 - Configuração da ligação deformada, conforme observado no ensaio.

O modelo para o cálculo da deformabilidade à flexão para a ligação com chapas soldadas foi desenvolvido analiticamente em FERREIRA (1993) e está apresentado no item 5.2 deste capítulo. A seguir, faz-se algumas considerações com respeito a alguns parâmetros que fazem parte do equacionamento teórico, com base na observação e análise do comportamento da ligação ensaiada.

A chapa de ligação na borda superior do elemento de viga sofreu uma rotação inversa à rotação da extremidade do elemento de viga, havendo assim um ponto de inflexão na região da extremidade da viga. Isto ocorreu devido à ação de alavanca da armadura negativa sobre a chapa metálica. Esta ação também foi responsável pelo aparecimento de uma flexão localizada na armadura negativa próxima à ligação com a chapa. 
A excentricidade " $e_{1}$ " é definida pela excentricidade entre a face do pilar e a força normal de compressão sobre a chapa metálica, que no caso é a componente negativa da ação de binário aplicada pela extremidade da barra da armadura negativa na região da ligação da solda com a chapa metálica de topo, conforme indicado na figura 5.36. No caso do protótipo estudado, estima-se que a excentricidade seja da ordem de:

$$
e_{1}=1,5+6,0+5 / 3=9 \mathrm{~cm}
$$

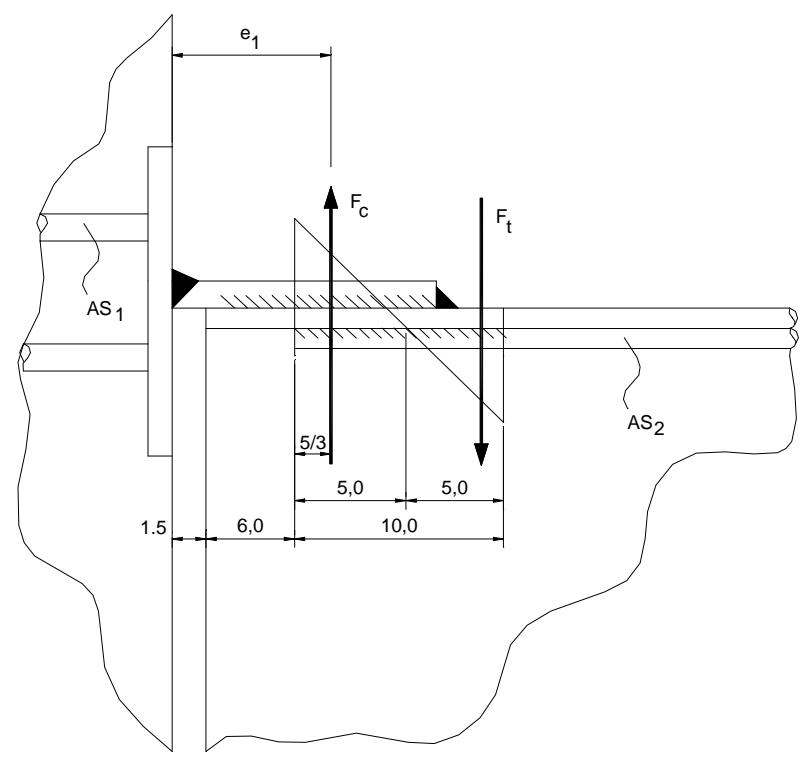

Figura 5.36 - Definição da excentricidade " $e_{1}$ ".

No equacionamento apresentado no item 5.2, idealizou-se que todo o trecho na extremidade da viga que estava apoiado sobre o consolo se comportava como um corpo rígido que, por sua vez, girava sobre o consolo. Assim, o parâmetro " $h_{2}$ " estava relacionado com o próprio comprimento do apoio da viga sobre o consolo. Segundo a configuração indicada na figura 5.37, o valor do parâmetro " $h_{2}$ “ neste caso, que está relacionado ao trecho com movimento de corpo rígido, foi definido como sendo o comprimento da chapa de ligação inferior subtraído pelo valor da excentricidade " $e_{1}$ ", sendo:

$$
h_{2}=22-9=13 \mathrm{~cm}
$$




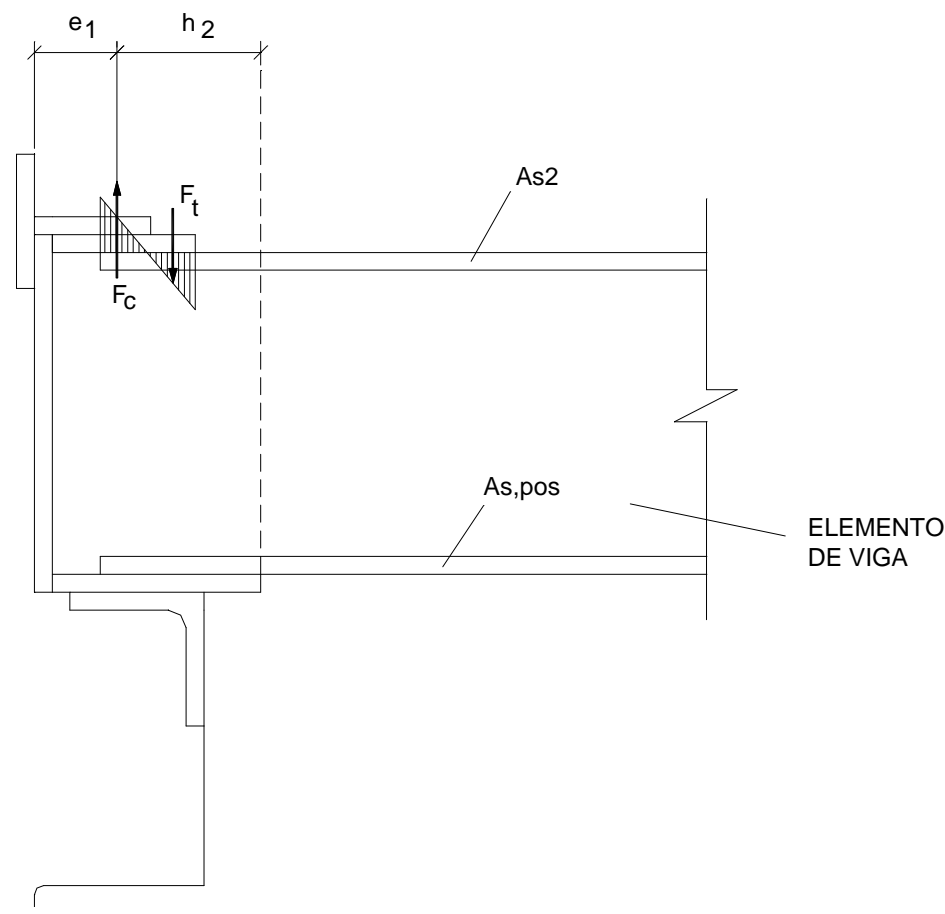

Figura 3.37 - Definição do parâmetro " $h_{2}$ ".

Na figura 5.38 é apresentada uma esquematização com o caminho das forças desde o atuador até o elemento de viga. Para esta configuração, a armadura negativa se mantém em níveis próximos de tensões dentro do trecho que é compreendido pela ligação da armadura com a chapa de topo e o ponto de encontro da biela comprimida com a armadura, que no caso está próximo do valor de braço de $\mathrm{z} \cong 30 \mathrm{~cm}$.

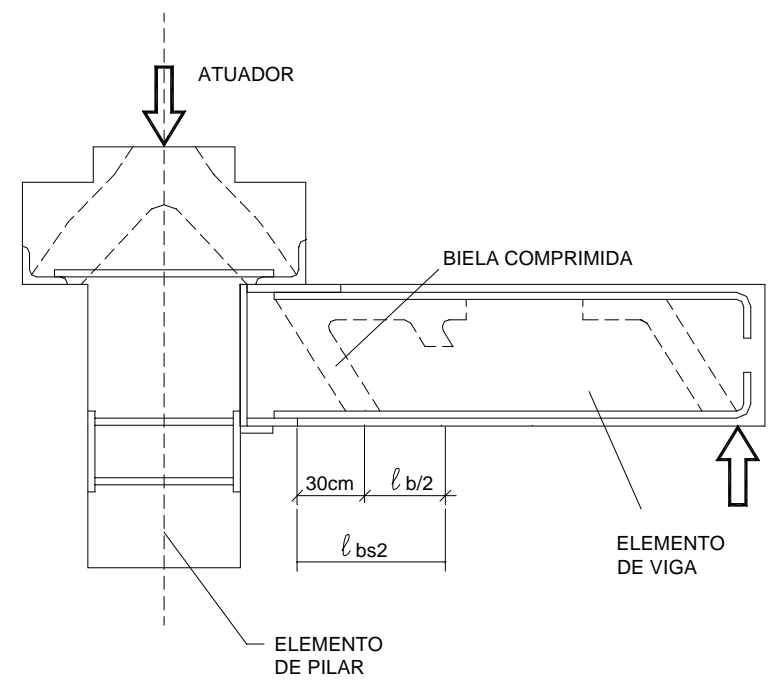

Figura 5.38 - Esquema do caminho das forças para o elemento de viga. 
Assim, o comprimento a ser considerado para a deformação à tração da barra da armadura negativa, definido por $\ell_{\mathrm{S} 2}$, foi dado pelo braço $\mathrm{z}=30 \mathrm{~cm}$ somado à metade do valor do comprimento de ancoragem da barra da armadura, $\ell_{\mathrm{b}} / 2=26 \mathrm{~cm}$, conforme discutido nos itens 3.2.1 e 5.2, sendo:

$$
\ell_{s 2}=30+\ell_{b} / 2=30+52 / 2=56 \mathrm{~cm}
$$

sendo:

$$
\ell_{b}=26 . \phi=26 * 2,5=52 \mathrm{~cm}
$$

Os demais parâmetros do protótipo com ligações soldadas, que foram utilizados no cálculo da sua deformabilidade à flexão, estão indicados na tabela 5.7.

\begin{tabular}{|c|c|c|}
\hline & Parâmetros da Ligação & Dados \\
\hline $\mathrm{A}_{\mathrm{S} 1}$ & Amadura negativa ancorada no pilar & $18,84 \mathrm{~cm}^{2}$ \\
\hline$A_{S 2}$ & Amadura negativa da viga & $12,56 \mathrm{~cm}^{2}$ \\
\hline $\mathrm{E}_{1}$ & $\begin{array}{l}\text { Excentricidade entre a face do pilar e a resultante de compressão } \\
\text { promovida pela ação de alavanca da armadura negativa sobre a } \\
\text { chapa. }\end{array}$ & $9 \mathrm{~cm}$ \\
\hline $\mathrm{H}_{1}$ & Altura da viga & $40 \mathrm{~cm}$ \\
\hline $\mathrm{H}_{2}$ & $\begin{array}{l}\text { Comprimento do trecho na extremidade da viga com comportamento de } \\
\text { corpo ńgido. }\end{array}$ & $13 \mathrm{~cm}$ \\
\hline $\mathrm{E}_{\mathrm{S}}$ & Módulo de Elasticidade do aço & $20.000 \mathrm{kN} / \mathrm{cm}^{2}$ \\
\hline $\mathrm{I}_{\mathrm{Ch}}$ & Momento de Inércia da Chapa de topo. & $5,12 \mathrm{~cm}^{4}$ \\
\hline$\ell_{\mathrm{S} 1}$ & Metade do comprimento da armadura Asl dentro do pilar, & $18,8 \mathrm{~cm}$ \\
\hline$\ell_{\mathrm{S} 2}$ & $\begin{array}{l}\text { Metade do comprimento de ancoragem da a madura As2 } \\
(\mathrm{ls} 2=30+\mathrm{b} / 2=30+(26 . \phi) / 2=30+52 / 2=61 \mathrm{~cm})\end{array}$ & $56 \mathrm{~cm}$ \\
\hline Z & Braço de alavanca da seção resistente ao Momento negativo. & $29,5 \mathrm{~cm}$ \\
\hline
\end{tabular}

Tabela 5.7 - Parâmetros do Protótipo com ligações soldadas

$$
\begin{aligned}
& \lambda_{\phi l i g}=\frac{e_{1}^{3}}{12 \cdot E_{s} \cdot I_{c h} \cdot h_{2}} \cdot\left(\frac{e_{1}^{3} \cdot A_{s 1} \cdot h_{1}^{2}}{12 \cdot \ell_{s 1} \cdot I_{c h} \cdot h_{2}}+h_{2}\right)^{-1}+\frac{\ell_{s 2}}{E_{s} \cdot A_{s 2} \cdot z \cdot h_{1}} \\
& \lambda_{\text {фlig }}=\frac{9^{3}}{12 \cdot 2000 \cdot 5,12 \cdot 13} \cdot\left(\frac{9^{3} \cdot 18,84 \cdot 40^{2}}{12 \cdot 18,8 \cdot 5,12 \cdot 13}+13\right)^{-1}+\frac{56}{2000 \cdot 12,56 \cdot 29,5 \cdot 40} \\
& \lambda_{\text {фlig }}=2,2 \cdot 10^{-7} \mathrm{rad} / \mathrm{kN} . \mathrm{cm}=2,2 \cdot 10^{-5} \mathrm{rad} / \mathrm{kN} . \mathrm{m}
\end{aligned}
$$


O valor médio da deformabilidade à flexão da ligação a partir dos resultados experimentais foi de $\lambda_{\phi \operatorname{lig}(\exp )}=2,57.10^{-5} \mathrm{rad} / \mathrm{kN} . \mathrm{m}$. Assim, o valor calculado foi um pouco menor, da ordem de $86 \%$ do valor experimental. No gráfico 5.23 são apresentadas a reta teórica da deformabilidade à flexão, dada por $\lambda_{\phi l i g(\text { calc })}=2,2.10^{-5} \mathrm{rad} / \mathrm{kN} . \mathrm{m}$, e as curvas experimentais Momento-Rotação da ligação, conforme já apresentadas no gráfico 5.16. Pode-se observar que, para o regime linear, a reta teórica apresentou uma boa aproximação dos resultados experimentais.

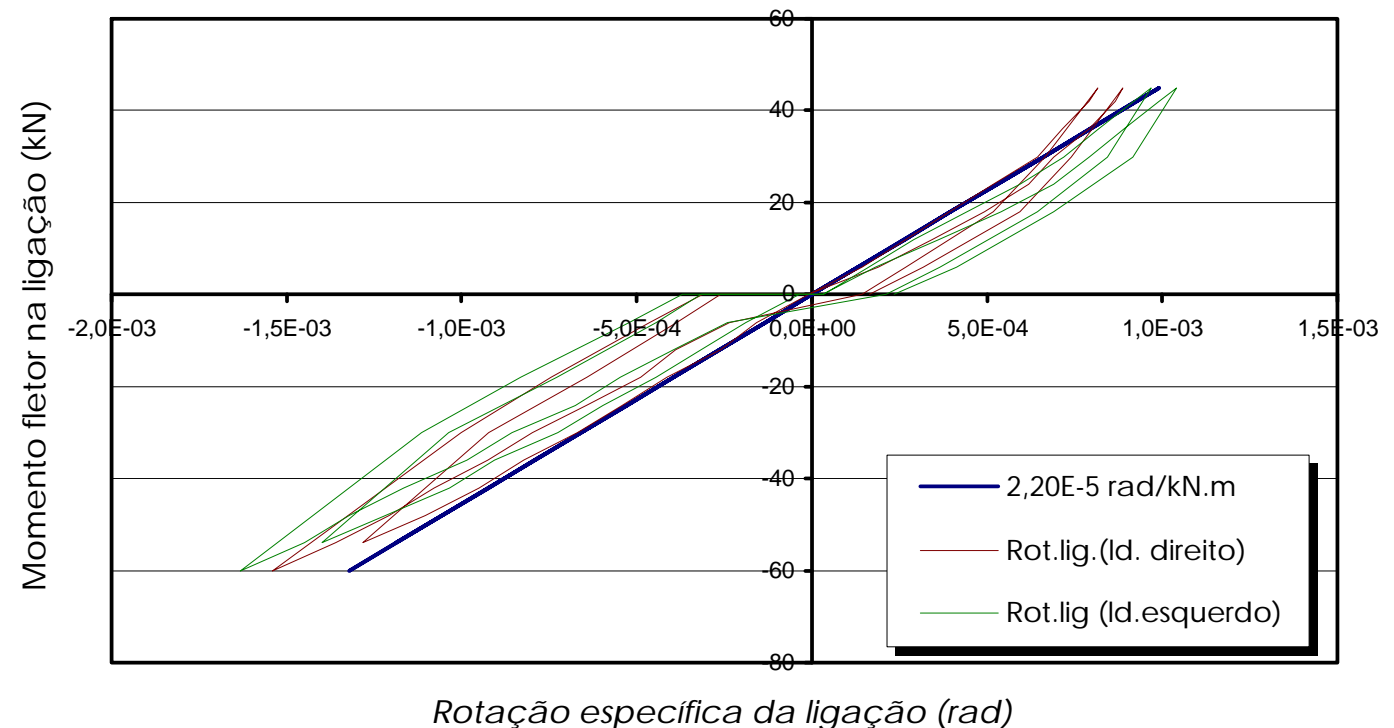

Gráfico 5.23 - Comparação da curva experimental $(M-\theta)$ com a reta teórica para a ligação

A rigidez tangente da ligação, $\mathrm{K}_{\phi, \exp }$, obtida a partir da deformabilidade à flexão experimental, é dada por:

$$
K_{\phi, \exp }=\left(2,57 \cdot 10^{-5}\right)^{-1}=39.115 \mathrm{kN} \cdot \mathrm{m} / \mathrm{rad}
$$

A rigidez secante da ligação, a partir do cálculo analítico, $\mathrm{K}_{\mathrm{E}, \mathrm{cal}}$, é dada por:

$$
K_{E, \text { calc }}=0,9 \cdot K_{\phi, \text { calc }}=0,9 \cdot\left(2,2 \cdot 10^{-5}\right)^{-1}=40.955 \mathrm{kN} . \mathrm{m} / \mathrm{rad}
$$

Assim, o valor da rigidez secante calculada foi $K_{E, \text { cal }}=1,05 . K_{\phi, \text { exp }}$, significando uma boa aproximação para a aplicação do modelo analítico. 


\subsubsection{Caracterização e Classificação da Rigidez da ligação}

Para a avaliação da rigidez da ligação idealizou-se uma viga de comprimento $\ell_{\text {virtual }}$ $=6 \mathrm{~m}$, com uma relação $\ell / \mathrm{h}=600 / 40=15$, conforme indicada na figura 5.39, a qual foi serviu também para a aplicação do método "Beam-Line".

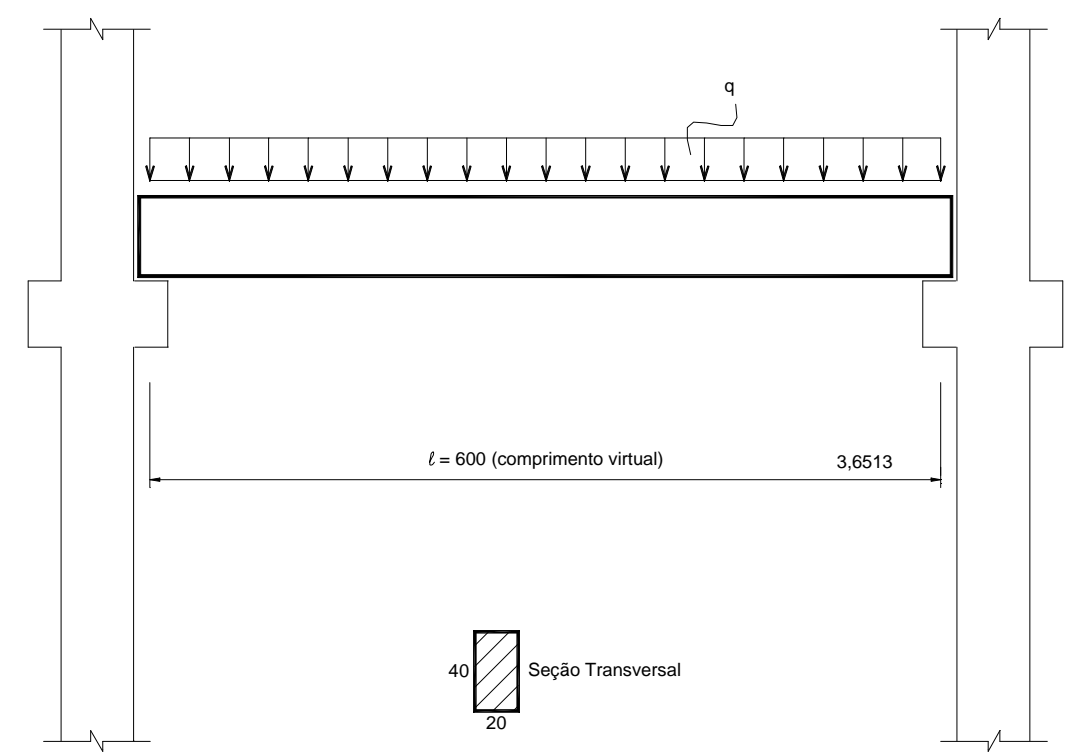

Figura 5.39 - Elemento de viga virtual para avaliação da rigidez da ligação

A rigidez equivalente da viga virtual, definida por $K_{s}$, é dada por:

$$
K_{s}=\frac{K_{E} \cdot \ell}{4 \cdot E_{c} \cdot I}
$$

sendo:

$$
\begin{aligned}
& E_{c}=37500 \mathrm{MPa}=37,50 \mathrm{kN} / \mathrm{mm}^{2} \\
& I=\frac{0,2 \cdot 0,4^{3}}{12}=1,06 \cdot 10^{-3} \mathrm{~m}^{4}=1,06 \cdot 10^{9} \mathrm{~mm}^{4}
\end{aligned}
$$

tendo-se:

$$
\begin{aligned}
& E_{c} \cdot I=39750 \mathrm{kN} \cdot \mathrm{m}^{2}=3,975 \cdot 10^{10} \mathrm{kN} \cdot \mathrm{mm}^{2} \\
& K_{s}=\frac{40955 \cdot 6}{4 \cdot 39750}=1,55>1,50
\end{aligned}
$$


A partir do limite $K_{S}>1,50$, considera-se que a aproximação linear da rigidez da ligação é bastante razoável, conduzindo a bons resultados para a aplicação na análise estrutural.

Segundo o EUROCODE 3 (1992), para o caso de estruturas contraventadas, os valores limites mínimos da rigidez para que a ligação seja considerada como rígida, $K_{\phi, r i g}$, ou semi-rígida, $K_{\phi, s e m i r i g}$ são dados pelas expressões:

$$
\begin{aligned}
& K_{\phi, \text { rig }} \geq \frac{8 \cdot E_{c} \cdot I}{\ell}=\frac{8 \cdot 39750}{6}=53000 \mathrm{kN} . \mathrm{m} / \mathrm{rad} \\
& K_{\phi, \text { rig }}>K_{\phi, \text { semirig }} \geq\left(0,5 \cdot E_{c} \cdot I\right) / \ell=(0,5 \cdot 39750) / 6=3312,5 \mathrm{kNm} / \mathrm{rad}
\end{aligned}
$$

Segundo um outro sistema de classificação, proposto por BJORDHODVE (1990), os valores limites para a rigidez da ligação são relacionados com a altura da viga, através das expressões:

$$
\begin{aligned}
& K_{\phi, \text { rig }} \geq \frac{E_{c} \cdot I}{2 \cdot h}=\frac{39750}{2.0,40}=49688 \mathrm{kN} . \mathrm{m} / \mathrm{rad} \\
& K_{\phi, \text { rig }}>K_{\phi, \text { semirig }} \geq\left(E_{c} \cdot I\right) /(10 \cdot h)=(39750) /(10 \cdot 0,4)=4969 \mathrm{kNm} / \mathrm{rad}
\end{aligned}
$$

Sendo, a rigidez secante teórica, $\mathrm{K}_{\mathrm{E}, \mathrm{cal}}$, da ordem de:

$$
K_{E, \text { calc }}=40.955 \mathrm{kN} . \mathrm{m} / \mathrm{rad}
$$

Então, a ligação foi classificada como uma ligação semi-rígida, segundo os dois sistemas de classificação. Todavia, o valor da rigidez secante calculada $\mathrm{K}_{\mathrm{E}, \mathrm{cal}}$ se aproxima dos limites mínimos de rigidez para as ligações rígidas, correspondendo a cerca de $74 \%$ do valor limite definido pelo EC3 (1992) e 78\% do valor limite definido por BJORDHODVE (1990).

Como, $K_{E, \text { cal }}=1,05 . K_{\phi, \text { exp. }}$ Então, pode-se dizer também que, segundo esses sistemas de classificação, a ligação ensaiada apresentou um bom desempenho quanto à sua rigidez inicial. 


\subsubsection{Momento Máximo de Bloqueio e sua Rotação Associada na Ligação}

A correção do momento de engastamento perfeito para se levar em conta a influência da deformabilidade da ligação no comportamento de uma viga com carregamento uniforme, segundo BRUN \& PICARDI (1976), pode ser feita pela expressão:

$$
M_{l i g}=\left(\frac{q \ell^{2}}{12}\right) \cdot\left[3 \cdot \gamma_{i} \frac{\left(2-\gamma_{j}\right)}{\left(4-\gamma_{i} \cdot \gamma_{j}\right)}\right]
$$

Para o caso de duas ligações com deformabilidades iguais nas extremidades da viga, com os fatores de restrição $\gamma_{\mathrm{i}}=\gamma_{\mathrm{j}}$, a expressão anterior fica:

$$
M_{\text {lig }}=\left(\frac{q \ell^{2}}{12}\right) \cdot\left[3 \cdot \gamma \frac{(2-\gamma)}{\left(4-\gamma^{2}\right)}\right]
$$

O fator de restrição da ligação, $\gamma$, proposto por MONFORTON \& WU (1963), é dado em função da deformabilidade da ligação através da expressão:

$$
\gamma=\left[1+\left(\frac{3 \cdot E_{c} \cdot I \cdot \lambda_{\phi, l i g}}{\ell}\right)\right]^{-1}=\left[1+\left(\frac{3 \cdot 39750 \cdot 2,2 \cdot 10^{-5}}{6}\right)\right]^{-1}=0,70
$$

Assim, o momento máximo de bloqueio será:

$$
M_{\text {lig }}=\left(\frac{q \ell^{2}}{12}\right) \cdot\left[3 \cdot 0,7 \frac{(2-0,7)}{\left(4-0,7^{2}\right)}\right]=0,78 \cdot\left(\frac{q \ell^{2}}{12}\right)
$$

Em um desenvolvimento análogo, ELLIOTT et al. (1998) propõem que:

$$
\begin{aligned}
& M_{l i g}=M^{p} \cdot\left[\frac{K_{\phi}}{K_{\phi}+\left(2 \cdot E_{c} \cdot I\right) / \ell}\right] \\
& M_{l i g}=M^{p} \cdot\left[\frac{45506}{45506+(2 \cdot 39750) / 6}\right]=0,78 \cdot M^{p}
\end{aligned}
$$


No caso da utilização da rigidez secante, $K_{E}$, tem-se:

$$
M_{\text {lig }}=M^{p} \cdot\left[\frac{40955}{40955+(2 \cdot 39750) / 6}\right]=0,76 \cdot M^{p}
$$

Adotou-se o valor de $M^{p}$ como igual ao momento de projeto da ligação, $M_{d}$, dado

$$
M^{p}=M_{d}=168,5 k N . m
$$

por:

Utilizando-se a rigidez secante, o momento máximo de bloqueio na ligação é dado

$$
M_{\text {lig }}=0,76 \cdot 168,5 \cong 128 k N . m
$$

por:

A rotação da ligação $\theta_{\text {lig }}$ associada ao momento $\mathrm{M}_{\text {lig }}$ é dada por:

$$
\theta_{\text {lig }}=M_{\text {lig }} / K_{E}=128 / 40955=0,003 \mathrm{rad}
$$

\subsubsection{Aplicação do Método "Beam-line" para a Avaliação da Ligação}

O método "Beam-line" é um método gráfico que permite a determinação do momento de bloqueio na ligação e a sua rotação associada. A reta "Beam-line" é construída a partir do momento de engastamento perfeito, correspondente à uma rotação nula na extremidade da viga, dado por:

$$
M^{p}=168,5 k N . m
$$

$\mathrm{Na}$ outra extremidade da reta, tem-se a condição de momento nulo na ligação com uma rotação na extremidade de uma viga, dada por:

$$
\theta_{r o t}=\frac{q \cdot \ell^{2}}{24 \cdot E_{c} \cdot I}=\frac{M^{p} \cdot \ell}{2 \cdot E_{c} \cdot I}=\frac{168,5 \cdot 6}{2 \cdot 39750}=0,0127 \mathrm{rad}
$$


A determinação do valor de $\mathrm{M}_{\text {lig }}$ e $\theta_{\text {lig }}$, levando-se em conta a rigidez da ligação e a rigidez do elemento de viga, é feita graficamente a partir da interseção da reta da ligação, de rigidez secante $K_{E}$, com a reta "Beam-line", conforme indicado na figura 5.40.

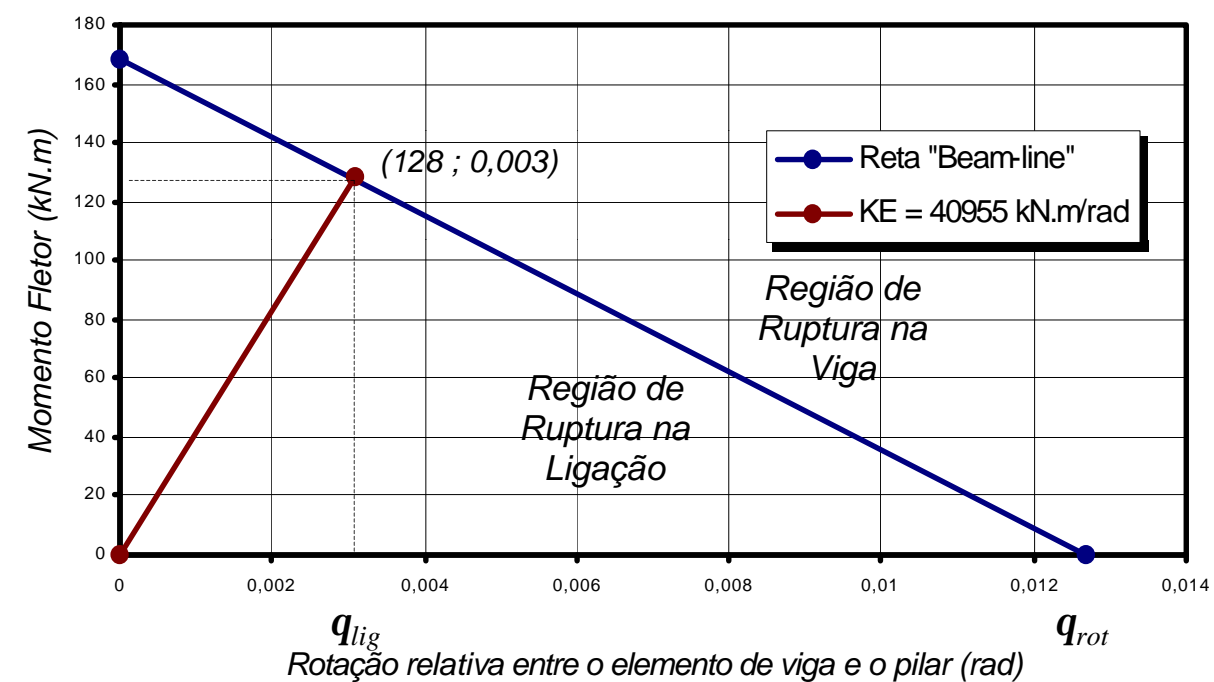

Figura 5.40 - Diagrama teórico com as retas “Beam-line” e da rigidez da ligação.

Nos gráficos 5.24 e 5.25 são apresentadas as curvas experimentais MomentoRotação das ligações soldadas, para os dois lados do protótipo, a reta "Beam-line" e a reta teórica da ligação obtida a partir da rigidez secante $K_{E}=40955 \mathrm{kN} . \mathrm{m} / \mathrm{rad}$.

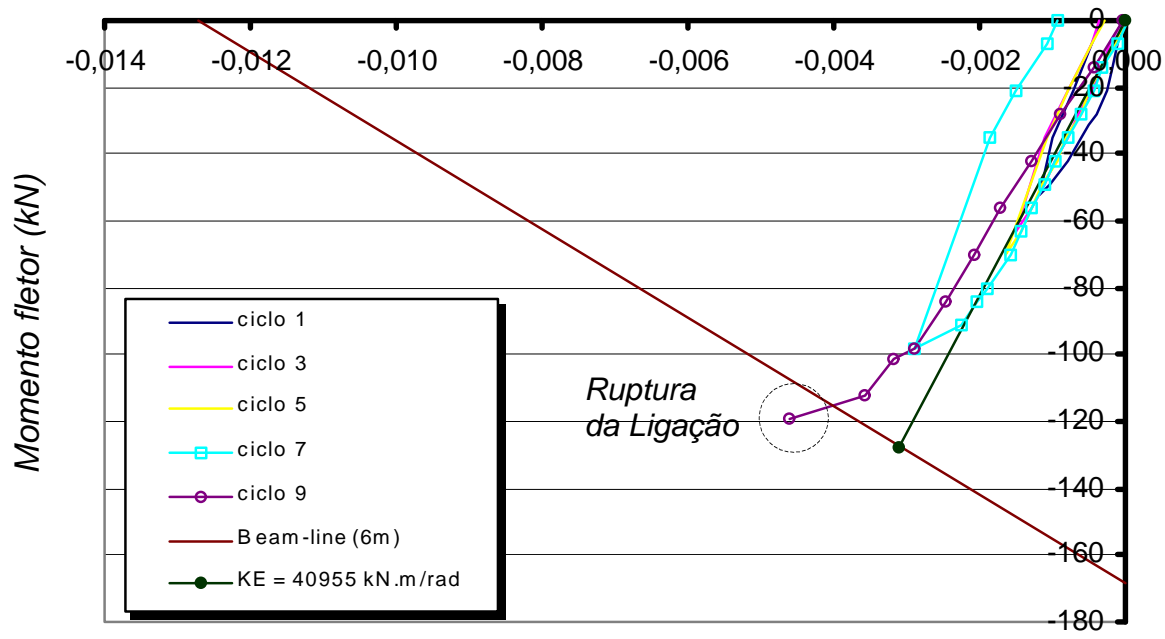

Rotação relativa entre a viga e a coluna (rad)

Gráfico 5.24 - Curvas Momento-Rotação da ligação em confronto com procedimentos teóricos. (lado esquerdo do protótipo, onde ocorreu a ruptura na ligação) 


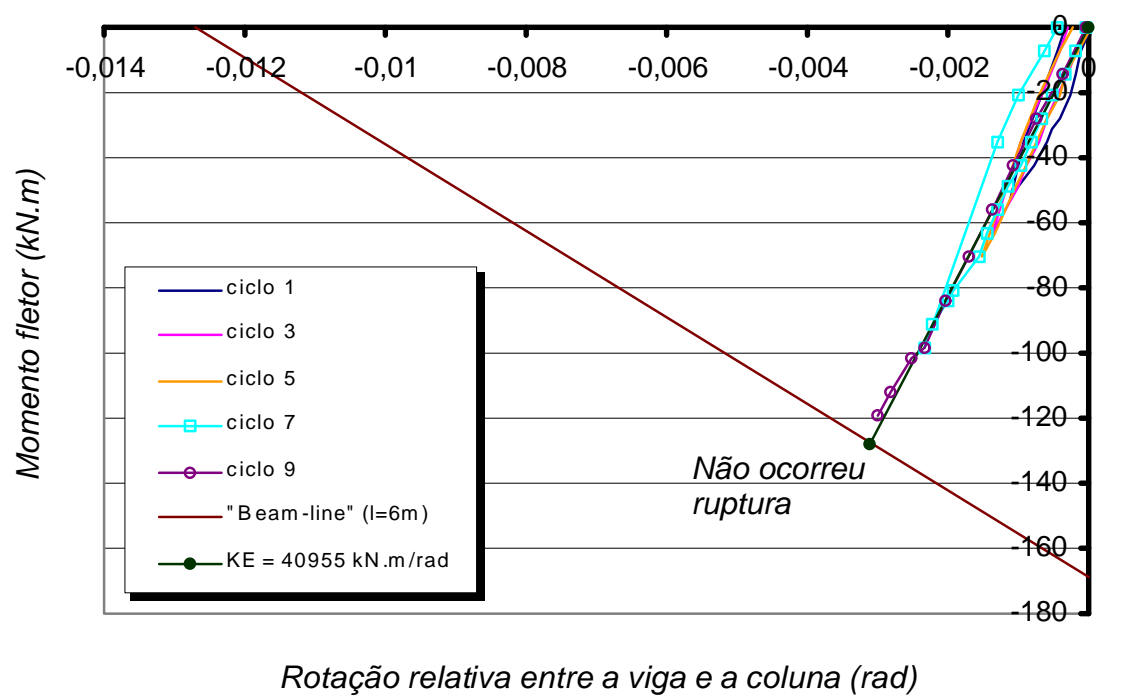

Gráfico 5.25 - Curvas Momento-Rotação da ligação em confronto com procedimentos teóricos. (lado direito do protótipo, onde não ocorreu a ruptura na ligação)

Segundo os procedimentos teóricos para a avaliação de rigidez, o Protótipo com Ligações Soldadas apresentou um bom desempenho quanto à sua rigidez. Embora a ligação estudada tenha sido classificada como uma ligação semi-rígida, a mesma atingiu níveis de rigidez próximos aos limites mínimos estabelecidos para a classificação de uma ligação como sendo rígida.

Entretanto, a ligação não apresentou um desempenho satisfatório quanto à sua resistência e quanto à sua ductilidade, as quais foram prejudicadas pela ruptura prematura, ainda no ciclo 7, da ligação com solda em uma das barras da armadura negativa do lado esquerdo do protótipo, para uma ação no atuador da ordem de $\mathrm{F}=-115 \mathrm{kN}$. Assim, com uma barra a menos, houve uma queda de rigidez no ciclo 9 e, consequentemente, uma diminuição da resistência e da ductilidade na ligação.

Acredita-se que essa ruptura ocorreu na região da solda entre a barra da armadura negativa e a chapa metálica de topo, próxima à borda da chapa metálica, onde as tensões de cisalhamento na solda foram acrescidas pelo aumento das tensões de tração nas fibras superiores das barras das armaduras negativas, causadas pela flexão localizada. Ao mesmo tempo, houve uma grande concentração de tensões normais de tração na solda de filete, as quais foram causadas pelo movimento de alavanca da extremidade das barras da armadura negativa sobre a chapa de topo. 
No caso da ligação estudada, esta situação se tornou ainda mais crítica em função da utilização de uma chapa metálica com $16 \mathrm{~mm}$, com barras da armadura negativa de $20 \mathrm{~mm}$, havendo com isto, na região da ligação com solda, um maior impedimento aos giros das extremidades das barras da armadura negativa, aumentando assim a resultante normal de tração na solda.

Tal comportamento, aponta para a necessidade de um estudo mais cuidadoso com relação ao detalhamento da ligação, buscando minorar os efeitos desfavoráveis causados pela presença do consolo na ligação.

Finalmente, com base na comparação dos resultados experimentais, o equacionamento para o cálculo da deformabilidade da ligação forneceu uma deformabilidade que da ordem de $86 \%$ da deformabilidade apresentada pela inclinação da curva experimental. Se for considerada a deformabilidade secante, o valor calculado correspondeu a $95 \%$ da deformabilidade experimental. Assim, o equacionamento forneceu uma boa estimativa para os resultados experimentais.

A partir da aplicação do valor calculado da deformabilidade à flexão da ligação em conjunto com o método "Beam-Line", obteve-se um momento máximo de projeto permitido para a ligação da ordem de $\mathrm{M}_{\mathrm{u} \text {,lig }}=128 \mathrm{kN}$, o qual correspondeu a um valor $6 \%$ superior ao momento de ruptura da ligação (lembrando que a ruptura só ocorreu em um dos lados).

Desta forma, a comparação com os resultados experimentais demonstrou que a aplicação dos procedimentos analíticos são uma alternativa interessante e com grande potencial de utilização no projeto de ligações semi-rígidas em estruturas de concreto prémoldado. 


\section{Capítulo 6}

\section{Considerações Finais e Conclusão}

No Capítulo 2, além da formulação para a análise de pórticos com nós semirígidos, também são apresentadas formulações e procedimentos simplificados para análise de elementos estruturais considerando a rigidez das ligações. Acredita-se que esse conhecimento poderá ser de grande utilidade para projetistas de ligações de estruturas de concreto pré-moldado. Embora alguns procedimentos simplificados, como o método "Beam-Line", sejam aplicados para o caso particular de vigas em pórticos contraventados, que pode não ser a situação mais corrente nas estruturas de concreto pré-moldado, tais procedimentos constituem-se como ferramentas para a estimativa da resistência da ligação com base na sua rigidez. Ressalta-se, que a aplicação desses procedimentos nas estruturas de concreto pré-moldado está condicionada ao conhecimento prévio das deformabilidades que fazem parte da estrutura.

No Capítulo 3, através da revisão teórica de mecanismos básicos de deformação não se buscou esgotar o assunto. Ao contrário, procurou-se introduzir a questão e apontar para a necessidade da realização de mais pesquisas nacionais específicas sobre o assunto.

No estudo do mecanismo de compressão da almofada de elastômero, as expressões propostas para o cálculo do módulo de elasticidade longitudinal da almofada de elastômero simples, apresentaram boas estimativas para os valores experimentais.

No caso das superfícies de contato aço-neoprene-aço, para coeficientes $\mathrm{K}_{1}=10 \mathrm{e}$ $\mathrm{K}_{2}=2$, obteve-se, em média, a uma relação entre os valores teóricos e experimentais de $95 \%$, com um coeficiente de variação de $15 \%$. 
No caso das superfícies de contato concreto-neoprene-concreto, para coeficientes $\mathrm{K}_{1}=7$ e $\mathrm{K}_{2}=6$, obteve-se, em média, uma relação entre os valores teóricos e os resultados experimentais de $98 \%$, com um coeficiente de variação de $12 \%$.

Observou-se, a partir dos ensaios, que para uma tensão média $\sigma_{\mathrm{m}}<3 \mathrm{MPa}$, a geometria da almofada é o fator de maior influência na deformabilidade à compressão da almofada. Na medida em que as tensões na almofada aumentam, o efeito do atrito na superfície de contato passa a ter uma maior influência na deformabilidade.

$\mathrm{Na}$ falta de uma normalização brasileira para ensaios de compressão em almofadas de elastômeros simples, para futuros ensaios recomenda-se, para o procedimento de aplicação da força de compressão, que seja aplicado um primeiro ciclo até atingir o limite de tensão desejada para o ensaio e, em seguida, que a almofada seja descarregada, sem zerar a carga, para então se prosseguir um novo carregamento. Tal procedimento é adequado ao caso de carregamento com deformações controladas, para se evitar um aumento "aparente" da deformabilidade à compressão nos ensaios. Neste sentido, também, recomenda-se que a velocidade da aplicação da força de compressão não seja lenta demais para permitir um "escorregamento" da almofada, alterando assim a deformabilidade da mesma.

No Capítulo 4, a revisão teórica sobre o estudo da resistência ao cisalhamento da ligação, constitui-se numa síntese de conhecimentos introduzidos à literatura nacional. Também, os ensaios descritos nesse capítulo constituem-se numa fonte de dados que poderão servir para pesquisadores e a projetistas.

A deformabilidade ao cisalhamento de uma ligação é inversamente proporcional ao fator de forma da almofada de elastômero.

Para ações de cisalhamento, a ligação com 1 chumbador de $16 \mathrm{~mm}$ e com uma almofada de 150x300x10 mm 3 (fator de forma $\mathrm{B}=5$ ) apresentou uma deformabilidade axial da ordem de $22 \times 10^{-3} \mathrm{~mm} / \mathrm{kN}$, que correspondeu a um fator de restrição ao deslocamento axial na extremidades de uma barra da ordem de $\beta=0,02$. Para a ligação com 2 chumbadores de $25 \mathrm{~mm}$ e com uma almofada de 200x300x15 mm³ (com fator de forma $\mathrm{B}=4$ ), obteve-se uma deformabilidade da ordem de $7,5 \times 10^{-3} \mathrm{~mm} / \mathrm{kN}$, que 
correspondeu a um coeficiente de restrição axial da ordem de ordem de $\beta=0,06$. Já para o caso de uma ligação com os mesmos 2 chumbadores de $25 \mathrm{~mm}$, mas com uma almofada de $250 \times 300 \times 10 \mathrm{~mm}^{3}$ (com fator de forma $\mathrm{B}=6,81$ ), obteve-se uma deformabilidade de $3,7 \times 10^{-3} \mathrm{~mm} / \mathrm{kN}$, que correspondeu a um fator de restrição da ordem de $\beta=0,11$, verificando-se assim, que, em função do aumento do fator de forma da almofada de elastômero, aumenta-se também a restrição aos deslocamentos horizontais na ligação. A partir do modelo analítico, obteve-se uma boa estimativa para a deformabilidade da ligação para os casos de ligações com almofadas com um fator de forma B < 5, obtendose, em média, uma relação entre os valores teóricos e os resultados experimentais da ordem de $123 \%$, com um coeficiente de variação de $11 \%$.

Acredita-se que, no caso do Protótipo B com um fator de forma B > 5, a razão pela qual o valor experimental para a deformabilidade ao cisalhamento tenha sido bem inferior ao valor obtido através do modelo analítico adotado seja decorrência de uma somatória de efeitos que foram gerados, basicamente, a partir de dois fatores. Um primeiro fator está relacionado com a relação entre o diâmetro do chumbador e a altura da almofada, dada por $\phi_{\mathrm{b}} / \mathrm{h}_{\mathrm{n}}=2,5$; a qual atribuiu um aumento de rigidez da barra do chumbador na região da interface da ligação. A espessura da almofada influi no mecanismo de deformação da barra do chumbador (quanto menor a espessura, menor a deformabilidade). O aumento da espessura da almofada, faz com que haja um aumento da excentricidade entre as forças de cisalhamento nos elementos de viga e de pilar, aumentando o efeito da flexão na barra do chumbador. Um segundo fator está relacionado com a utilização de uma almofada larga de pequena espessura, a qual apresentou uma restrição maior às rotações relativas entre os elementos de viga e coluna, aumentando o efeito do atrito sobre a ligação.

Com base nos procedimentos propostos por ENGSTRÖM (1992a), para o cálculo da resistência ao cisalhamento da ligação, forneceram uma ótima estimativa para os valores experimentais. Obteve-se, em média, uma relação entre os valores teóricos e os resultados experimentais de $100 \%$, com um coeficiente de variação de $16 \%$, para o cálculo de $\mathrm{F}_{\mathrm{vy}, \min }$, uma relação de $99 \%$, com um coeficiente de variação de 7,5\%, para o cálculo de $\mathrm{F}_{\mathrm{vy}}$ e uma relação de $96 \%$, com um coeficiente de variação de $8 \%$, para o 
cálculo de $\mathrm{F}_{\mathrm{vu}}$. Foram verificadas tensões de tração na barra do chumbador que no caso das barras lisas podem não ser desprezíveis, principalmente para solicitações de cisalhamento próximas à resistência da ligação. Desta forma, quando se pretende explorar a resistência ao cisalhamento da ligação, faz-se necessária a utilização de mecanismos de ancoragem na extremidade superior do chumbador, como, por exemplo, a utilização de pequenas chapas presas por meio de porcas rosqueadas. Em geral, este detalhamento já vem sido utilizado com outro objetivo que é o de garantir o a estabilidade lateral do elemento de viga, impedindo o tombamento.

A utilização em conjunto dos dois procedimentos teóricos para a obtenção da resistência e da deformabilidade da ligação, possibilitou a construção de um diagrama simplificado para a representação do comportamento força de cisalhamento $x$ deslocamento horizontal da ligação, constituindo-se em mais uma ferramenta prática de projeto.

Quanto ao comportamento da ligação para os esforços de flexão, as ligações ensaiadas chegaram mobilizar deslocamentos de rotação, gerando esforços na barra do chumbador. Todavia, mesmo para a maior rigidez à flexão, da ordem de $421 \mathrm{kN} \cdot \mathrm{m} / \mathrm{rad}$, para o caso da ligação com 2 chumbadores de $25 \mathrm{~mm}$ e almofada de 250x300x10 mm $\mathrm{mm}^{3}$, a rigidez da ligação seria da ordem de $\mathrm{K}_{\mathrm{S}} \cong 0,005$, indicando que a rigidez à flexão da ligação é desprezível em relação à rigidez do elemento de viga. Assim, para o caso de carregamento distribuído ao longo da viga, com rotações de rótula da ordem de 0,010 rad, a ligação se aproxima de uma rótula perfeita. Entretanto, cabe ressaltar que o efeito da restrição aos giros na ligação pode ser maior com a formação do mecanismo de binário chumbador-elastômero, para o caso de grandes rotações relativas existentes entre os elementos de viga e de pilar, devido à ação de forças horizontais na estrutura, onde os esforços de flexão na ligação podem não ser desprezíveis.

O fator de forma da almofada também interferiu fortemente na deformabilidade à torção da almofada. Para ligações com os mesmos chumbadores, a ligação com uma almofada com um fator de forma aparente $\mathrm{B}=4,3$ (considerando só a área comprimida), apresentou uma rigidez à torção 10 vezes maior do que a rigidez de uma ligação com uma almofada com fator de forma aparente $\mathrm{B}=2,6$. 
Com base na observação da influência da geometria da almofada sobre o comportamento da ligação, para as várias deformabilidades, recomenda-se a utilização de almofadas com fator de forma $\mathrm{B}<5$, para uma relação entre o comprimento e a espessura da almofada dada por a $/ h_{n}<20$. Também, um importante parâmetro a ser levado em conta seria a relação existente entre a altura da almofada em função do diâmetro, onde recomenda-se que essa relação seja $\phi_{b} / h_{n}>1$ e, quando se deseja um desempenho maior para a rigidez da ligação, recomenda-se uma relação $\phi_{b} / h_{n}>1,5$.

No relato dos ensaios no Capítulo 5, tem-se a primeira experiência de um ensaio de uma ligação viga-pilar de concreto pré-moldado resistente à flexão com carregamento alternado no Brasil. Espera-se que esta experiência, através dos seus erros e acertos, possa ser útil para as futuras pesquisas na área.

Com base na comparação com os resultados experimentais, constatou-se que o equacionamento para o cálculo da deformabilidade à flexão (para momentos negativos) da ligação viga-pilar com chapas soldadas, proposto nesse capítulo, forneceu uma boa estimativa para os resultados teóricos, onde se obteve uma rigidez secante teórica que correspondeu a $105 \%$ do valor da rigidez obtida pela curva experimental da ligação.

A ruptura da ligação ocorreu para um valor de $93 \%$ do máximo momento de projeto permitido na ligação, calculado através da aplicação do método "Beam-Line", levando em conta a deformabilidade calculada para ligação. Com base nesse procedimento, a ruptura do protótipo com ligações soldadas ocorreu em um trecho da curva momento $x$ rotação da ligação um pouco abaixo da interseção dessa curva com a reta "Beam-Line", atingindo uma capacidade um pouco abaixo da máxima capacidade de projeto permitida para a ligação, significando que a ruptura deve ter ocorrido na ligação.

Segundo os procedimentos teóricos para a avaliação de rigidez, o Protótipo com Ligações Soldadas apresentou um bom desempenho quanto à sua rigidez, com uma rigidez equivalente $\mathrm{K}_{\mathrm{S}}>1,5$. A rigidez à flexão da ligação soldada correspondeu à $83 \%$ da rigidez da ligação monolítica.

Entretanto, em função dos efeitos desfavoráveis da concentração de tensões na região da ligação, a ligação não apresentou um desempenho satisfatório quanto à sua 
ductilidade. De fato, ainda no penúltimo ciclo, para os momentos negativos, ocorreu uma ruptura prematura na ligação com solda em uma das barras da armadura negativa do lado esquerdo do protótipo, para um momento fletor da ordem de $\mathrm{M}=-81 \mathrm{kN} . \mathrm{m}$. Assim, com uma barra a menos, houve uma queda de rigidez no último ciclo, atingindo-se uma capacidade máxima da ordem de $\mathrm{M}=-120 \mathrm{kN} . \mathrm{m}$, com uma ruptura frágil da ligação.

Com relação às tensões de tração nas seções mais solicitadas das barras da armadura negativa das vigas, constatou-se que as fibras mais solicitadas, próximas às ligações no caso do protótipo com ligações soldadas, apresentaram o dobro das tensões de tração em relação às tensões apresentadas pelas barras da armadura negativa das vigas no protótipo monolítico, para esforços da mesma ordem. Este fenômeno foi consequiência do efeito de alavanca da extremidade da viga sobre o consolo, fazendo com que houvesse uma flexão localizada nas barras da armadura negativa, na região próxima à ligação. Também, em função desta flexão localizada nas barras da armadura negativa, essas barras tendem a girar, sendo impedidas pela chapa metálica da ligação, gerando esforços desfavoráveis na região da solda entre as barras e a chapa metálica. Desta forma, a presença do consolo na ligação, se por um lado é um fator favorável por garantir a segurança com relação ao cisalhamento nos apoios, constitui-se em um fator desfavorável por gerar esforços de flexão localizada na barra e na região da solda.

Por outro lado, as tensões de cisalhamento na região da solda foram acrescidas pelo aumento das tensões de tração nas fibras superiores das barras das armaduras negativas causadas pela flexão localizada próxima à ligação. Ao mesmo tempo, houve uma grande concentração de tensões normais de tração na solda de filete, as quais foram causadas pelo movimento de alavanca da extremidade das barras da armadura negativa sobre a chapa de topo. No caso da ligação estudada, esta situação se tornou ainda mais crítica em função da utilização de uma chapa metálica de $16 \mathrm{~mm}$, com barras da armadura negativa de $20 \mathrm{~mm}$, havendo com isto, na região da ligação com solda, um maior impedimento aos giros das extremidades das barras da armadura negativa, aumentando assim a resultante normal de tração na solda de filete.

Tal comportamento aponta para a necessidade de estudos futuros para buscar alternativas de detalhamentos para ligações resistentes à flexão, com o objetivo de minorar 
esses efeitos desfavoráveis causados pela presença do consolo, observados na ligação ensaiada. Este trabalho não teve por objetivo principal a proposta de novos detalhamentos para a ligação em questão, mas estudar as possibilidades da aplicação de procedimentos analíticos para as estimativas da deformabilidade e da resistência da ligação.

Feitas essas últimas considerações, espera-se ter contribuído para o estudo da deformabilidade de ligações viga-pilar em estruturas de concreto pré-moldado através da sistematização do conhecimento existente e do alargamento da base de dados experimentais sobre as ligações estudadas, o que poderá servir de direcionamento para futuros trabalhos dentro dessa linha de pesquisa.

Também, espera-se que, a partir dos equacionamentos analíticos e procedimentos práticos propostos, possa-se contribuir para a formação de um novo conceito dentro do projeto de estruturas de concreto pré-moldado no Brasil, que é o projeto das ligações baseado não somente nos critérios de resistência, mas também nos critérios de rigidez da ligação.

Acredita-se que, como avanço do conhecimento, além dos equacionamentos e procedimentos analíticos propostos neste trabalho, está a consolidação de uma proposta metodológica para o desenvolvimento analítico de modelos que representem o comportamento da rigidez de uma ligação, em conjunto com a verificação experimental, a qual se apresentou como uma alternativa interessante e viável.

A partir da consolidação desta proposta metodológica, onde são construídos modelos analíticos para a representação do comportamento da deformabilidade de uma ligação, o estudo das deformabilidades das ligações e suas aplicações, deve-se encaminhar em duas direções. A primeira delas, está relacionada com a continuidade desta abordagem metodológica no estudo teórico e experimental outras ligações de uso corrente nas estruturas de concreto pré-moldado, para que se construam ferramentas para se obter analiticamente as deformabilidades das ligações. Na segunda direção está justamente o estudo das aplicações da consideração das deformabilidades das ligações na análise das estruturas de concreto pré-moldado, criando inclusive modelos numéricos que representem os modelos analíticos. 
Anexo A:

Detalhes das Ligações Soldadas 

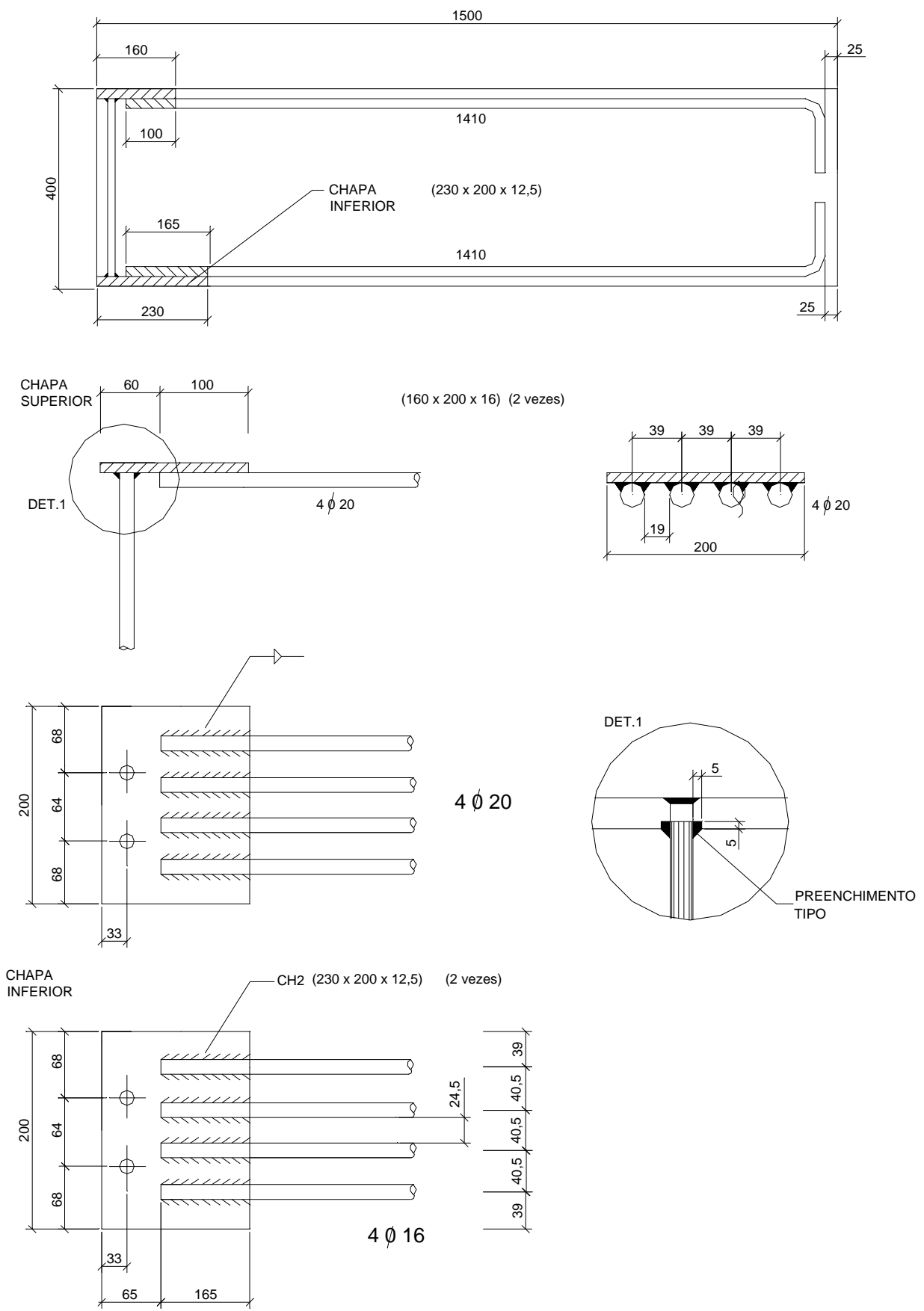

Figura A.1 - Detalhes das ligações inseridas no elemento de viga 

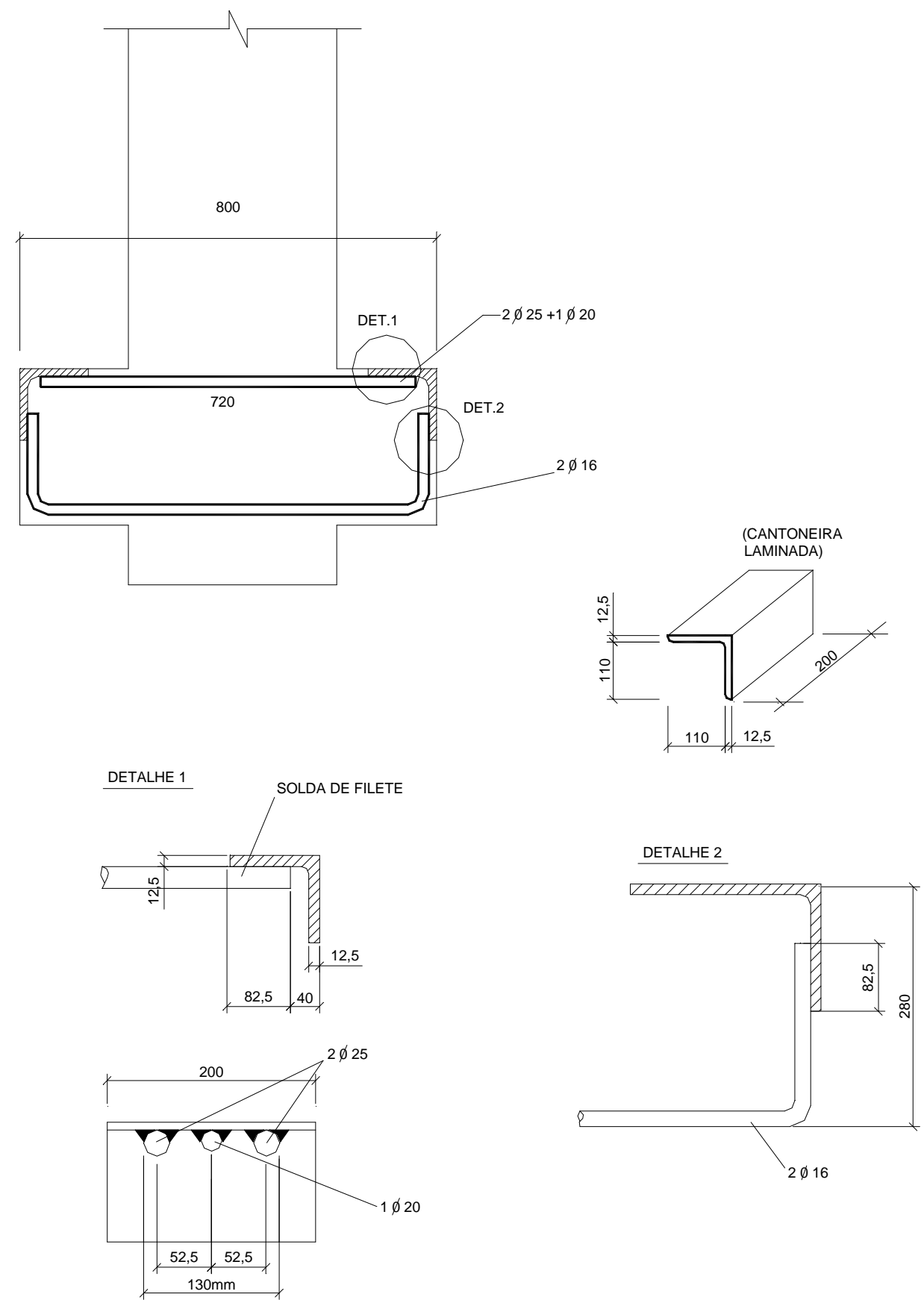

Figura A.2 - Detalhes das ligações inseridas no consolo 

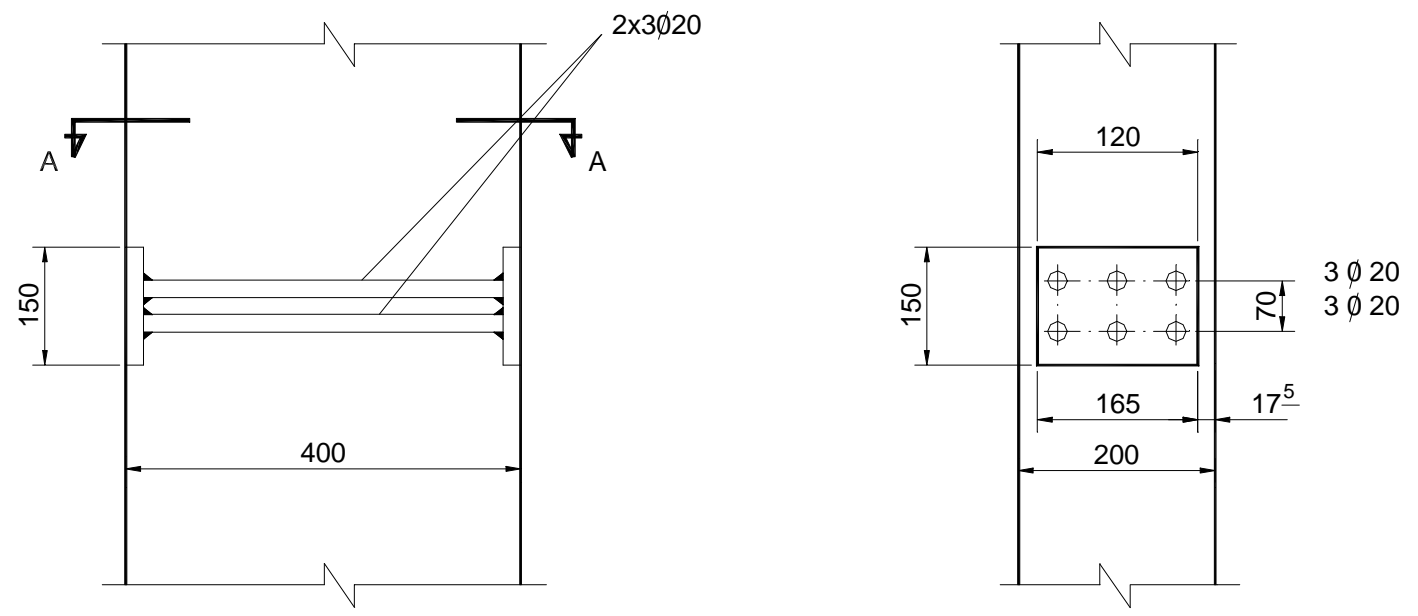

(PILAR - 20x40)

Figura A.3 - Detalhes das ligações inseridas no elemento de pilar 


\section{Capítulo 7}

\section{Bibliografia}

ASSOCIAÇÃO BRASILEIRA DE NORMAS TÉCNICAS, (ABNT), (1985). NBR-9062: Projeto e Execução de Estruturas de Concreto Pré-moldado. RJ.

BALlARIN, A.W., (1993). Desempenho das Ligações de Elementos Estruturais Prémoldados de Concreto. São Carlos, Tese Doutorado, EESC-USP.

BJLUGER, F.E., (1988). Design of Precast Concrete Structures. New York, John Wiley \& Sons. 297 p.

BJORHOVDE, R., (1984). Effect of End Restraint on Column Strength - Practical Applications. AISC Engineering Journal. V.20, $\mathrm{N}^{\mathrm{o}}$ 1, pp 1-13.

BJORHOVDE, R., (1990). Classification System for Beam-to-Column Connections. J. Struct. Div., ASCE. V.116, N ${ }^{\circ}$ ST11, pp. 3059-3076.

BRAGA, W.A, (1985). Aparelhos de Apoio das Estruturas. São Paulo, Edgard Blücher. $107 \mathrm{p}$.

BRUN, P., PICARD, A., (1976). “Étude d'un Assemblange Imparfaitament Rígide et des Effets de son Utilization dans un Multi-Étage.”, Rapport gct76-03. Quebec, Universitté Laval, Departament de Génie Civil. 236 p.

CHEFDEBIEN, A , (1994). "Experimental Investigations on Current Connections between Precast Concrete Components." COST 1 Proc. 2nd Workshop, Semi-rigid Behaviour of Civil Engineering Structural Connections, CTU, Prague.

CHEFDEBIEN, A , (1996). "Promotion of the Mechanical Performance of Precast Concrete Skeletal Frames.” IN ANAIS: BIBM 96, Paris.

CHEOK, G.S., LEW, H.S., (1991). "Performance of Precast Concrete Beam-to-Column Connections Subject to Cyclic Loading”. PCI JOURNAL. V.36, n.3, May-June. pp 5667.

CHIRKO, A H., KIRBY, P. A, (1995). “An Approximate Method for Estimation Bending Moments in Continuous and Semirigid Frames." Canadian Journal or Civil Engineering. V. 22, pp 1120-1132. 
DEI POLI, S., DI PRISCO, M., GAMBAROVA, P.G., (1987). In Tema di Transmissione del Taglio negli Elementi di Calcestruzzo Armato: Alcuni Risultati Sperimentali Attinenti alla Cosiddetta Azione di Spinotto. Corso di Perfezionamento per le Construzioni in Cemento Armato Fratelli Pesenti. STUDI E RICERCHE - Vol.9, Politecnico di Milano, Italia. p 217.

DEI POLI, S., DI PRISCO, M., GAMBAROVA, P.G., (1992). Shear Response, Deformations and Subgrade Stiffness of Dowel Bar Embedded in Concrete. ACI Structural Journal, V.89, No.6, pp 62-74.

DOLAN, CW, PESSIKI, S.P., (1989). "Model Testing of Precast Concrete Connections." PCI JOURNAL. V.32, No. 2, pp 62-74.

DOLAN, CW, STANTON, S.F., ANDERSON, R.G., (1987). "Moment Resistant Connections and Simple Connections.” PCI JOURNAL. Mar-Apr. n.2 . pp 84-103.

ELliOTT, K.S., DAVIES, G., GORGUN, H., (1994). The Determination of MomentRotation in Semi-Rigid Precast Concrete Connections using the Component Method. COST 1 Proc. 2nd Workshop, Semi-rigid Behaviour of Civil Engineering Structural Connections, CTU, Prague.

ELLIOTT, K.S., DAVIES, G., GORGUN, H., (1997). Semi-Rigid Connections in Precast Concrete Frames. FIP Symposium 97, Johannesburg.

ELLIOTT, K.S., DAVIES, G., MAHDI, A., (1992). Semi-rigid Joint Behaviour on Columns in Precast Concrete Buildings. COST 1 Proc. 1st Workshop, Semi-rigid Behaviour of Civil Engineering Structural Connections, E.N.S.A.I.S., Strasborg.

ELliOTT, K.S., DAVIES, G., GORGUN, H., OMAR, W., ADJPARVAR, M.. (1997). Testing Precast Concrete Skeletal Structures. IN ANAIS: XXVIII JORNADAS SULAMERICANAS DE ENGENHARIA ESTRUTURAL, EESC-USP, São Carlos, BRASIL.

ELLIOTT, K.S., DAVIES, G., GORGUN, H., ADJPARVAR, M. (1998a). The Stability of Precast Concrete Skeletal Structures. PCI JOURNAL. Mar-Ap. pp 42-60.

ELLIOTT, K.S., DAVIES, G., MAHDI, A., GORGUN, H., VIRDI, K., RAGUPATHY, P. (1998b). Semi-rigid Joint Behaviour on Columns in Precast Concrete Buildings. COST 1 Proc. Conference, Semi-rigid Behaviour of Civil Engineering Structural Connections, E.N.S.A.I.S., Liege.

ENGSTRÖM, B. (1985). “Bolted Beam-column Connections for Precast Structures”. IN ANAIS: CONNECTIONS BETWEEN PRECAST CONCRETE ELEMENTS-VTT SYMPOSIUM 62, Nordic Seminar, Sweden, 12 March 1985. 
ENGSTRÖM , B., (1992a). Combined Effects of Dowel Action on Friction in Bolted Connections. COST 1 Proc. 1st Workshop, Semi-rigid Behaviour of Civil Engineering Structural Connections, E.N.S.A.I.S., Strasborg.

ENGSTRÖM , B., (1992b). Anchorage of Ribbed Bars in the Post Yield Stage. COST 1 Proc. 1st Workshop, Semi-rigid Behaviour of Civil Engineering Structural Connections, E.N.S.A.I.S., Strasborg.

EUROCODE EC3 (1992). Design of Steel Structures, Part 1.1, European Commitee for Standardization, CEN, Brussels.

FAFARD, M., PICARD, A., BEAULIEU, D., (1990). "Analyse des Structures Avec Joints à Rigité Partielle: Une Approche Unifiée”. Canandian Journal of Civil Engineering, V.17, pp. 730-738.

FERREIRA, M.A., (1993). Estudo de Deformabilidades de Ligações para Análise Linear em Pórticos Planos de Elementos Pré-Moldados de Concreto. São Carlos, Dissertação de Mestrado, EESC-USP.

GARCIA, S., BENITO, R.D., DANESI, R.F., (1993). Performance de Uniones de Elementos Prefabricados. In: JORNADAS SUDAMERICANAS DE INGENIERIA ESTRUCTURAL, 26., Montevideo, Uruguai, 15-19 Nov. 1993. Memorias. Montevideo, CLAES/ASAIE, V.3, pp 431-443.

GIBBONS, C., KIRBY, P. A, NETHERCOT, D. A, (1996). Calculation of Serviceability Deflections for Non-Sway Frames with Semi-Rigid Connections. Proc. Instn. Civ. Engrs. Structs. \& Bldgs.. Vo. 116, May, pp 186-193.

JOHAL, L.S., JENNY, D.P., SHAIKH, A F, (1991). Impact os Past Research and Future Research Needs of the Precast and Prestressed Concrete Industry. PCI JOURNAL, V.36, n.6, pp.52-59.

KERONEN, A., (1994). Portal Frame with Semi-rigid Support: Loading Tests. COST 1 Proc. 2nd Workshop, Semi-rigid Behaviour of Civil Engineering Structural Connections, CTU, Prague.

KERONEN, A., (1996). Effect of Semi-Rigid Connections in RC Portal Frame: Load Tests. Department of Civil Engineering, Tampere University of Technology, Tampere, FINLAND. Publication 69. 94 pp.

LIN, C., (1993). Friction Connection of Precast Concrete Construction. G.B. HASSELWANDER (Ed.). "Anchorage to Concrete". SP-103 (pp.27-46). Detroit: American Concrete Institute.

LINDBERG, R. (1992). Semi-rigid Behaviour of a RC Portal Frame. COST 1 Proc. 1st Workshop, Semi-rigid Behaviour of Civil Engineering Structural Connections, E.N.S.A.I.S., Strasborg 
MARTIN, L.D., (1980). Derivation of stiffness coefficients for column base plates. PCI JOURNAL. Appendix A, Jan-Feb., pp 39-41.

MONFORTON, G.R., WU, T.S., (1963). "Matriz analysis of semi-rigidly connected frames". Journal of the Structural Division, ASCE, V.89, December, pp 13-42.

OCHS, J.E., EHSANI, M.R., (1993). "Moment Resistant Connections in Precast Concrete Frames for Seismic Regions.” PCI JOURNAL. V.38, n.5, Sept.-Oct. pp 64-75.

ORDOÑEZ, J.A.F. et alii, (1974). Prefabricacion teoria y prática”. Barcelona, V.2.

PRECAST CONCRETE INSTITUTE, PCI, (1992). Design Handbook. Vol. 1. Chicago, ILLINOIS.

PRECAST CONCRETE INSTITUTE, PCI. (1988). Design and Typical Details of Connections for Precast and Prestressed Concrete. Chicago, ILLINOIS.

PRIESTLEY, M.J.N., (1991). "Overview of PRESSS Research Program.” PCI JOURNAL. V.36, n.4 . July-August. pp 50-57.

PRIESTLEY, M.J.N., TAO, J.R., (1993). "Seismic Response of Precast Prestressed Concrete Frames with Partially Debonded Tendons.” PCI JOURNAL. V.38, n.1 . JanFev. pp 58-69.

RAGUPATHY, P., VIRDI, K.S., (1992). Analysis of Precast Concrete Frames with semirigid joints. Proc. of the First State of the Art Workshop, COST C1, Strasborg.

RAGUPATHY, P., VIRDI, K.S., (1996). Simplified Method to Design Precast Concrete Frames. (Second Report). Proc. ${ }^{\text {rd }}$ Workshop, COST C1, Brussels.

SEMI-RIGID CONNECTIONS IN STEEL FRAMES.(1993). Council on Tall Buildings and Urban Habitat. MacGraw-Hill, USA.

SOROUSHIAN, P., CHOI, K. B., (1991). "Analytical Evaluation of Straight Bar Anchorage Design in Exterior Joints”. ACI STRUCTURAL JOURNAL. V.38, No. 2, Mar-Apr, pp 161-168.

STANTON, J.F., ANDERSON, R.G., DOLAN, C., McCLEARY, D.E., (1986). "Moment Resistant Connections and Simple Connections". PCI SPECIAL RESEARCH PROJECT N. $.^{\circ} 1 / 4$, PRECAST/PRESTRESSED CONCRETE INSTITUTE. Chicago, IL. 436 p. 
SUCUOGLA, H., (1995). "Effects of Connection Rigidity on Seismic Response of Precast Concrete Frames”. PCI JOURNAL. Vol 40, Jan-Feb. , pp. 94-130.

VINJE, L., (1985). Design of Plain Elastomeric Pads in Precast Concrete Structures. IN ANAIS: CONNECTIONS BETWEEN PRECAST CONCRETE ELEMENTS-VTT SYMPOSIUM 62, Nordic Seminar, Sweden, 12 March . 